\title{
The Night Sky: What have we Lost?
}

Investigating how we can strengthen our personal " connection to the night sky through Landscape

Architecture.

$\therefore$ By,

William Chrisp

A 120-point thesis

submitted to the Victoria University of Wellington in partial fulfilment of the requirements for the degree of Master of Landscape Architecture

Under the supervision of Carles Martinez Almoyna Gual

Victoria University of Wellington School of Architecture 


\section{Acknowledgements.}

To my parents, thank you for all the support and love you have given me this year.

To my supervisor, Carles, thank you for the continious support and for believing in me and my research.

Thank you to my darling for sticking by me and supporting me from afar throughout this year.

Finally, to my classmates, thank you for an unforgettable 5 years. From countless trips to subway, the unnecessary dairy runs and drinks at the pub, I couldn't have done it without any of you guys. 


\section{Ethics.}

This document has ethics approval.

Notice number: 0000028470 


\section{Motivation.}

In 2017 I worked part time for a food delivery company while I completed my studies. On a delivery to Island Bay on the south coast of Wellington, I was amazed by how many stars I could see in the sky. I felt immediately calm, as if for a brief moment, the worries of life disappeared. Since then, star gazing has become a regular therapeutic activity in my life, taking me around the world in the hunt for darker skies. However, it has also made me aware of how large an impact light pollution is having on our planet. 


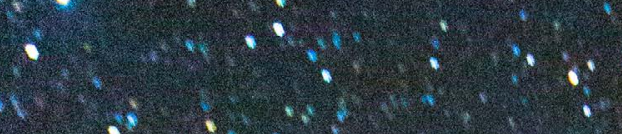

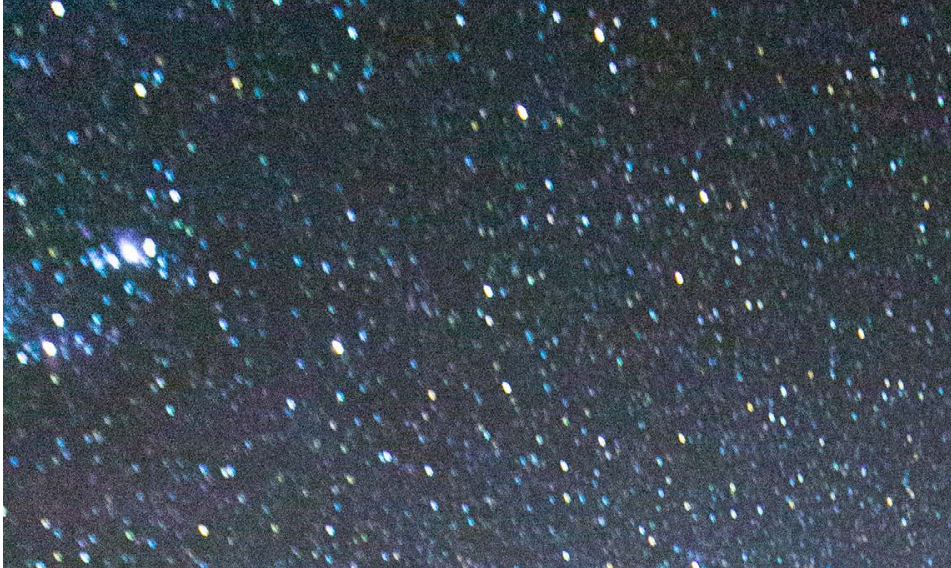

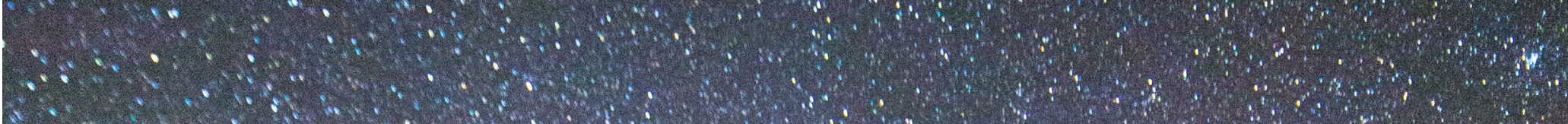

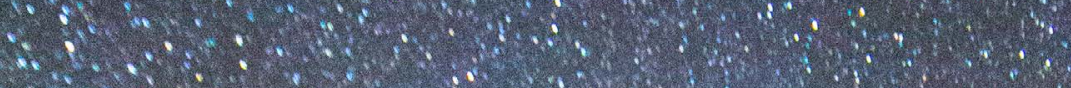

P.

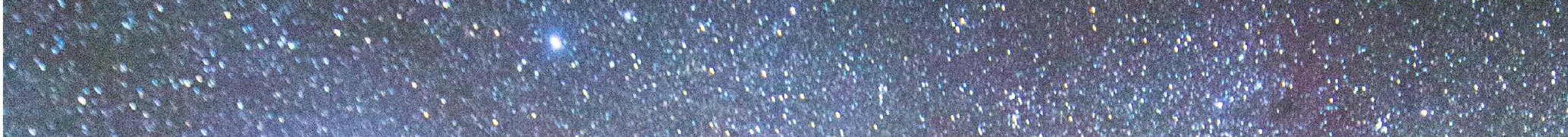

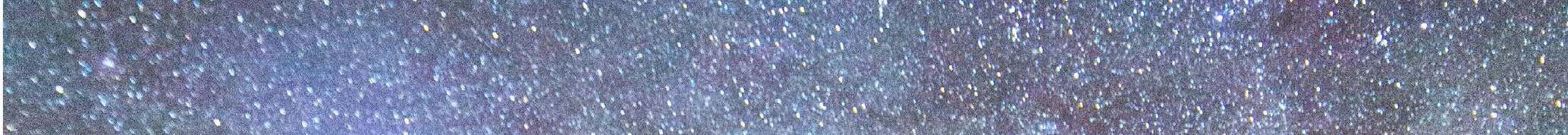

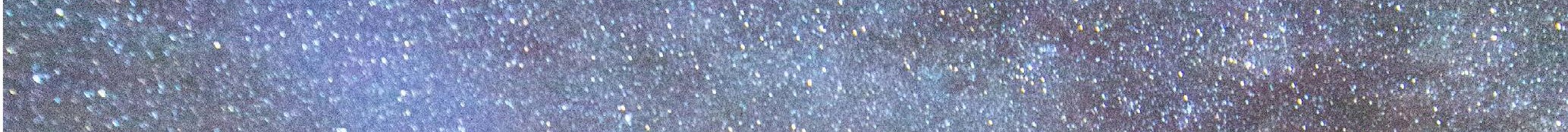

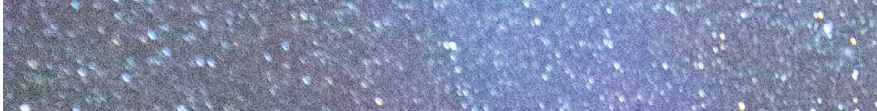

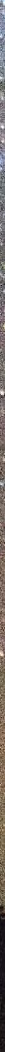




\section{Abstract.}

Over the last 70 years, there has been a dramatic increase in the population living in urban areas across the globe. As a result, the once natural ability to look up at the night sky and ponder our existence has been lost to bigger, brighter and ever-expanding urban development. In our outdoor public spaces, the design tends to focus only on how the space can be enjoyed during the day time, and lighting is placed as a means to allow people to continue this day time experience at night. Yet, often at night our public spaces are empty, as they don't provide a special night time experience that is different to during the day. We focus on the action of looking forward and around us but never upwards toward the night sky.

This research addresses how landscape architecture can help facilitate a night time experience so that the naturally dark environment can be enjoyed. It analyzes how the relationship between lighting and the physical elements in an outdoor space can be improved to provide greater visibility of the stars. Wellington, the capital of New Zealand, will be used as a case study. The stars can be seen within the central urban perimeter, and the Milky-Way is visible only a 20 minute drive away.

As this research is based in New Zealand, this thesis recognizes Māoritanga and acknowledges the importance of Tatai Arorangi within New Zealand's history and culture and addresses this within the development of this night time experience.
Wellington was split into five different areas based on their differing intensity of lighting as well as typological characteristics. Within three of these areas, a variety of different outdoor public spaces were identified and analyzed using an experiential approach, with fieldwork as the primary method of analysis.

Theanalysisfindings resulted in the generation of a design toolkit to test how specific physical features used in landscape design impacted the night time experience. This toolkit was then applied and tested into 3 different sites in Wellington. It was concluded that the design and implementation of lighting, vegetation and seating has not considered the night time experience. This research aims to contribute to this unaddressed area, by attempting to develop a connection to the night sky through looking at these features in a new perspective. 


\section{Vocabulary}

\author{
Bortle Scale
}

Celestial bodies

Glare

Heliacal rising

Light Clutter

Light pollution

Light trespass

M33

Milky Way

Night time experience

Sky Glow

Stargazing

Zenith

Zodiacal light
- A 9 unit scale that measures the brightness of the night sky in a particular location

- phyiscal entity, form or structure that is observable in our universe

- excessive brightness causing visual discomfort

- the annual rising of a star that briefly becomes visible above the eastern horizon just before dawn, after a period of invisibility behind the sun

- bright groups of light that are often excessive and confusing

- The brightening of the night sky caused by artificial light

- Light entering into spaces it was intended or needed to be in

- triangulum galaxy, third largest member of the local group of galaxies

- Galaxy that contains our solar system, seen as a hazy band of light in the night sky formed from stars

- The active enjoyment of our naturally dark environment

- brightening of the night sky in specific areas

- To observe the stars

- The point in the sky directly above the observer

- A faint cone of light extending from the horizon in the night sky, only seen in the darkest of skies

Fig 1.3 Milky way at Red 


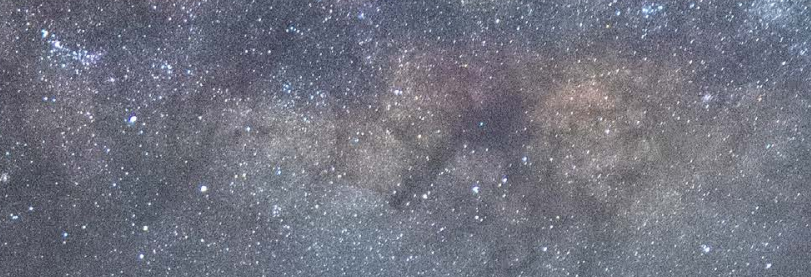




\section{Contents Page}

01 Introduction
1.1 Background
1.2 The Problem
1.2 Research Opportunity
1.4 Aims + Objectives
1.5 Research Questions
1.6 Methodology

02 Theoretical Framework

Introduction

2.1 Sub Topics

2.2 Night Time Landscape Experience

2.3 Space and Comfort at Night

2.4 Role of lighting in public space

2.5 Maori Astronomy

Reflection
03 Setting the Scene

Introduction

3.1 New Zealand

3.2 Wellington City

3.3 Light Pollution in Wellington

3.4 Wellington Geomorphology

3.5 Research Areas

Reflection
04 Initial Fieldwork
4.1 Revisiting Literature
4.2 Units chosen for further study
4.3 Wellington Watefront
4.4 Town Belt
4.5 South Coast
Reflection

05 Analysis Summary

Introduction

5.1 Waterfront Findings

5.2 Town Belt Findings

5.3 South Coast Findings

Reflection

\section{Toolkit Exploration}
6.1 Toolkit
$6.2 \quad$ Lighting
6.3 Vegetation
6.4 Seating
Reflection 
07 Initial Design Exploration Introduction

7.1 Chosen sites

7.2 Moa Point

7.3 Moa Point Reflection

7.4 Te Papa Walkway

7.5 Te Papa Walkway Reflection Reflection
08 Ataturk Analysis \& Design Introduction

8.1 Ataturk

8.2 Platform Layout

8.3 Platform Design

8.4 Developed Design

Reflection

09 Reflection

Introduction

Conclusion

Limitations

Reflection 


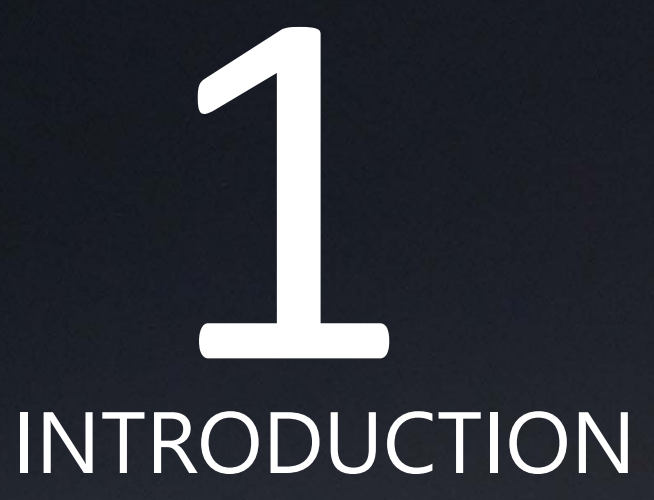

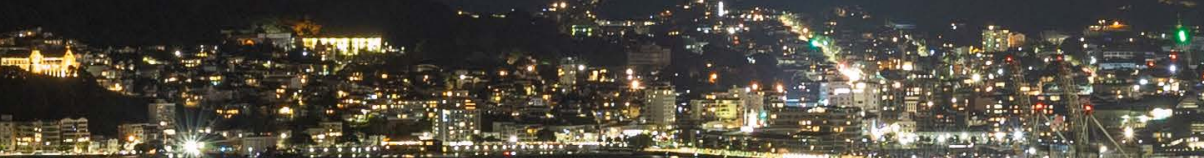

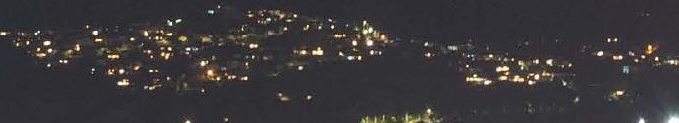




\subsection{Background}

"Light pollution" can be defined as the brightening of our night sky caused by the inappropriate or excessive use of street lighting(About IDA, 2020).

It can have detrimental effects on our physical and mental health, and disrupts many of the natural systems on earth. Due to the expansion of the urban realm there has been an exponential increase in the amount light being generated across the globe. Light pollution is a side effect of exterior and interior lighting, advertising, commercial properties, offices, factories, streetlights, public spaces, and illuminated sporting venues. Much of this light is wasted as it is unshielded, spilling into the sky (About IDA, 2020).

Despite its rapid growth, light pollution is one of the easiest forms of pollution to reduce.

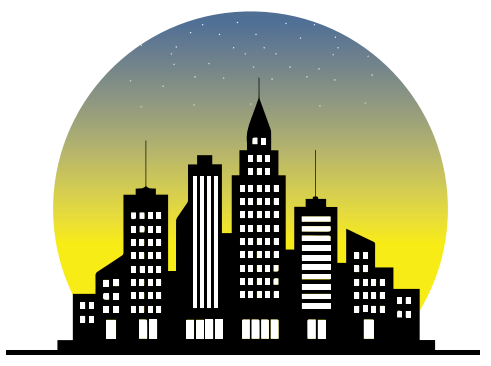

Sky Glow

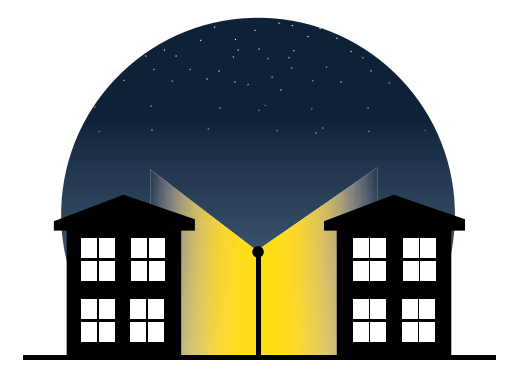

Light Trespass

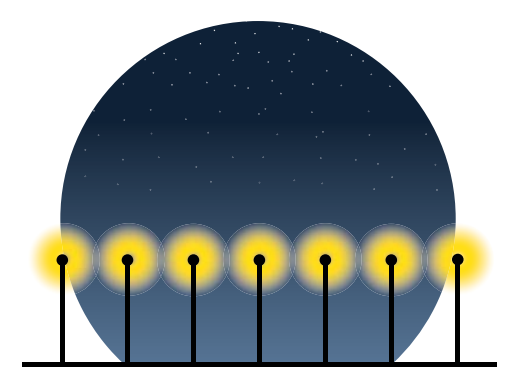

Light Clutter

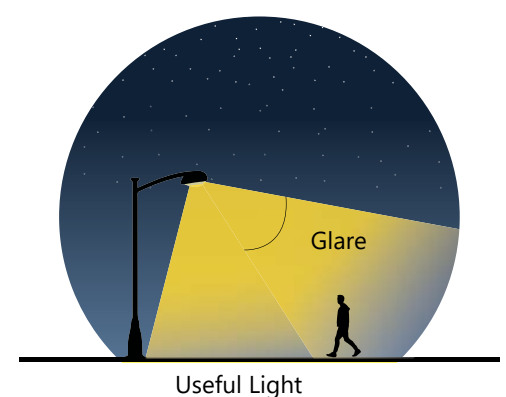

Glare 


\section{$80 \%$ of the worlds population live under light polluted skies}


This image has not been reproduced due to copyright

(refer to figure list for full details) 

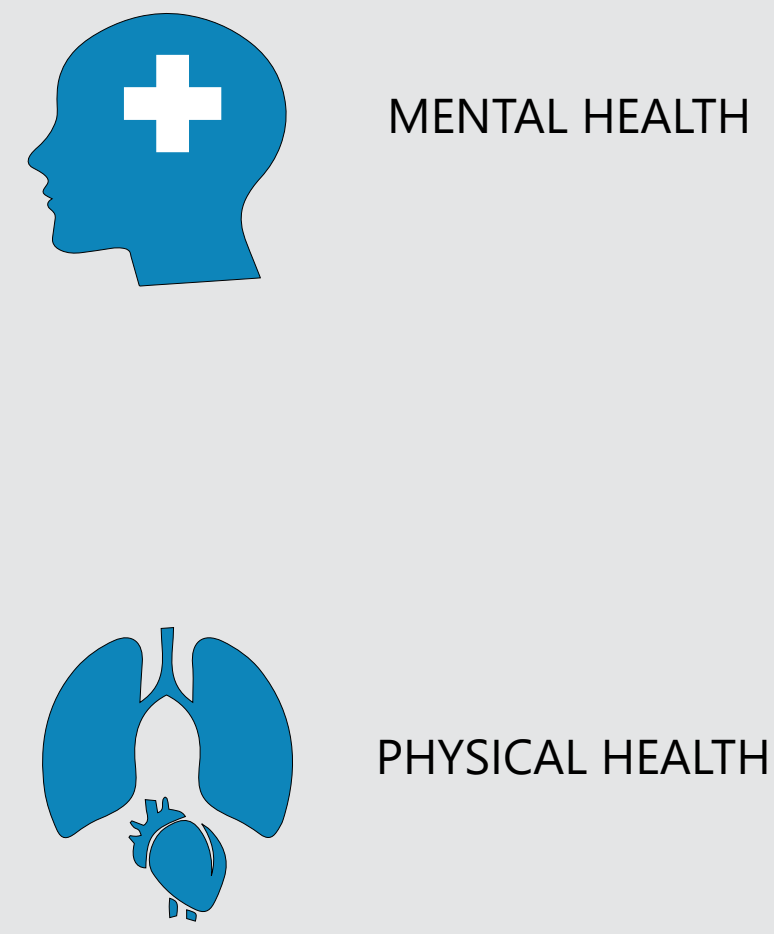

\title{
PHYSICAL HEALTH
}

\author{
SPIRITUAL HEALTH
}
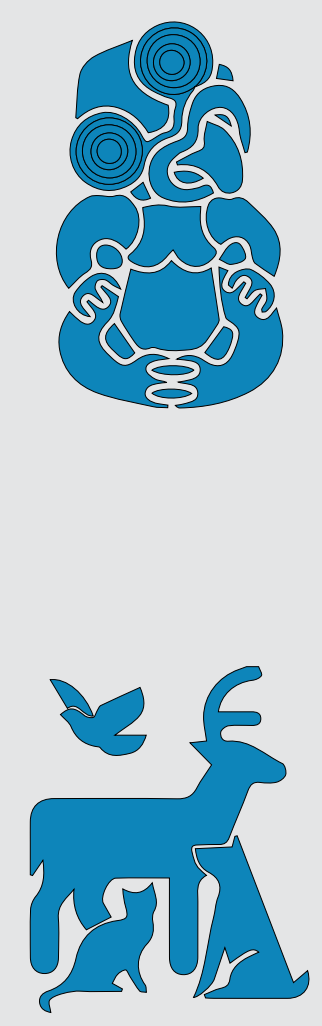

\section{ENVIRONMENTAL} HEALTH 


\subsection{The Problem}

At night there is a completely different experience that can be enjoyed in outdoor public space but is often unattainable due to the current design perspective on public spaces after dark.

Lighting is a brilliant technological advancement, but it draws the human gaze to the ground plane at night through overlit homogeneous lighting in an attempt to extend the daytime into night. As a result, many outdoor public spaces receive less use at night as there is no separate experience or purpose that can't be achieved during the day.

A change is needed in the way we think about the use of space at night. Almost half of human life is spent in darkness and to only encourage the use of public space during the day disregards half of the natural environment we can interact with (Bell et al., 2014). 


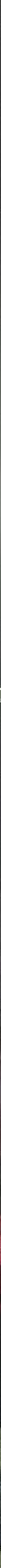




\subsection{Research Opportunity}

Landscape architecture has unknowingly contributed to the loss of the stars in public space. Current design processes often focus on the use of the space during the day and the use at night second, yet this focus continues the daytime experience into night.

This research address how public spaces can be re-designed to help facilitate the night time experience so that the sight of stars, the milky way and other features in the nocturnal environment can be enjoyed.

This research will take place in Wellington, the capital of New Zealand. Due to its varied topographical conditions and relatively small infrastructure, it produces very little light pollution compared to other major cities in New Zealand.

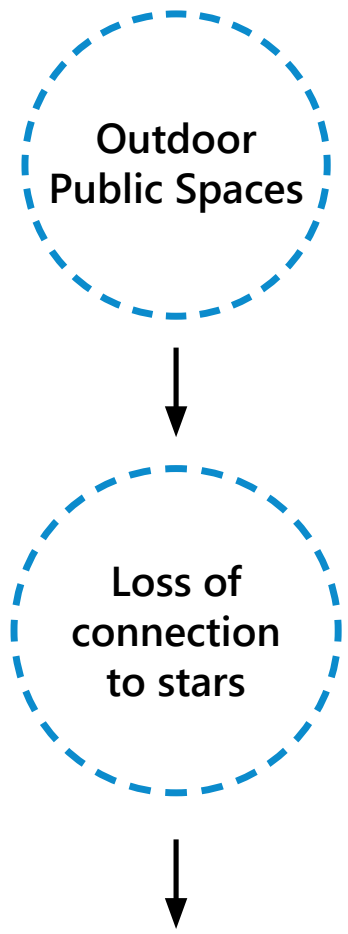

GAP in research on how we can facilitate a night time experience different to the day

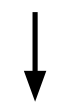

OPPORTUNITY

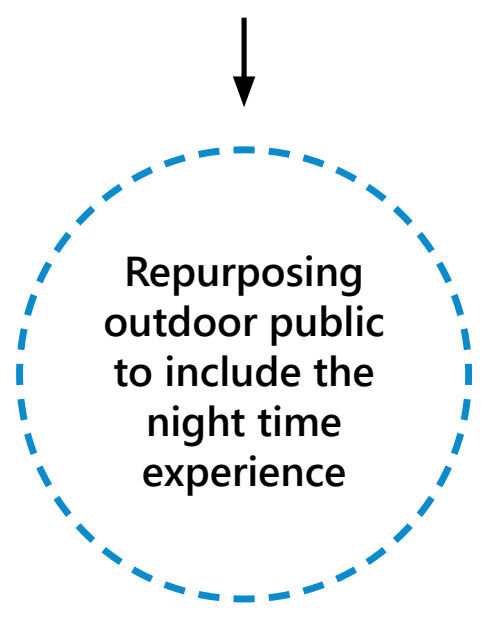




\subsection{Research Question}

1. How can Landscape Architecture facilitate an enhanced connection to our night time environment, through specific changes in the design of lighting and other physical elements in outdoor public spaces? 


\subsection{Aims + Objectives}

The aim of this design research is to explore how outdoor public spaces can facilitate a night time experience through the exploration of lighting and other physical elements. Understanding the effect of individual landscape features will be useful in determining why public spaces are seemingly avoided at night.

Objectives

1. Analyze and interpret the existing discussion between public spaces and their use 1. at night

2 Investigate the current night time experience in public spaces in Wellington

2. through reoccurring fieldwork during the day and at night

3 Investigate the impact of different physical elements of an outdoor space at night 3. on feelings of comfort and perceived safety

1 In a design Toolkit, explore how the implementation and design of these features

4. can be modified to enhance the night time experience through physical, digital, analogue and on site iterations.

5 In specific areas designated from the fieldwork, explore how the night time ex5 . perience can be supported through the reapplication of features designed in the toolkit 


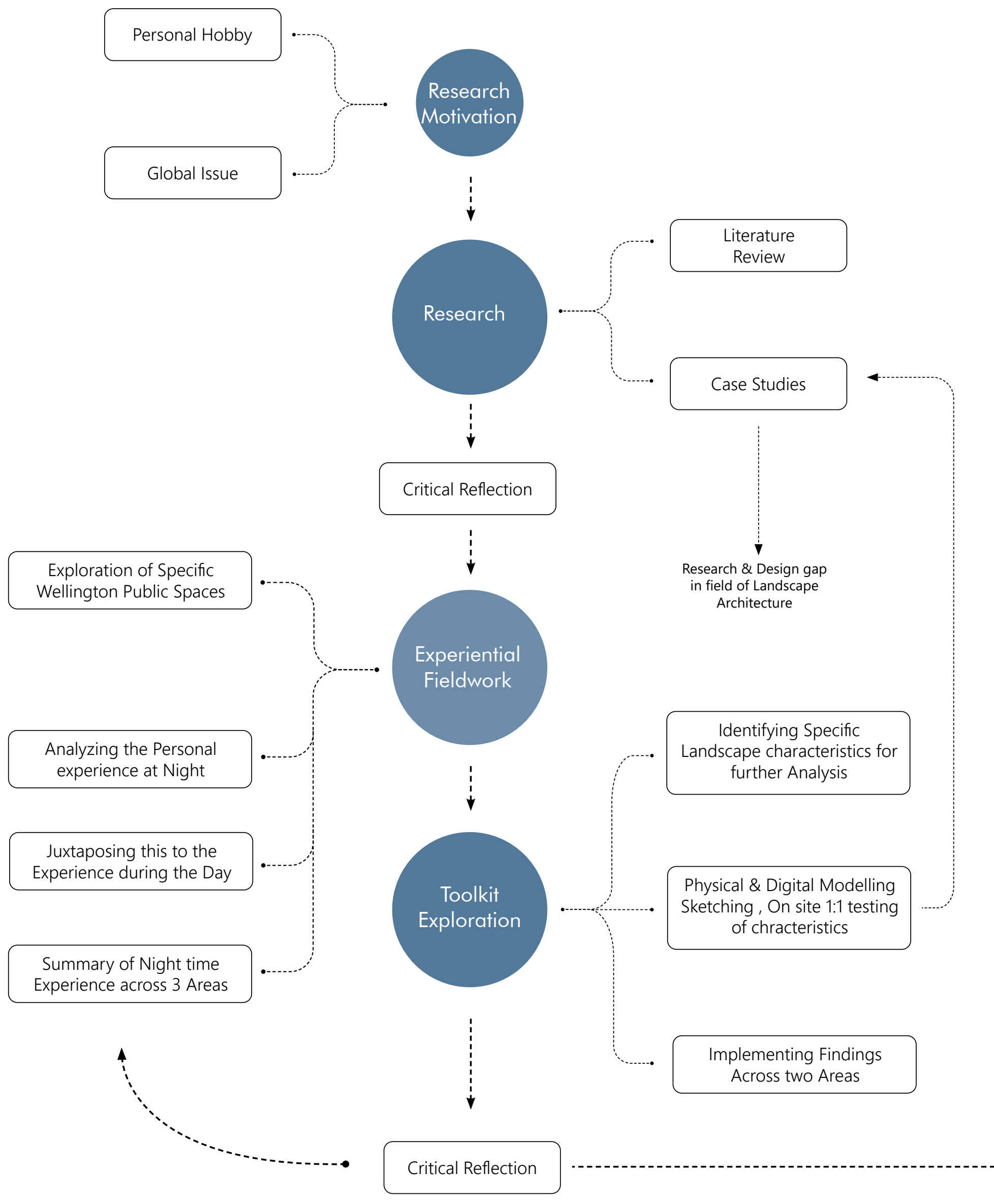




\subsection{Methodology}

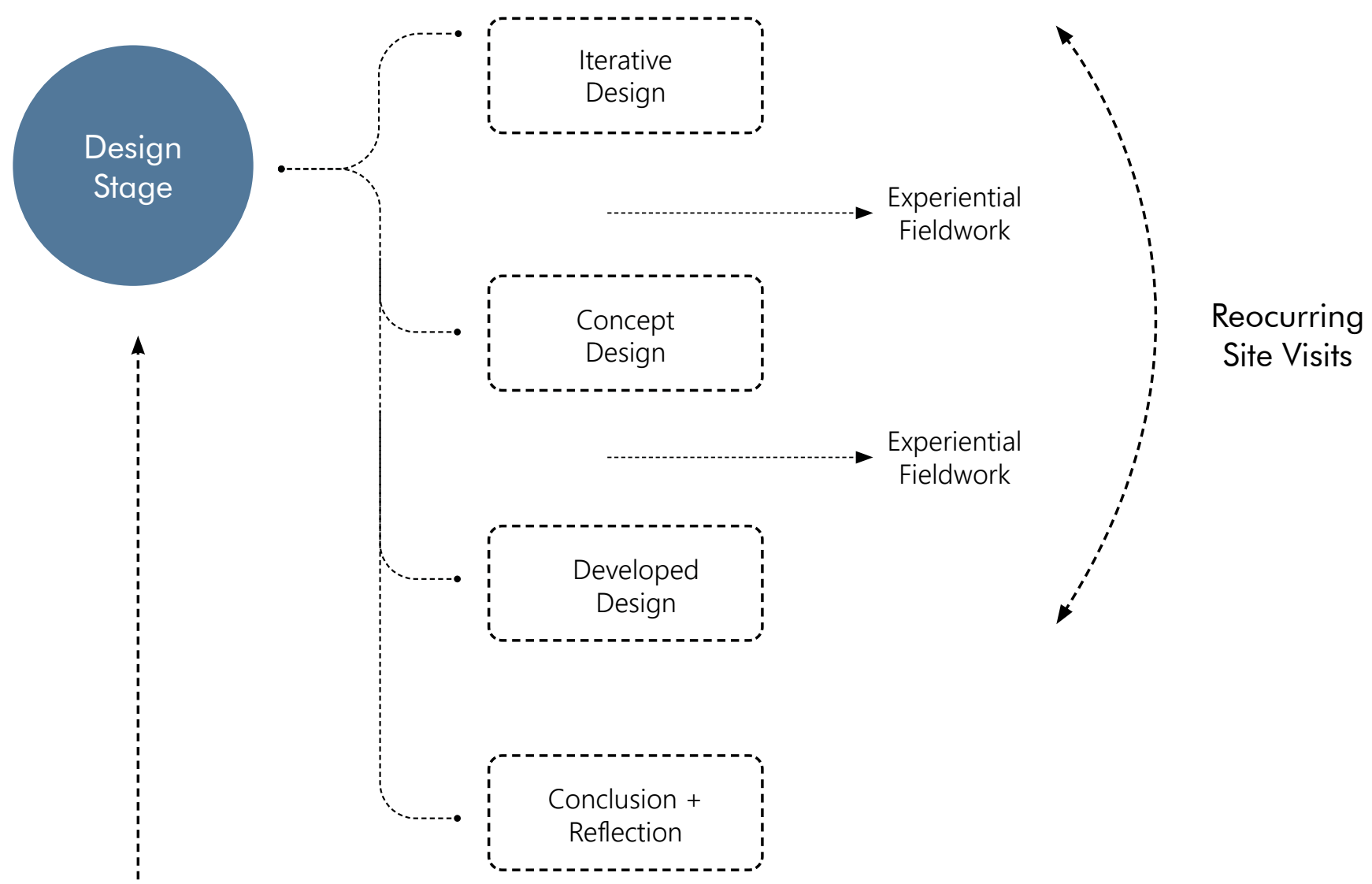

Fig 1.9 Research Methodology 



\section{Introduction.}

In the beginning of the research, the focus was on the night sky, and how the user of a space can connect to it. But over the course of the process it was revealed that the natural environment on the ground at night was also very influential in determining how successful the night time experience was. There was already a large gap in the literature on how design can be used to connect to the night sky, so the topic was split into 4 sub topics for research.

These were, nighttime landscape experience, comfort in spaces at night, the role of lighting and Maori Astronomy. Each sub topic is investigated through a literature review followed by case studies at the local level for Maori Astronomy and local / international level for the remaining 3. Key design theories and the application to the design research were drawn out and summarized. 
2.1 Sub Topics for Research

1. Night time Experience in the Landscape

2 Comfort in spaces at night

3. Role of Lighting in public space

4. Maori Astronomy 
The "night time experience" is defined in this thesis as the active enjoyment of our naturally dark environment, the viewing of stars, planets, nebula and our milky way galaxy. In a design sense, this is creating spaces which encourage people to take part in this experience 


\subsection{Night Time experience in Landscape}

There has been extensive literature explaining the benefits of increased interactions with nature on our mental health (Jansson et al., 2013; Sreetheran \& van den Bosch, 2014), but the majority of these studies, if not all of them, focus on our interactions during the day. Research on the benefits of the night sky has been minimal. This may be due to the unconscious neglect the night sky faces from our design fields, where design decisions regarding the use of spaces at night have continued to stem from the continuation of things we see and do during the day (Bell et al., 2014). As a result, stargazing has been reduced to a niche activity in most communities and cities, with the only conversation on its benefits from astronomers, amateur astrophotographers, and dark sky enthusiasts. However, a small amount of literature has been accessed, and the following benefits were revealed. The enjoyment of stargazing comes from its ability to bring people together and encourage social interaction through a mutual interest in what is beyond our planet (Bell et al., 2014). Gazing at the night sky was also shown to alleviate personal stress by putting things into perspective as we reflect on something much bigger than ourselves.

In today's modern era, we have become so focused on our industrial and technological growth, with the continued focus on building bigger, brighter architecture that the environment at night has been almost completely disregarded and harder to access. This may come from what architects and urban planners associate with the terms landscape and nature. "Landscape" has always been associated with what was happening on the ground plane. In paintings and old landscape photographs, features such as mountains, forests, open fields, and waterways are commonly what our eye is drawn to (Ingold, 2011), yet the sky was always one half of the picture. As landscape architects, we often describe our role as managing the connection between people and natural systems, but we often limit our thoughts to ground-based terminologies such as trees, plants, rocks, animals and their habitats which is why it may seem that the inclusion of the sky and specifically the night sky has been lost (Blair, 2018).
This apparent nature-sky disconnect has led to the utilization of only one half of the natural environment around us: its use during the day. These interactions with nature are often very visually orientated (Bell et al., 2014) and the engagement of our other senses a seemingly rare experience. At night we lose our visual sight as the primary sense, which has been shown to increase anxiety and stress because of the "lack of visual stimuli" (Levos \& Lowery Zacchilli, 2015). Conversely, our nocturnal environment may provide a more engaging and enriching experience with nature as we interpret our environment through sound, touch, taste and smell, so that what we can see receives our complete focus.

On clear nights when our galaxy's beauty and scale reveal themselves, this becomes the visual stimuli. It provides us with a feeling of amazement and fascination, followed by admiration and clarity (Bell et al., 2014). Emotions such as these have been shown to lead us to a moment of intense happiness (Boniwell, 2012). The amount of natural spaces in our urban environment is finite; this difference in experience at night can allow us to reuse these spaces, giving them a "dual experience" (Bell et al., 2014).

\section{Key theories to apply into design research}

- Public Spaces can have a different experience at night to during the day

- Landscape architecture must respond to not only what we perceive and respond to on the ground but also what is in the sky above us at night

- The final design outcome must provide an experience suitable for not only the individual but also for groups

- The final design outcome must respect the value of the nocturnal experience and not disrupt areas already uninterrupted by the urban realm 


\section{Day vs Night Engagement of Senses}

The day time is very visually orientated

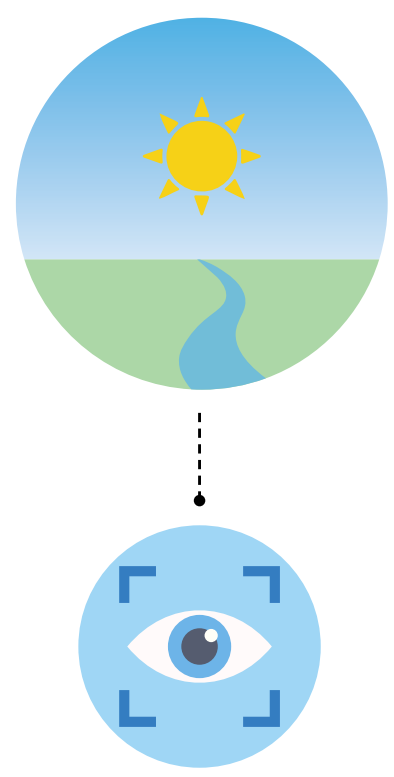

Through Vision

At night we can have a more enriched experience with nature, through the increased use of our other senses
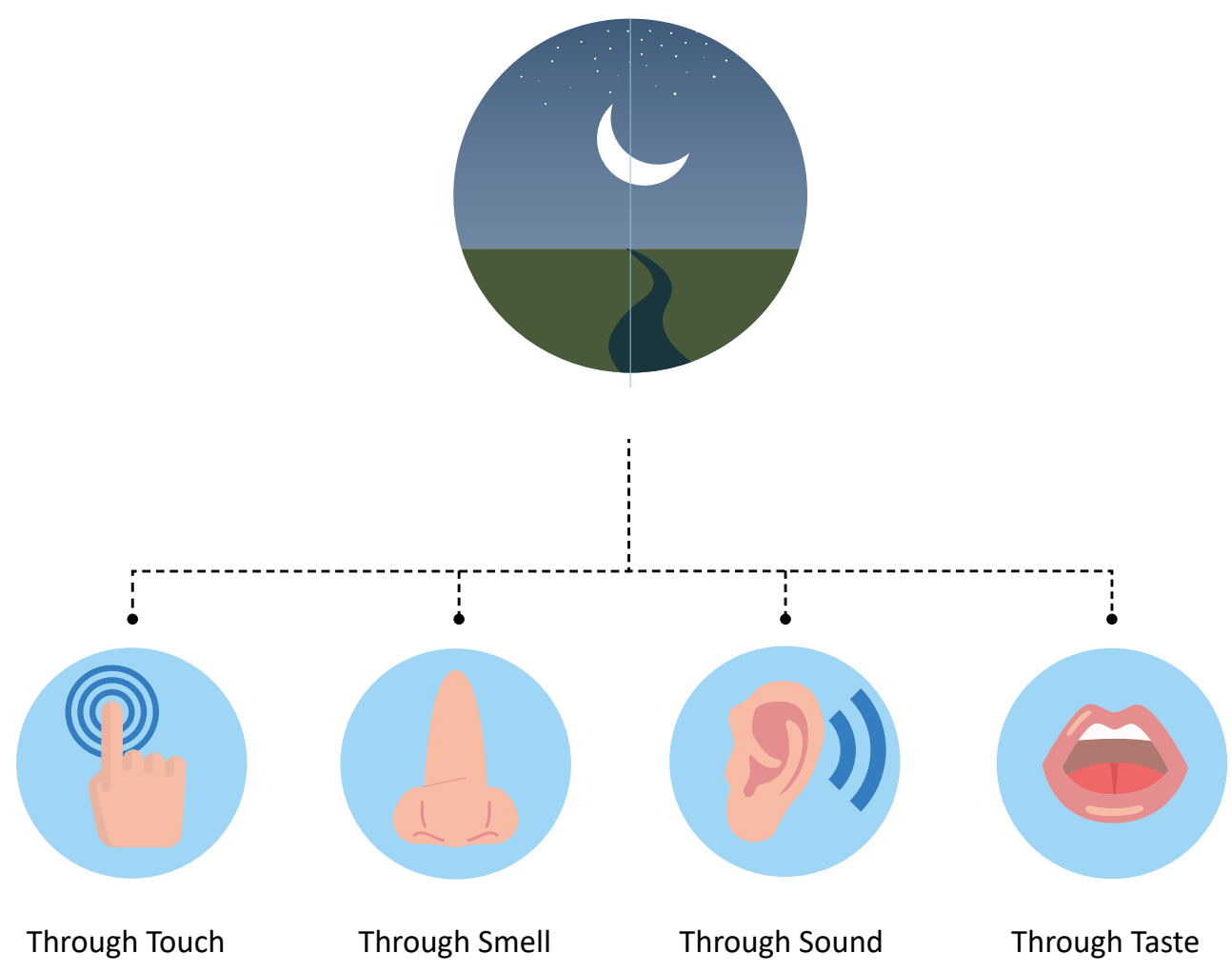

Fig 2.2 Day vs Night Experience 
Night time Landscape Experience

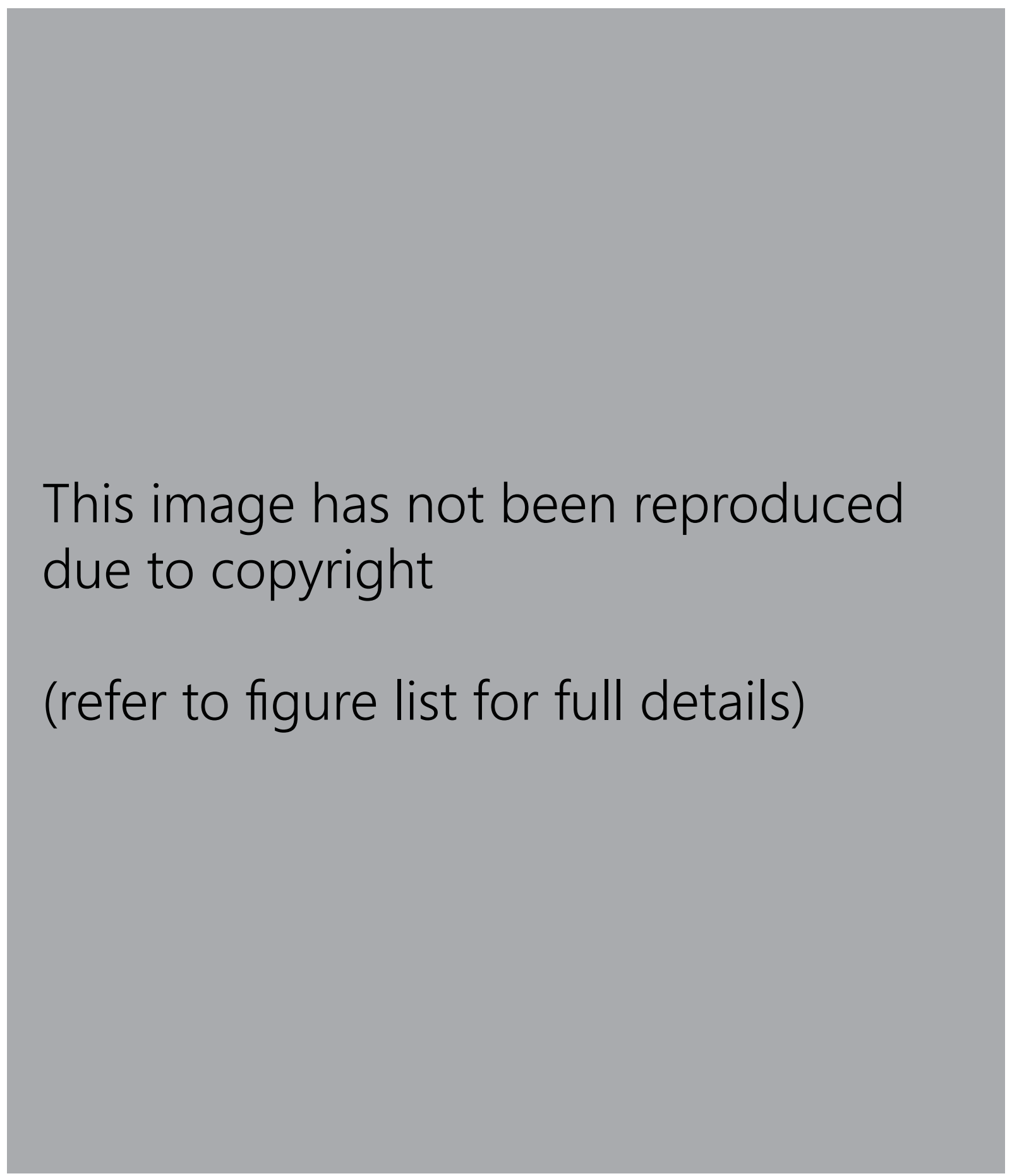

Fig 2.3 Penguin Viewing

Platform

Blue Penguin Landing 


\section{Blue Penguin Viewing Platform}

\author{
(Local) Pilots Beach, Dunedin, New Zealand \\ Royal Albatross centre, 2008
}

This platform at Pilots Beach, Dunedin, New Zealand, allows for the viewing of Kororā (the blue penguin) in their natural habitat when they return from the ocean, scurrying up the beach to their nests. The platform was a joint venture by the Royal Albatross Centre and Pekekura trust, who operate tours every evening at dusk to the platform built specifically to view the penguins in their natural habitat. From the car park, a walkway with interactive lighting leads you down to the top of the beach, where directional lights illuminate the entire beach where the penguins come ashore.

While not a case study that focuses specifically on the night sky, the platform affords people to spend time in the nocturnal environment, with the mutual fascination and enjoyment over the viewing of the penguins outweighing any lingering thoughts of anxiety being outside at night with strangers. The platform's design also allows it to be a suitable viewing platform during the day and, as it faces west, an ideal location to admire the sunset. As discussed in the literature, when public spaces can provide a dual experience, this is when they can have the highest value.

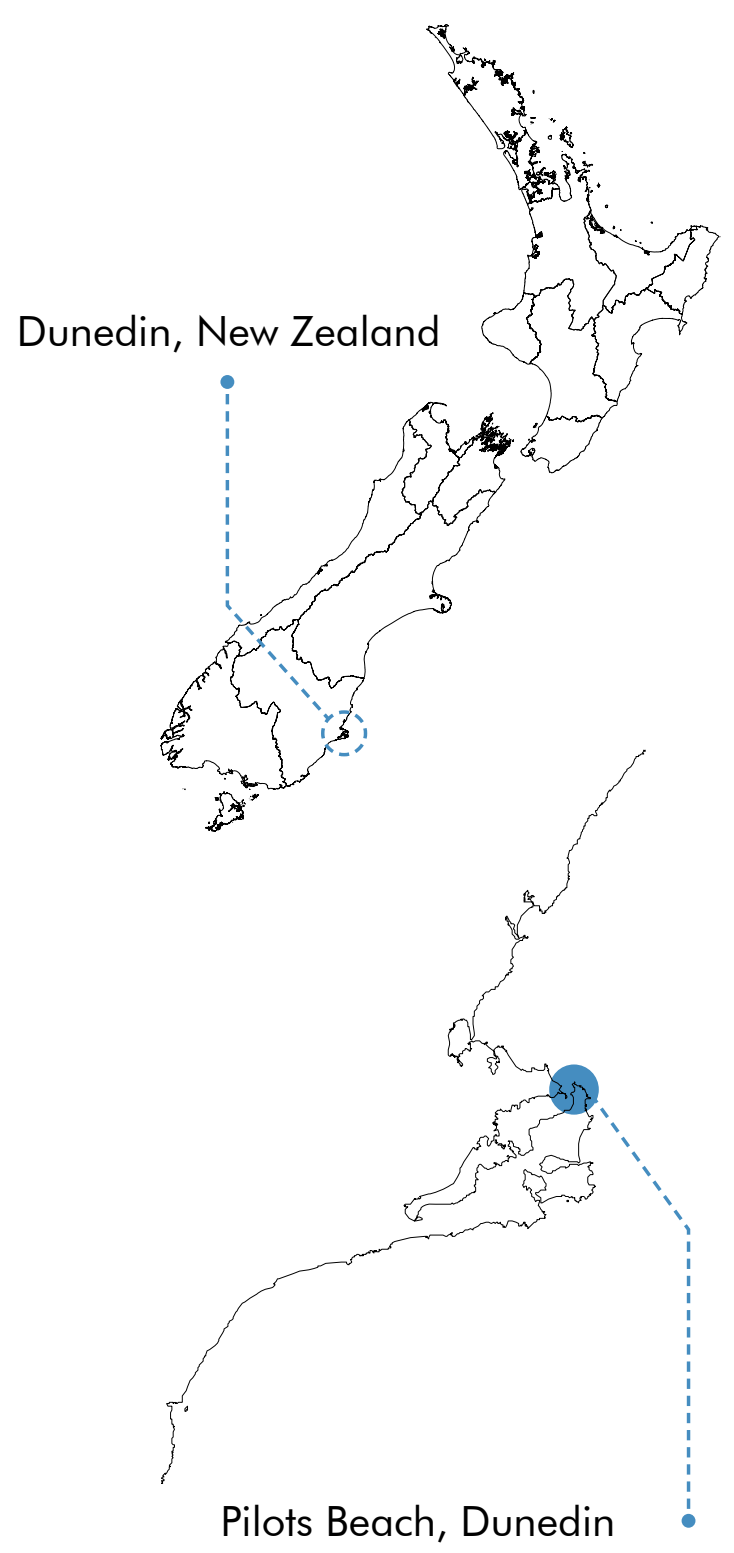




\section{Design Features}

Encouraging Social Interaction

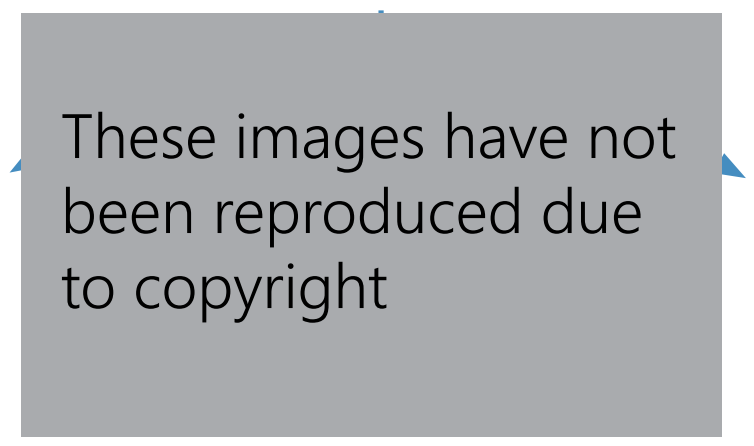

Affording view of surroundings

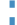

Directing focus down and outwards

I

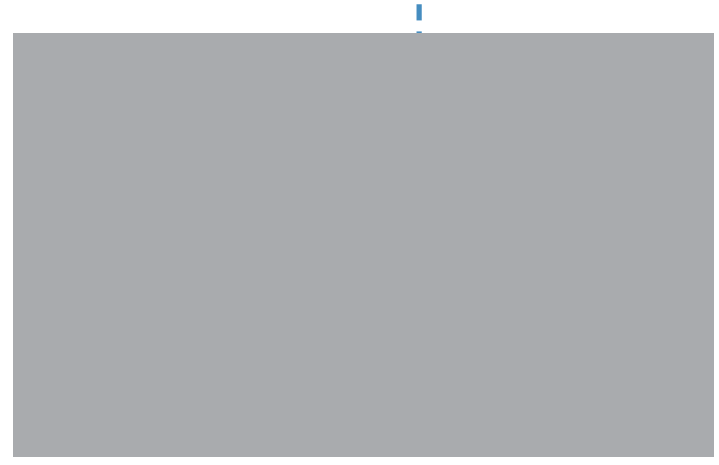

Light panels guide the way

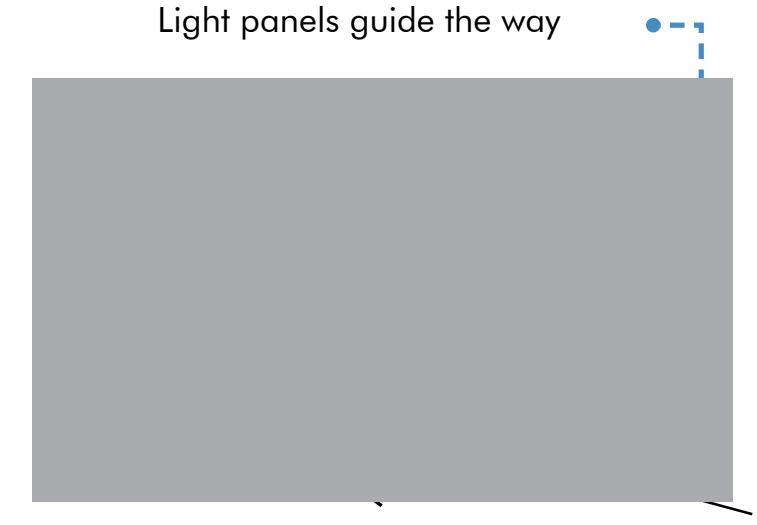

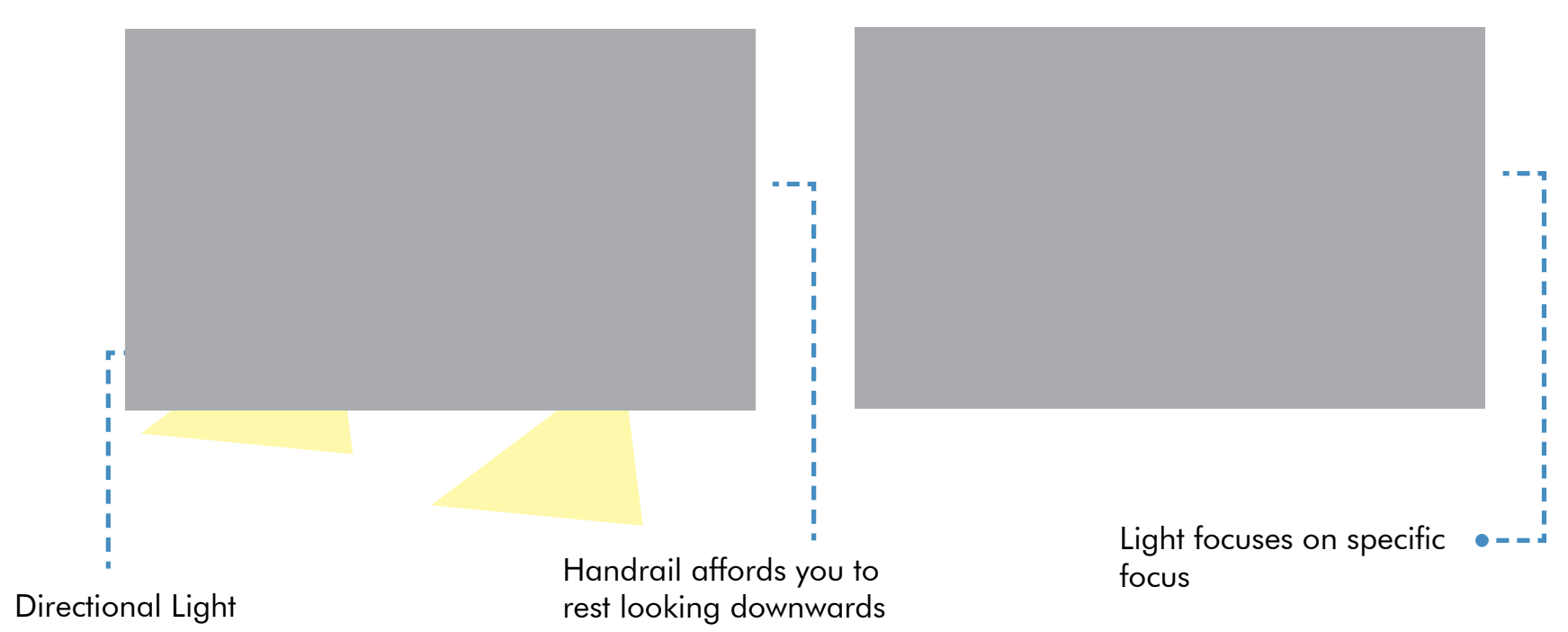




\section{Design Principles}

Impact of Form on Gaze

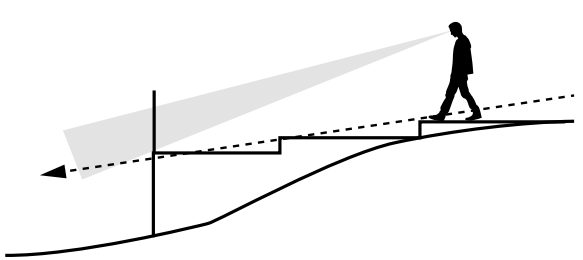

Community Interaction

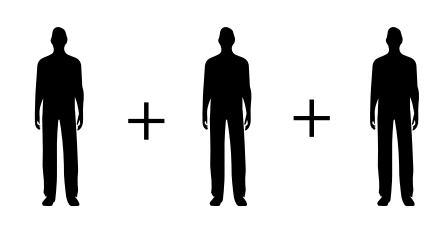

Comfort with Others

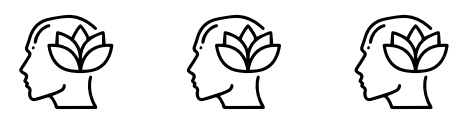

Comfort at Night

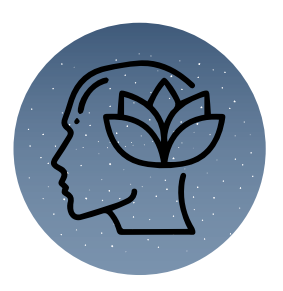

Application to design research

- Encouraging social interaction outside of daylight hours through the focus of a mutually enjoyable interest

- Providing a comfortable (in terms of your anxious/ relaxed state of mind) space through giving it a specific focus

- Provides an experience suitable for the surrounding environment outside of its intended purpose 
Night time Landscape Experience

This image has not been reproduced due to copyright

(refer to figure list for full details) 


\section{Rhön Unesco Biosphere Reserve}

(International) Rhön Biosphere Reserve, Germany Community project 2016-2019

The Rhön biosphere reserve is an area spreading across three separate states in Germany: Hesse, Bavaria and Thuringia. It was given International Dark-Sky Reserve status in 2014, one of 16 in the world certified by the International Dark Sky Association (Star Park Rhön, n.d.). In response to this, many groups within these communities have set up star park areas (Biospharenreservat Rhon, n.d.) that encourage spending time under the stars. The areas can be split into three categories: the "heavenly theatres", "Astro platforms", and official guided tours around the various dark sky parks within the reserve. The project was a collaboration between the community, free and private sponsors, local institutions, astronomers and lighting companies (Star Park Rhön, n.d.).

The heavenly theatres use multiple interactive features such as information boards, binoculars, curved seating and star finders to encourage people to visit at night. The astro platforms provide flat platforms to set up tripods for taking photos of the stars.

Reviewing the literature, the spaces allow the passer-by to reflect on the space during the day and return at night to interact with the nightscape, giving it a dual experience, recycling the existing landscape.

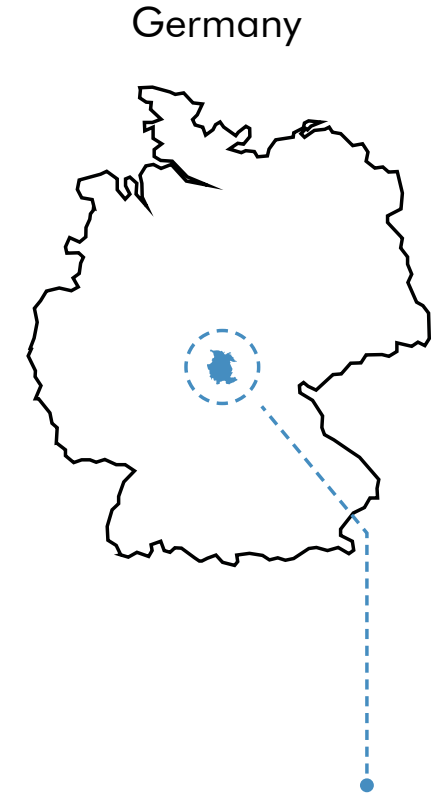

Rhön Biosphere Reserve

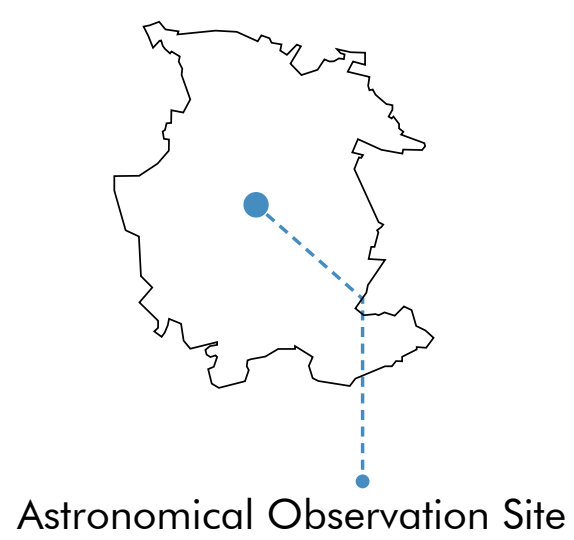




\section{Design Features}

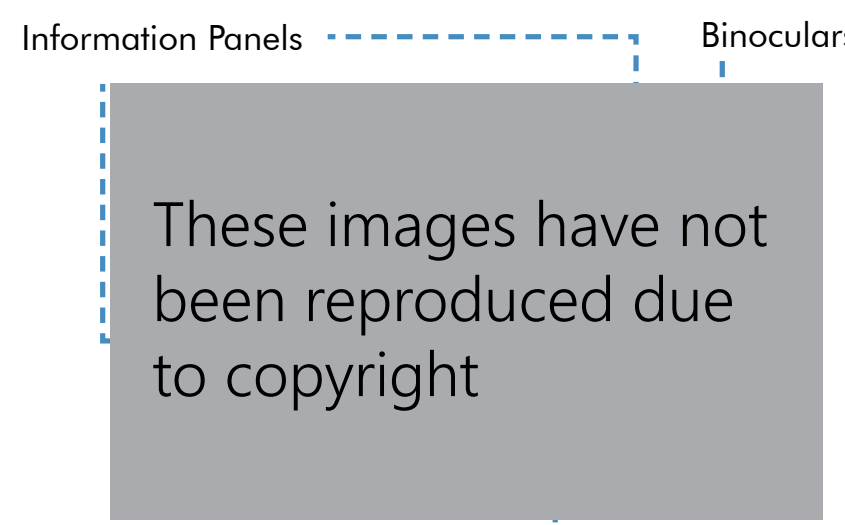

Curved Seating

Information Panel on stars

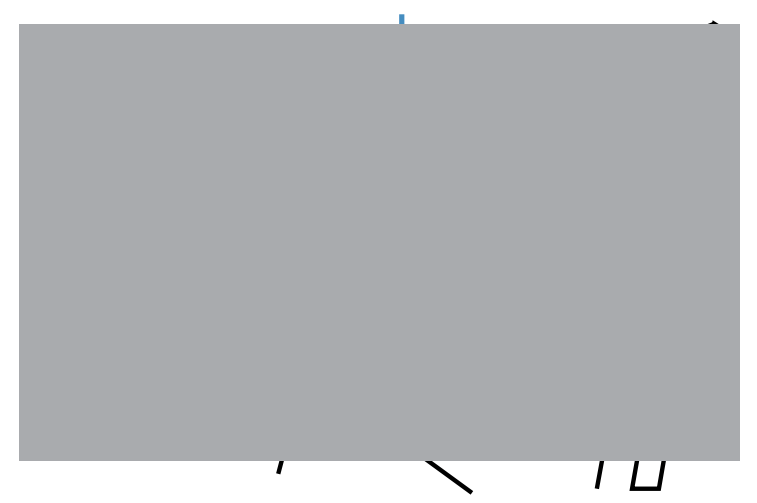

Frame for wind shelter

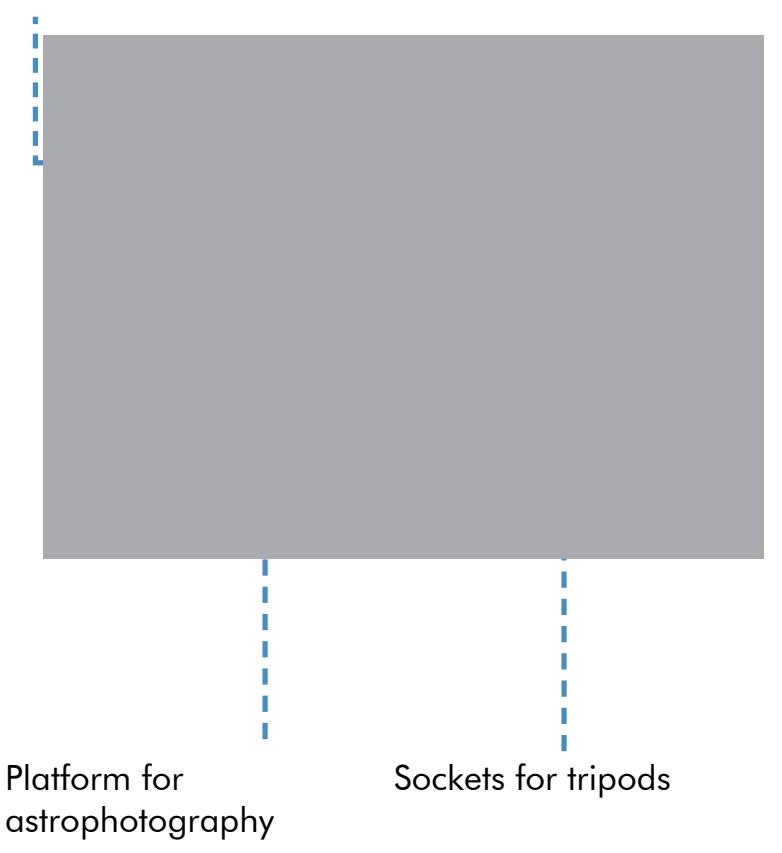

Rotating Seat that can direct view upwards

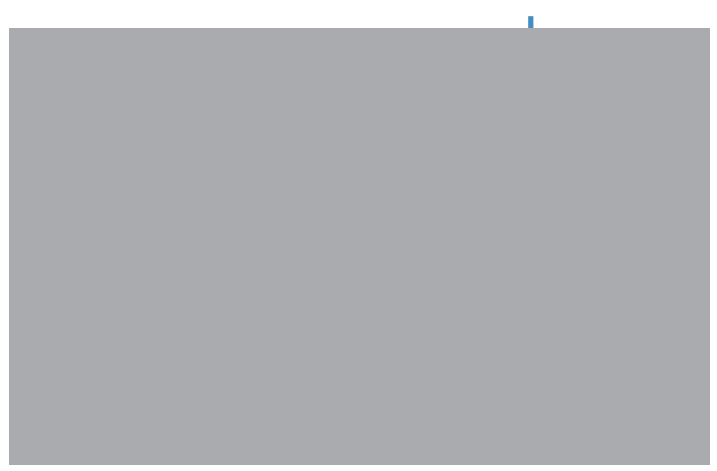

Information Panel

Polaris star finder

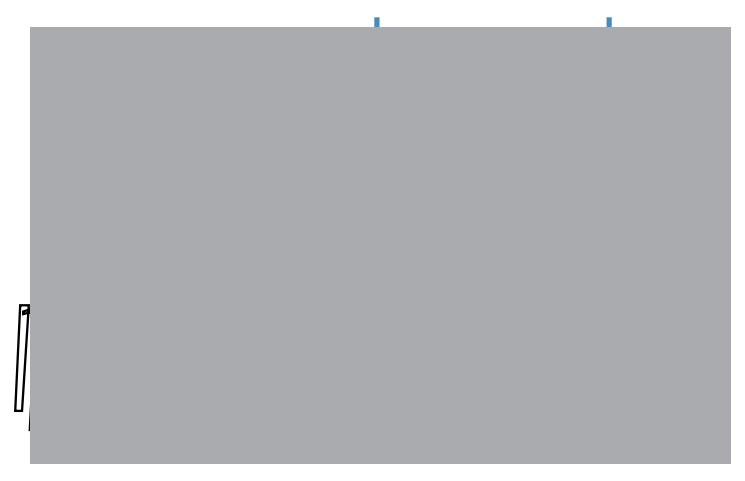

Polaris star finder

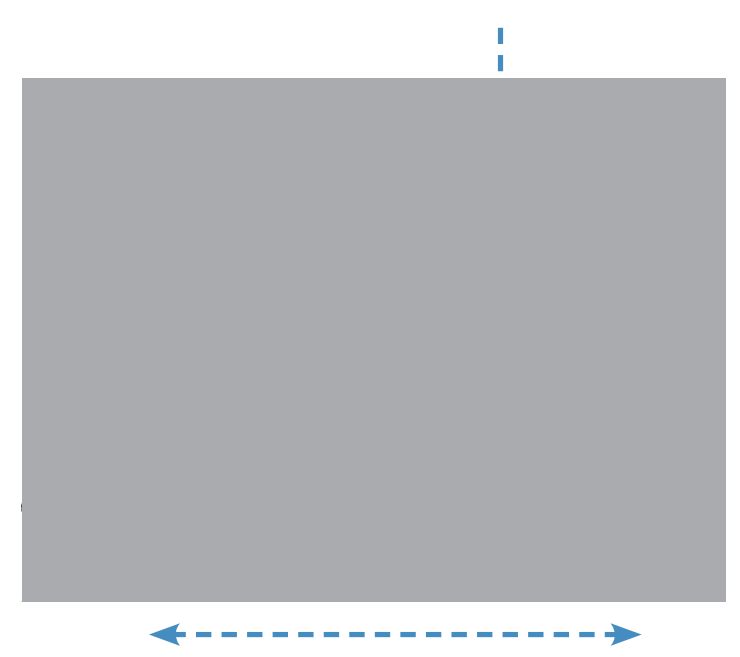

Interaction through mutual fascination 


\section{Design Principles}

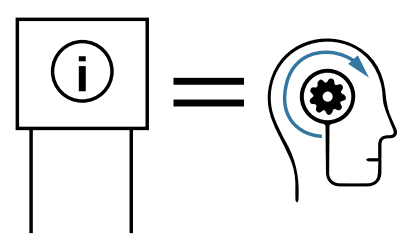

Education as a design tool

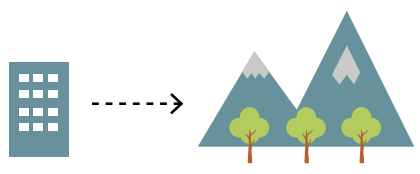

Encouraging time spent in larger landscapes

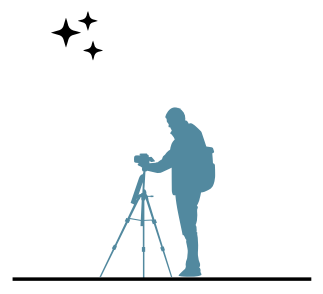

Providing interaction specifically with night sky

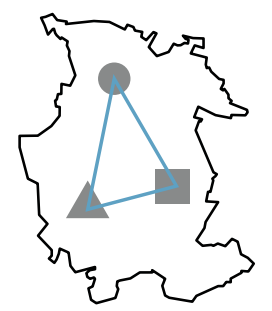

Small scale design elements in different locations

\section{Application to design research}

- Small scale interventions across multiple areas can prove to be a successful solution rather then the development of one large area

- Varying the purpose of the interventions affords greater interaction and fulfilment in a space

- Designing for the human scale is a helpful tool when considering the night time experience 


\subsection{Comfort in spaces at Night}

Numerous studies have proven that humans are inherently afraid of the dark and the hidden dangers it may contain (Levos \& Lowery Zacchilli, 2015). While this fear originates from prehistoric times when the risk of being attacked by predators or enemies was much higher (Emanuel, 2017), it has also been ingrained into our upbringing, where we are taught to associate light with safety and darkness with danger (Hilary, 2014). As a result, people commonly tend to avoid visiting or passing through open public spaces at night. This fear is linked to the landscape's specific characteristics that afford hidden places for predators or enemies to hide. This was first discussed in the "prospect/ refuge" theory proposed by Jay Appleton in 1975 (Jansson et al., 2013). If an environment provides potential hiding spots for attackers (refuge), limits the user's view of nearby surroundings (prospect) and creates a feeling of entrapment, people will perceive it to be less safe (Rahm et al., 2020). Refuge in an environment may provide "dual affordances" (Blöbaum \& Hunecke, 2005), where it can conceal the attacker and provide the user with a place to hide.

At night because of the decreased visibility, prospect and refuge are switched. Instead of a series of possible hiding spots in the space around us, we have small amounts of visibility with an infinite number of hiding spots due to the decreased visibility (refuge) (Loewen et al., 1993). Therefore, in an environment at night, people prefer environments where there is an increased prospect with no refuge at all (open space) as it gives no hiding spots for attackers around them, besides the overall darkness. These are important concepts to understand as star gazing often takes place in the darkest of environments.

In the past, lighting was introduced as a solution to reduce potential crime. Lighting is what affords prospect, and low lighting leads to poor visibility of our surroundings. In an environment at night, this can bring the concern of concealment back, leading to avoidance. In the early stages of design, we should consider the relationships between lighting and landscape characteristics that provide concealment (Loewen et al., 1993).
Landscape characteristics to consider may be vegetation density and structure, shown in several texts (Jansson et al., 2013) to lead to feelings of entrapment and topography. The wild and more natural appearance of vegetation was considered frightening (Jansson et al., 2013). Patches of greenery that are too close together, on the sides of a path, lead to fear of entrapment. However, in a space surrounded by vegetation, if the environment behind it is visible, this presents possibilities to escape and increases a sense of prospect. Topography also impacts perceived prospect. If the ground is raised on one side of the paths yet open on the other this provides prospect. These specific landscape characteristics can be applied to the fieldwork for further investigation.

\section{Key theories to apply into design research}

- Landscape characteristics can be defined into 3 considerations, prospect, entrapment and concealment.

- Open spaces increase prospect.

- Increased Prospect equals increased comfort in a space.

- Densevegetation increases fears of entrapment and concealment of potential attackers.

- Fear of entrapment and concealment leads to Avoidance.

- Vegetation structure and appearance is important to how we perceive environments at night.

- Vegetation \& lighting must be considered together since they can influence prospect. 
Fig 2.5 Perceived comfort at night

Vegetation Structure
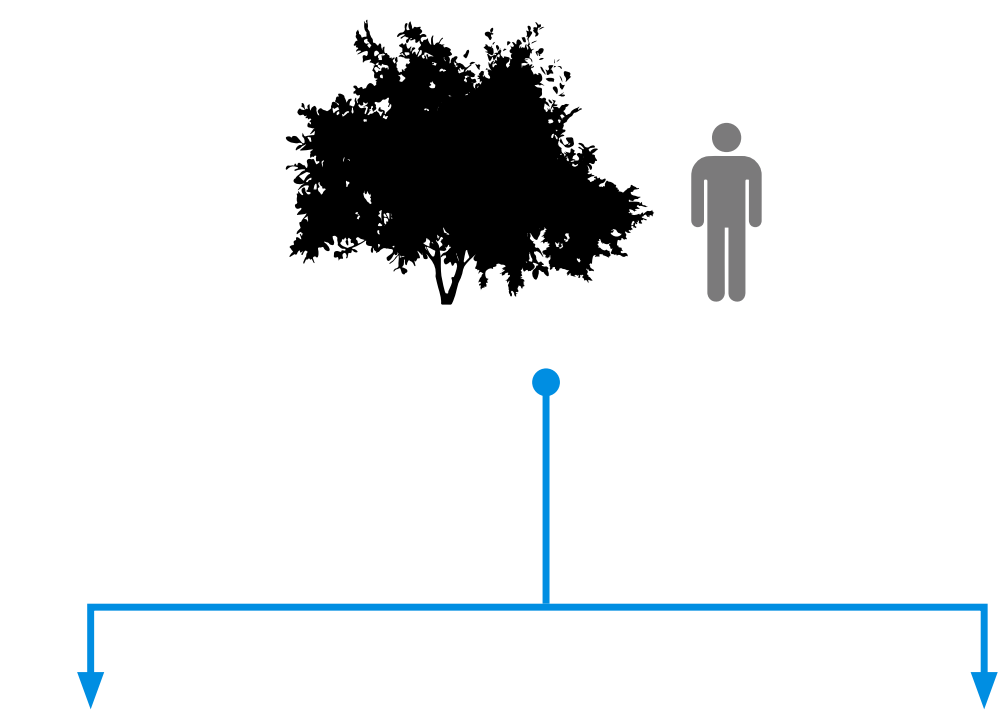

Prospect
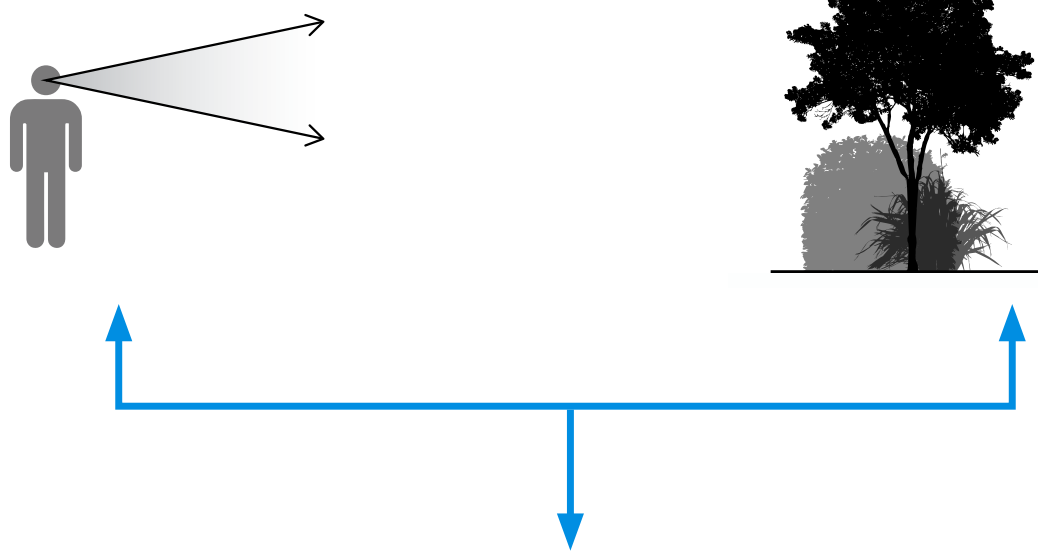

Perceived Safety
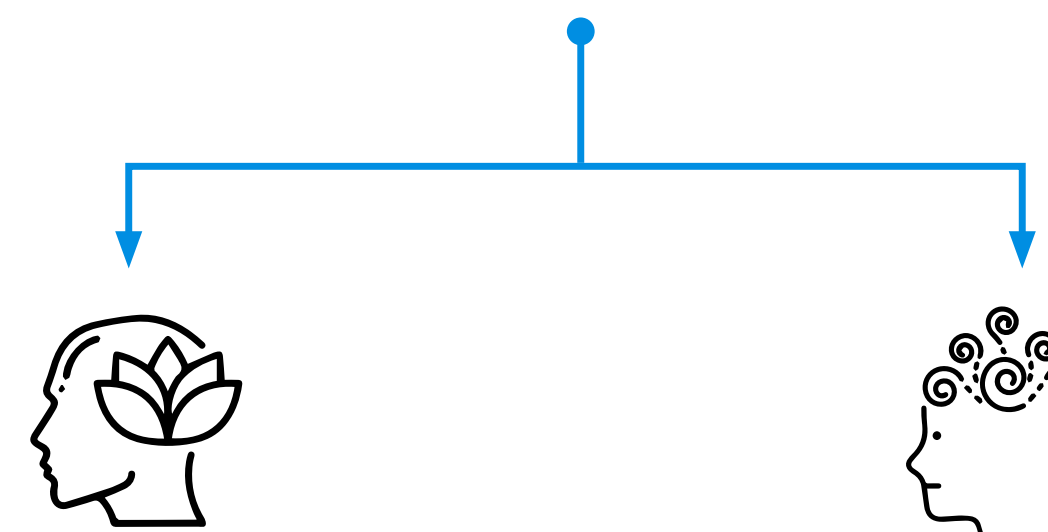

Comfortable /

Calm
Entrapment
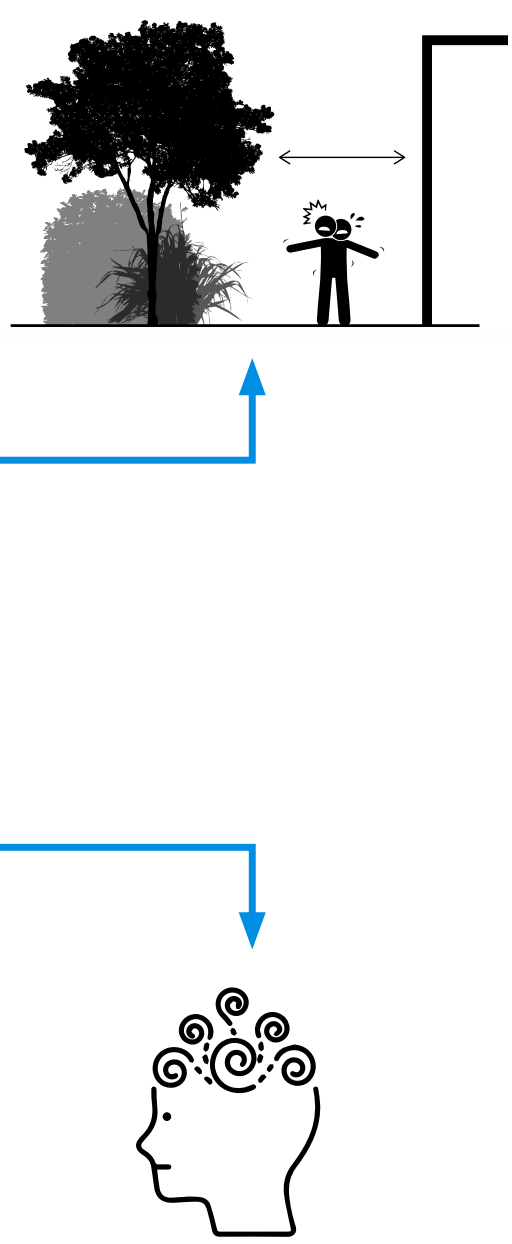

Uncomfortable / Anxious 


\title{
Comfort in space at Night
}

\section{Mt Victoria Wellington (Town Belt)}

\author{
(Local) Wellington, New Zealand, Wellington City \\ Council, 2020
}

Mount Victoria is the central town belt area running through Wellington City. Wellington's southern walkway track runs from the summit down towards the south, with many different public leisure spaces dotted along the way. Many of the theories explored in the literature were recognized within the various spaces. Spaces with:

more open space created comfort because of increased prospect (bottom right)

vegetation on both sides led to feelings of entrapment (middle left)

dense vegetation on at least one side evoked fear due to the possibility of concealment (top left) tall vegetation was frightening, but when able to see through it, there was increased prospect (top left) low elevation decreased prospect whereas areas at high elevation provided the opposite (middle right) vegetation had a wilder appearance which decreased perceived safety. (bottom left)

The combination of different individual landscape characteristics sometimes changed the perception of the individual characteristics. For example, sites at a high elevation with little open space and the proximity of vegetation went from a feeling of increased prospect to entrapment.

Application to design research

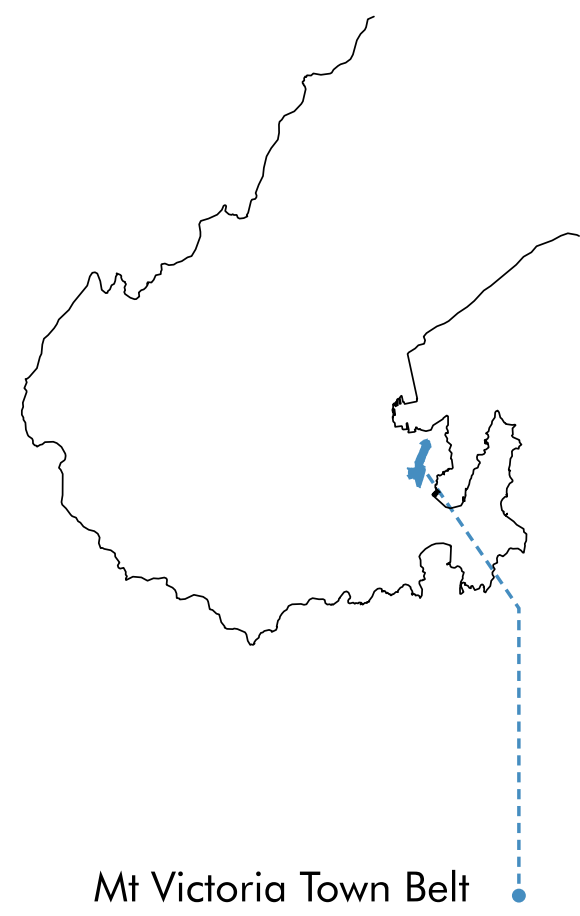

- Importance of vegetation when designing an outdoor space

- Importance of elevation and access of a site 


\section{Design Features}

Tall dense vegetation creates fear of concealment, but the open side provides prospect

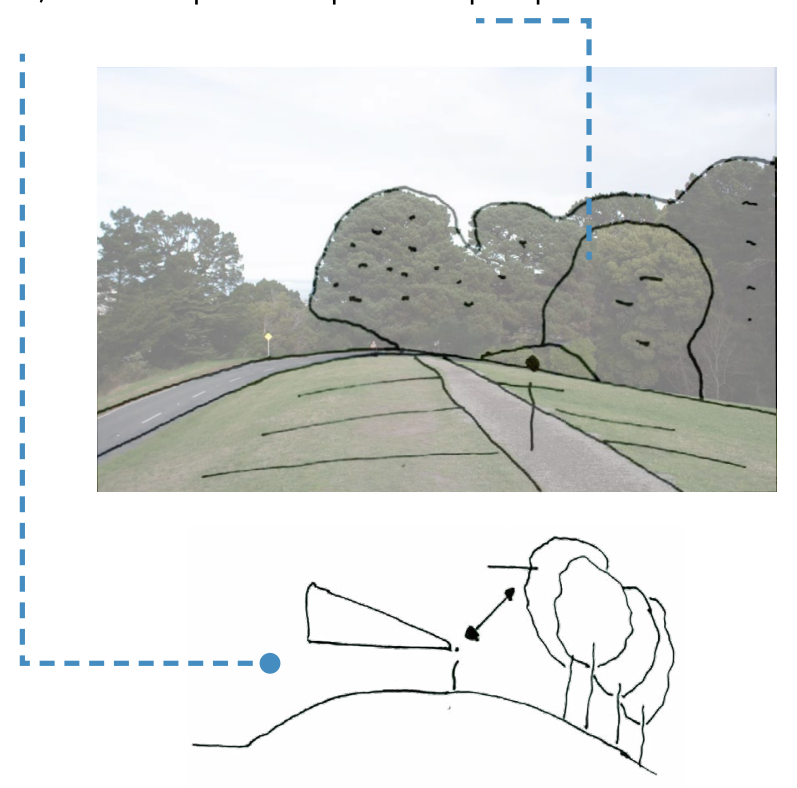

Vegetation close together - Entrapment

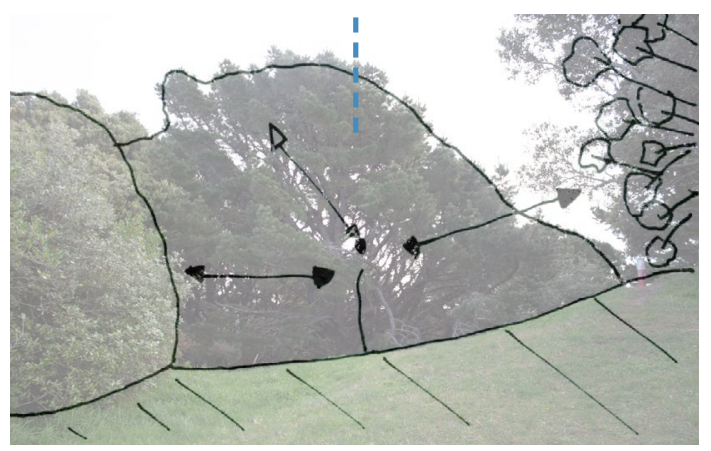

Entrapment

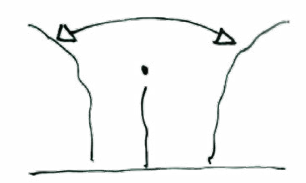

wild nature of the surrounding vegetation

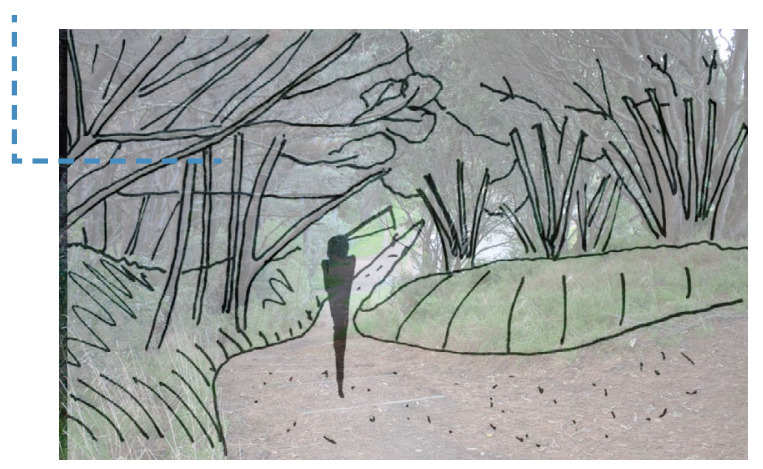

Silhouettes evoke fear due to concealment
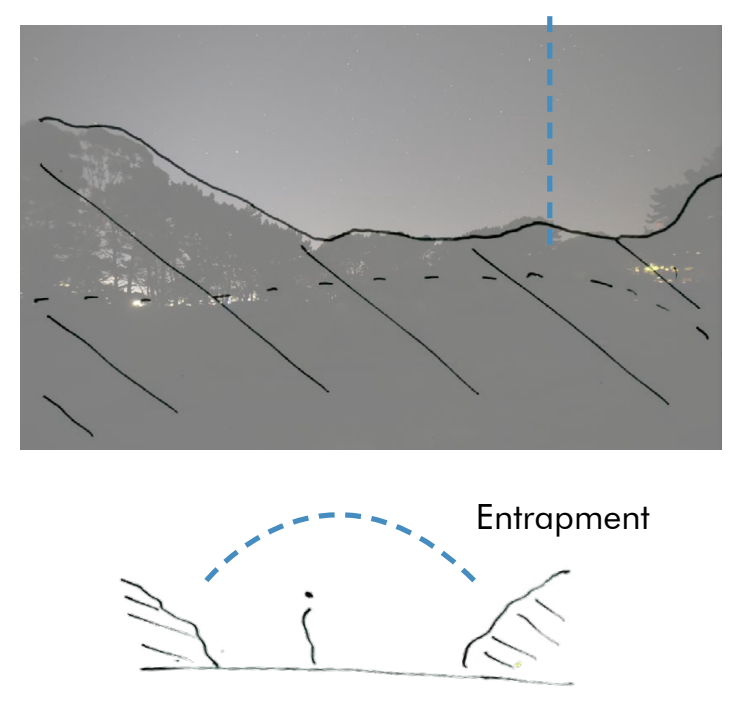

Low elevation $=$ decreased prospect
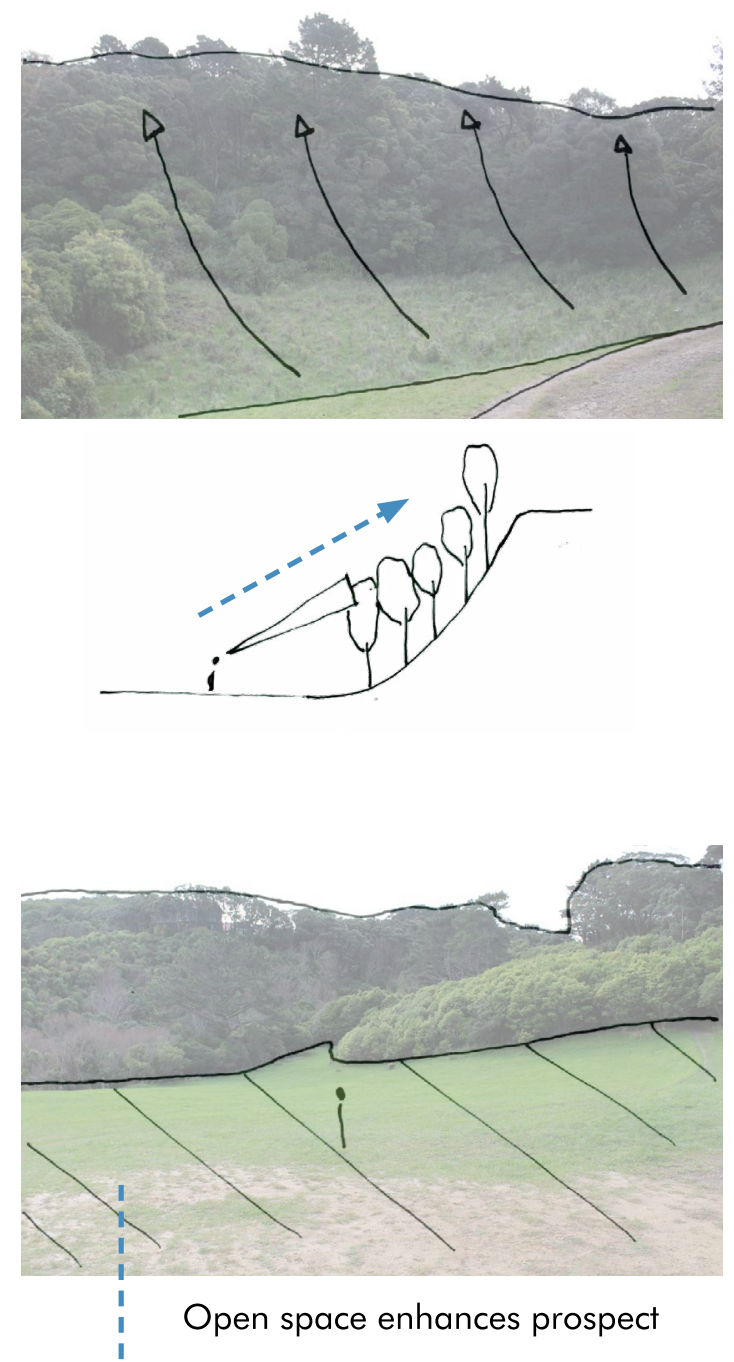


\subsection{Role of Lighting in Public Space}

The introduction of the light bulb is one of the greatest inventions in human history. It changed our economy's structure and provided longer working hours, which led to many technological advances. However, as we have developed cheaper and more efficient light bulbs, we have become careless with their use in society.

Despite intentions to reduce running costs and energy consumption, the white light emitted from LEDs has created more issues than before. An unresolved discussion revolves around how cities are installing more LEDs than required due to their cheapness to run (Entwistle \& Slater, 2020). In one case in Palmerston North, LED implementation in the existing street lights left residents perceiving the street far brighter than previously with the amber/sodium lighting. As a result, the dark spots between the lights' glare felt even darker, which caused more LED lights to be implemented (Rankin \& Mays, 2017).

Lighting and perceived safety is an intricate discussion. When the first street lights were created, the reasoning provided was that more light reduced crime, but research has shown no evidence proving increased outdoor lighting decreases crime, only that it may make us feel safer at night (Lighting, Crime and Safety, n.d.; Morrow \& Hutton, 2000; Edensor, 2015). This means that the lighting we use at night must actually reflect our emotional response and not just be measured in terms of its illumination amount (Bannister, 2020).

The difficulty of recording emotional responses, and the inherent fear of the dark mentioned previously, reflects the outdated view that increasing the amount of light will make us safer. Outdoor spaces that are overly lit can decrease safety by making victims easier to see. In one study in Melbourne, researchers found that overlit spaces were considered less safe across 80 spots deemed unsafe by women (Bannister, 2020). This is because if outdoor unshielded light is used, the glare generated can impair the user's view and create places where offenders can hide (Davoudian, 2019).
Many debates on lighting revolve around energy usage and economic value, never around the social issues and how designers can design with lighting. At night, our outdoor spaces have become dull, even referred to as a "nocturnal blandscape" (Edensor, 2015). Many public spaces use homogenous lighting in the form of tall posts with lights that "bleach" out the ground (Entwistle \& Slater, 2020) which is the same style and quantity of lighting used on motorways and streets. These methods are often used to afford the same use of the space during the day at night and provide people with a sense of safety, but it would be more effective to evaluate how people use the space and how lighting can support this (Entwistle \& Slater, 2020).

The only times where we see the light used as an interactive feature that supports the darkness in a public space is in the form of a light festival, art piece, cultural event or any other form of temporary installation (Entwistle \& Slater, 2020). In most cases, the function of lighting has been reduced to displays that do not add anything to the city's experience or a particular space at night.

\section{Key theories to apply into design research}

- To encourage social interaction at night, the lighting must reflect our emotional response

- Lighting is used in homogenous typologies that do not add anything to space

- Lighting does not necessarily create safer spaces; it is the type of lighting used

- The implementation of LEDs can lead to increased lighting due to their brightness 


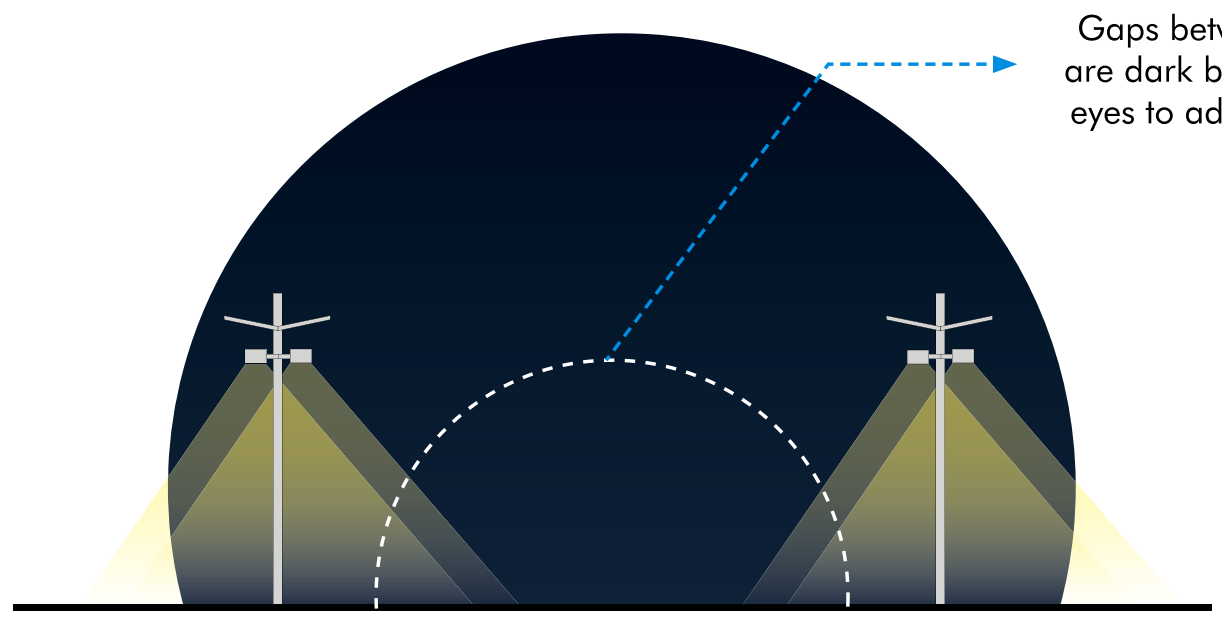

Gaps between amber lighting are dark but it is easier for your yes to adjust with the reduced glare

\section{Existing Amber Lighting}

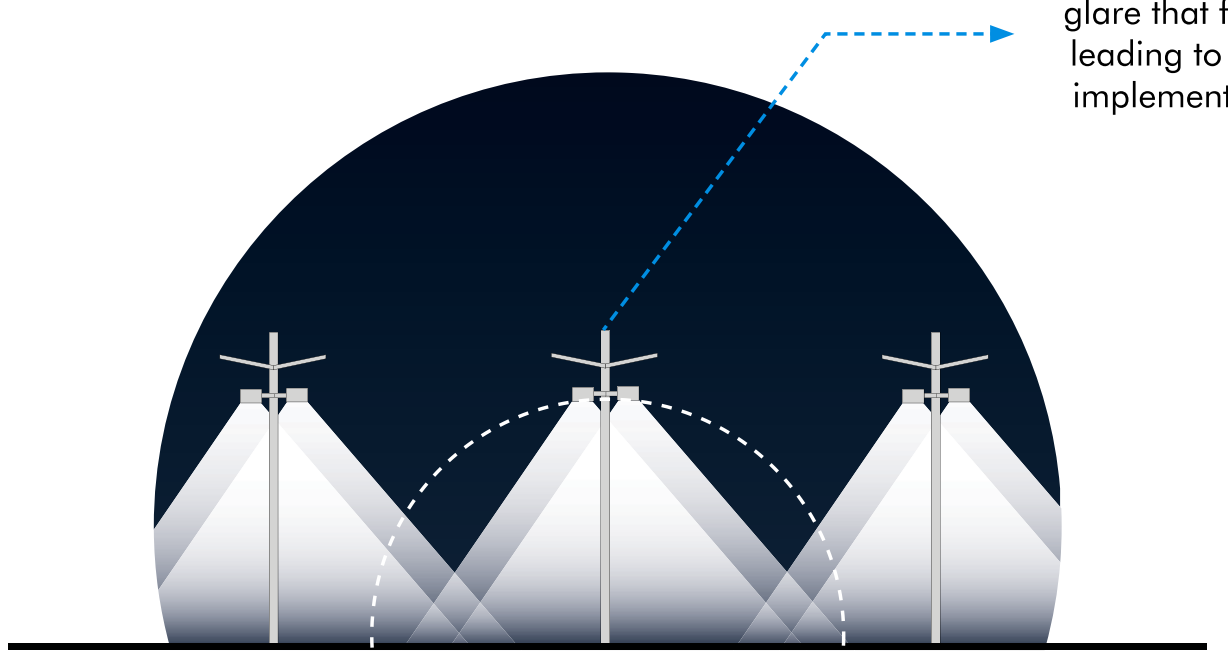

The white light of LEDs creates glare that feels more intense, leading to more lights being implemented to fill the gaps

LED lighting which is far brighter

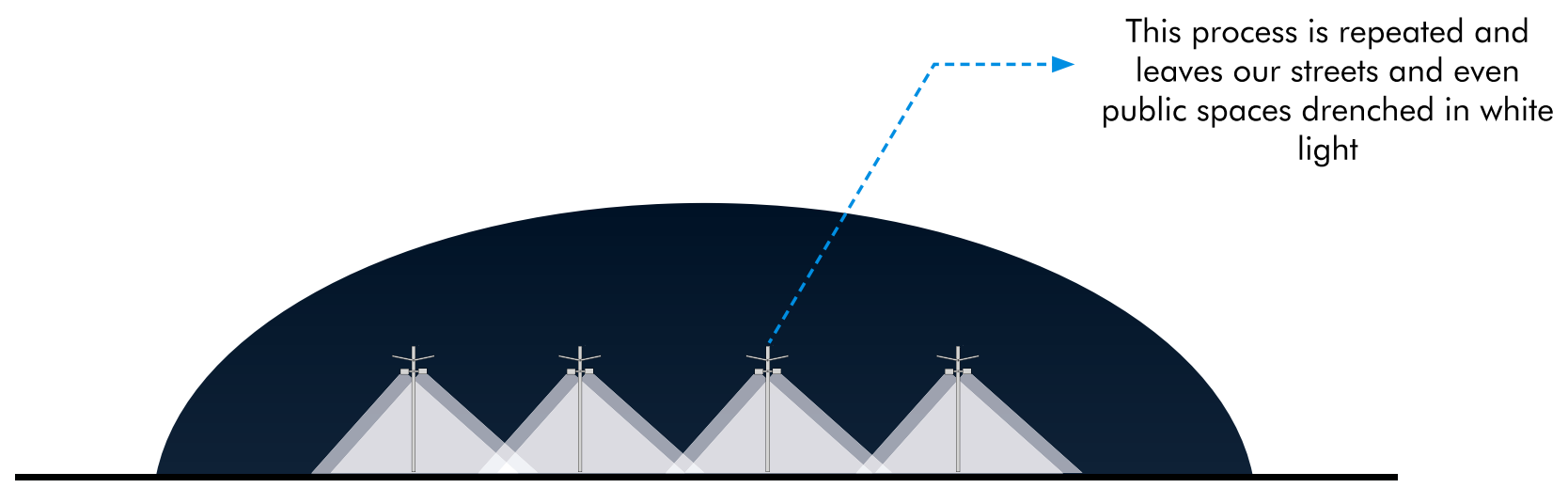

Result

Fig 2.6 Effect of current lighting 
Role of Lighting in Public Space

This image has not been reproduced due to copyright

(refer to figure list for full details)

Fig 2.7 Ambient Lighting in Garema Place (Street Furniture, 2017) 


\section{\#BackyardExperiment}

(International) Canberra, Australia

Street Furniture Australia, 2017

Street Furniture Australia proposed a design solution to the "blandscape" called the Backyard Experiment. A pop-up park, designed by the landscape architecture firm Context, was implemented in underused Garema Place in the heart of Canberra, Australia, with the design goal to attract more people to make it more familyfriendly (Street Furniture Australia, 2017).

Despite being surrounded by cafes and shops, the space was bland and did not afford much social interaction. At night, homogeneous pole-mounted lighting did not offer much of a change either. Among the changes proposed was an entirely new lighting scheme. The existing lighting was turned off, and spotlighting highlighted the newly added seating and colours. Blue coloured lighting added to the tree canopies also created a cathedral-like ambience (Bannister, 2020)

In the research conclusions participation at night was particularly interesting. The nightlife in the space usually consisted of adults, but due to the various interactive features, many of which were supported by different coloured ambient lighting, many families and young children visited the site.

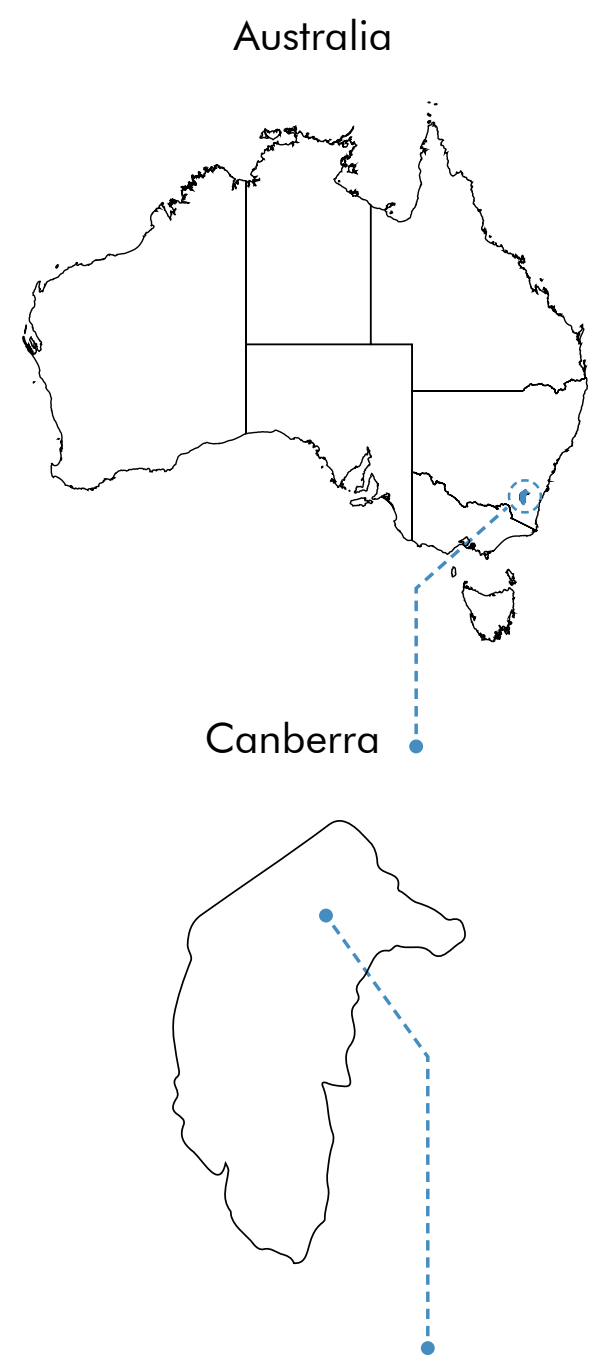

Garema Place 


\section{Design Features}

Ambient light

and change in

colour encourage

more interaction

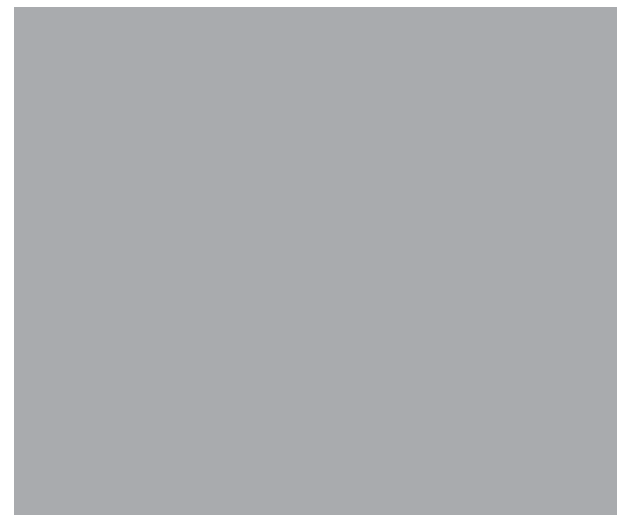

Lights with

low luminance targeting a small area can create interest

These images have not been reproduced due to copyright

Blue ambient light creating atmosphere

\section{Warmer tones}

reduce glare

while still lighting

the space

adequately 


\section{Design Principles}

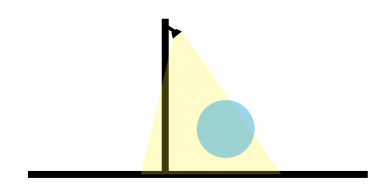

Using lighting to highlight specific elements, for interaction, not for safety

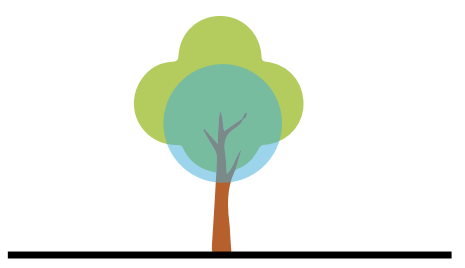

Using a sites natural features to display lighting

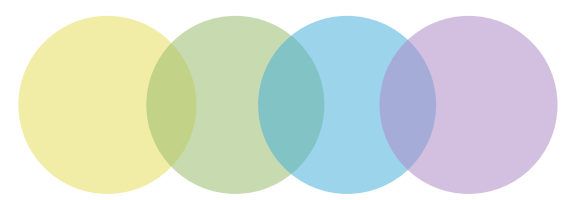

A variety of warm lighting tones can provide a more engaging epxerience

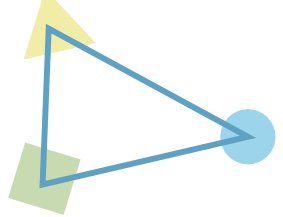

Small scale design elements in different locations

\section{Application to design research}

- Small scale interventions at the human scale can greatly alter the use of a space at night

- Various lighting colour and illuminance levels encourage interation in a space at night

- Using the sites natural features as a method of displaying lighting can be more engaging that pole mounted lighting shining from above 
Role of Lighting in Public Space

This image has not been reproduced due to copyright

(refer to figure list for full details)

Fig 2.8 Van Gogh Path (Studio Roosegaarde, 2014) 


\section{Van Gogh Path}

\section{(International) Eindhoven, Netherlands Studio Roosegaarde 2014}

The Van Gogh path by Studio Roosegaarde in the Netherlands represents how low illuminance lighting solutions can add a new social experience at night. Along a $600 \mathrm{~m}$ bike route in Eindhoven, where Vincent Van Gogh lived from 1883 to 1885, thousands of solar-powered stones were placed in compositions based on his famous painting, 'starry night' (Studio Roosegaarde, 2014).

The project has given the area a new social experience with a purpose at night. Unlike just using it to pass through or to get home, people go there specifically to interact with the path. There is a feeling of curiosity and awe, gazing at the stone's different patterns, the same emotions shown to resonate from staring at the night sky (Bell et al., 2014).

It also represents how we do not always need to use lighting that shines down from above to enjoy outdoor space and feel safe. If the local council implemented standard overhead lighting, the path would lose this unique experience, with another nocturnal 'blandscape" left in its place.

\section{Netherlands}

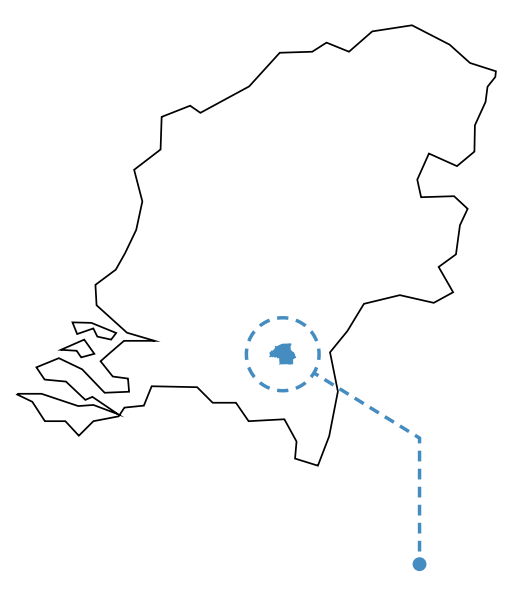

Eindhoven

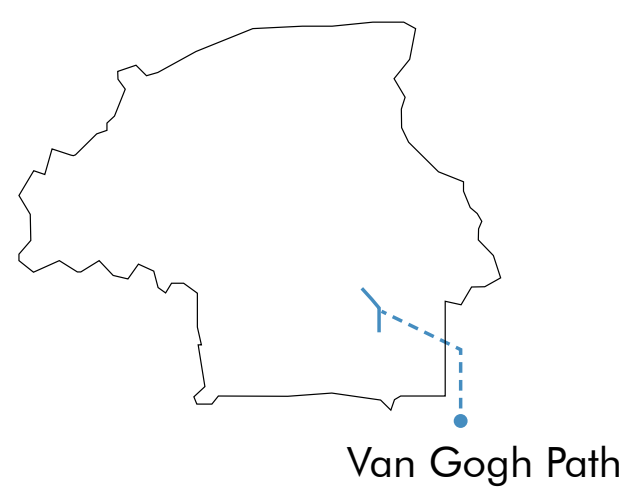




\section{Design Features}

The only light glare visible in the site is the suburban lights from afar

These images have not been reproduced due to copyright

Despite the darkness, cyclists still use the path at night

The stones patterns reflect the stars we see in the sky

Fig 2.9 Van Gogh Path (Studio Roosegaarde, 2014) 


\section{Design Principles}

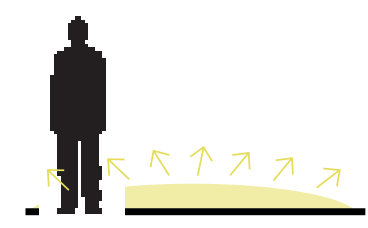

Low luminance lighting solutions

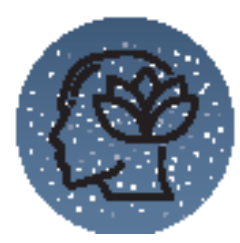

Comfort at Night

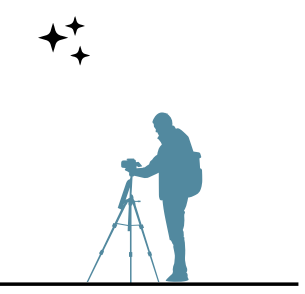

Using the stars as an inspiration for Design

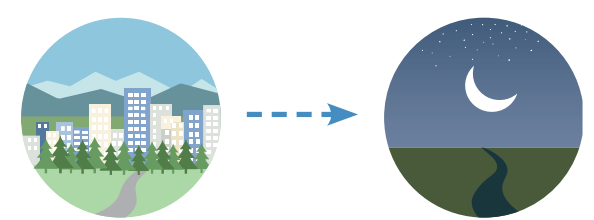

Encouraging time spent outdoors at night

\section{Application to design research}

- How the use of lighting that shines from beneath can be used as a guiding tool in the darkness

- How to facilitate engagement with a space at night

- The importance of giving space at night purpose in order to facilitate interaction 


\subsection{Māori Astronomy}

Tatai Arorangi

Māori astronomical understanding was once infused throughout almost all of pre-colonial Māoritanga. They had extensive knowledge of the night sky (Best, 1922), which influenced various aspects of their lives. The movement of different constellations, heliacal rising of stars, and the moon phases were all recorded and shared between generations via teachers and specialists known as Tohunga Kōkōrangi (Harris et al., 2013).

This detailed knowledge resulted in Māori having a deep understanding of the seasons and patterns in the sky, allowing their ancestors to navigate the Pacific Ocean and arrive in Aotearoa, New Zealand. They used the moon and stars, ocean and wind currents as guides in the darkness to know precisely where they were and what direction they needed to travel. (Arnold, 2019). The stars' repetitive motions, moon and sun, were utilized as a clock for knowing when to plant and harvest food, fish, predict the weather and when to fight (Arnold, 2019).

Within New Zealand, much of this astronomical knowledge was lost due to the impacts of colonization. The first Europeans who arrived in New Zealand could not believe that Māori had purposefully sailed there due to their lack of navigational instruments and simple canoes. They spread lies to dismiss this (Arnold, 2019), and soon European navigation, backed by science, became the dominant method of navigation written about in New Zealand.

\section{Key theories to apply into design research}

- Celestial navigation was a primary tool used by Māori sailors

- Loss of Māori Astronomical knowledge due to colonization

- There are specific star constellations and star movements that are important in Māori culture
When to Plant and harvest

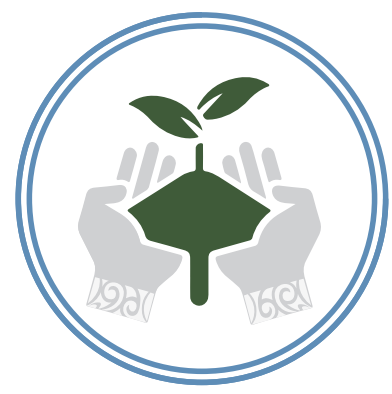

How to track wildlife

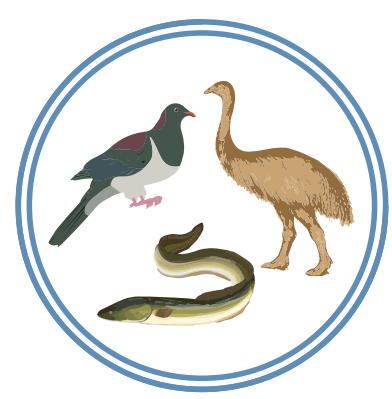

When to fight

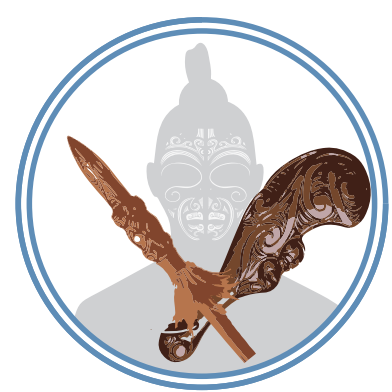

How to navigate

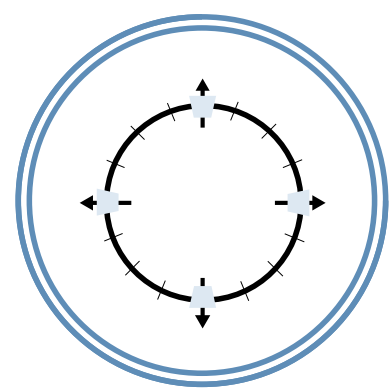

Fig 2.10 Knowledge gained from Tatai Arorangi 


\section{Matariki}

Spearheading the revitalization of Māori Astronomy is the celebration of Matariki, more commonly worldwide as Pleiades. It is an open star cluster consisting of hundreds of various stars, but only nine are visible to the naked eye. In early Māori culture, the rising and setting of Matariki was associated with the planting and harvesting of crops (Matamua, 2017). In New Zealand, it is visible for much of the year except May, where it sets in the western sky. Its disappearance signals the time to harvest and preserve crops (Arnold, 2019). It reappears in the eastern sky in early July, rising with the sun (heliacal rising); each day appearing earlier and ascending higher. Its reappearance marks the beginning of the Maori new year, Te Hau Hou. It is honoured as a time to reflect and gather with whanau (Arnold, 2019).

While Matariki is the star cluster's name, it also refers to a single star within the cluster. There are various interpretations of its origin story, but a shared narrative is the mother and her children. Matariki sits in the sky with her eight children, five females and three males (Matamua, 2017). Every star within the cluster has an important role and is recognized intrinsically in Māori Culture.

\section{Origin stories}

A key component of Māori Astronomy are the narratives associated with the origins of the universe. Every star in Māori Astronomical knowledge has a story behind it.
1. Waita = Represents "salt" and the food Maori Gather from the sea

2. Tupuanuku = Food grown in the ground

3. Waiti = Represents "water" and the food Maori gather from lakes and rivers

4. Tupuarangi $=$ Food from the sky

5. Waipunarangi $=$ The rain

6. Ururangi $=$ The winds of the sky

7. Pohutukawa $=$ Connects Maori to the deceased

8. Matariki - Health and Wellbeing

9. Hiwa $-I-$ te - rangi $=$ Reflection

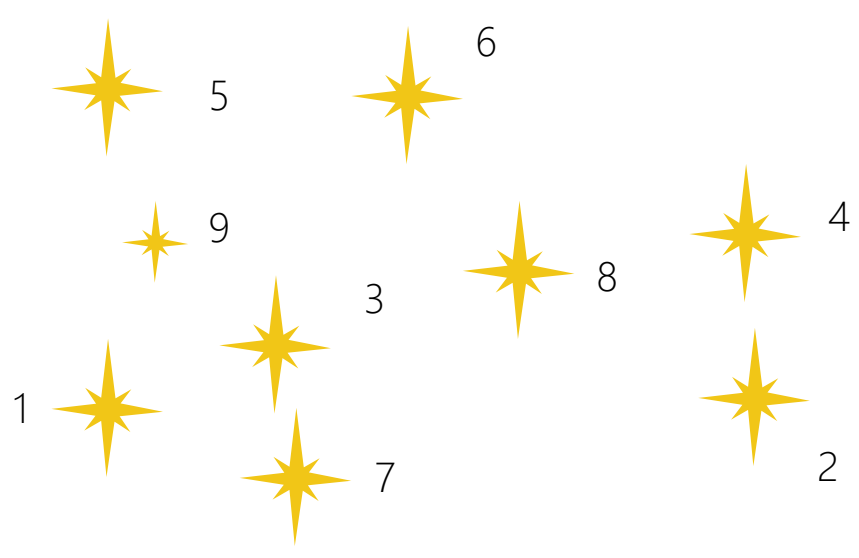

\section{Key theories to apply into design research}

- There is a hierarchy within the stars in Matariki, each star represents something in Māori culture with the order based on their importance and place in nature

- There are multiple narratives surrounding the origin of Matariki 


\section{Māori Creation Story}

In the beginning, there was Te Kore, the darkness. It encloses $T e P \bar{o}$, the night which encloses Te Ao Marama, the realm of people. Te Kore is tapu (sacred) and is the source of all things in Te Po and Te ao Marama.

As darkness separated from light, so did male and female. The first parents, Ranginui and Papatūānuku, were brought into the world. They clung together tightly, and within their embrace, the forces of creation began to swirl. Their children, the gods, were trapped in the darkness, frustrated at their entrapment.

Tāne Mahuta, the god of the forests, pushed at his parents, but they clung tightly, forcing him to cut Ranginuis arms, propping him up on four posts that symbolize the four corners of the world. Ranginui became the sky father with Papatūannuku, the earth mother. Naked in the world, Tāne clothed Papatūānuku in animals, forest and birds. He asked his siblings for their children, Tamanuiterā (the sun), Marama (the moon and whetū (the stars), so that he may cloak his father.

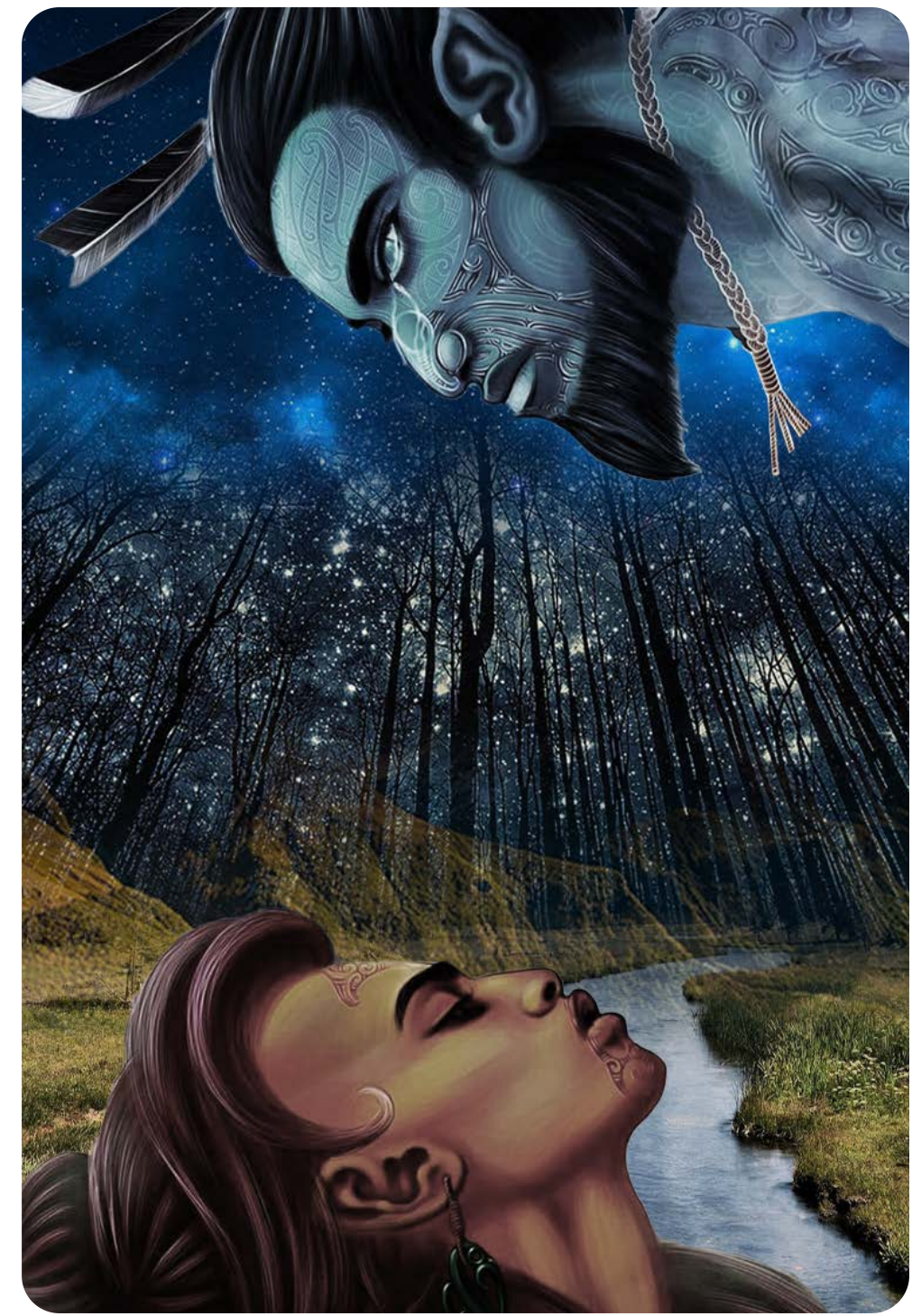

Fig 2.11 Ranginui propped up by the 4 posts above Papatūānuku 


\section{Te Waka o Tama-rereti}

Tāne Mahuta asked for his relative, Tamarereti, to help transport the children to Ranginui.

Additionally, he was sent in his canoe, Puna Ariki, to retrieve the different stars from their darkness on the mountain to complete this cloak. Tama loaded all the stars into his waka, with the most important ones on individual baskets outside his canoe and the stars with less importance piled in the middle. He sailed his waka into the sky, dropping his anchor, Te Punga, the southern cross. He then placed the two guardians of the seasons, Rehua and Takurua (Antares and Sirius), on the right and left sides of Te Punga. Above his waka, he placed Atutahi (Canopus). He then placed the seasonal and navigational stars. When this was done, he turned his waka upside down, pouring the remaining stars out to form Te Ikaroa, the milky way. Ranginui was pleased with Tamarereti and asked him if his canoe could be placed permanently in the sky. Today Te waka o Tama-rereti sits between Antares and Sirius.

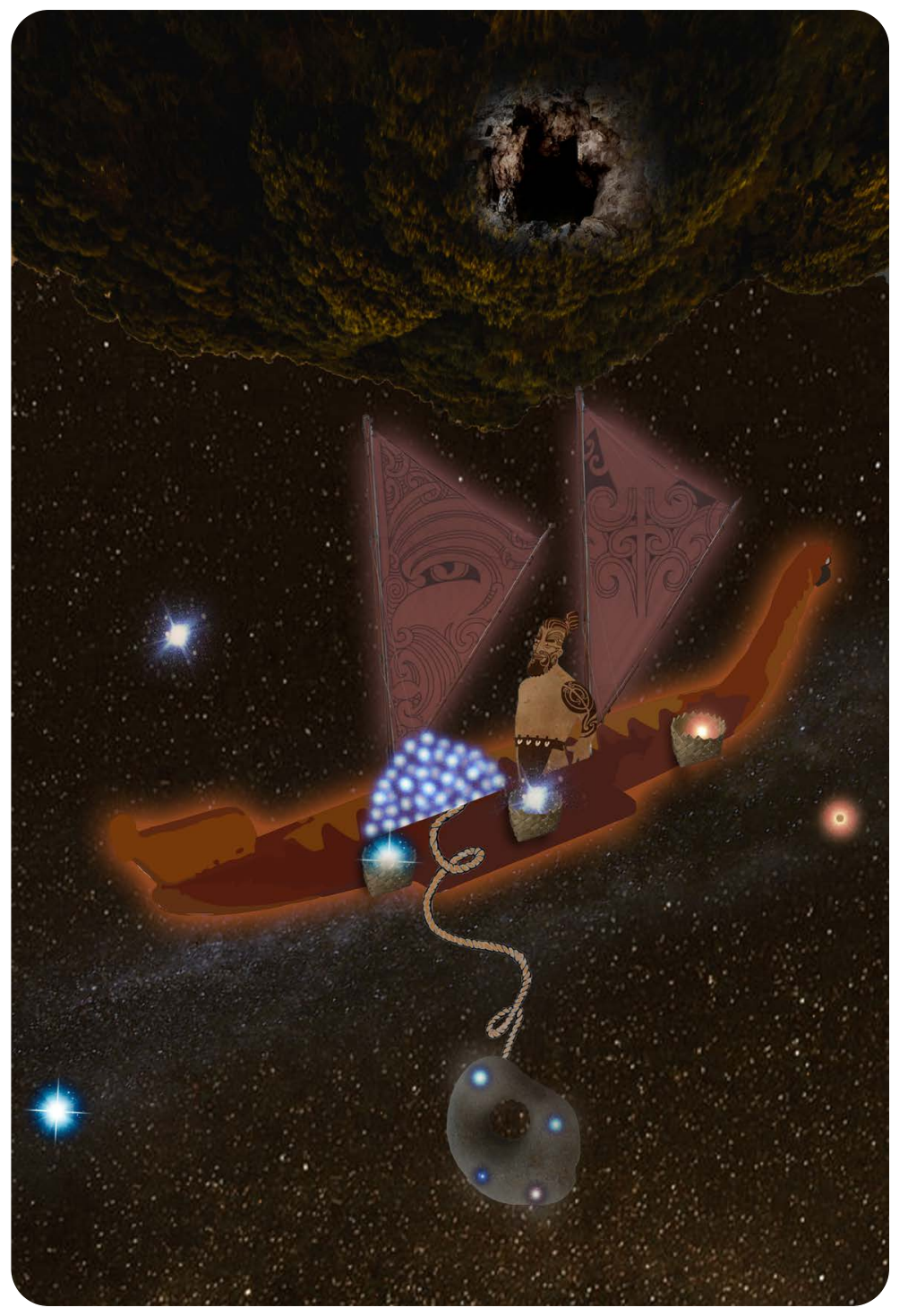

Fig 2.12 Tamarereti with his waka full of stars 
Māori Astronomy

This image has not been reproduced due to copyright

(refer to figure list for full details)

Fig 2.13 Milky Way Rising over the Star Compass (Caldwell, 2018) 


\section{6 Ātea star Compass}

(Local) Waitangi Regional Park, Hawkes Bay, New Zealand Boffa Miskell, 2017

The Atea a Rangi star compass provides an immersive and interactive space to learn about Maori celestial navigation. In collaboration with Maori astronomy experts, Boffa Miskell and Wayfinder LP\&S Itd sought to help bring recognition back to the area as it marks the first place where Europeans and Maori lived together as a community (NZILA, 2019).

The design reflects the real-life star compass that Maori sailors used in their original journey to Aotearoa. Several Pou designed by expert carves Nathan Foote and Philip Belcher represent the compass points and rising and setting points of the various celestial bodies that Maori use to navigate (Ātea a Rangi Star Compass, n.d.)

The coastal open environment affords people to reconnect to the earth's natural process at all times of the day and expand their knowledge of Te ao Maori and Tatai Arorangi (Maori Astronomy). The compass marks the beginning of a larger project to develop over time in the area.

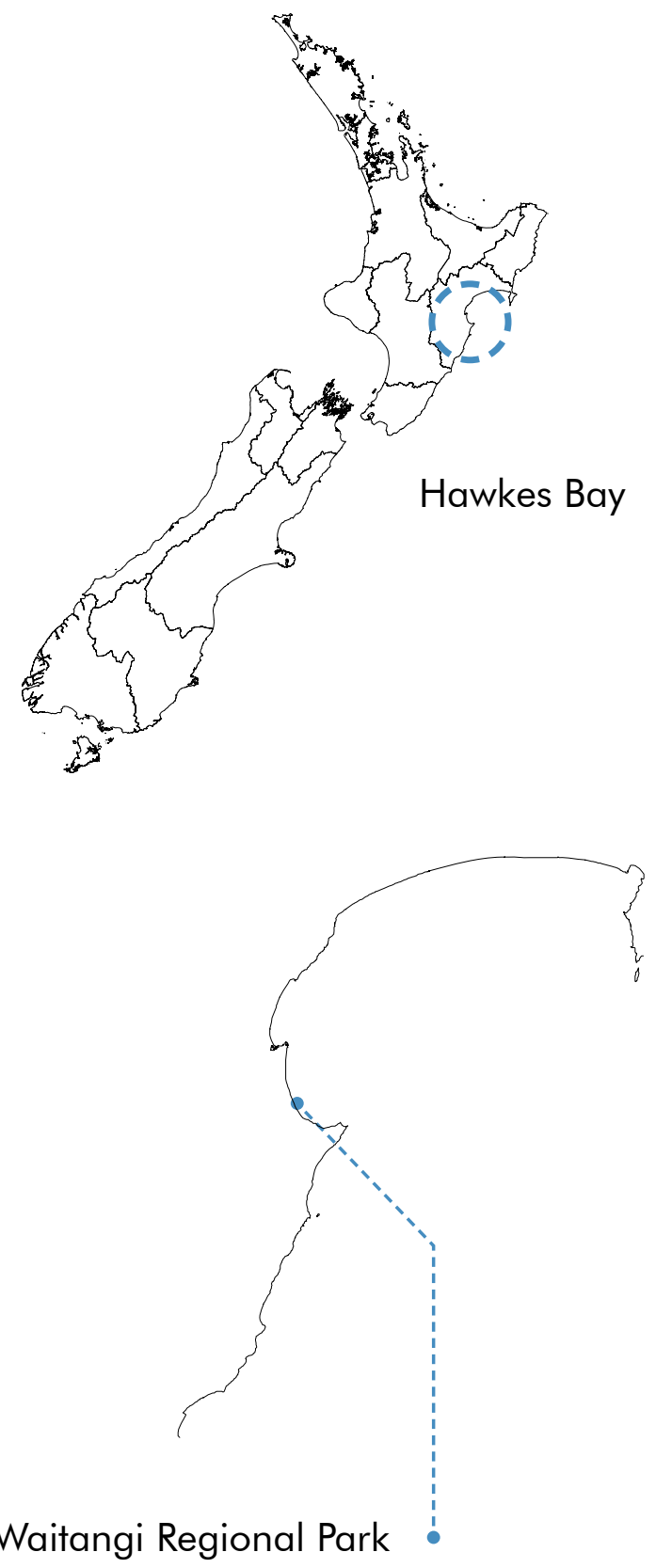


Key Features

The rising points of matariki are also marked
The star compass marks out the 4 points on the compass with 4 specially carved Pou used from old timber logs

\section{These images have not been reproduced due to copyright}

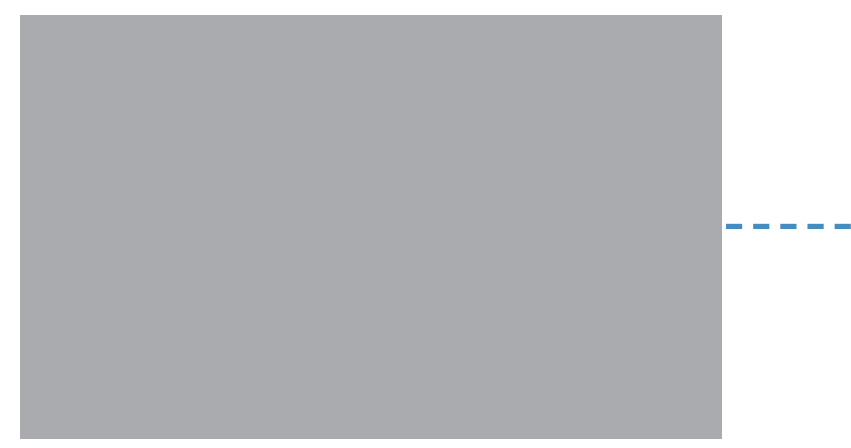

Once you understand the rising and setting points of the moon and stars you can use the star compass as a way to memorize their locations

7 whare lie between each north, south, east and west Pou

Fig 2.14 Atea star compass Precedents 


\section{Key Principles}

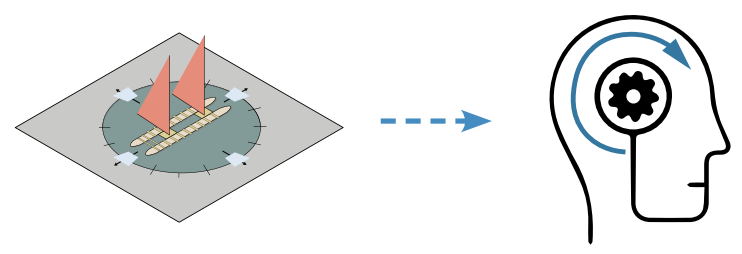

How design can afford education

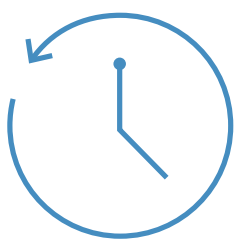

Connecting to the past

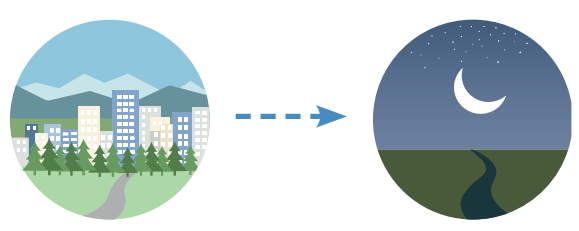

Aligning ourselves with natural processes

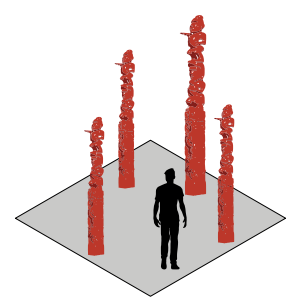

How design can afford interaction with cultural values

\section{Application to design research}

- Designing a connection to the night sky should include reference to our past, as this is the same night sky our ancestors looked at

- Providing information not only visually but also with signage.

- Landscape features can be arranged to represent aspects of Maori culture through symbolism 


\subsection{Reflection}

From the literature 5 main points were discussed:

- Humans have a natural fear of the dark, which is mainly drawn from the heightened sense of awareness we perceive at night when we lose our visual perception

- Landscape features are shown to have an effect on how comfortable the user feels in a space

- Over-lighting bleaches out the landscape and ignores the social experience

- The night sky has not been considered a public space that can be enjoyed because we associate the night with having no visual stimuli.

Moving forward, these findings conclude that to understand the experience in outdoor public spaces at night, it is necessary to understand the relationship between lighting and landscape characteristics. This provides two questions to be explored in the fieldwork:

Does the presence of stars in an outdoor space decrease the heightened sense of awareness initiated from darkness due to having something to focus on?

What is the relationship between prospect, entrapment, concealment and the natural environment at night when the stars are shining above? 



\section{Introduction.}

This chapter discusses New Zealand and Wellington specifically as the testing ground for this design investigation. The relationship between the city's urban fabric, its geomorphology and how it effects the spread of light pollution are explored. From this analysis, both through fieldwork and desk mapping, Wellington was divided into 5 typologies of space, 3 of which were chosen for further research and investigation. 

This image has not been reproduced due to copyright

\section{(refer to figure list for full details)}




\section{1 Site location}

Isolated as an island, New Zealand/Aotearoa is among the countries with the lowest levels of light pollution across the globe. With $53 \%$ of the land mass in pristine conditions (Falchi et al., 2016), New Zealand contains 2 of 12 International Dark Sky Sanctuaries; Great Barrier Island and Stewart Island, and 1 of 16 International Dark Sky Reserves; the Aoraki McKenzie Basin. Assigned by the International Dark Sky Association (IDA), these are protected areas in the natural environment that have an exceptional quality of the night sky.

Unfortunately, $56 \%$ of the population still live in areas where the natural sky is lost. But as most of the major cities in New Zealand are very small in terms of their density, the light pollution generated does not spread as far as other cities across the globe. $97 \%$ of the population in New Zealand live in areas where the milky is visible with the naked eye.
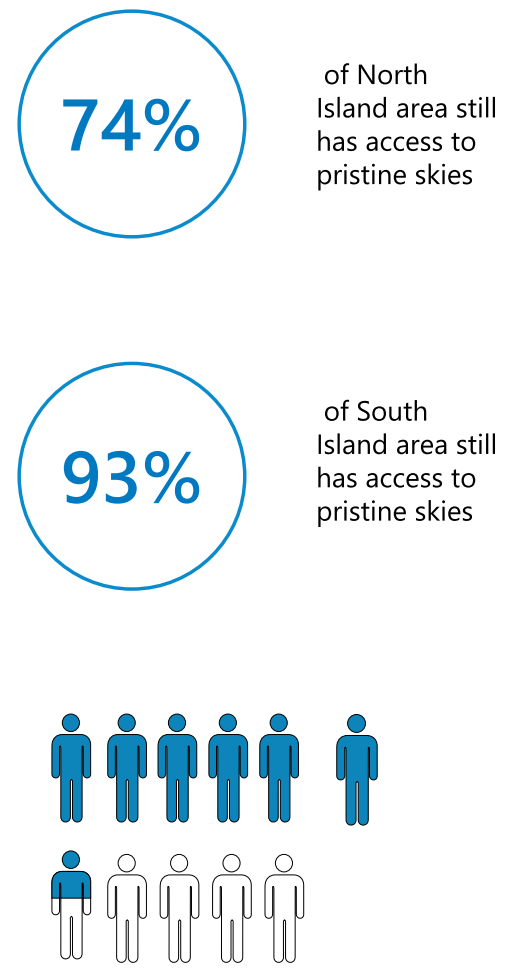

$=500000$ people 
This image has not been reproduced due to copyright

(refer to figure list for full details) 


\title{
Impact of Light Pollution across entire Wellington Region
}

This image has not been reproduced due to copyright

\author{
(refer to figure list for full details)
}




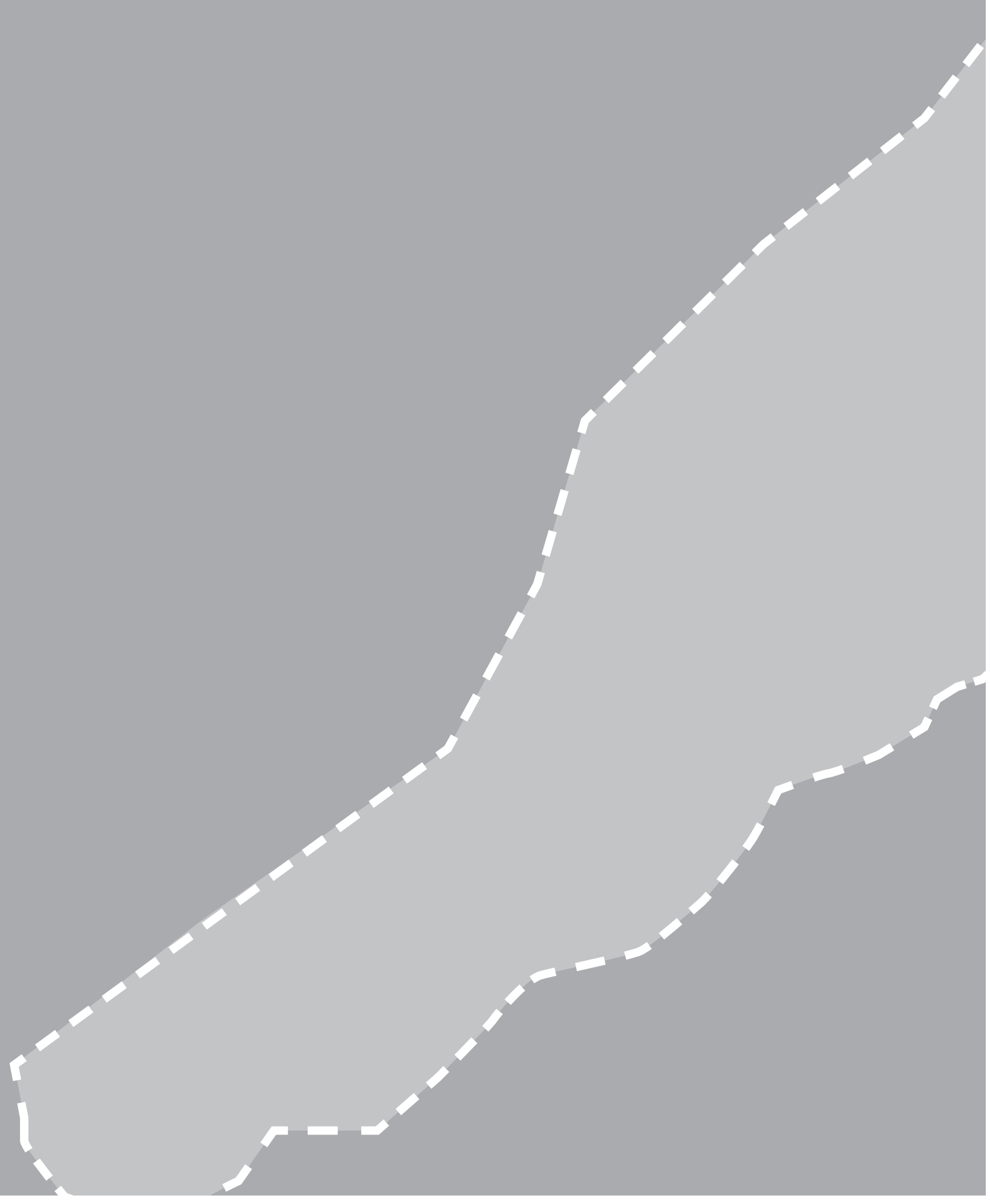




\subsection{Wellington City}

Wellington will be the case study for this research process as its diverse topographical landscape, low light pollution levels and relatively small size, provides multiple typologies of spaces for developing research. The stars and Milky Way can be seen within

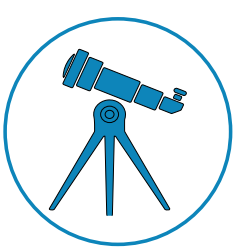
the central city perimeter, which is necessary to understand the relationship between public space and the night sky.

It was also chosen as the researcher has lived here for the last nine years and already has a basic understanding of the stars and light pollution in the area.

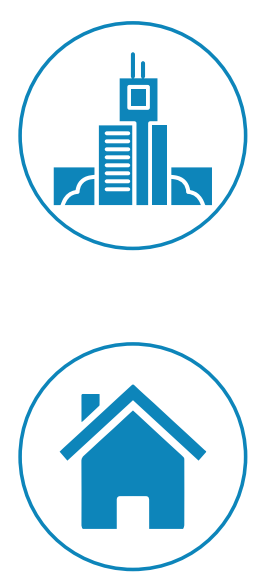




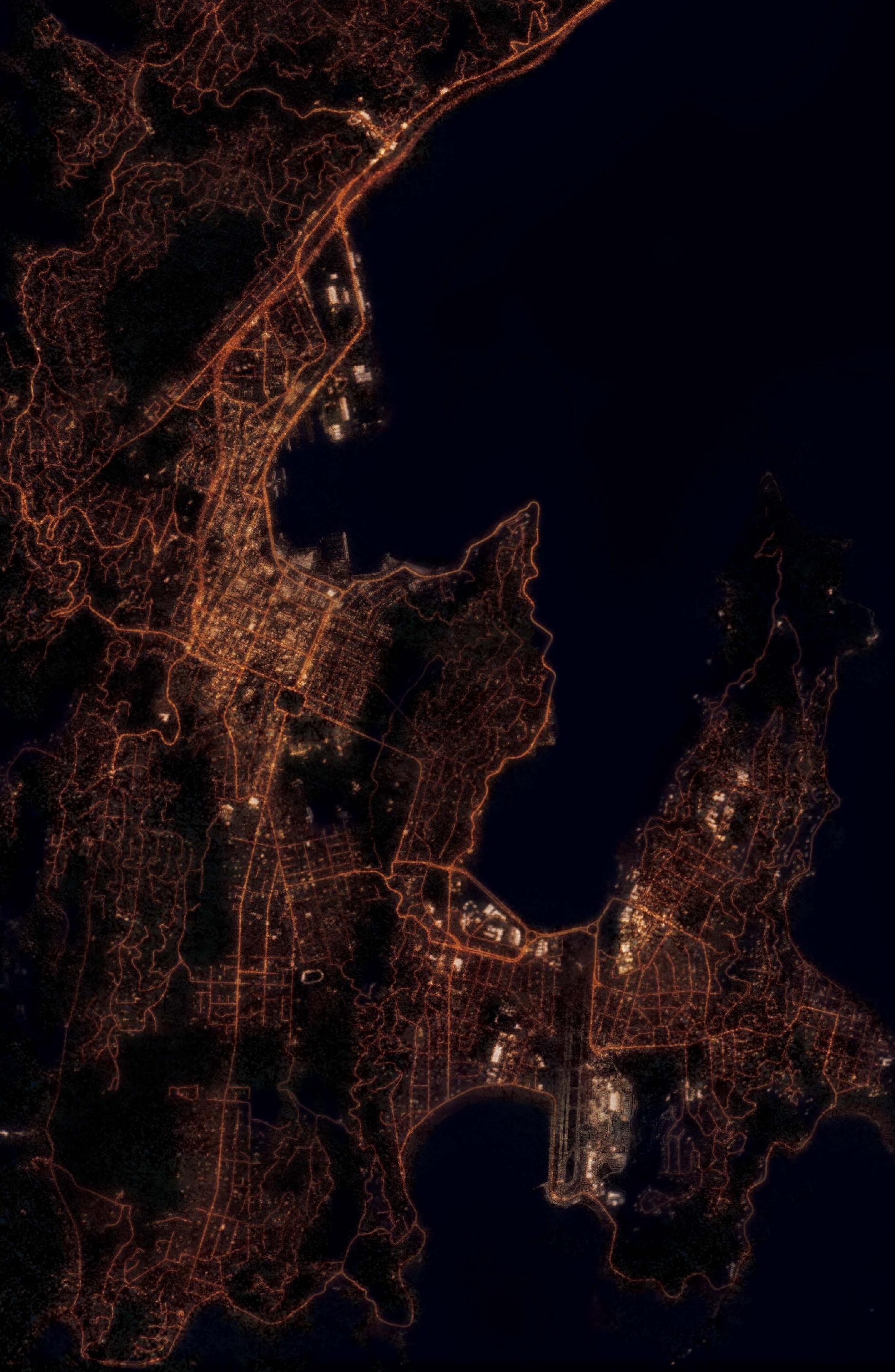




\subsection{Light Pollution in Wellington}

\section{Overlighting}

Wellington, as any urban environment has many different sources of light that are excessive or are improperly used that contribute to its Light Pollution. Examples are lights being left on in buildings after working hours, using street lights in public spaces instead of experiential lighting, urban spaces, and industrial areas.

Lights left on after hours

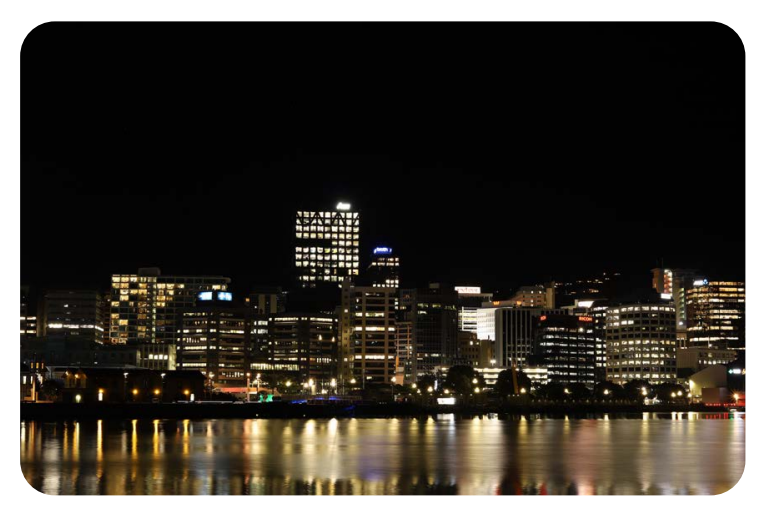

Urban Spaces

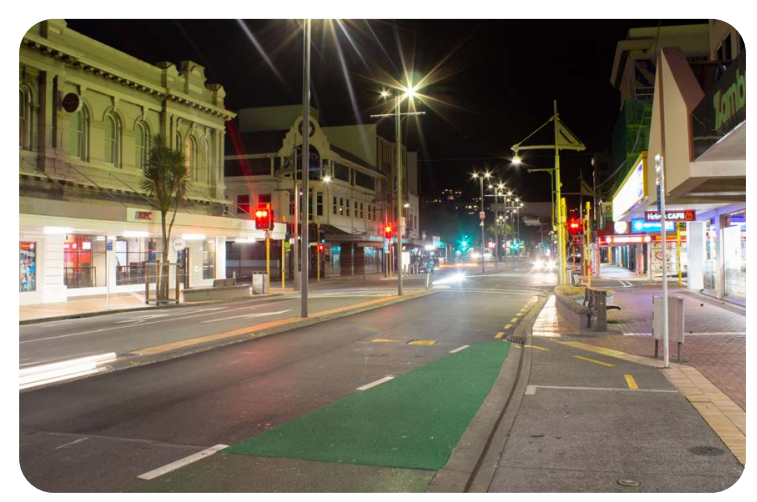

Street Lights used in Public Spaces

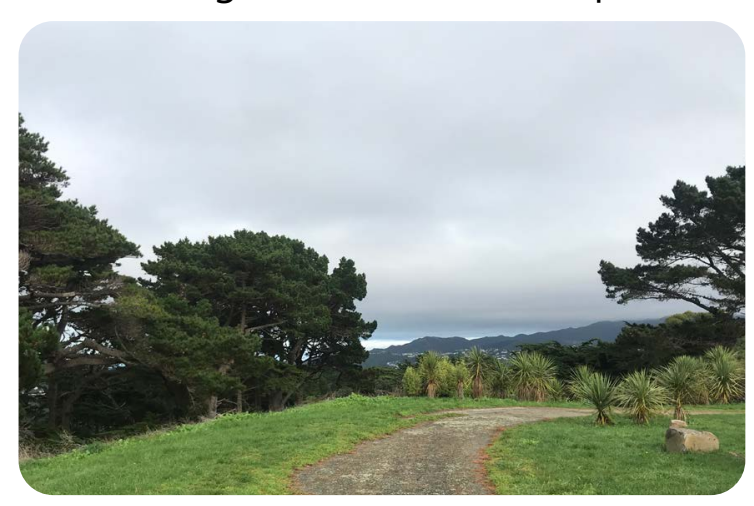

Industrial areas

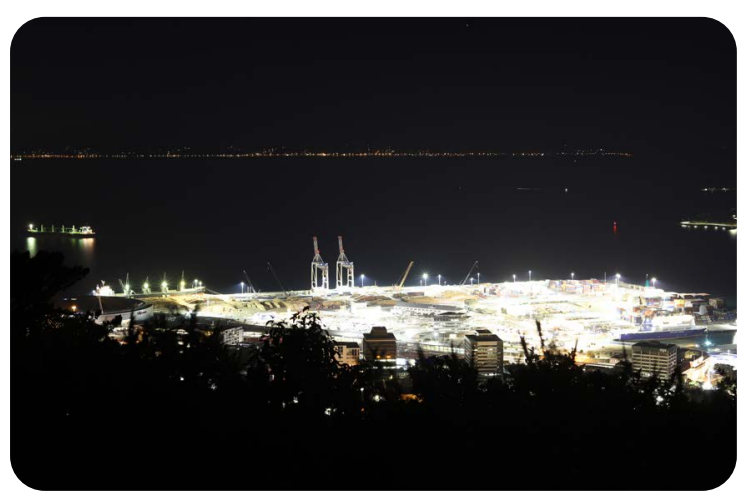

Fig 3.6 Examples of Excessive Lighting 


\section{LED lighting}

Wellington recently converted 15000 of their 18000 street lights to White LEDS. The council has recognized the important of reducing light pollution as the bulbs used are the standard required by the International Dark Sky association.

High Pressure Sodium Lamps

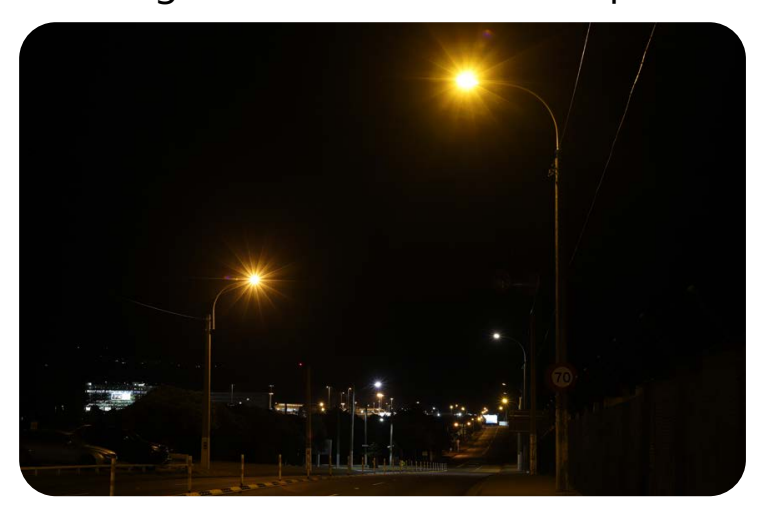

LED Conversion

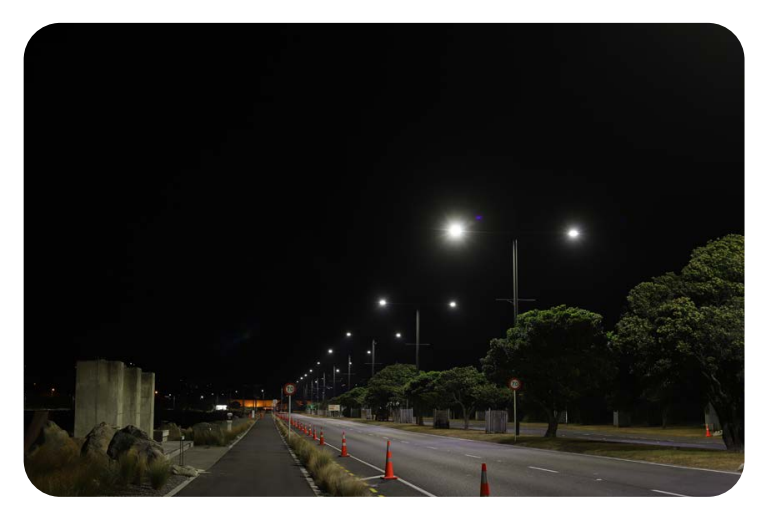

IDA Approved lighting

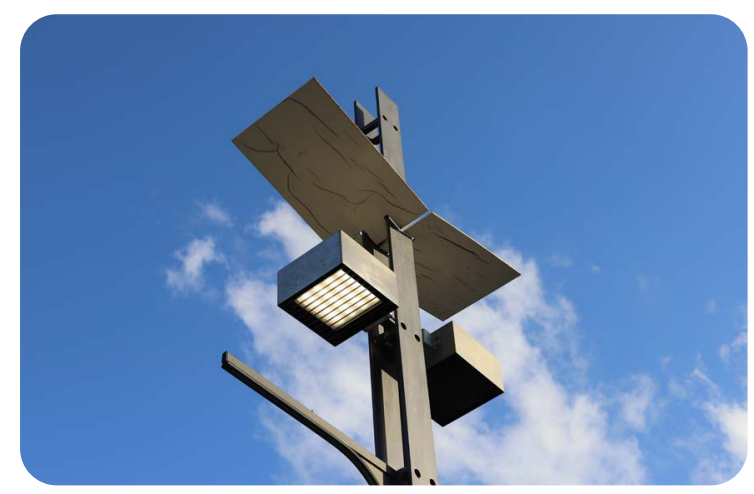

IDA Approved lighting

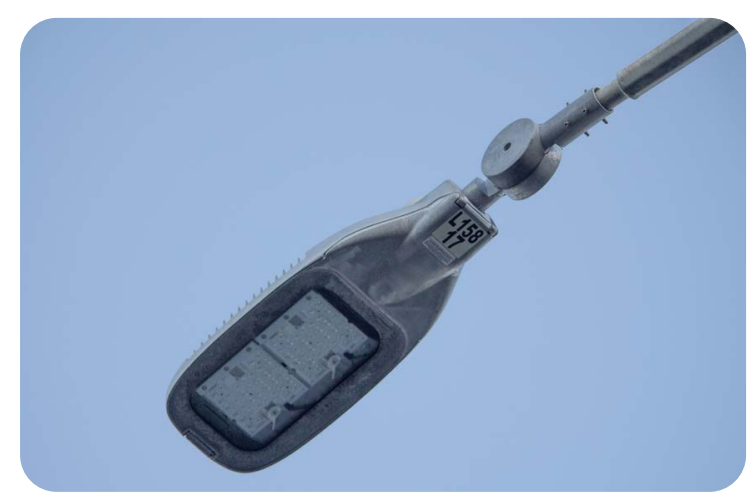

Fig 3.7 Use of LEDS in Wellington 


\section{Khandallah Lookout}

Miramar Peninsula

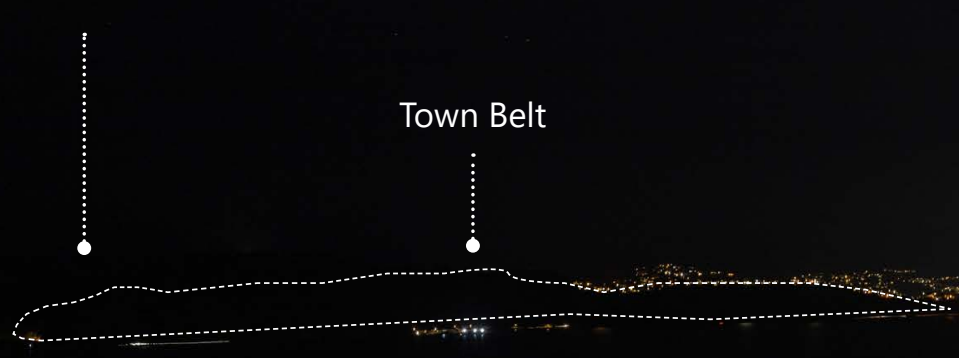

Mt Victoria 196 ASL

Wellington Airport

own B

Fig 3.8 Khandallah Lookout

\section{Te Ahumairangi Hill Lookout}

Petone

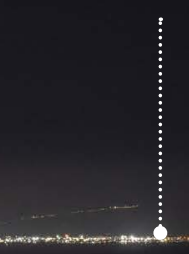

Fig 3.9 Te Ahumairangi Hill Lookout

Miramar Peninsula

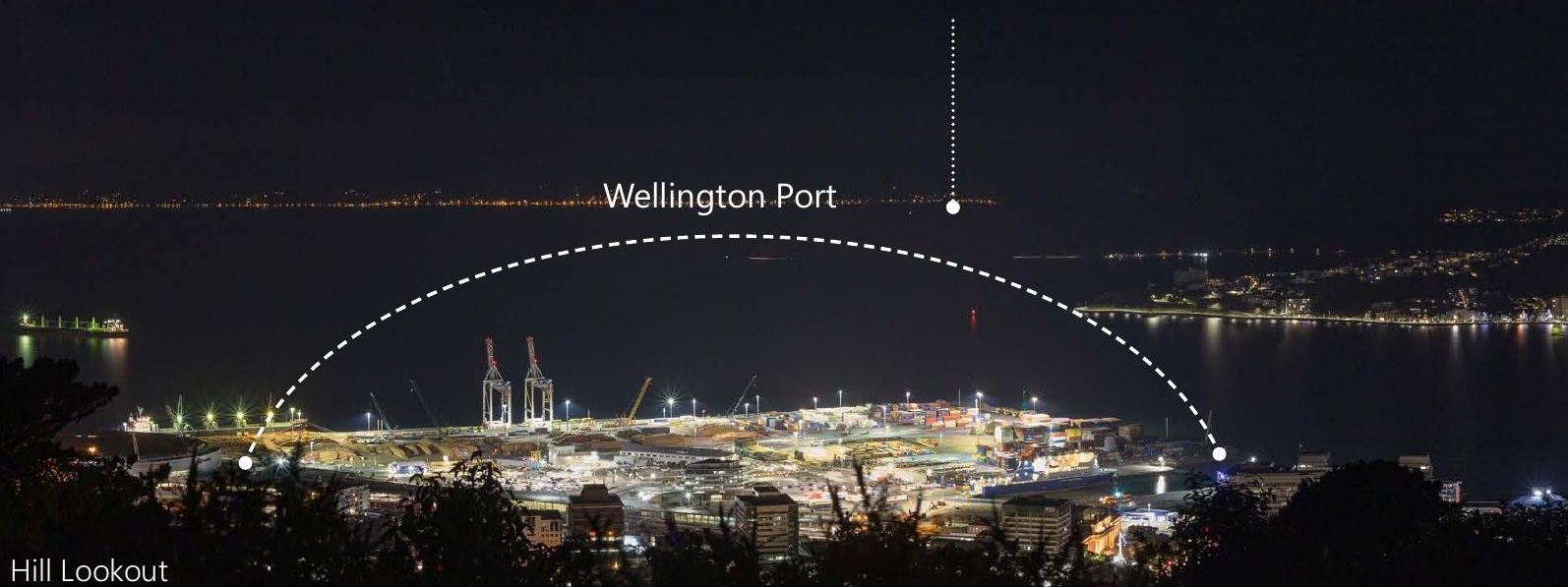

\section{Mt Victoria Lookout}

Brooklyn wind turbine

Fig 3.10 Mt Victoria Lookout 


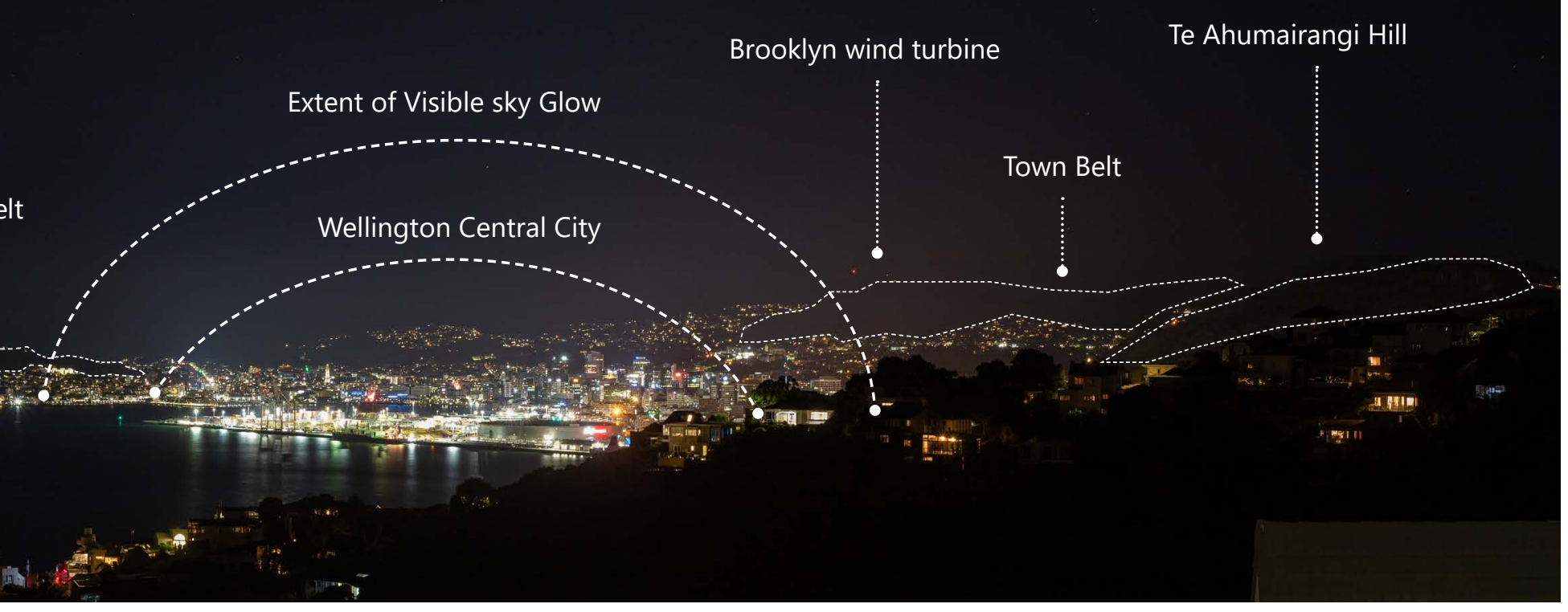

Mt Victoria 196 ASL

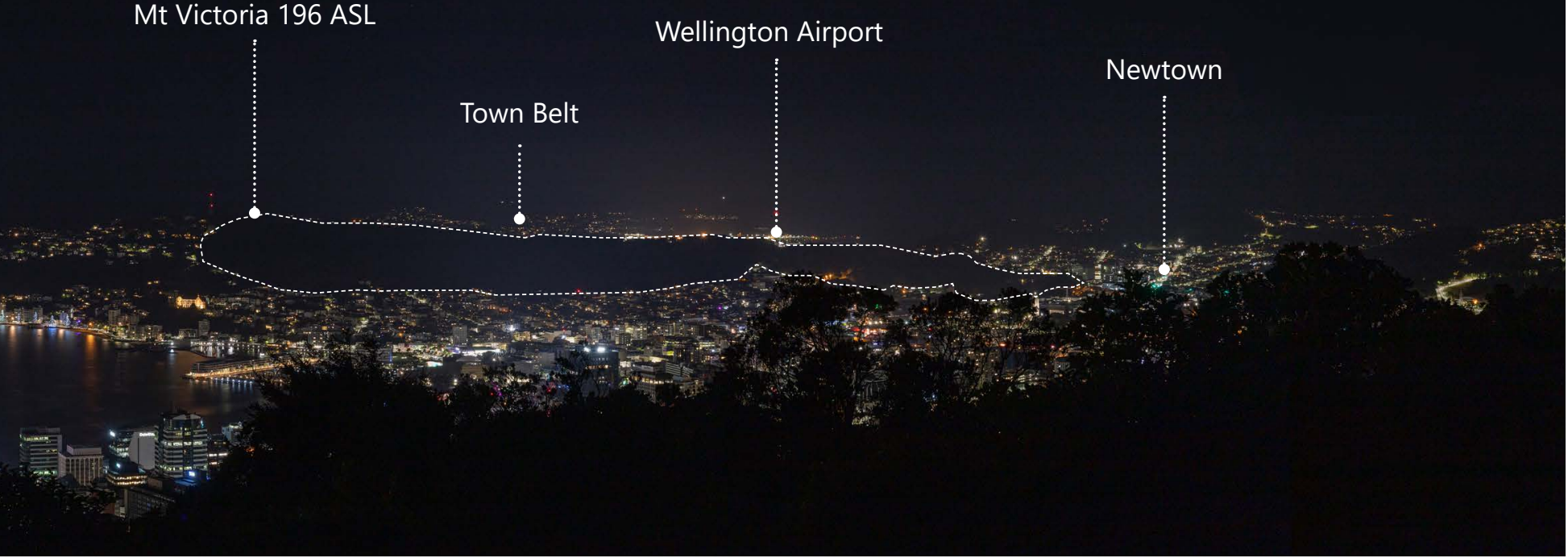

Newtown

Te Ahumairangi Hill (Town Belt)

- Wellington Port

$x=$ 


\section{Mt Victoria Lookout (Facing South)}

Miramar Peninsula

Fig 3.11 Mt Victoria Lookout (facing south)
Moa Point

Wellington Airport

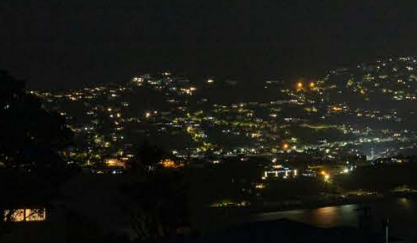

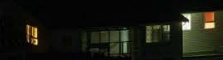

\section{Moa Point}

Brooklyn wind turbine

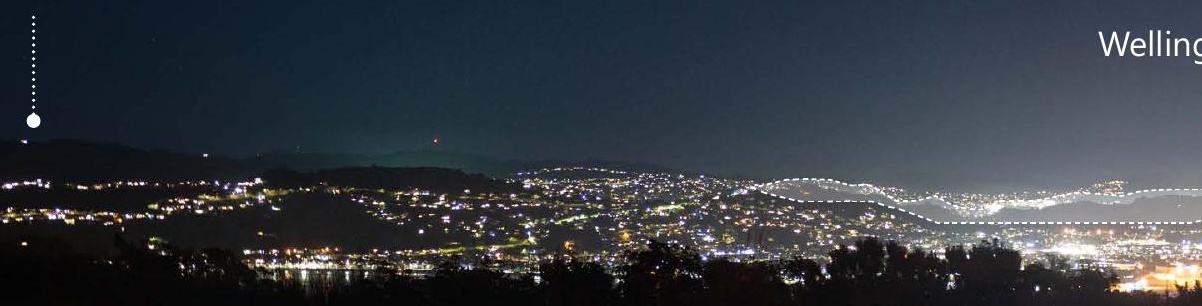

Fig 3.12 View from Moa Point over Wellington City

\section{Wellington Central CBD Waterfront (as seen from behind Te Papa}

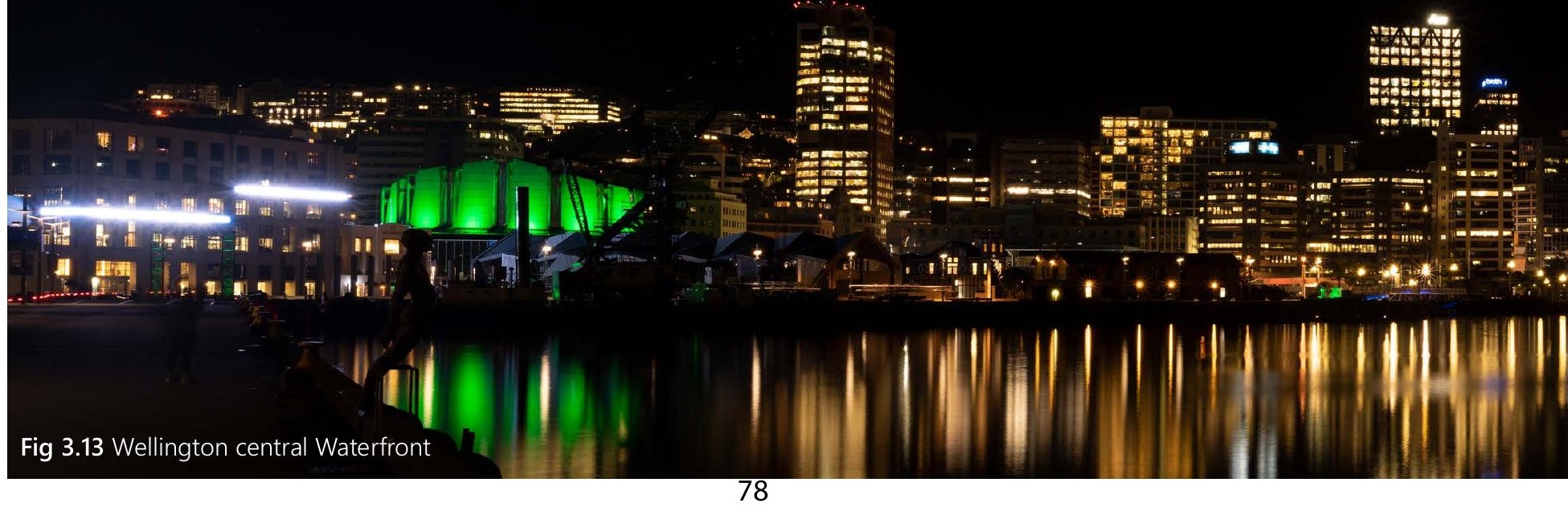


Island Bay

Kilbernie

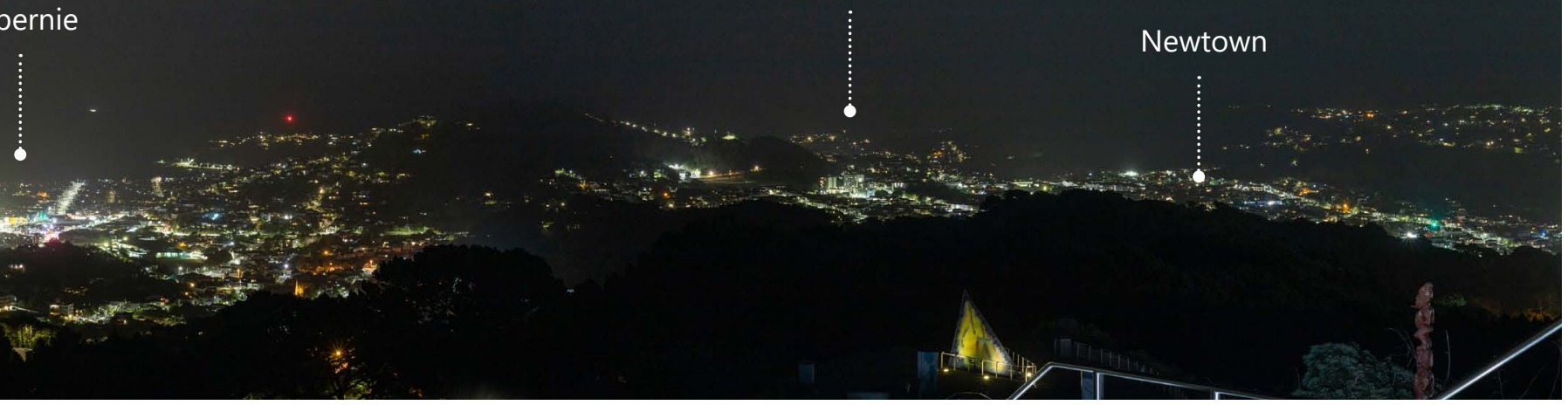

Newtown

Mt Victoria 196 ASL

ton Airport

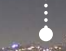

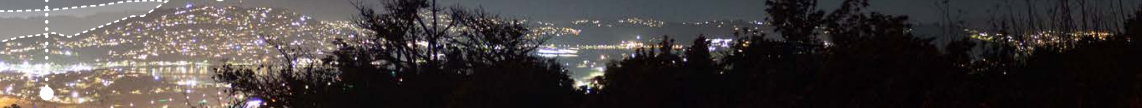

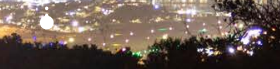

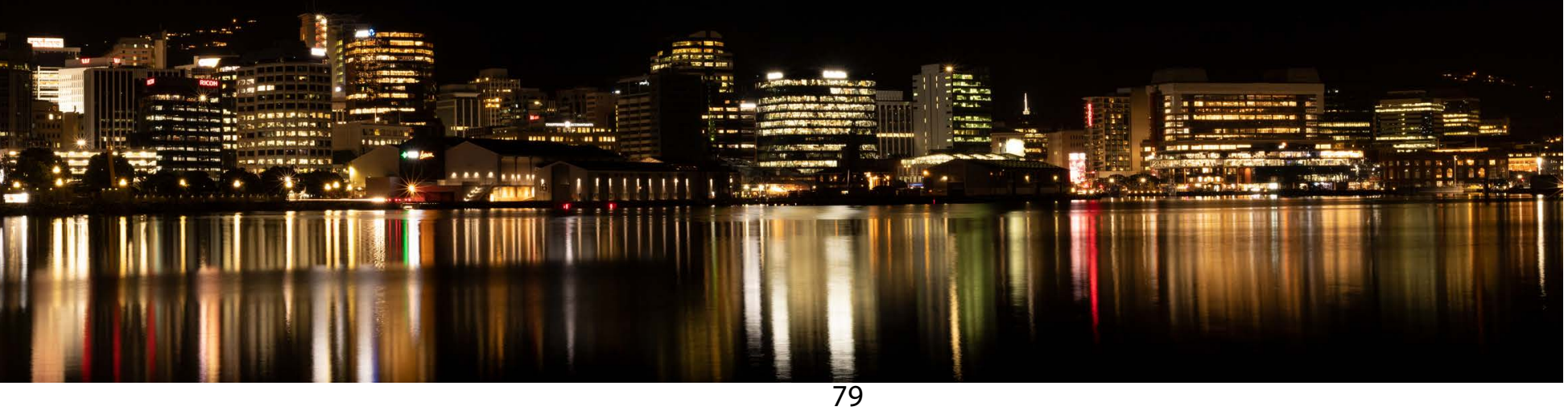




\section{Artificial brightness}

This map represents the artificial brightness of Wellington. Artificial brightness is measured against the sky's natural brightness set at 174 $\mathrm{ucd} / \mathrm{m}^{2}$.

$\mathrm{ucd} / \mathrm{m}^{2}=$ microcandelas per sq metre

Artifical Sky Brightness $=U \mathrm{~cd} / \mathrm{m}^{2}$
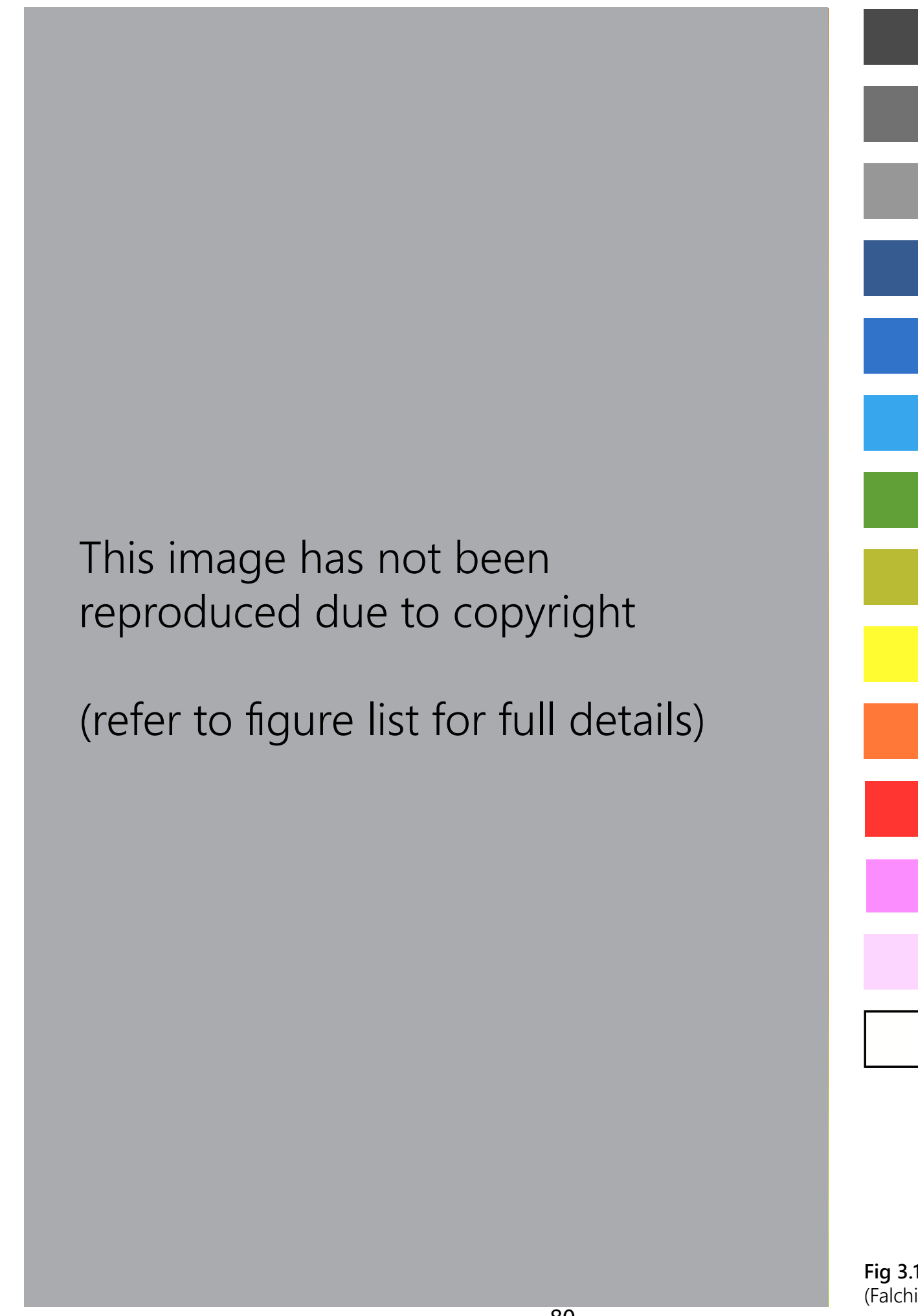

$>0.01$

$0.01-0.02$

$0.02-0.04$

$0.04-0.08$

$0.08-0.16$

$0.16-0.32$

$0.32-0.64$

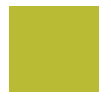

$0.64-1.28$

$1.28-2.56$

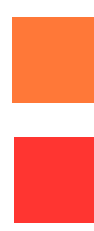

$2.56-5.12$

$5.12-10.24$

$10.24-20.5$

20.5-41

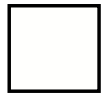

$>41$ 


\title{
Visual Impact
}

This map represents the visual Impact of Light Pollution in Wellington. It represents the quality of the night sky based on your location in Wellington

This image has not been reproduced due to copyright

\author{
(refer to figure list for full details)
}

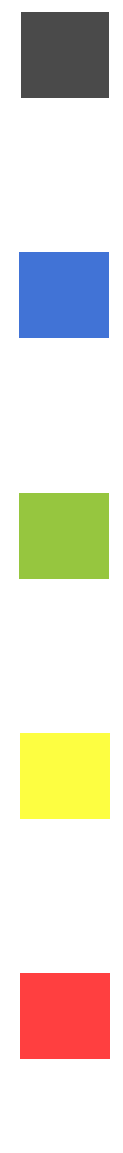

Pristine Sky

$1 \%$ above natural light $\left(0-1.7 \mathrm{ucd} / \mathrm{m}^{2}\right)$

Degraded near the horizon

1-8 \% above natural light (1.7-14 ucd/m²)

Degraded to the zenith

8-50\% above natural light (14-87 ucd// $\left.\mathrm{m}^{2}\right)$

Natural sky lost

$50 \%$ above natural light (87-688 ucd/m²)

Milky Way lost $\left(688\right.$ - $\left.3000 \mathrm{ucd} / \mathrm{m}^{2}\right)$

No darkness adaption possible (>3000 ucd $/ \mathrm{m}^{2}$ ) 


\section{Bortle Scale}

The Bortle scale is a 9 unit scale that measure the brightness of the sky in a particular location (Faichi et al., 2016). Each unit contains limitations of what can or cant be seen in the night sky. It is useful for understanding which areas of Wellington are the most polluted by light, not just through visual interpretation, but from scientific data as well.

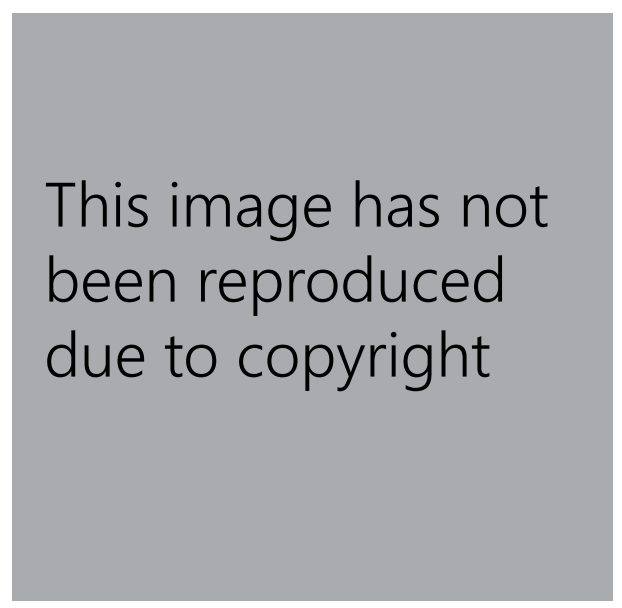

Fig 3.16 Bortle Class Identifier (Light Pollution Map, n.d) 


\section{Public space and Sky Brightness}

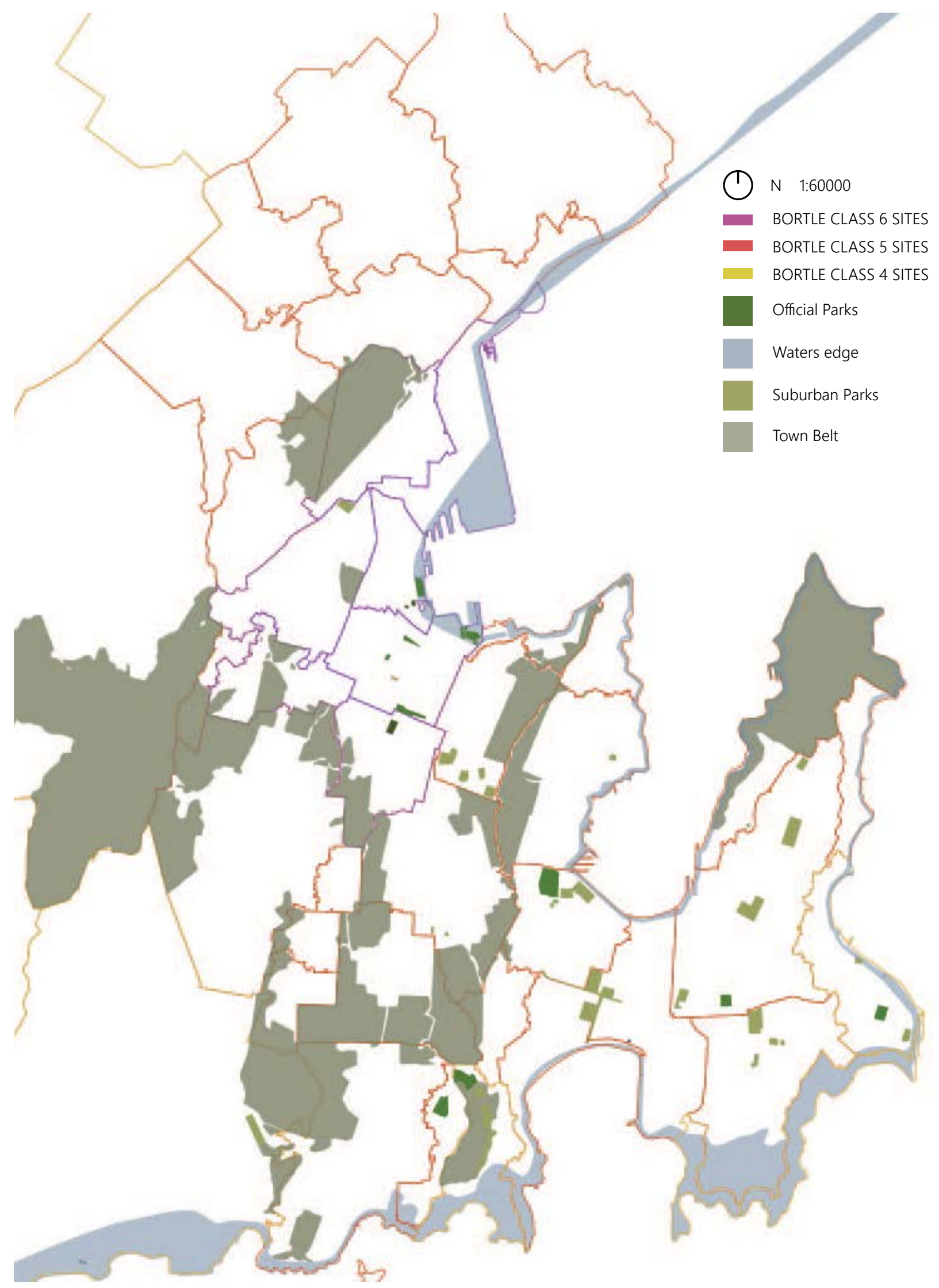

Fig 3.18 Types of Public Space \& Bortle Classes in 


\section{Suburb Bortle Classes}

The central city in Wellington is at Bortle Class six meaning the Milky Way is only visible at the zenith, which is the point in the sky directly above. The outer suburbs are a mix between Class five and class four which are shown below . By understanding the class scale, this will

\section{Class 6 - Highest to lowest brightness}

$\begin{array}{lll}\text { Pipitea }= & 2550 & \\ \text { Te Aro }= & 2500 & \text { Areas chosen } \\ \text { Wellington central }= & 2470 & \text { for Waterfront } \\ \text { Aro valley }= & 1570 & \\ \text { Kelburn }= & 1570 & \\ \text { Mount Cook }= & 1870 \\ \text { Thorndon }= & 1440-2080\end{array}$

\section{Class 5 - Highest to lowest brightness}

$\begin{array}{lll}\text { Mount Victoria } & 1540 & \text { Area chosen } \\ \text { Northland }= & 1380 & \text { For Town Belt } \\ \text { Rongotai } & 1360 & \\ \text { Oriental bay }= & 1350 & \\ \text { Kilbernie } & 1290 \\ \text { Hataitai }= & 1270 \\ \text { Kaiwharawhara }= & 1190 \\ \text { wadestown }= & 1180 \\ \text { Newtown }= & 1150 \\ \text { Lyall Bay }= & 1120 \\ \text { Highbury }= & 1070 \\ \text { Wilton }= & 1070 \\ \text { Roseneath }= & 1010 \\ \text { Vogeltown }= & 1000 \\ \text { Brooklyn }= & 991 \\ \text { Melrose }= & 951 \\ \text { Khandallah }= & 885 \\ \text { Miramar }= & 848 \\ \text { Crofton downs }= & 841 \\ \text { Berhamphore }= & 838 \\ \text { Mornington }= & 785 \\ \text { Ngaio }= & 760 \\ \text { Maupuia }= & 710 \\ \text { Karori }= & 680\end{array}$

provide additional insight into whether or not it is worth investigating public spaces in these areas. From this analysis, specific typologies of public space were revealed to fall under each class, such as waterfronts, urban areas, suburban areas and open green space

$\begin{array}{ll}\text { Karaka bays }= & 616 \\ \text { Southgate }= & 614 \\ \text { Kingston }= & 613 \\ \text { Strathmore park } & 603 \\ \text { Island bay = } & 589 \\ \end{array}$

\section{Class 4 - Highest to lowest brightness}

$\begin{array}{lll}\text { Seatoun }= & 452 & \\ \text { Moa Point }= & 445 & \\ \text { Houghton Bay }= & 443 & \text { Area chosen } \\ \text { Breaker Bay }= & 391 & \text { For Waterfront } \\ \text { Owhiro bay }= & 258 & \\ \text { Makara }= & 159 & \end{array}$




\subsection{Wellington Topography}

There are three main ridgelines in the Wellington City area. These are:

Mt Victoria to Houghton Bay Miramar Peninsula to Moa Point Te Ahumairangi Hill to Owhiro Bay

The majority of Wellingtons suburbs are located in between these three ridgelines. These three areas also contain the majority of Wellington's Town Belt excluding streets or houses which means that the light pollution generated is able to be contained within each suburb.
The wide range of public spaces with differing light levels can facilitate the assessment of the night time experience.

The map below represents this change in elevation with reference to the different Bortle Class Scales across Wellington on the following page.

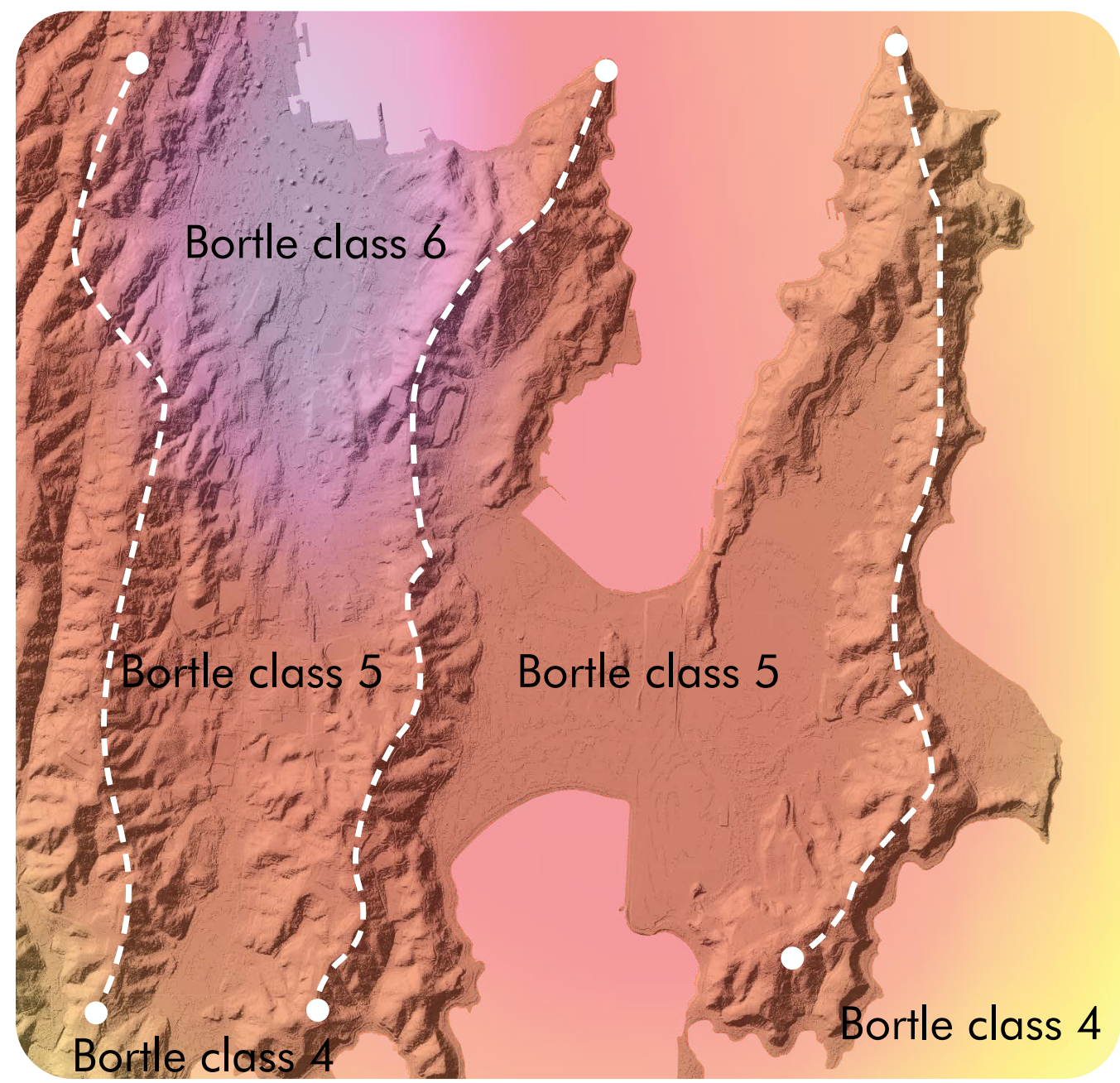

Fig 3.19 Fig Wellington Topographical Map + Sections (From Arc Gis) 

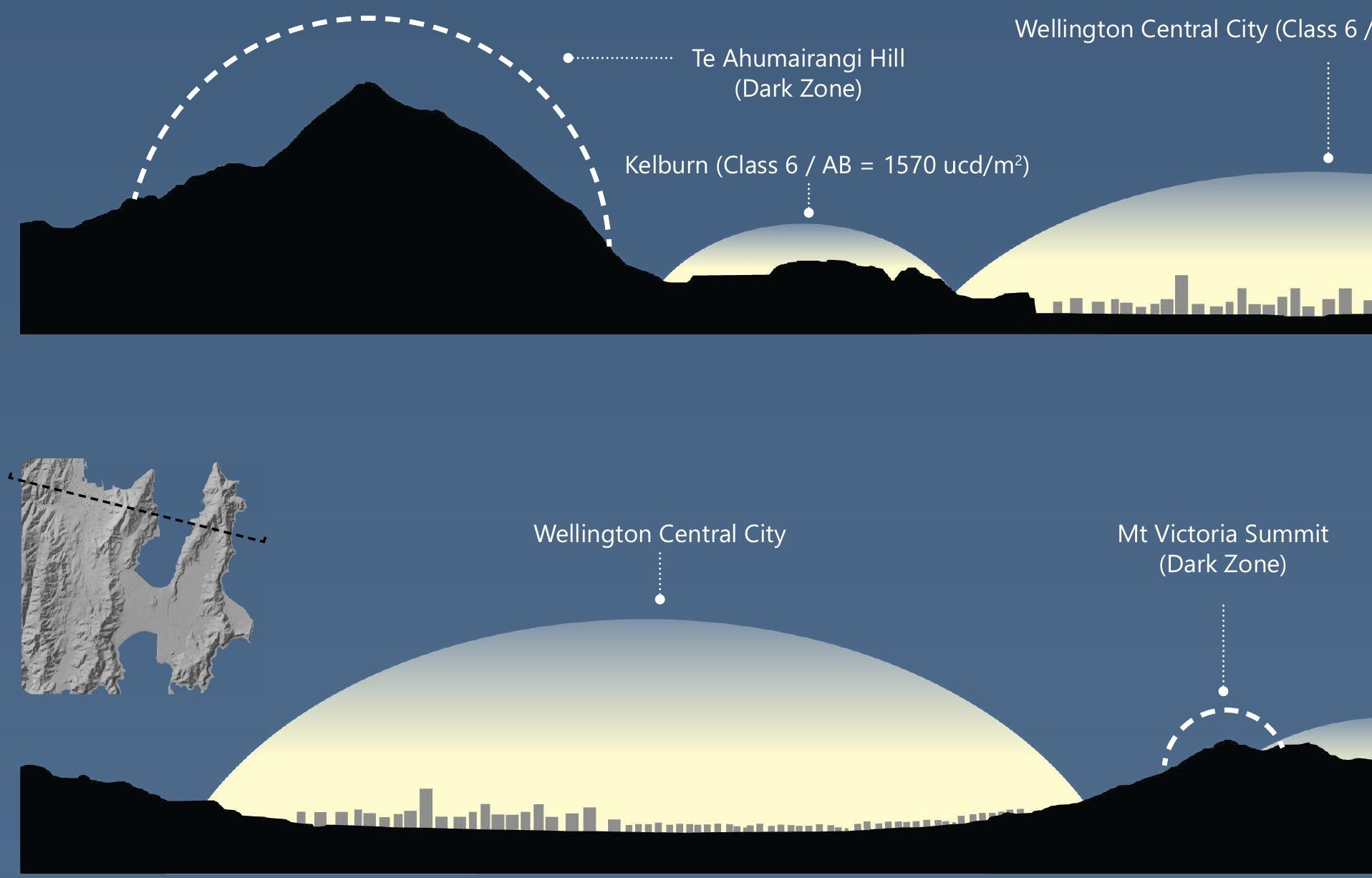

(2) Wellington City / Miramar Peninsula 1:15000

Newtown (Class $5 / \mathrm{AB}=1150 \mathrm{ucd} / \mathrm{m}^{2}$ )
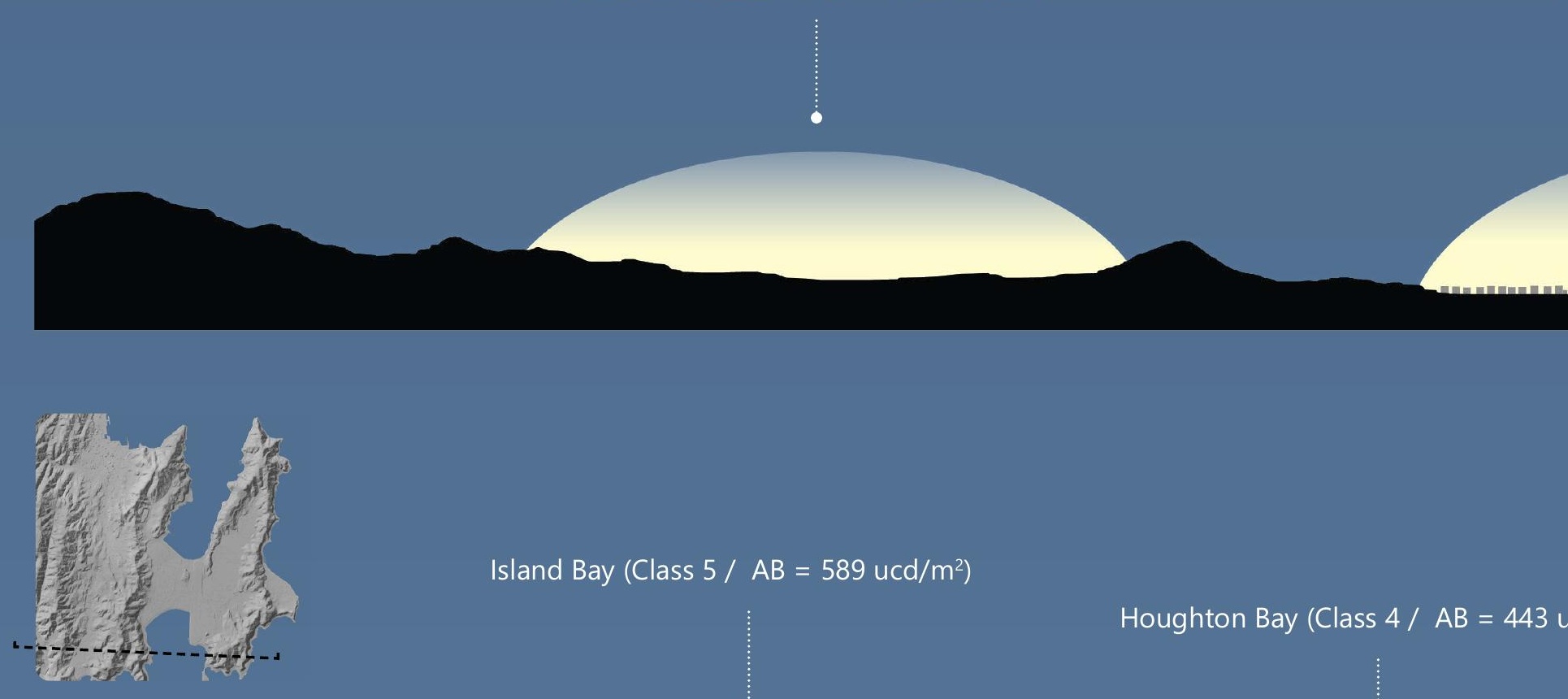

Island Bay (Class $\left.5 / \mathrm{AB}=589 \mathrm{ucd} / \mathrm{m}^{2}\right)$

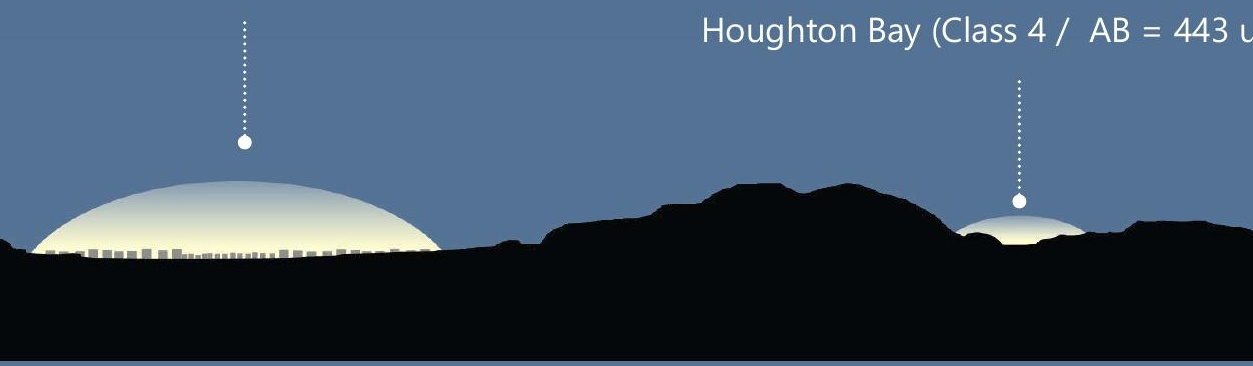

(4) Island Bay / Moa Point 1:15000 


\subsection{Research Areas}

The use of the Light Pollution maps overlaid on Wellingtons urban environment, revealed the areas of the highest and least amount of artificial sky brightness. From the large section cuts and visual panoramas, it can be seen that the protected Town belt areas prevent the spread of lighting with areas of darkness in between the urban fabric. From this analytical research and fieldwork around Wellington it was deduced that there are 5 typologies of public space affected by light pollution where this research could be investigated. These are located in the gaps, boundaries and centre of our urban environments.

The centres are the urban and suburban realm which generate the most amount of light pollution above due to street lighting.

The gaps refer to areas of darkness between the edges of the urban fabric which are the town belt areas.

Finally, there are the boundaries of urban space, areas with the urban environment on one side and water on the other. These are:

- Edges that face North into Wellington harbour and the light polluted areas

- Edges that face south over the South coast and Cook Strait, where there is no visible sky glow.

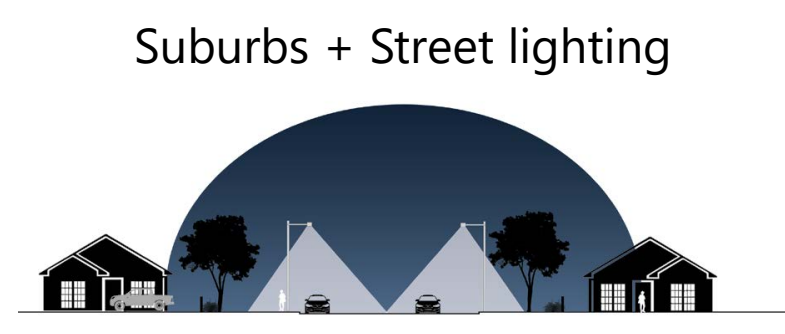

Dense urban area

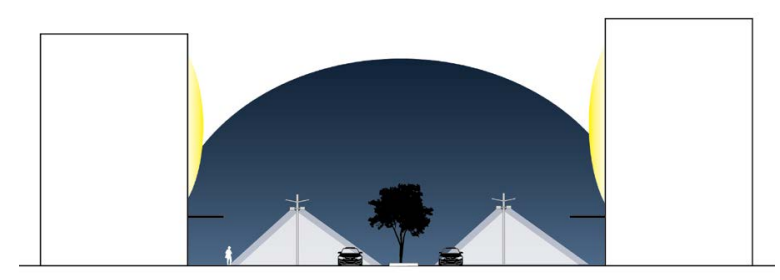

The gaps in the urban fabric

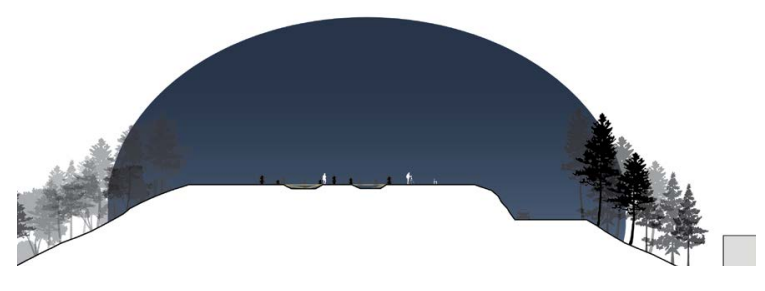

Boundaries of the urban fabric facing North

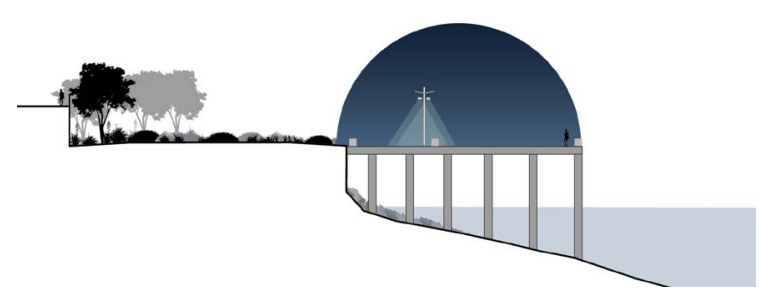

Boundaries of the urban fabric facing South

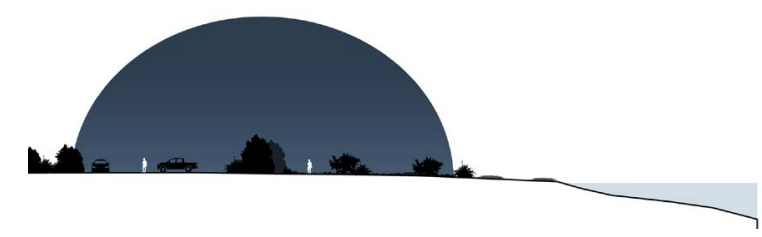



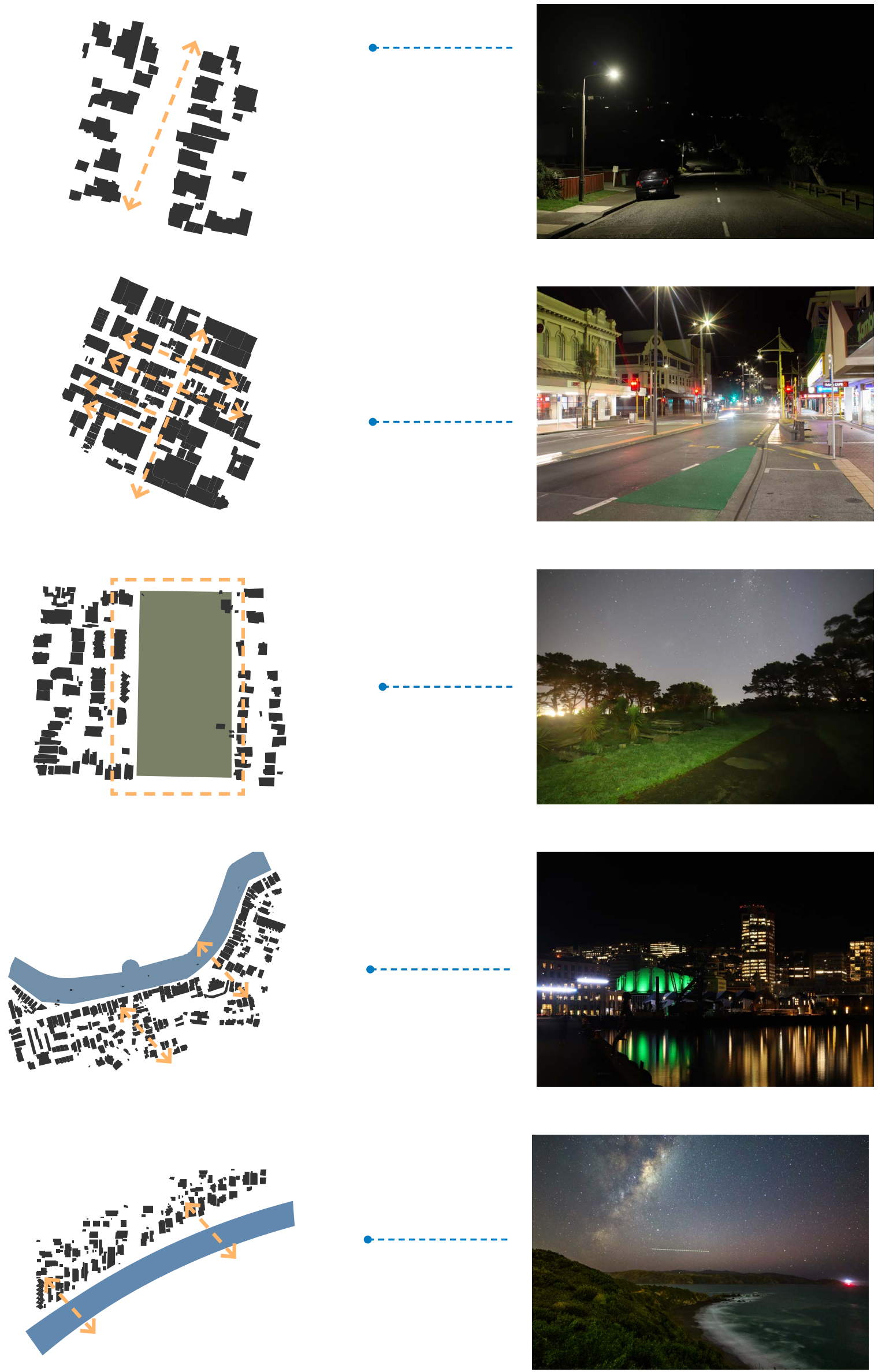


\subsection{Reflection}

Wellington has a variety of light intensities in multiple different areas across the city. The many trips taken out to the different vantage points provided an overall idea of where the light pollution was concentrated and where it was more spread out. It also presented an idea of how Wellington's topography and town belt areas effected the spread and visibility of sky glow.

From the 5 research areas initially discovered, three were pursued in further depth in the experiential fieldwork. The research was developed around the gaps and boundaries of the urban space where there is urban fabric on one side and the natural environment on the other. These were the Waterfront, Town Belt and South Coast. The central city area and the street scape were removed as research areas because they were in the center of the urban realm which the analysis revealed to be too polluted by light for a connection to be made to the night sky. 


\subsection{Final Areas for further Research}

The Boundaries of the urban fabric

(North)

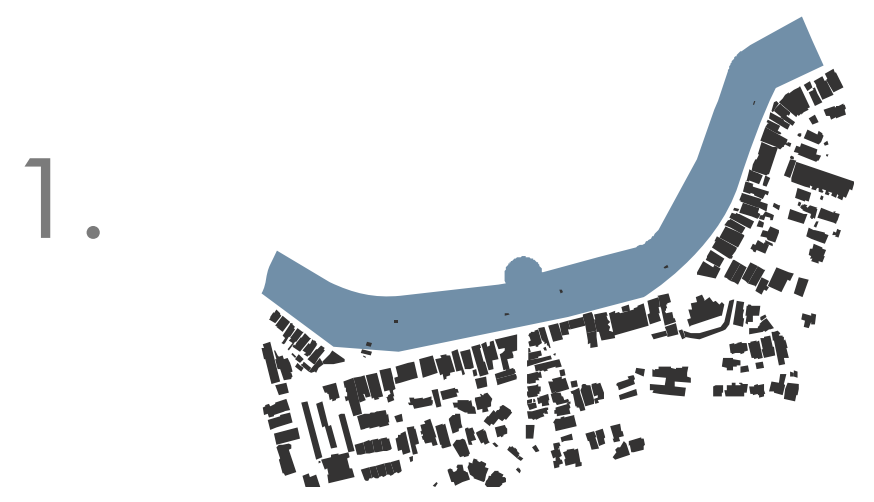

Gaps, Non Built areas in the urban Fabric
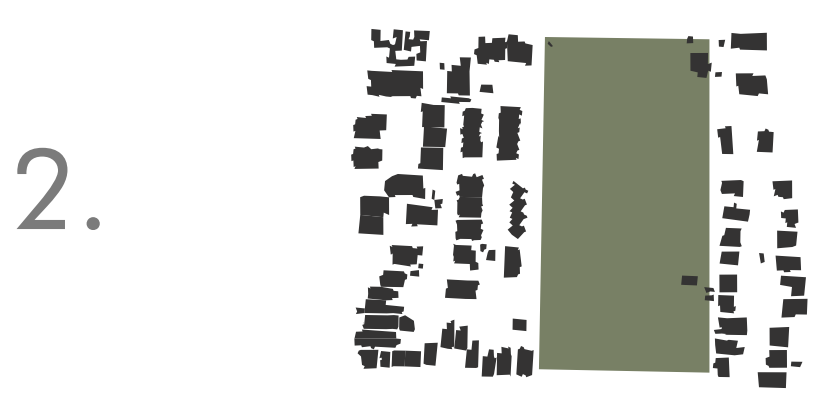

The Boundaries of the urban fabric (south)

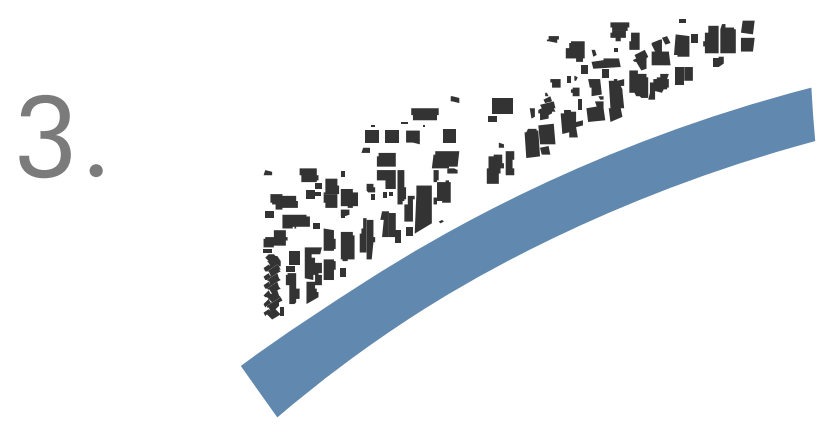




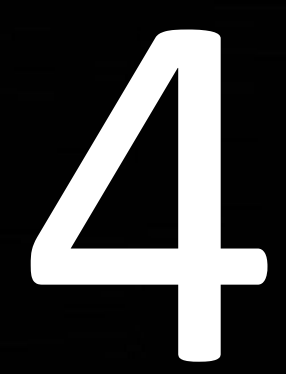

\section{INITIAL FIELDWORK}

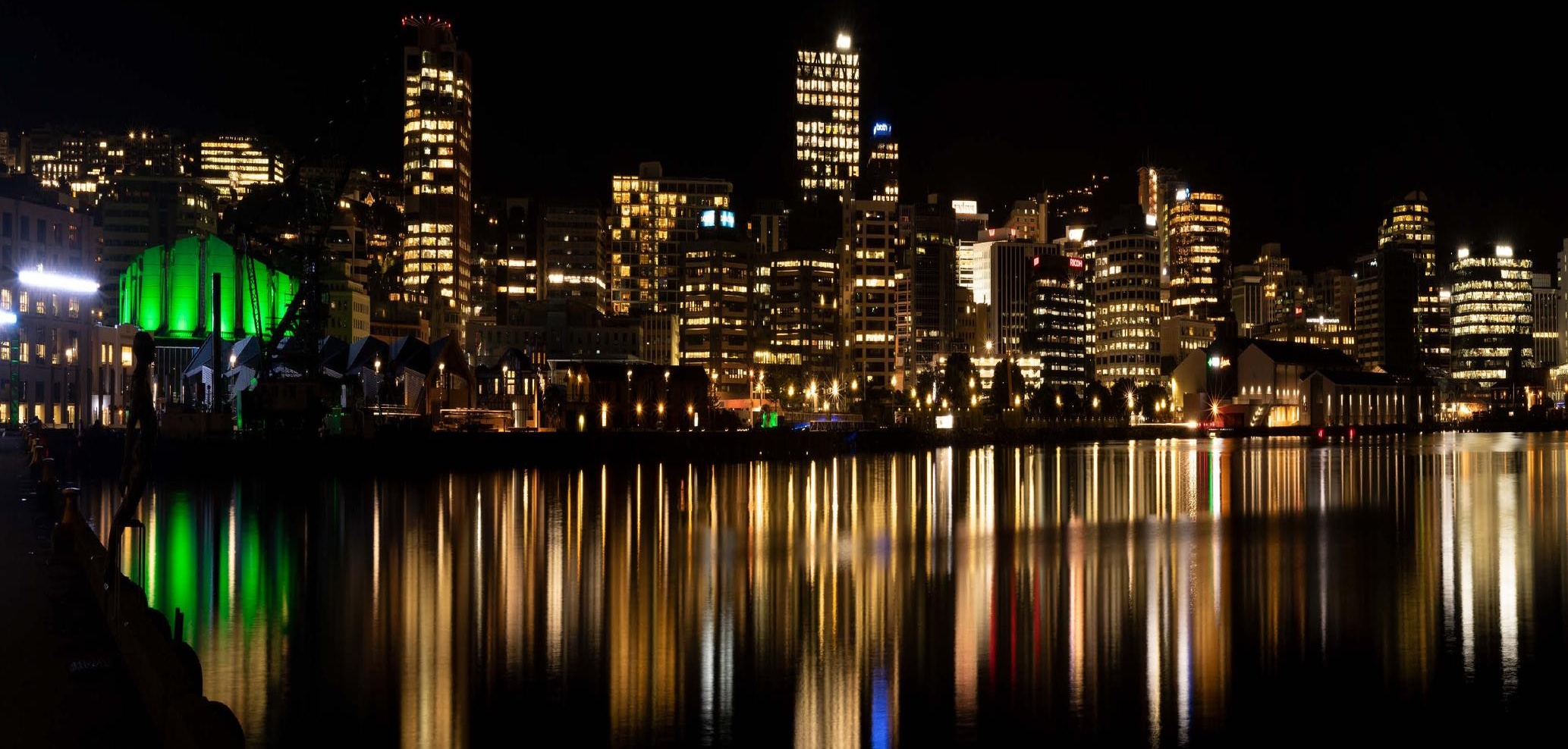




\section{Introduction.}

Experiential fieldwork was identified as a key method in understanding the night time experience in public spaces as it was not specifically discussed nor were examples found in the Theoretical Framework. Wellington was divided into units for analysis based on it's outdoor public spaces and amount of light pollution in each one. Journeys across Wellington were then undertaken to these spaces, with information on comfort, star quality and overall experience compared, contrasted and summarized between day and night. This provided a sense of the relationship between the physical characteristics of a space and the lighting used and how this was either improving or impairing the night time experience. These findings were then used as the foundations of the Design testing. 


\subsection{Revisiting literature}

Findings from the literature indicated that different landscape characteristics had different effects on our perception of a place during the day and at night. We don't often recognize that being in a public space during the day leads to a more relaxed state of mind, where as at night, due to the increased use of our other senses, we feel more tense and aware of how we are feeling.

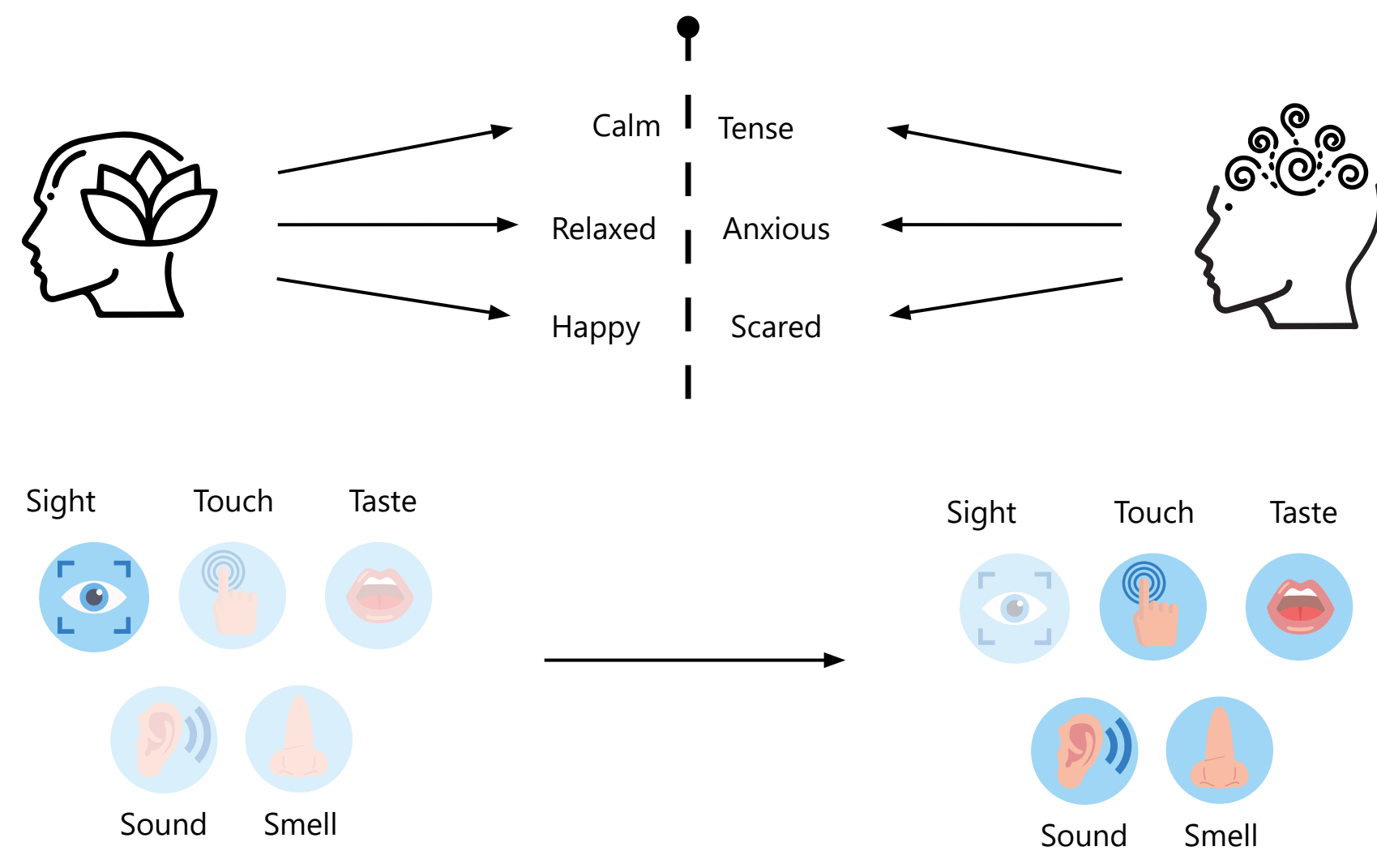

This day vs night comparison was explored in the Experiential fieldwork, with reoccurring site visits across the 3 different areas during the day and at night.

The effect of specific landscape characteristics we commonly design for during the day were contrasted against how they are perceived at night, and how the different typologies of lighting that were in place affect this. This was then used to generate conclusions on how the relationship between the location of the public space and the surrounding light pollution impacts how we use a space at night.

Specifically documented was the change in comfort felt, the quality of the stars, and the overall experience. 


\section{Day time}

- Vegetation

- Topography

- Accessibility

- Materiality

- Elevation

- Shelter

- Location
Night Time
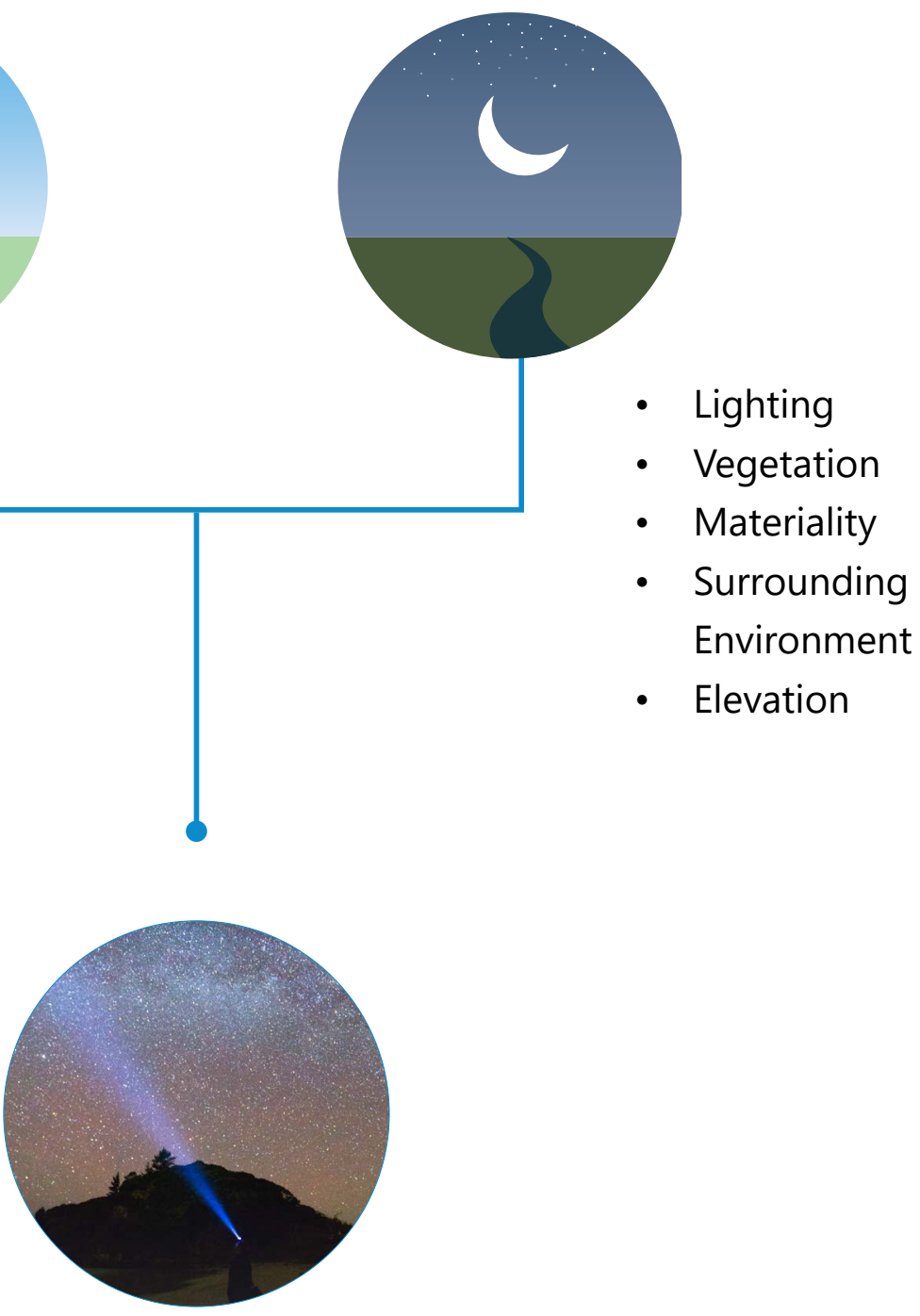

Experience

- How comfortable was the site?

- How many stars were visible

- What was the overall night time Experience? 


\subsection{Specific Areas For Study}

\section{Central Waterfront}

- The waterfront on the central CBD of Wellington presented a variety of different typologies of spaces where the nighttime experience could be explored.

- This was the only North facing space on the water's edge investigated, as the aim in this space was to explore the relationship between the dense urban environment on the waters edge and the nighttime experience

\section{Mount Victoria Town Belt}

This section of the Wellington Town belt was chosen for analysis because:

- It was a popular destination for walkers, runners, families and tourists during the day, as it offered expansive views across Wellington. This provided a good daytime experience to compare the night against.

- The western town belt could also have been chosen, but Mt Victoria's position in the center of Wellington allowed the differing light pollutions levels in the east and west sides of wellington to be compared.

\section{East South Coast}

The South east coast of Wellington was chosen over the west coast because:

- It had a wider view of the night sky uninterrupted by light pollution, with a greater variety of public spaces to test the literature findings.

- The west coast had similar view shafts, but most of the open spaces were on the water level as residential housing dominated the hillsides facing the water.

- The east coast was also a lot darker then the west due to the majority of the housing being tucked behind the hillside that faces the cook strait. 


\section{Central CBD Waterfront}
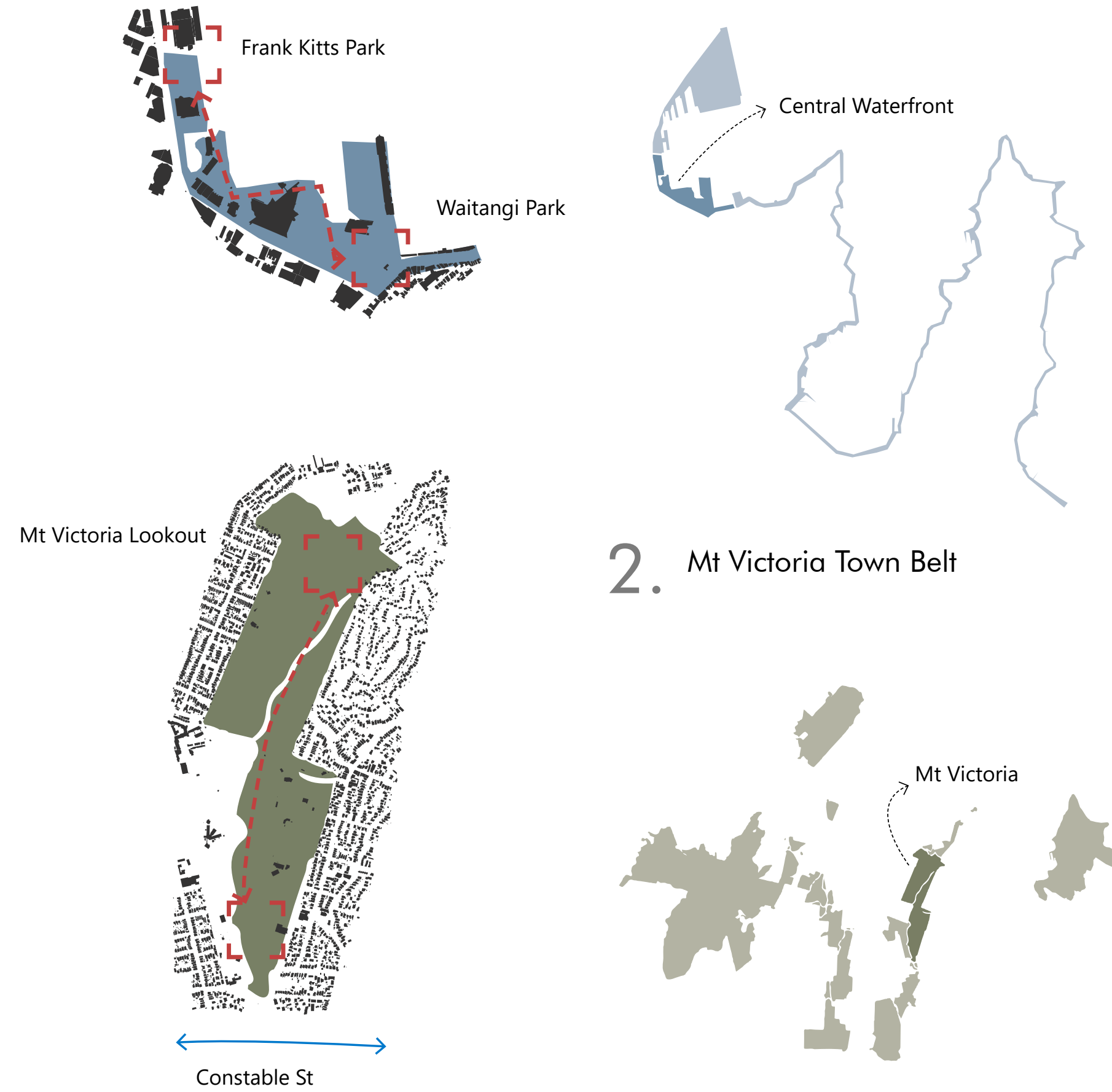

2. Mt Victoria Town Belt
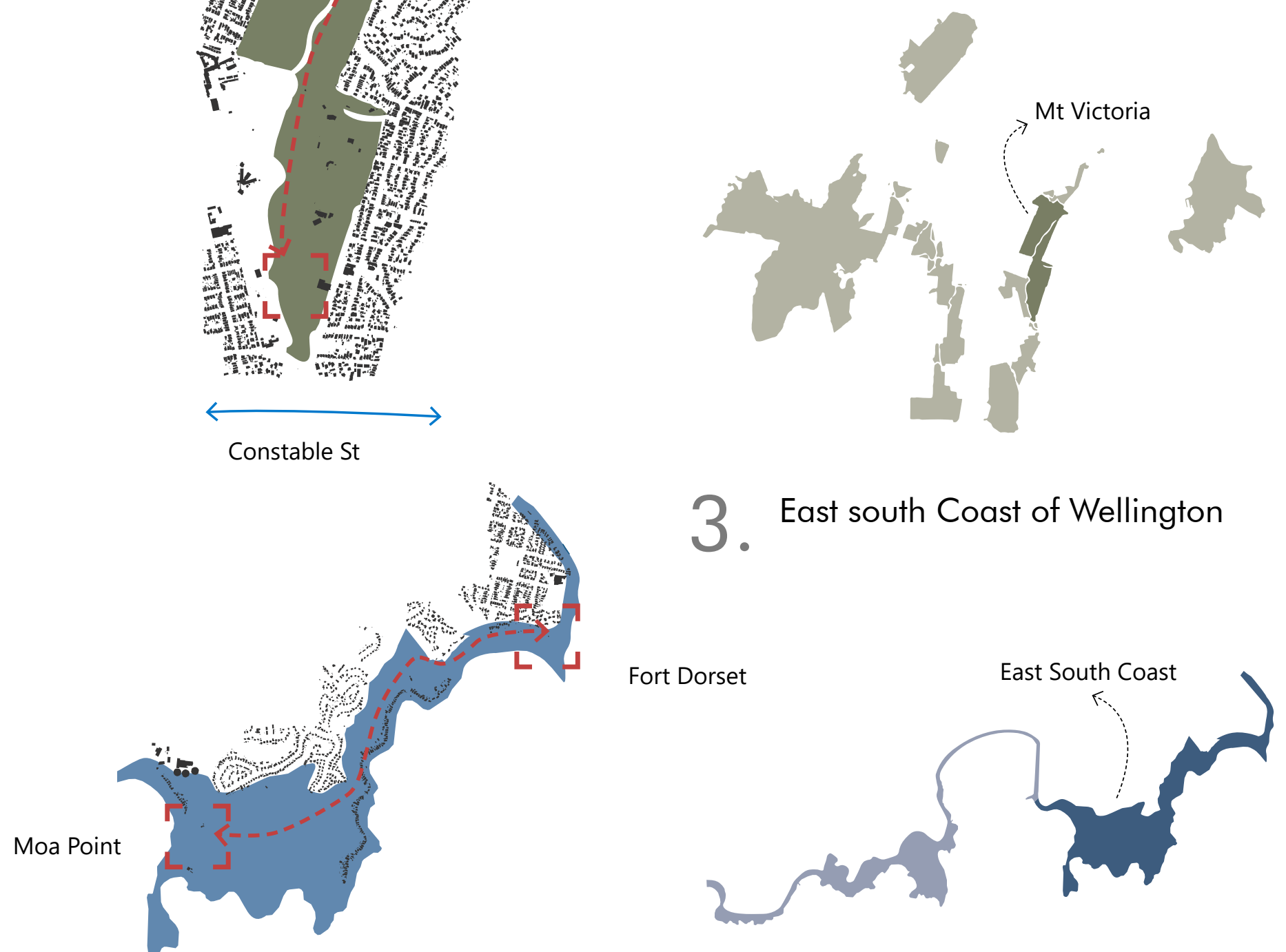

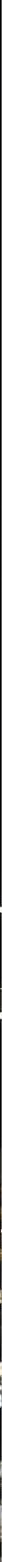


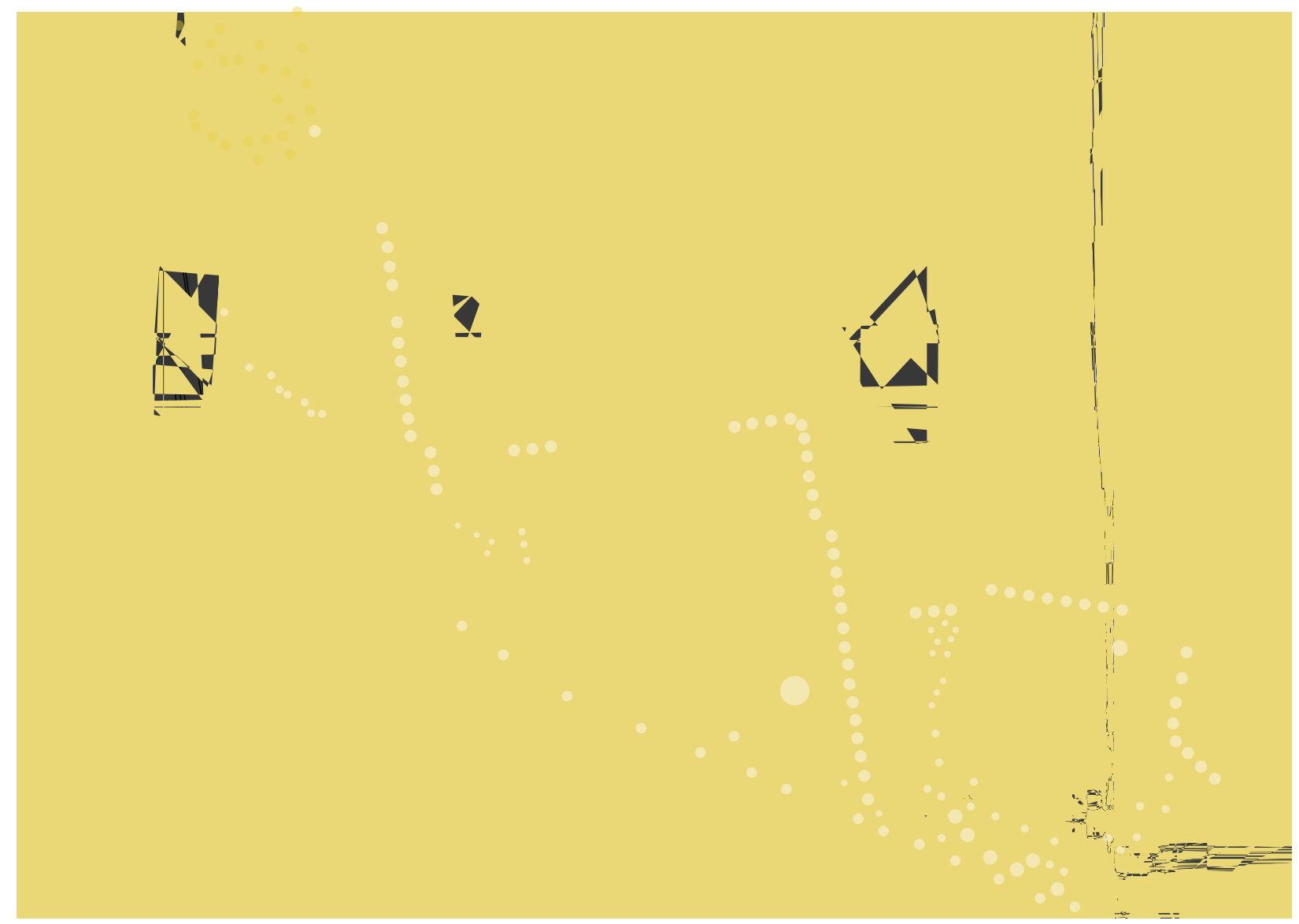




\section{FRANK KITTS PARK}

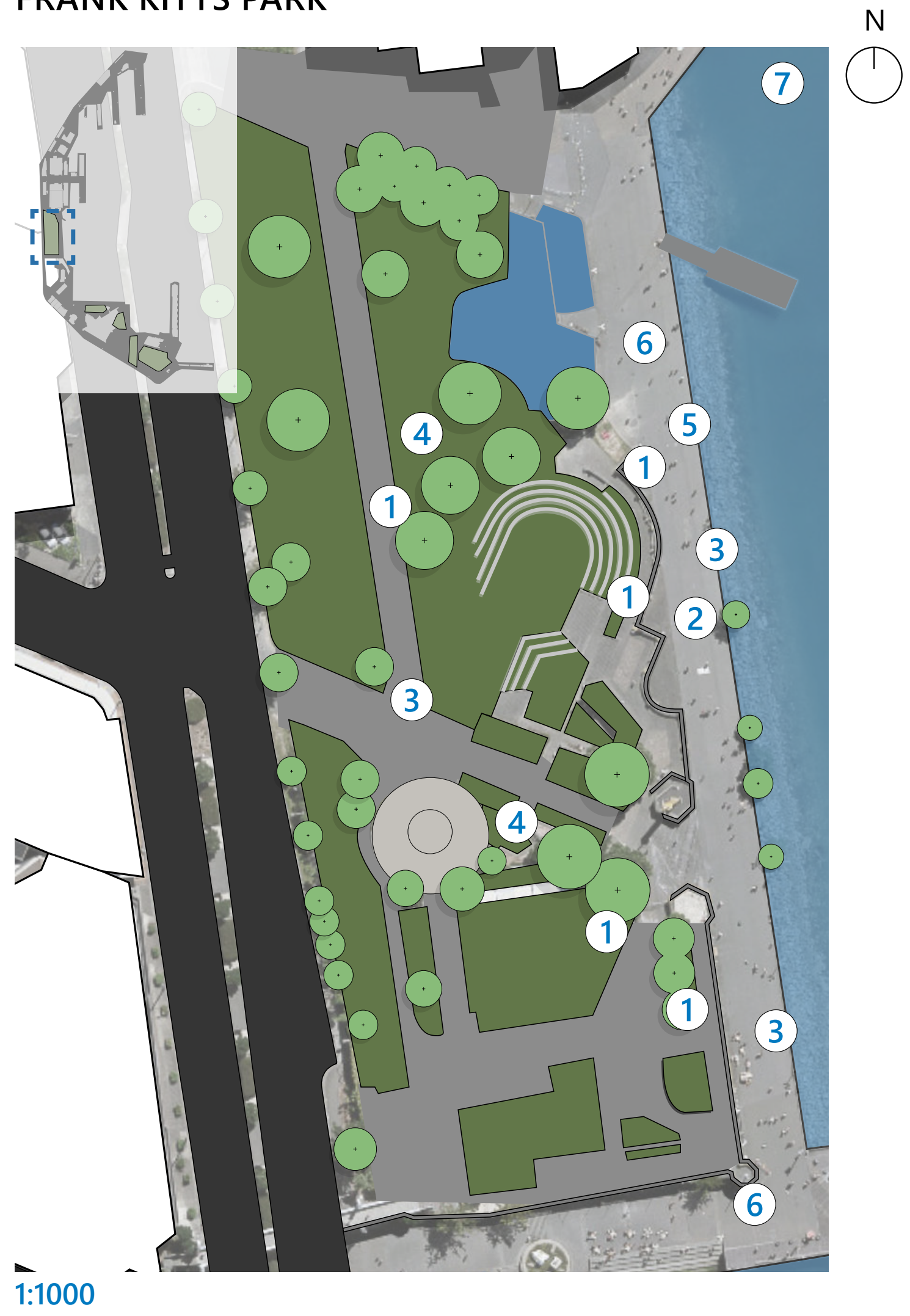




\section{Day Experience}

1. Seating at the park is set at the normal 80-90 degee angle which doesn't create any other purpose besides just using it as a place to rest

2. People use the space frequently due to its large open walkways

3. Site affords nice views out over the harbour

\section{Night Experience}

4. Silhouette of Pohutukawa trees prevents light glare from entering certain spaces making them more ideal for star gazing

5. Lighting in the site is very ornamental and doesn't have any shielding which creates glare

6. The walkways are devoid of life at night due to the daytime use disappearing

7. At night the view of the sky is interrupted by the bright lights of the port

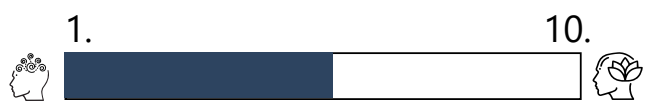

Overall comfort level

1.

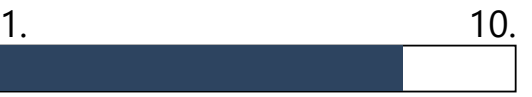

Amount of Light Coverage

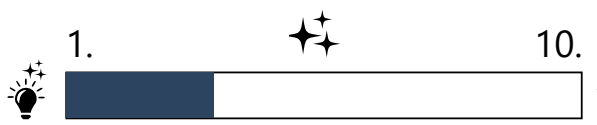

$(5)$

Star Visibility

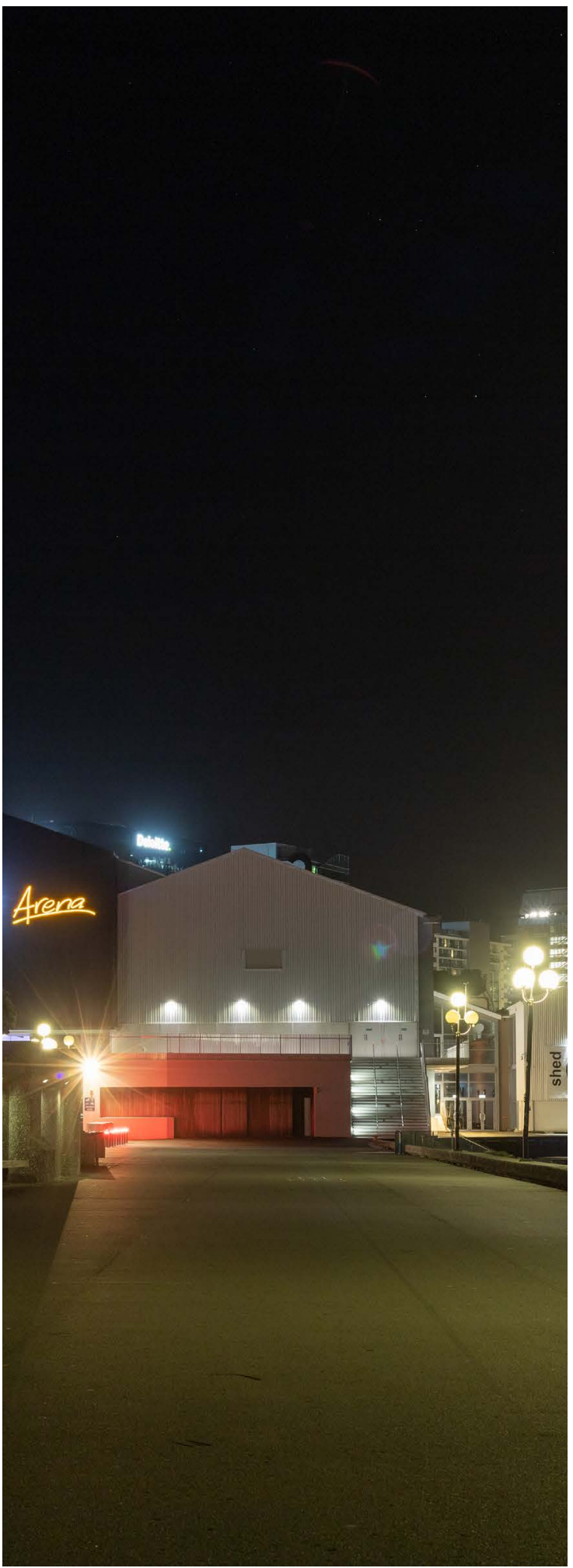

4.6 North facing Night Sky above Frank Kitts Park 


\section{Wide Open spaces}

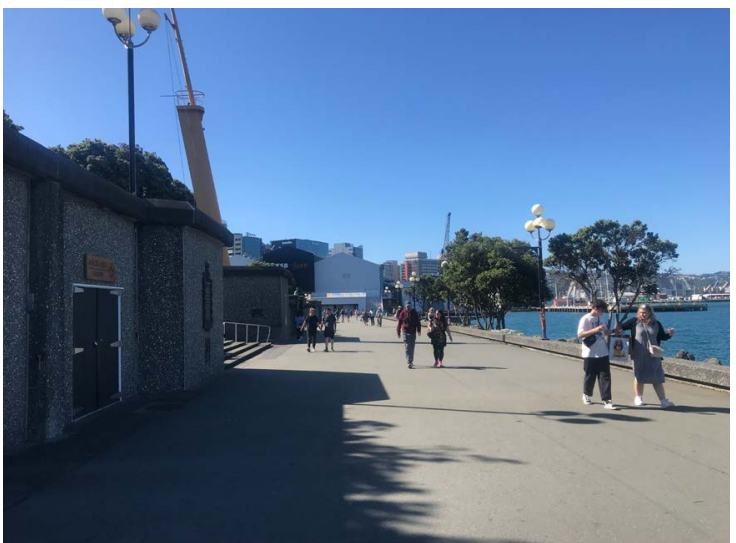

\section{Shade of trees}

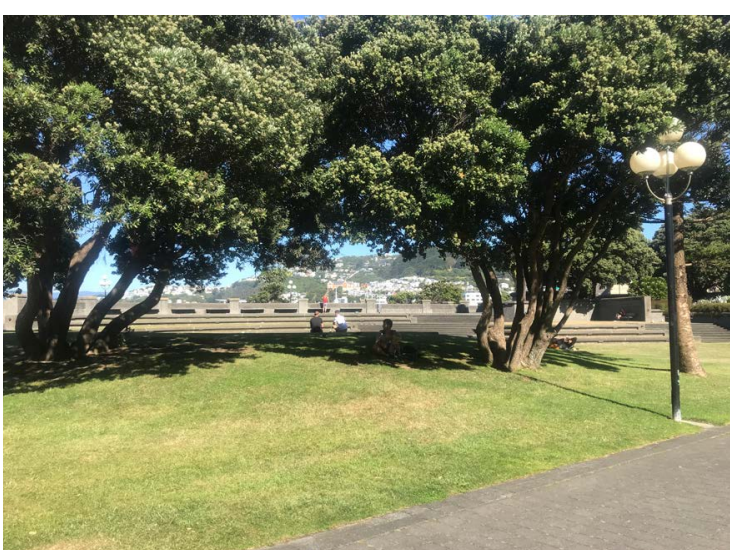

\section{Seating angle \& direction}

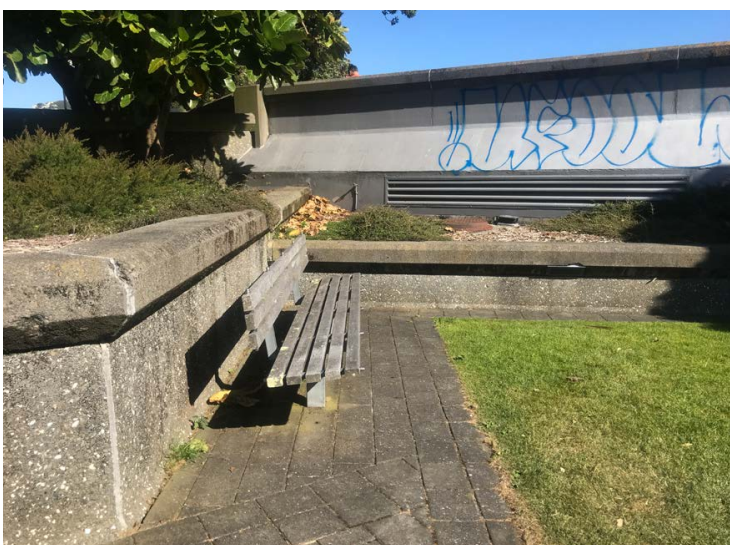

\section{Surrounding environment}

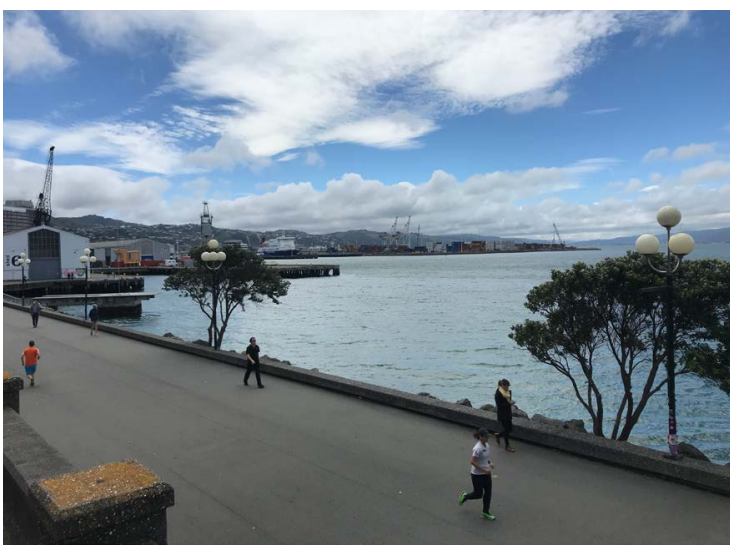

Contains a large amount of wide open walkways

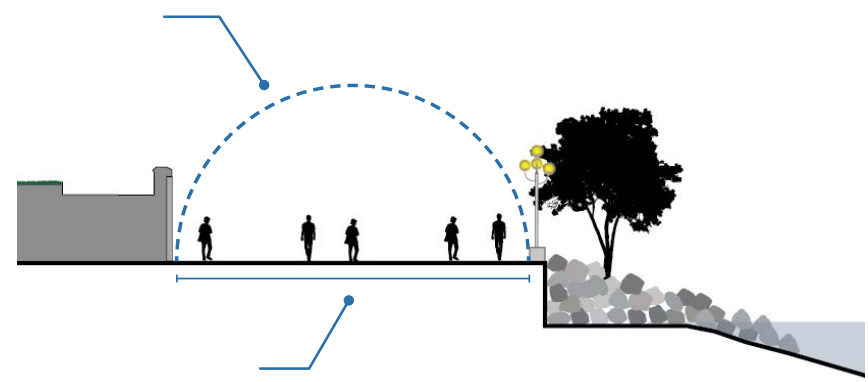

Used by many People throughout the day

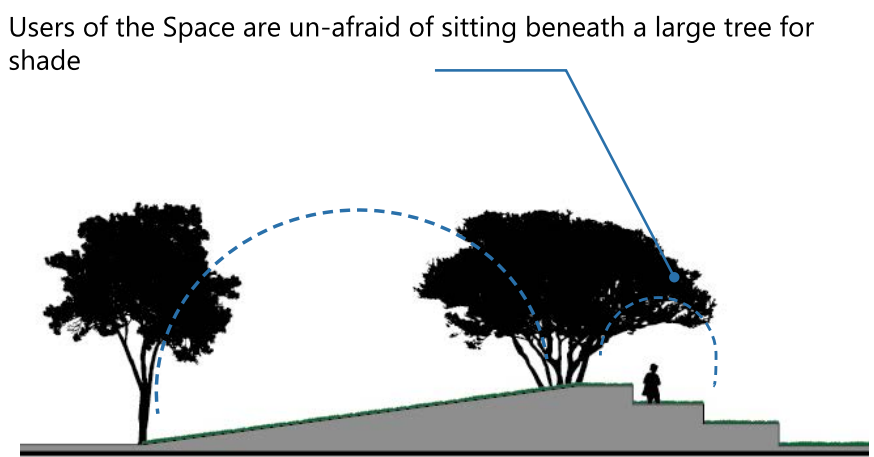

All the public benches in the park either have a 90100 degree backrest or nothing at all

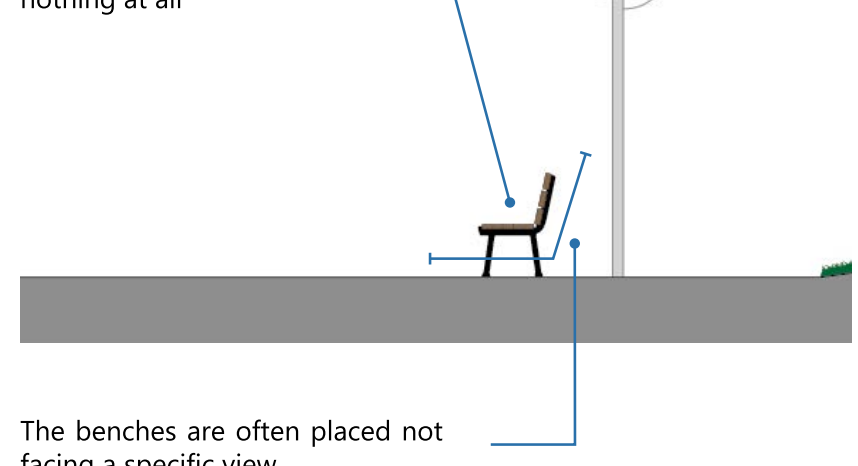
facing a specific view

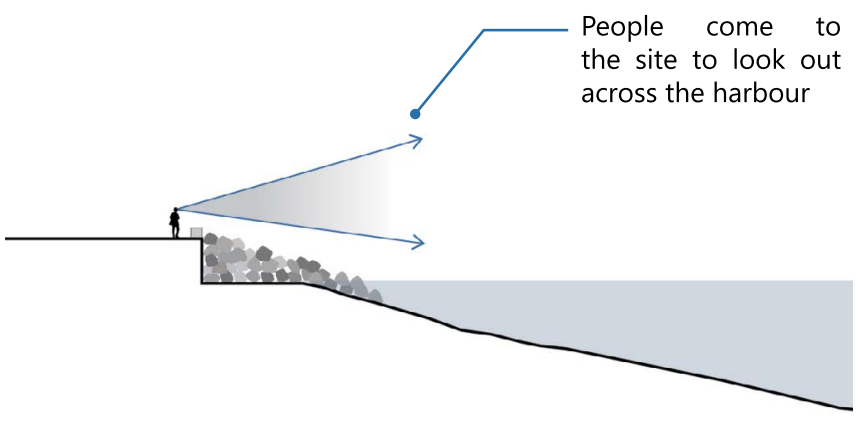


Full coverage of lighting at night

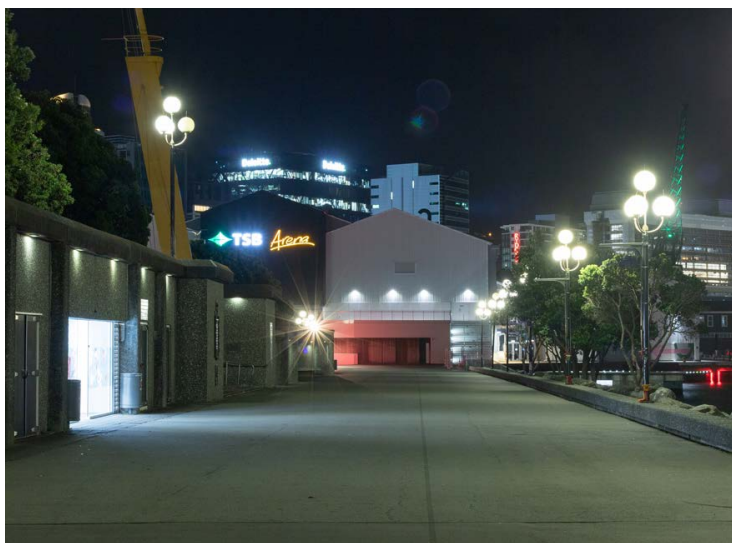

\section{Tree \& Lighting relationship}

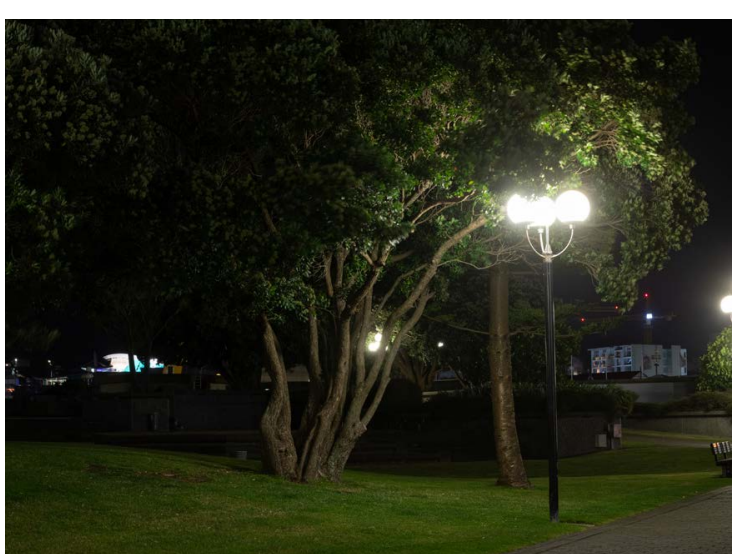

\section{Seating \& lighting relationship}

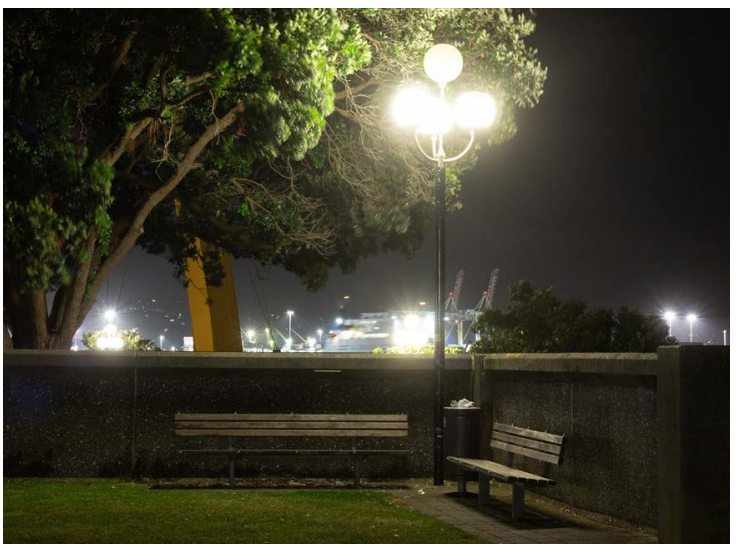

\section{Light from outside the space}

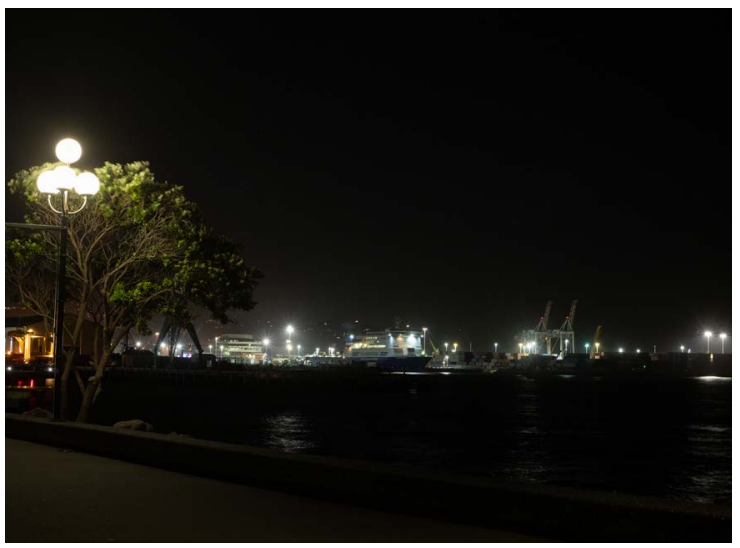

The entire walkway is lit up, despite the fact that hardly anyone is using it.

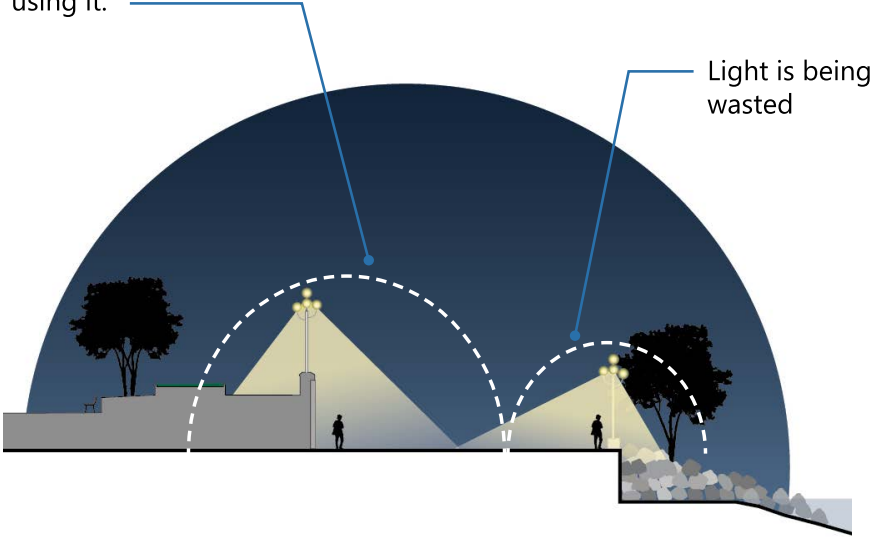

People avoid trees at night, but their

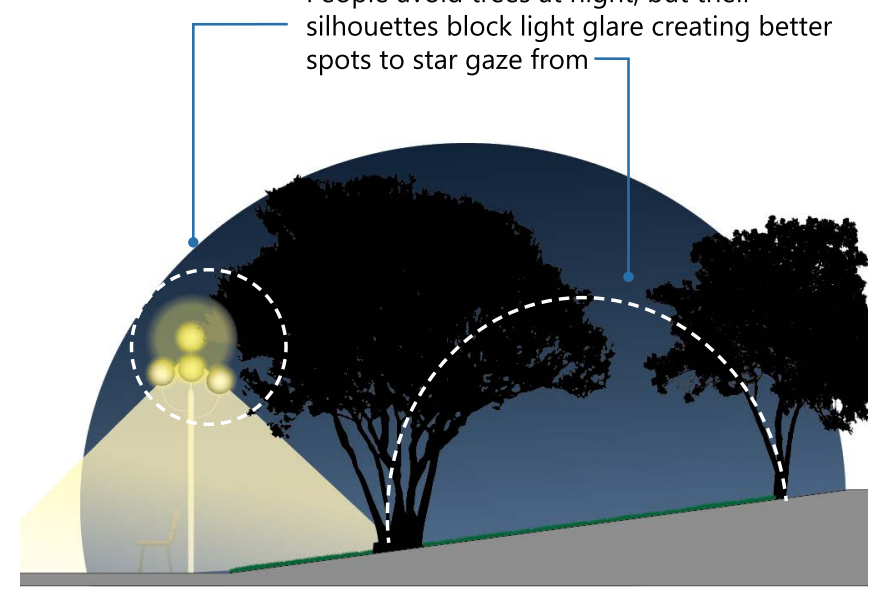

Benches are placed underneath Lamp posts for safety, but the view the bench allows you to normally see during the day is lost

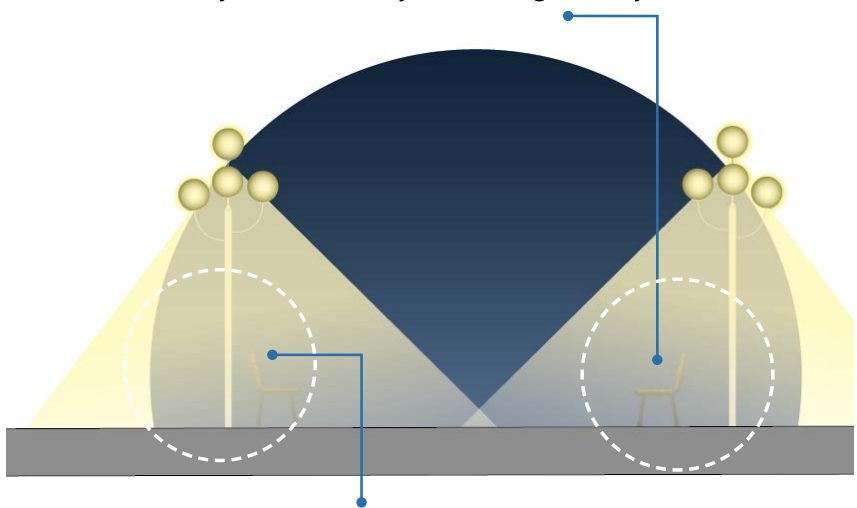

The glare from the lamp prevents you from sitting in the chair and looking up at the sky

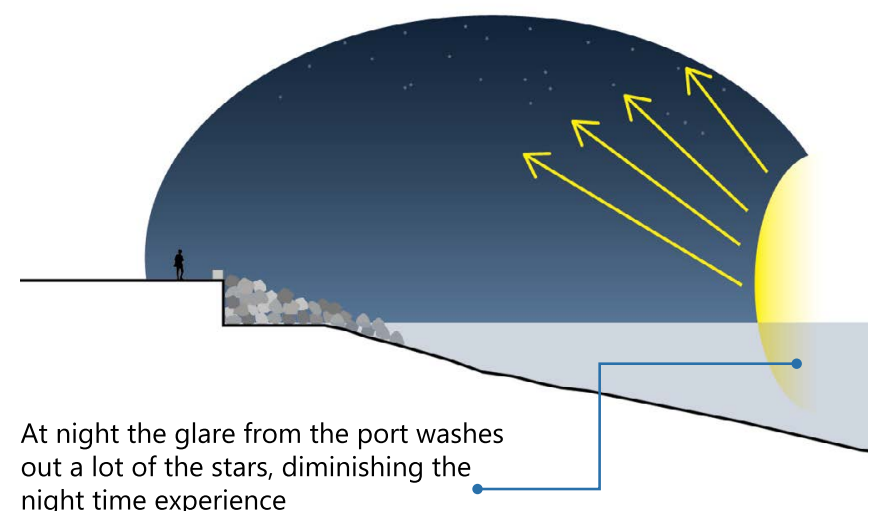




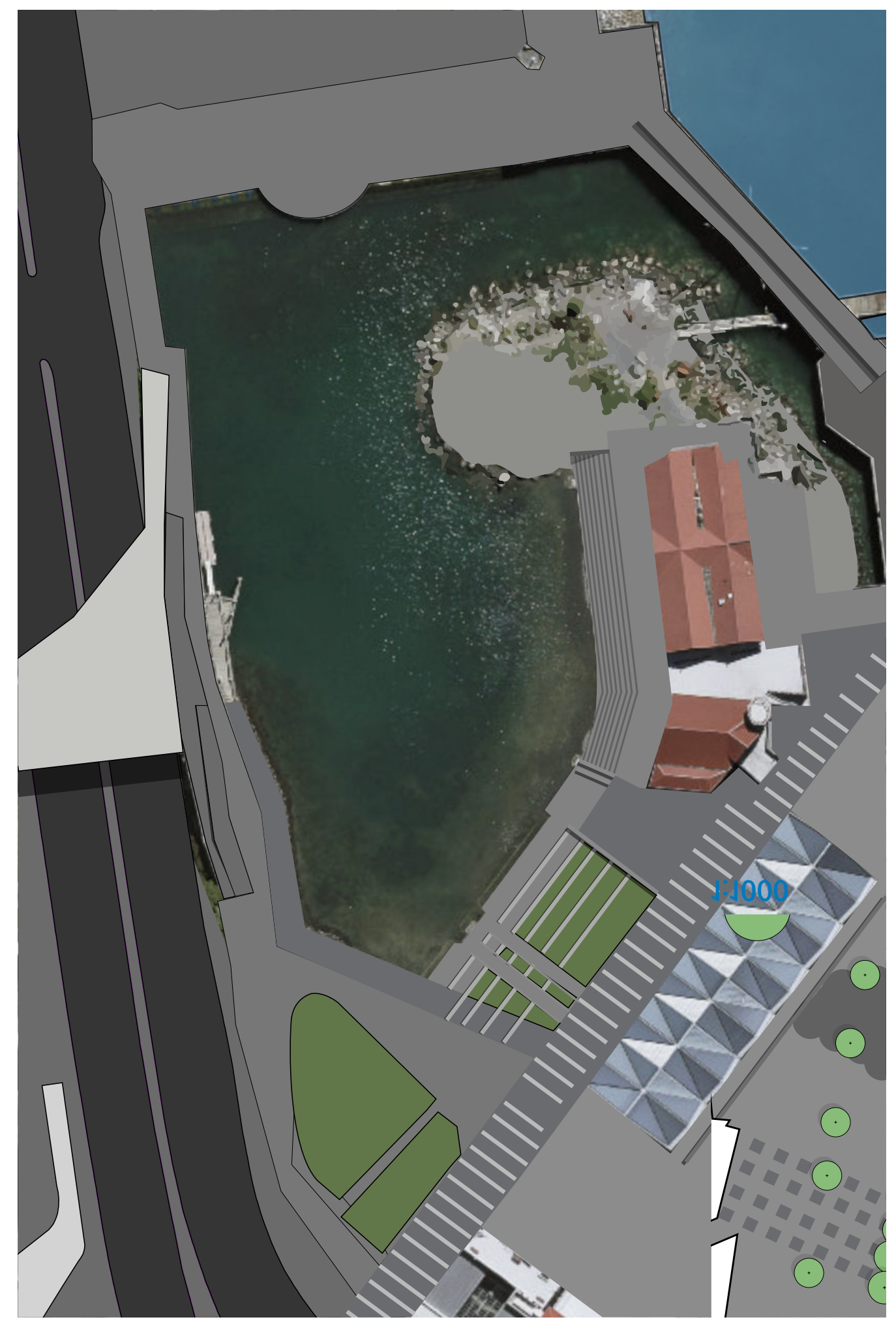




\section{Day Experience}

1. Vegetation provides interesting space to relax and feel close to nature in the middle of a busy urban area

2. During the day the area provides a nice place to relax in the sun

\section{Night Experience}

3. Light trespasses into the space from lights used in Frank Kitts Park

4. Vegetation in the space can lead to feelings of entrapment

5. However the vegetation also blocks the glare of any surrounding light

6. Lights shining from below in the space provide a less restrictive view of the stars

7. In the lower half of the lagoon, bright lights cover the seating in light.

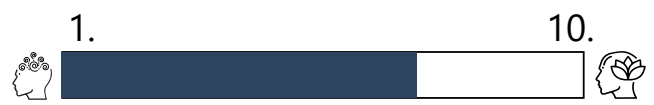

Overall comfort level

1.

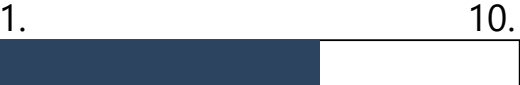

Amount of Illuminated Area

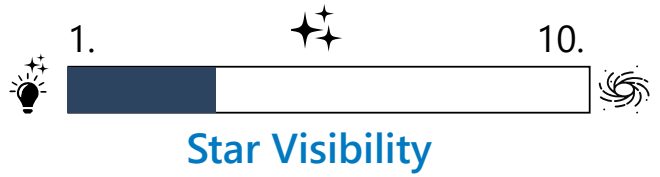

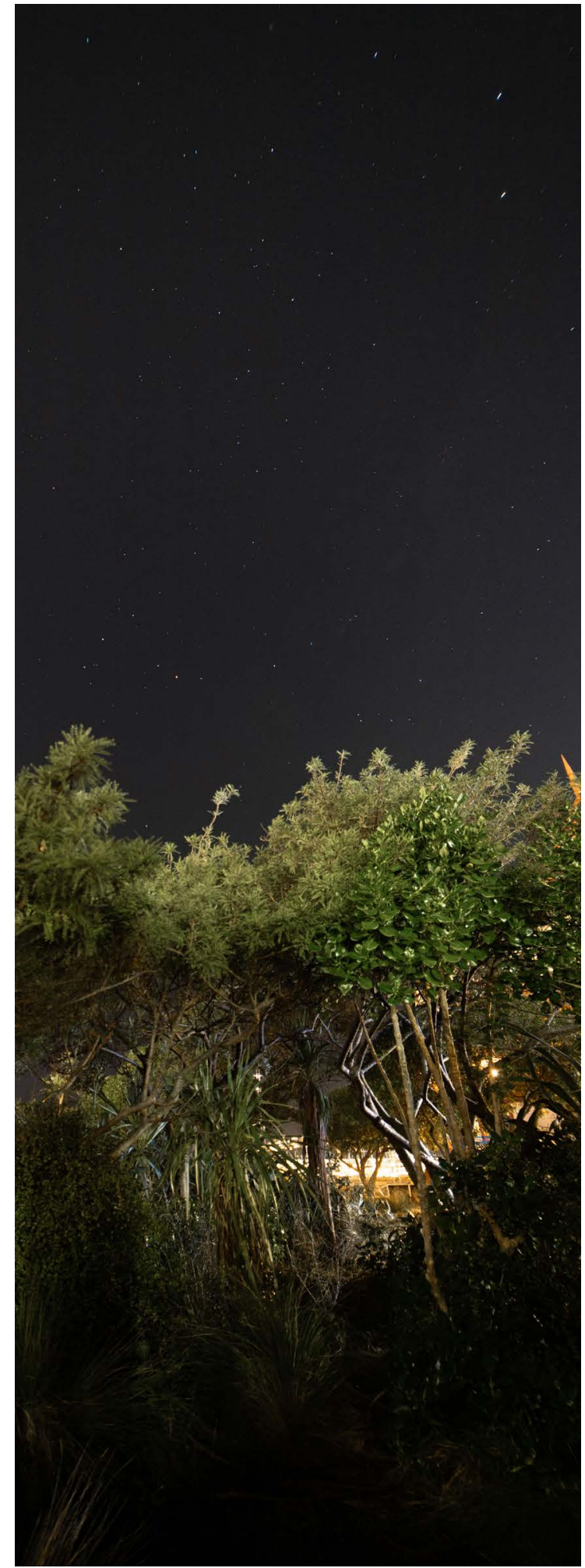

4.7 Night sky above Whairepo Lagoon 


\section{Vegetation / wellbeing}

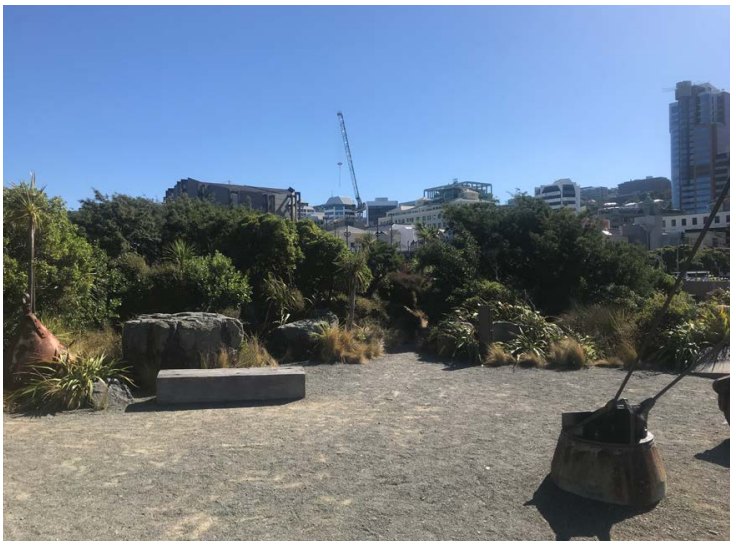

\section{Lookouts across the water}

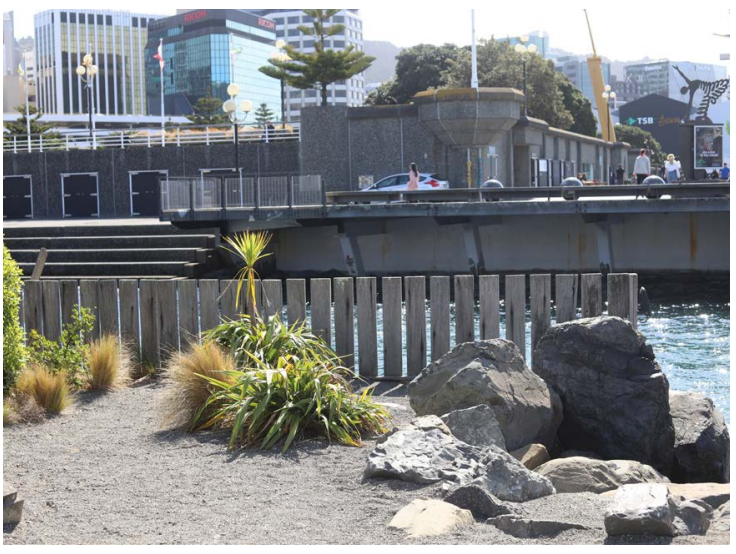

\section{Seating}

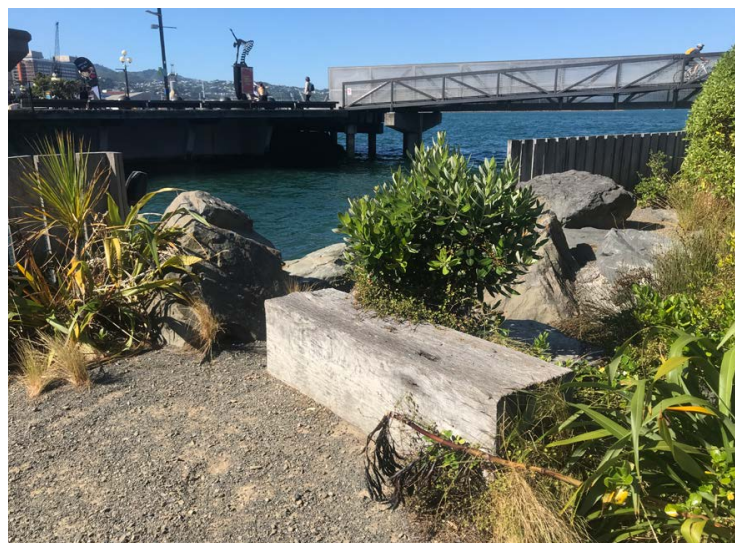

\section{Lighting below}

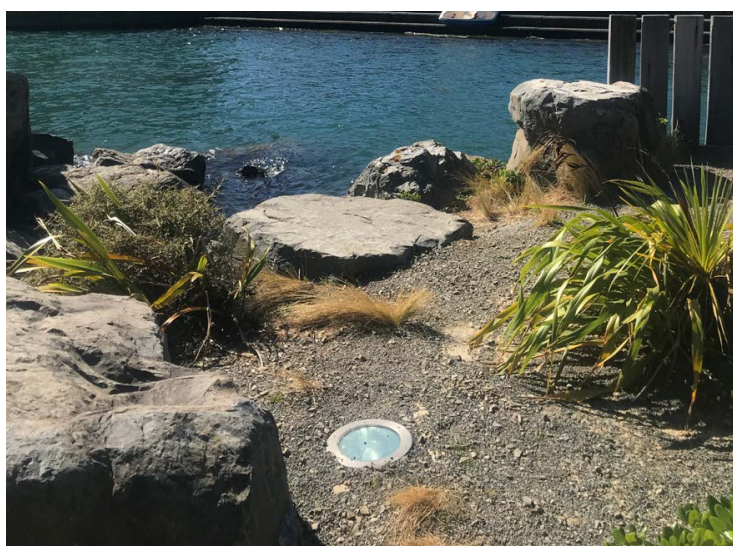

Relaxing green space to go in the middle of the urban city
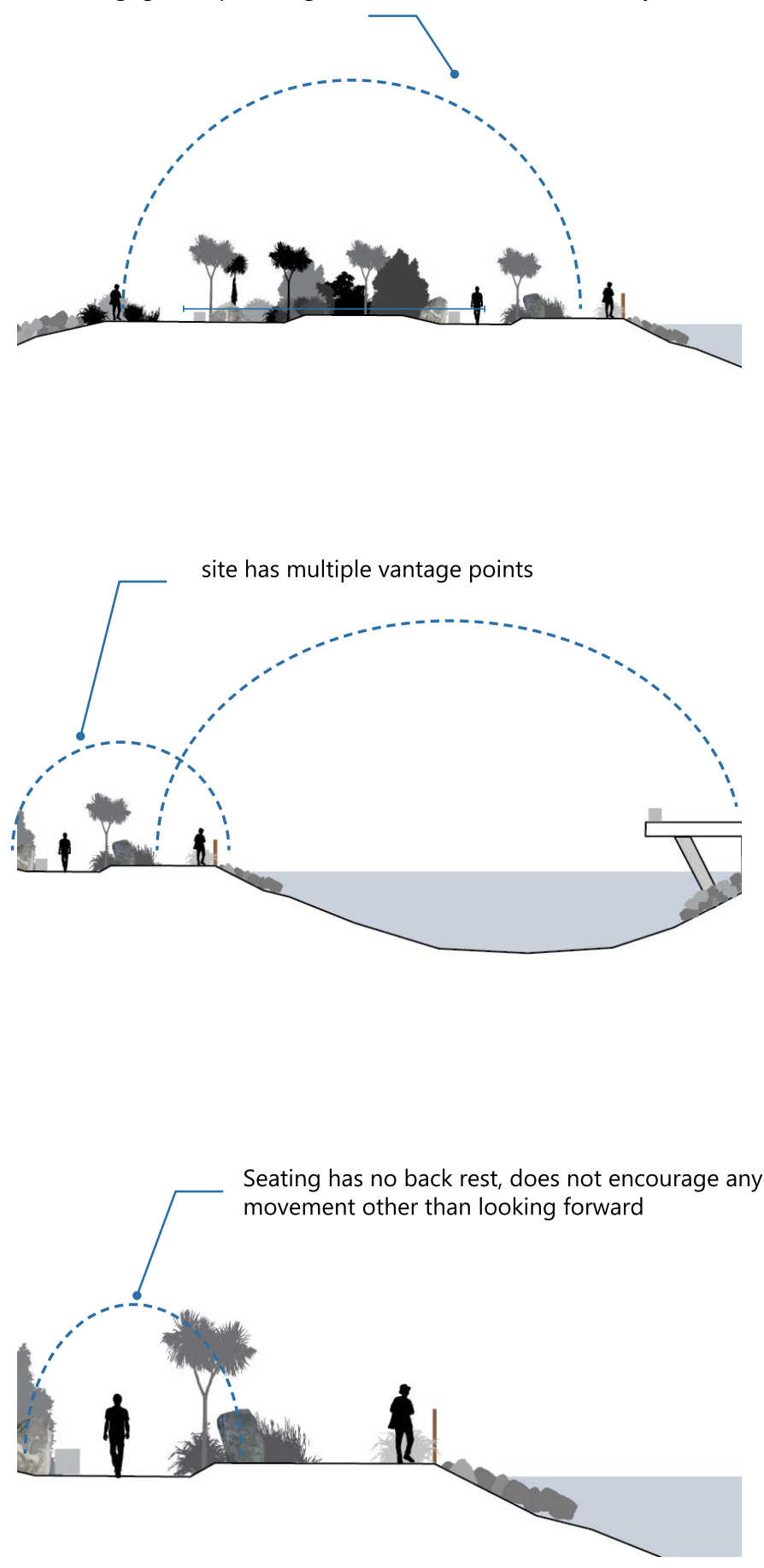

Lighting shines from below is a good alternative to lighting shining from above

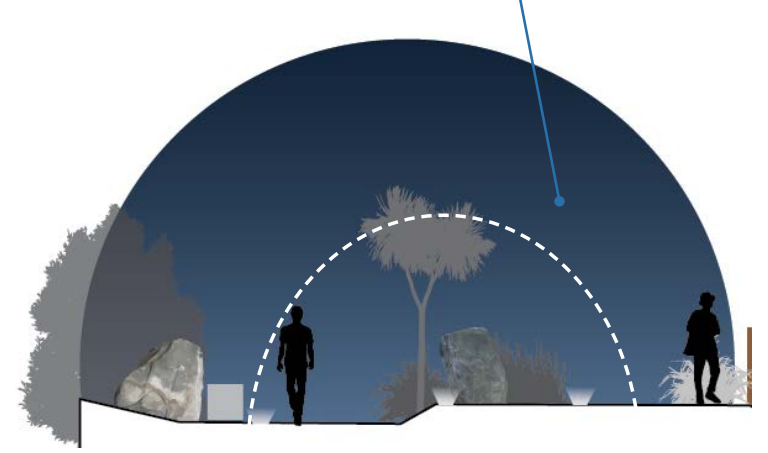


Lights lighting up areas that do not need it
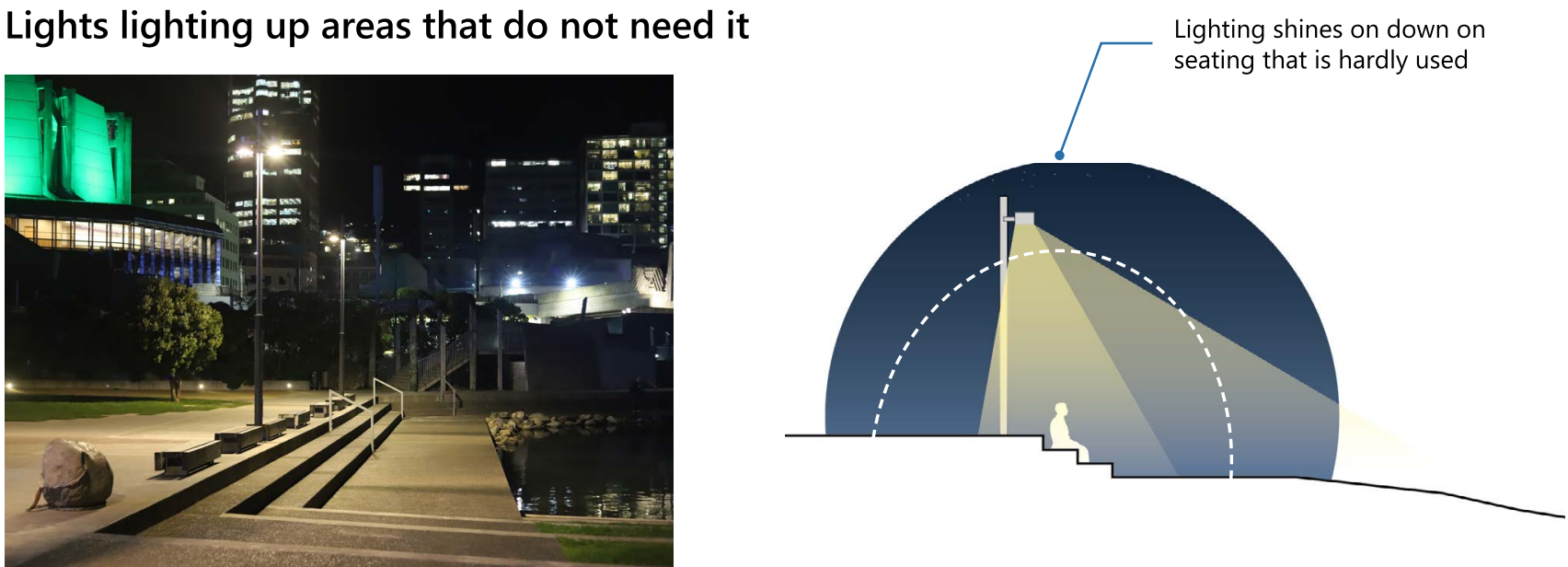

Infiltrating light from across the Lagoon
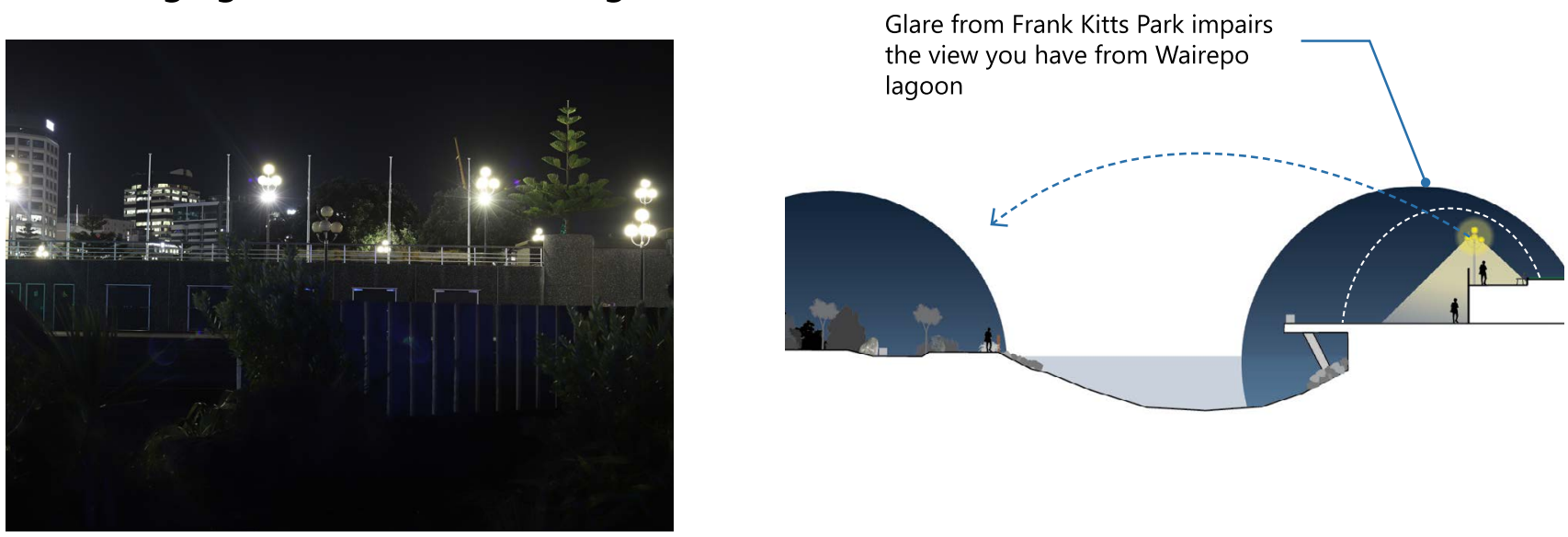

Surrounding building light
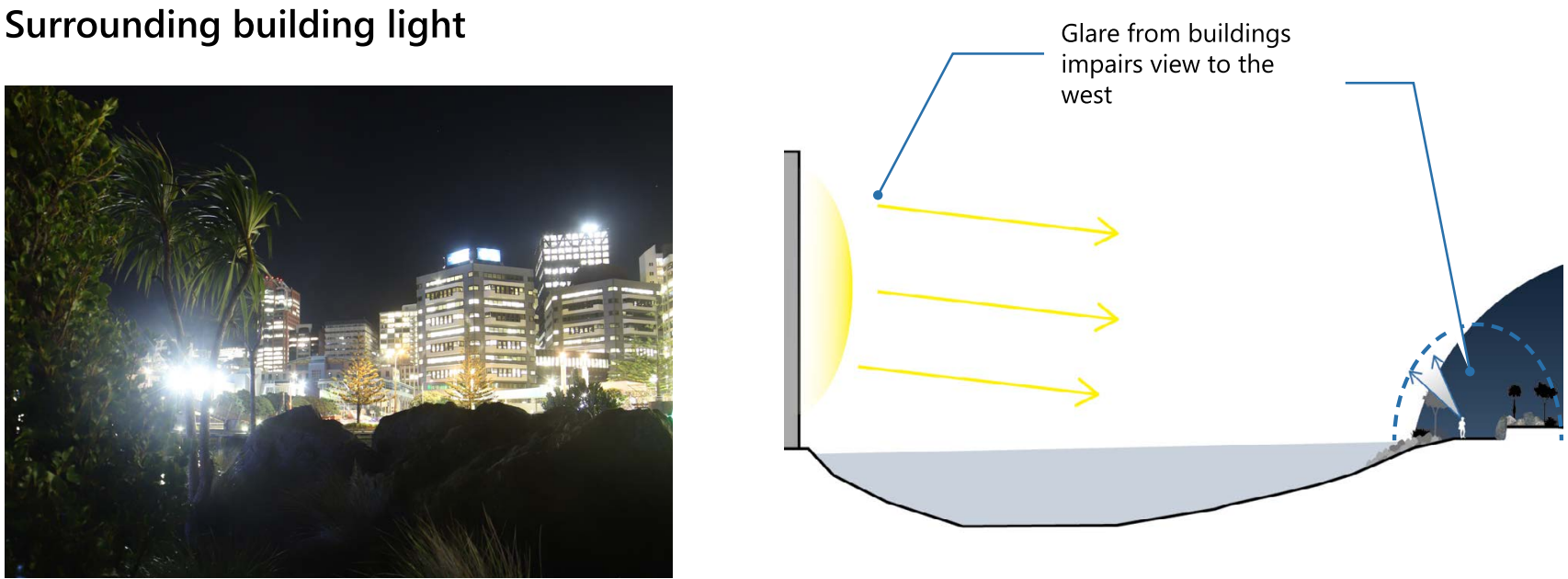

The vegetation shields the glare and gives this person a better view of the

Vegetation blocking the glare from lights
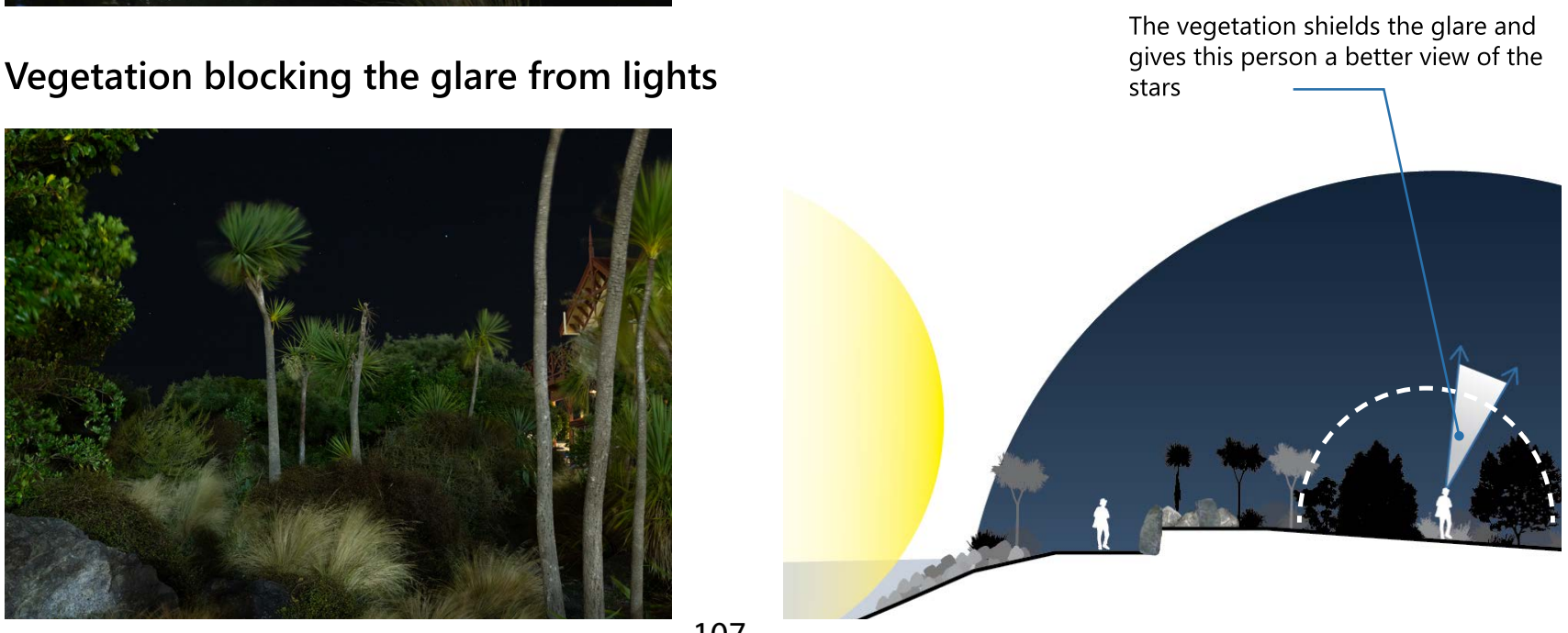
ODLINZ PLAZA

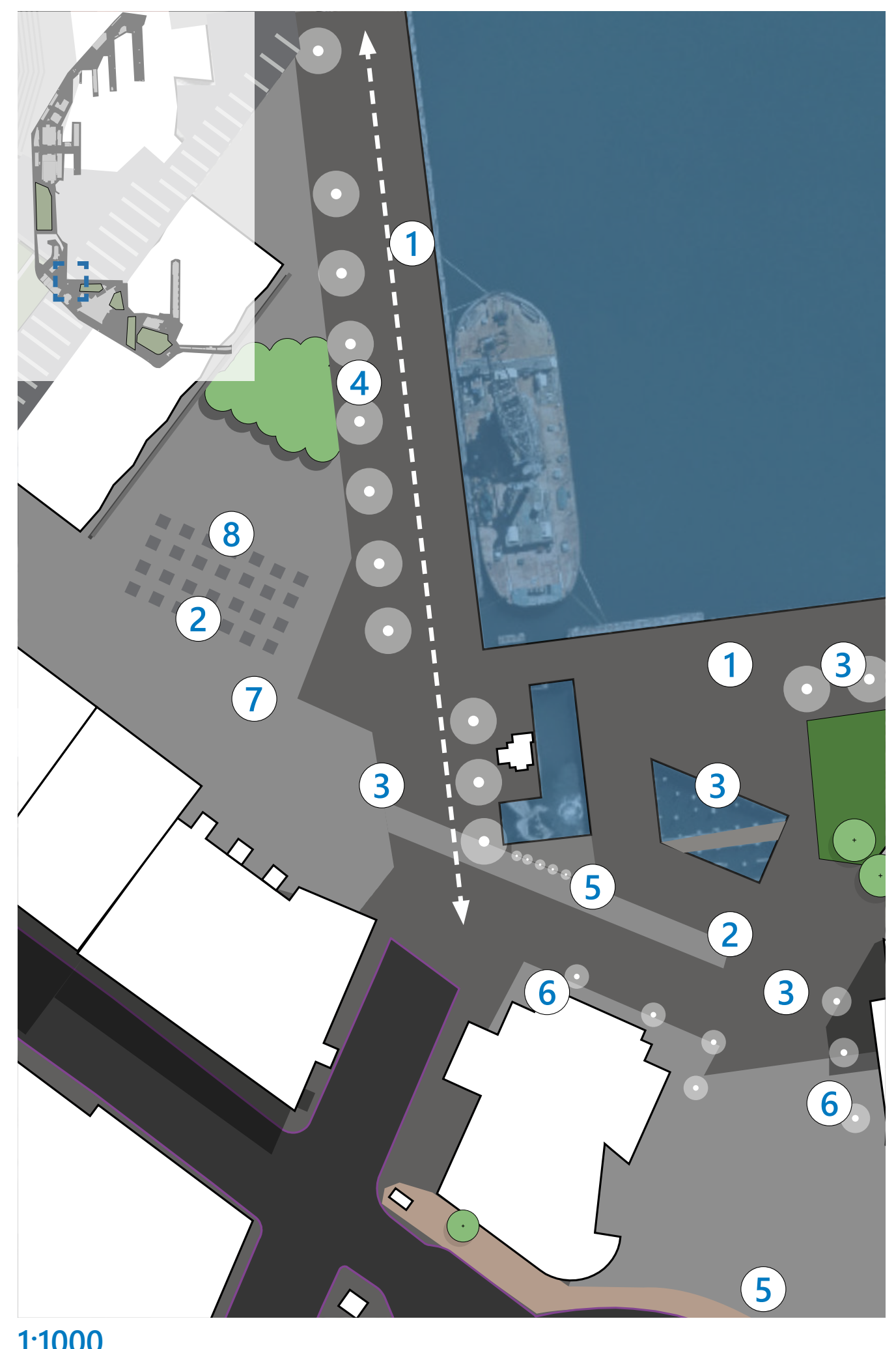

$\mathrm{N}$ 


\section{Day Experience}

1. Expansive views over the harbour

2. Very wide open space that allows many people to pass through the space during the day and at night

3. Seating did not afford the comfortable activity of looking up

\section{Night Experience}

4. Rows of homogeneous lighting used that illuminate the entire walkways in light

5. Some low level light did exist that provided a less restrictive view of the stars above

6. Some of the lights were unshielded

7. Area completely covered in concrete, nowhere that felt comfortable to lie down and look up

8. Areas of no overhead lighting were present which was quite a calming environment to be in

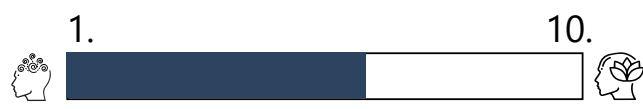

Overall comfort level

1. 10.

Amount of Illuminated Area

(6)

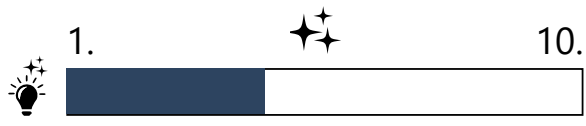
(s)

Star Visibility

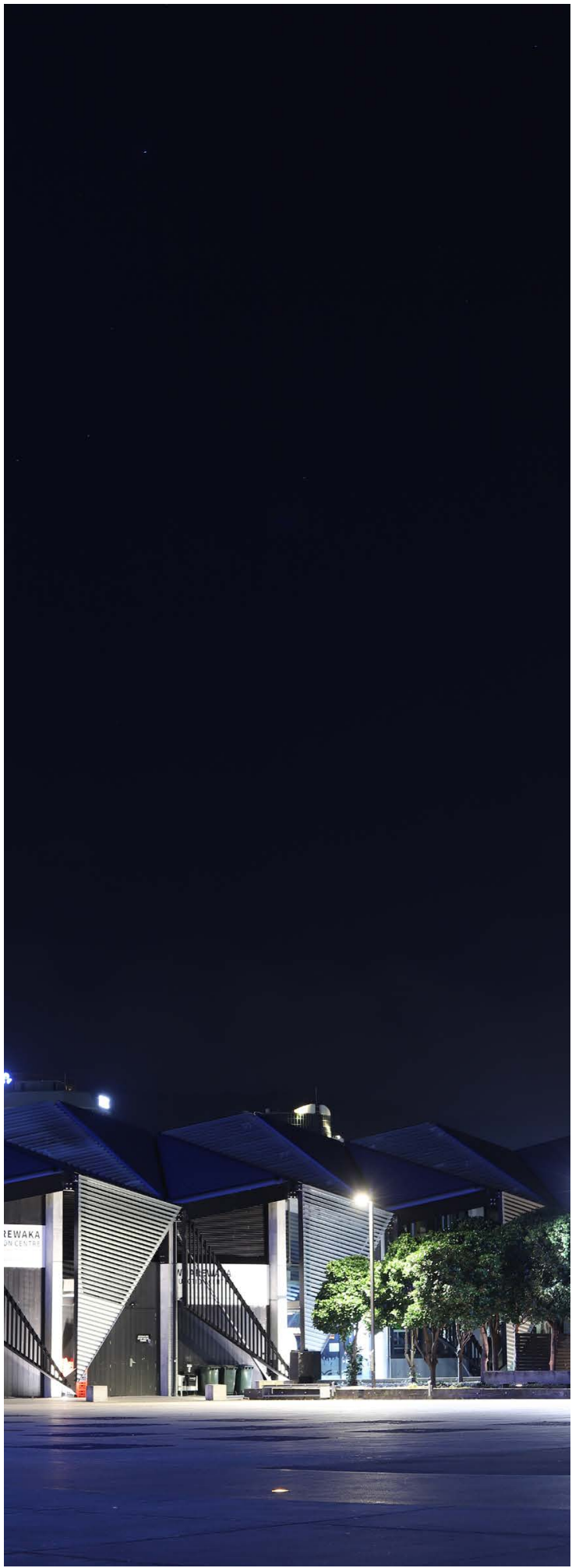

4.8 Polluted Sky above Odlinz Plaza 
Walkways for public access

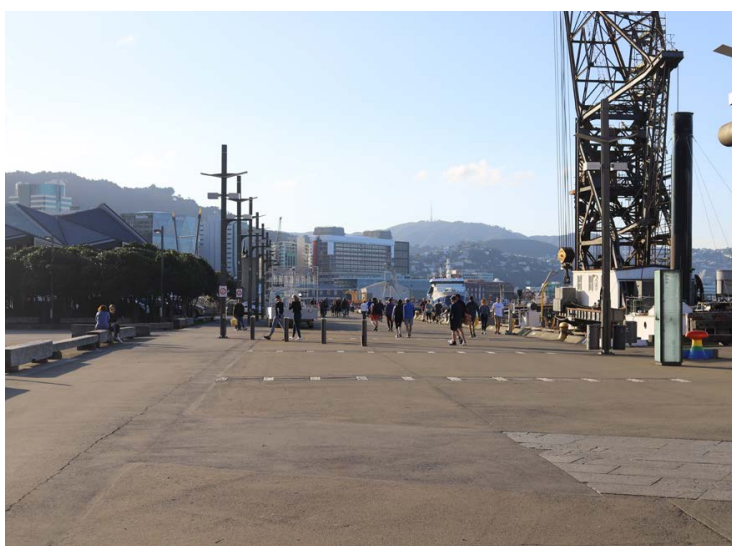

\section{Wide open spaces}

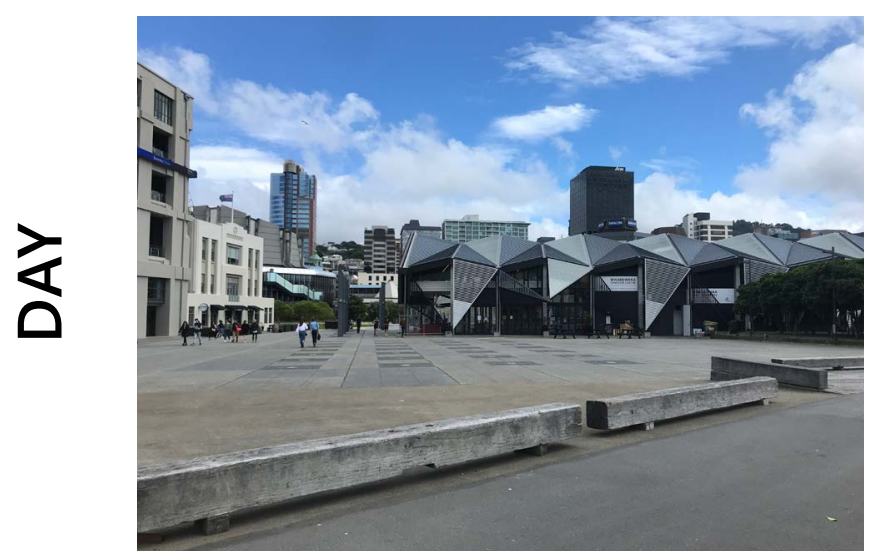

\section{Seating}

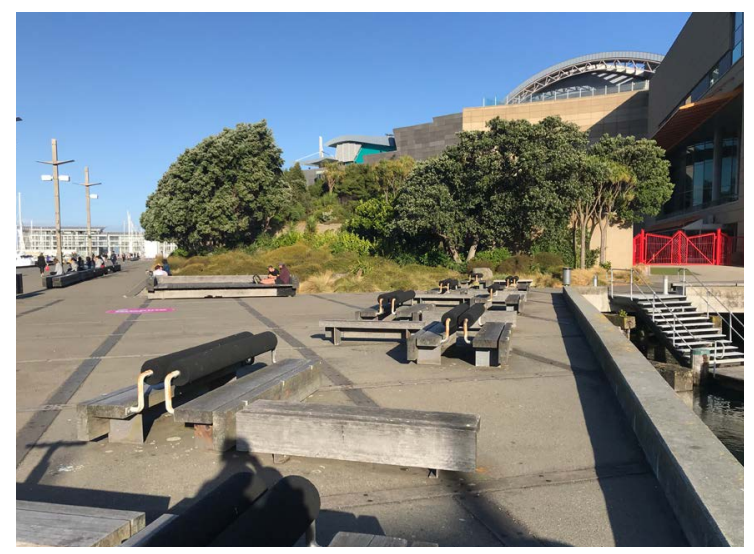

Very wide walkways that people can use to traverse around the waters edge

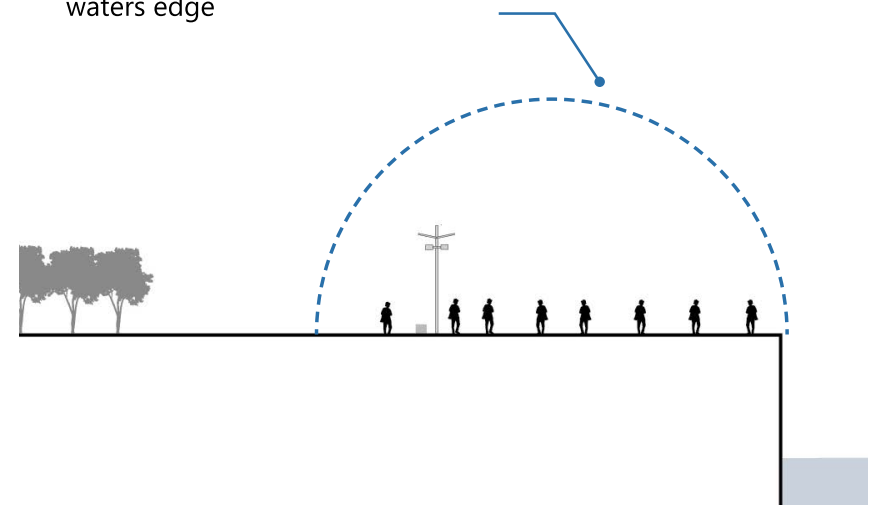

Wide open space with low levels of lighting in the centre

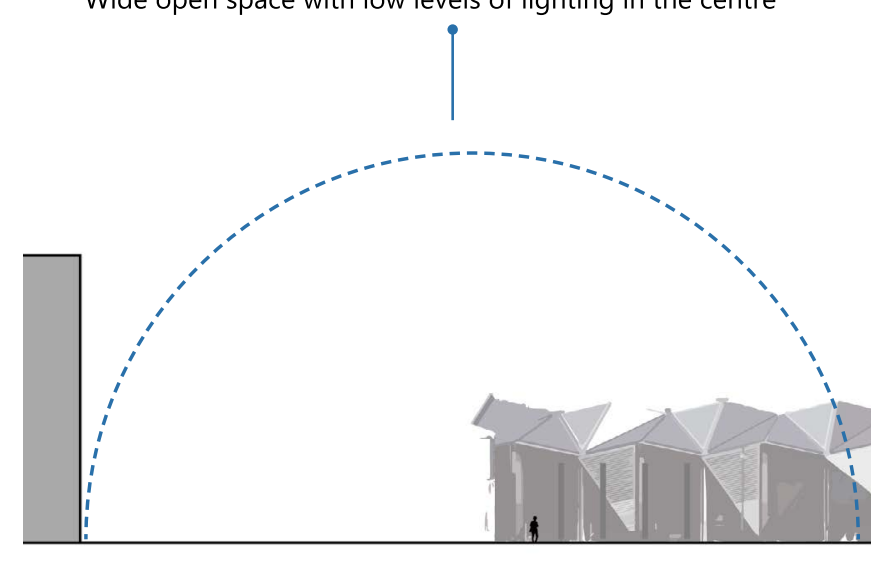

Seating that directs your view forward. In the city the light pollution is to great near the horizon but stars can be seen if you shift your gaze further upwards

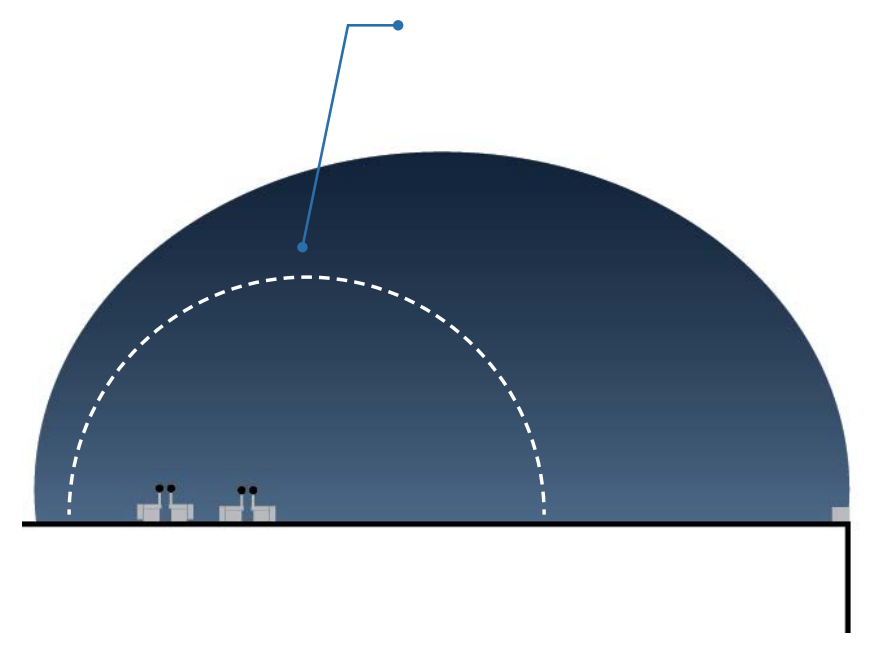




\section{Lighting overused on walkways}

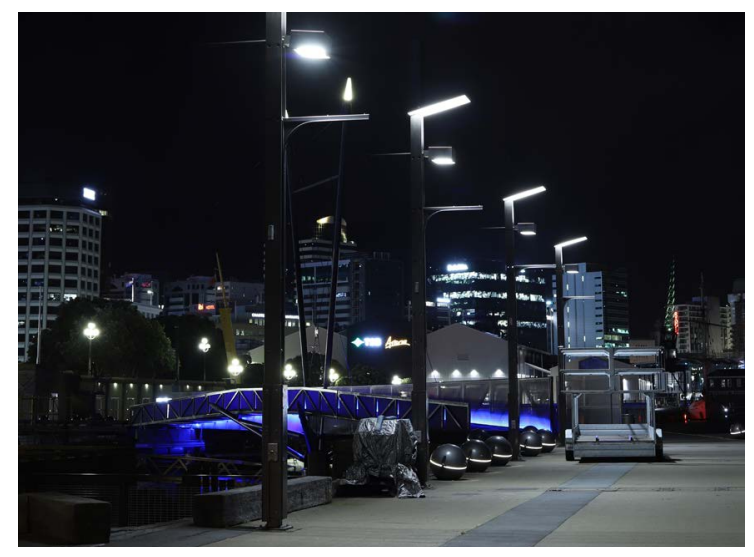

Almost the entirety of the walkways are lit with white LED lighting. in some section the light is similar to that of which you see on the city streets

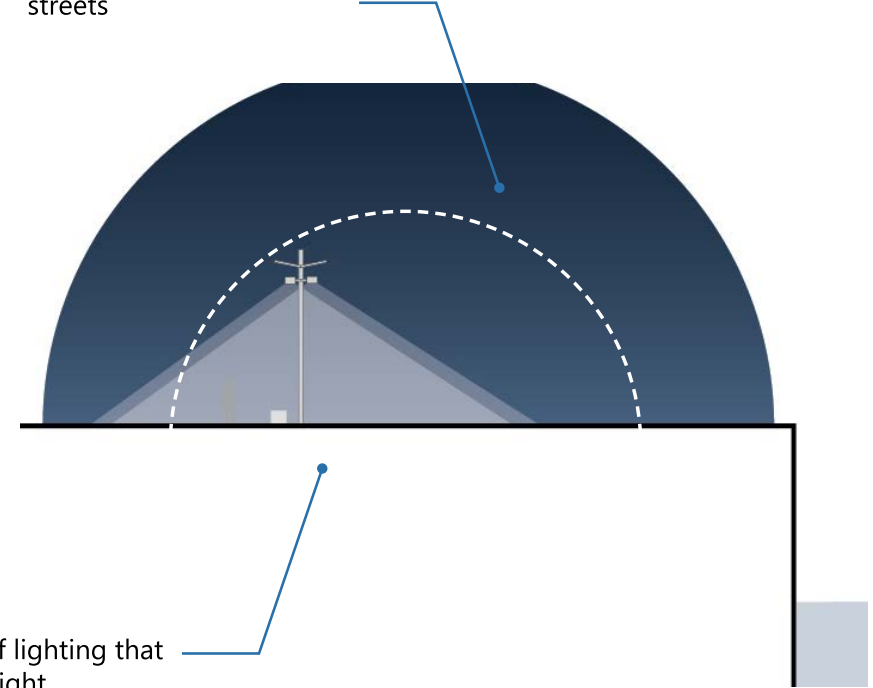

Rows of homogenous lighting are used instead of lighting that would respond to the social use of the space at night

\section{Homogeneity broken up by lighting}

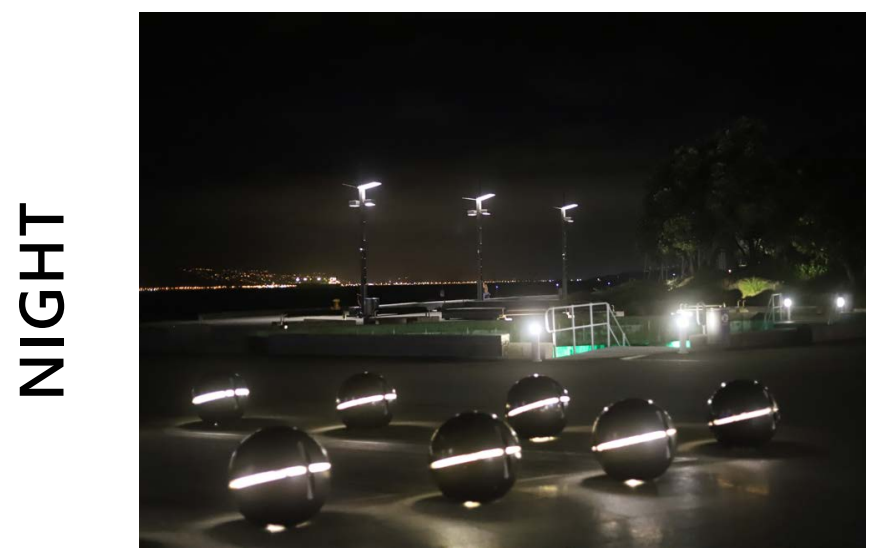

\section{Unshielded lighting}

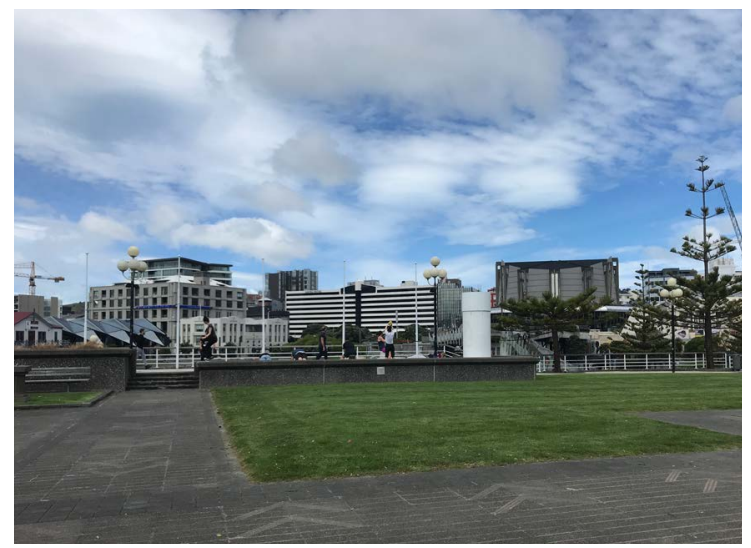

In some spots there is lighting that shines from beneath the waist, in these spots there is a more pleasant experience experience being outside

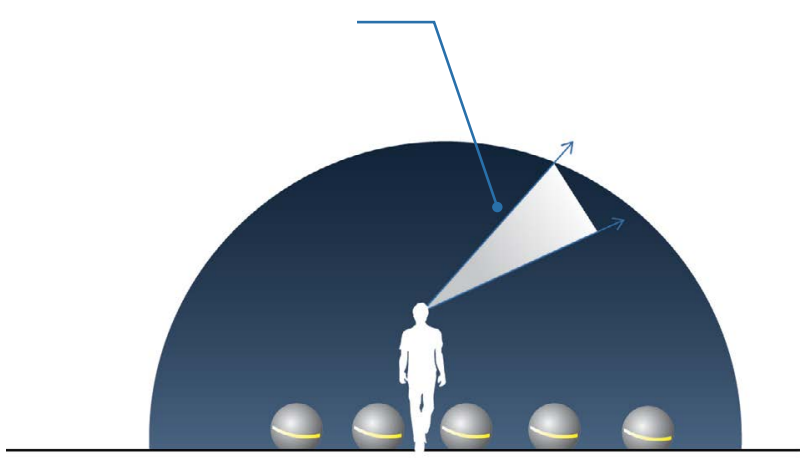

this lighting is being used for aesthetic purposes but is reflecting off the wall and

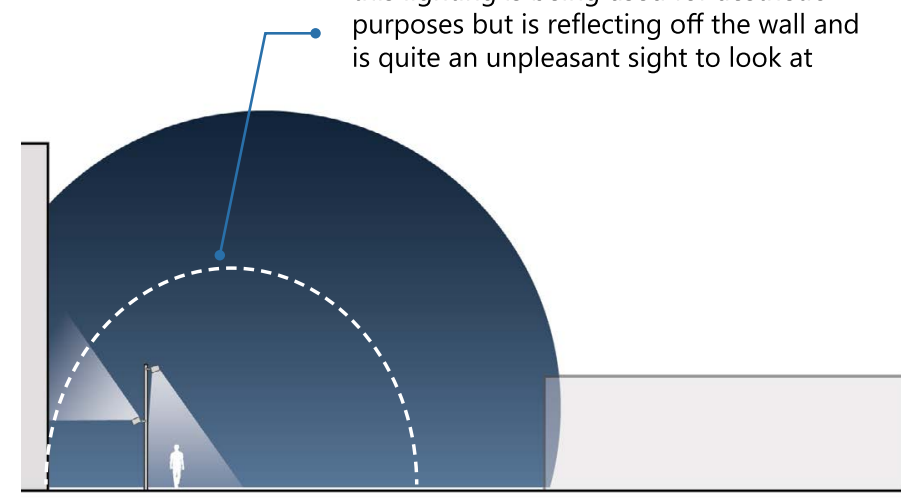

If the lighting was a different colour from the harsh white LED, it may provide a less irritating experience 
BACK OF TE PAPA
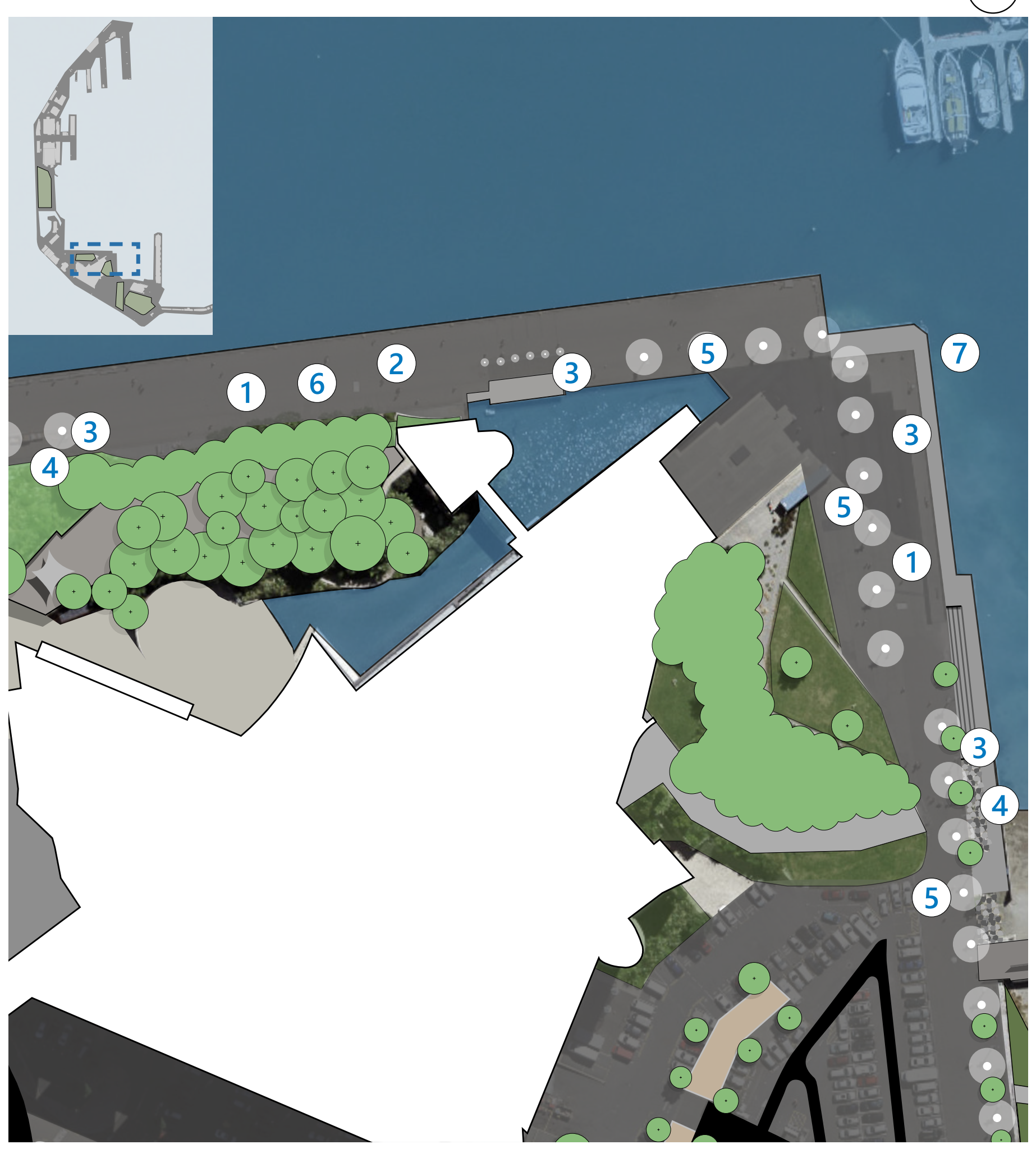

1:1000 


\section{Day Experience}

1. Wide open pathway encouraged many people using it during the day

2. This allowed people to take in the view of the harbour

\section{Night Experience}

3. Seating in the space was not promoting a comfortable experience looking up

4. Seating is placed directly under lights shining down from above, rendering them unavailable for star gazing

5. Lighting is used in homogeneous rows that bleach out the space

6. Some areas were in darkness which were actually a much more pleasant experience as it shifted your view to the surrounding environment

7. A dropped down walkway takes the user out of the light glare of the surrounding environment and allows interaction with the water

1.

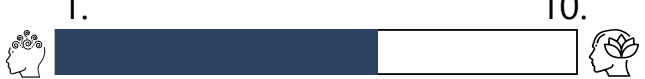

Overall comfort level

1.

Amount of Illuminated Area

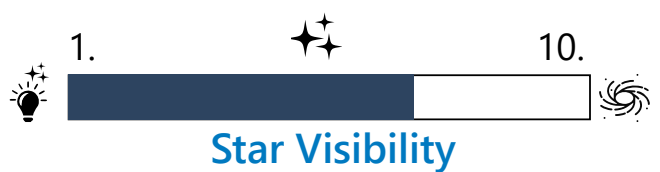

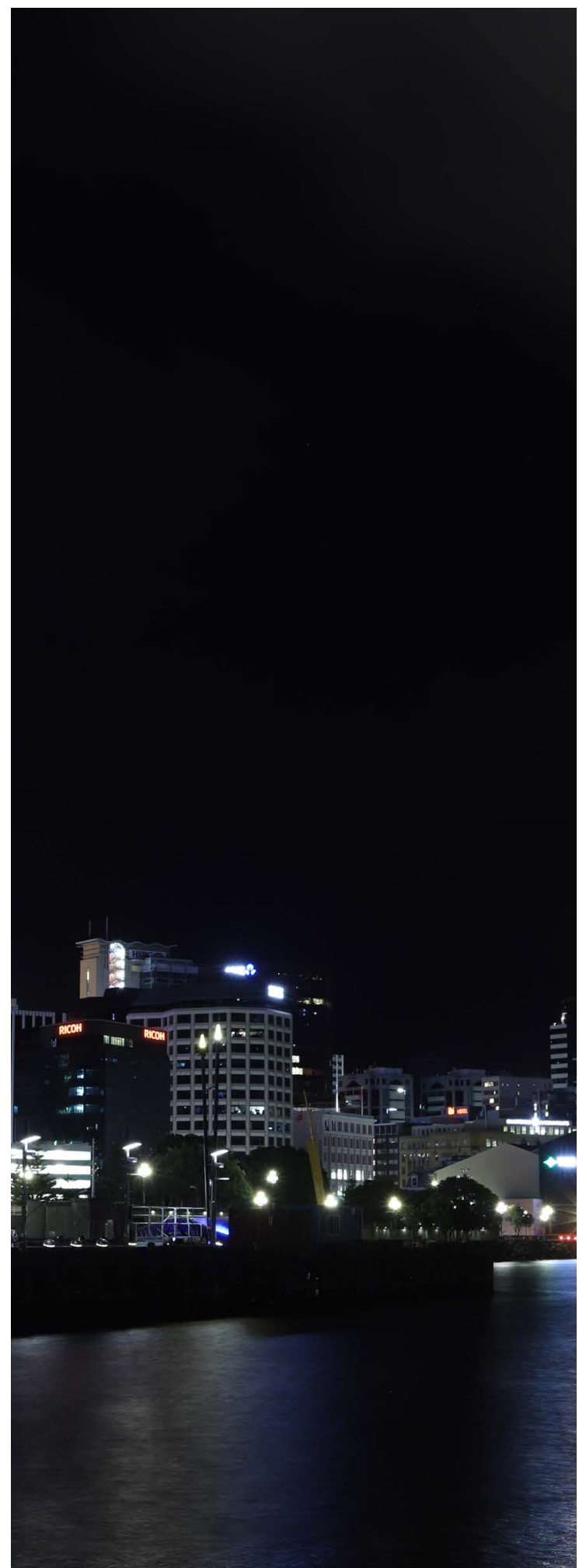

4.9 North facing Night Sky from the back of Te Papa 


\section{Seating angle}

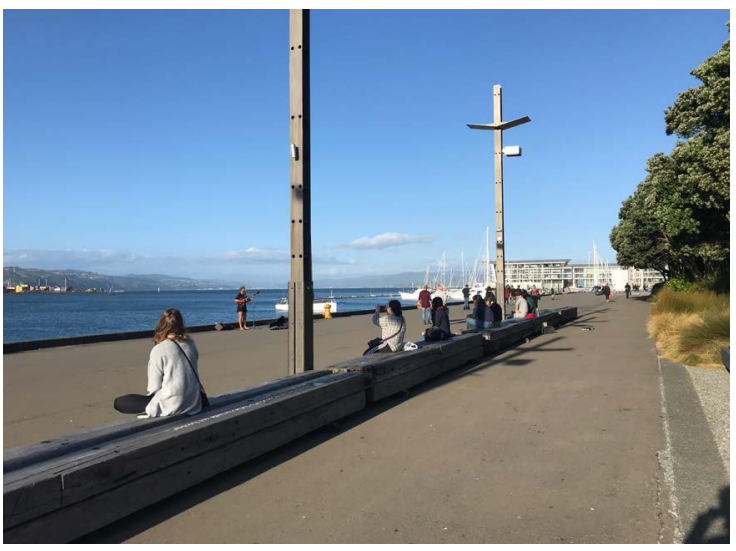

\section{Wide open pathway}

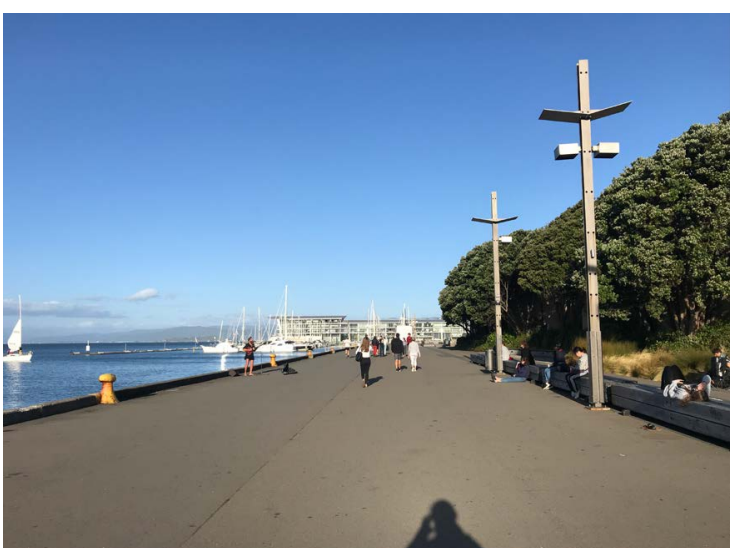

\section{Wide open pathway}

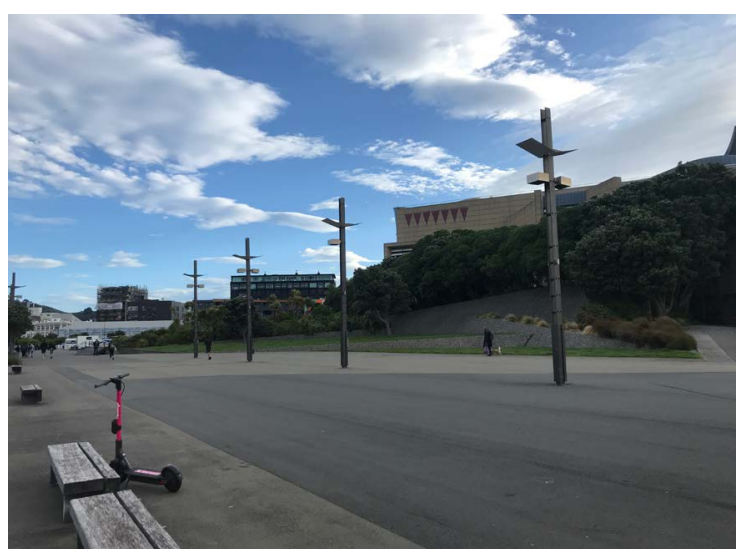

Seat directs your gaze forward but no option to encourage you to look up to the sky
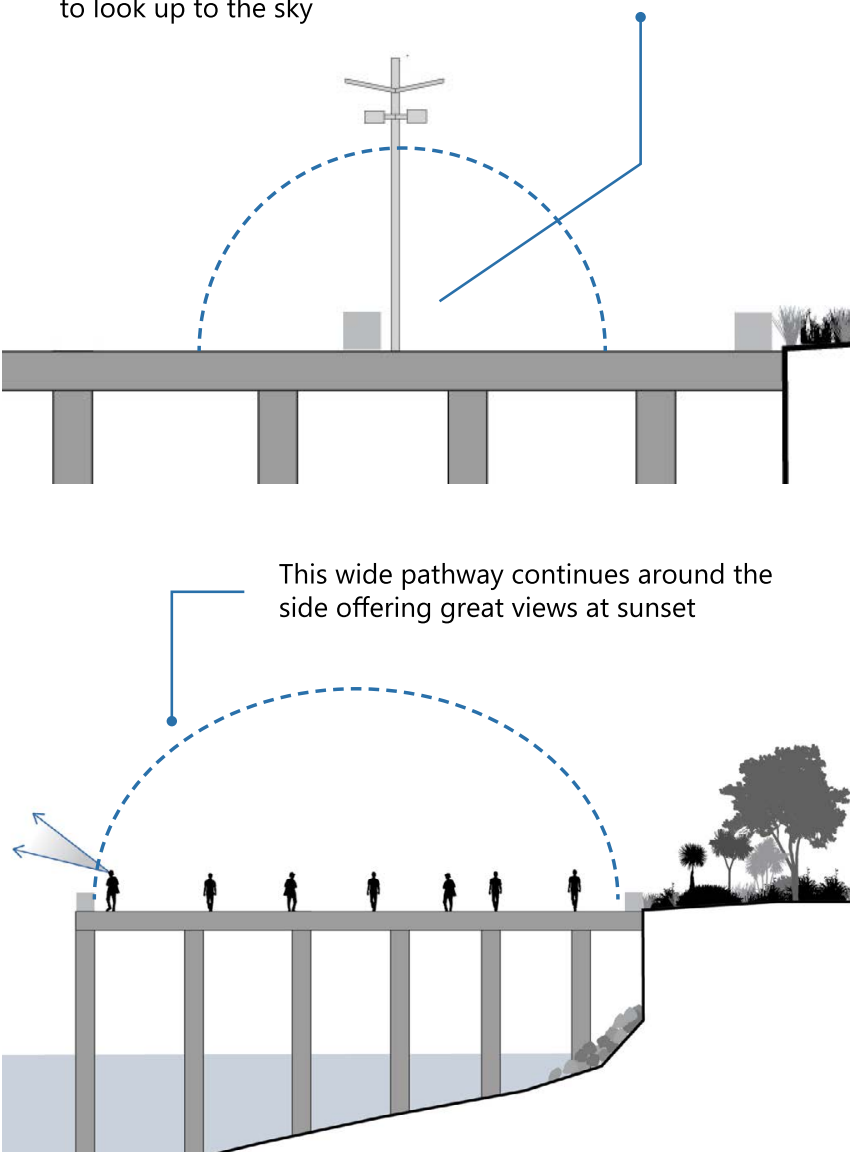

Wide open pathway which affords many people to walk along the waterfront during the day and in at sunrise

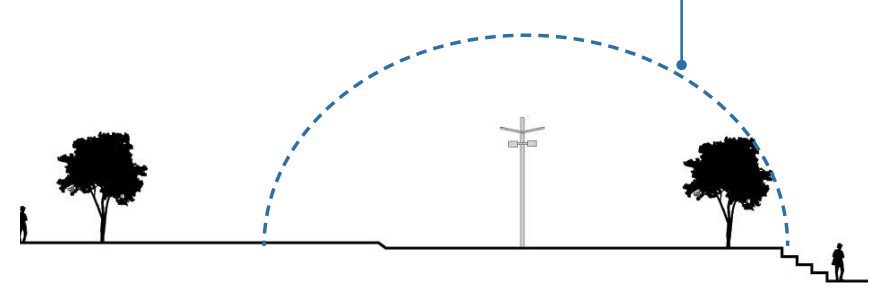

\section{Connection to water (the view of the city and harbour)}

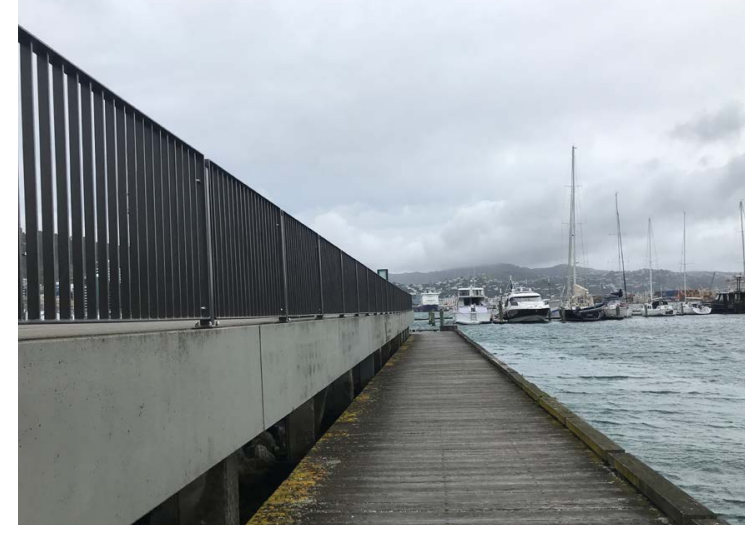

Was nice to be able to interact with the waters edge in this location here.

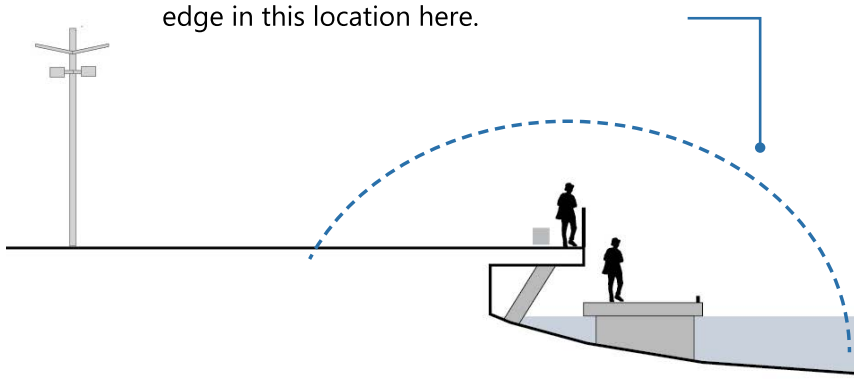

You could get out of the wind and take a step away from the main platform for your own 


\section{Lighting placed above seating}

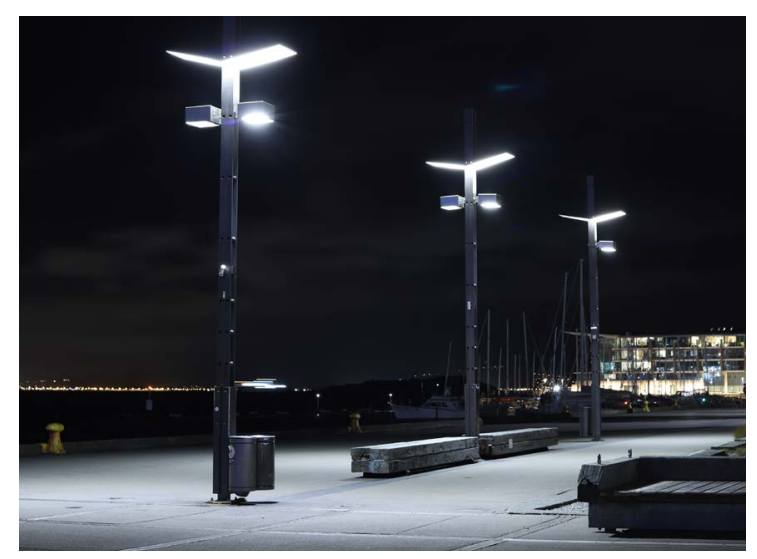

\section{Lighting entire pathway}

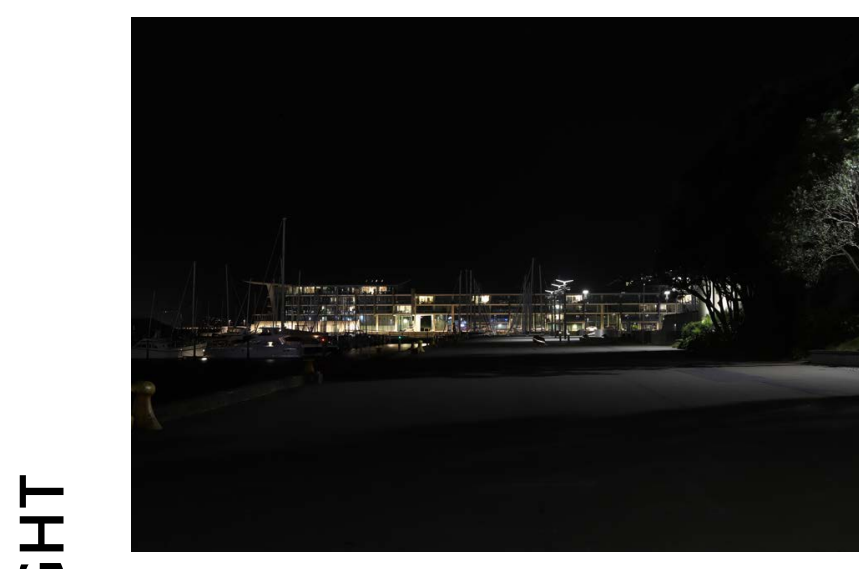

\section{Not lighting pathway}

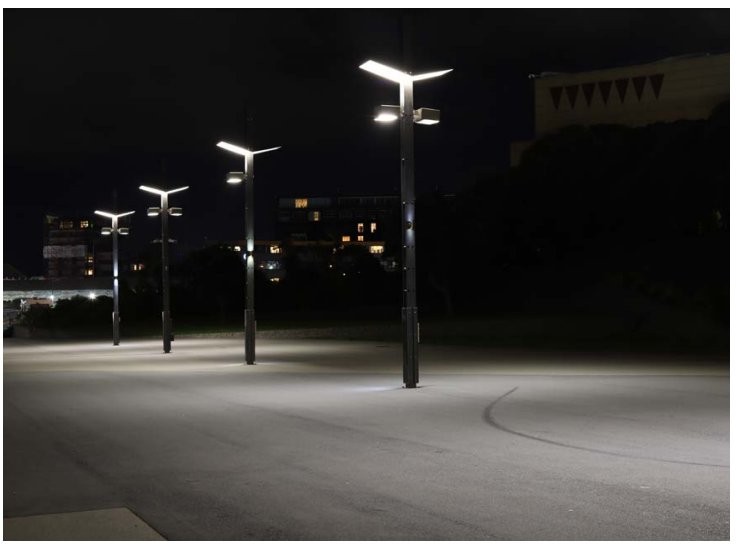

\section{Connection to Water}

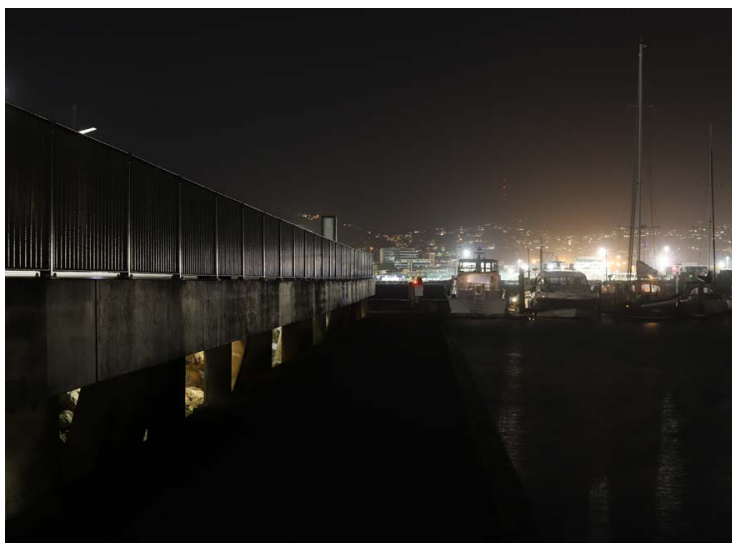

Lighting is placed above seating, preventing you from lying down on it to look up at the night sky. I didn't feel safer with it above me, I felt more exposed like everyone walking past could see me
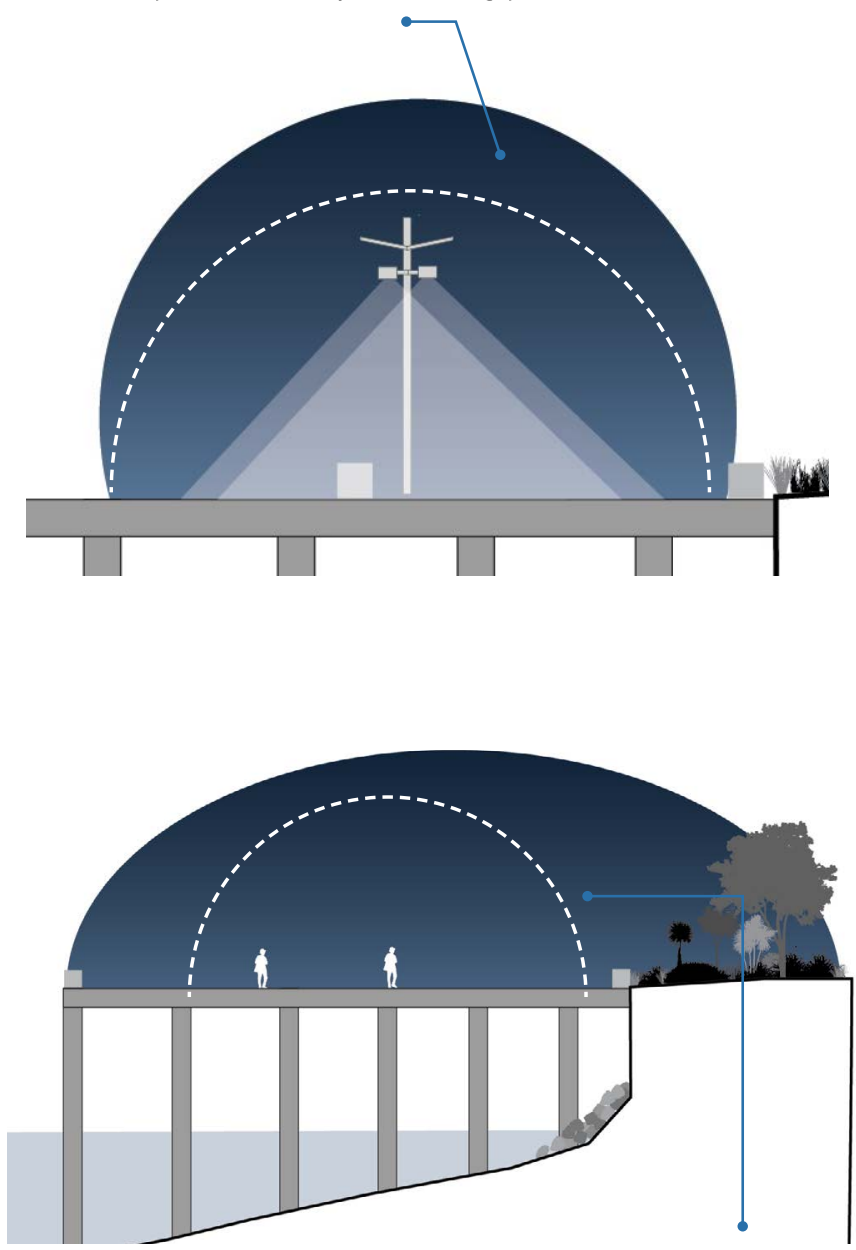

One of the few places on the waterfront, where there was light masts and no light shining down from above. The night time experience here was very enjoyable as there was no direct glare impairing it

the walkway here was very bright with almost the entire walkway covered in light. The ability to look up at the night sky was not completely impossible but was signifigantly impaired

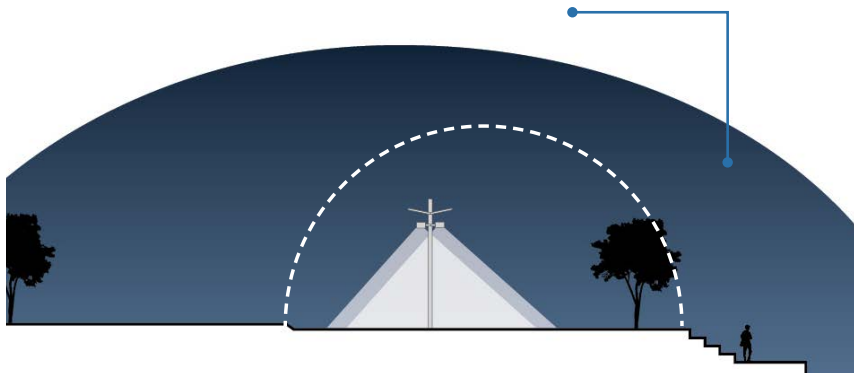

This was another enjoyable space to be in at night. Its dropped elevation from main path took it out of the glare

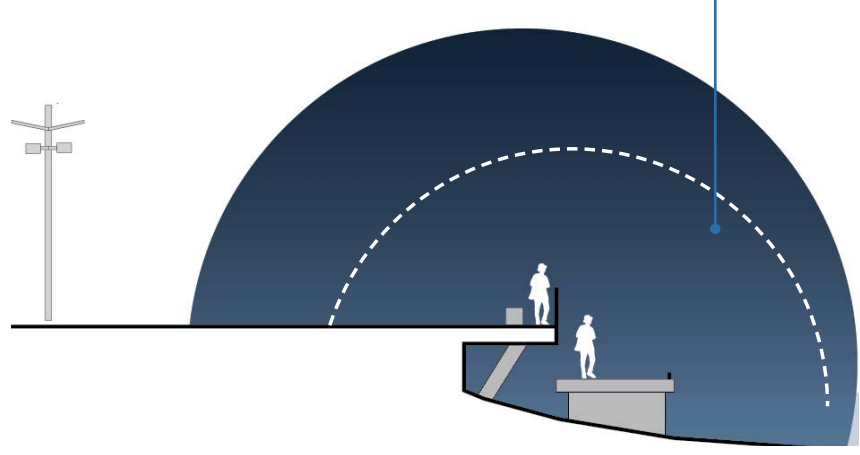




\section{EAST WAITANGI PARK}

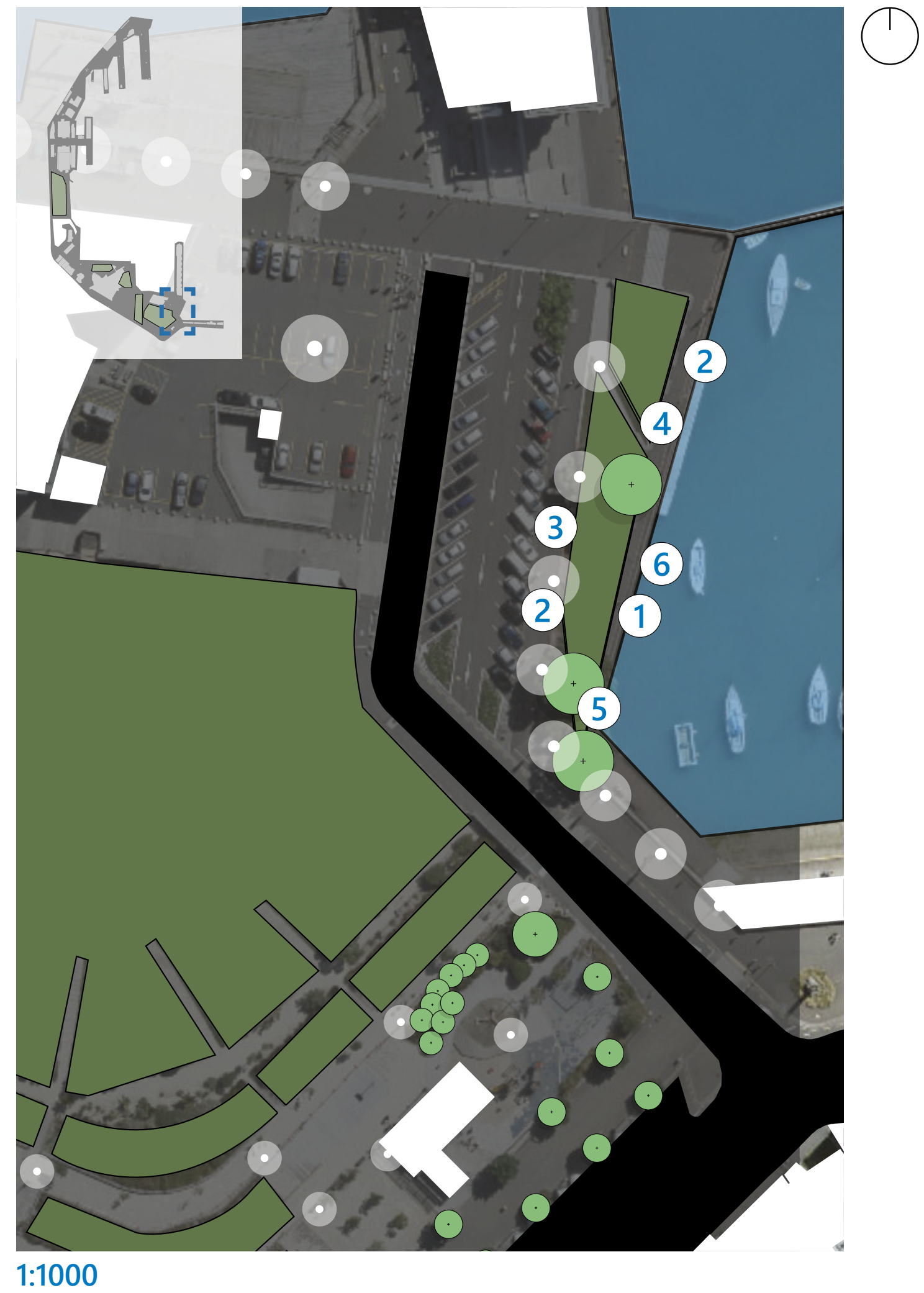




\section{Day Experience}

1. The site offers a relaxing spot to sit or lie down and watch the sunset or sunrise due to the large grass patch

2. The seating angles your gaze forward and does not support your body looking up

\section{Night Experience}

3. Lighting is placed above seating yet no one uses it because the day time experience has finished but the night time experience is unable to be enjoyed because of the light over the seat

4. The large pohutukawas provide shade during the day but their silhouettes at night may seem frightening to people passing by

5. However they are able to block the glare from the street lights entering the space near the water in specific spots

6. At night the patch of grass is blanketed in light inhibiting it from being used to star gaze

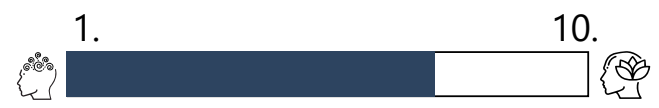

Overall comfort level

1.

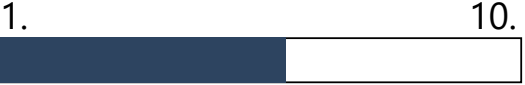

Amount of Illuminated Area

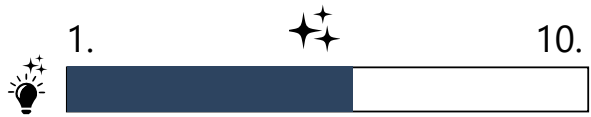

Star Visibility

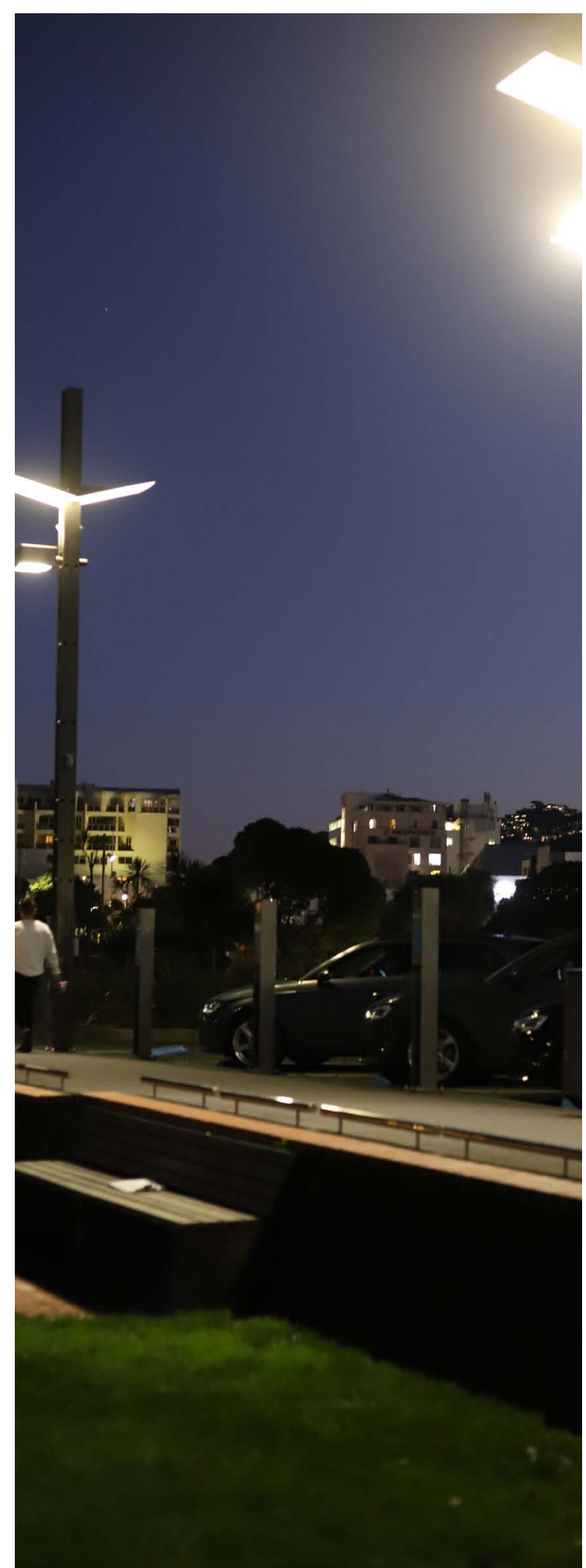

4.10 Night Sky above Hyde st Park 
Seated and Grassy Area

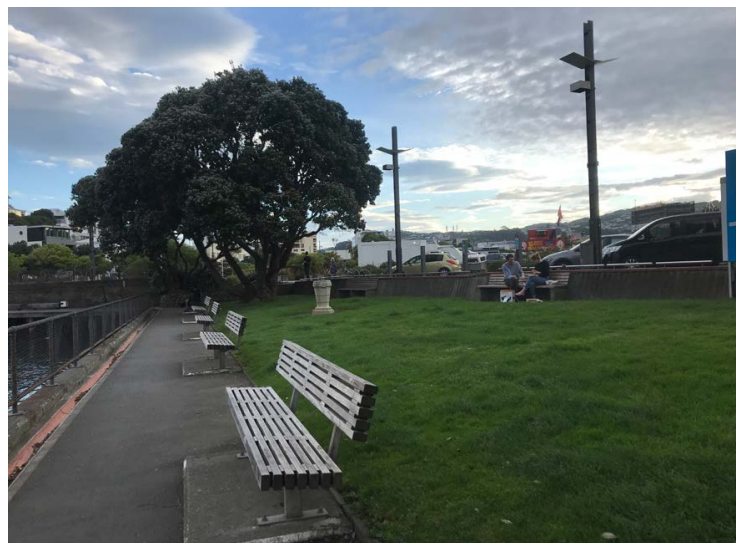

\section{Seat facing angle}

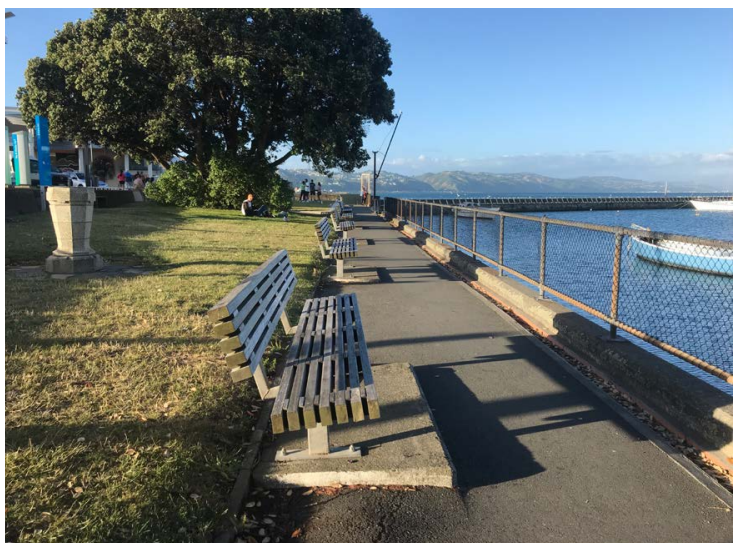

\section{Tree shade}

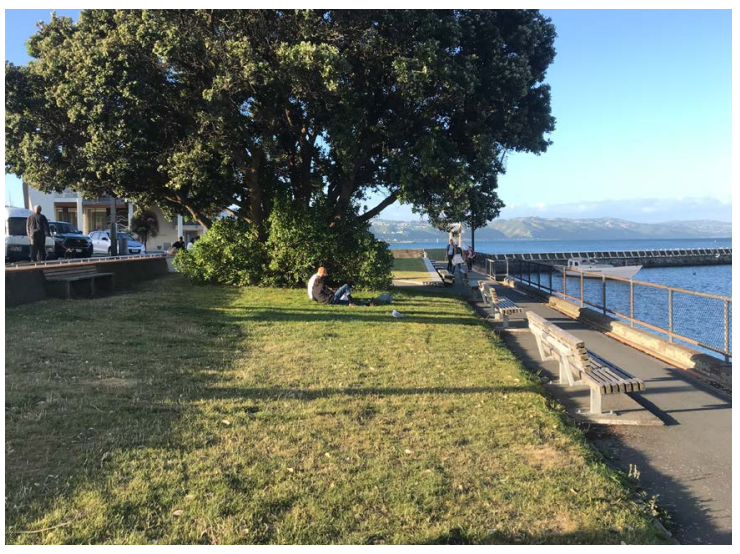

\section{Main pathway}

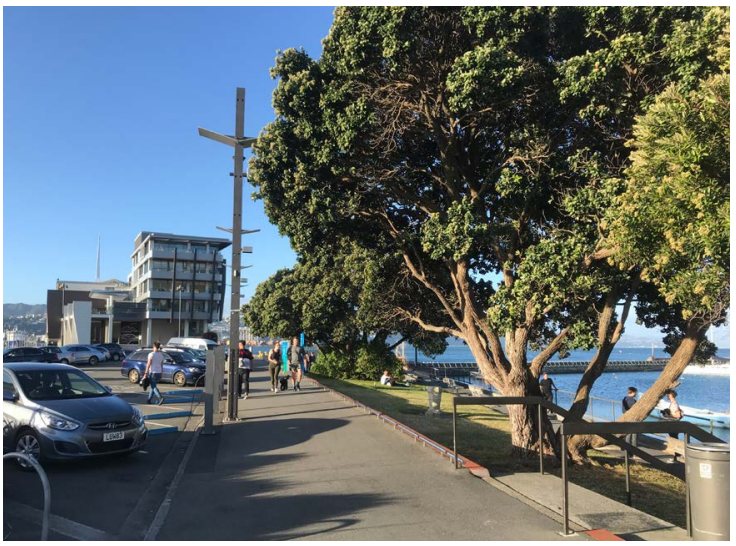

This space on the waters edge provided a nice area to sit and relax, lie on the grass, and take in the peaceful surrounding landscape

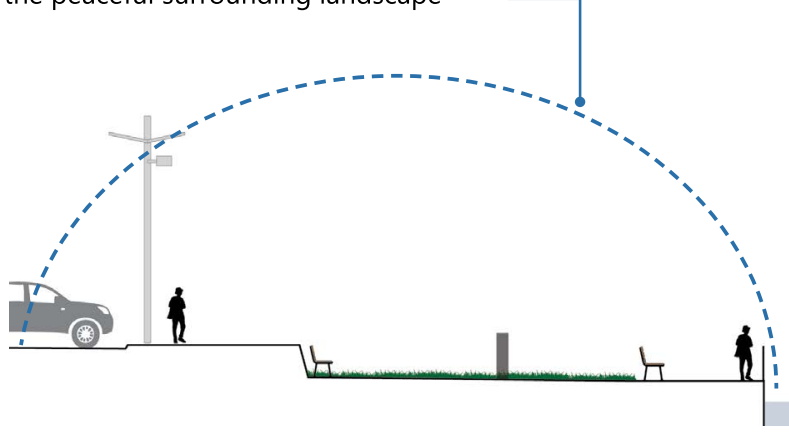

Waterfront seating affords you to look out over the water and out across the harbour
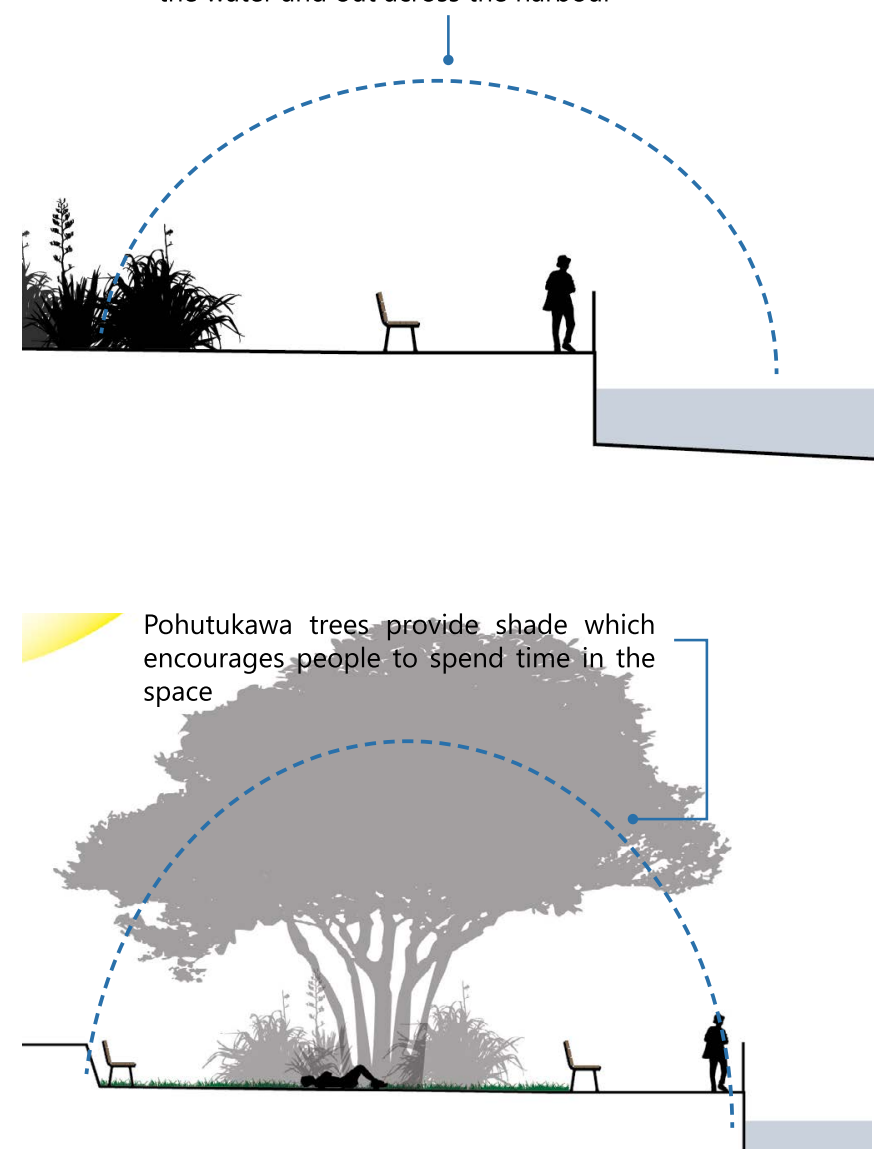

Pathway is used a lot during the day as

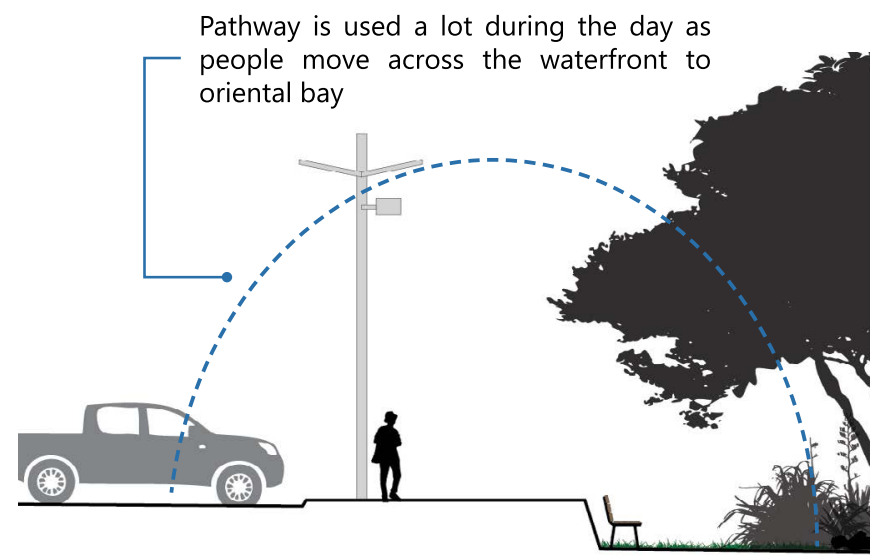




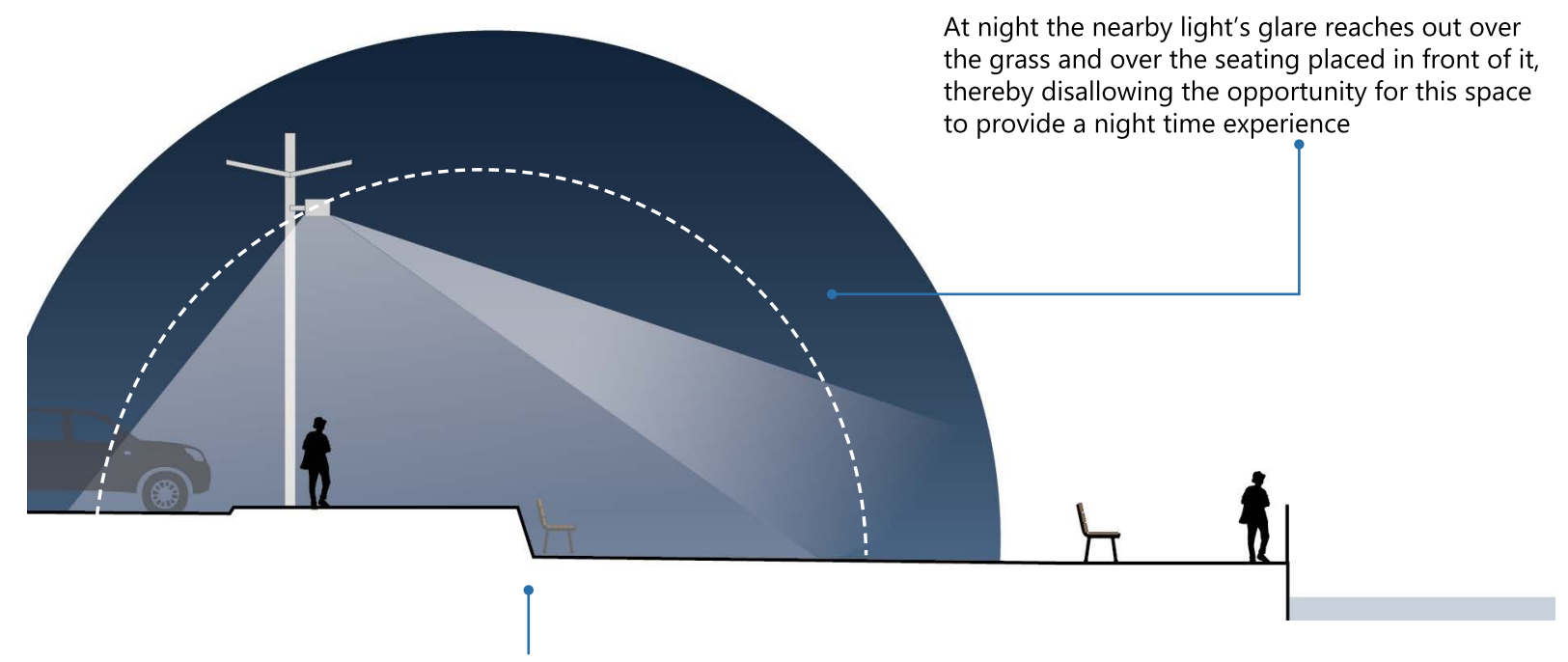

\section{Relationship between lighting and seating}

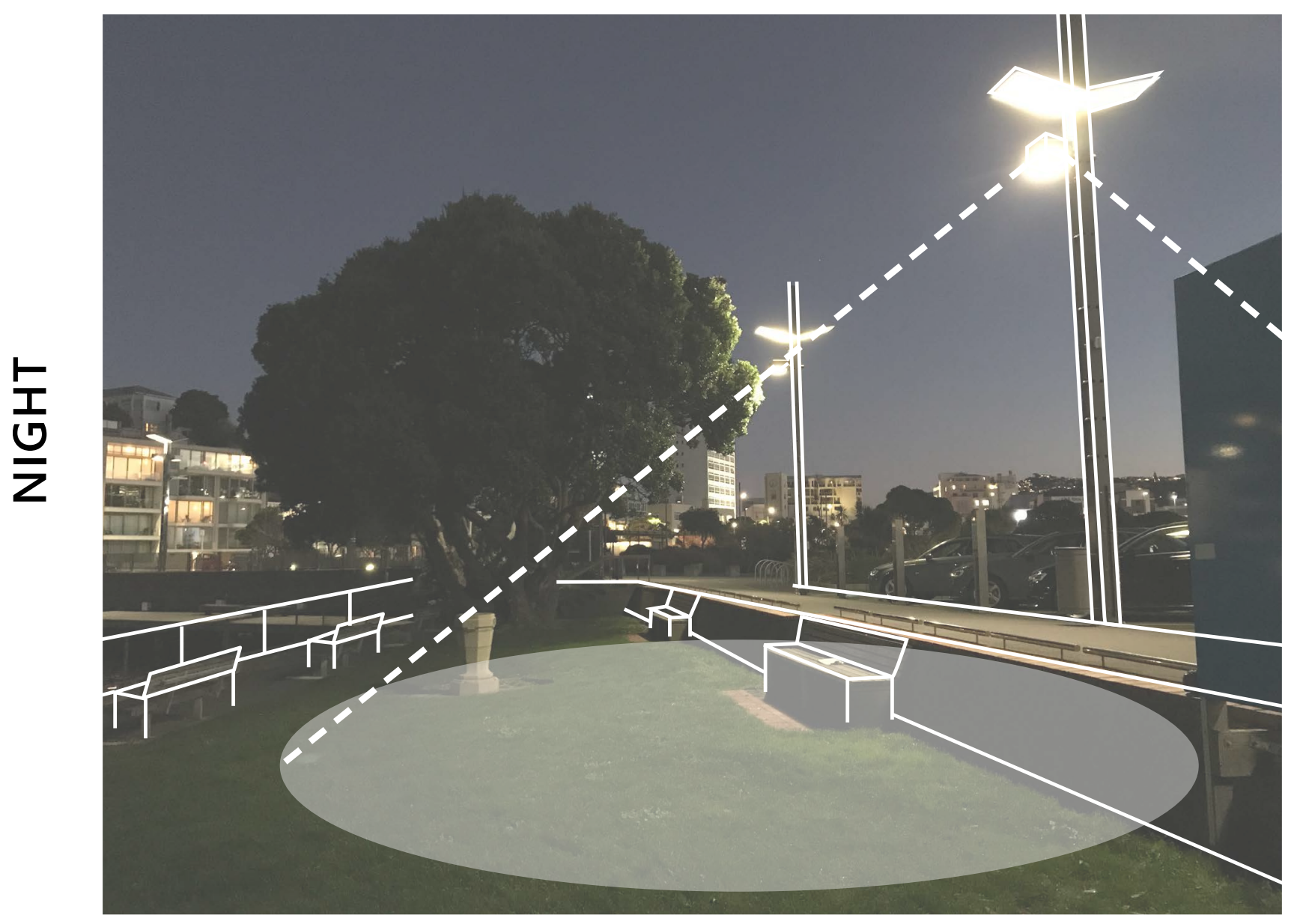

\section{Lit Walkways (vegetation and lighting}

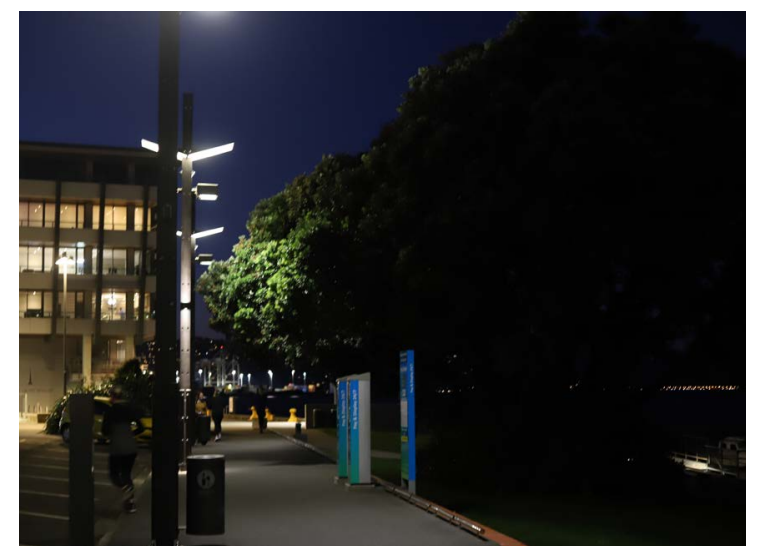

At night the vegetation is able to block the light glare providing a better experience at the front of the site

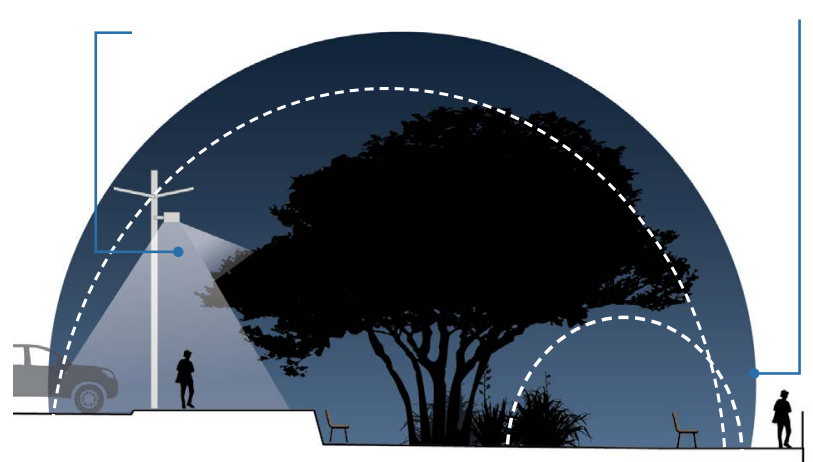




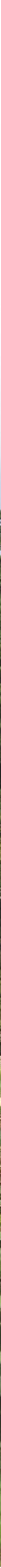




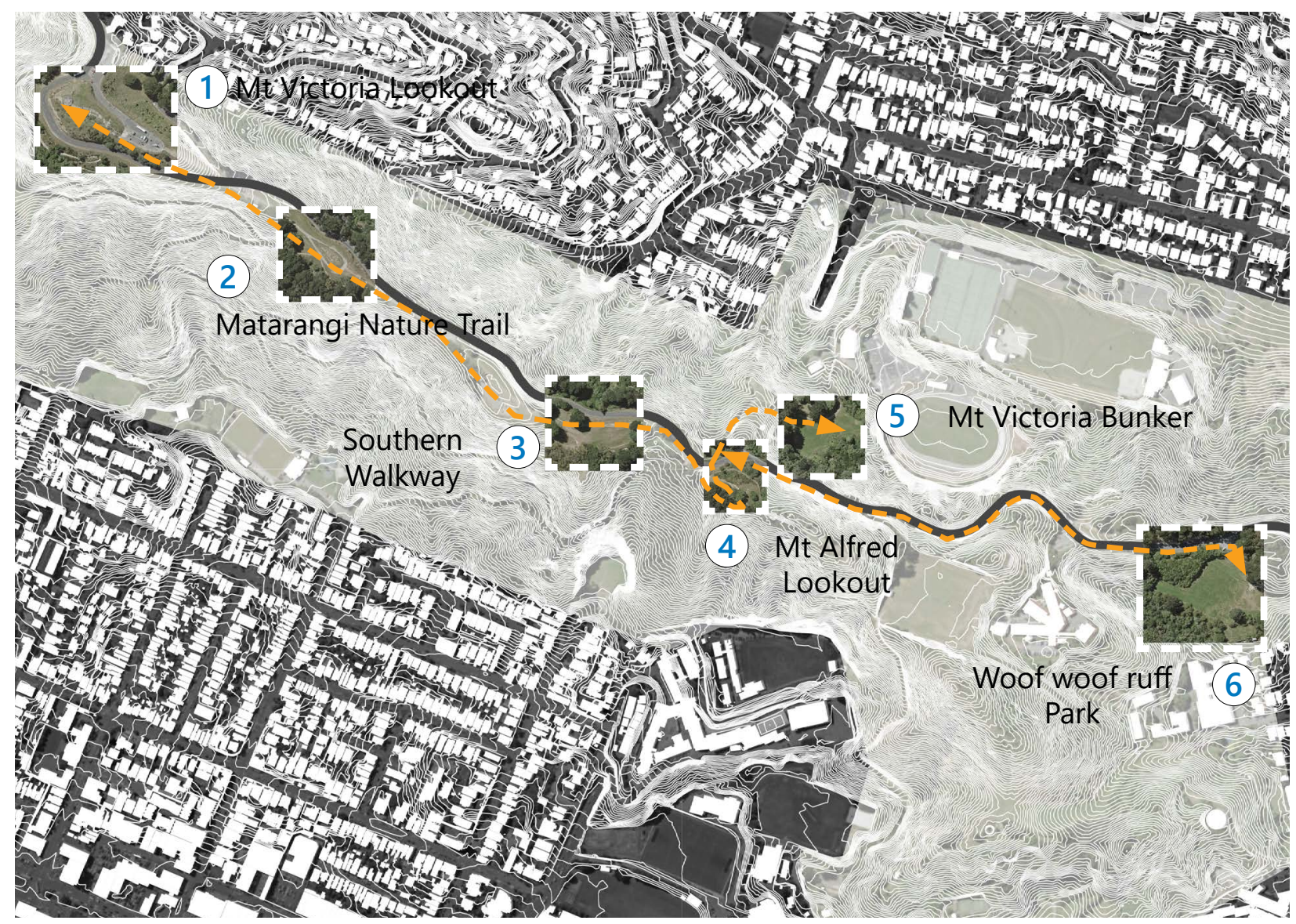

\subsection{Mt Victoria Town Belt}

Initial visits involved walking from Mt Victoria Lookout to the break in the town belt at Constable St during the day and then walking back once it was completely dark. Anything that influenced perceived comfort in the space or impaired the view of the stars was recorded.

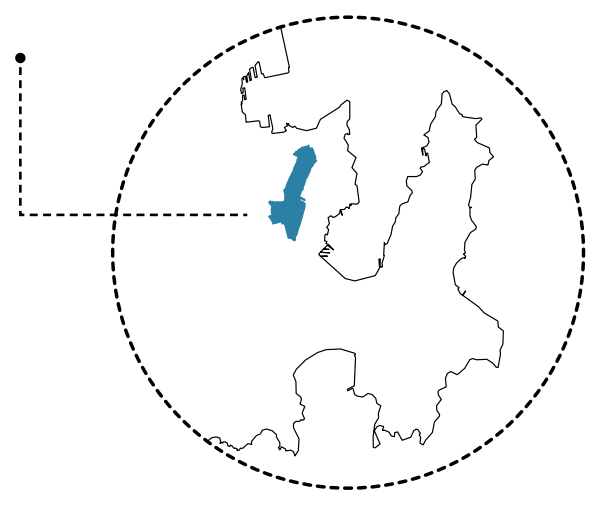




\section{MT VICTORIA SUMMIT}
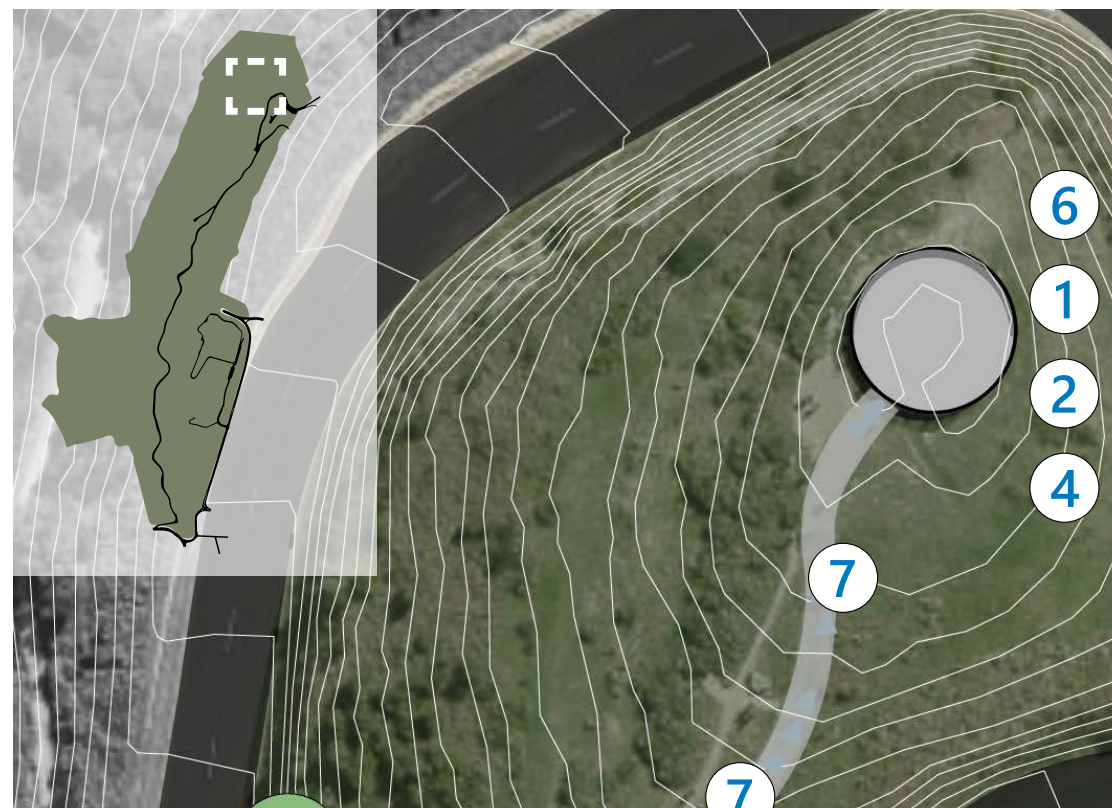

(7)

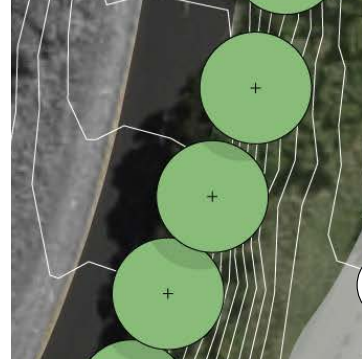

7.

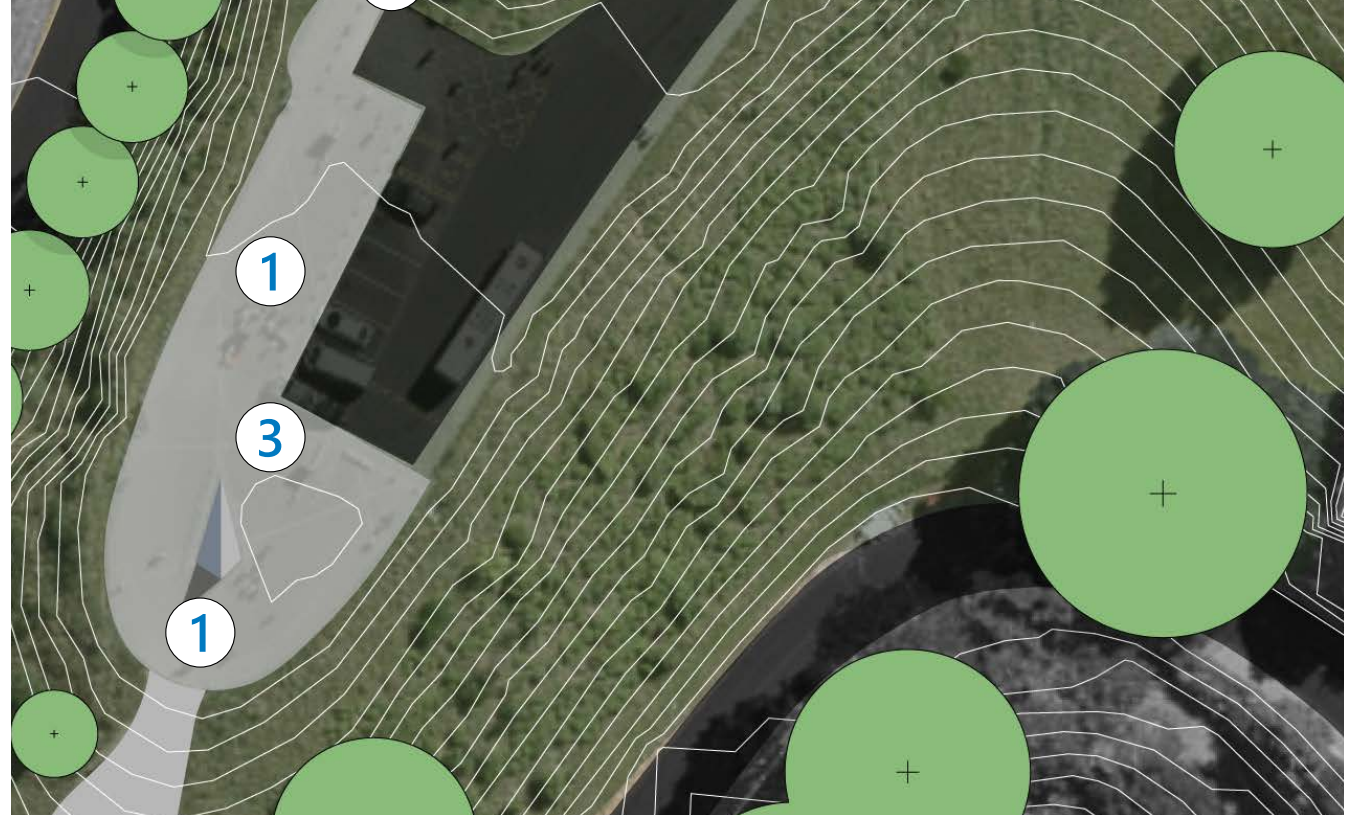

1:1000 


\section{Day Experience}

1. Lookout during the day provides expansive views over Wellington

2. The lookout encourages people to look forward by providing handrails that shift the gaze down.

3. The openness of the site increases prospect and decreases feelings of entrapment

4. The site receives just as many visitors at night as it does during the day due to the view over the city

\section{Night Experience}

5. At night there is no design that encourages us to look up

6. At the highest point of the town belt studied there is increased prospect with the wider view shafts

7. The lights used in the site to light the path create glare that trespasses into other areas of the site

1.

คำ?

10.

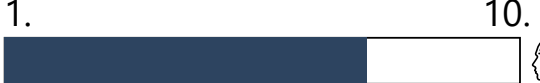
sis

Overall comfort level

1.

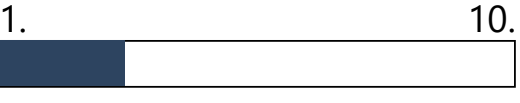

Amount of Illuminated Area

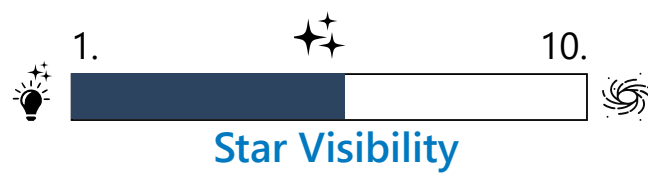

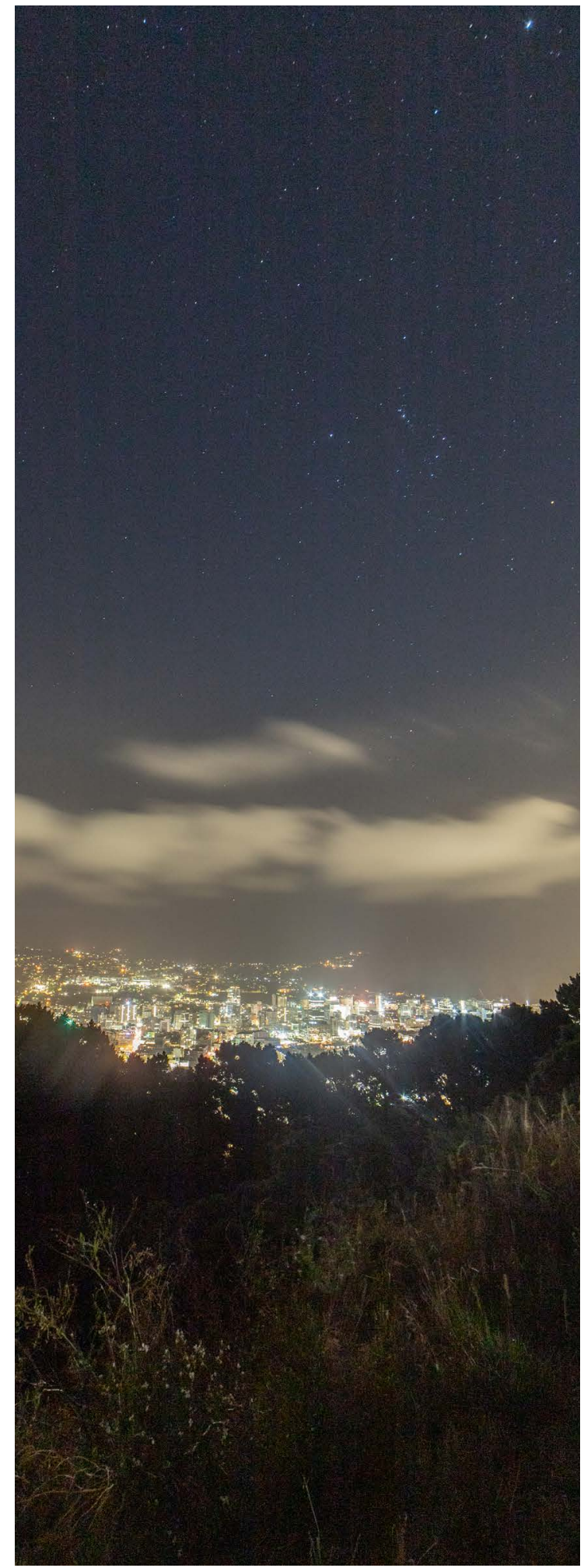

4.11 Light glare from Mt Victoria Summit 


\section{Lookout during the day}

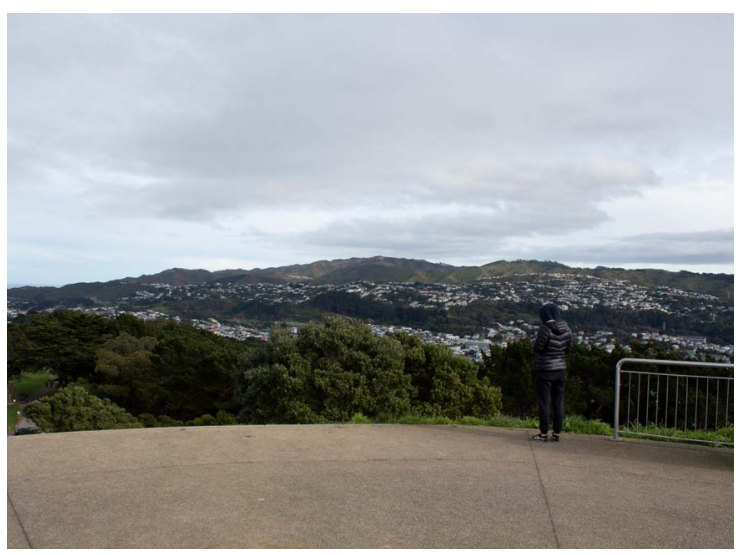

\section{Lookout Handrails}

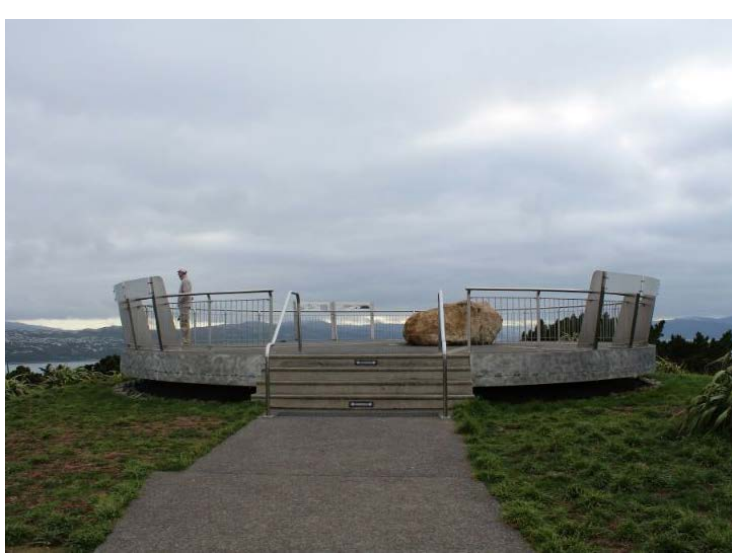

\section{Openness of the space}

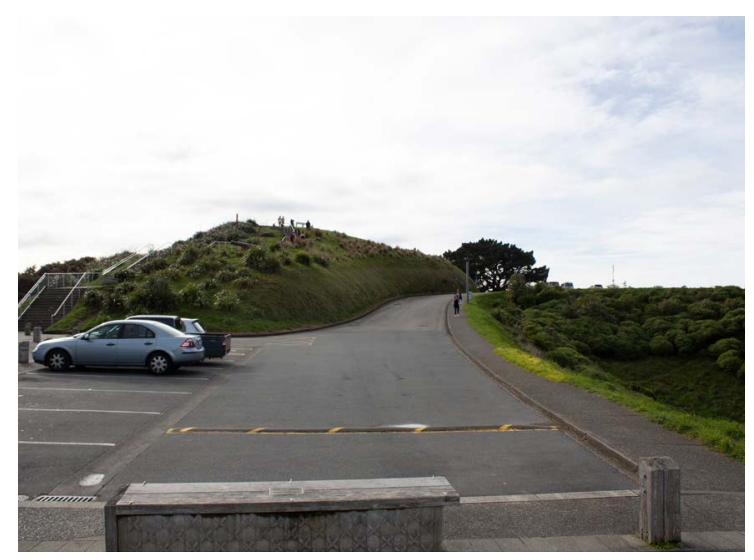

\section{Elevation of the site}

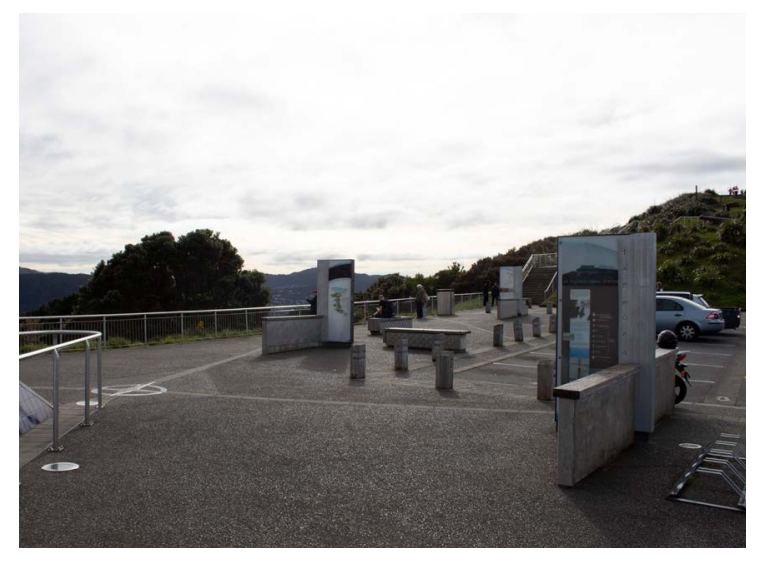

the site provides expansive views over wellington during the day

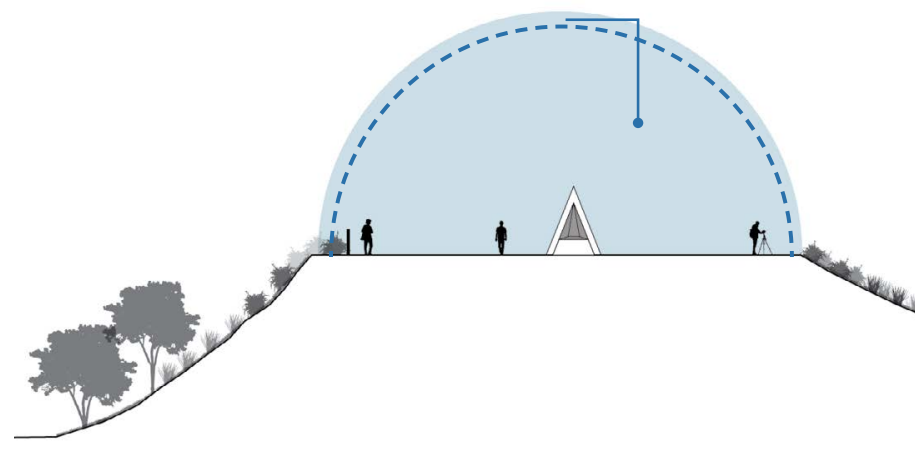

the lookout handrails provide something to rest on which shifts your gaze downwards towards the city

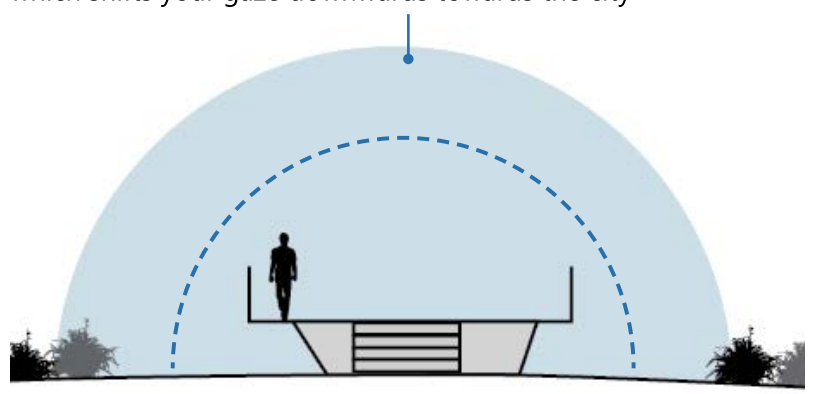

Site has a very open space with uninterrupted views

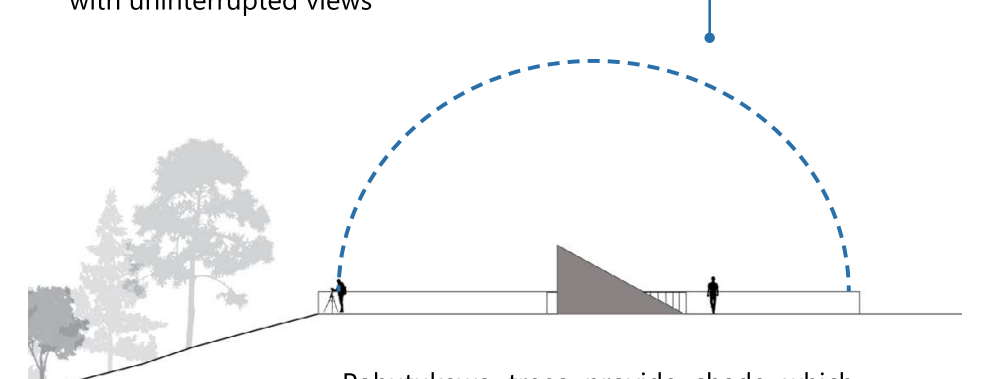

Pohutukawa trees provide shade which encourages people to spend time in the space
The sites high elevation increases prospect

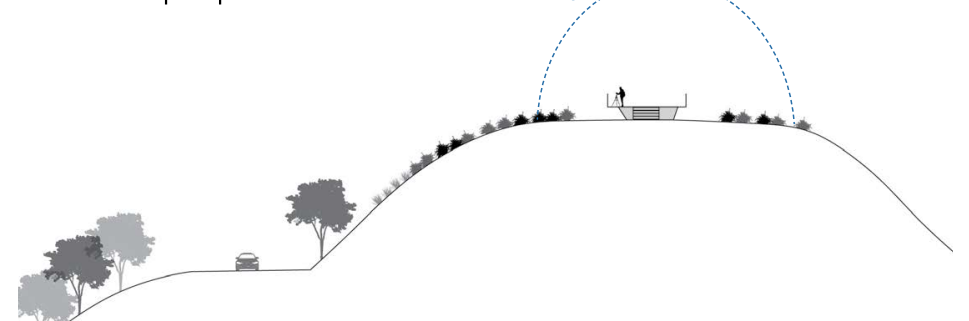




\section{Lookout at night}

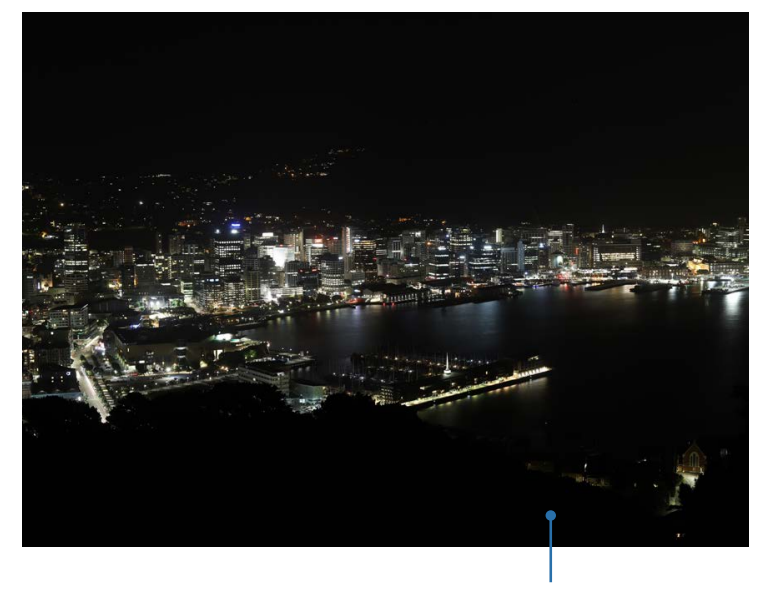

\section{Affect of handrails at night}

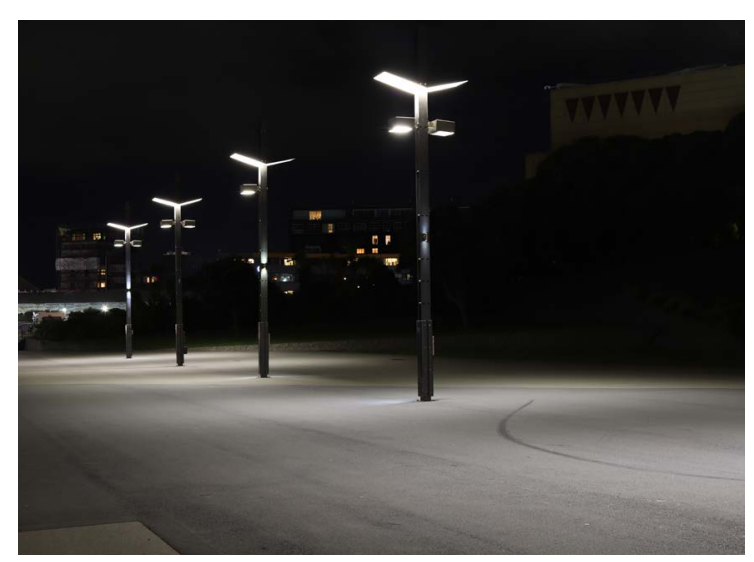

The design of the lookout does not encourage a position directed at the stars, it encourages the user to be standing or leaning on the rails, directing our view forward and downward

\section{Openness of space / exposure to city lights}

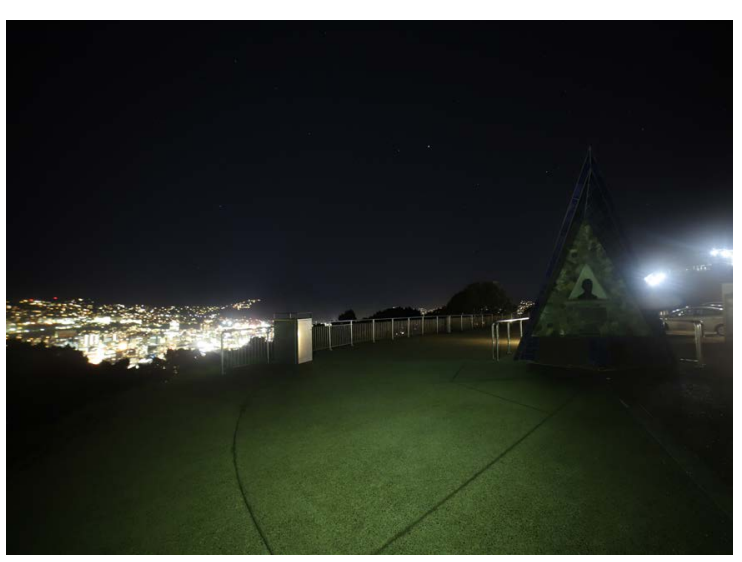

\section{Effect of Light glare}

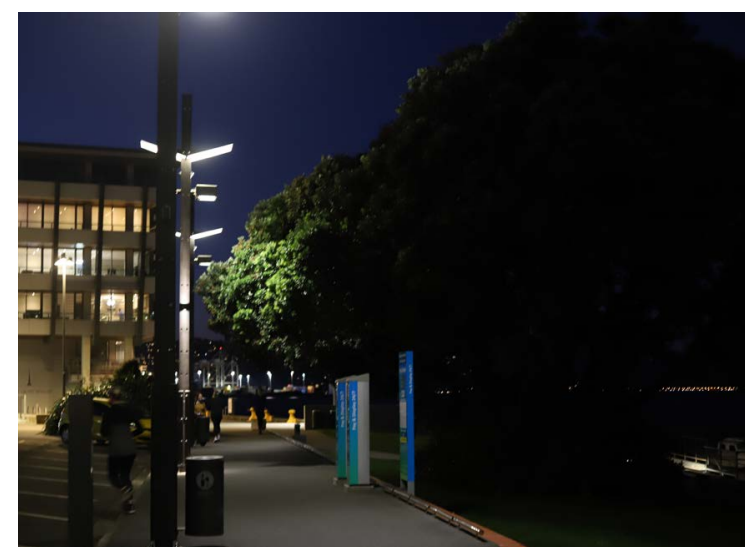

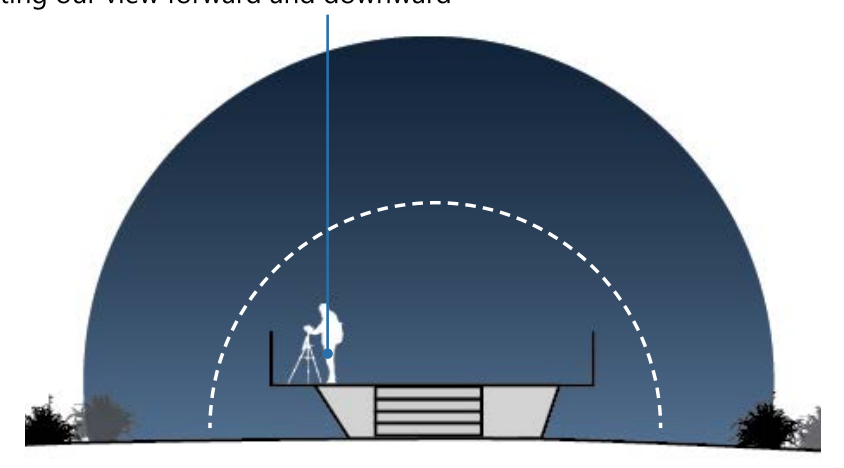

This site is probably the only area in Wellington to the day. People are drawn to the city lights

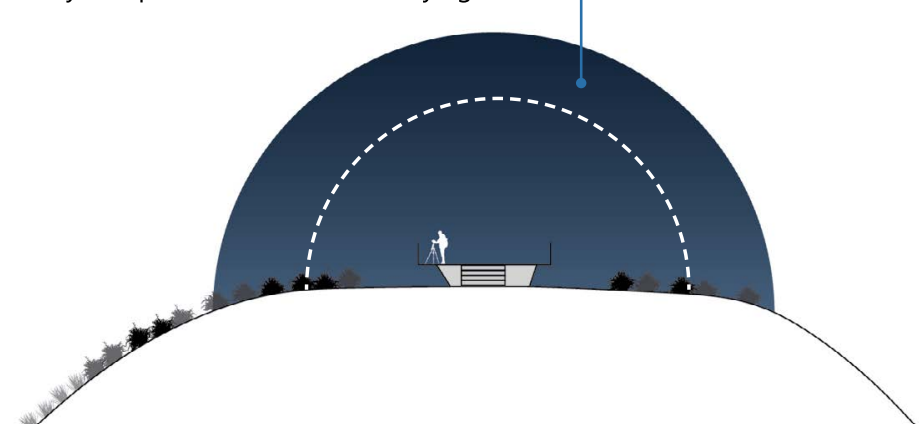

The uninterrupted views mean many different surrounding sources of light are visible from the lookout

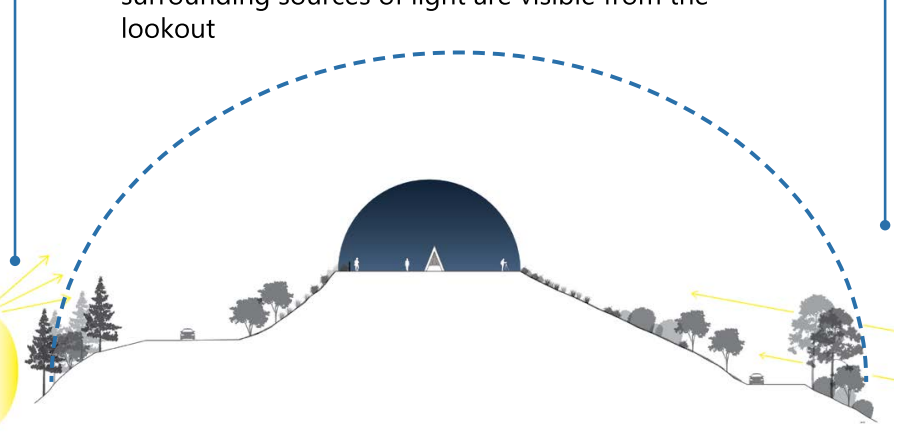

The lights used to illuminate the stairs produce a lot of glare which impairs your view of the path, and is irritating when looking at the sky

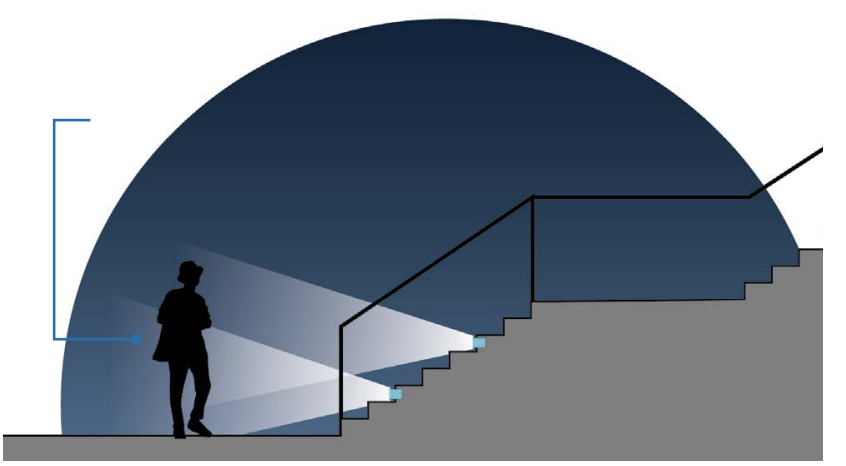
receive as many visitors at night as it does during 
MATAIRANGI NATURE TRAIL
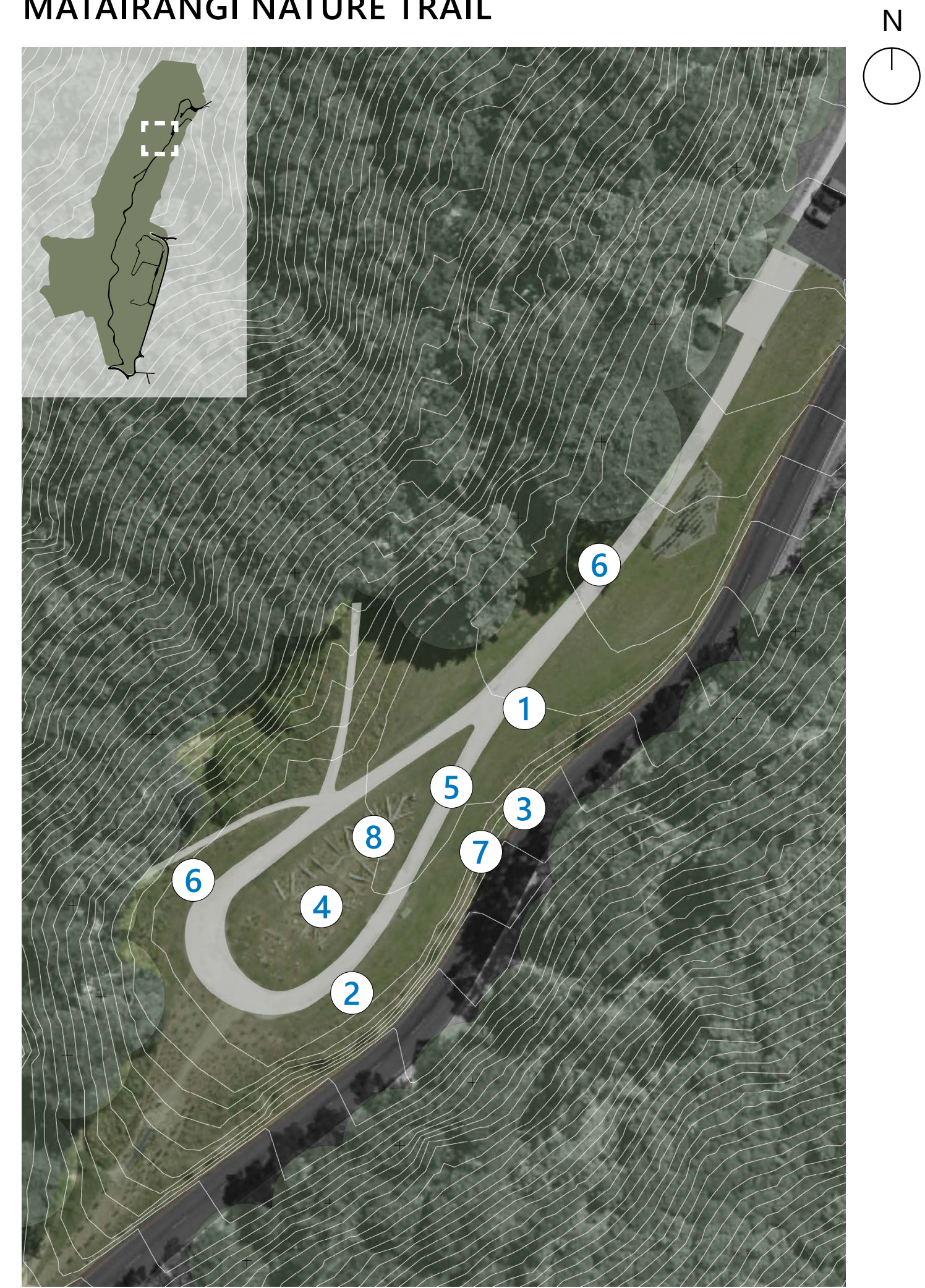

$1: 1000$ 


\section{Day Experience}

1. The sites openness led to increased feelings of comfort

2. Being outside in the natural environment surrounded by trees was very nurturing

3. There was seating provided on site, that afforded views over the eastern suburbs

4. The centre piece provided further interaction with the site and gave it a specific purpose

\section{Night Experience}

5. At night, the feelings of comfort remained when standing in the middle of the site due to the distance between vegetation

6. It was not comfortable being close to the west side where the tree line was taller and denser

7. The seating focuses on the city lights at night, and ignores the darker view to the south

8. The centre piece at night, was intimidating due to the structure of the of the cabbage tree mealybugs

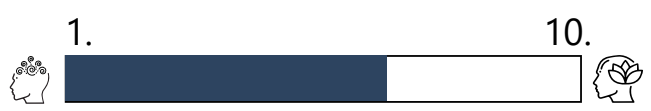

Overall comfort level

1.

10.

Amount of Illuminated Area

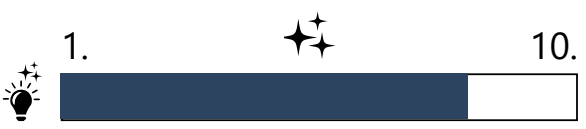

10

Star Visibility

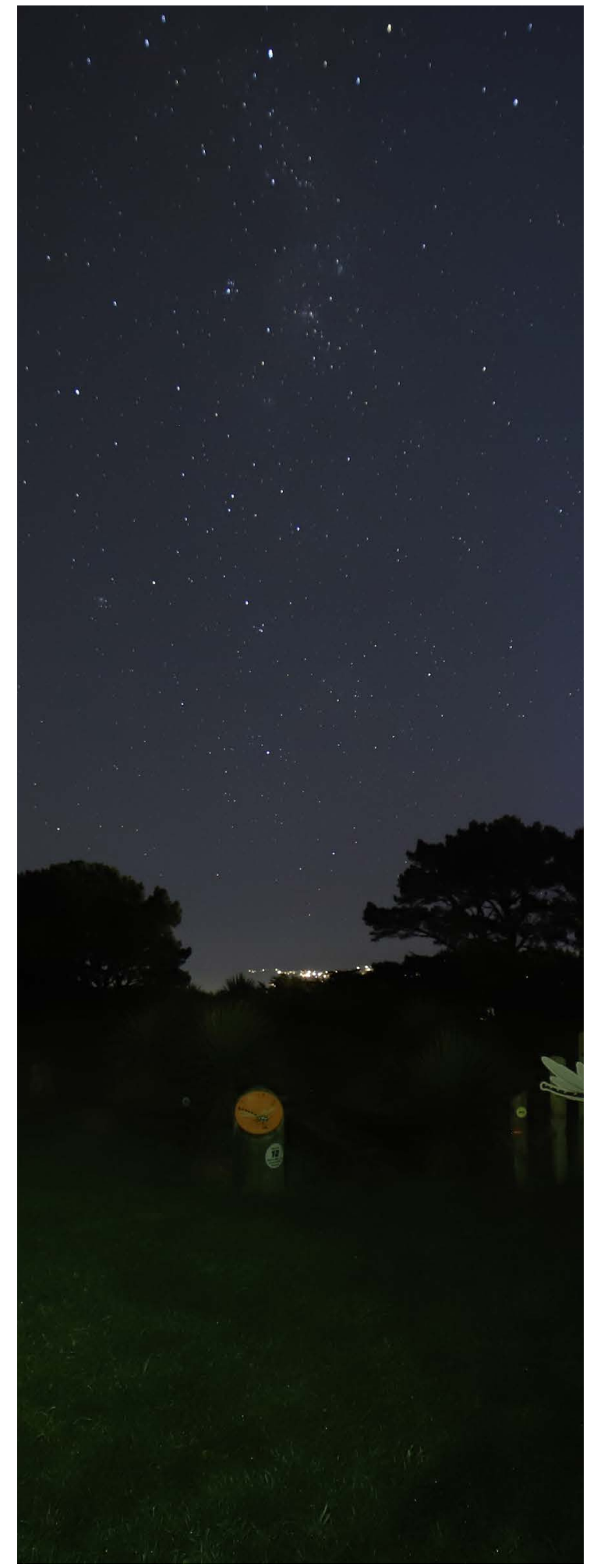

4.12 The stars above Matairangi nature trail 
No sense of discomfort in the site, because it was very open
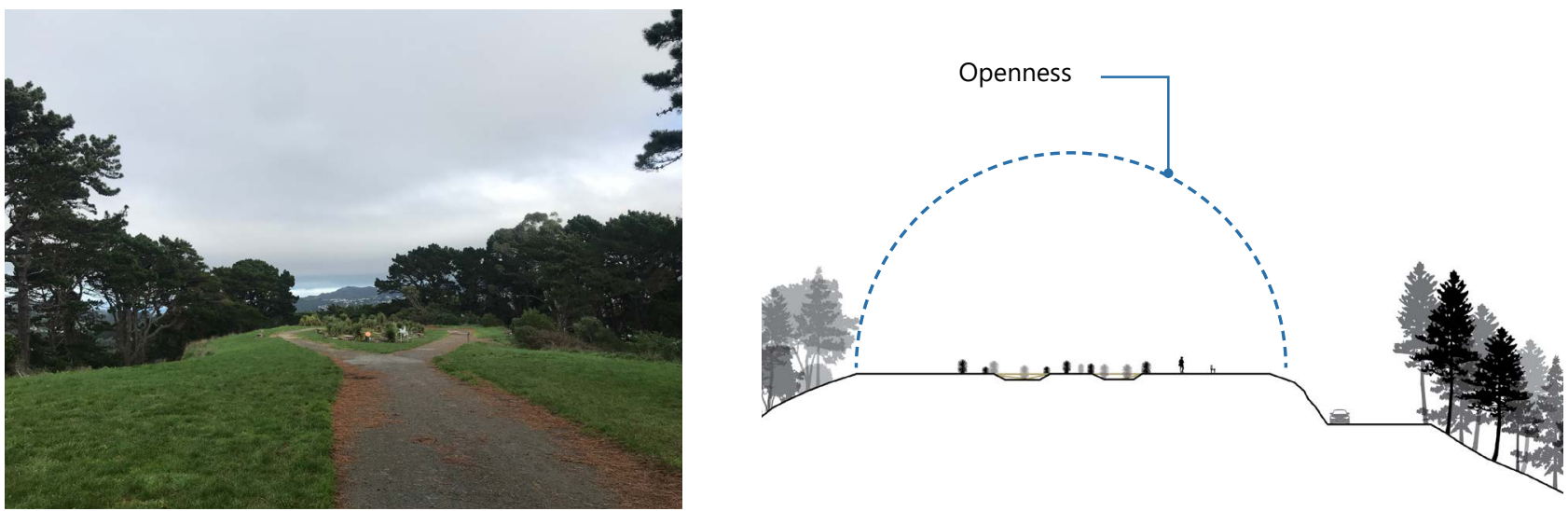

Being outside in the trees, calmness
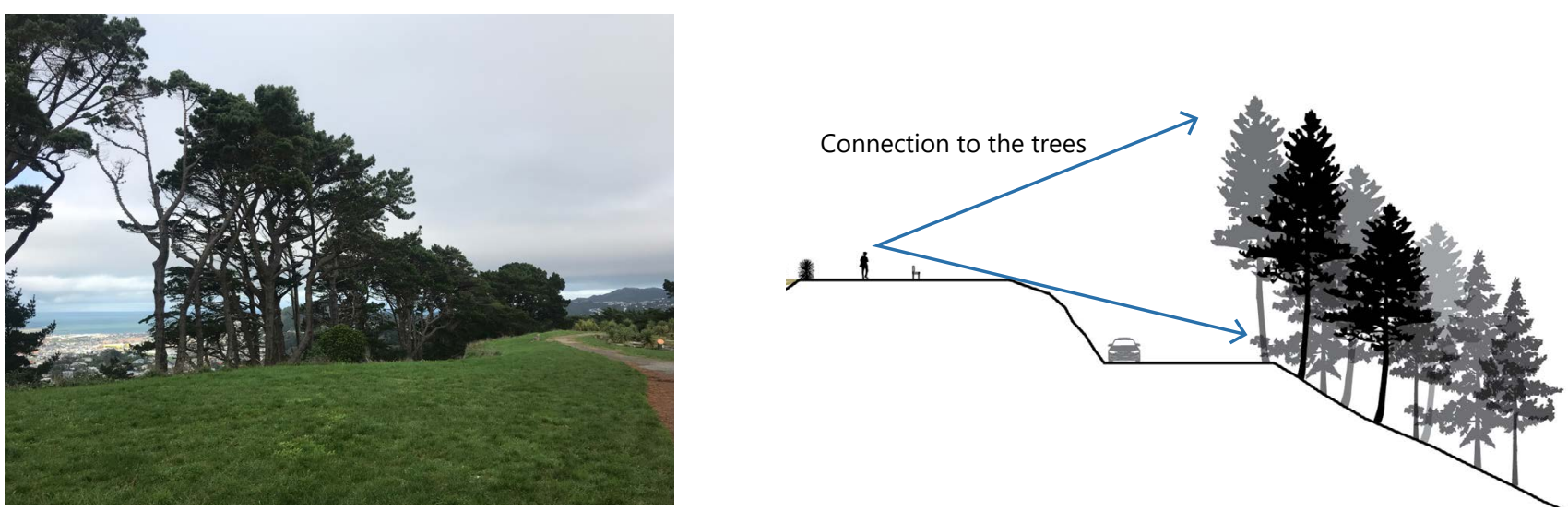

Seating during the day

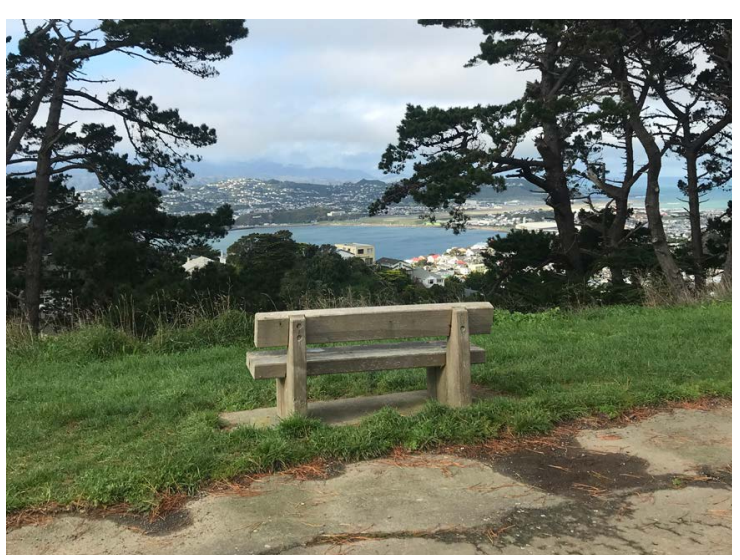

Seating provides a place to rest

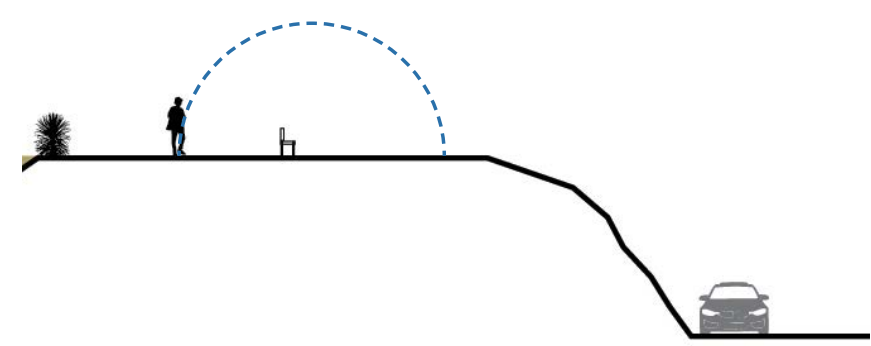

Centre piece

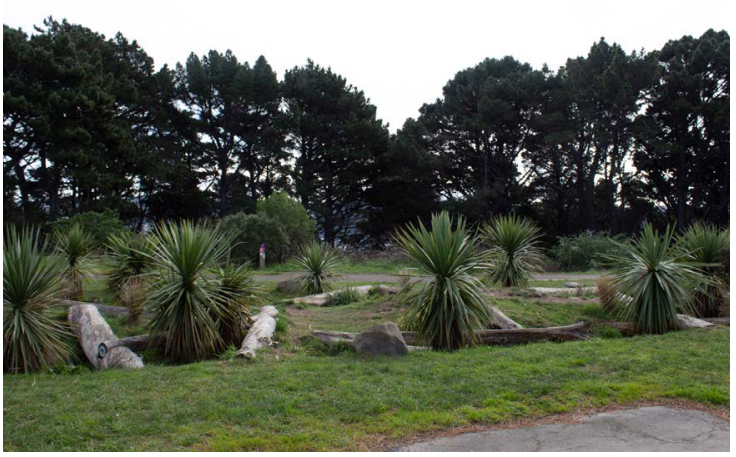

Interactive planting in the centre

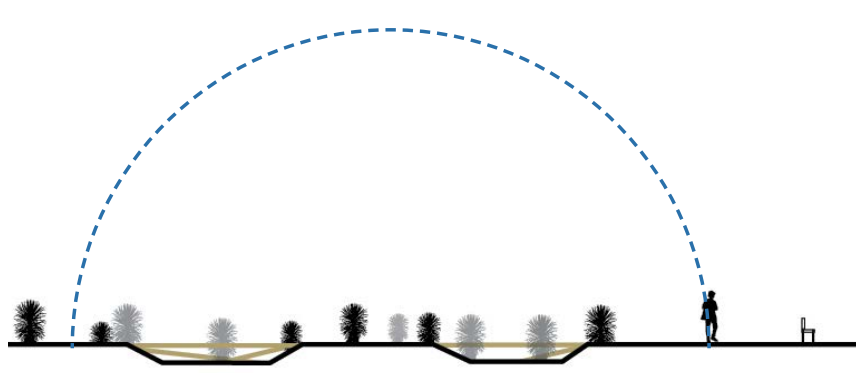


Distance between Vegetation = positive

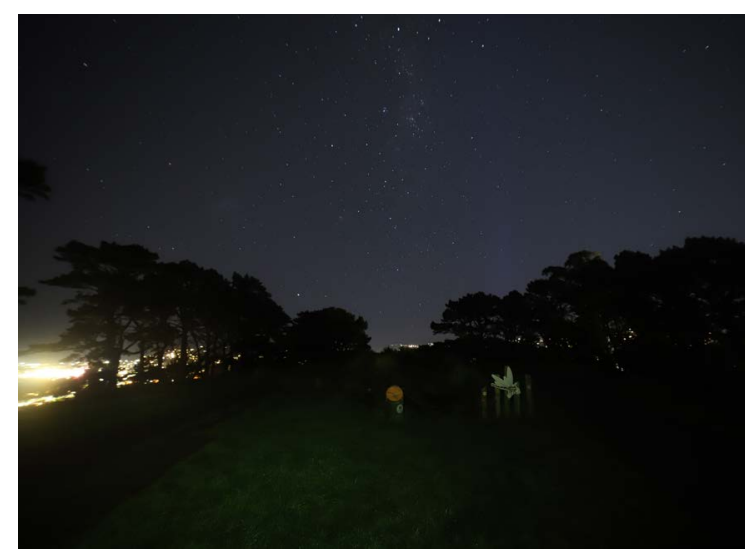

Site felt comfortable due to distance between vegetation

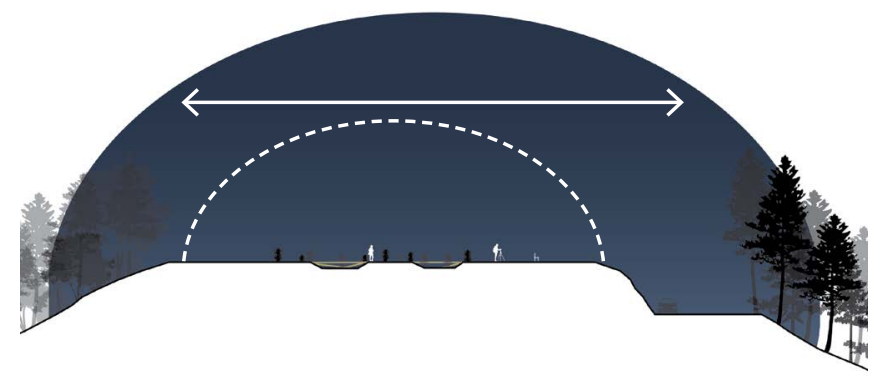

Not comfortable on west side where tree line was taller and denser
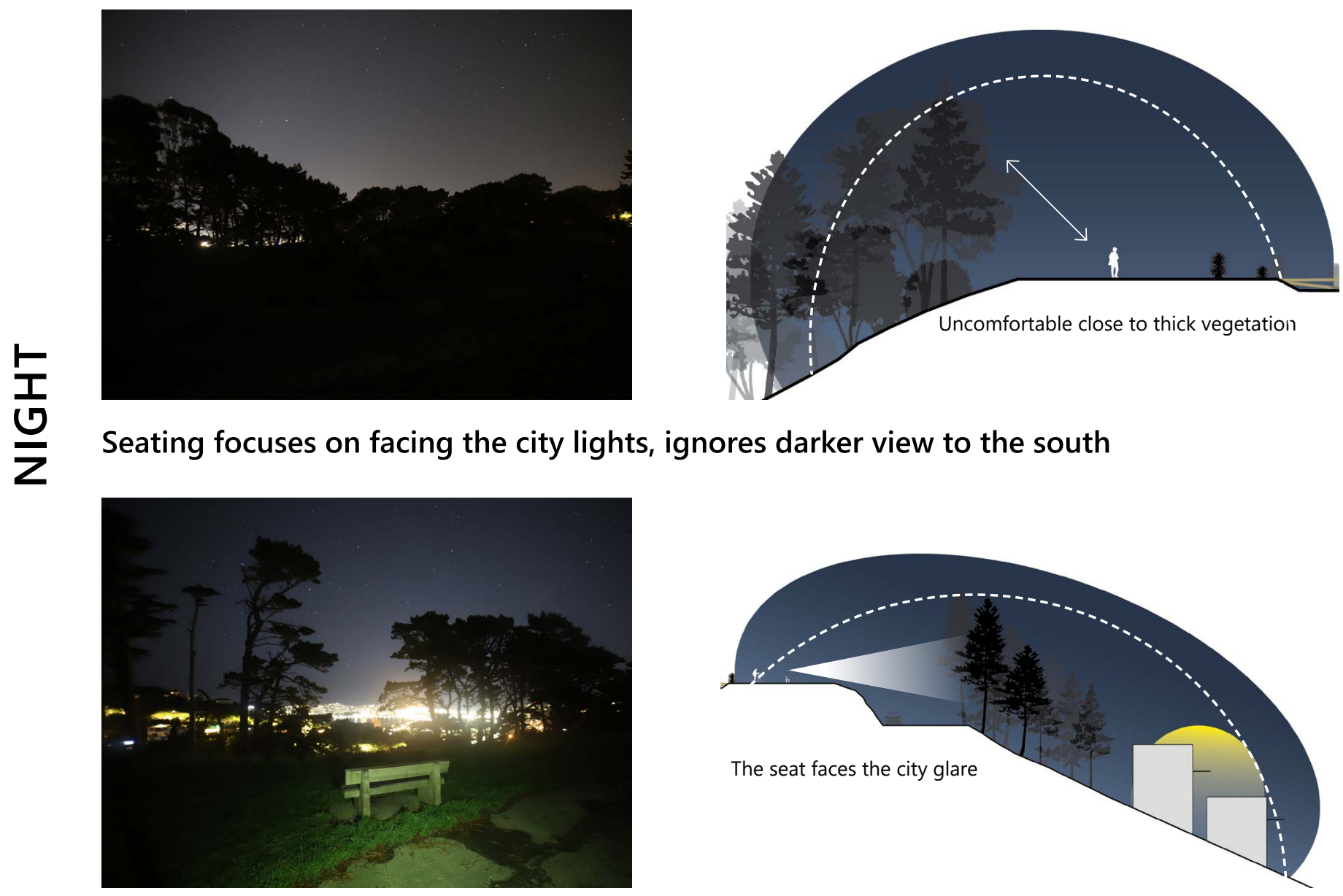

Seating focuses on facing the city lights, ignores darker view to the south

\section{Centre piece interaction}
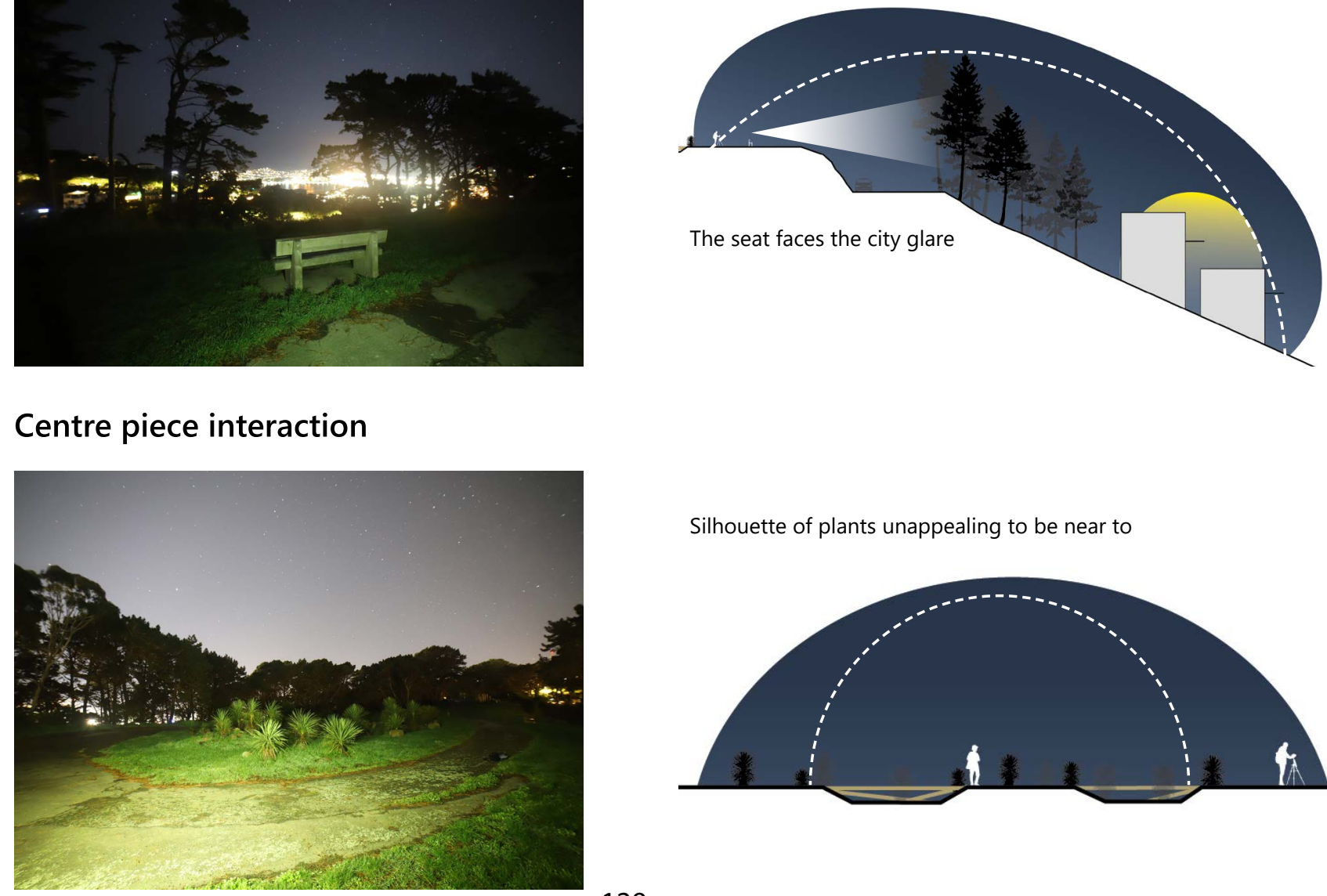

Silhouette of plants unappealing to be near to

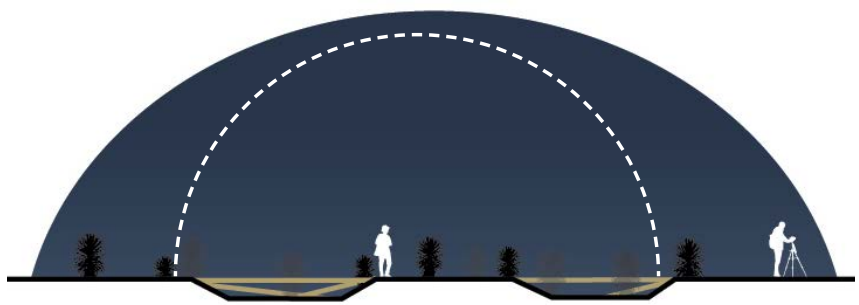


MT VICTORIA WALKING TRAIL
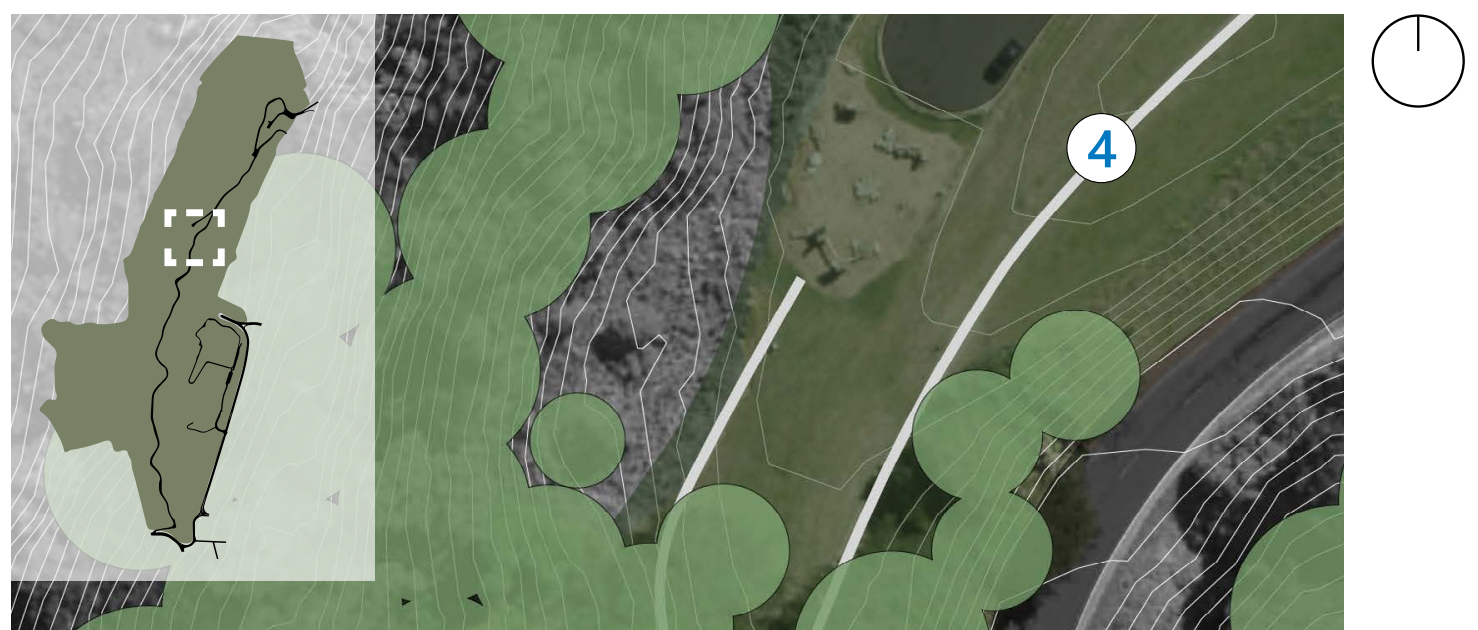


\section{Day Experience}

1. A large open space was very nice to be in during the day.

2. A thick line of vegetation forms the boundary on one side of the site

3. The openness of the site offered many views

4. A gravel path runs through the site, with the grass either side sloping away to the road and tree line

\section{Night Experience}

5. At night the distance between the vegetation sustained the positive feelings of comfort in the site

6. The dense tree line to the west blocked the surrounding light coming into the gaze of the stars but was less appealing to be close. However the sight of the stars began to drown out this fear.

7. The view of the stars was worst facing the open tree line to the east because the tree line was not as dense.

8. It felt uncomfortable leaving the gravel path at night.

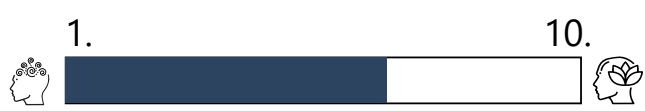

Overall comfort level

1.

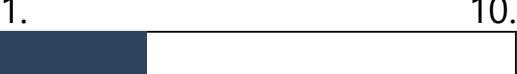

Amount of Illuminated Area

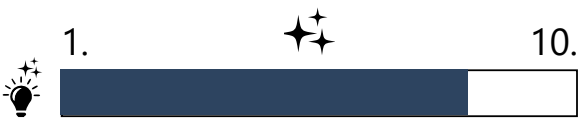

10.

Star Visibility

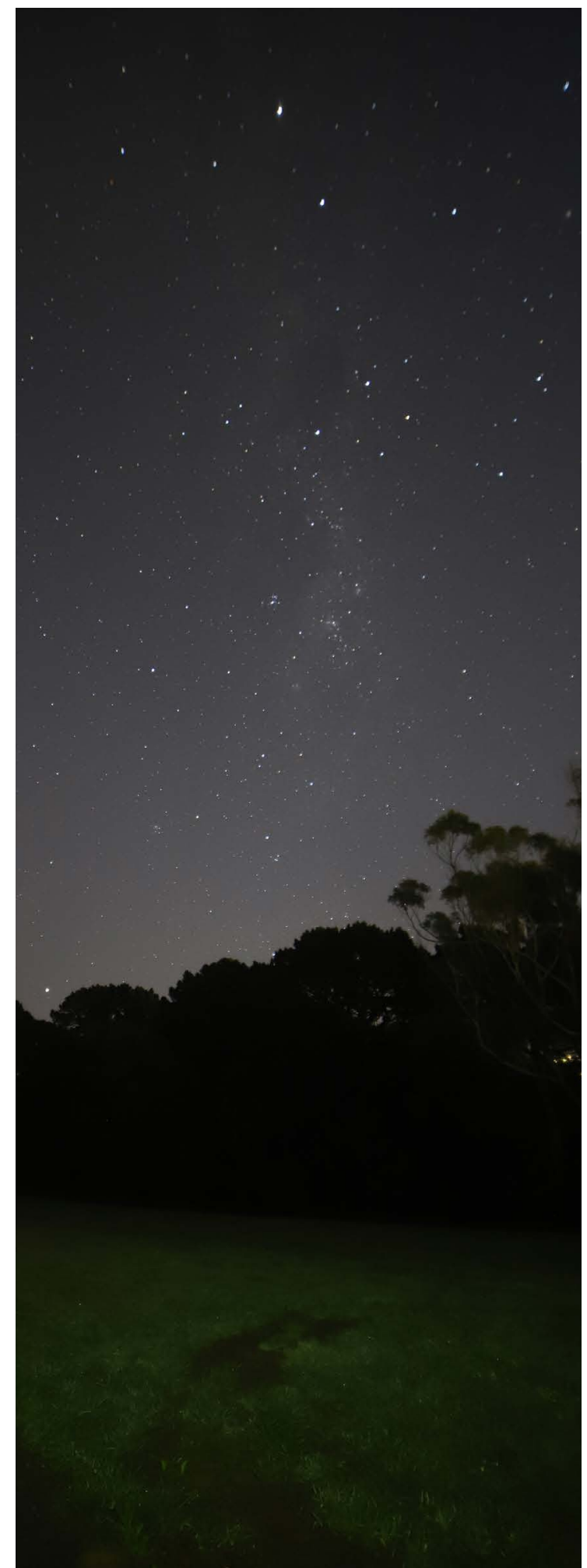

4.13 Faint Milky way seen from the Mt Victoria Walking track 
Open space, clear line of sight through

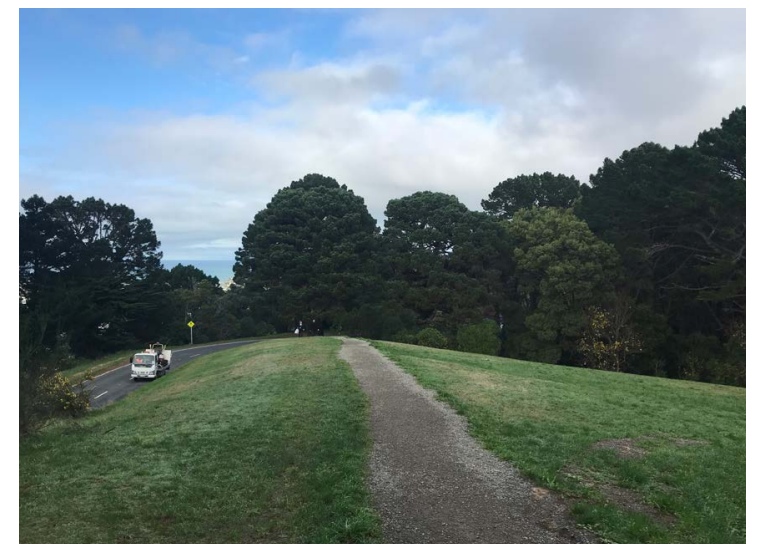

clear view down the site was comforting

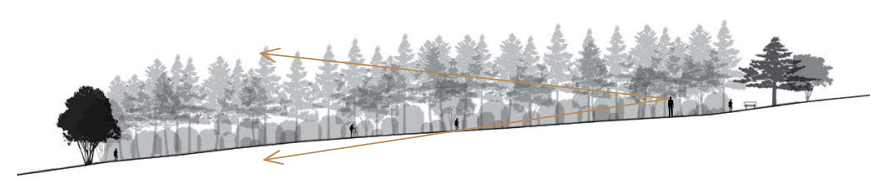

Trees form the boundaries of the site

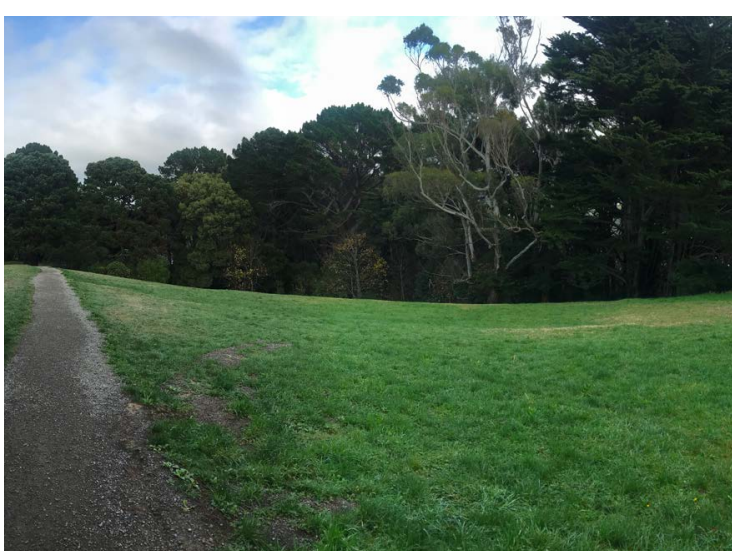

Tree line marking the site boundary

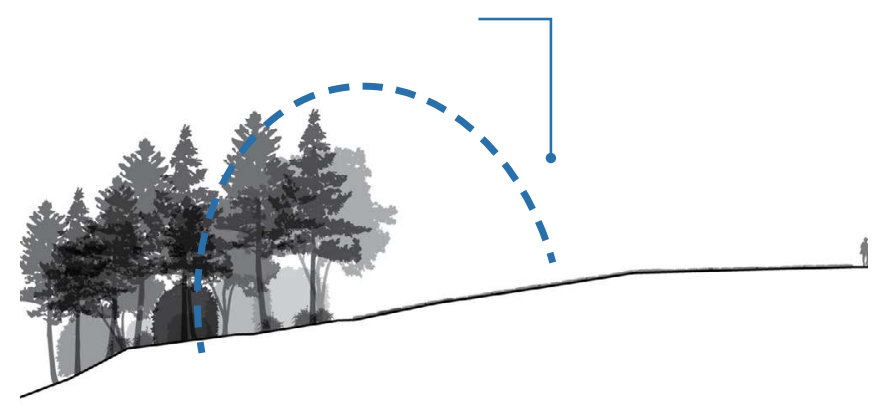

Views of the site
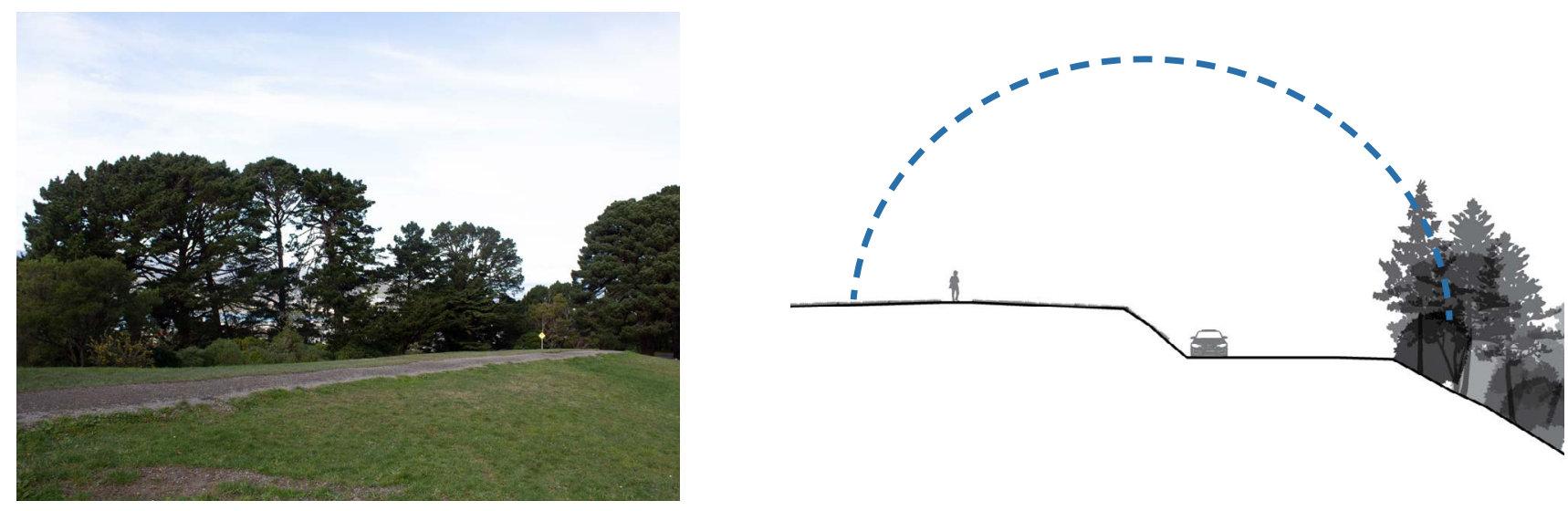

Materiality of the site - grass and gravel path
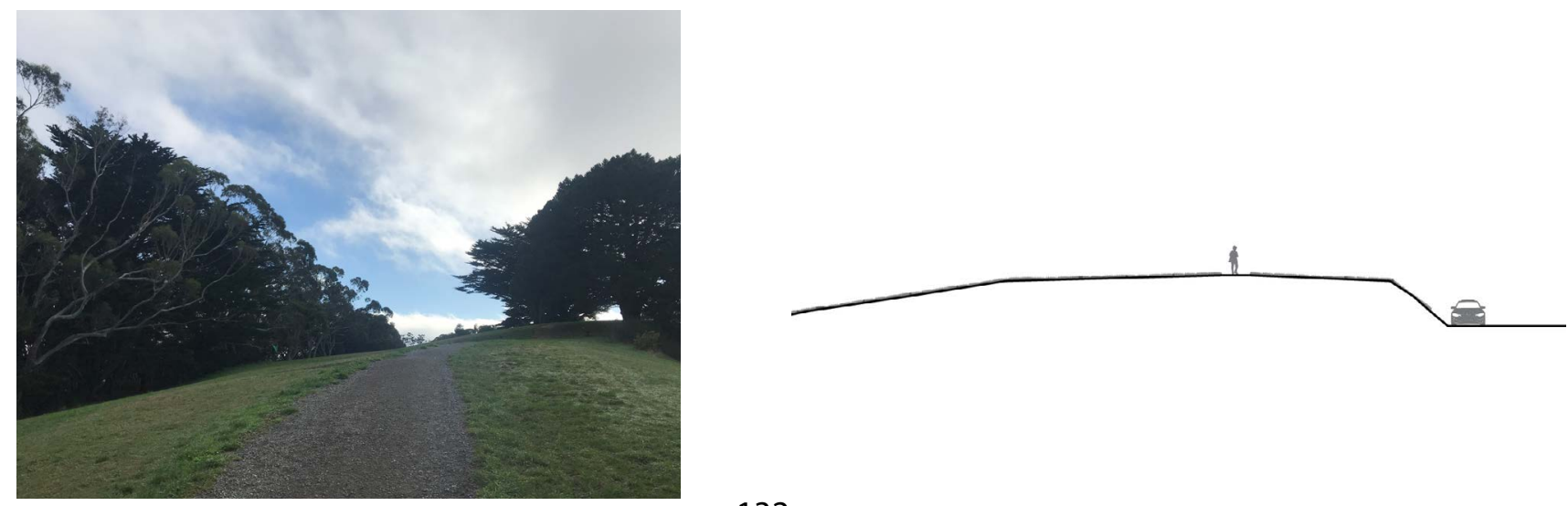

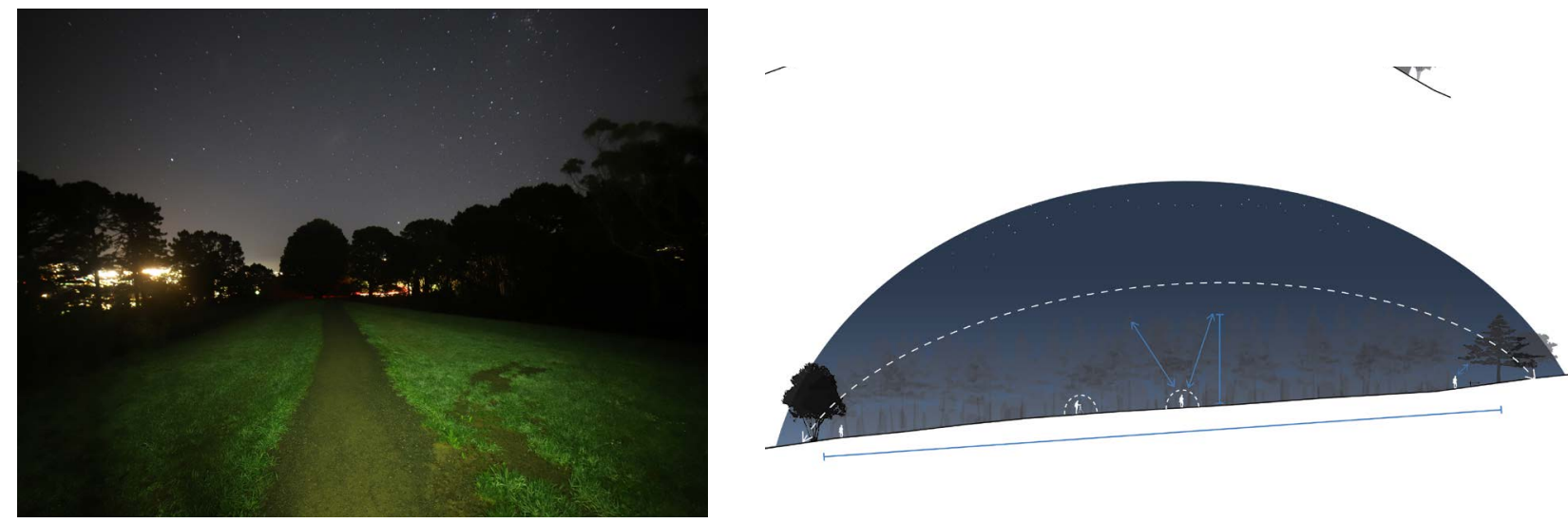

View of the stars was better towards the dense tree line (west) but less appealing to be close to
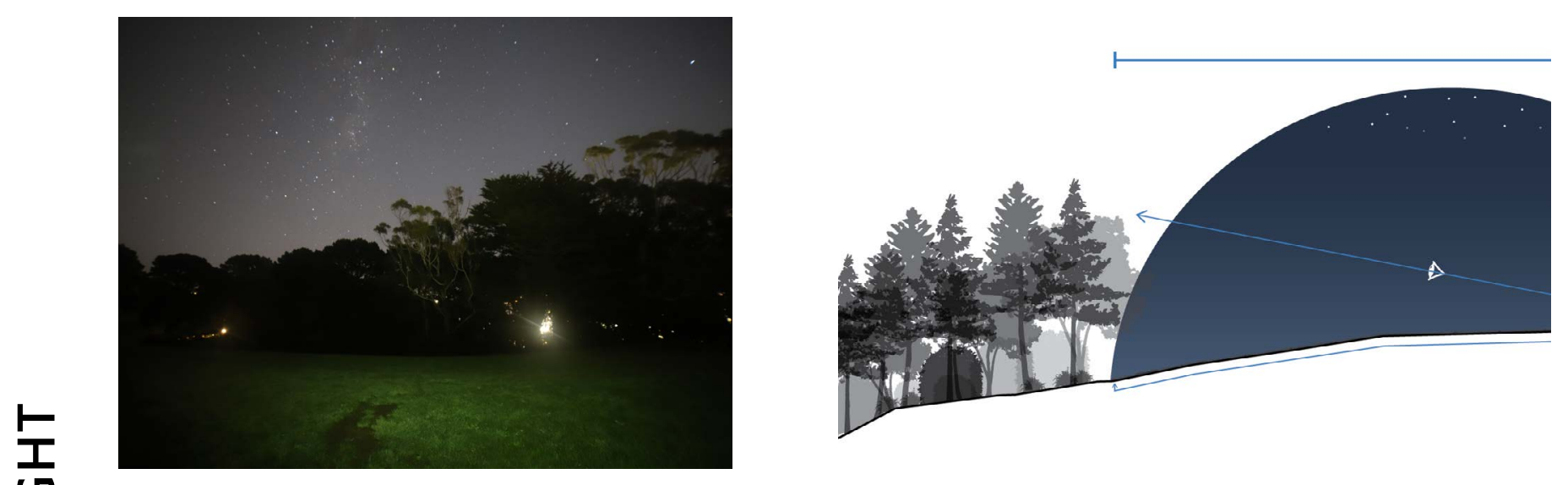

View of the stars was worst towards the open tree line (east) but more appealing to be close to
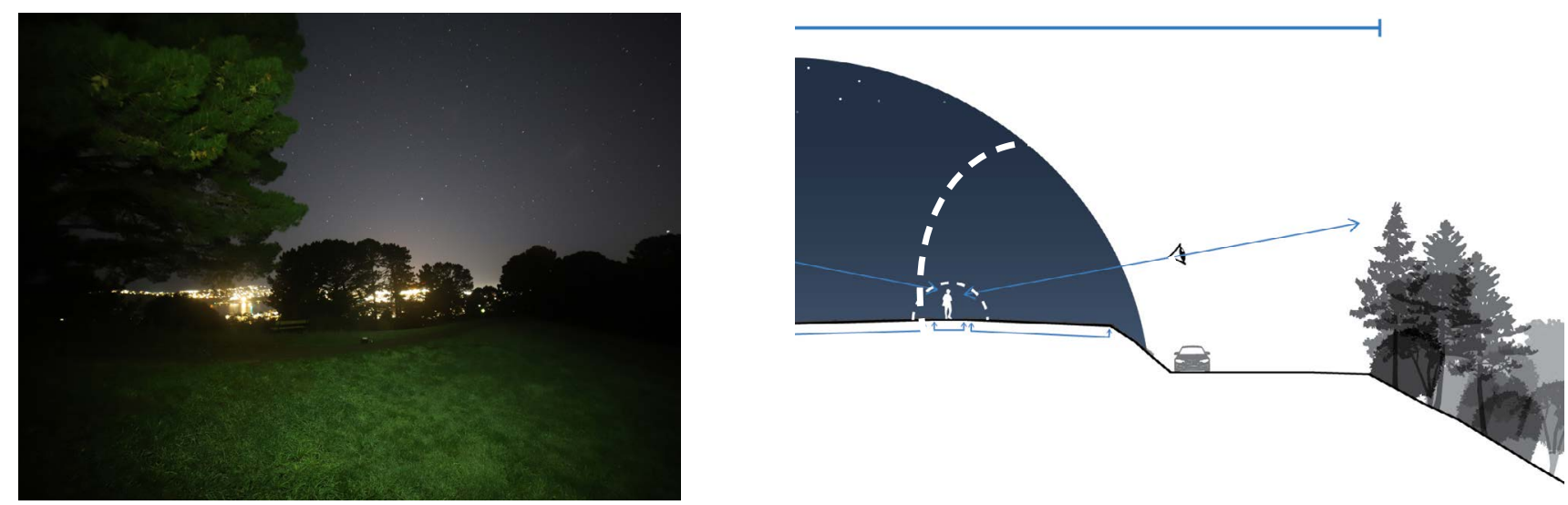

Uncomfortable to leave gravel path at night
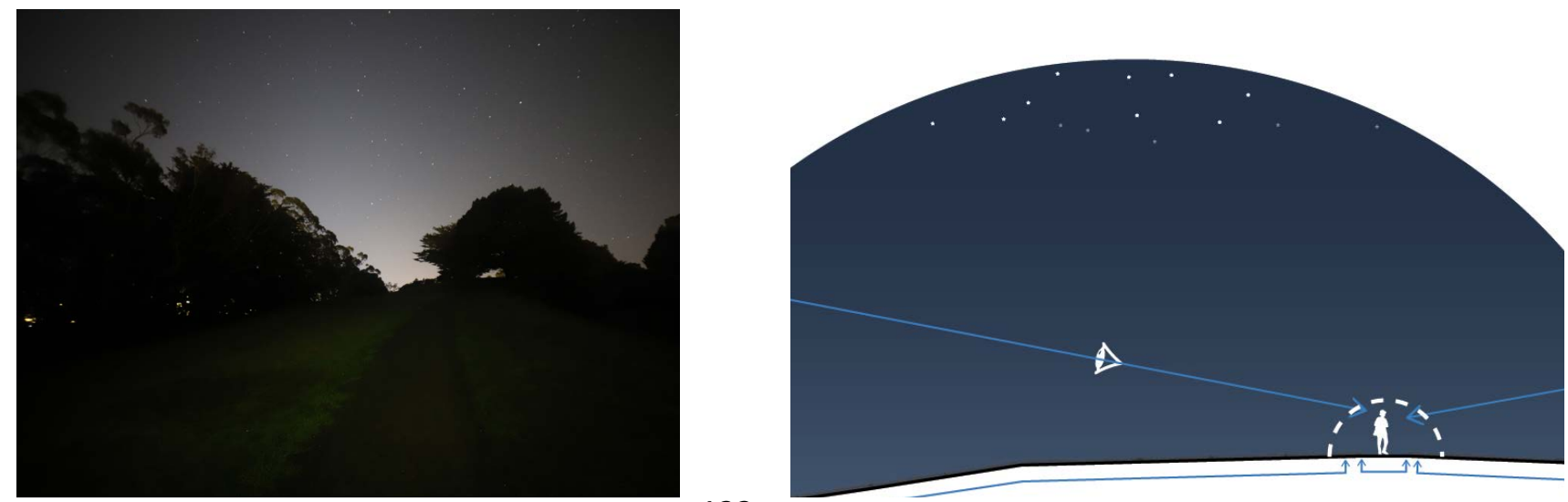


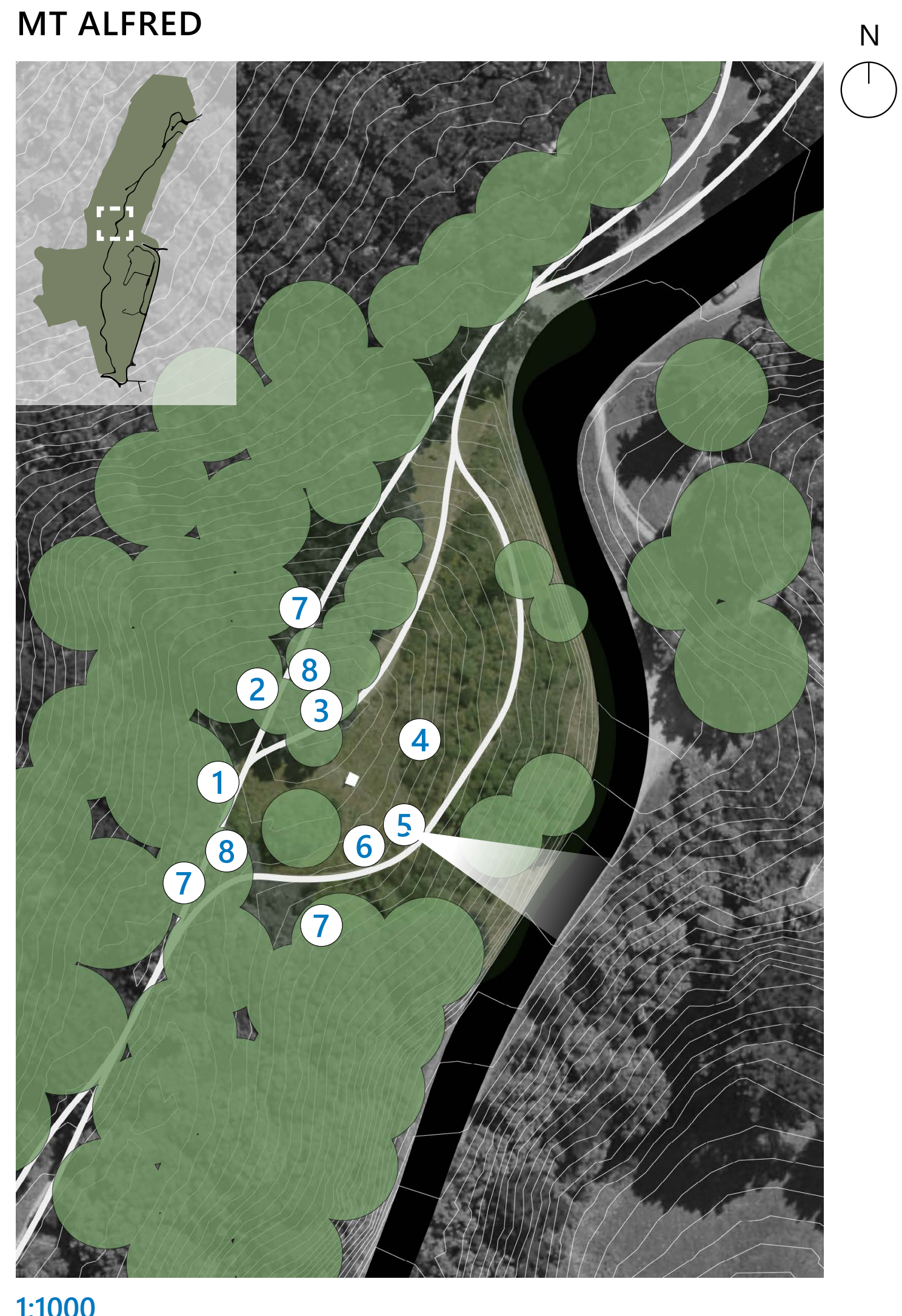




\section{Day Experience}

1. The site was tightly compacted into a little space at the summit of this small hill with very little open space

2. The area was surrounded by vegetation on one half which was a little unnerving at first but soon forgotten

3. The joined canopies from the Pohotukawas and pine trees created a boundary to the space

4. A bench provided a place to rest and take in the view

\section{Night Experience}

5. On one side was a beautiful view of the night sky, despite the glare from the suburbs

6. The high elevation made the user feel exposed

7. The dense tree line decreased prospect and created a fear of entrapment. The least amount of time was spent in this space out of the entire fieldwork.

8. There were two access points into the space, both of which were enclosed by the canopies from the Pohotukawa trees

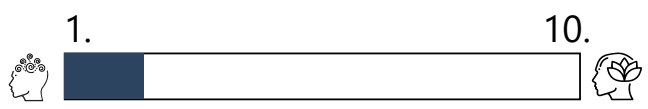

Overall comfort level

1. 10.

\section{Amount of Illuminated Area}

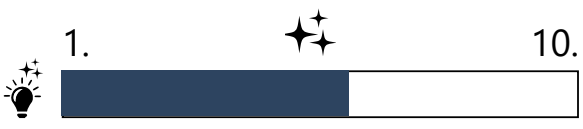

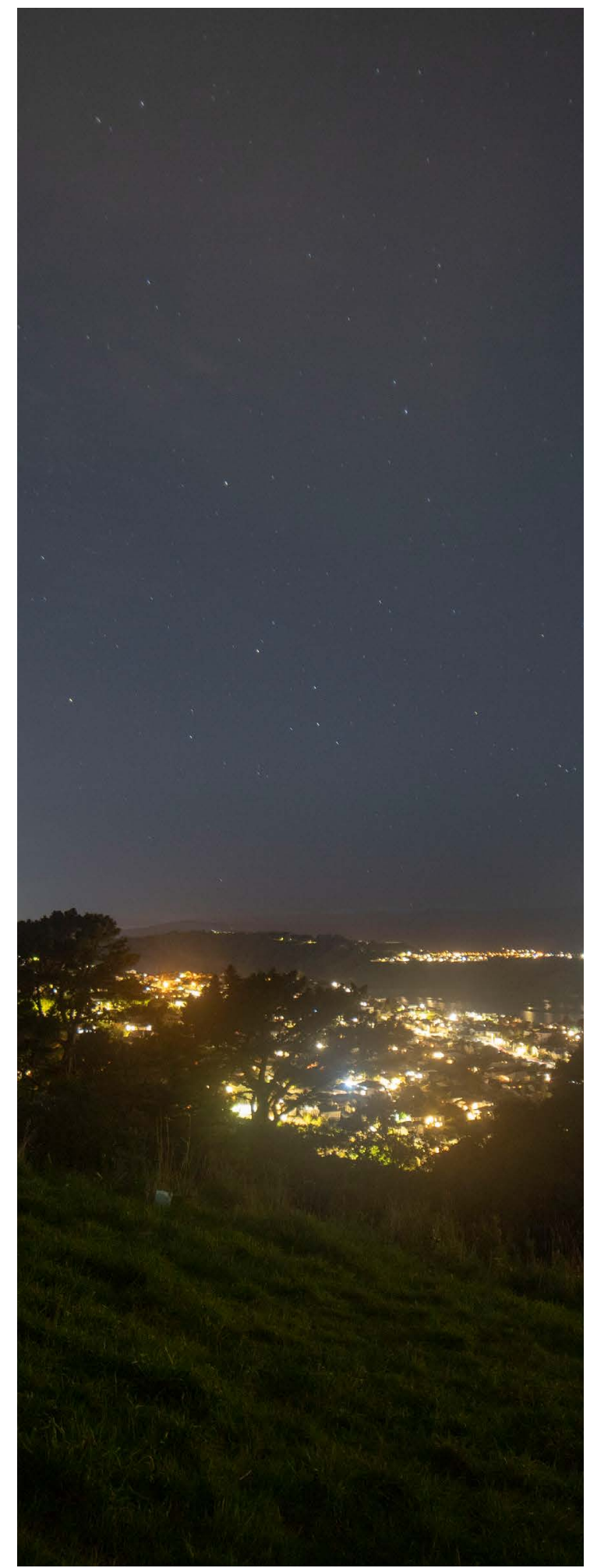

4.14 Light Glare above Miramar as seen from the Town Belt 
Small site with vegetation close by

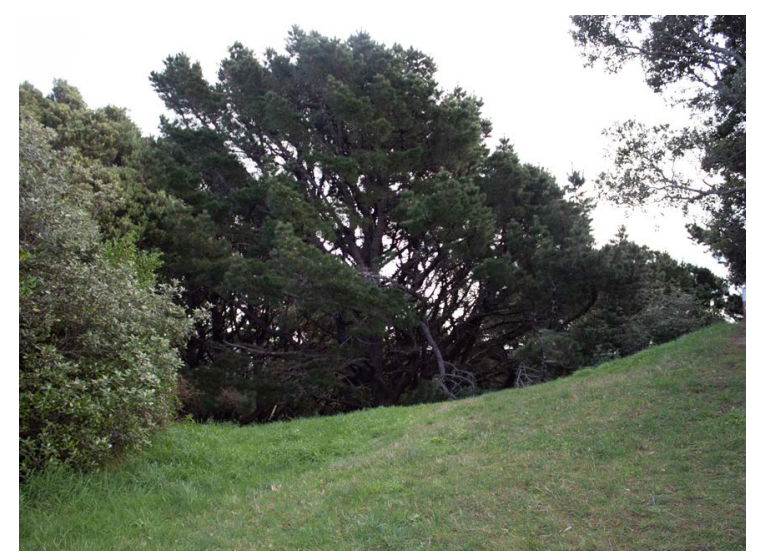

Small tightly packed by vegetation

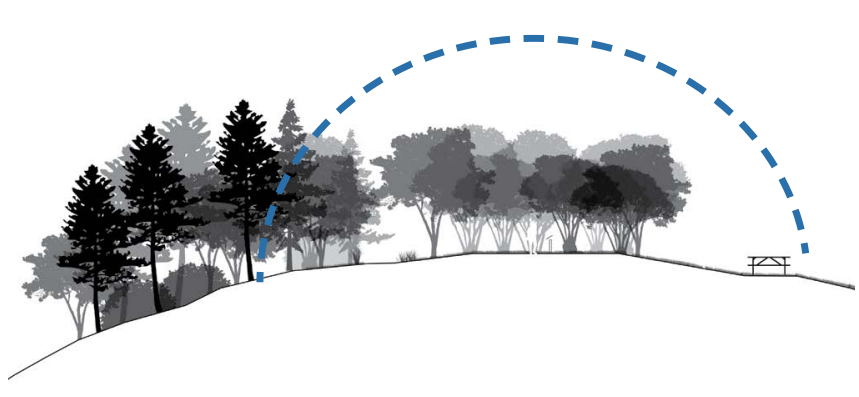

High elevated position with big views over the eastern suburbs

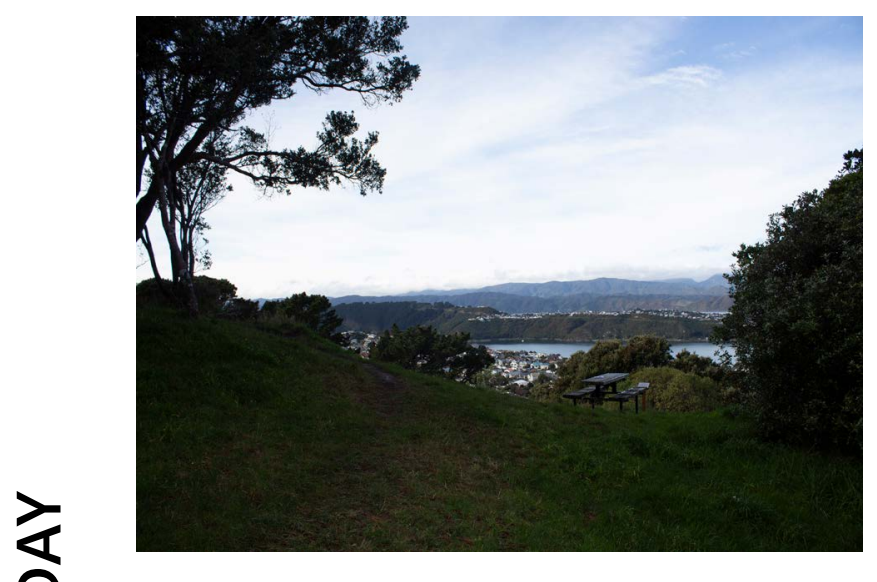

High elevation increased prospect

Canopy of trees over the space
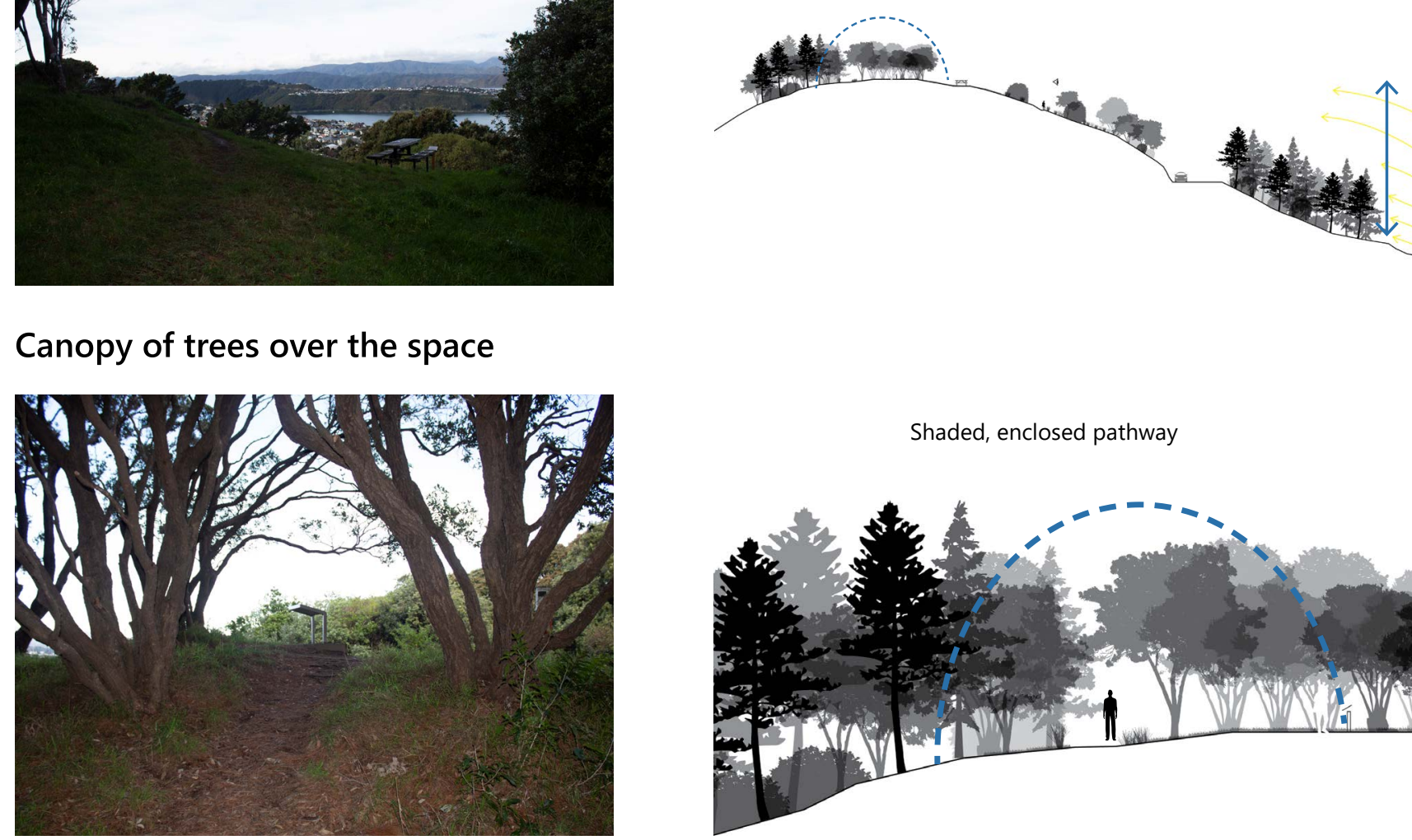

Shaded, enclosed pathway

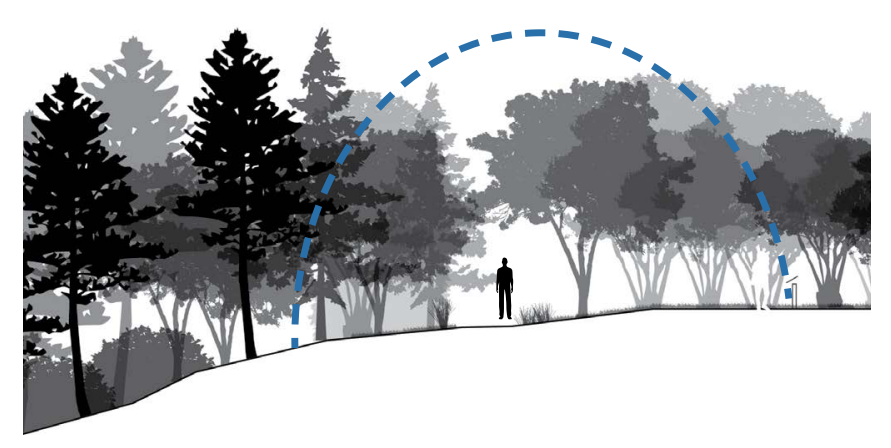

Affordances in the site
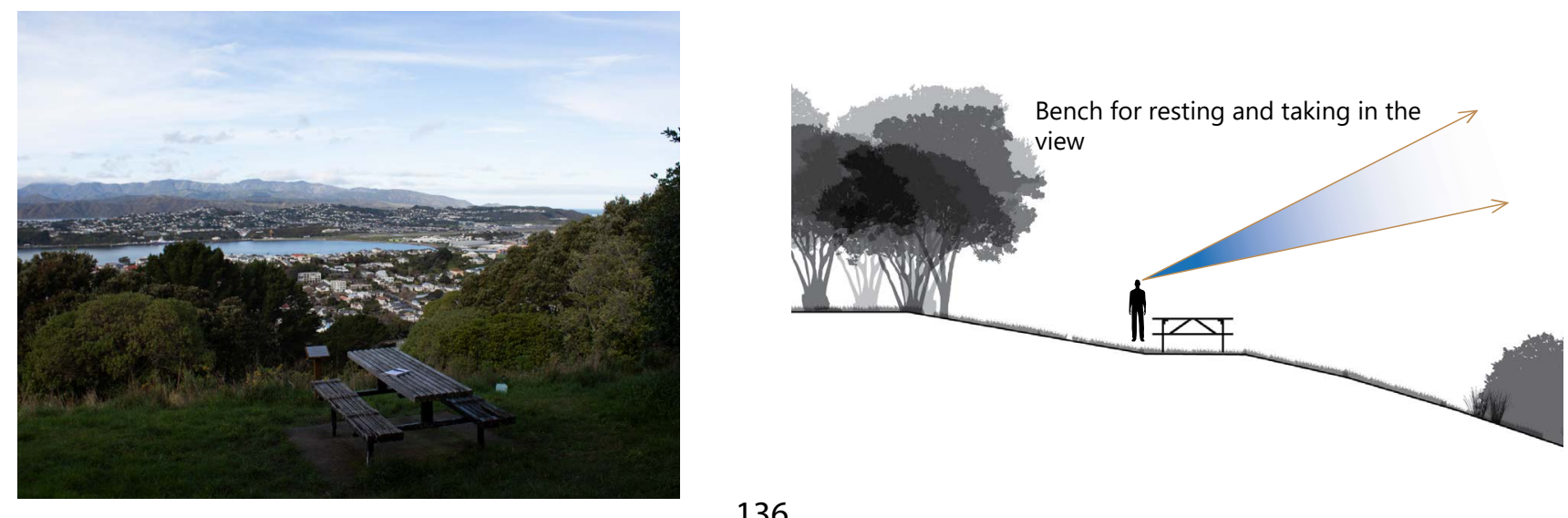
Close dense vegetation at night increased feelings of entrapment
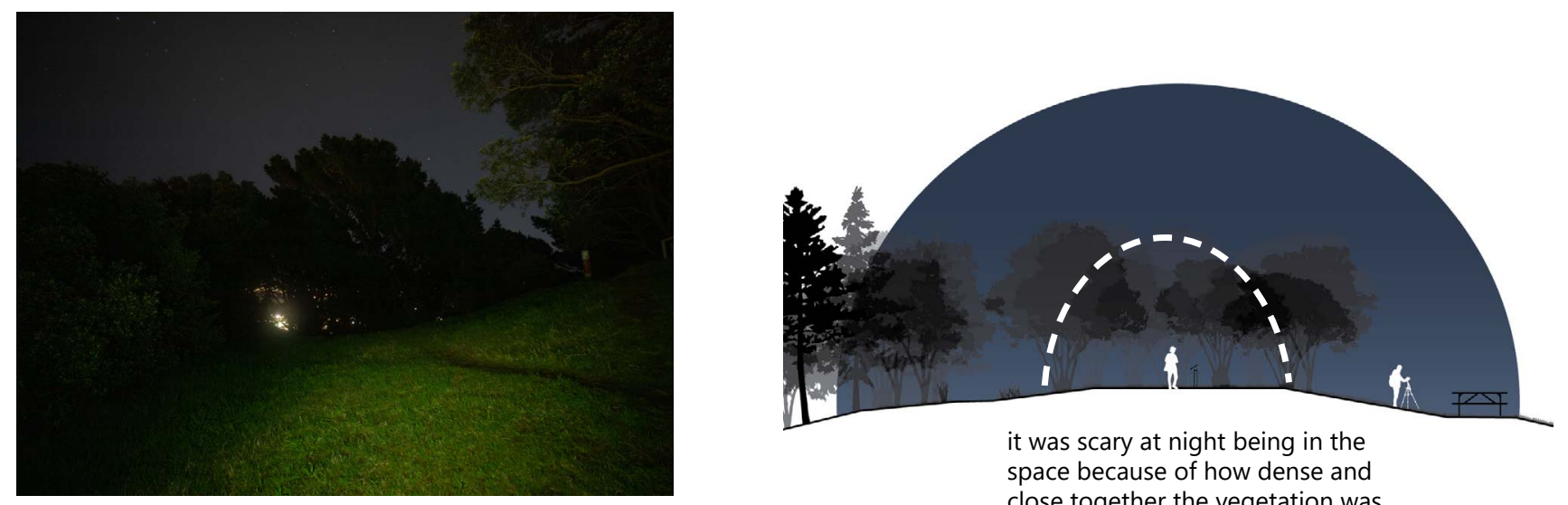

it was scary at night being in the

space because of how dense and

close together the vegetation was

The elevation made the area feel more exposed
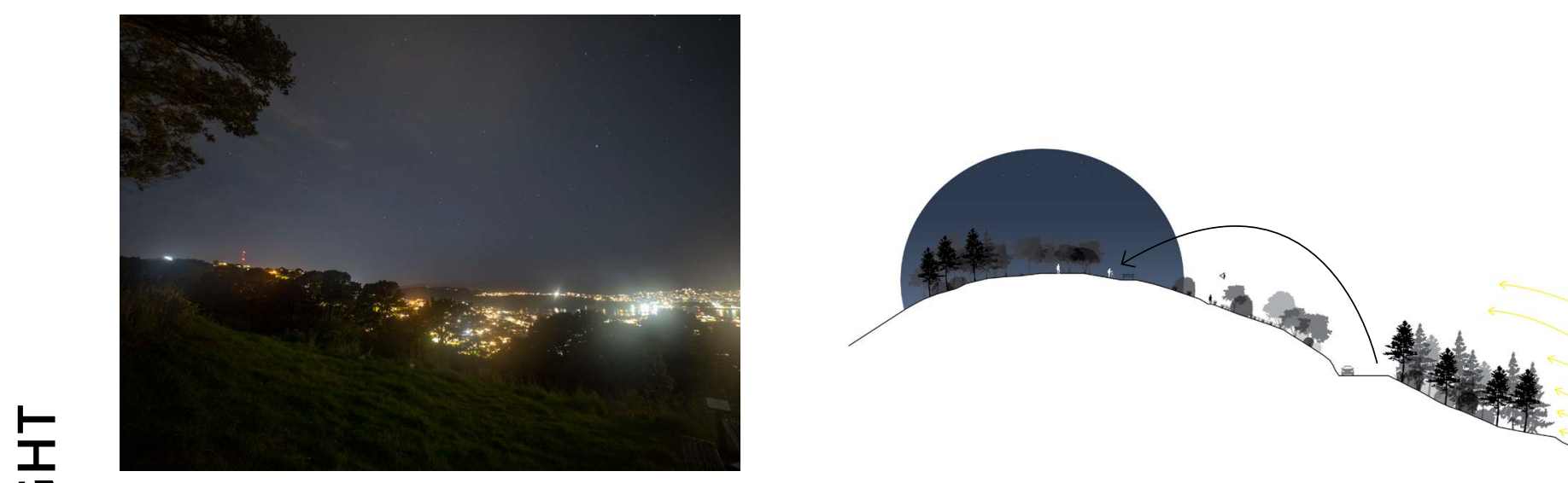

Silhouette of the pohutakawa branches frightening
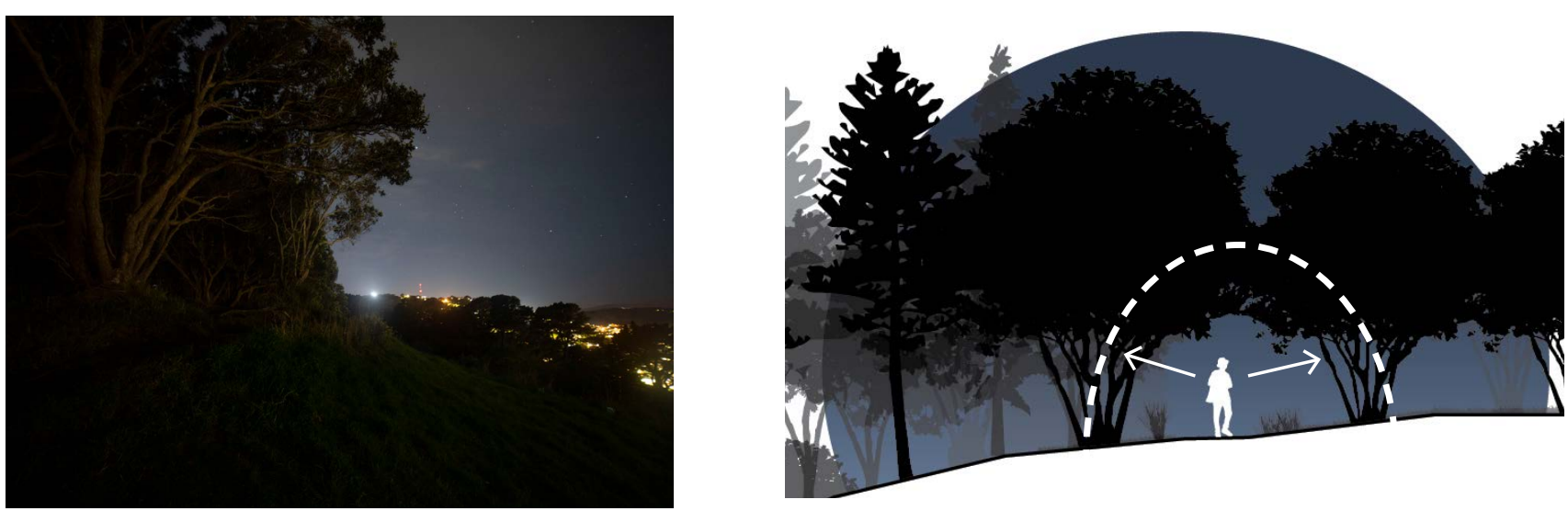

Bench provides good resting spot at night
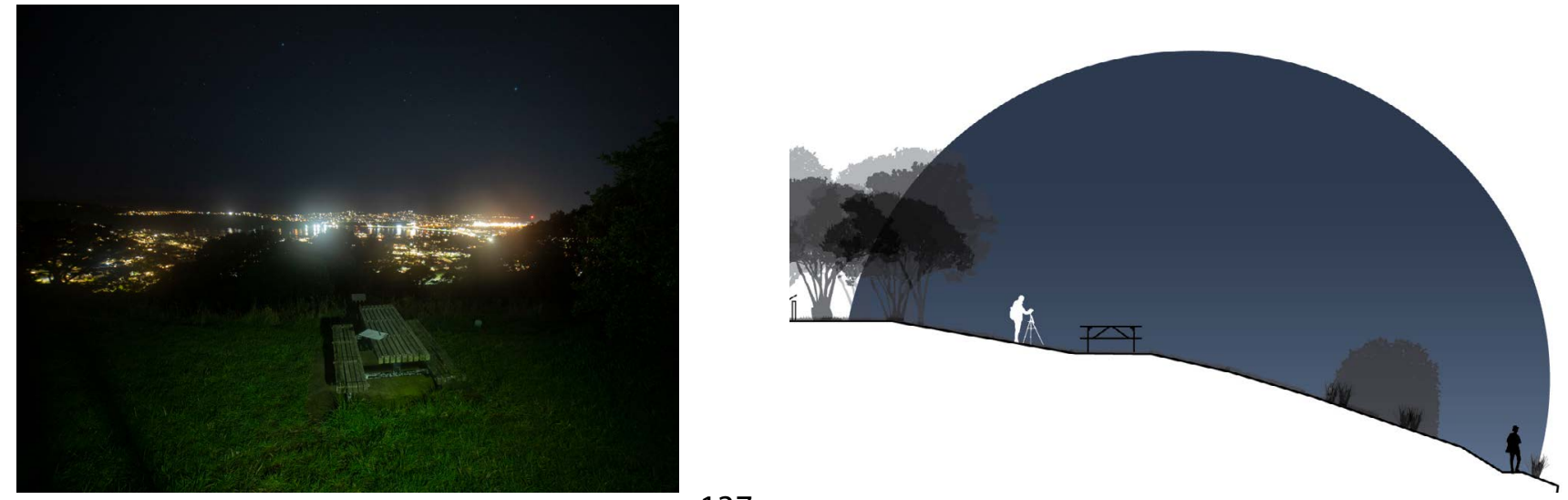


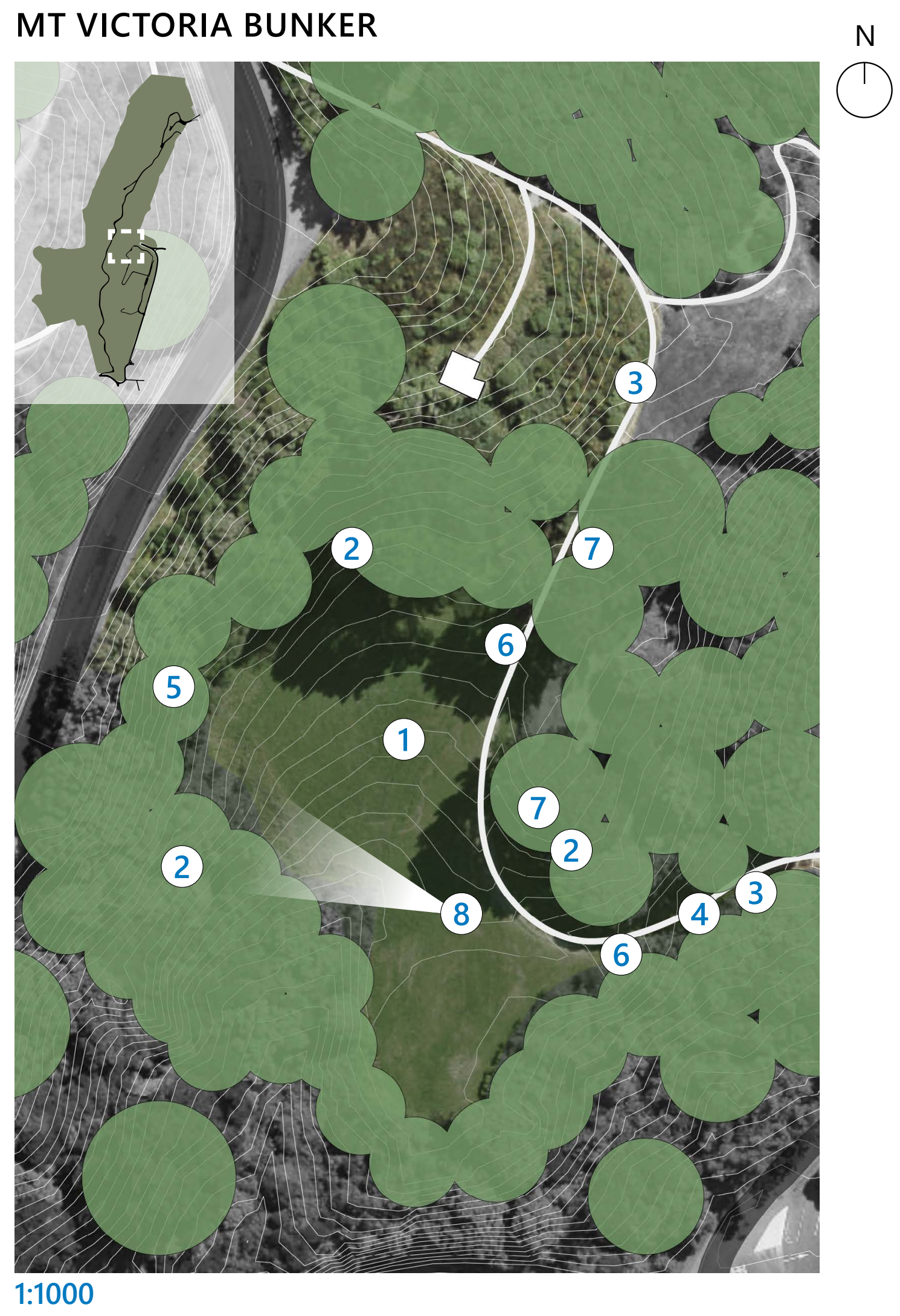




\section{Day Experience}

1. The site consisted of a large open space and was the lowest area visited in the town belt

2. It was a very secluded site with large trees surrounding the space

3. It had two entrances enclosed by vegetation

4. The site was used as a shortcut from Hataitai to the central city for runners and walkers.

\section{Night Experience}

5. The tall vegetation combined with the low elevation decreased prospect which made the site very uncomfortable

6. The multiple access points were unnerving due to the increased chance of someone entering the site

7. The density/wild character of the vegetation close to the path was unappealing

8. All of the above contributed to a dark environment that afford better star visibility. This increased comfort once the eyes adjusted

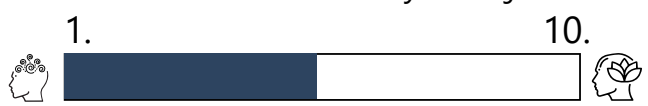

Overall comfort level

1.

10.

Amount of Illuminated Area

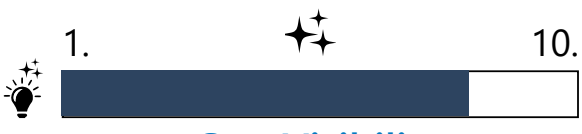

10.

Star Visibility

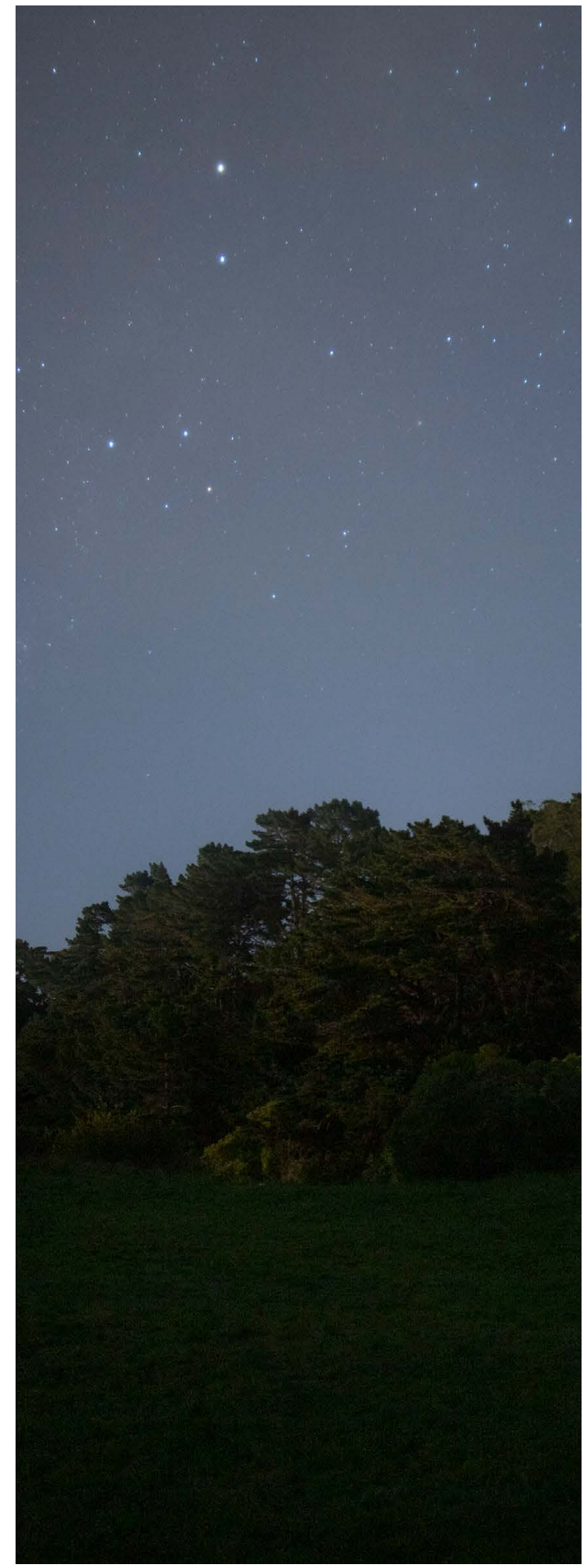

4.15 Night sky above the Mt Victoria Bunker 
A low elevated large open space surrounded by tall vegetation
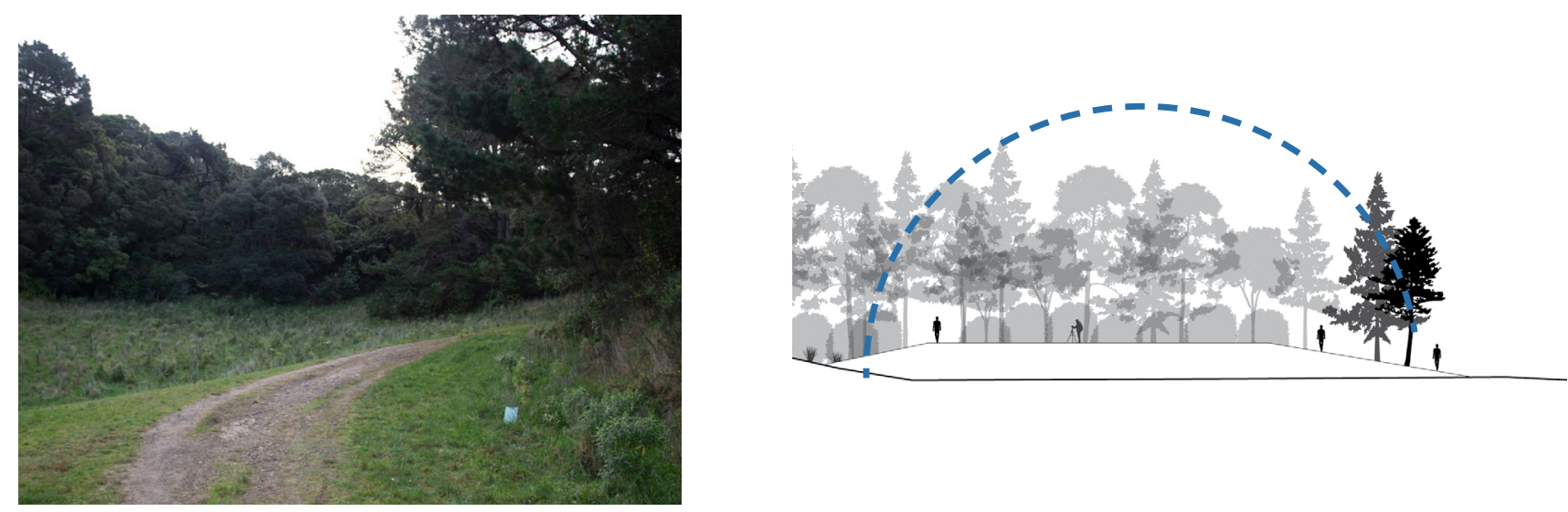

Natural site, with grass and concrete path

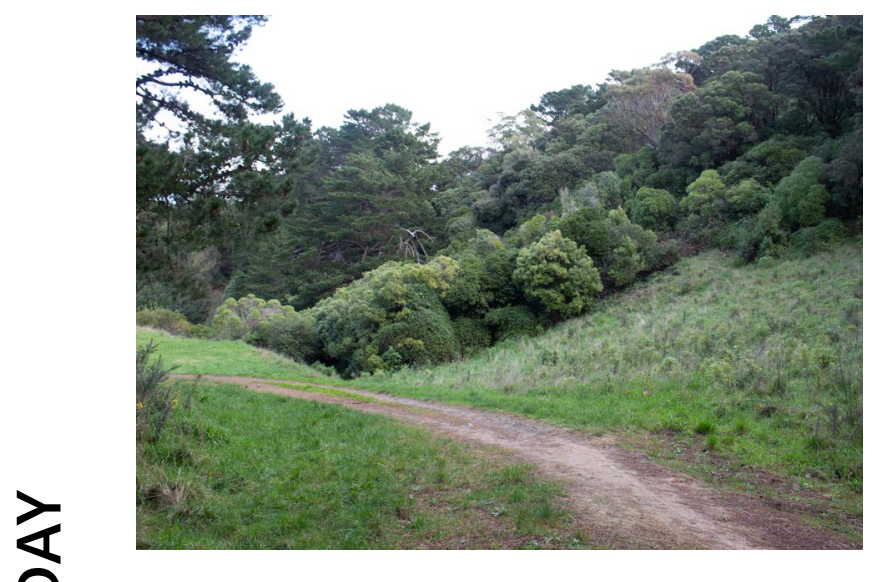

Path running through the site

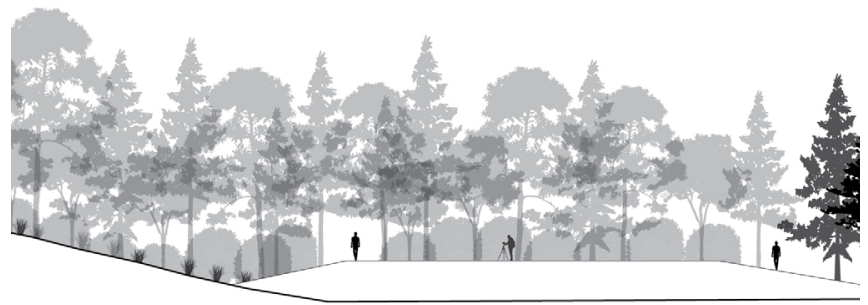

Entrance from road to site in between rows of vegetation
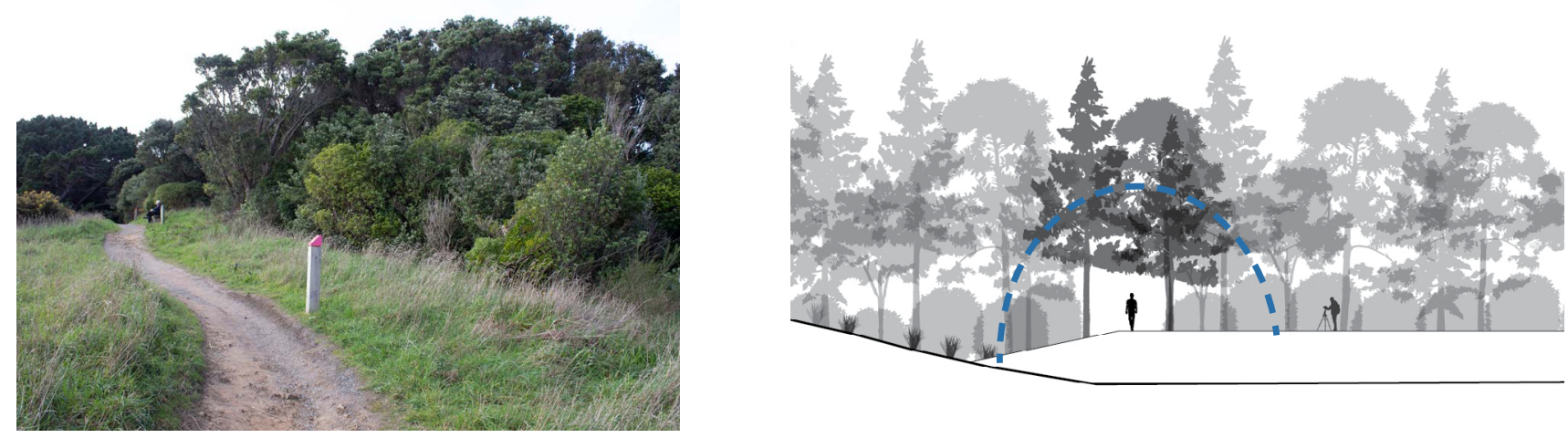

Visited by walkers
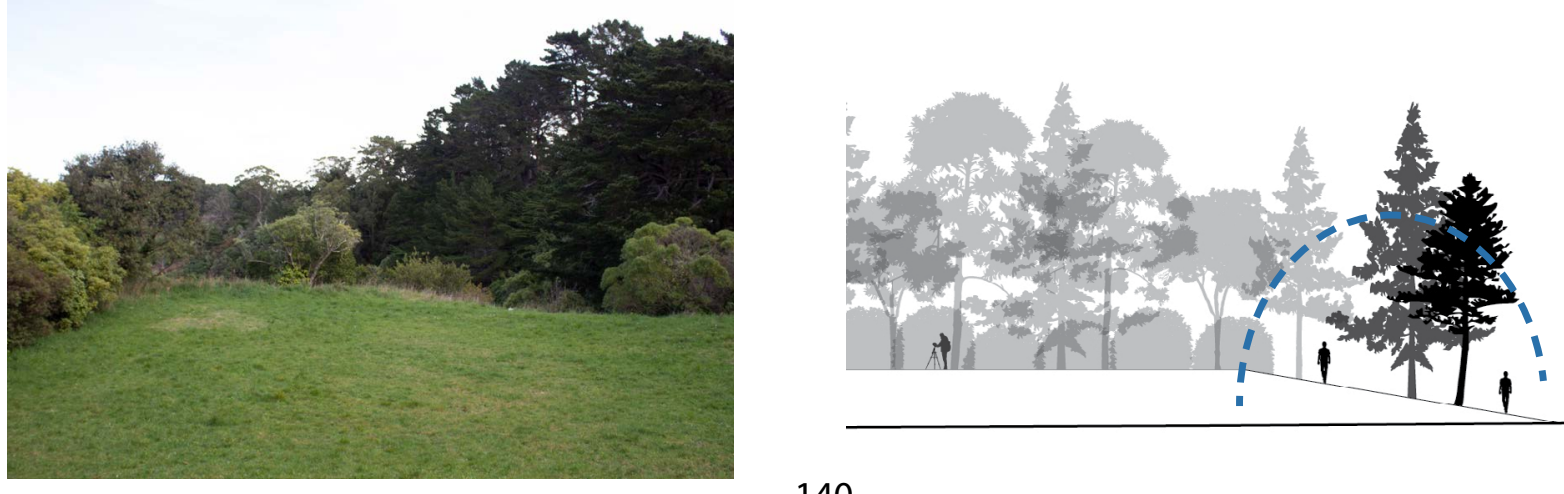
Tall vegetation/low elevation decreased view of surroundings which was uncomfortable
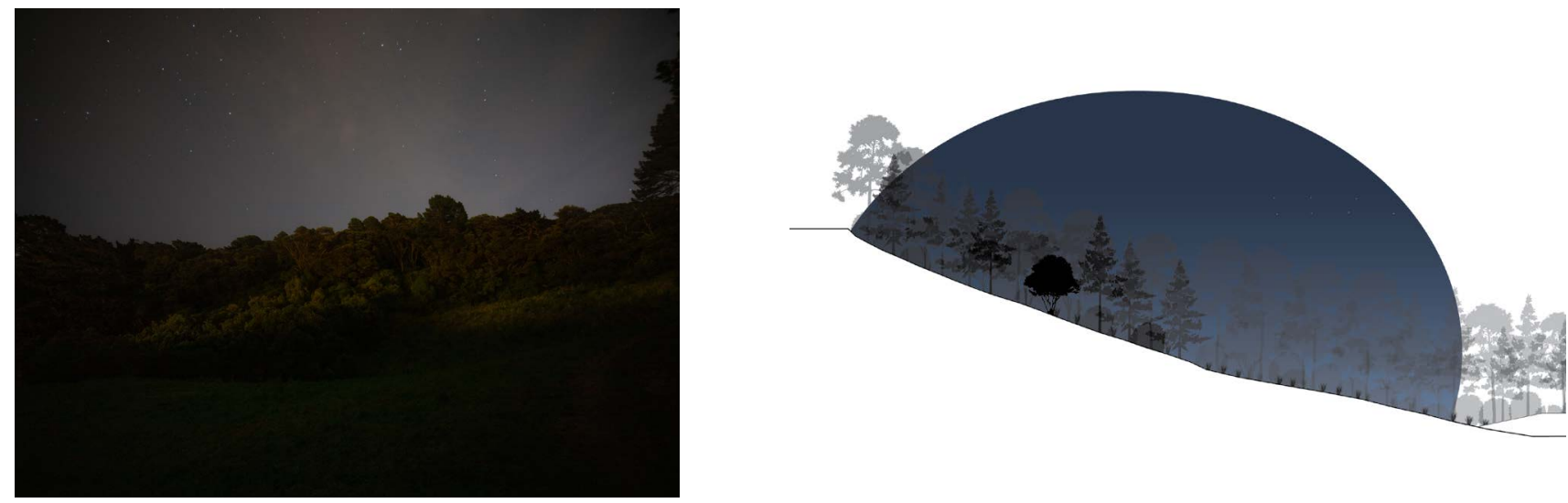

Two different access points was unnerving due to not knowing your surroundings
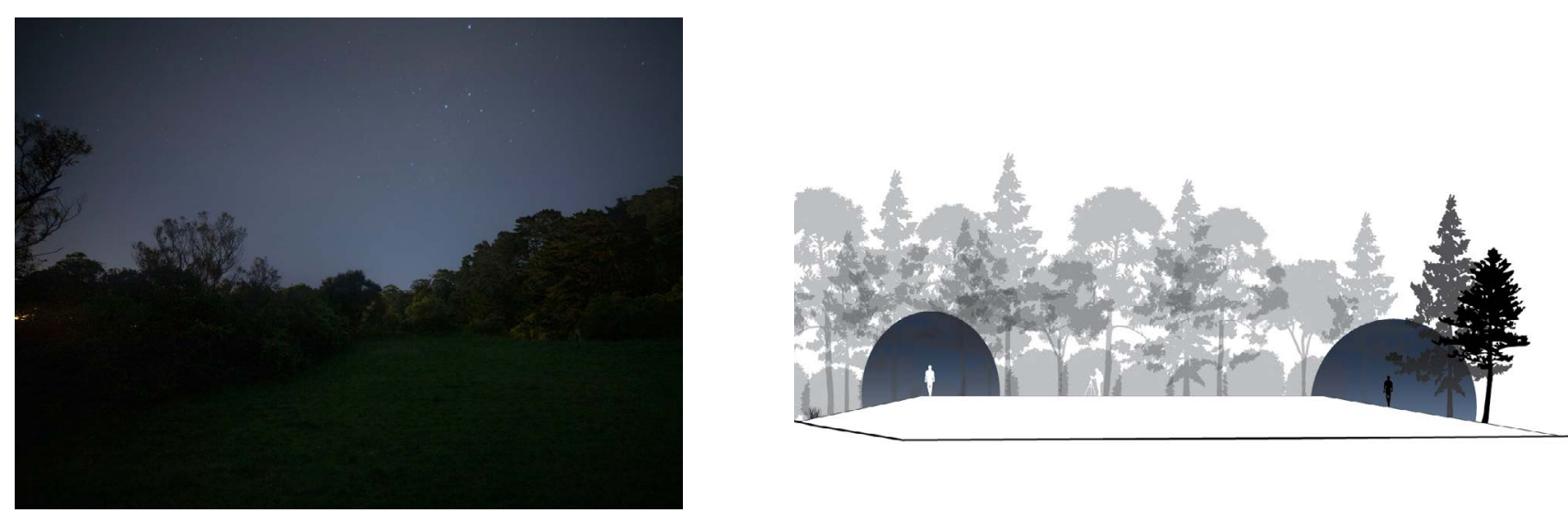

The dense/wild appearance of the vegetation was unpleasant

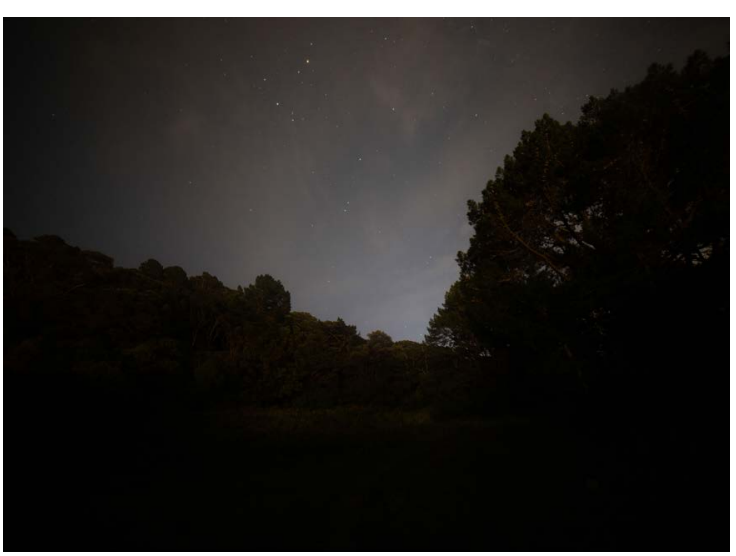

Wild vegetation close to the path

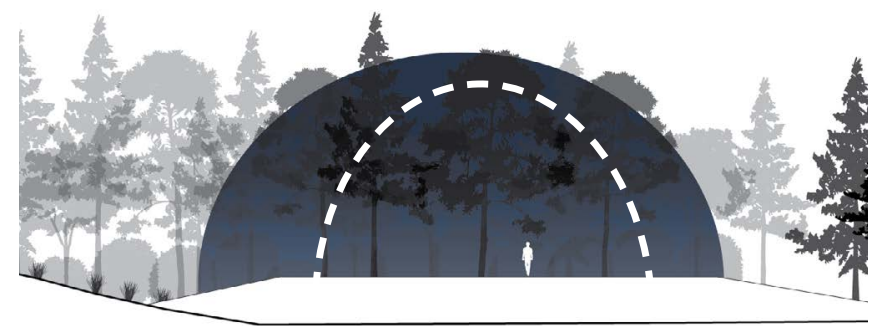

There was however a really good view of the stars which provided comfort in the space
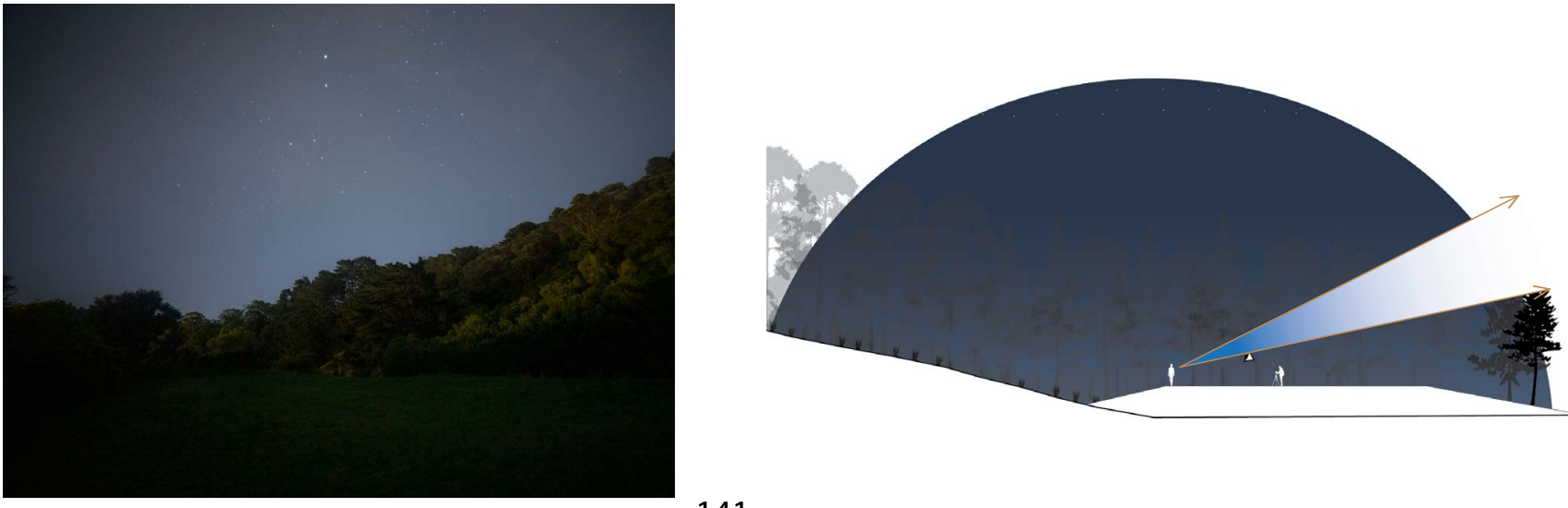


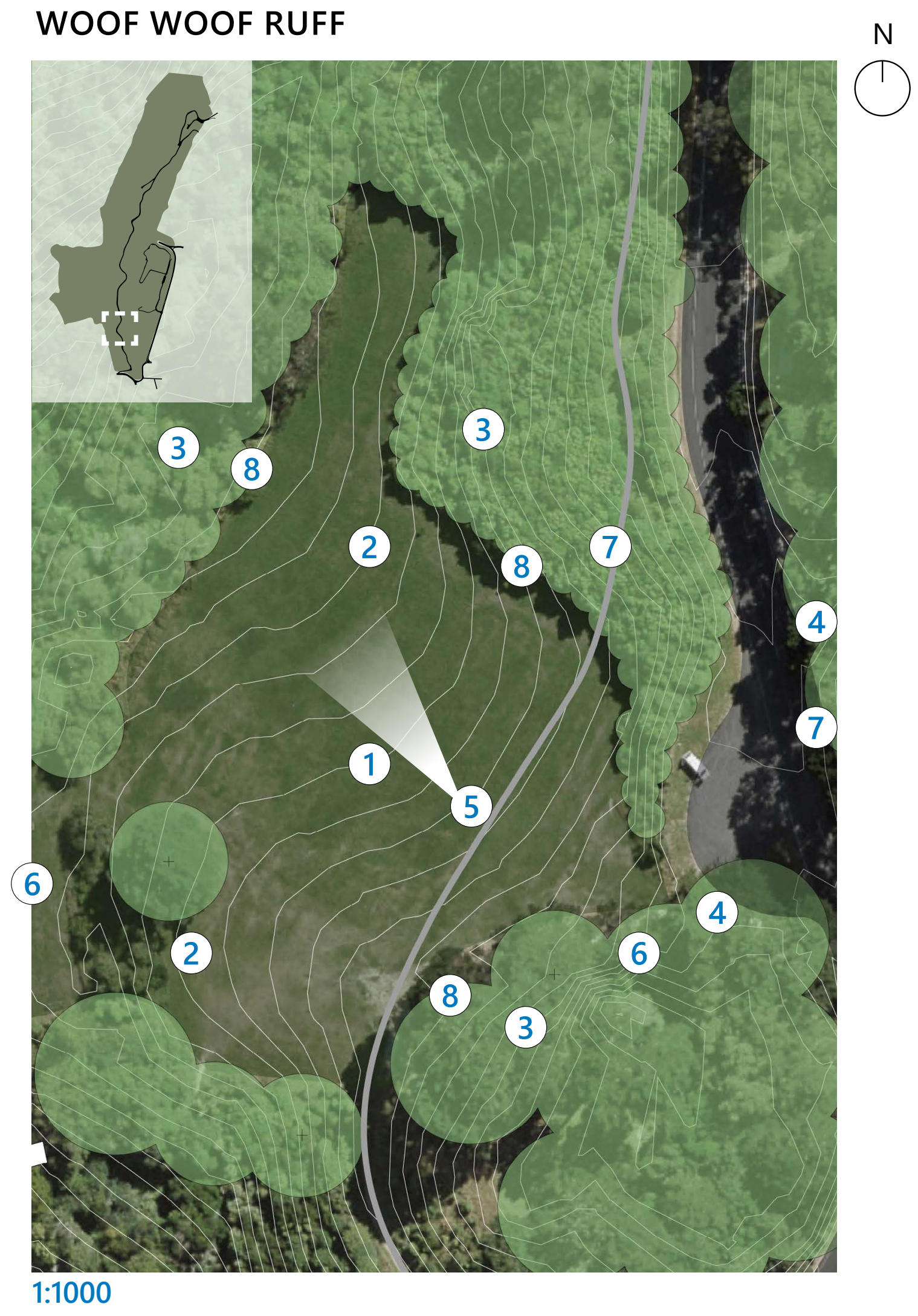




\section{Day Experience}

1. The site consisted of a very large open space with the vegetation edges spread very far apart

2. The sites slope drops away into Newtown affording a wide viewshaft over the surrounding environment

3. There was surrounding vegetation on 3 sides of the space enclosing it,

4. The south east edge of the space was marked by a large tall tree line

\section{Night Experience}

5. The absence of the vegetation afforded stargazing to be very relaxing as your immediate surroundings were visible

6. The glare from Newtown provided a visual marker to connect to when fears of concealment crept in

7. The high waisted canopies allowed glare from Kilbernie to enter into the space

8. The edges of the space were avoided due to the dense vegetation

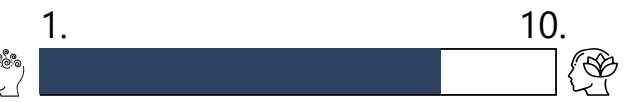

Overall comfort level

1.

10.

Amount of Illuminated Area

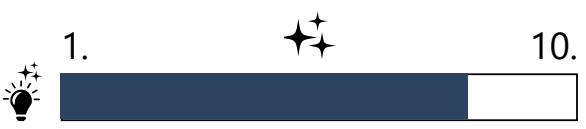

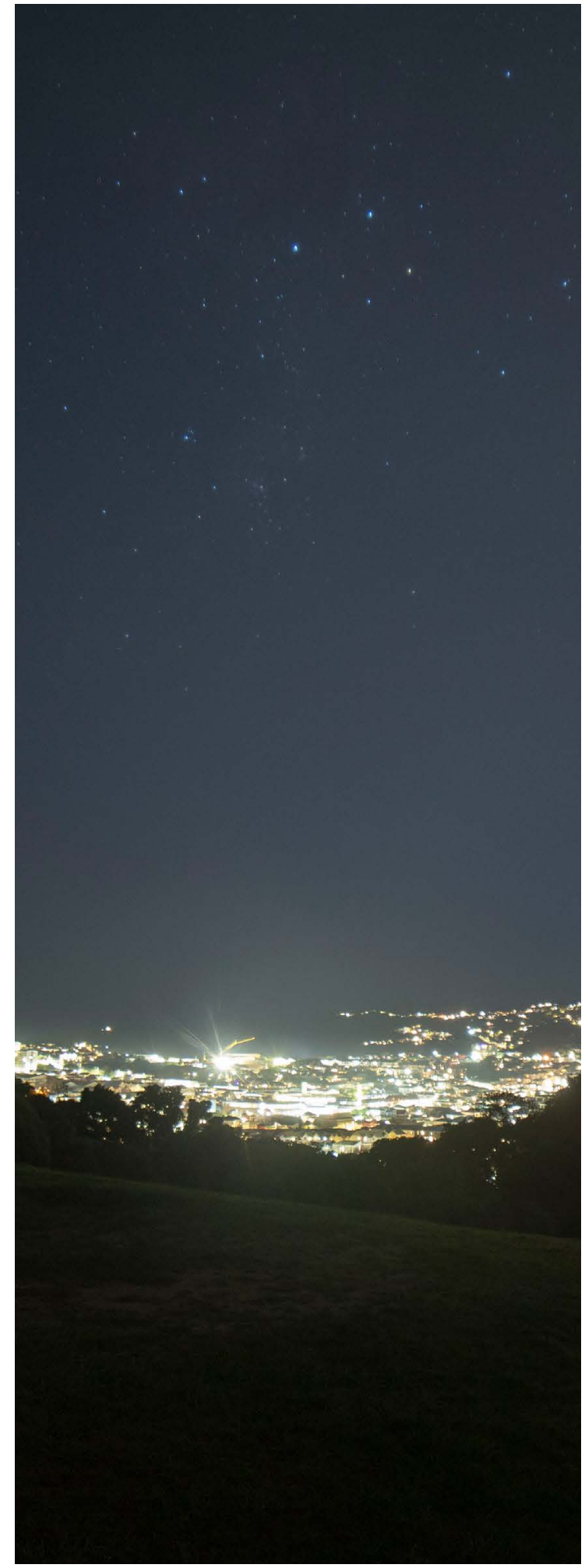

4.16 Light Glare above Newtown 
Large open space with vegetation lines spread far apart
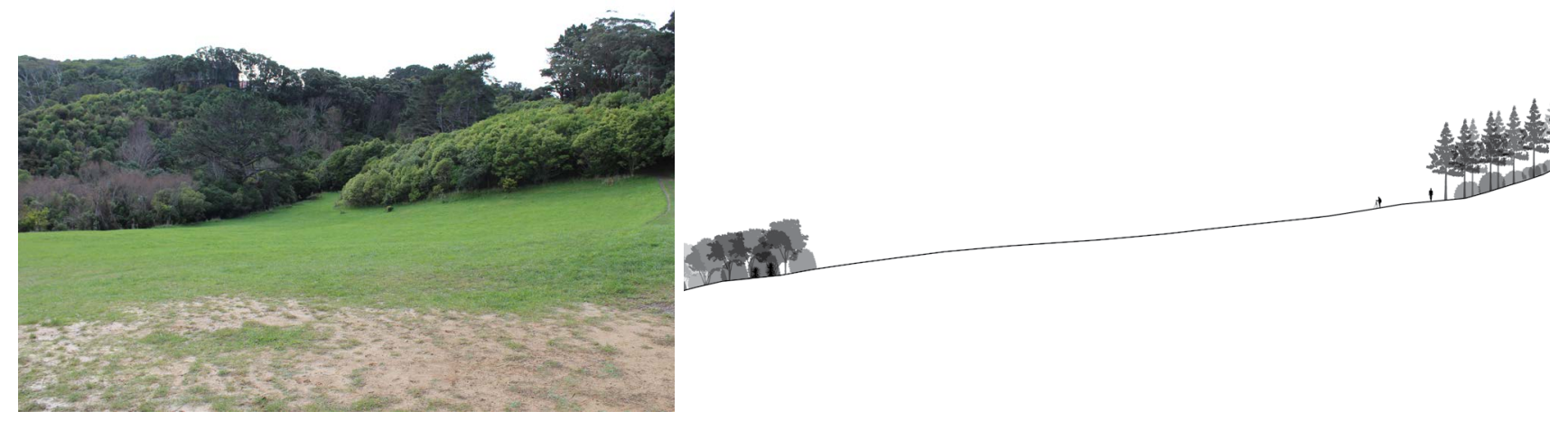

Wide viewshaft over the surrounding environment
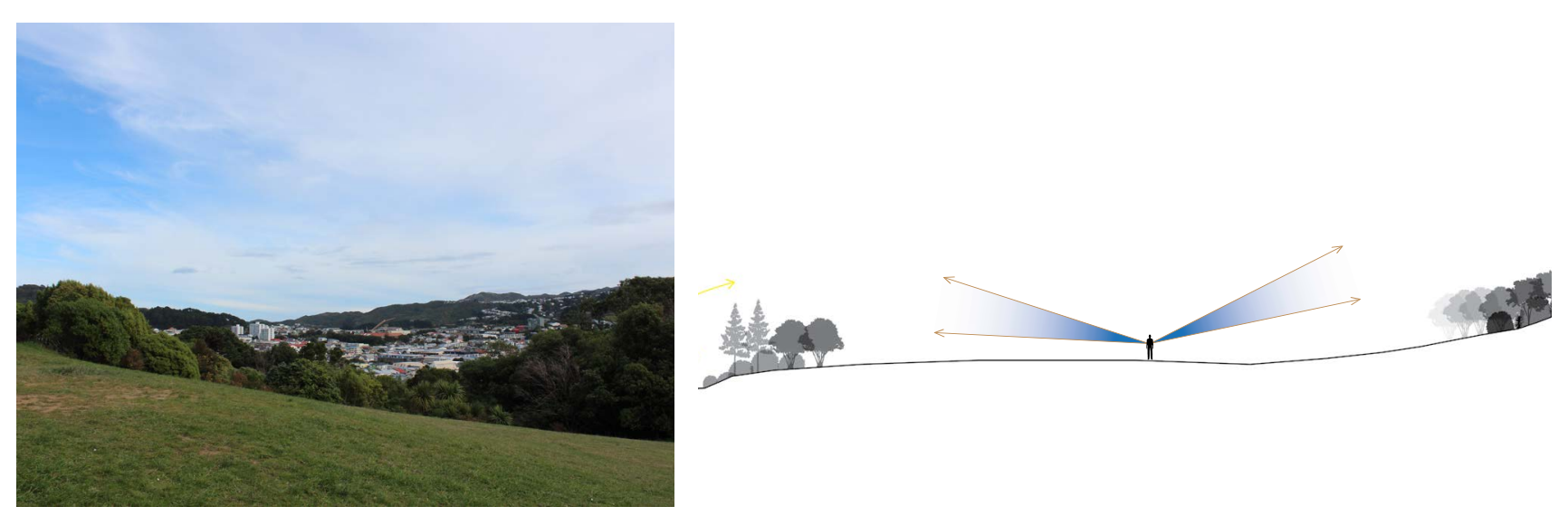

Tall tree line on east / south edge
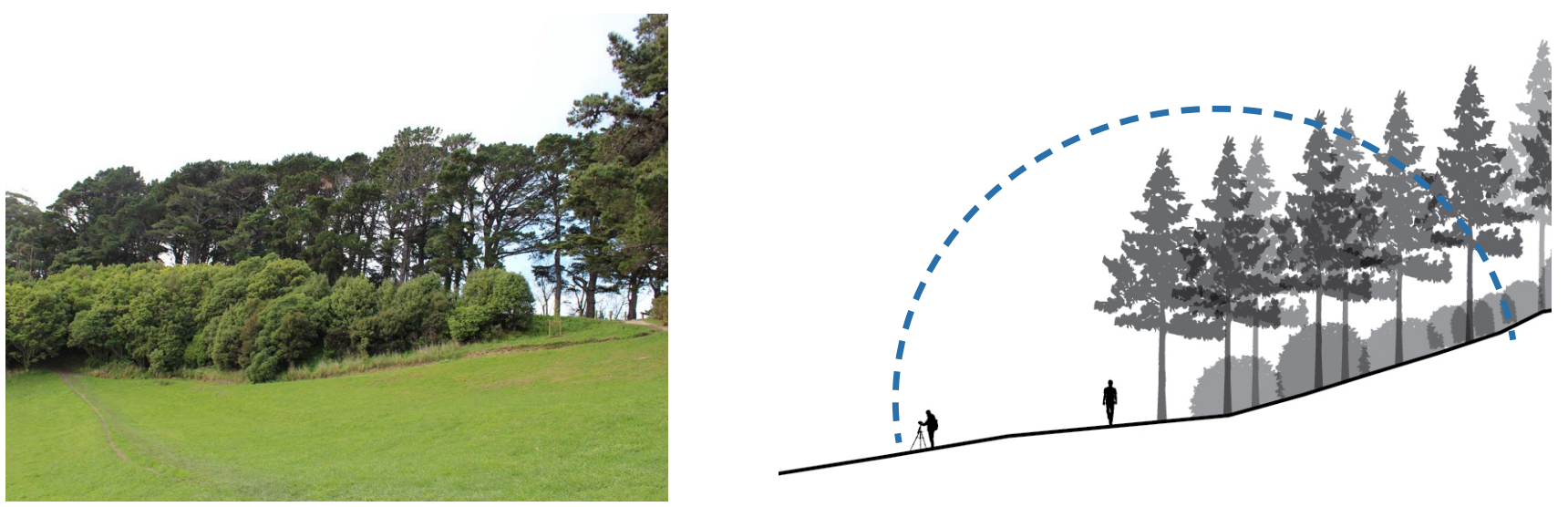

Big surrounding vegetation line on all 3 sides
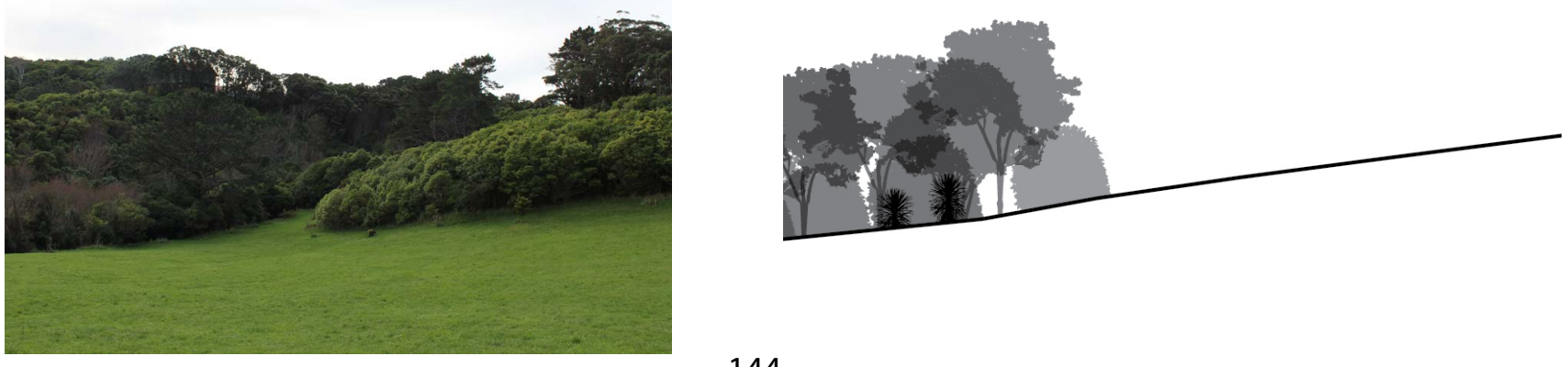
Absence of vegetation in the immediate surroundings was relaxing when looking at the stars
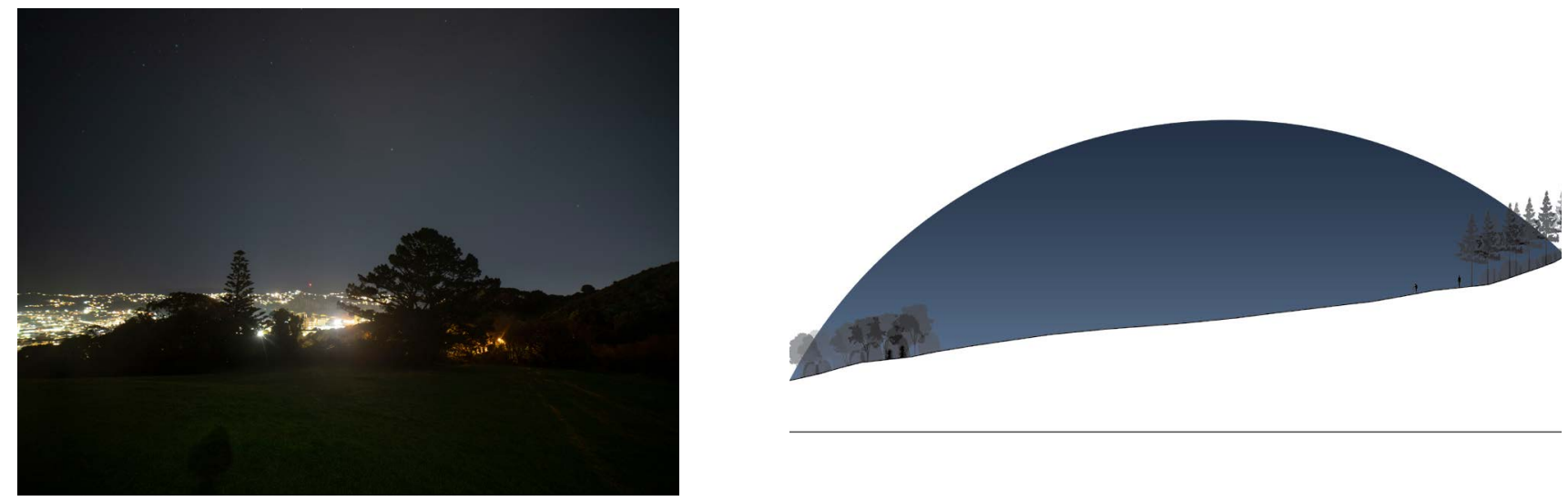

Drawn to glare coming from Newtown, provided comfort having that light source
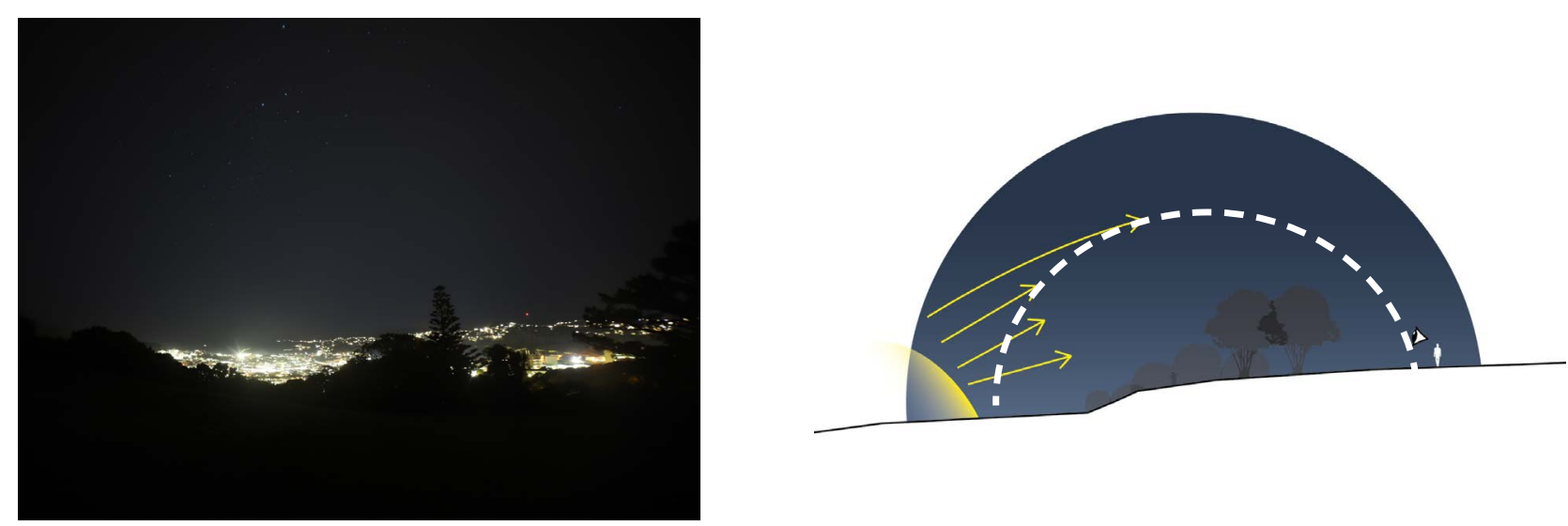

High waisted canopies allowed glare from eastern suburbs to enter
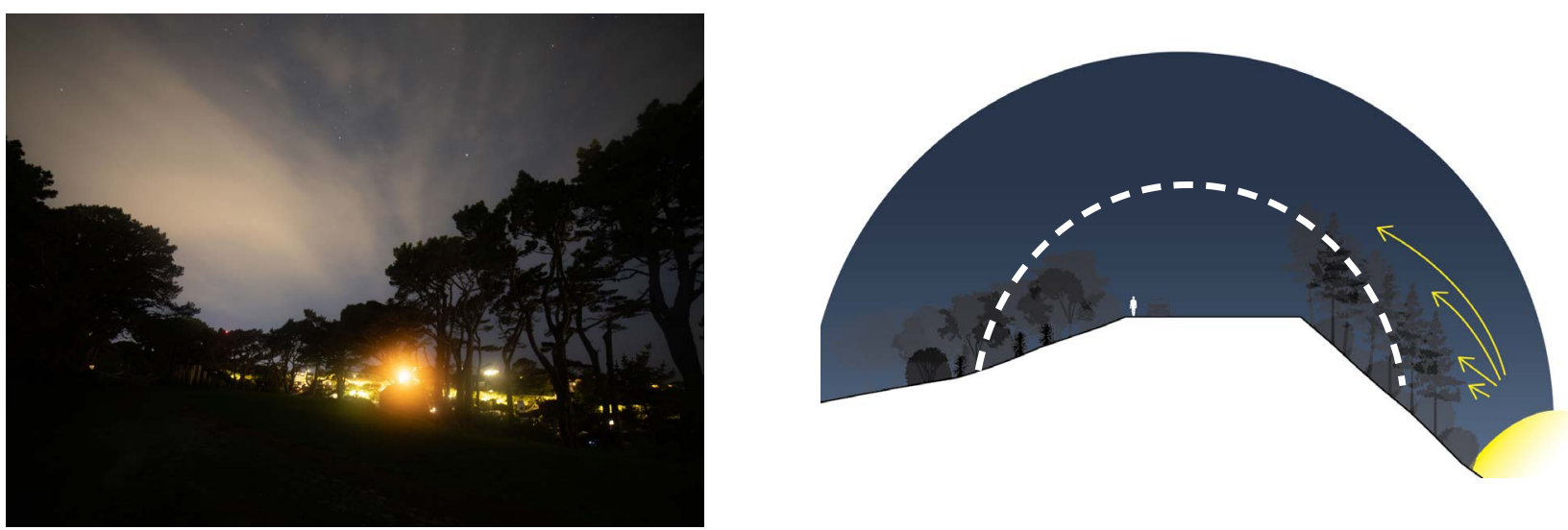

Avoided edges of the space due to the dense tree line

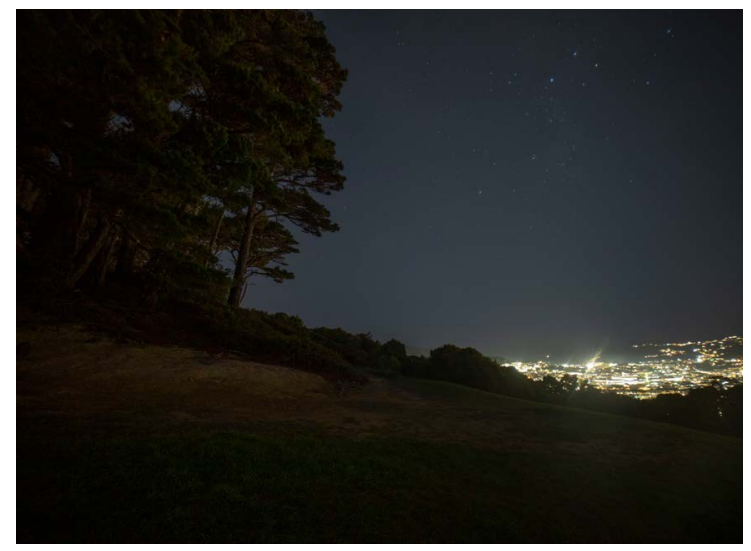




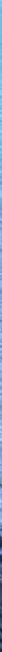

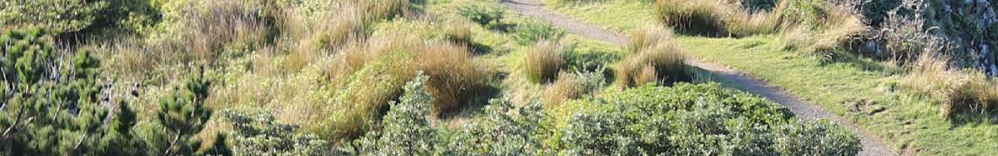

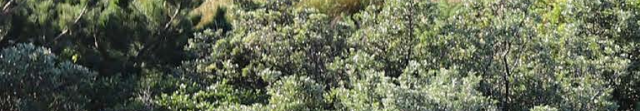

$13+1+4+25$

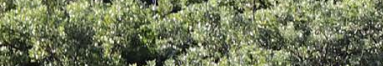

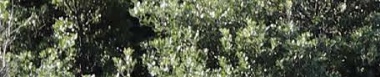

\section{SOUTH}

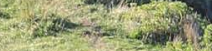

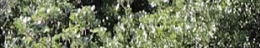

\section{$2+2$

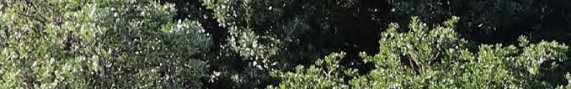 \\ 17.}

(2)

1

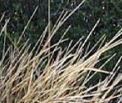

$-2+2-3$

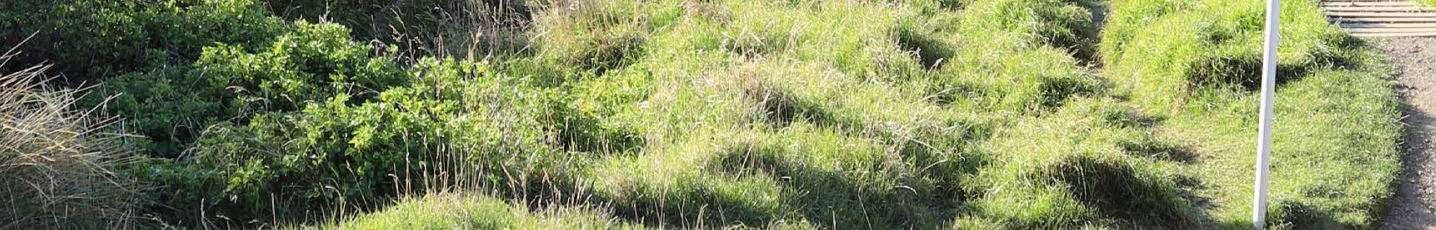

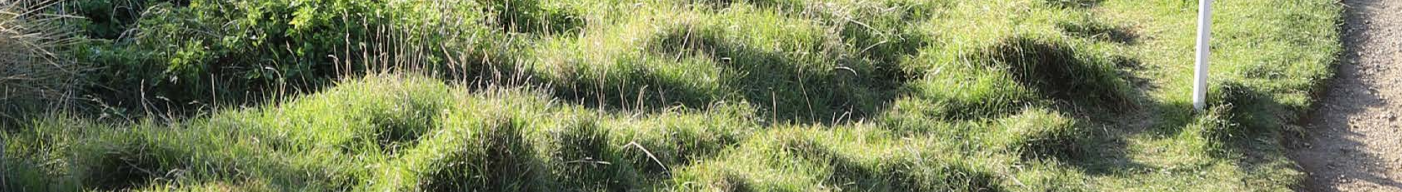

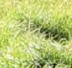

$-2-6-2 x^{-2-3}$

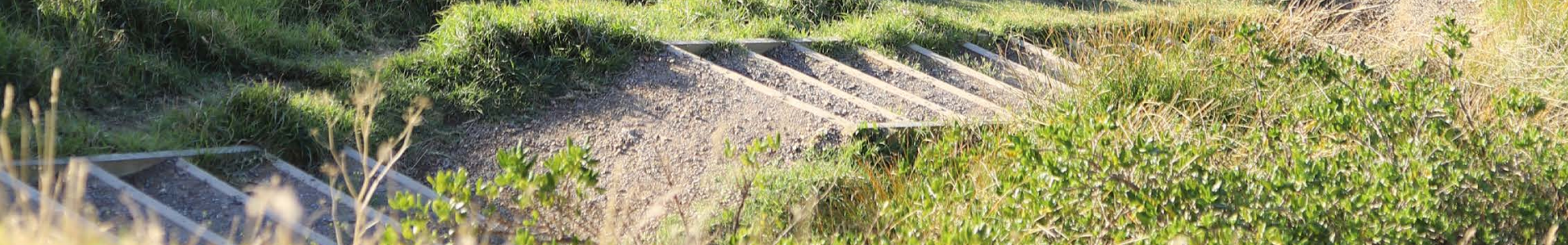




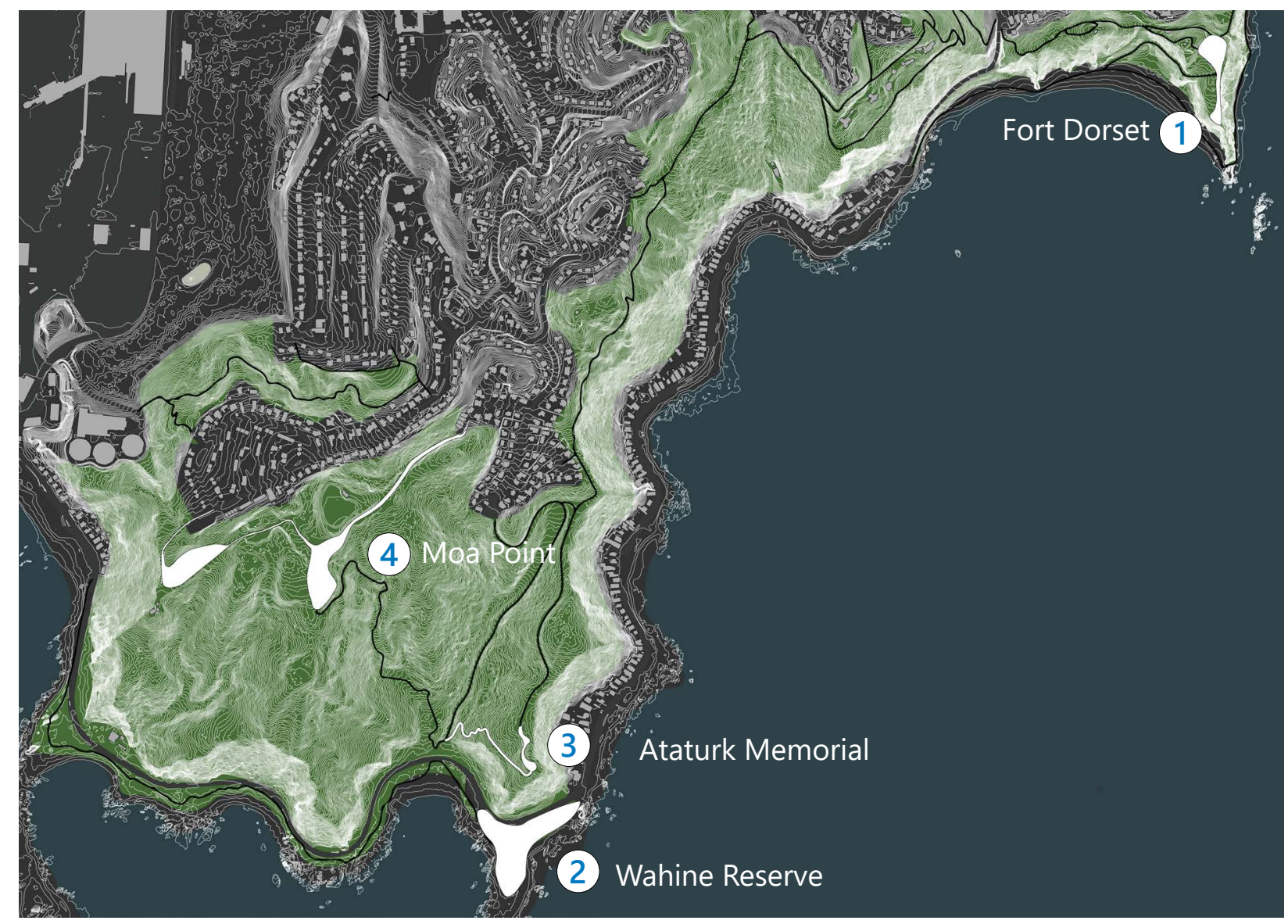

\subsection{East South Coast}

The fieldwork on the South Coast involved traveling between Fort Dorset / Oruaiti Reserve and Moa Point during the day and at night. To find spots of interest, the eastern walkway was used as well as driving along the coast. Perceived comfort in the spaces and the quality of stars were recorded.

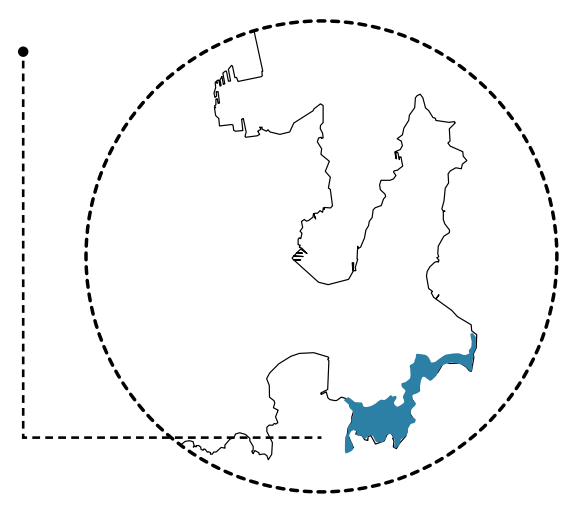




\section{ORUAITI RESERVE / FORT DORSET}

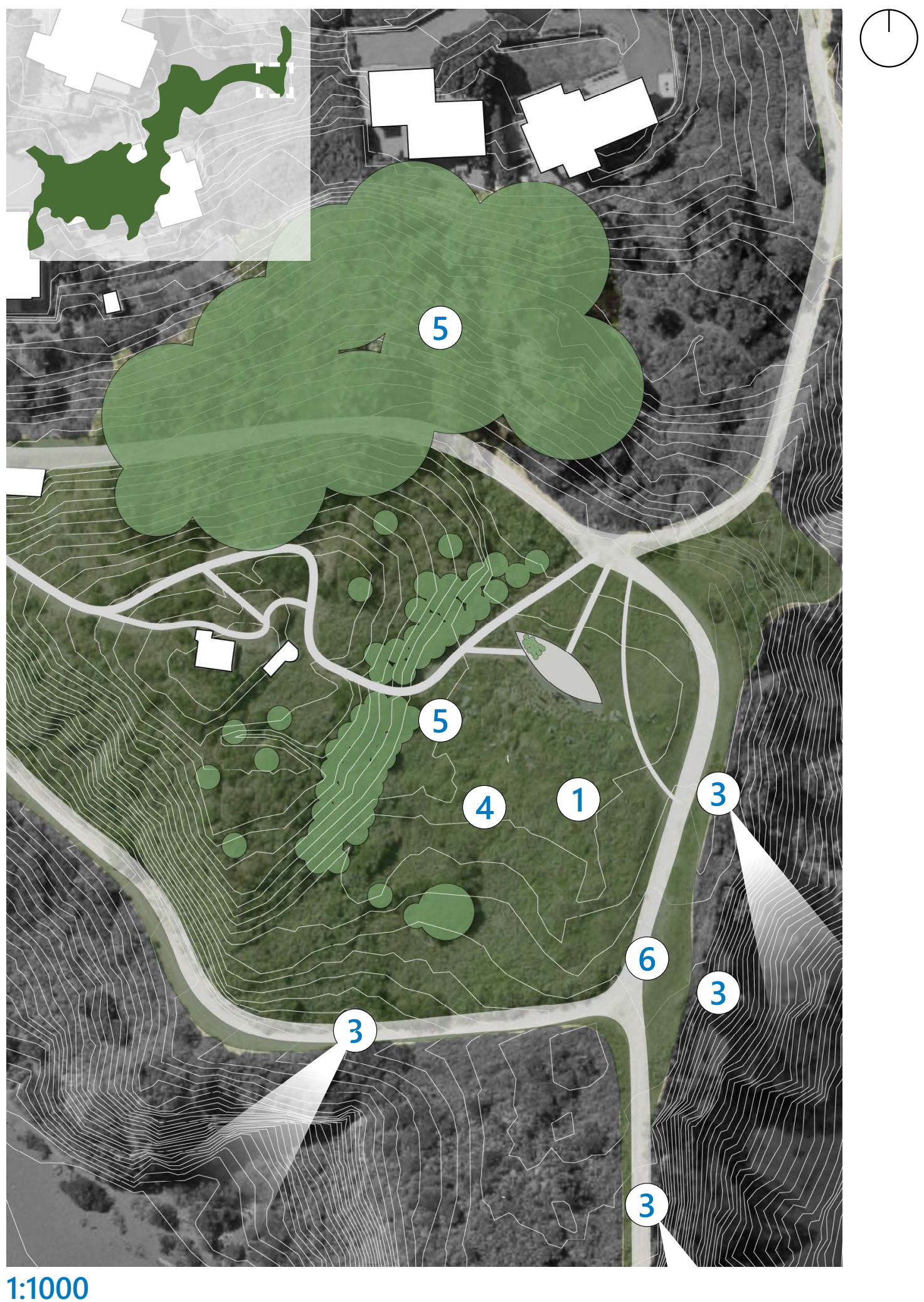




\section{Day Experience}

1. Fort Dorset consisted of a large open area at a high elevation on the edge of Seatoun, a residential suburb

2. The area during the day is heavily used by runners, families, couples, elderly and people on their daily walk

3. It offers beautiful expansive views of the southern coast, but is very exposed to the harsh winds flowing across the Cook strait

4. The open space increases prospect and gives a wide range of view

\section{Night Experience}

5. The silhouettes of the surrounding vegetation at night are quite frightening but are beneficial as they shield the space from the light glare coming from the streets in Seatoun and the city beyond

6. Away from the tree line the open space was very calming.

7. The Milky way was able to be seen as well as other celestial bodies. Taking these sights in relaxed the body and provided a sense of peace and clarity in the site

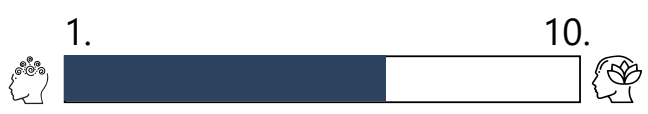

Overall comfort level

1.

10.

Amount of Illuminated Area

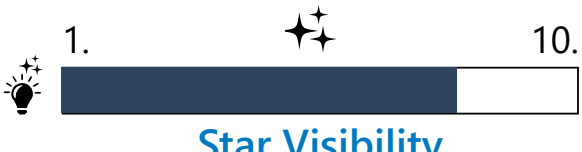

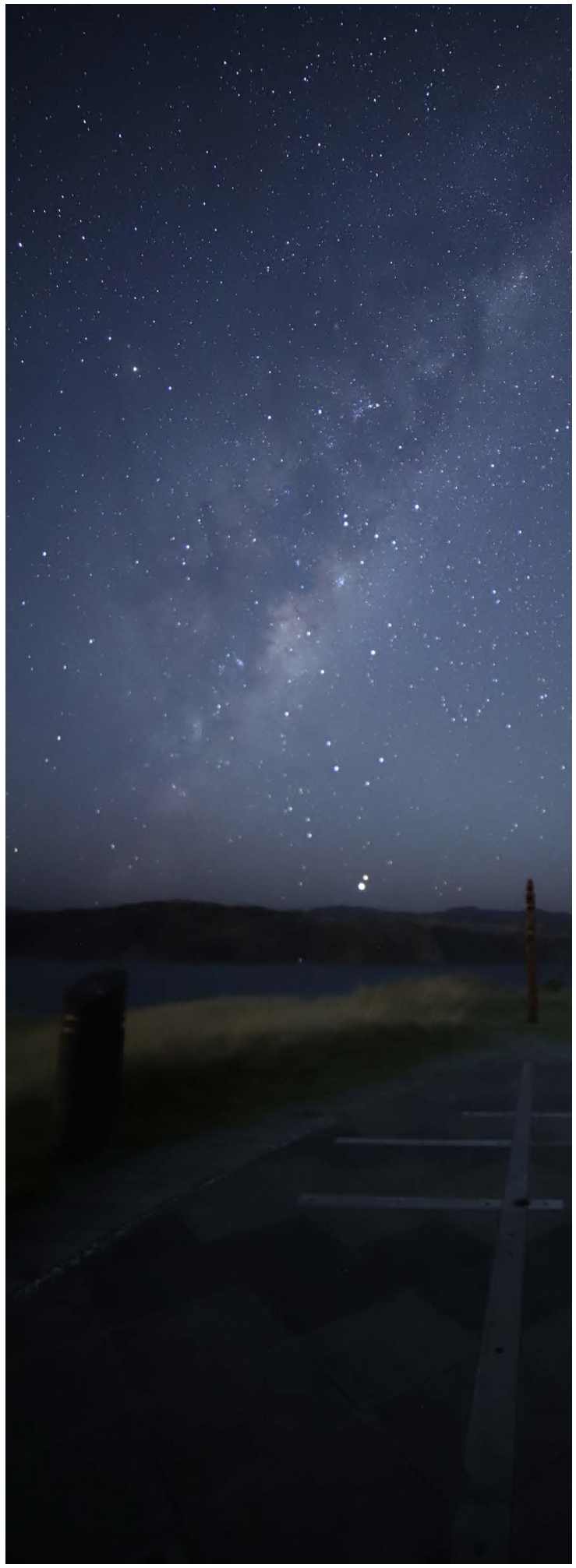

4.17 Milky Way at Fort Dorset 
Variety of vegetation
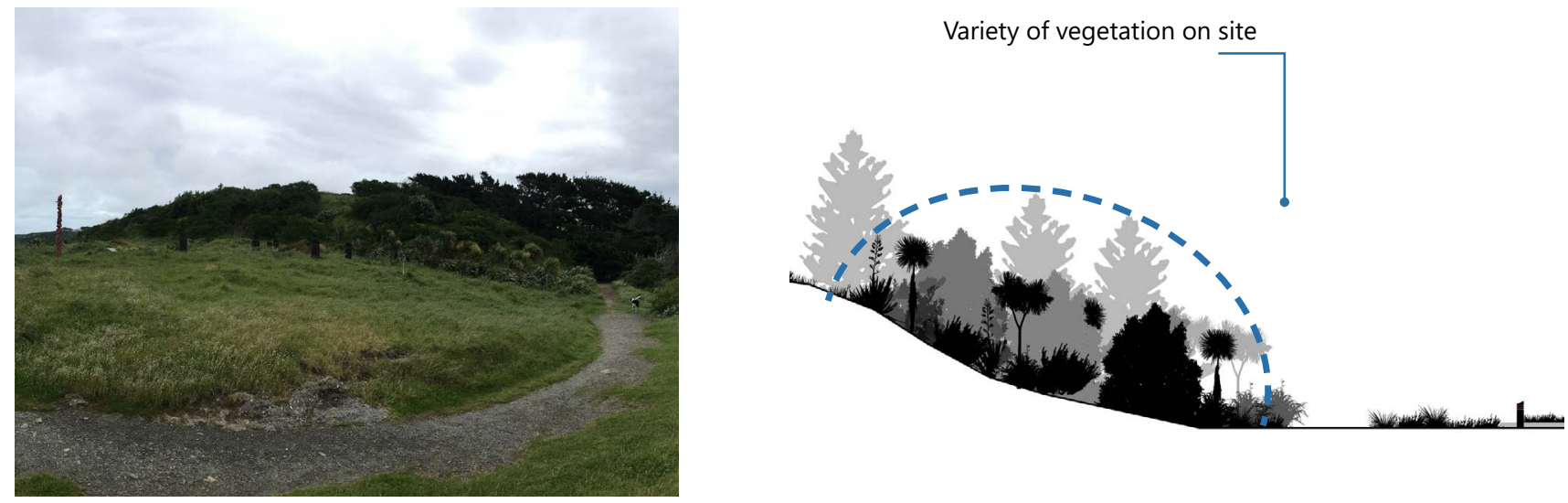

\section{Edge of a residential zone}

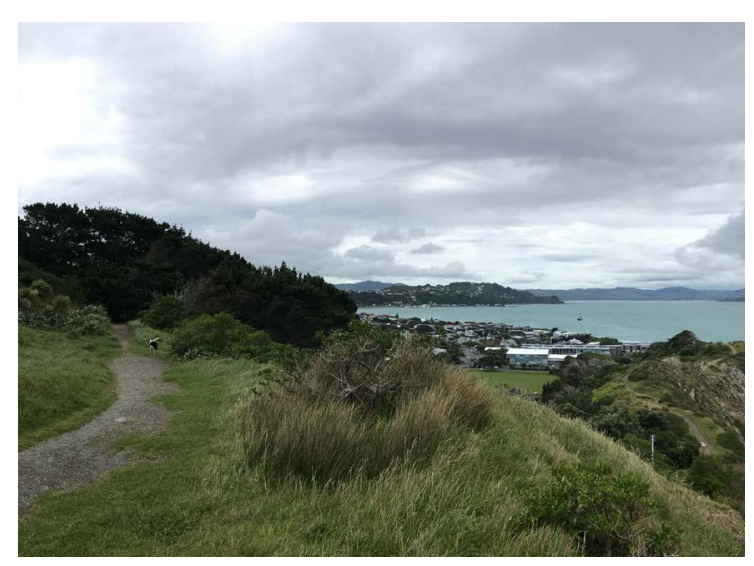

Close to suburbs provides easy access for residents

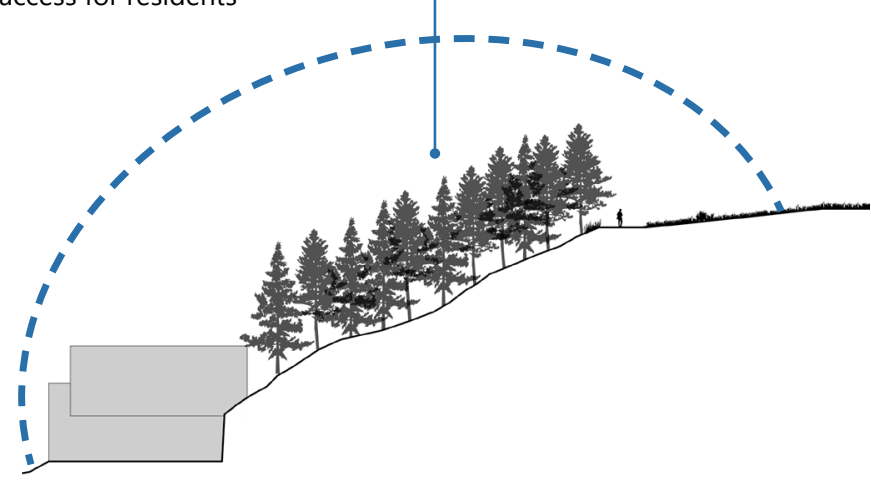

Open space leaves it exposed to southerly winds
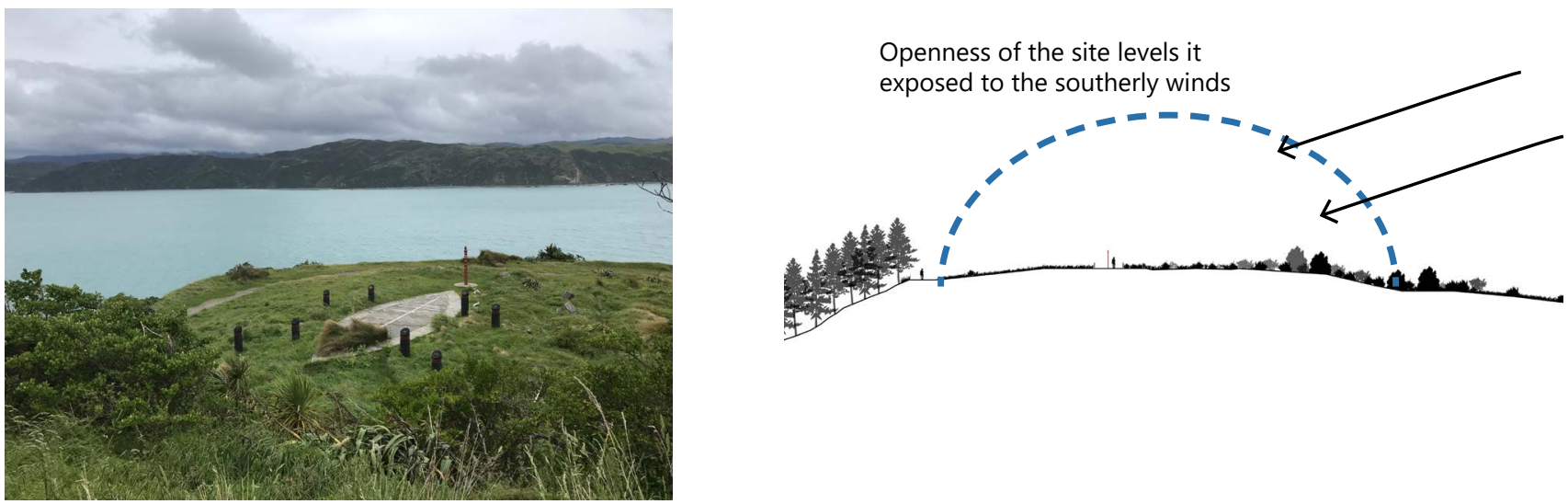

High Elevation increases prospect and gives wide range of view
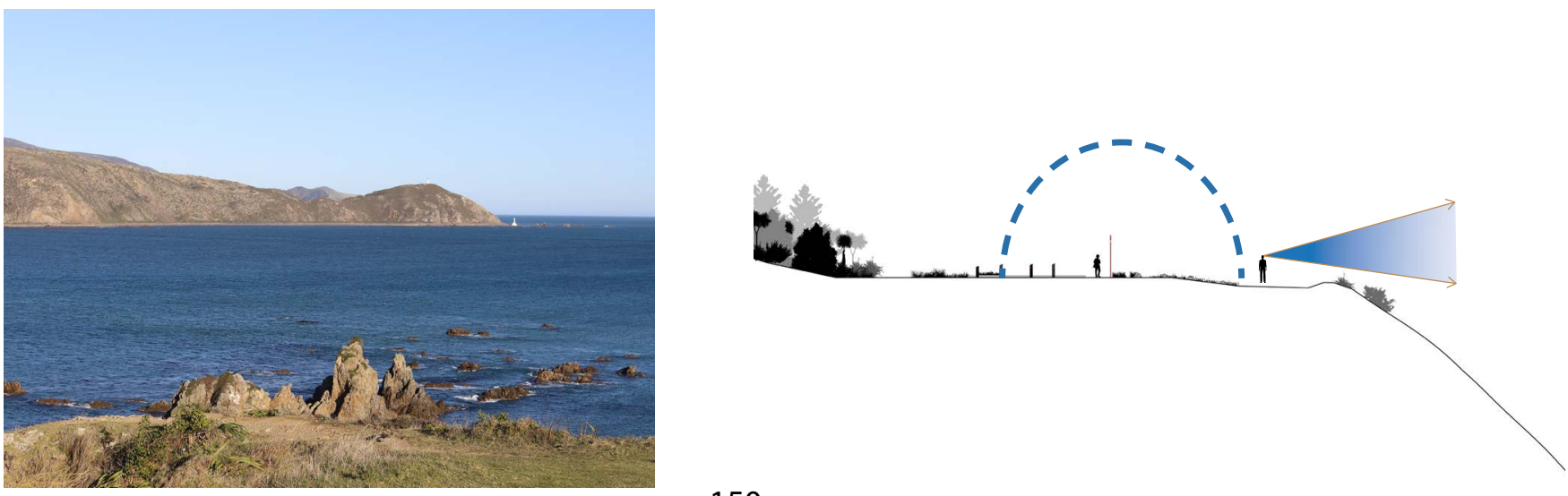
Surrounding vegetation is scary with all the different silhouettes but provides a barrier to the light coming from Seatoun

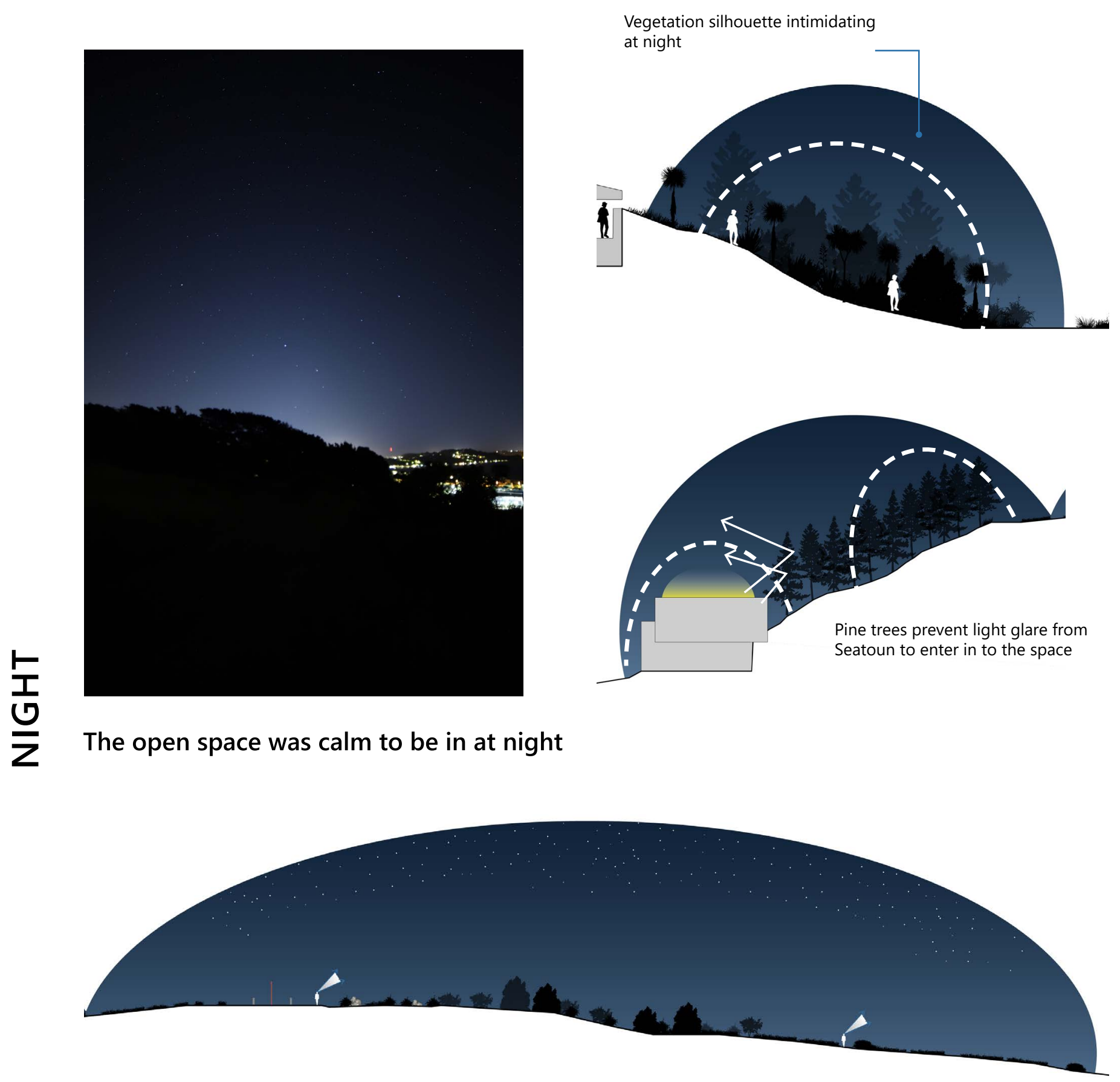

Calm atmosphere at night due to sight of the milky way and stars
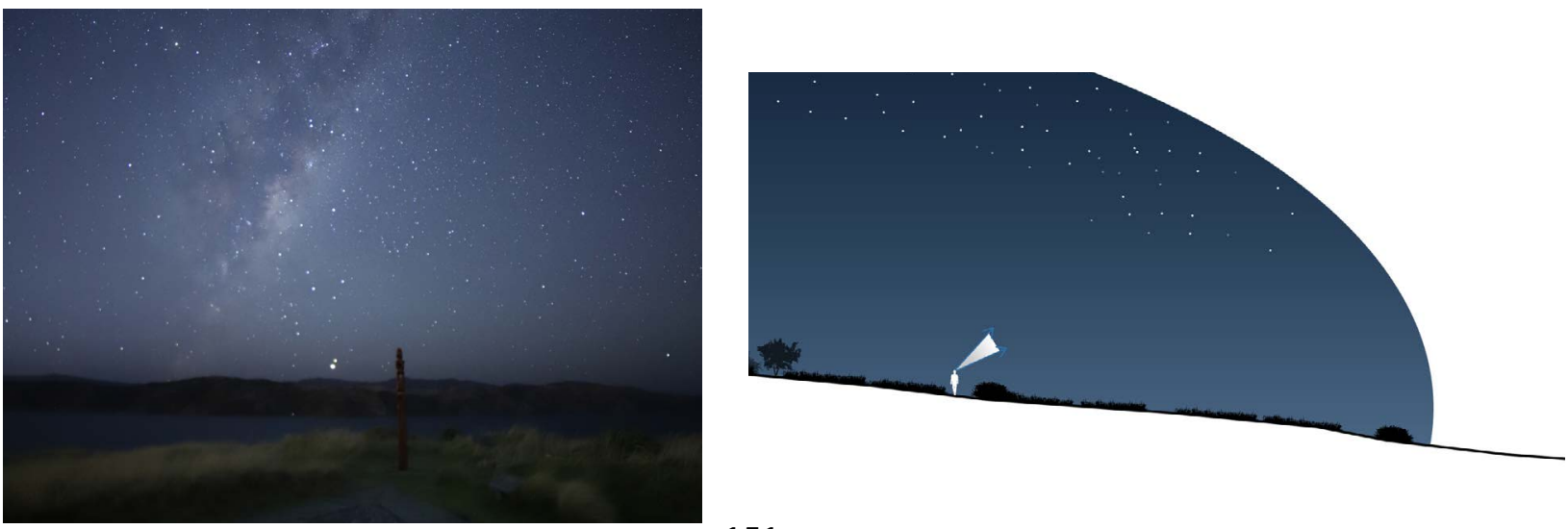


\section{WAHINE RESERVE}

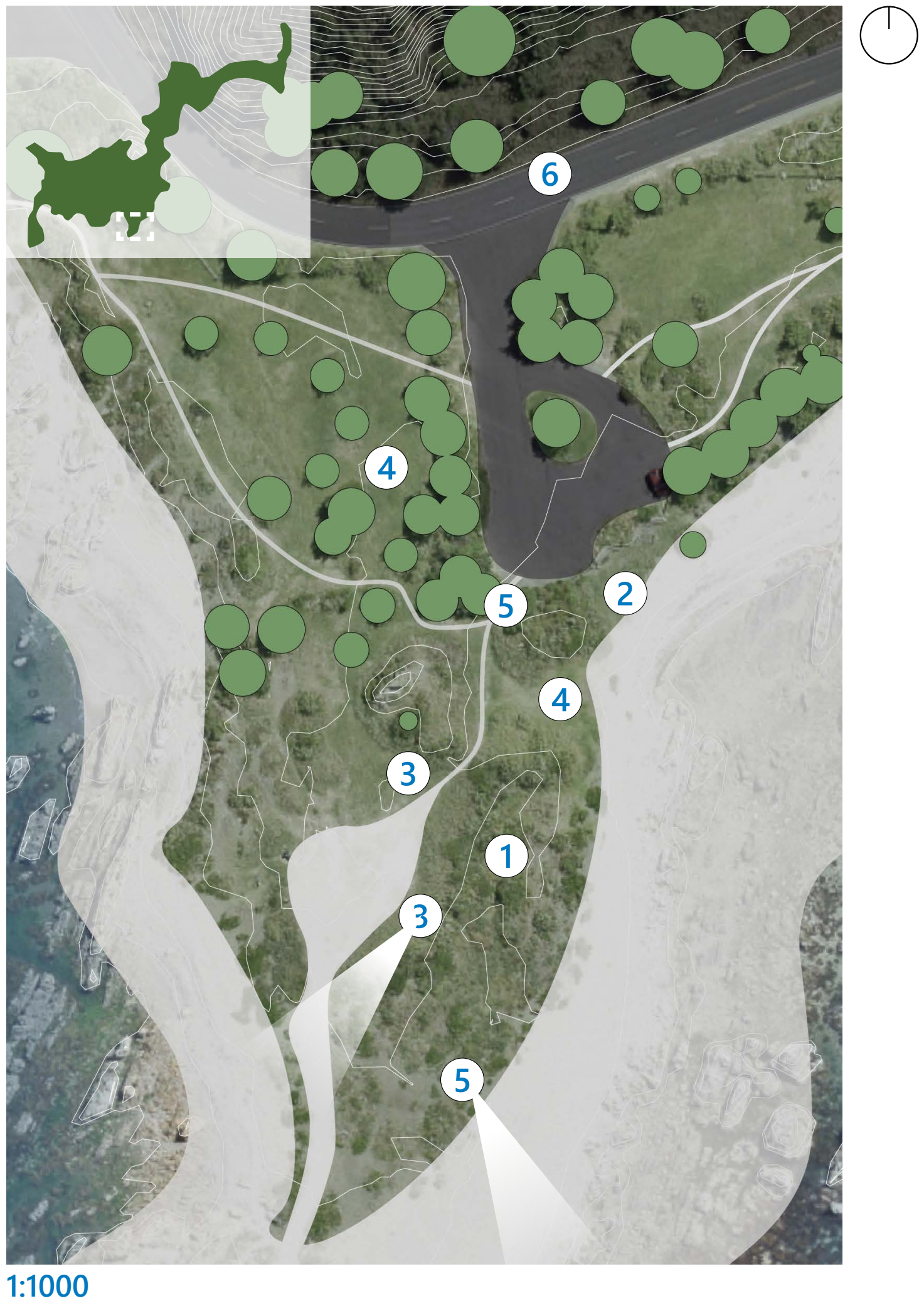




\section{Day Experience}

1. A large, flat, open space on the waters edge dotted with small vegetation patches

2. Being by the sea and taking in the sounds, smells and taste of the ocean was very relaxing

3. The sites openness left it exposed to the southerly winds, which impaired the relaxing atmosphere.

\section{Night Experience}

4. Walking through the center of the space was avoided at night due to large bushes. These were quite dense and was frightening walking past them

5. Being in the open areas by the water was very calming especially with the clear view of the milky way and stars in front.

6. The surrounding hillside sheltered the space from surrounding light pollution

1. ซํำ

10.

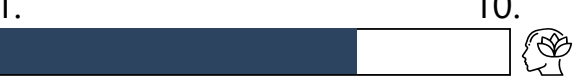

Overall comfort level

1.

Amount of Illuminated Area

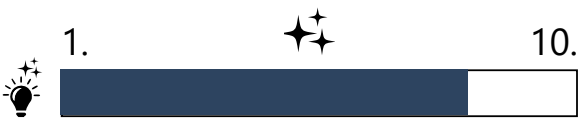

10.

Star Visibility

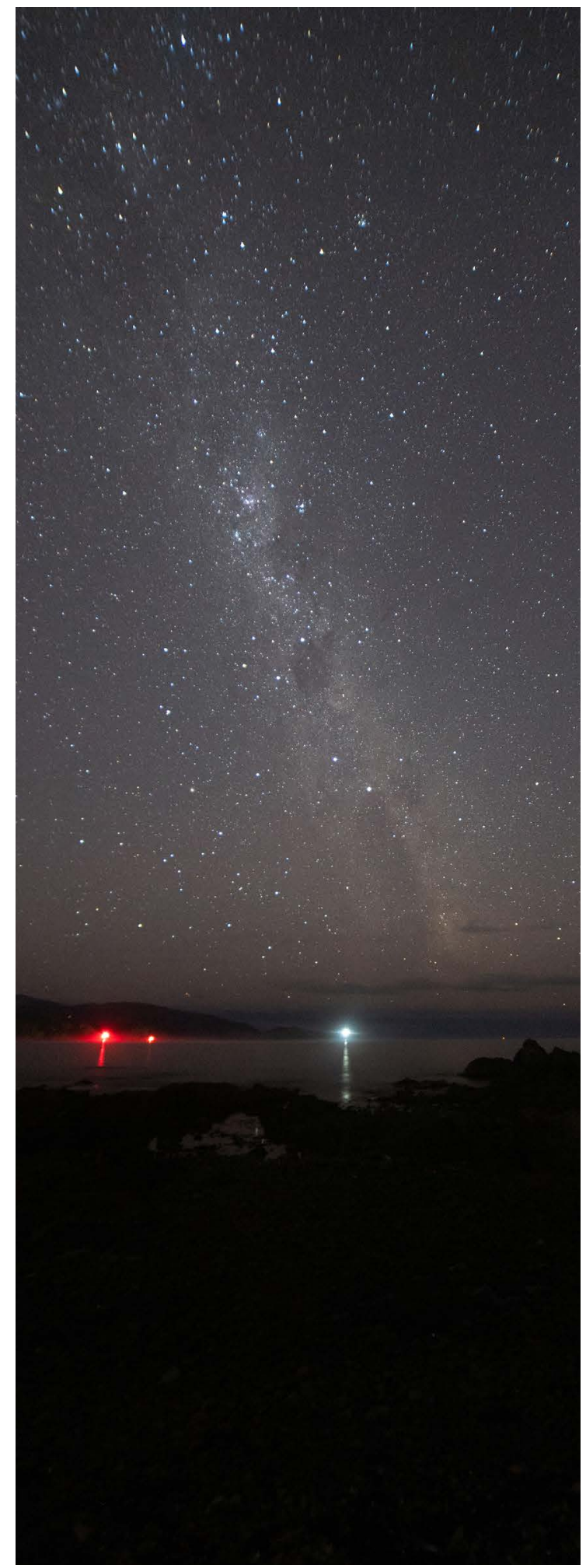

4.18 Milky Way above Wahine Reserve 
Flat open ground dotted with small vegetation patches
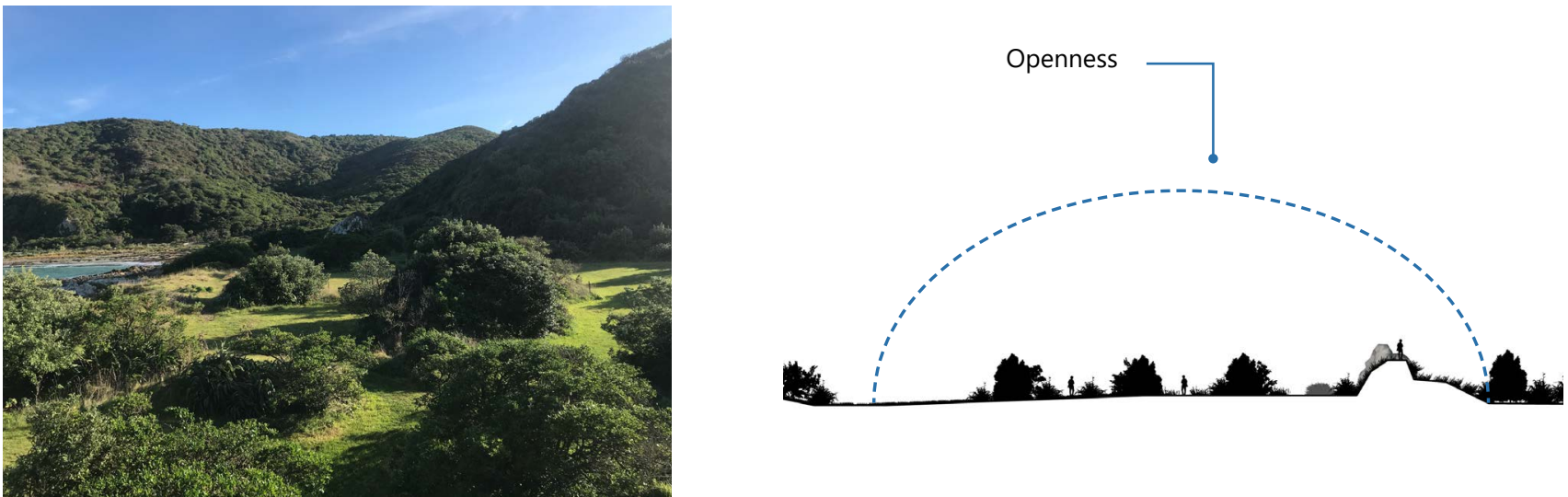

Being by the sea in an open area very calming
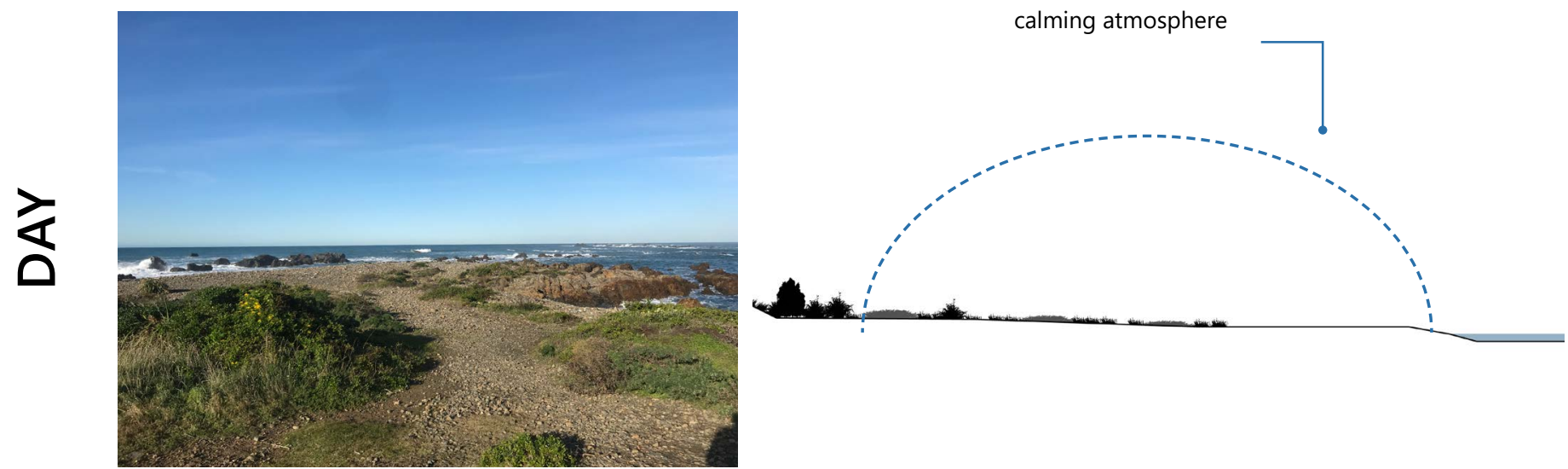

Very exposed to southerly winds
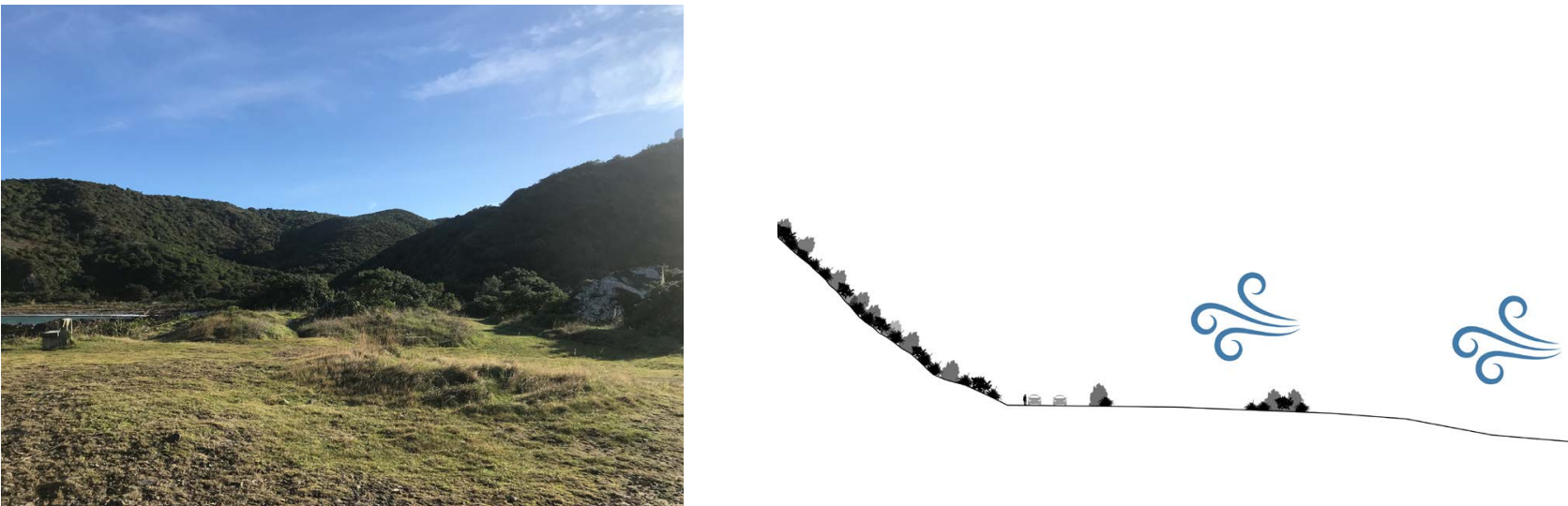
Walking through bushes increased fear of entrapment
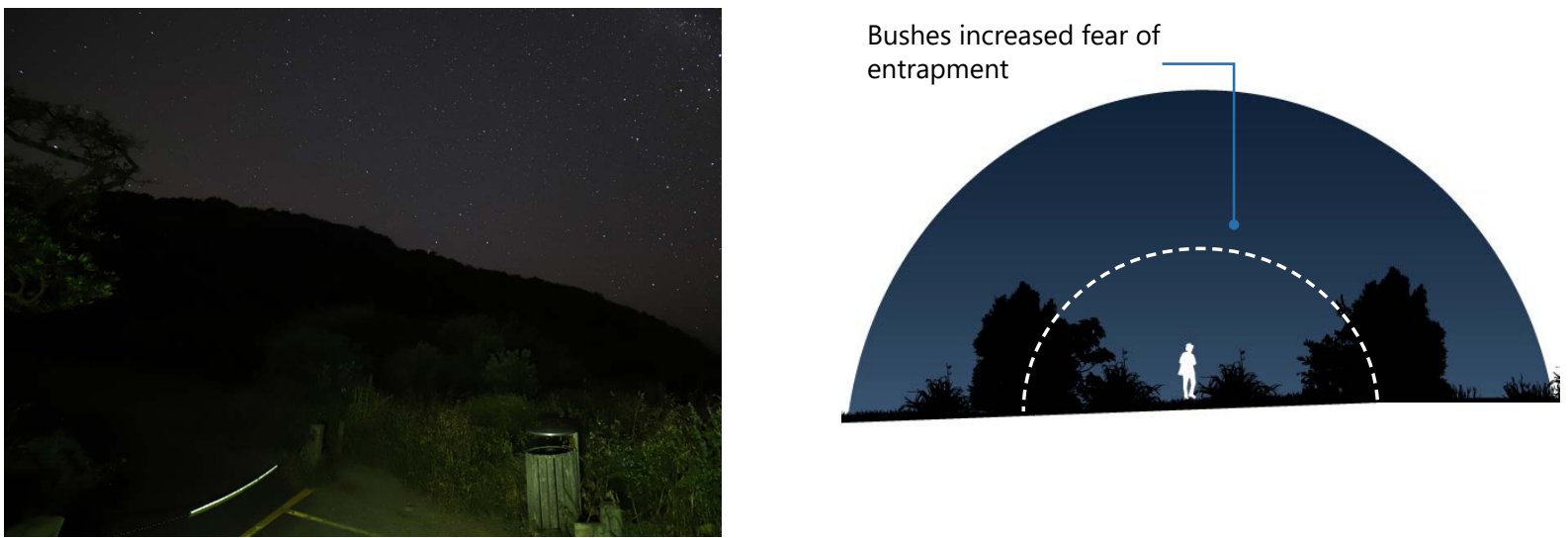

High Points and areas away from vegetation were calming
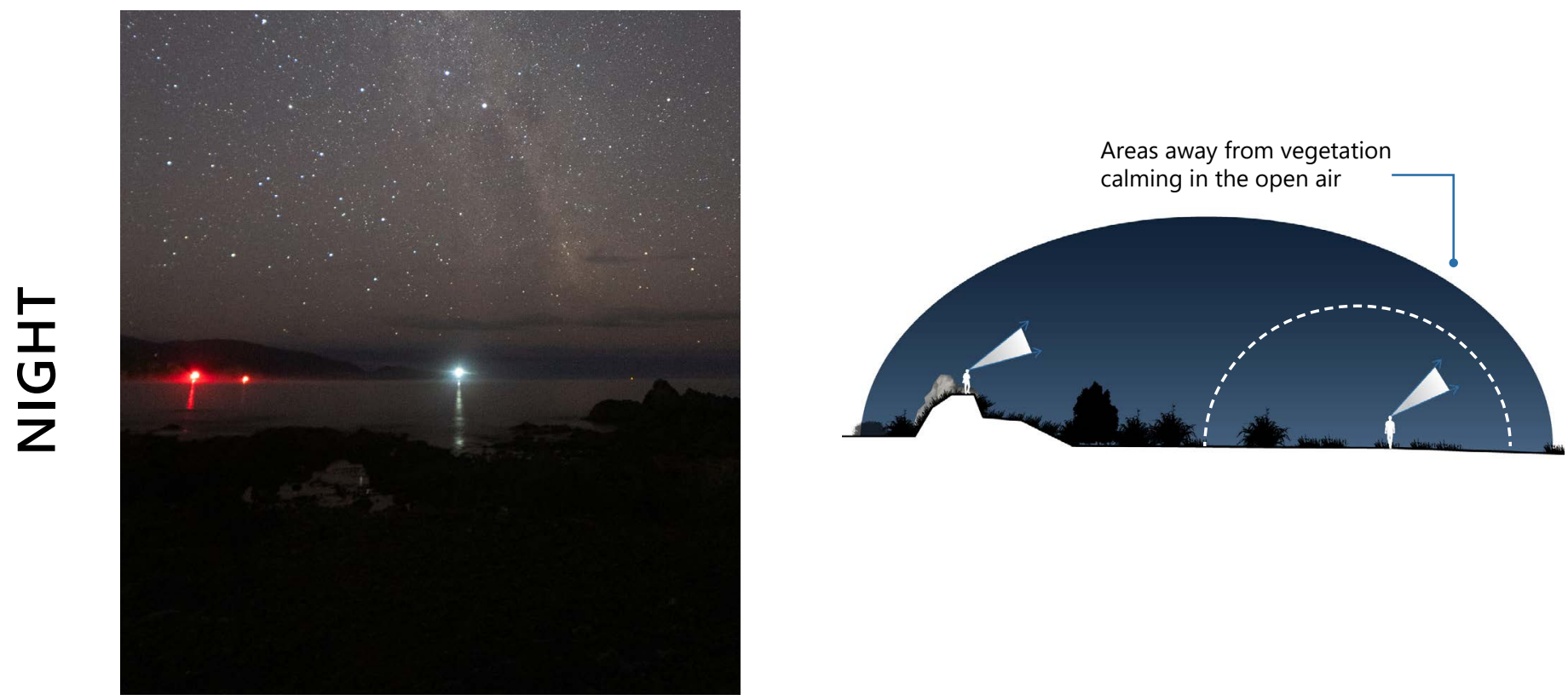

Protected from light pollution by hillside
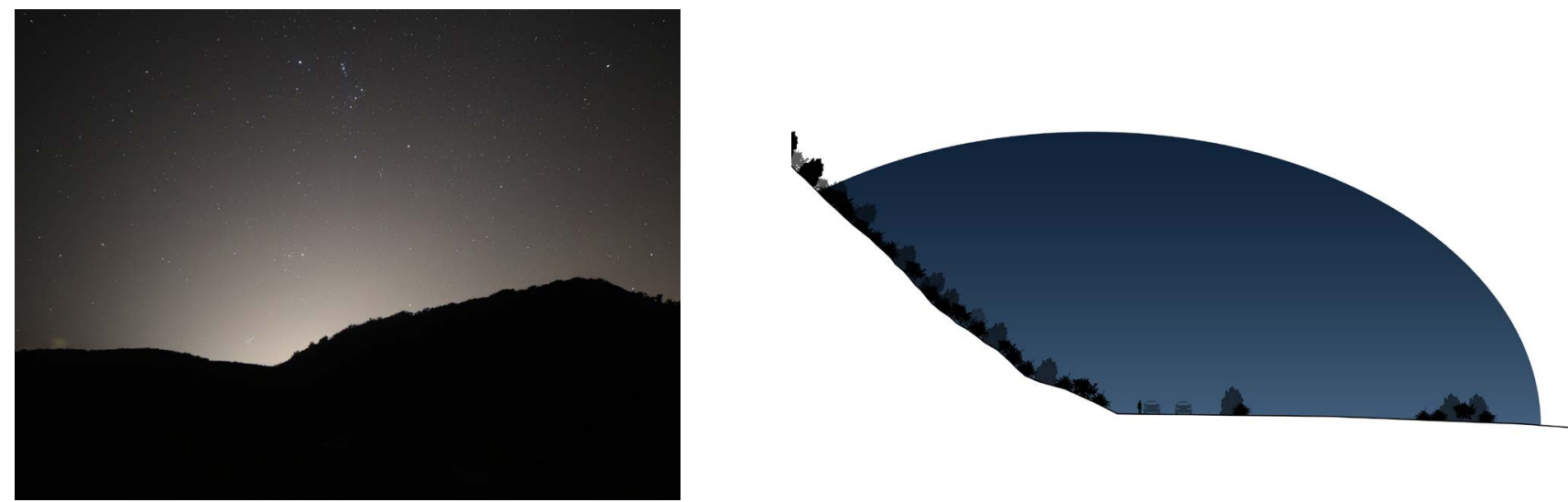


\section{ATATURK MEMORIAL}
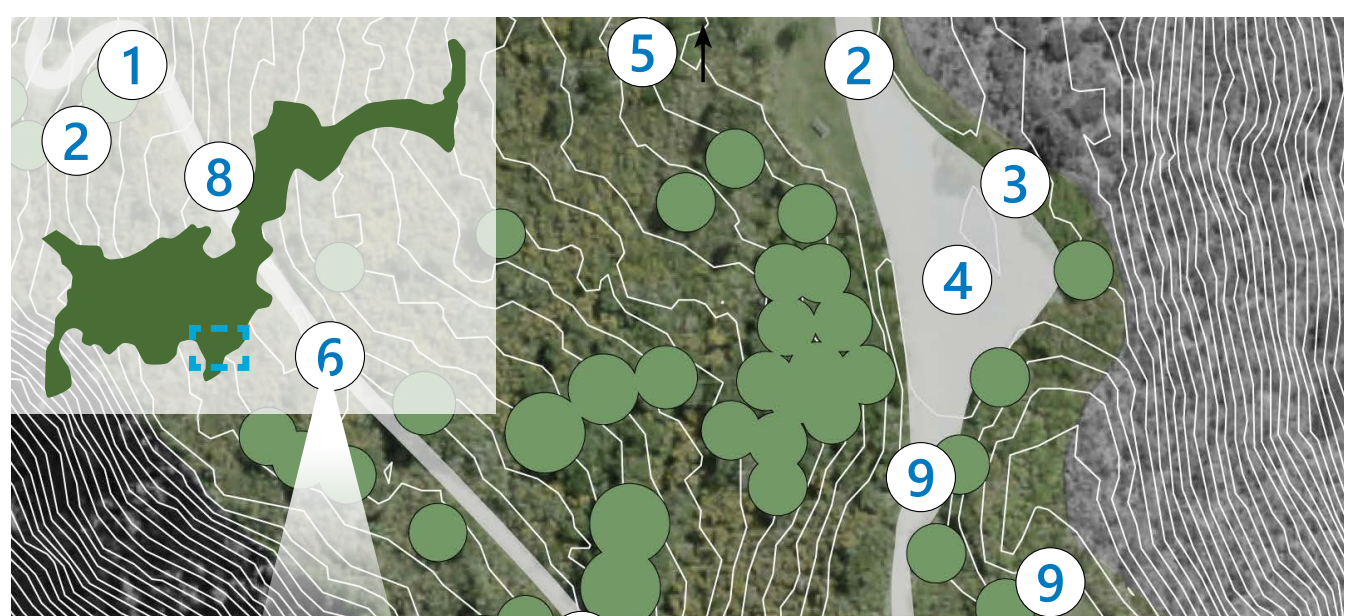

1
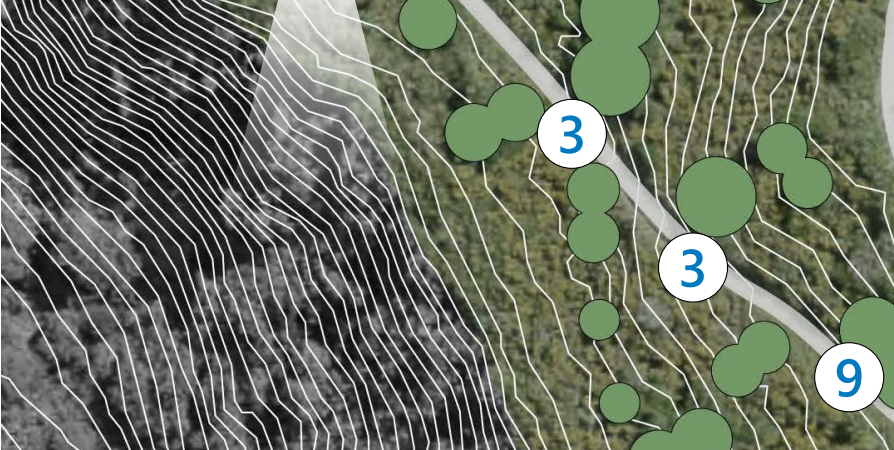

(4)

3

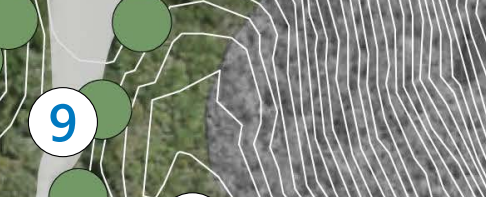

(9)

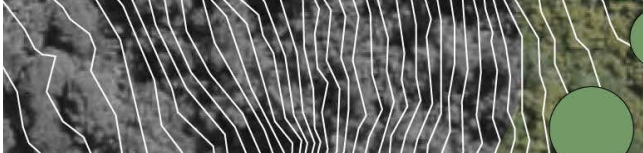

(5) 5 s.
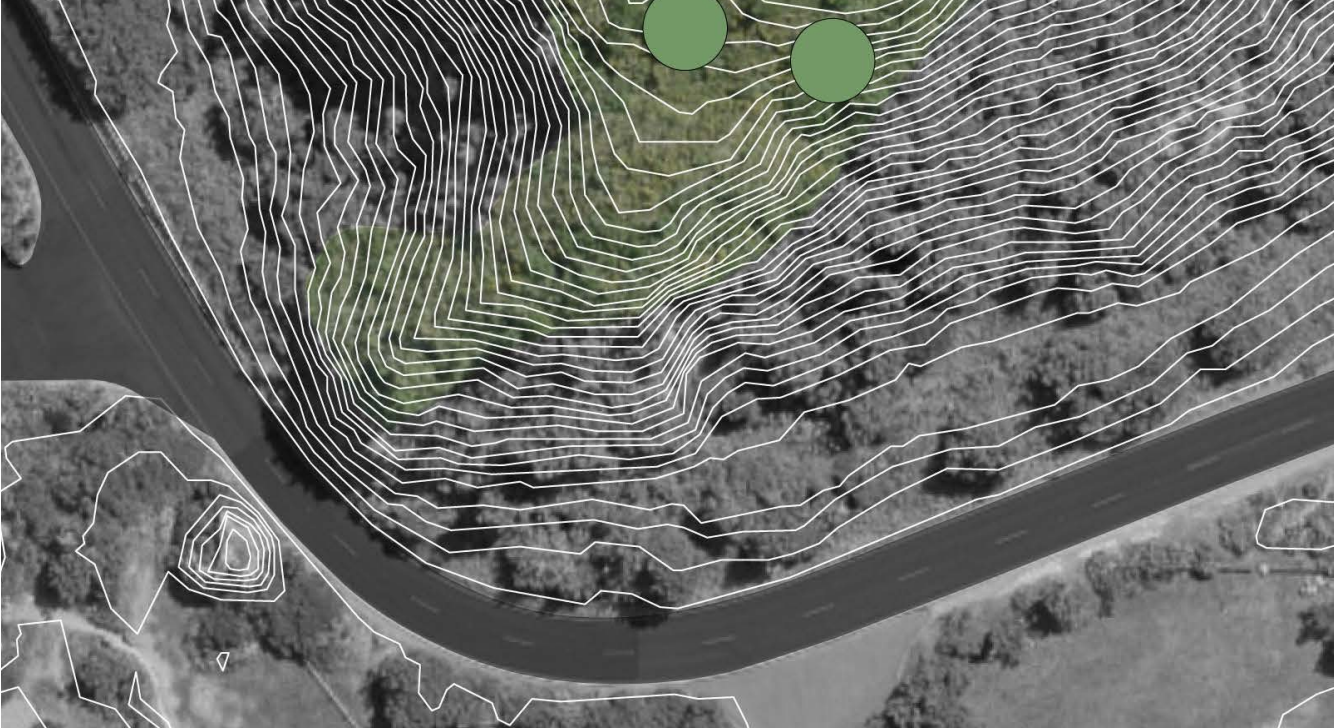

$1: 1000$ 


\section{Day Experience}

1. Winding path leading to a lookout on the southern coast

2. Is very accessible with two main entry and access points

3. The elevation of the site offers various lookout spots over different areas of the south coast and harbour.

4. Consists of many open areas

\section{Night Experience}

5. The site is well protected from surrounding light pollution due to the elevation of Strathmore park blocking its visual spread

6. This location is the perfect setting to watch the rising of the Milky way at the beginning of the year.

7. Many different constellations, stars and planets could be seen from this location

8. Areas of the path with vegetation on one side and an open view on the other were more comforting then areas with vegetation on both sides of the path

9. The silhouette shape of the plants at night were unappealing

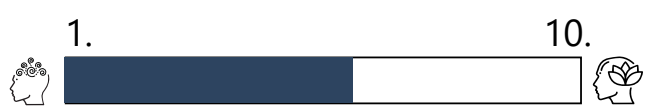

Overall comfort level

1.

10.

Amount of Illuminated Area

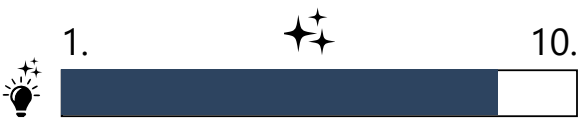

10.

Star Visibility

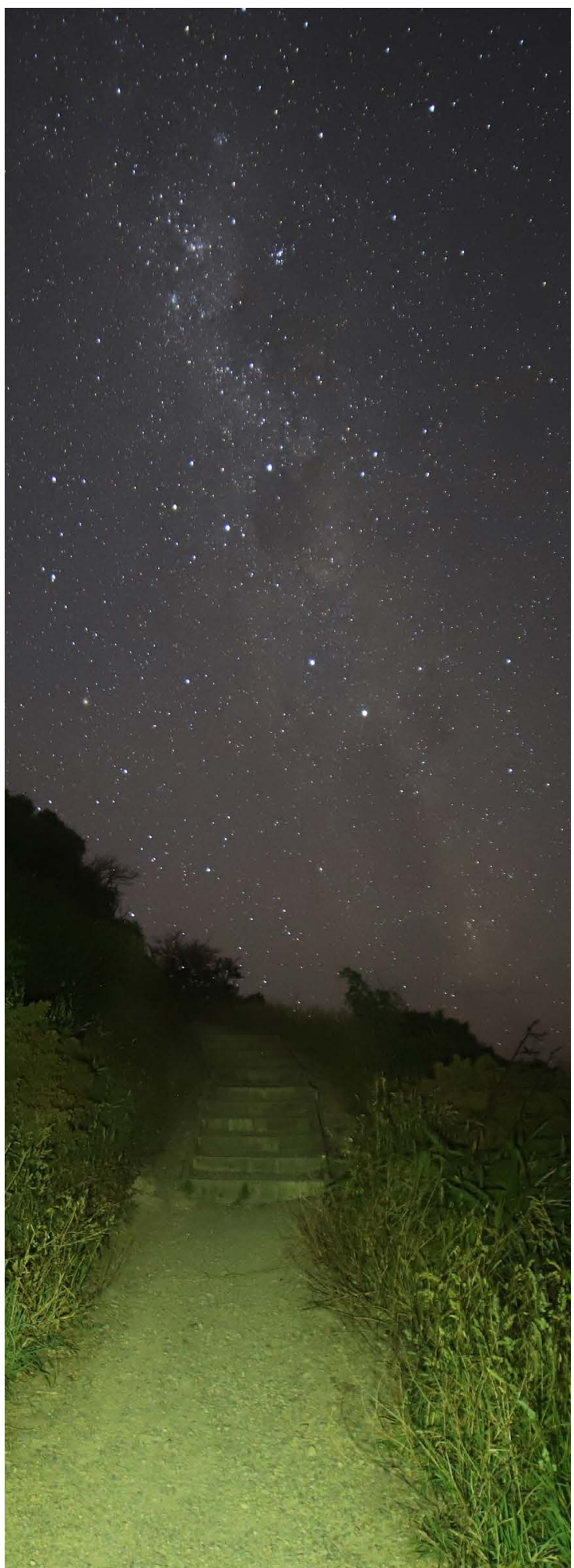

4.19 Milky Way rising above Ataturk Memorial 
High elevation site - almost 360 views around

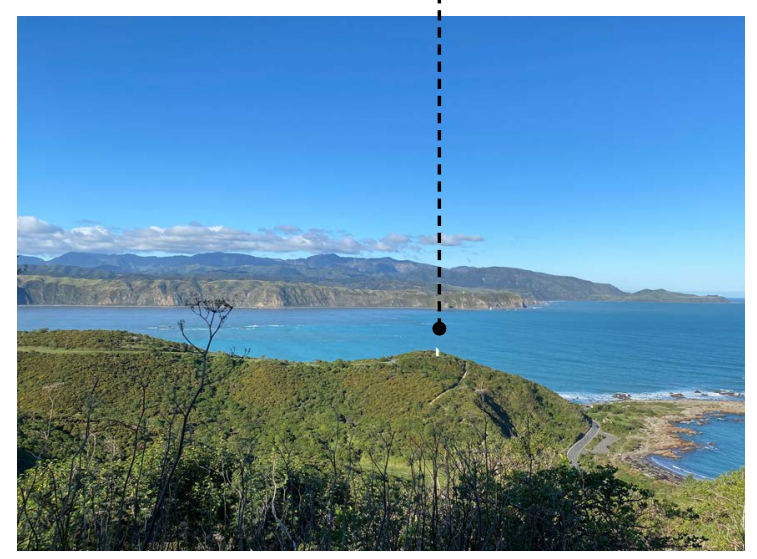

High elevation

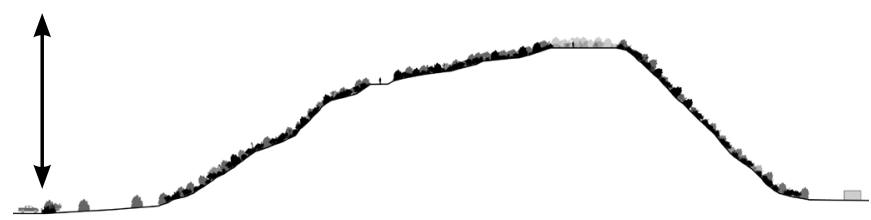

Features open and closed areas

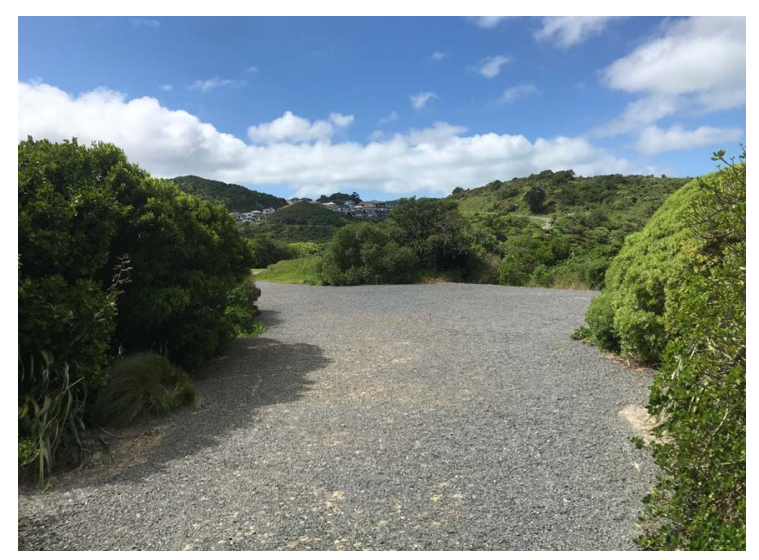

Open space

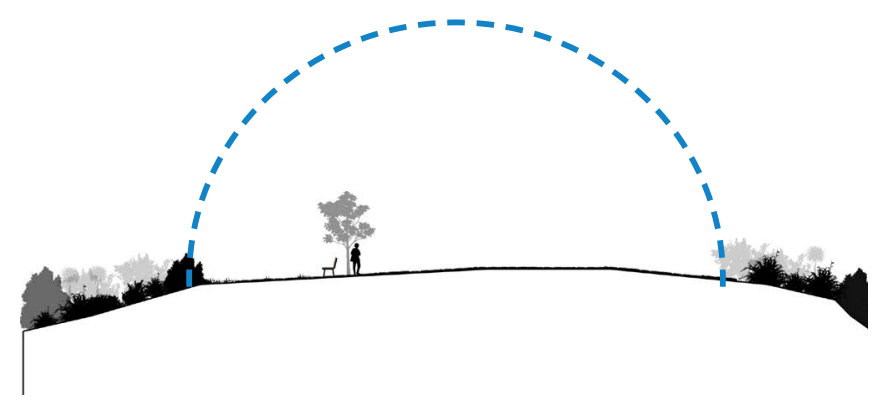

Variety of plant species line the pathway and along the hill side

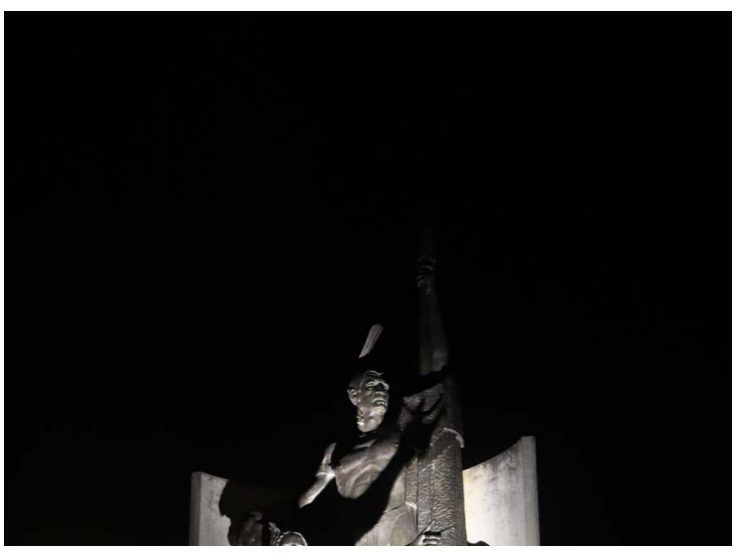

Vegetation lining the pathways

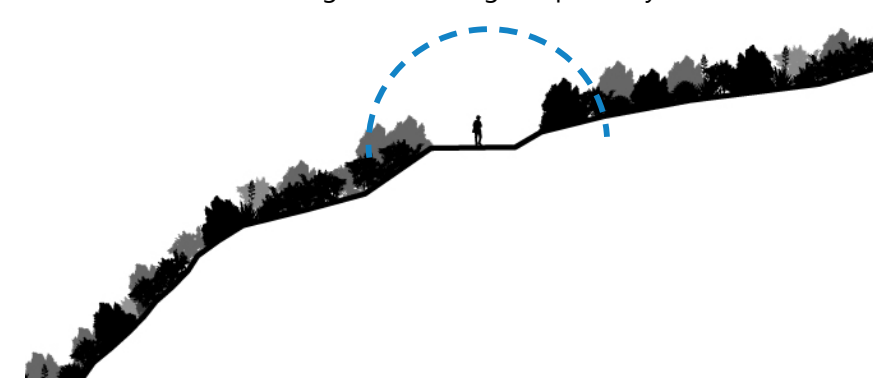

Existing Memorial design doubles as a lookout which attracts users during the day
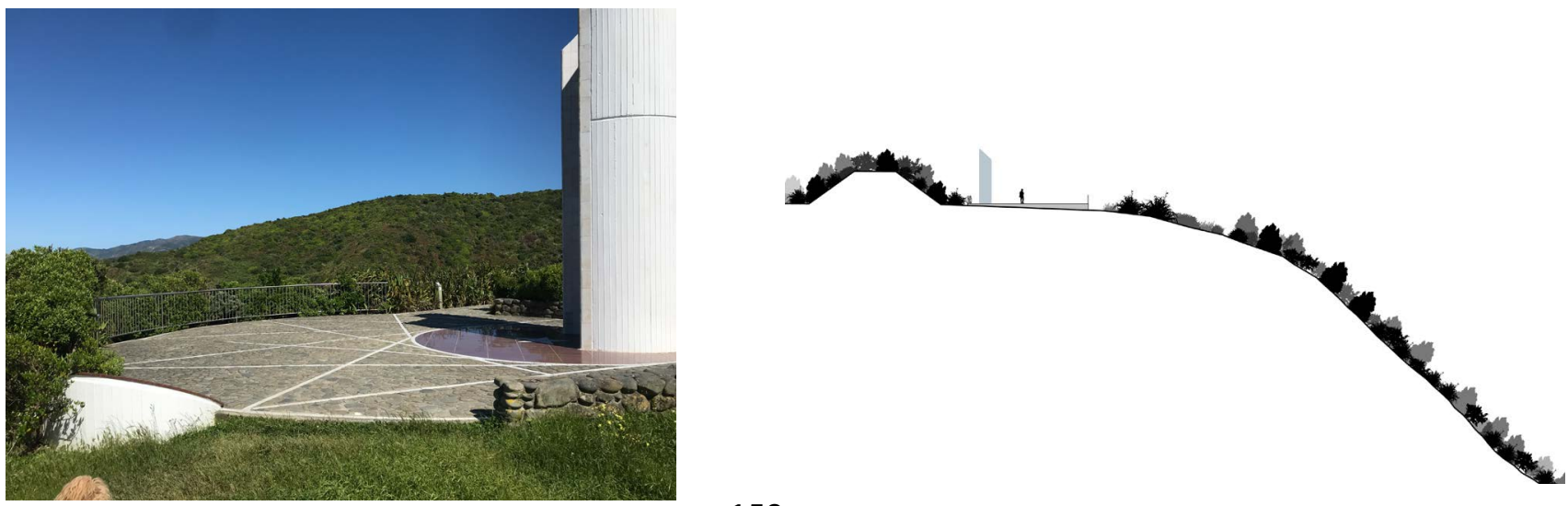
Elevation of the site brings user into contact surrounding pollution
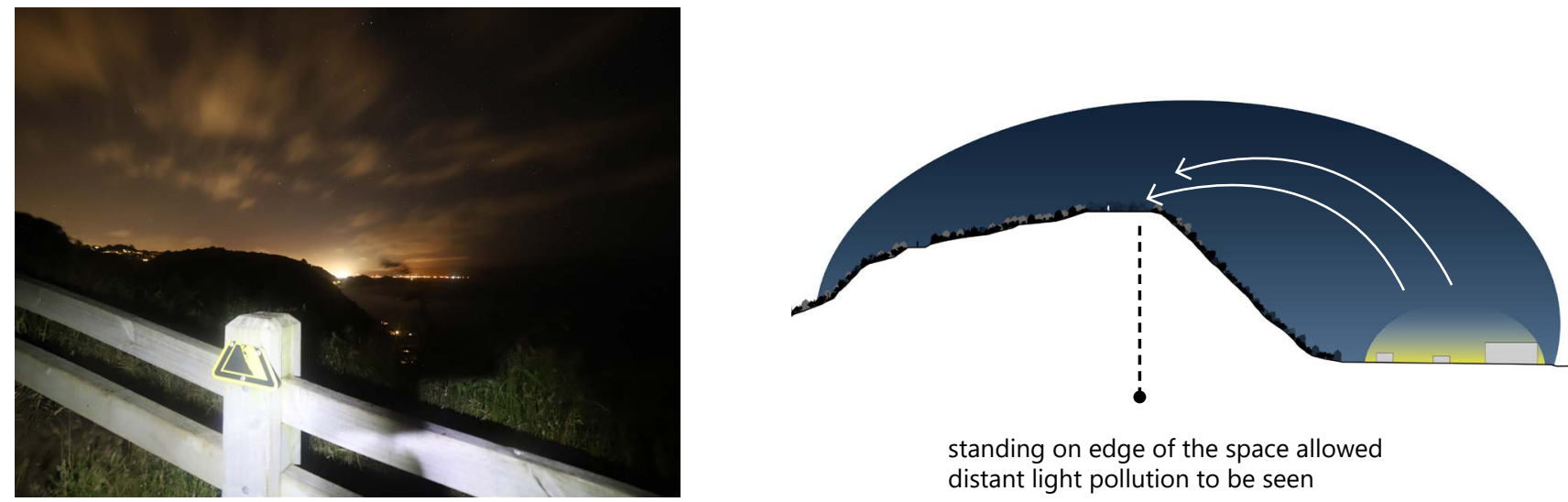

standing on edge of the space allowed distant light pollution to be seen

All provided a unique experience to being in the stars
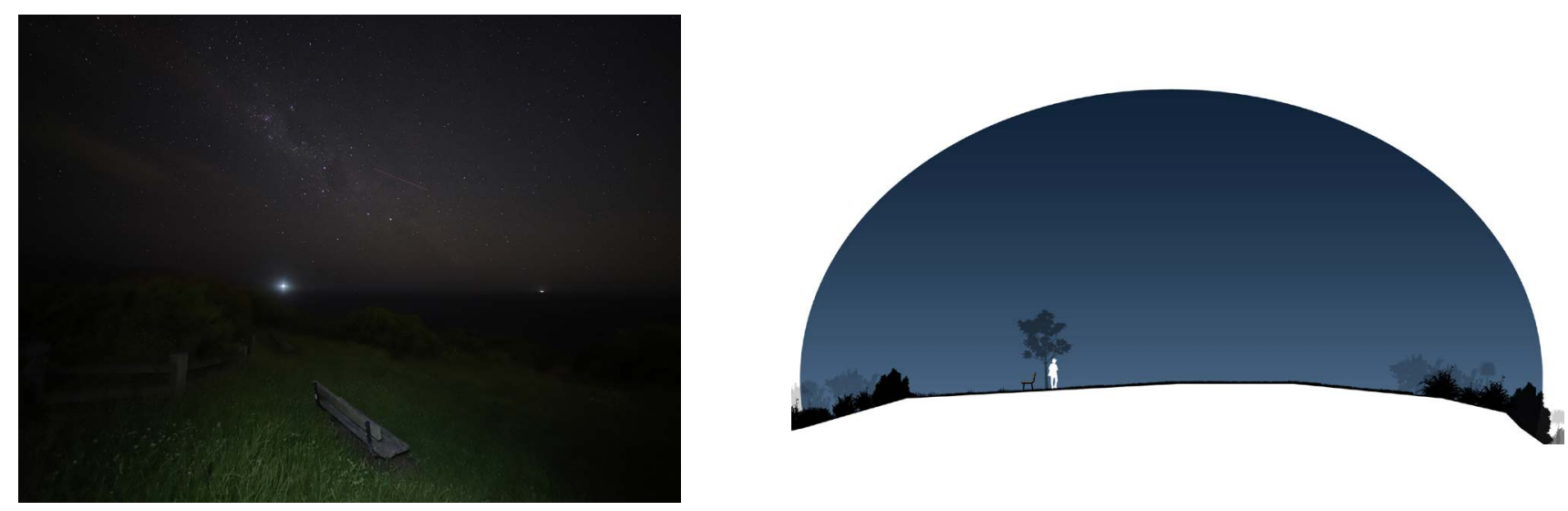

Walking up this is quite uncomfortable, lots of close bushes next to you
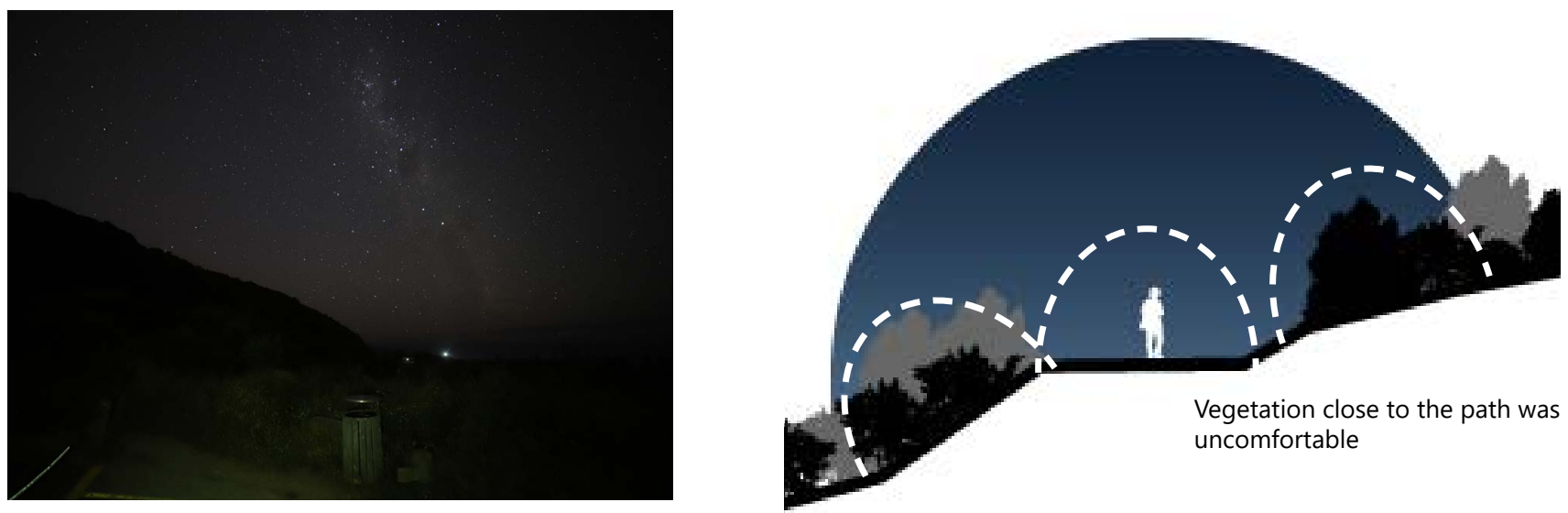

Sound and shape of plants next to pathway
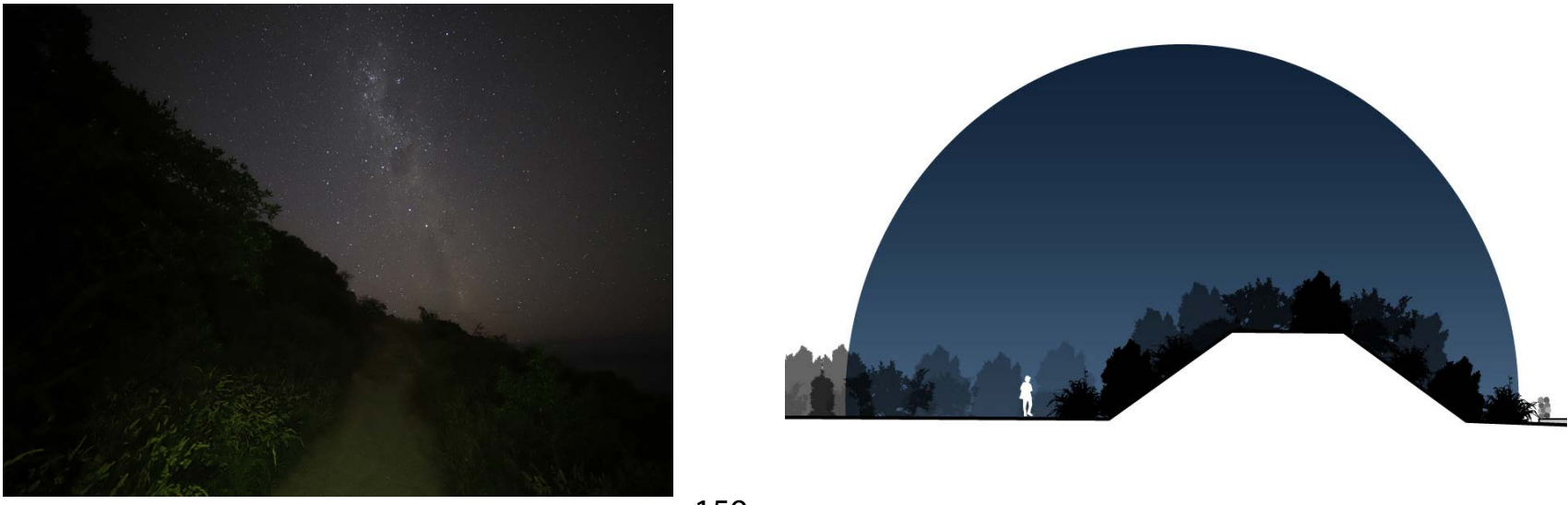

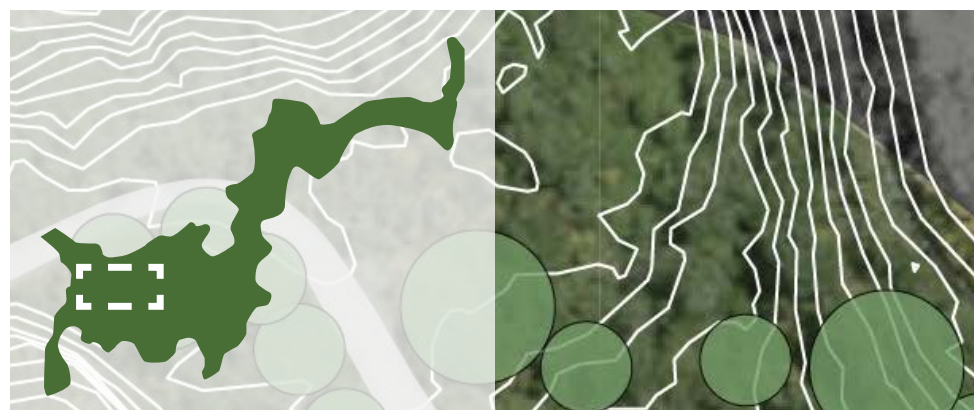

\section{C}
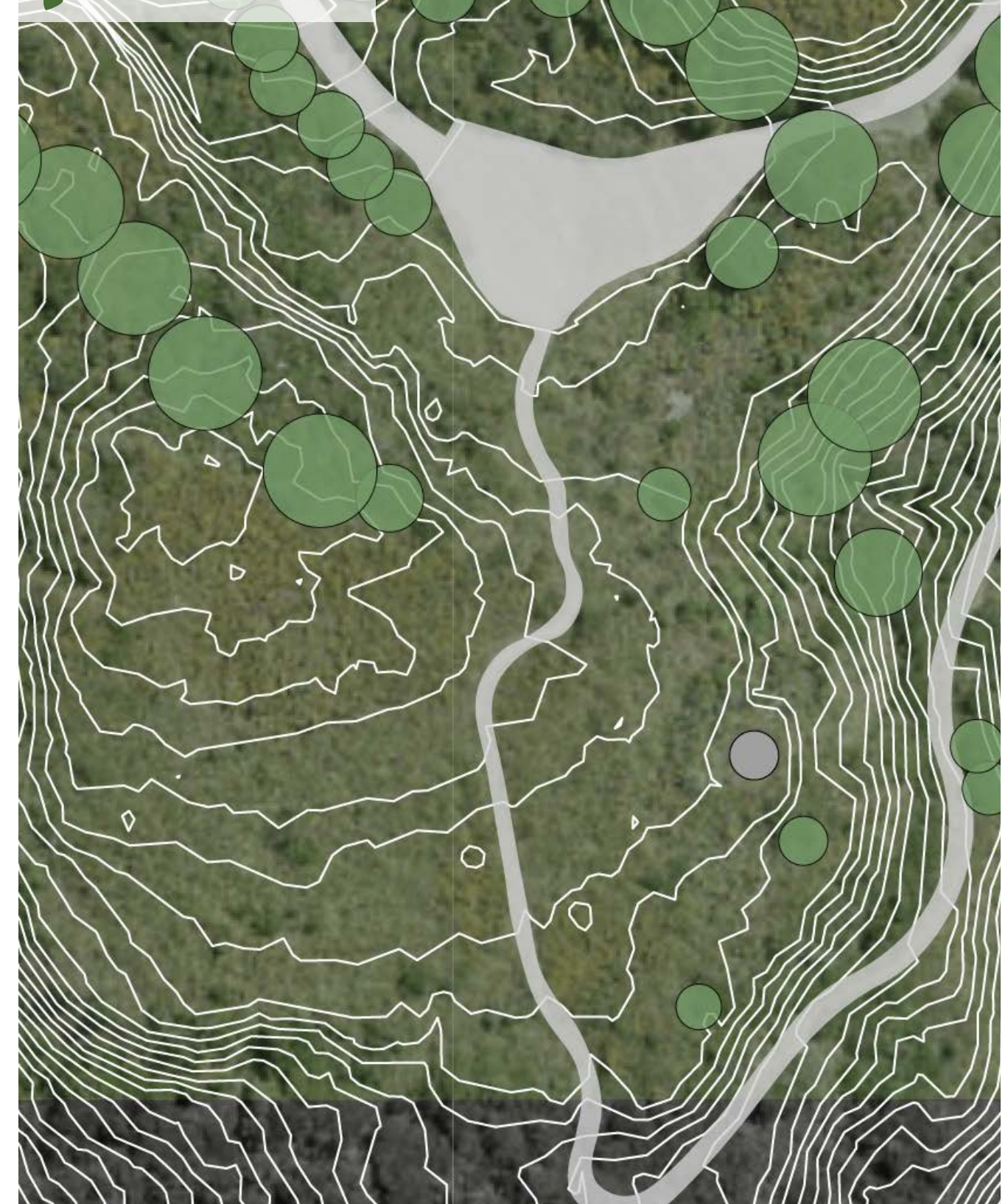

1:1000 


\section{Day Experience}

1. Specifically the track that wraps around the top of Moa point, the site had a variety of open and closed spaces

2. The site afforded expansive views across every direction in Wellington.

3. It is very sheltered and exposed to the southerly winds

4. It has three main access points

\section{Night Experience}

5. The site was very dark and many stars and the Milky Way could be seen which was a comforting sight.

6. The area was very quiet which created a serene experience being under the stars so close to the urban realm

7. Areas along the path were frightening when lined with tall very dense vegetation.

8. In other areas the path was completely open which provided increased prospect.

9. In some areas the path was closed on one side and has a view shaft on the other

10. The area provided multiple natural paths to explore off of the main paths.
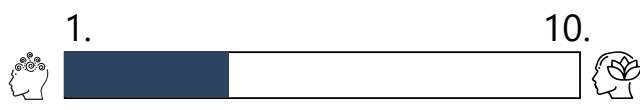

Overall comfort level

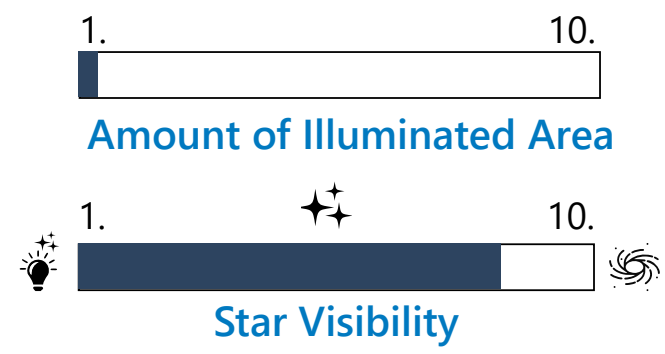

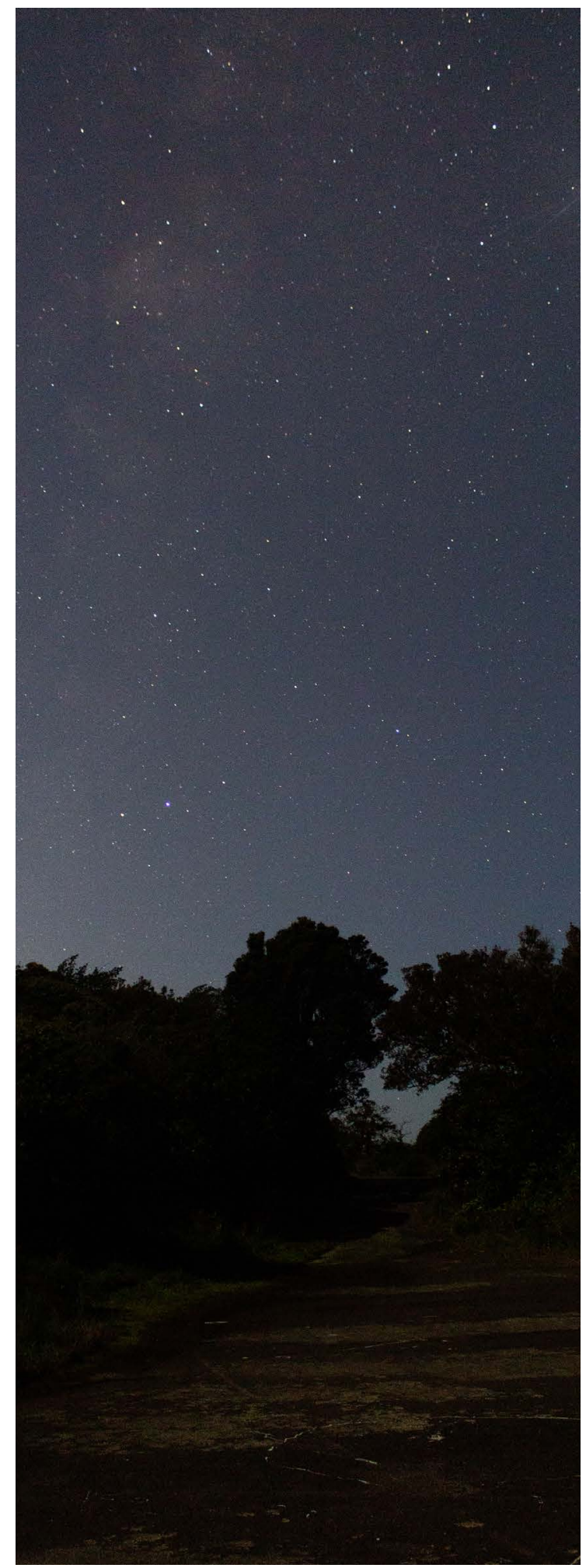

4.20 The stars above Moa Point 
High elevation with lookouts over every part of Wellington
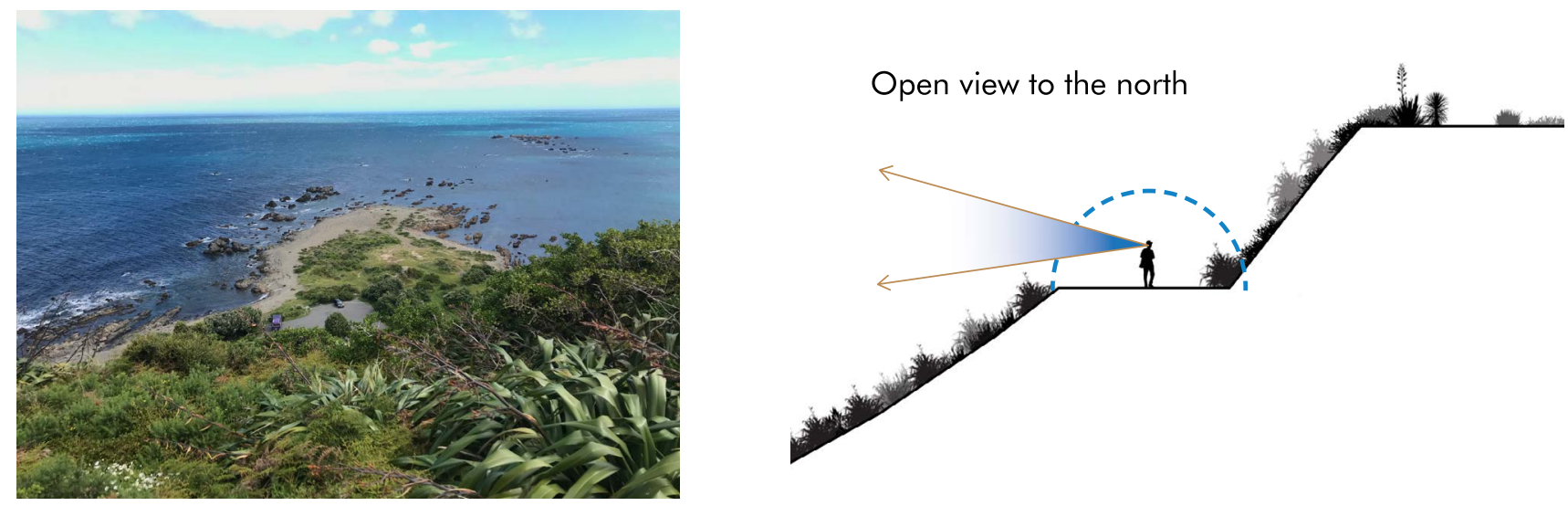

Topography \& Vegetation inhibiting and allowing viewshafts
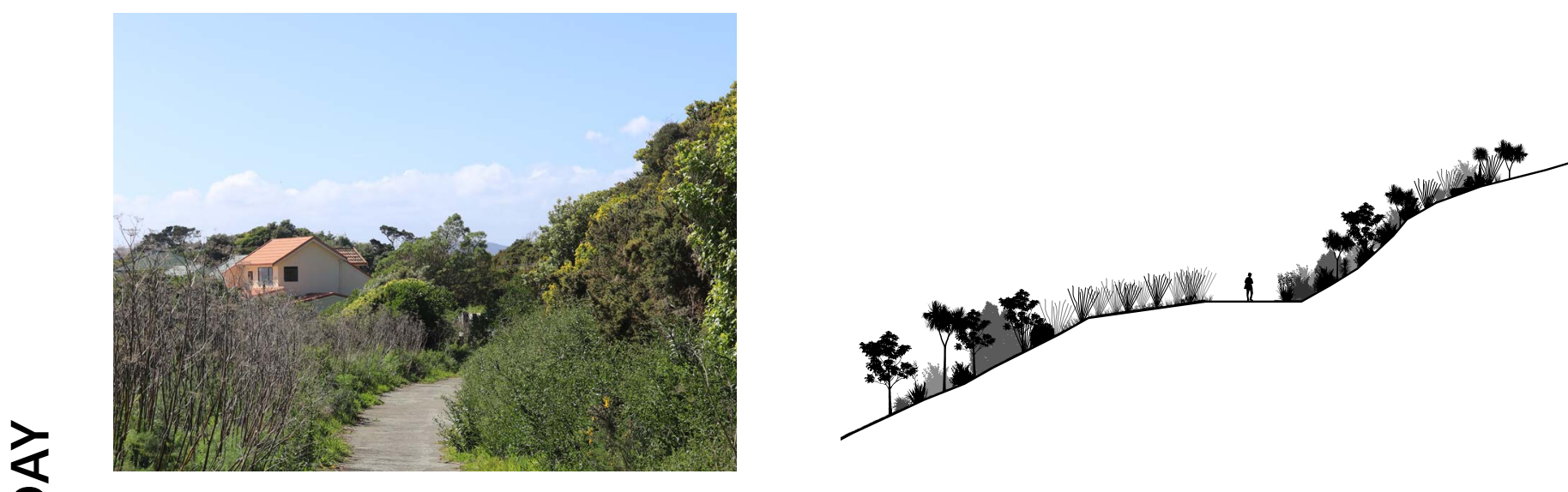

Wide variety of vegetation close to the path
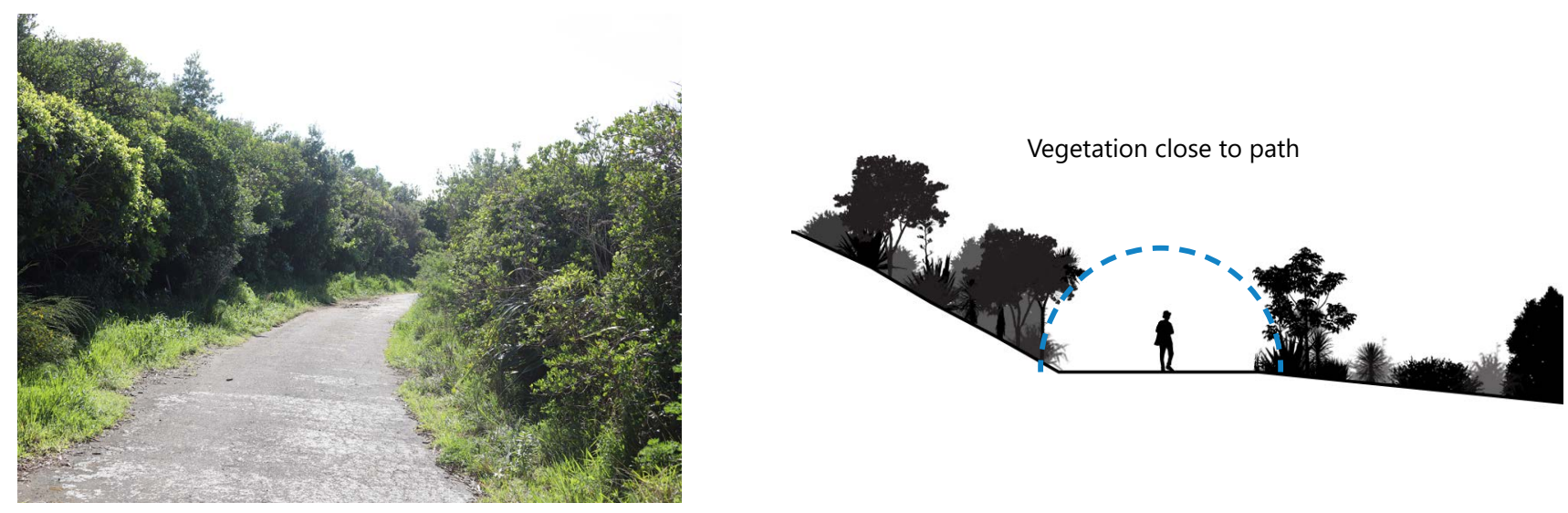

Wide central space with many access points

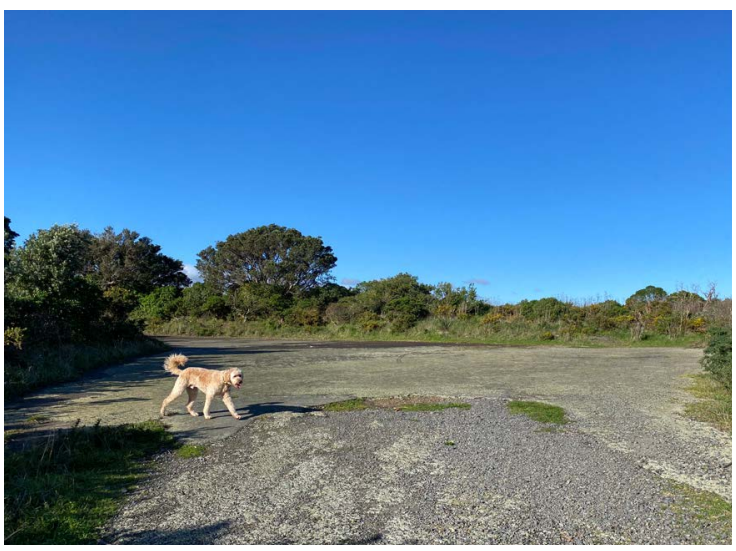

Wide central space increased prospect

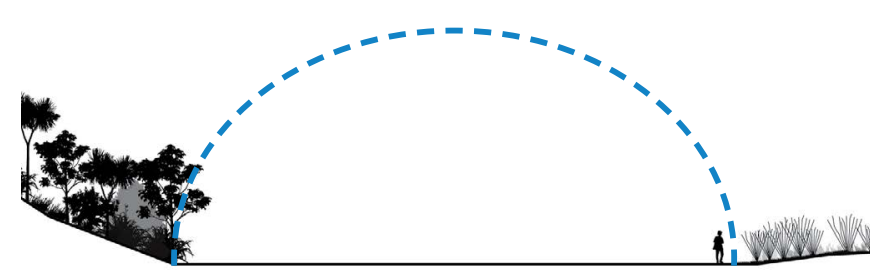


View of the stars was calming to have even when surrounded by vegetation
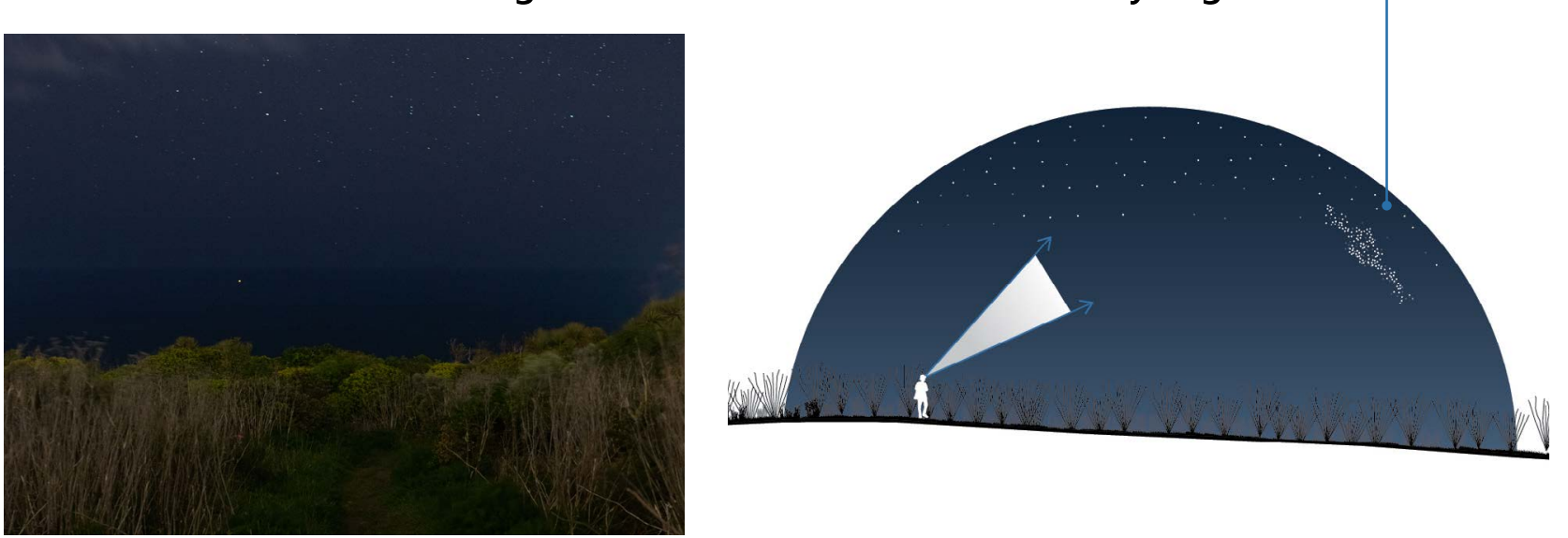

An open view on one side of the path was comforting
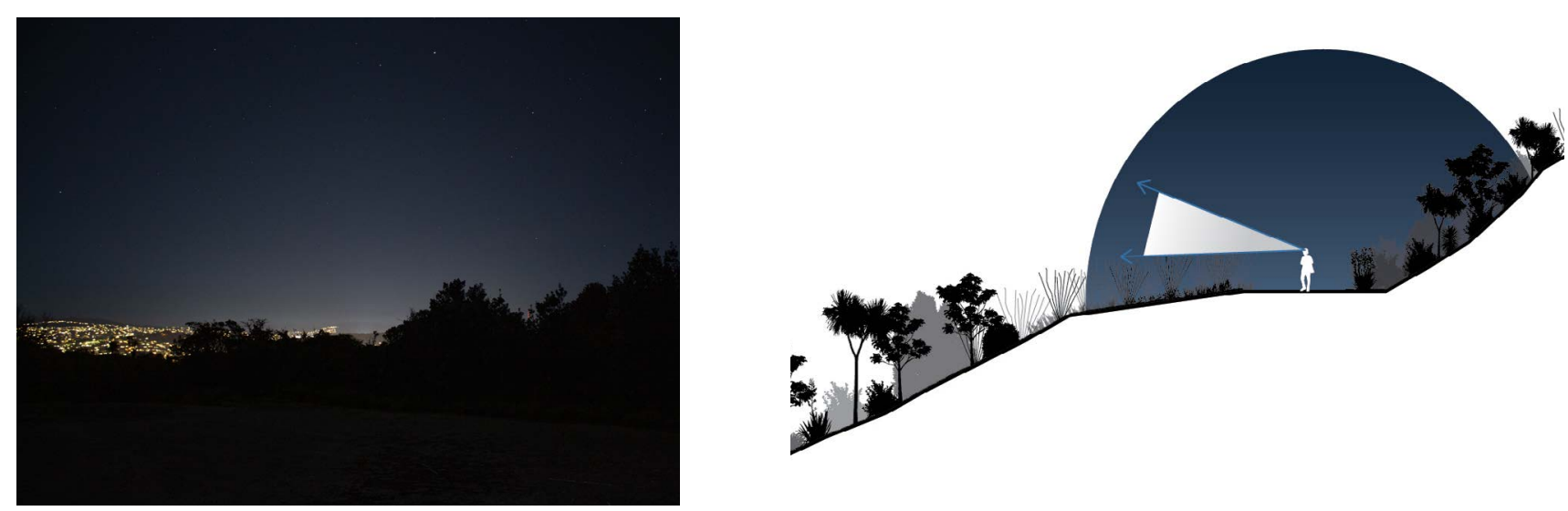

Paths with vegetation on both sides was frightening
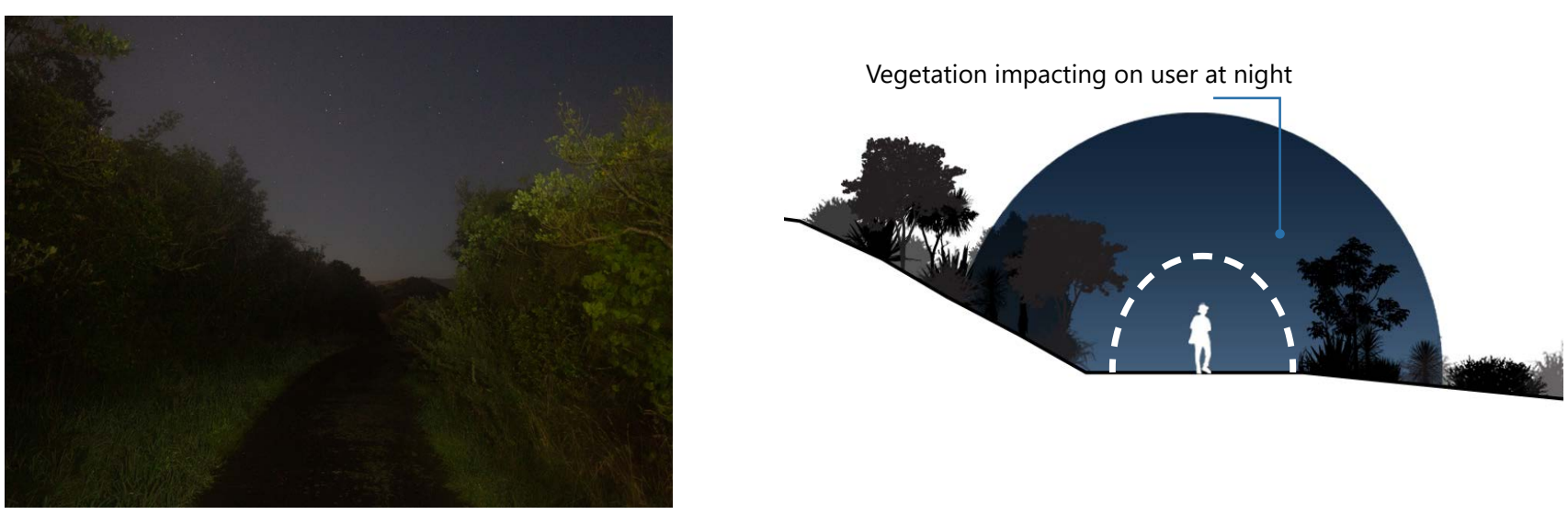

Open spaces at night were calming to be in but also unnerving
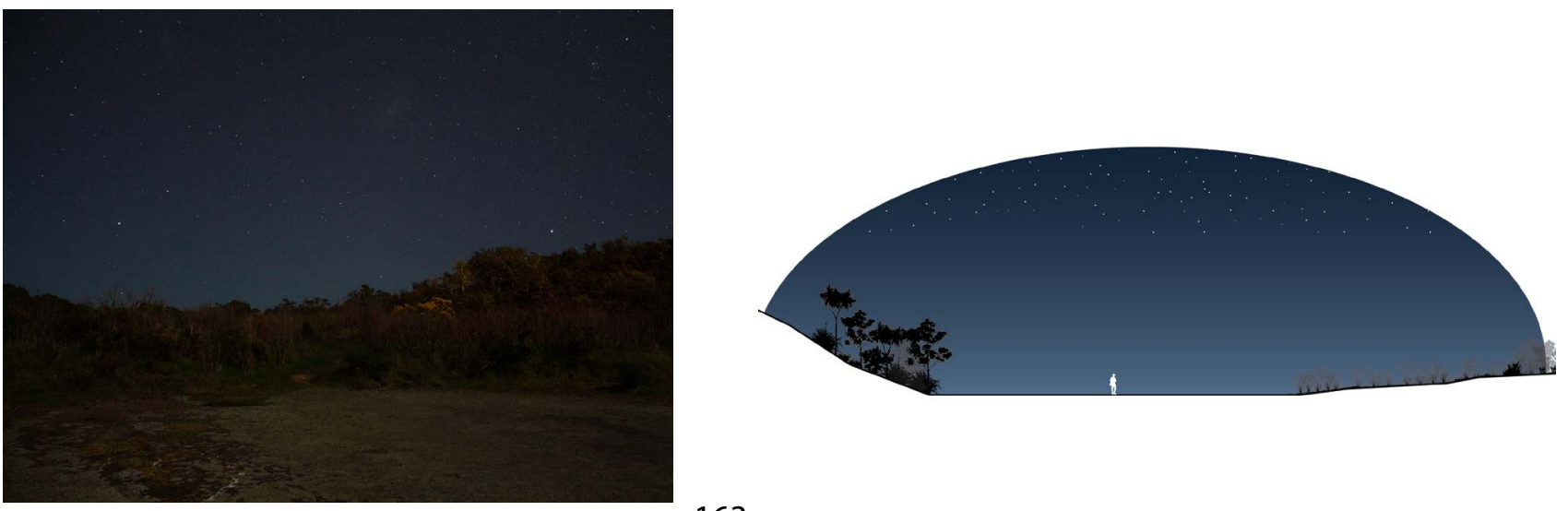


\subsection{Reflection}

The experiential fieldwork proved to be a hugely successful strategy in understanding the nighttime experience. Initially, fieldwork began by researching the areas solely at night, but after the first few site visits revealed the lack of public engagement, site visits began during the day to understand why the site is used during the day and not at night. The findings from the analysis reflected the theories represented in the literature and case studies. Specific landscape characteristics had positive and negative impacts on how comfortable the space felt at night and how visible the stars were. Additionally, the night sky in the Town Belt and South increased the overall feeling of comfort in almost entirely dark spaces. However, this feeling did not occur on overcast site visits, as there was nothing to focus on besides the dark environment; this led to increased anxiety when in the space. Each unit's landscape characteristics were extracted and represented individually in the following chapter to see what is explicitly affording the night time experience's failure. 


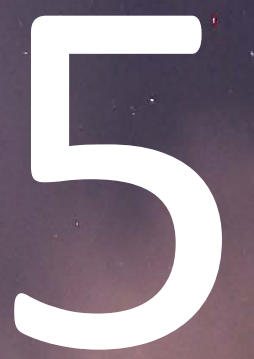

SITE REFINEMENT 


\section{Introduction.}

This chapter represents the findings from the initial fieldwork. 10 specific landscape characteristics/relationships from each area were drawn out and represented individually. The perceived comfort of each specific characteristic was measured and compared against one another. If they had an impact on the visibility of the stars, this was also measured and compared. The characteristics were then placed on a site map to figure out an area that is both comfortable and has good star visibility to test in the site specific design. It may be noticed that some characteristics are placed close together on the map with differing amounts of star visibility. This does not refer to the sky brightness or amount of light pollution, it refers to how the physical landscape feature impacts your vision of the stars. This will be discussed in detail in the final conclusions.

Fig 5.1 Reflection at Point Haswell, Miramar Peninsula 


\subsection{Waterfront Analysis Findings}
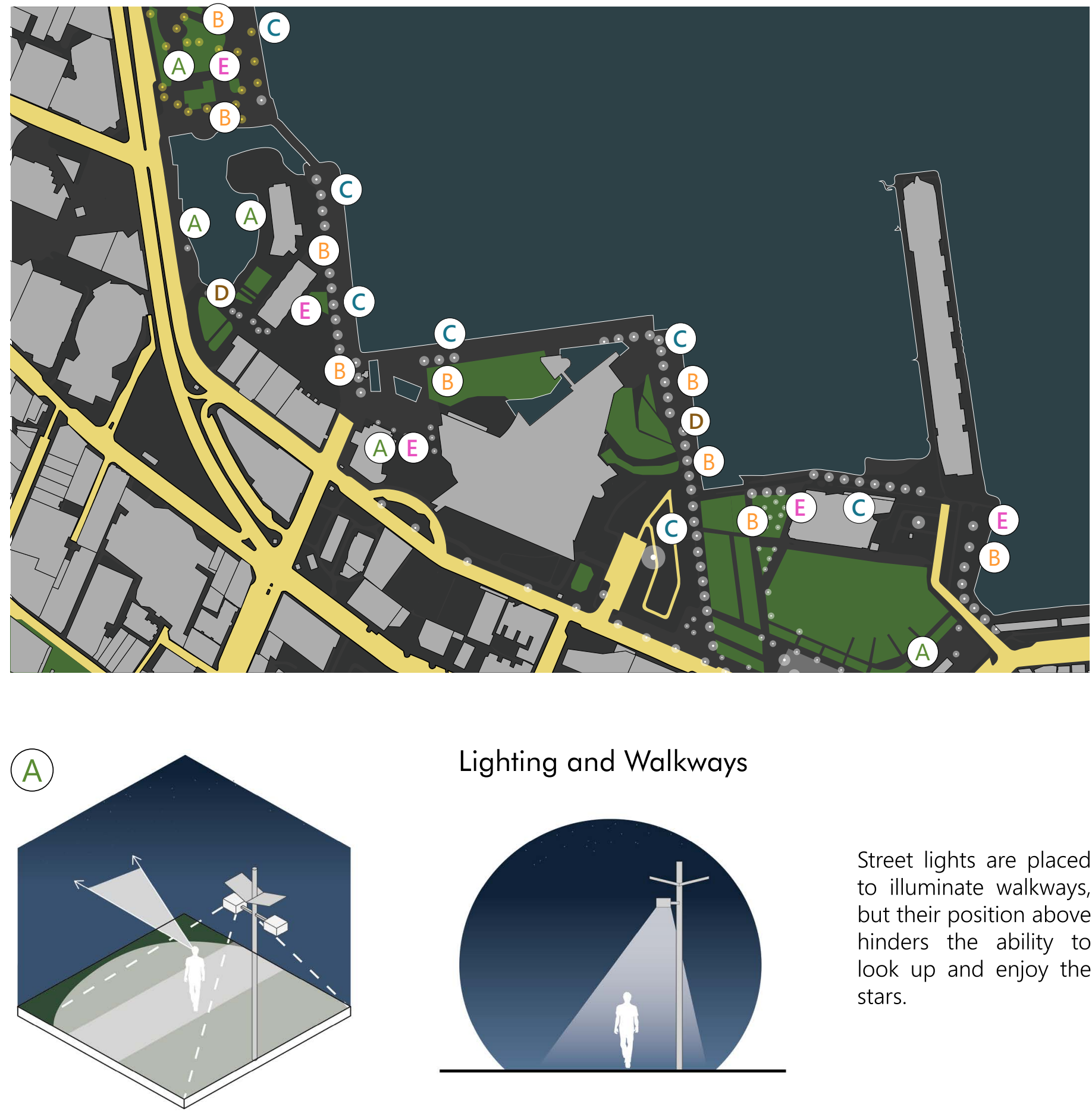

\section{Lighting and Walkways}
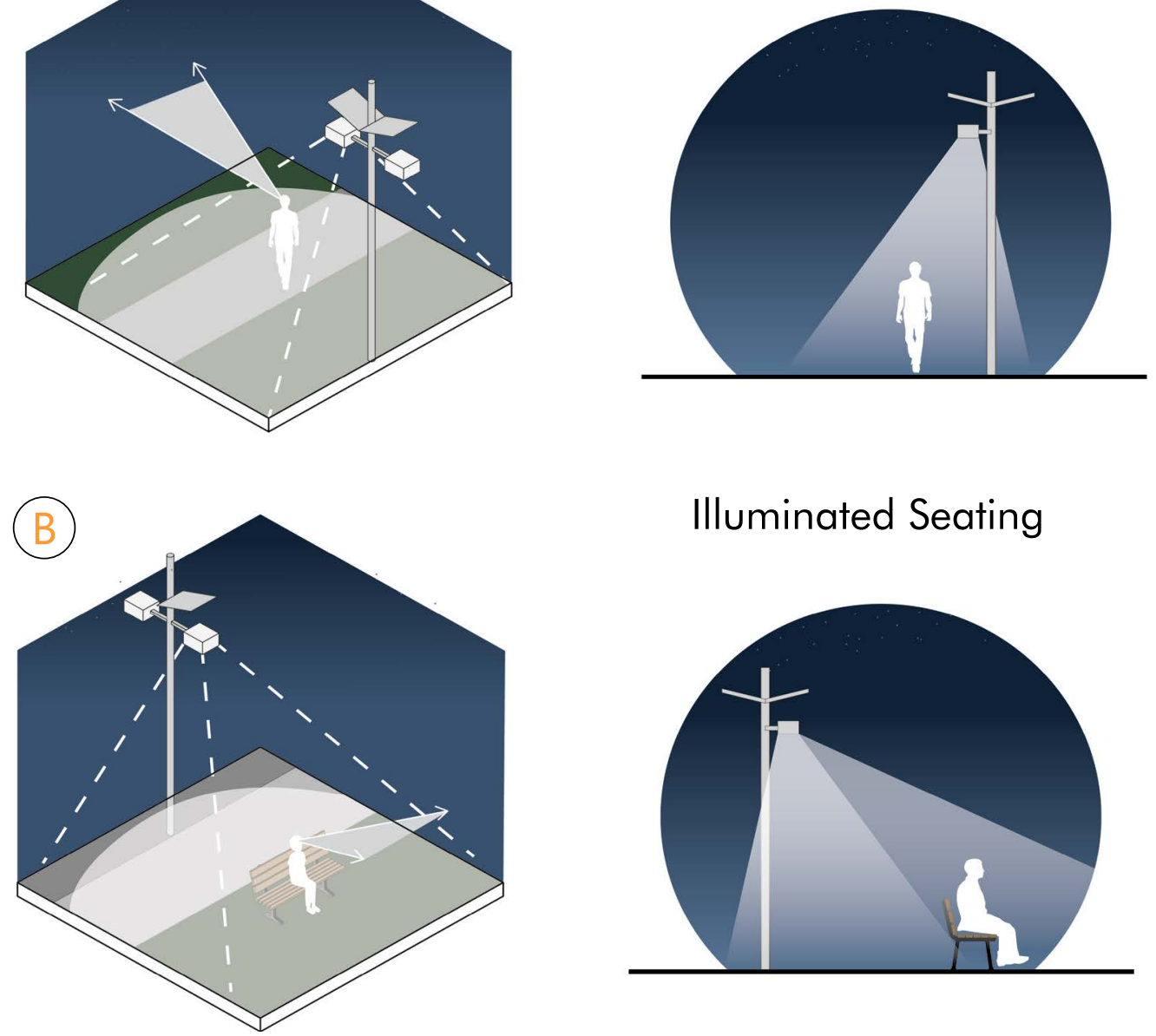

Street lights are placed to illuminate walkways, but their position above hinders the ability to look up and enjoy the stars.

Illuminated Seating

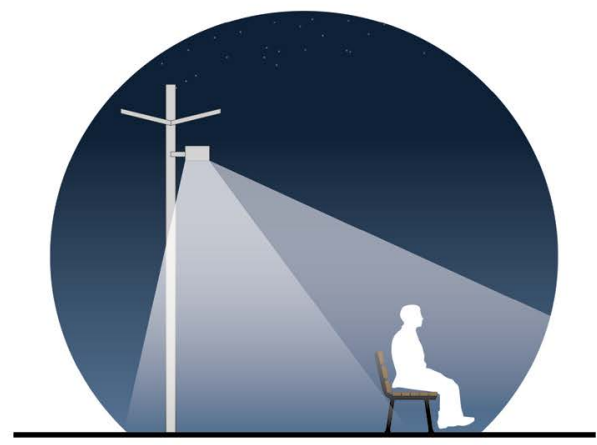

Street lights illuminate all outdoor seating at night, yet the public hardly uses these benches. The light shining down hinders the seats ability to be used for stargazing 

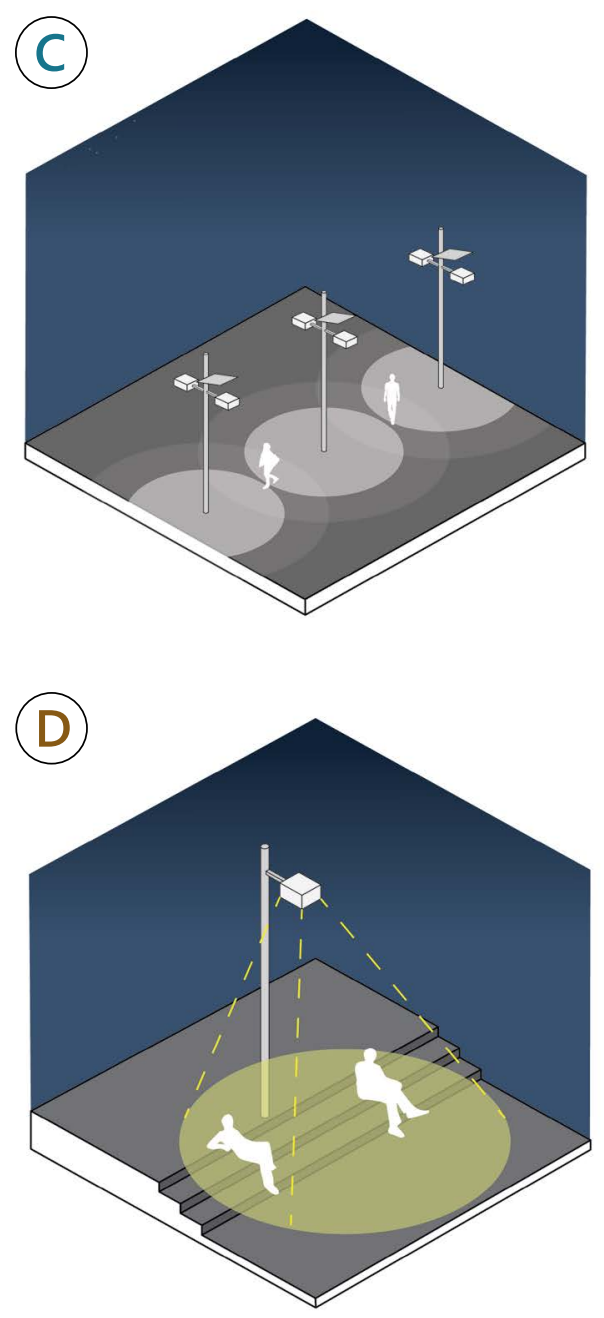

\section{Illuminated Terraced Seating}

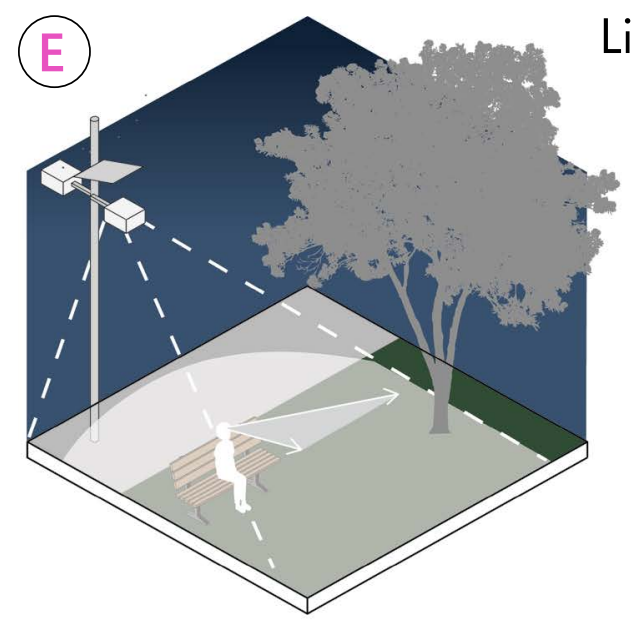

Star Visibility

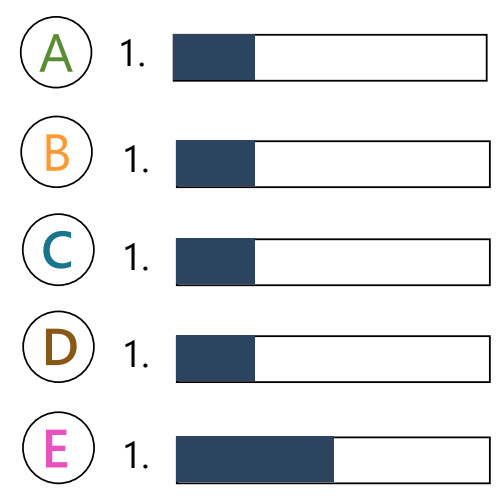

\section{Overall comfort level}

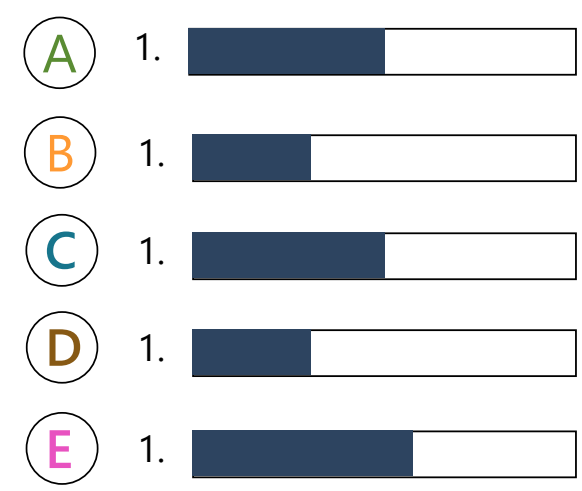

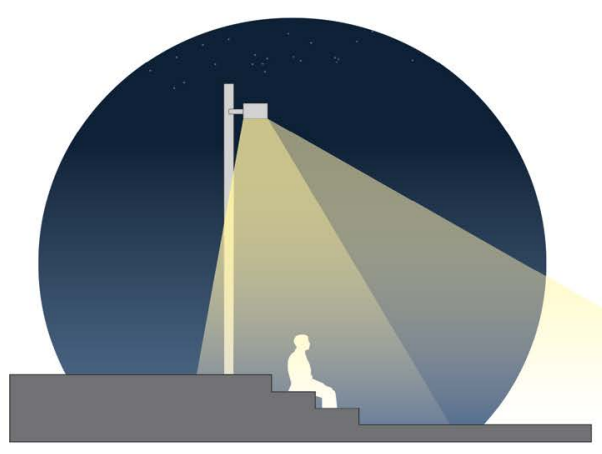

Overlit Walkways

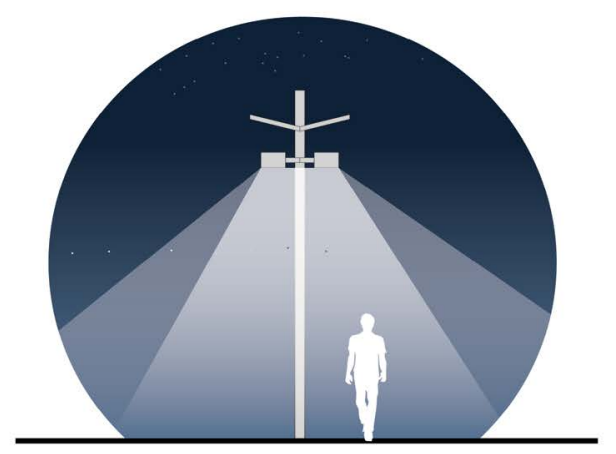

Almost every sq. meter of the open walkways is illuminated either directly or from light trespass of surrounding light sources. The glare from lights will often overlap as well.

Lighting illuminates terraced seating areas on the water's edge that have hardly any use at night unless there is an event happening in the area.

Vegetation in design is often placed not to impair the effects of lighting at night. However, in some cases, the trees' leaf and branch structure prevent the full glare from entering a space, creating better conditions for stargazing. 


\section{Waterfront Analysis Findings}
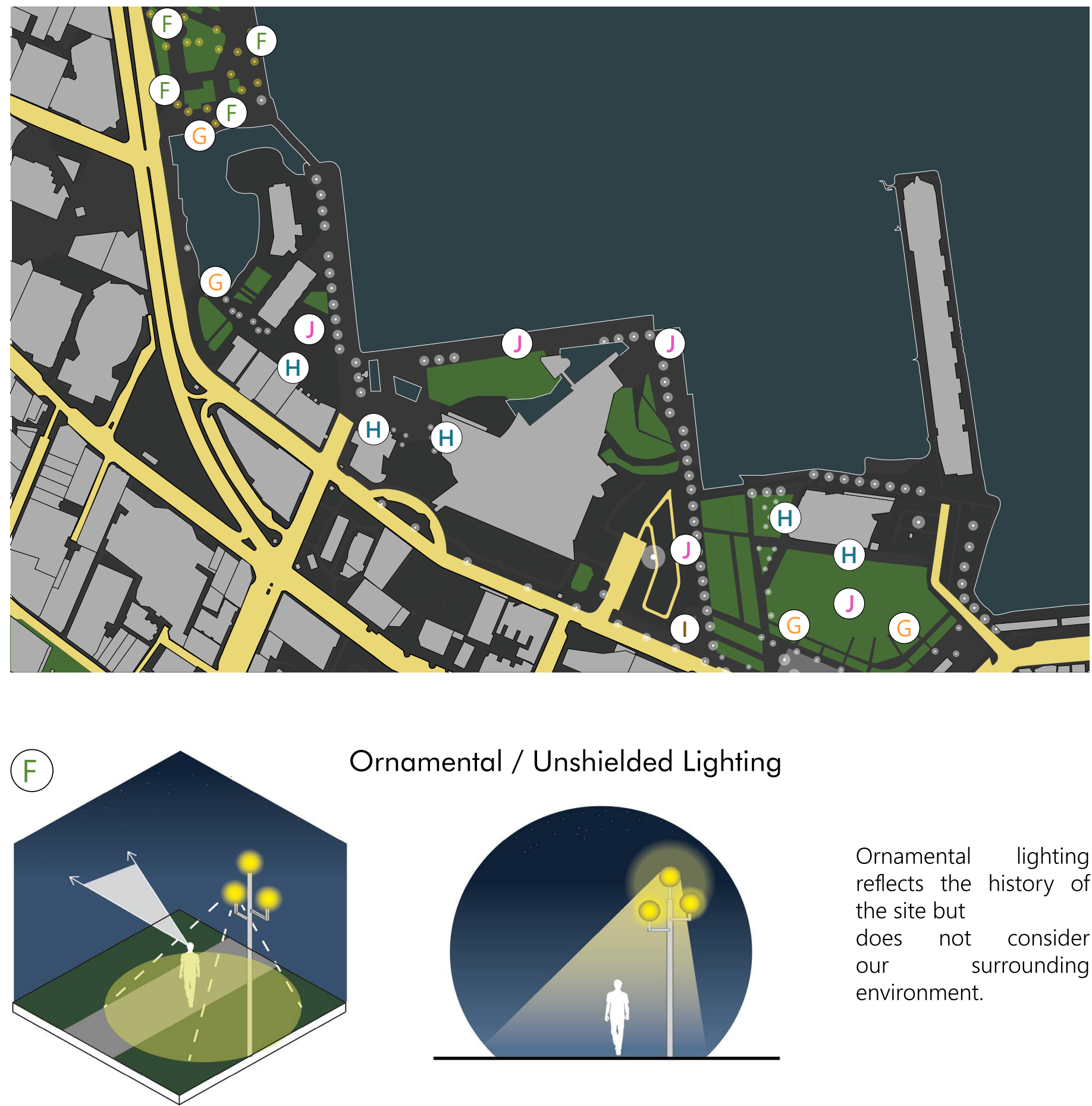

Ornamental / Unshielded Lighting
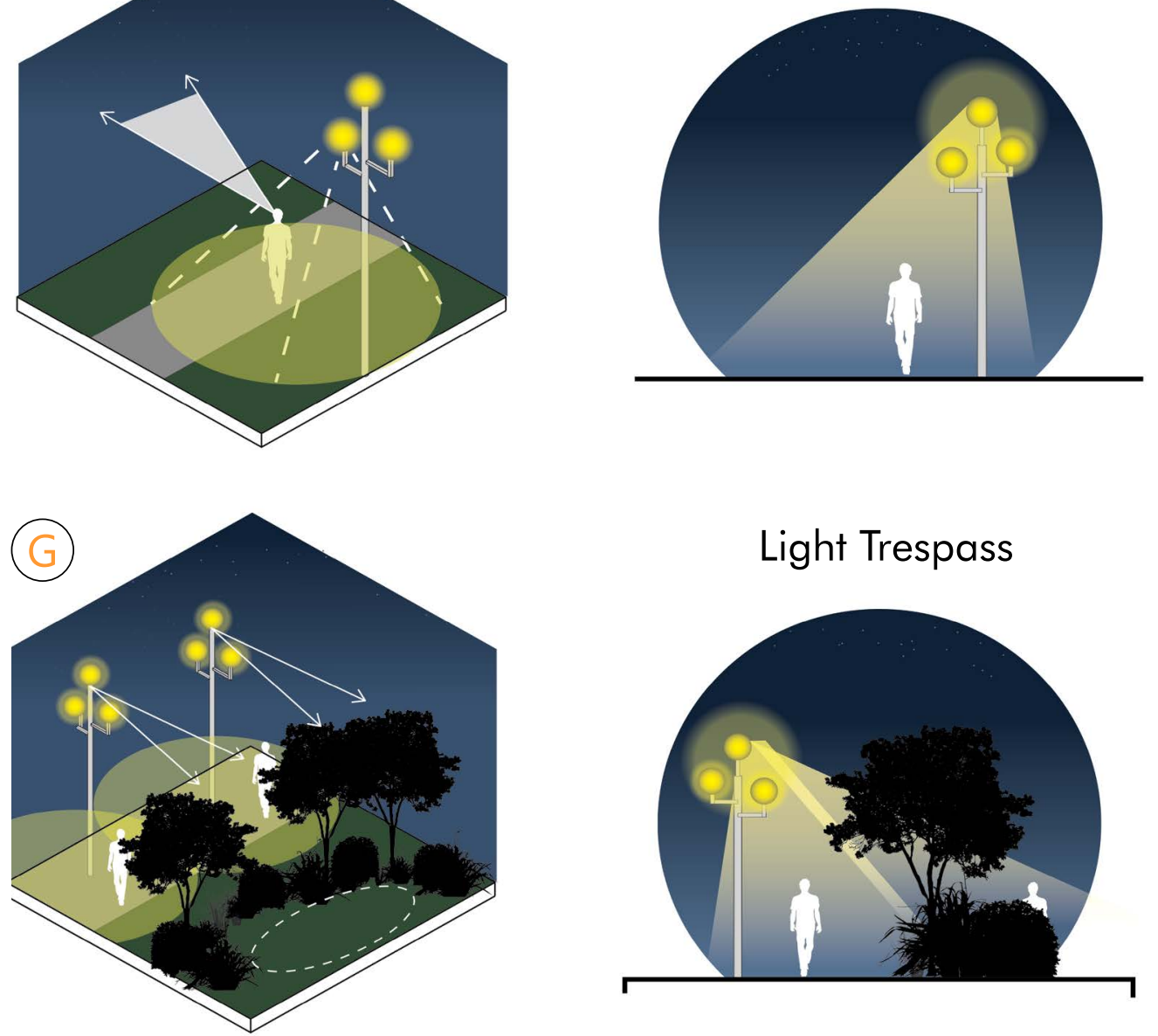

Ornamental lighting reflects the history of the site but

does not consider our surrounding environment.

Light Trespass

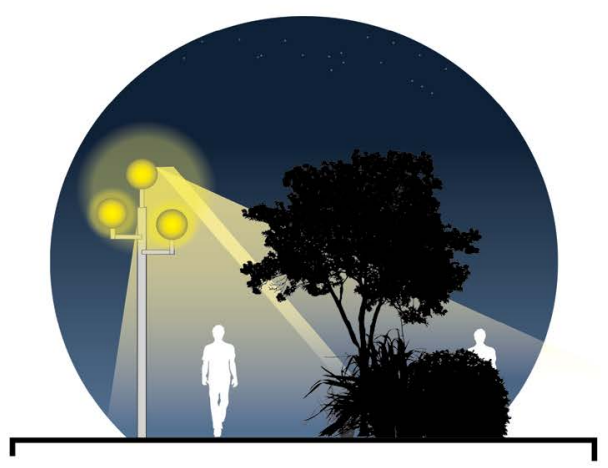

Ornamental and
unshielded lighting can trespass into other spaces, which hinders that spaces ability to provide the night time experience. 

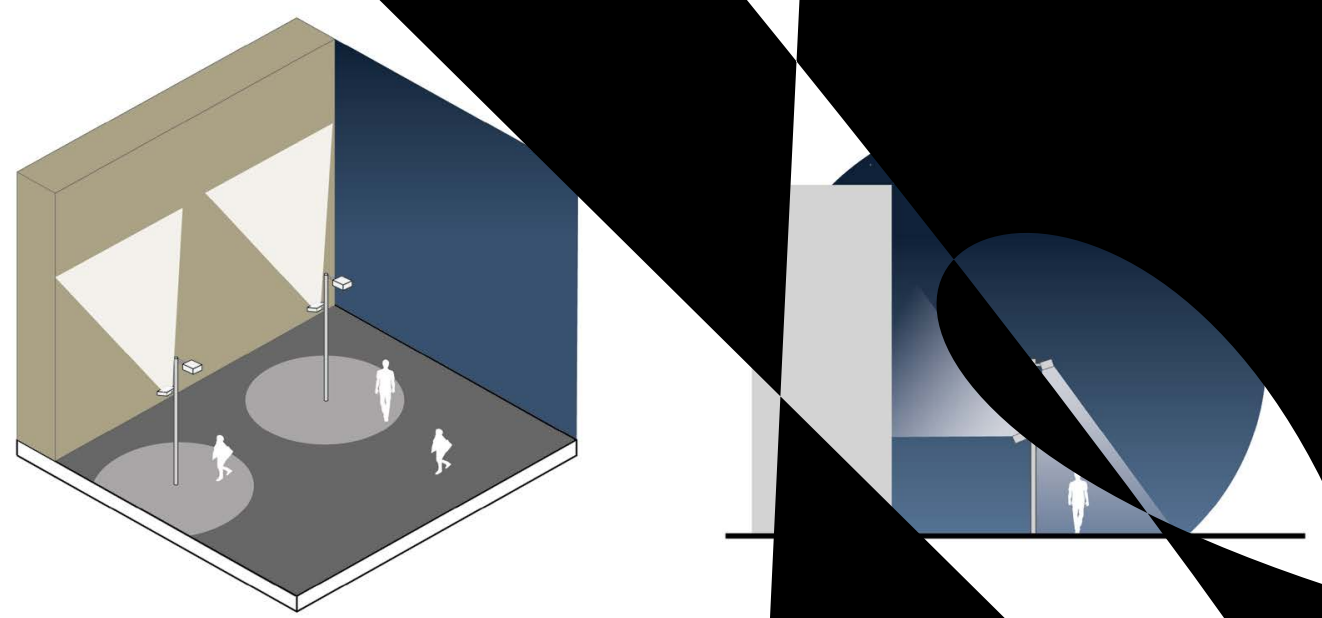

Lighting can boost the aesthetic value of certain surfaces. However, in some cases, it is misused, creating vast amounts of glare and white light that is unnecessary.
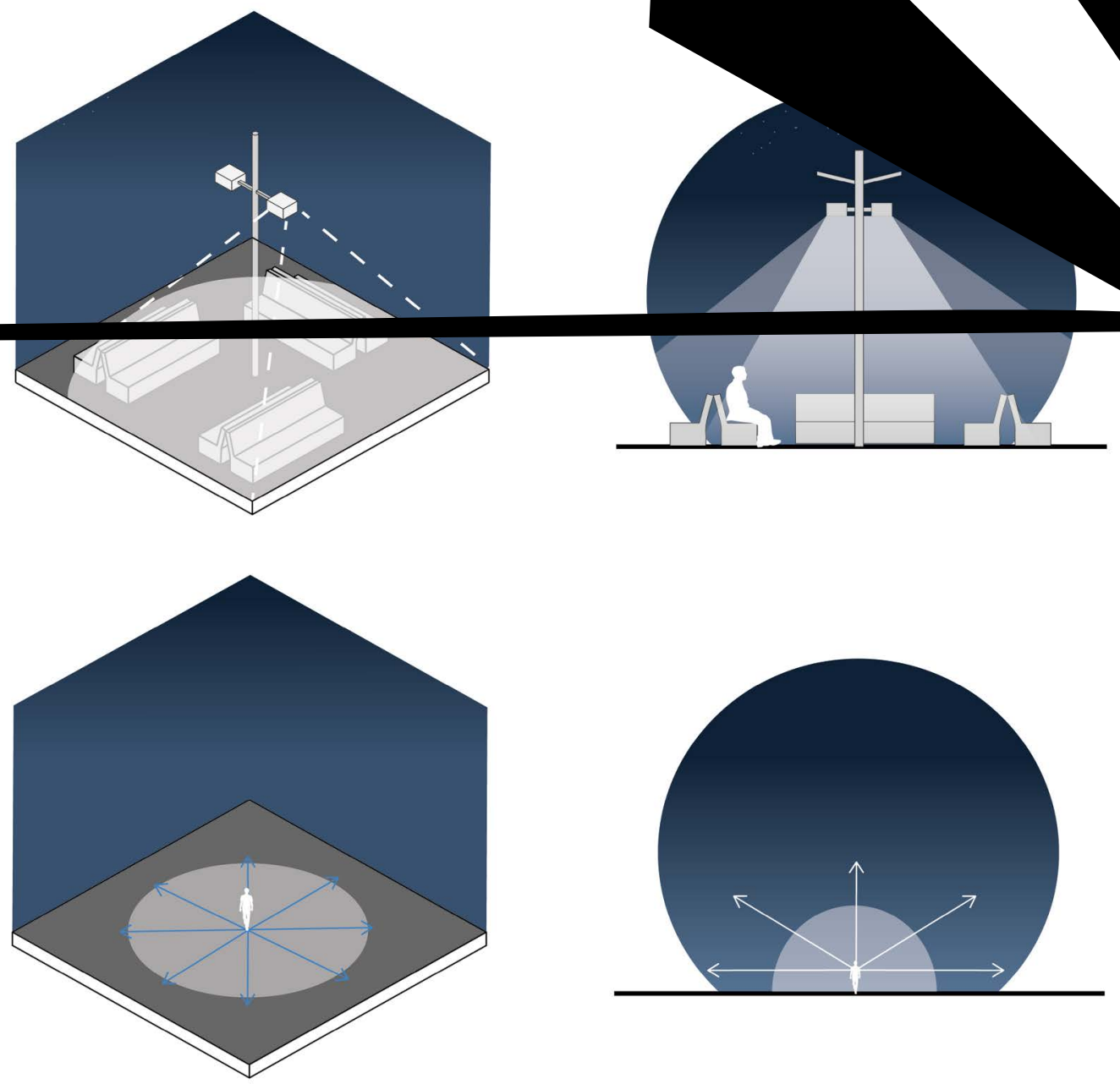


\subsection{Town Belt Analysis Findings}

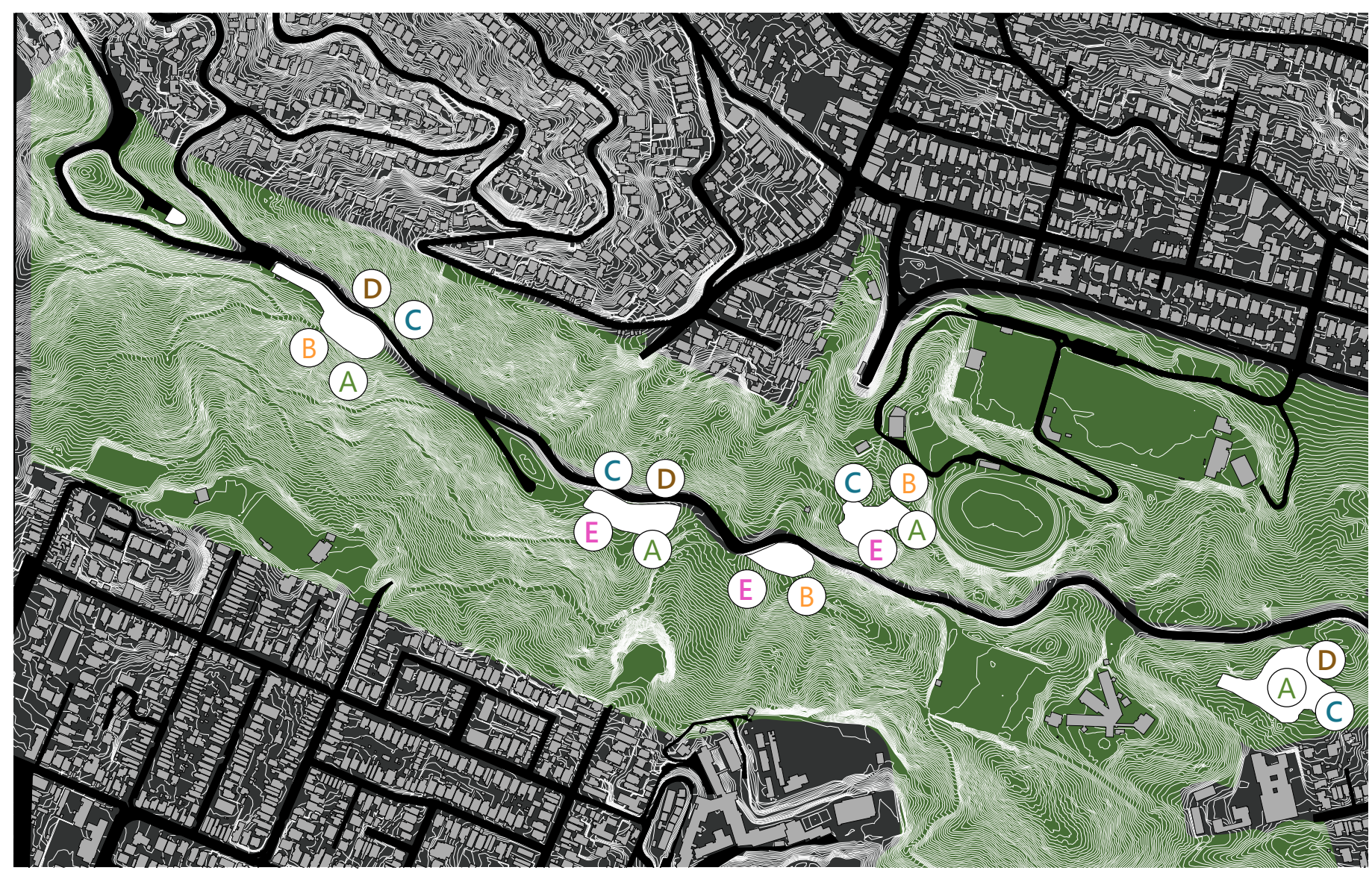

(A)
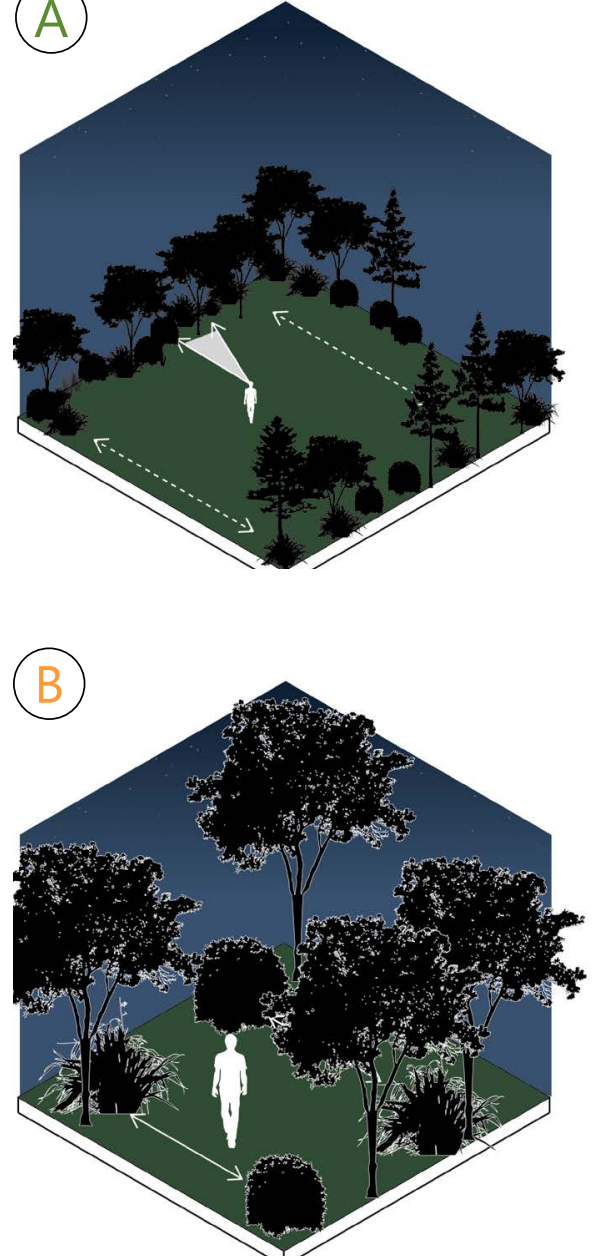

Space between vegetation

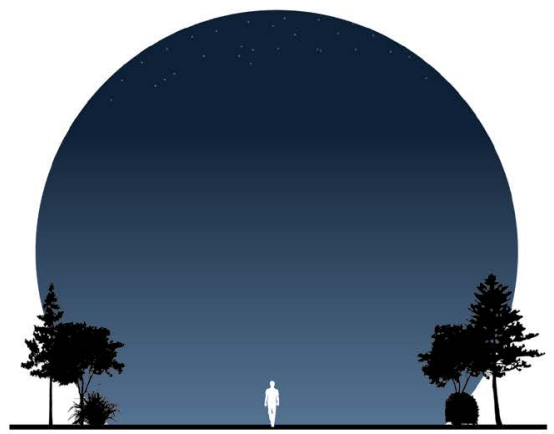

Less space between Vegetation

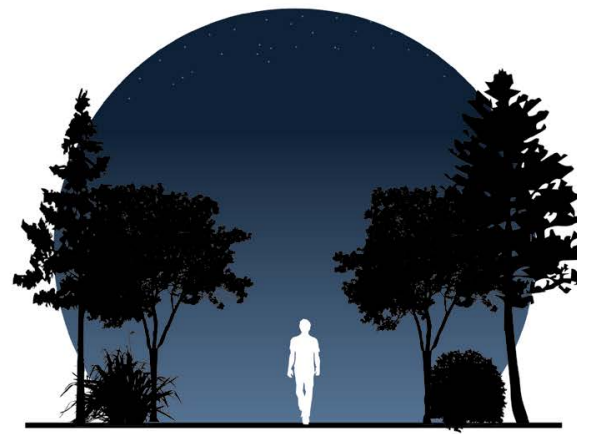

When vegetation lines are further apart and there is more open uninterrupted space in the site, it felt less enclosed and more comfortable
Less space between the vegetation strips increased fears of entrapment and negatively decreased comfort 
(c)
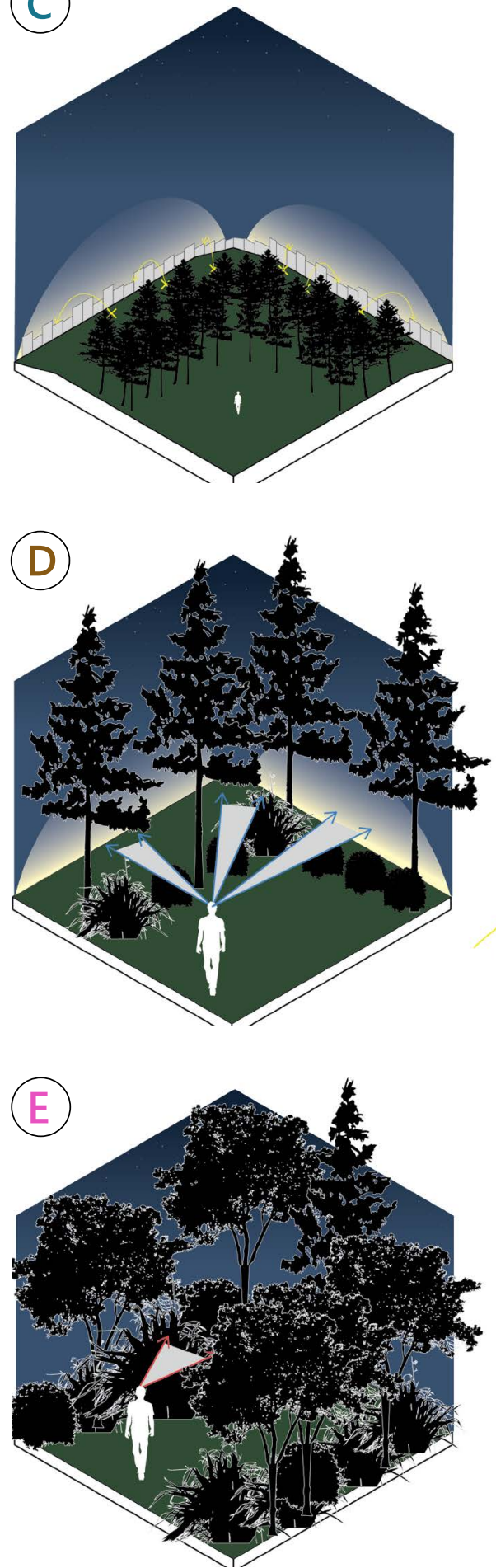

Star Visibility
Height of Vegetation

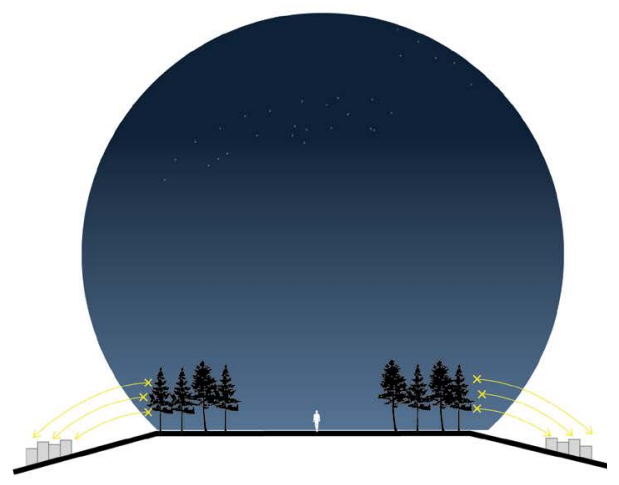

Less dense vegetation

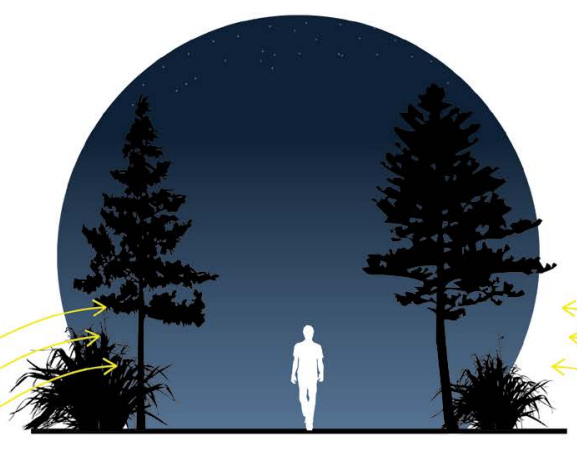

Very Dense Vegetation

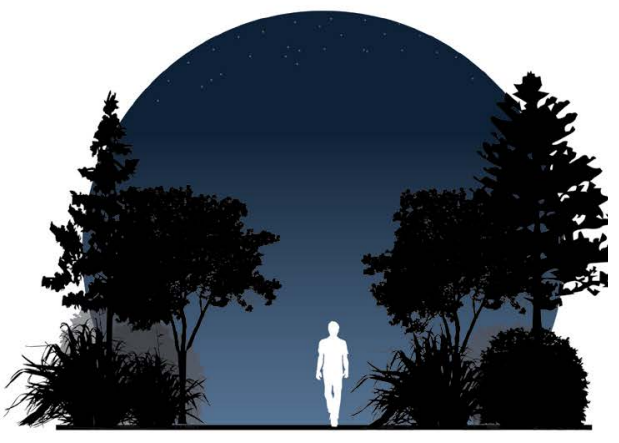

Overall comfort level

(A)

(B) 1

(c)

(D) 1

(E)

\section{(1)}

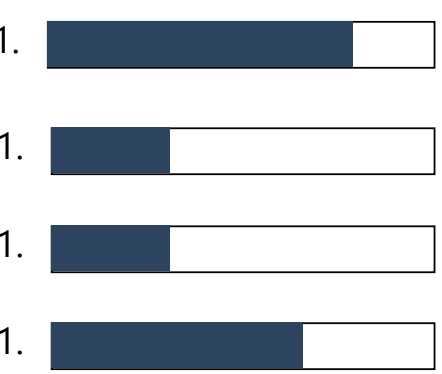

1.

1.

1.

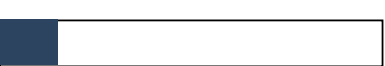

If the vegetation lines were further apart but the tree lines were very tall, this decreased feelings of comfort due to the loss of the surrounding visual sight of light.

When the distant environment was able to be seen through the vegetation, this increased prospect and positively increased comfort in the space, as the light provided visual stimuli to connect to

The fear of the unknown beyond very dense vegetation created fears of concealment and entrapment. However it shifted the focus to the night sky due to it being the only visual stimuli
(A) 1 .

(B) 1 .

(C) 1 .

(D) 1 .

(E) 1 .
L
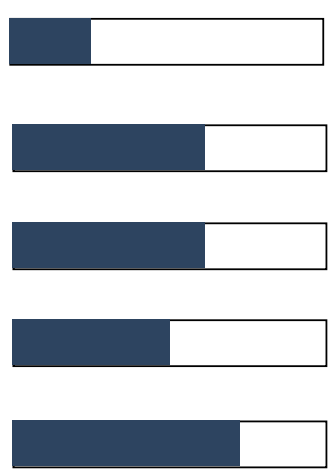


\section{Town Belt Analysis Findings}

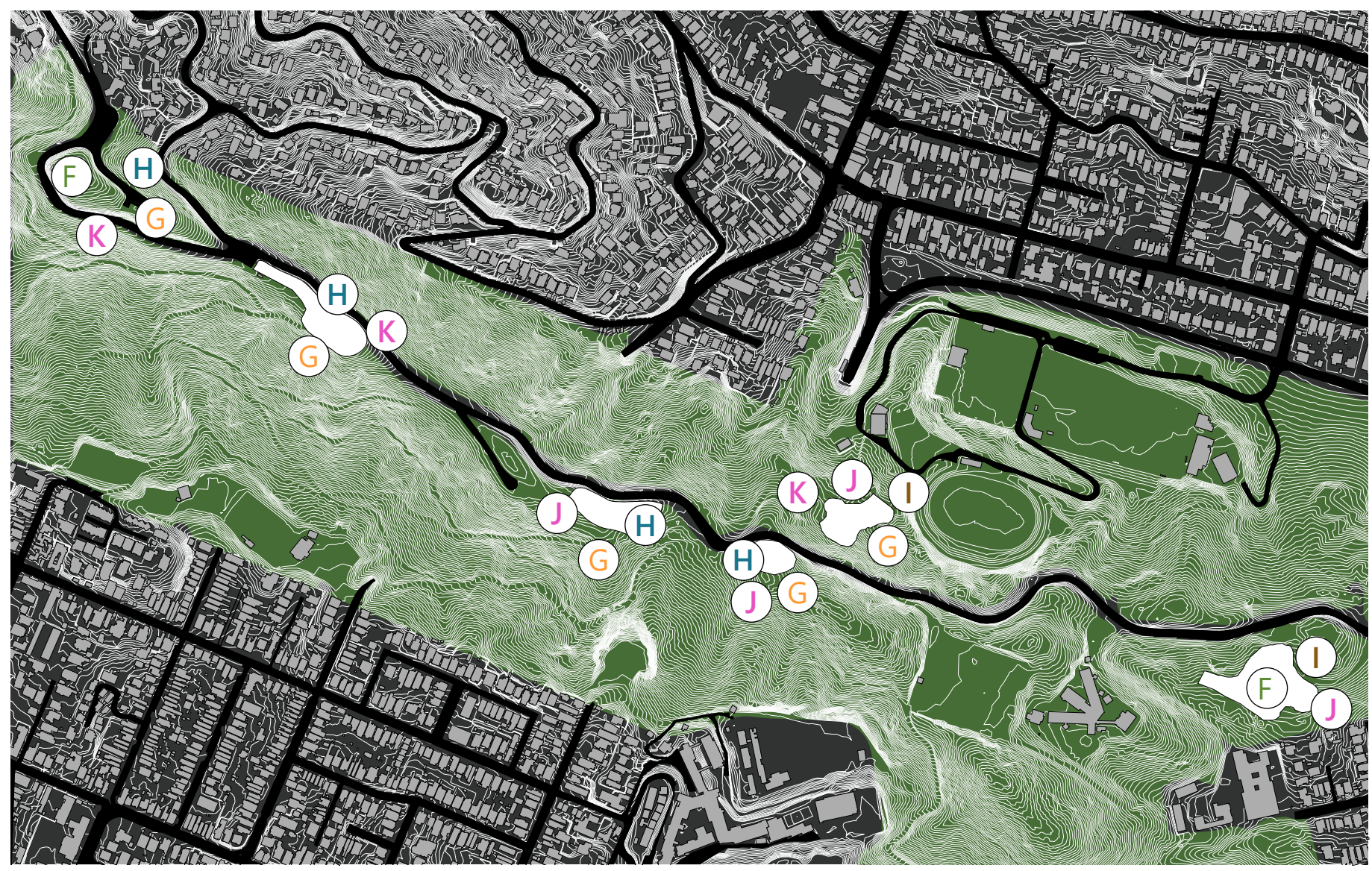

(F)
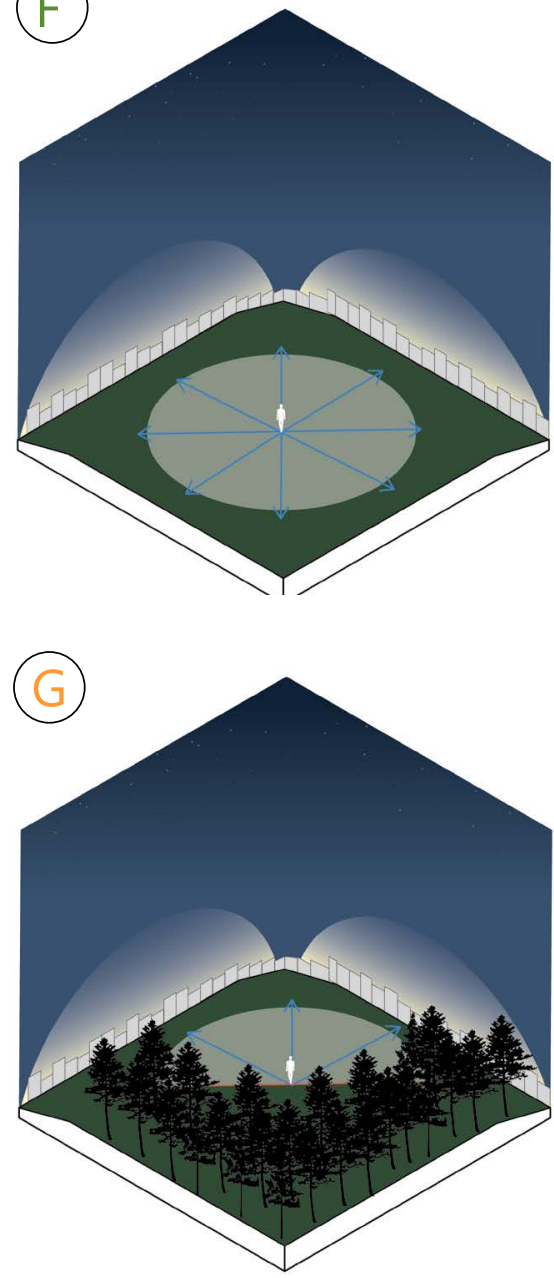

Available viewshafts

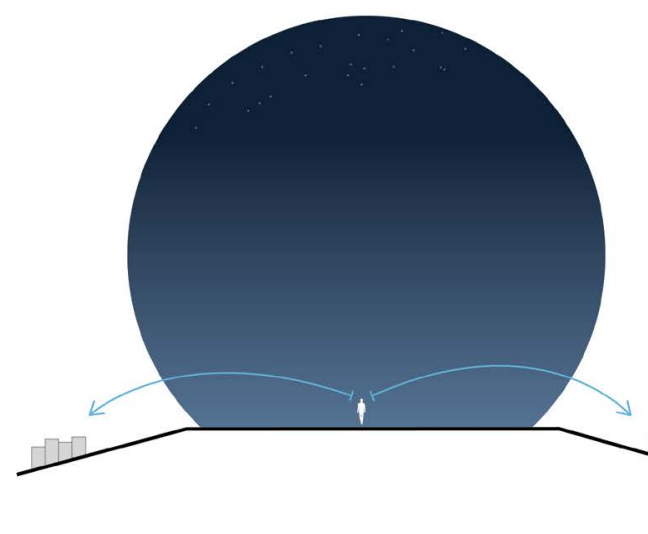

Less than $360^{\circ}$ viewshafts

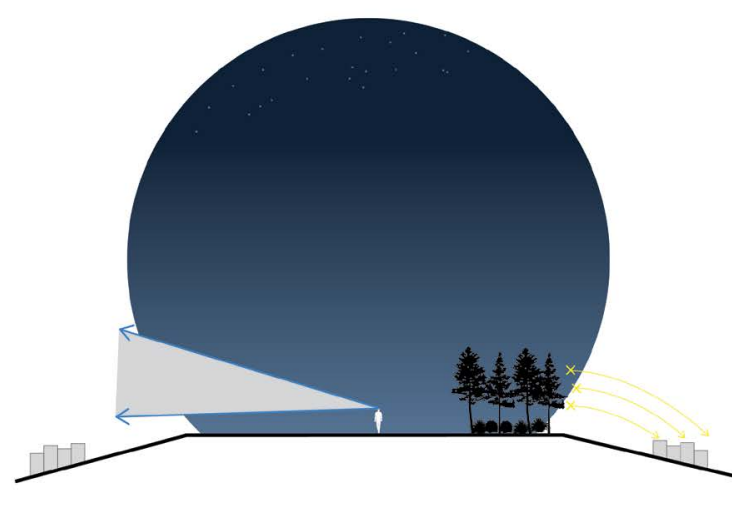

Where there were 360-degree views increased feelings of comfort.
Less than 360-degree views of the surroundings decreased feelings of comfort due to the possibility of entrapment. 


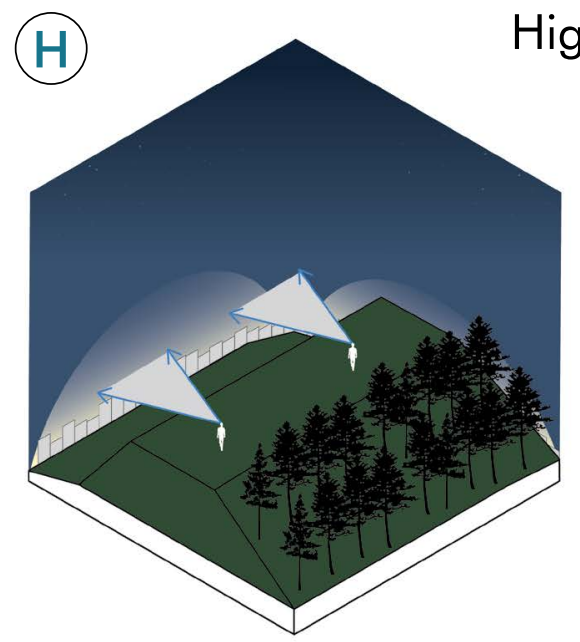

High elevation (compared to each other)
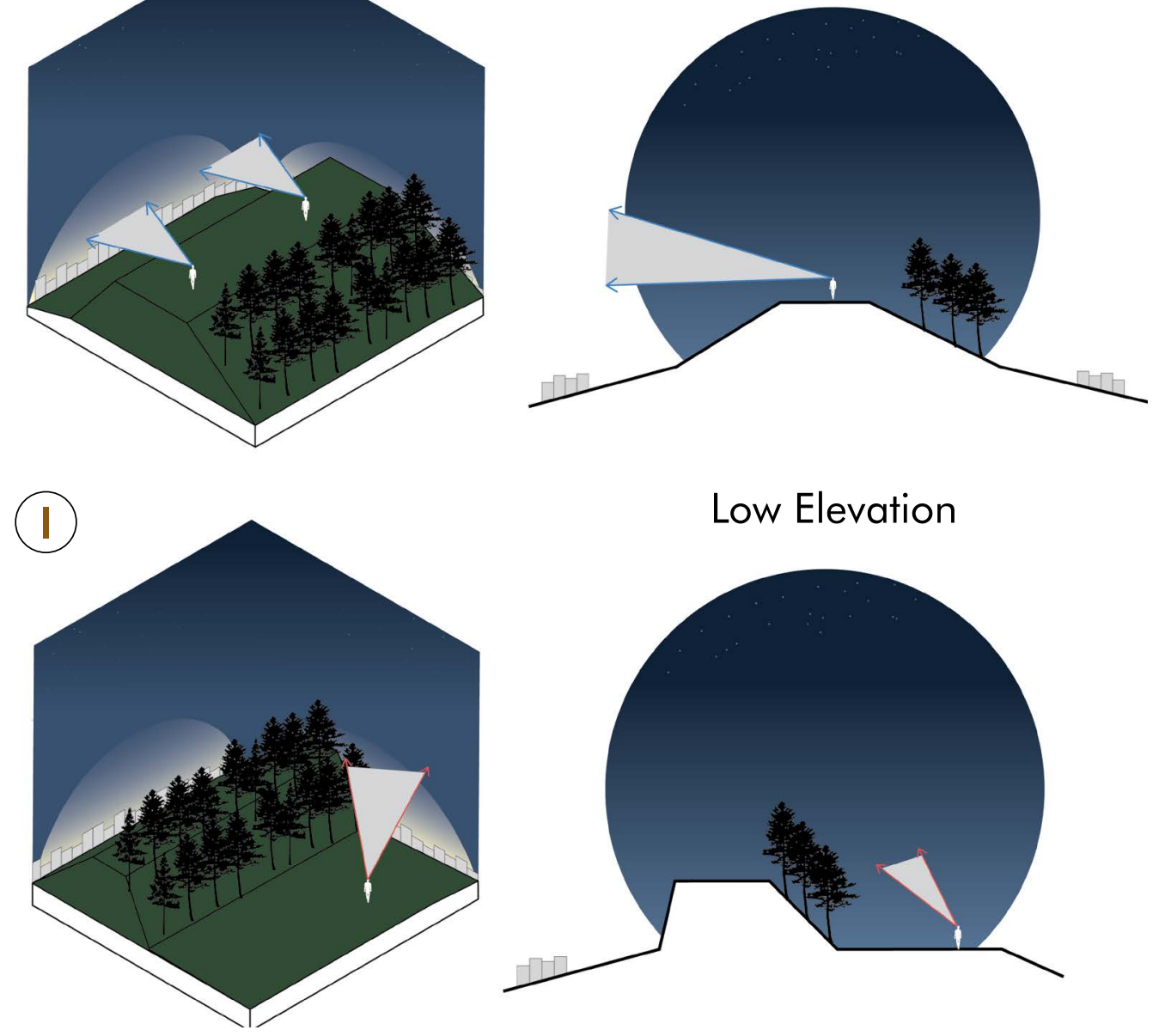

Sites at a higher elevation positively increased comfort due to increased prospect. However, high elevation and dense, close vegetation was frightening due to the fear of being exposed and unable to escape.

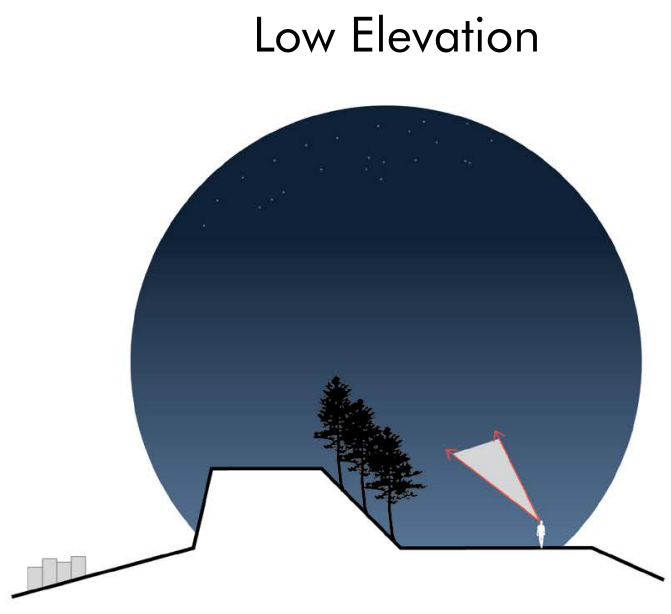

Sites at a lower elevation felt uncomfortable due to the fear of entrapment created by the dark silhouettes of the surrounding hills. However, the stars' view was better due to the reduced visible contact made with the city lights' glare.

\section{Materiality}

(J)

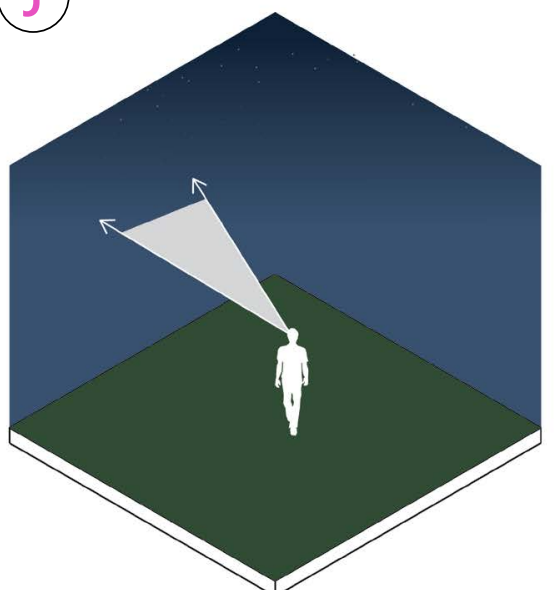

Star Visibility

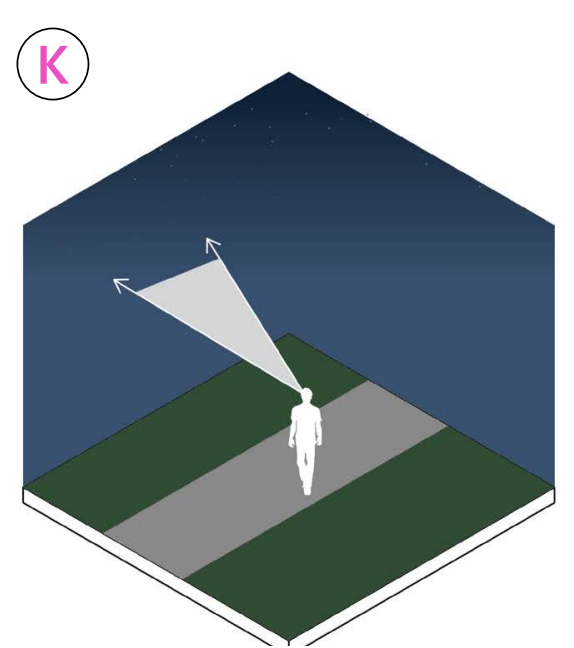

A change in materiality signified a purpose in the site. A gravel or concrete path signifies a human addition to the site and reminds the user they are in an urban environment close to home. In most areas, straying off the path negatively decreased comfort.

\section{Overall comfort level}

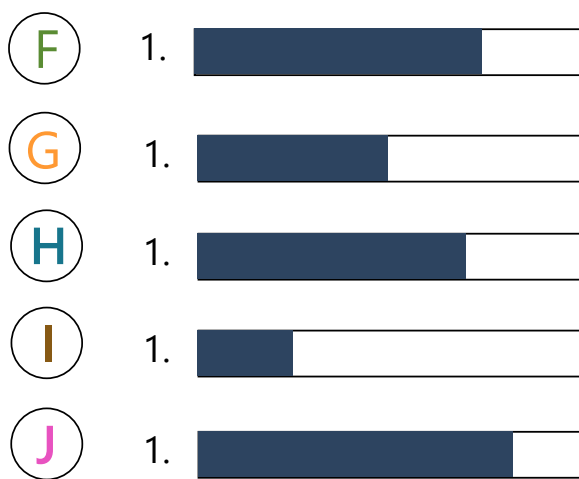

Grass
1.

Concrete 


\subsection{South Coast Analysis Findings}

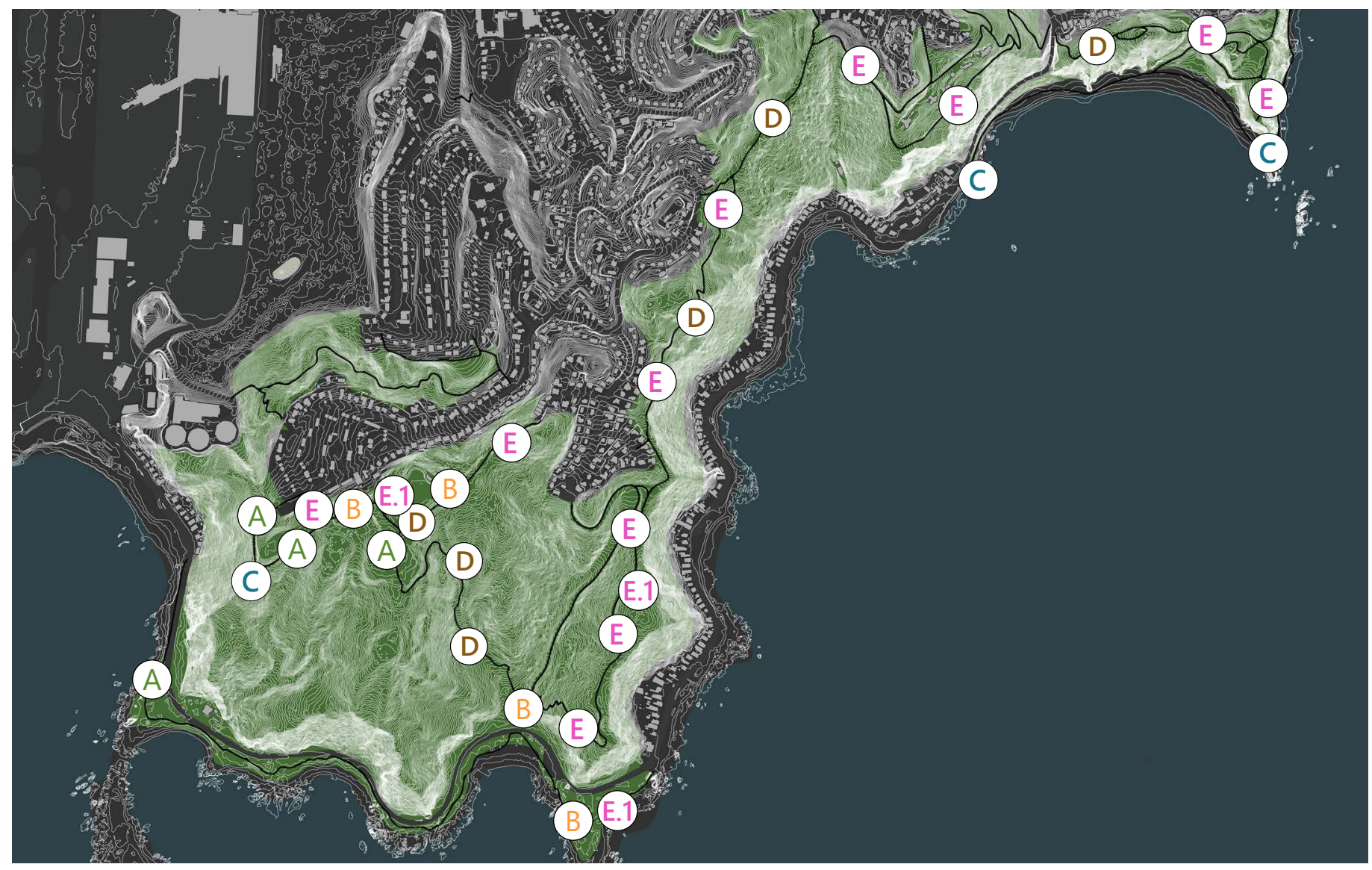

(A)

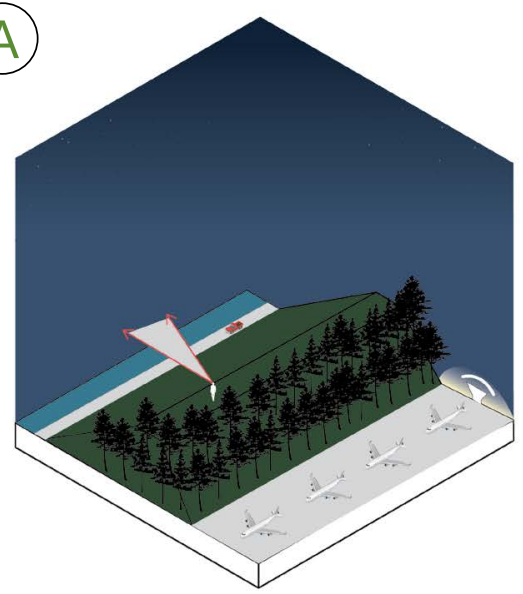

(B)

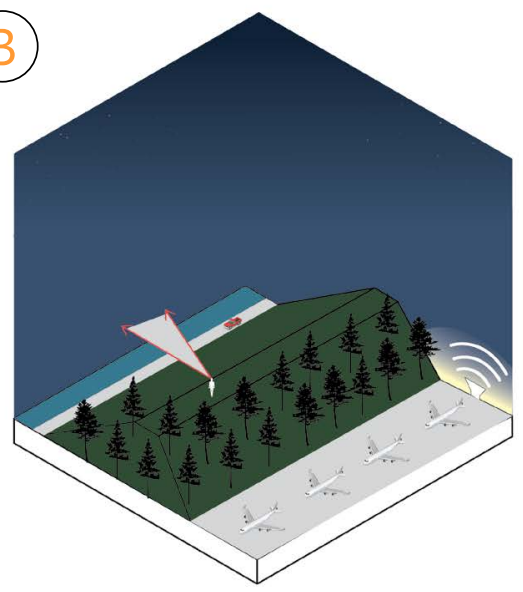

More Vegetation / Less Airport noise

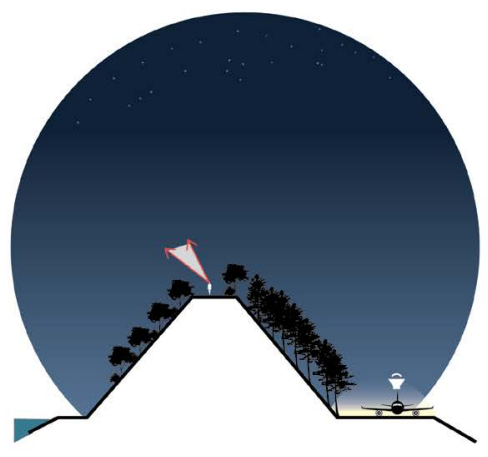

More vegetation increased feelings of entrapment but decreased surrounding industrial noise

Less Vegetation / More Airport noise

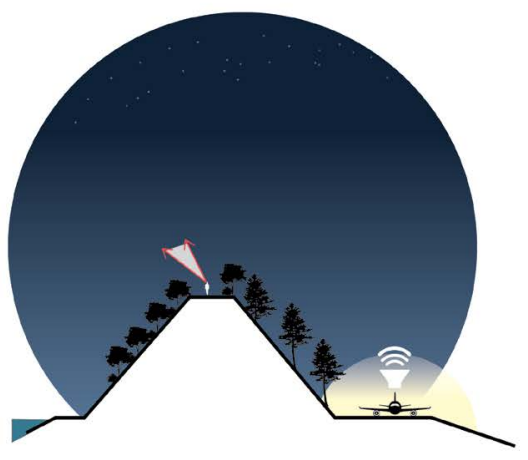

Less

vegetation decreased feelings of entrapment but allowed more surrounding noise to infiltrate disrupting the ambiance of the night time experience 


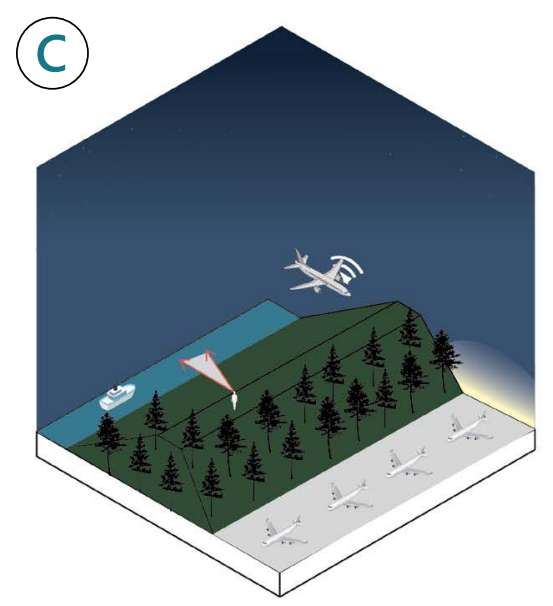

\section{Light \& sound from Planes and Ferries}
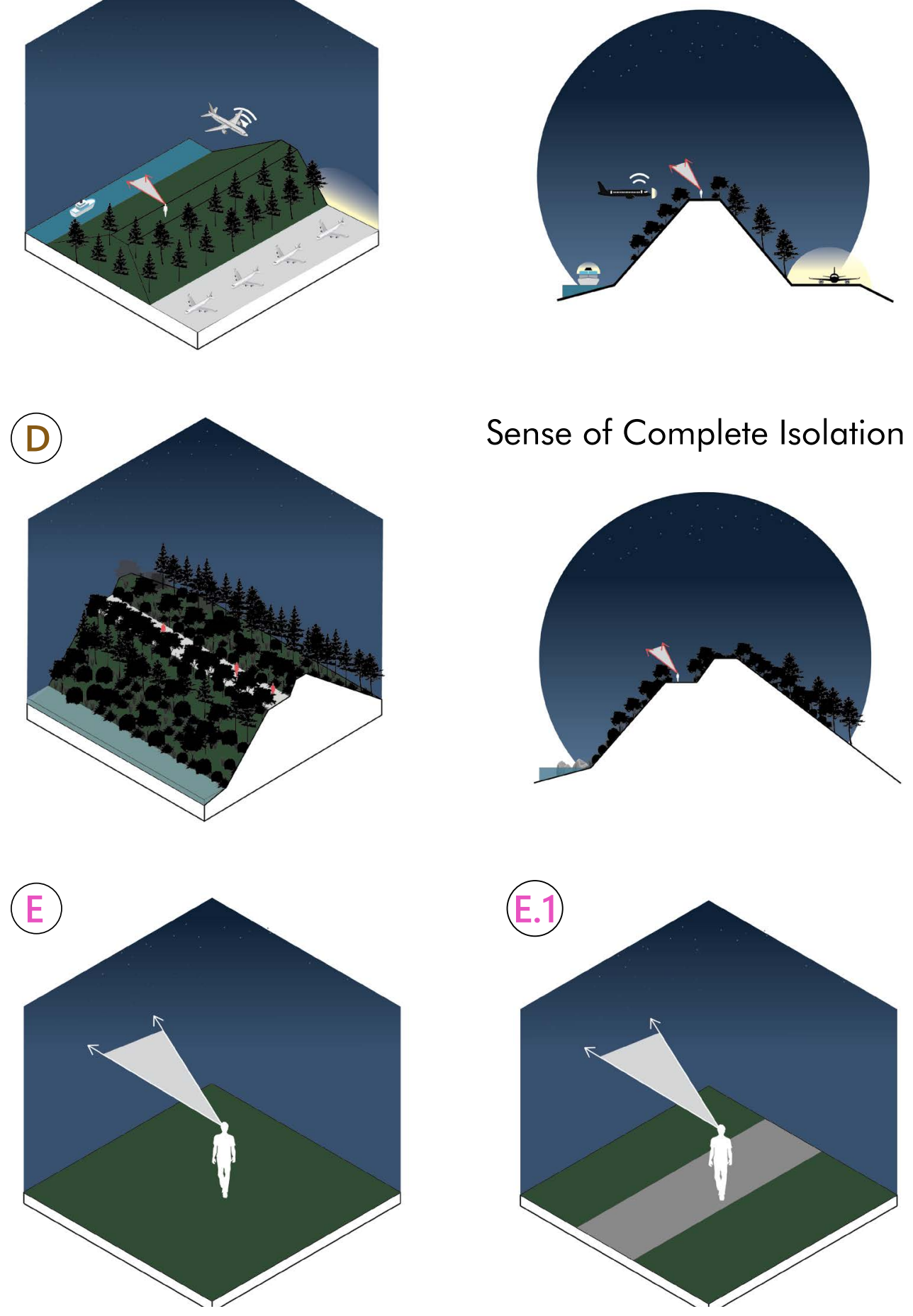

At certain positions, the feeling of complete isolation occurred where the sound and sight of the urban environment was completely shielded by the vegetation and topography. This was an unpleasant experience at first, but accustomed to once its benefits for star gazing were realized

\section{Materiality}

Grass, gravel and concrete were the common materials in the southern environment. A more relaxed feeling was felt in areas where a man made path was present

\section{Star Visibility}

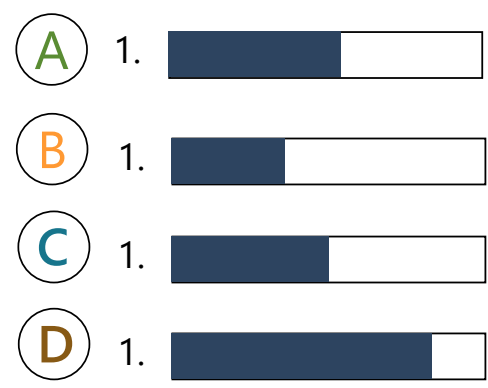

Overall comfort level

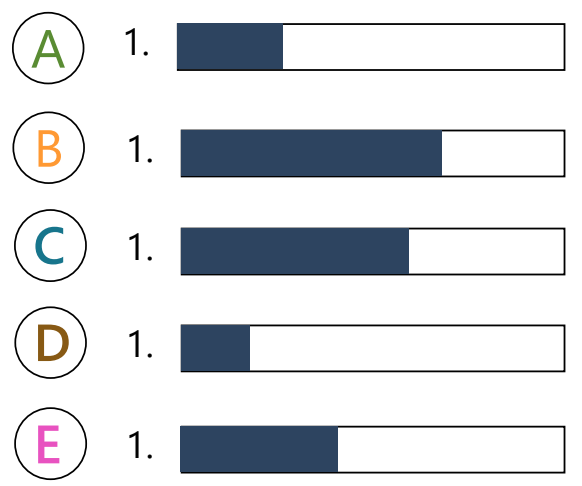

Grass
(E.1) 1 .

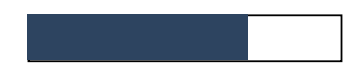

Concrete 


\section{South Coast Analysis Findings}

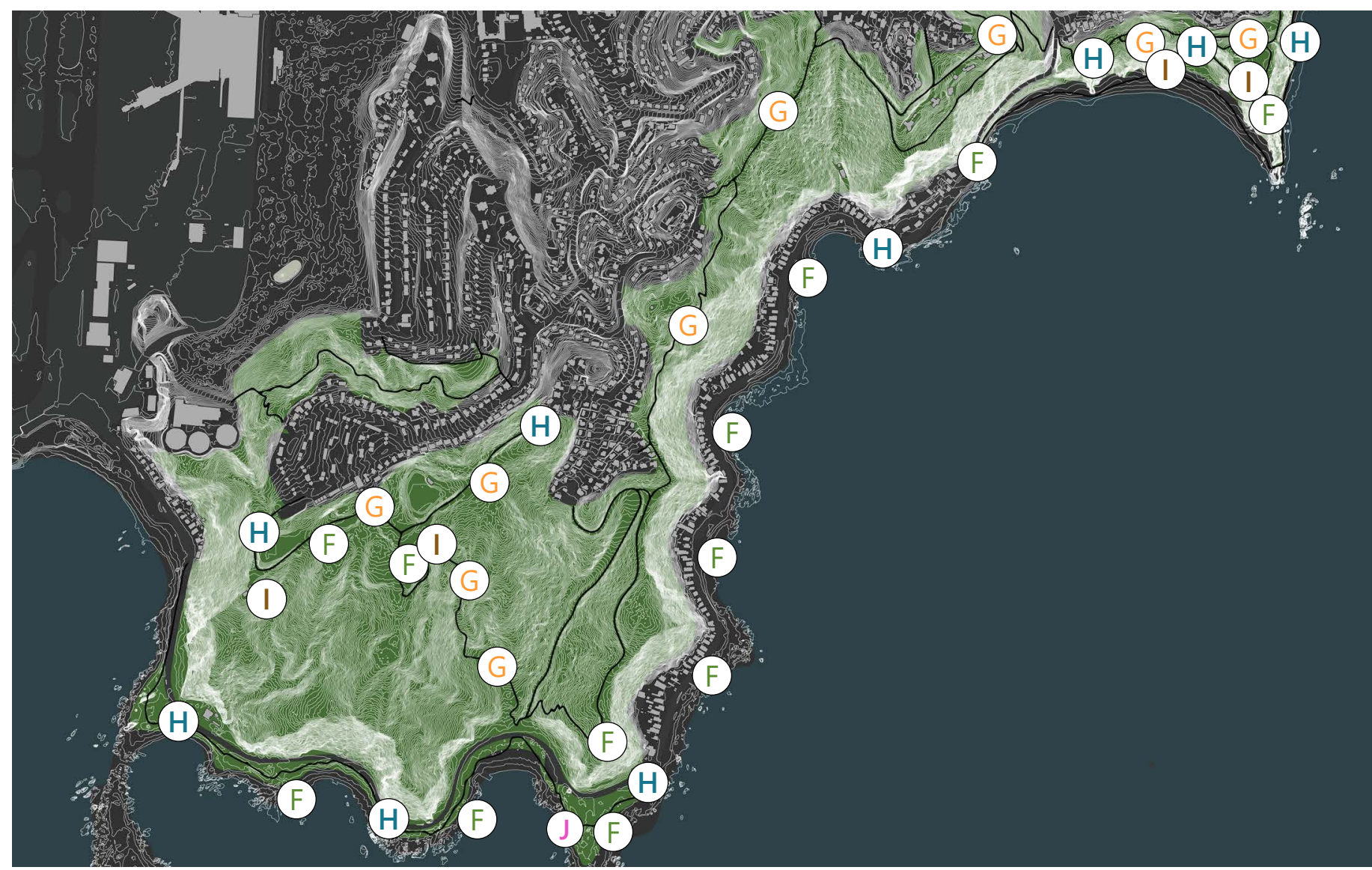

(F)
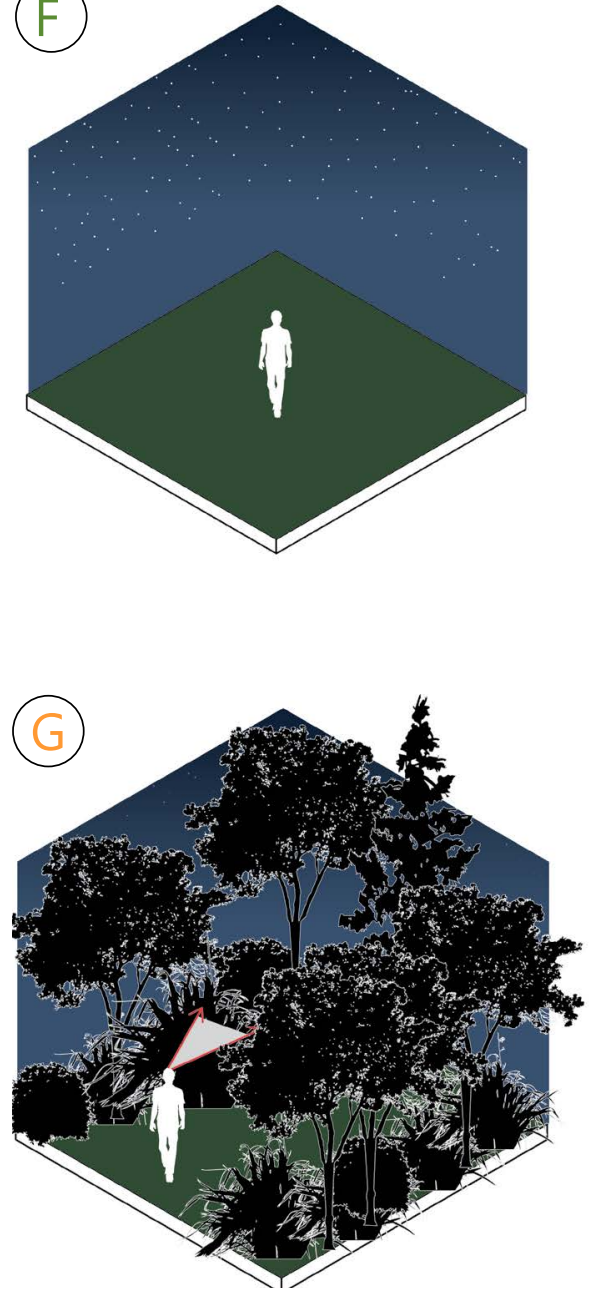

Less Light Pollution / More Stars

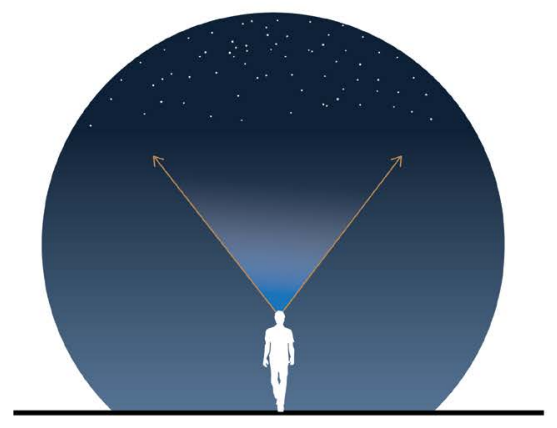

Dense Vegetation on both sides

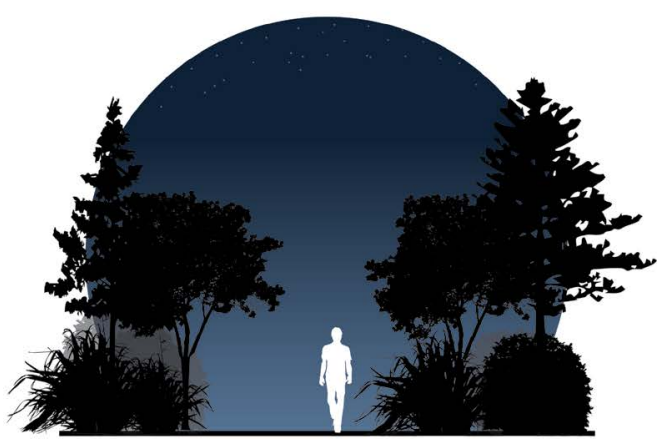

The amount of stars visible on the south coast far exceeded the what you could see in the two other study areas.
On the south coast, when walking along pathways with dense vegetation on both sides, it was very intimidating and uncomfortable. 
(H)
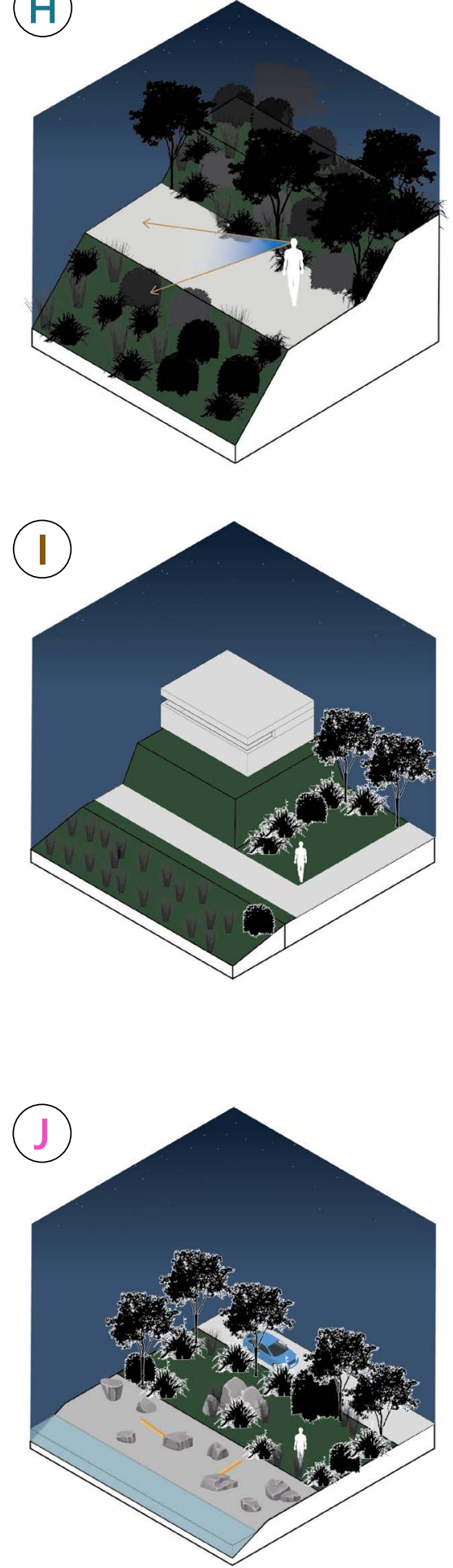

Star Quality

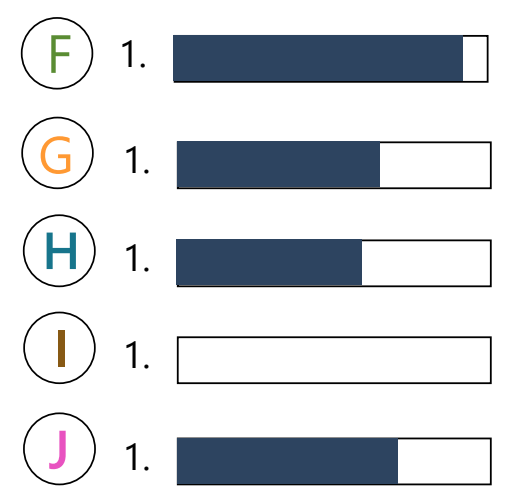

One side of Vegetation

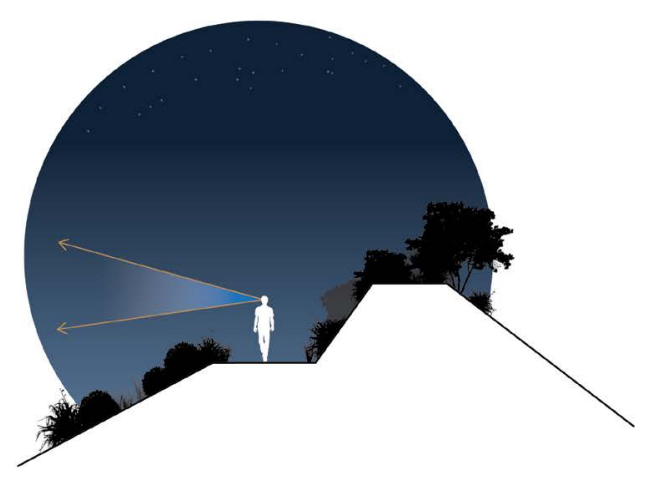

It was far more comforting when walking along pathways where only one side had vegetation lining it. When there was a view out across the ocean with the stars above, it was a lot more pleasant

\section{Remnants of Historic Infrastructure}

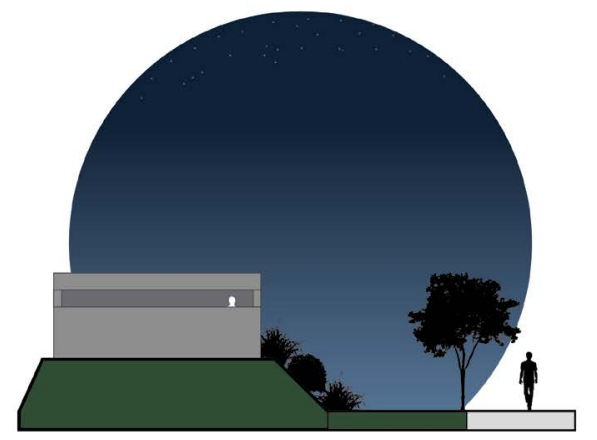

\section{South coast conditions}

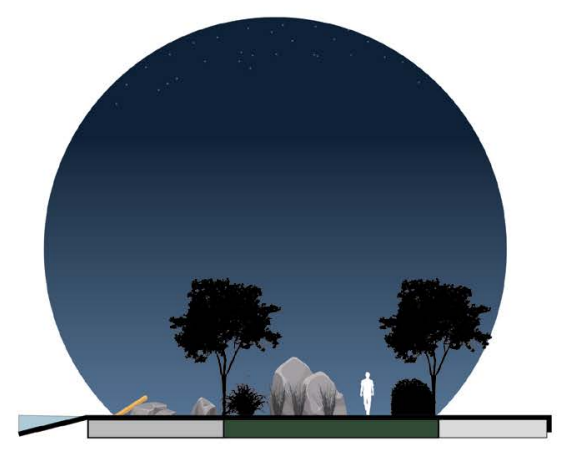

The south coast faces the cook strait, which generates many unpleasant southerly winds experienced in the site. But on calm nights, the sound and smell of the ocean and the stars above created a very serene experience

\section{Overall comfort level}

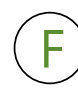

(G)

(H)

(1)

(D)
1.

1.

1.

1.

1.

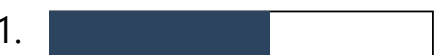




\subsection{Conclusions}

\section{Waterfront}

Impacts of Lighting on star and people visibility

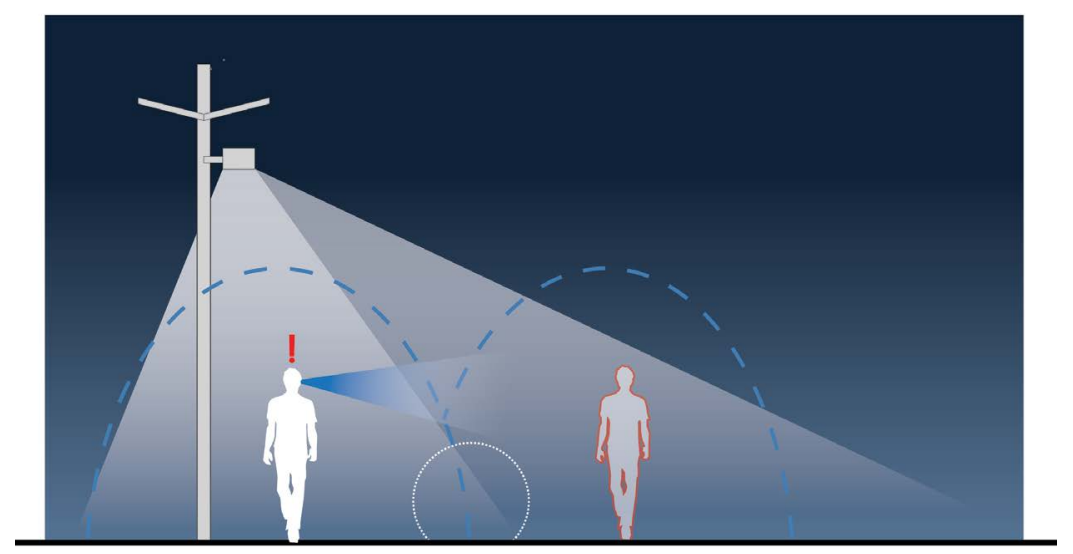

The glare of lighting can impair the sight of people standing directly behind the light.

As mentioned in the introduction, lighting has a direct impact on star visibility. The artificial sky brightness above all the waterfront spaces is relatively the same, but by allowing the eyes time to adjust, more stars can be seen in the sky in a specific space.

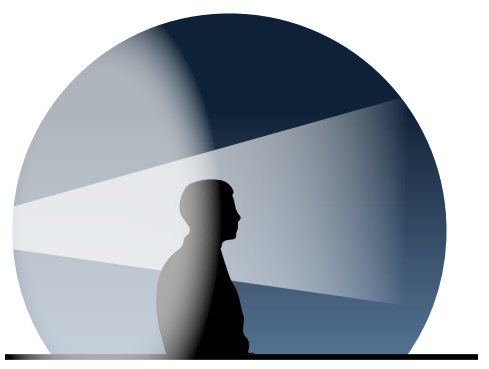

The glare of light in the peripheral vision is already interfering with our gaze upwards, increasing the time it takes to adjust to the night sky. Specific landscape characteristics that blocked the spread of light glare were given increased star visibility ratings due to this idea.

The relationship between lighting and seating

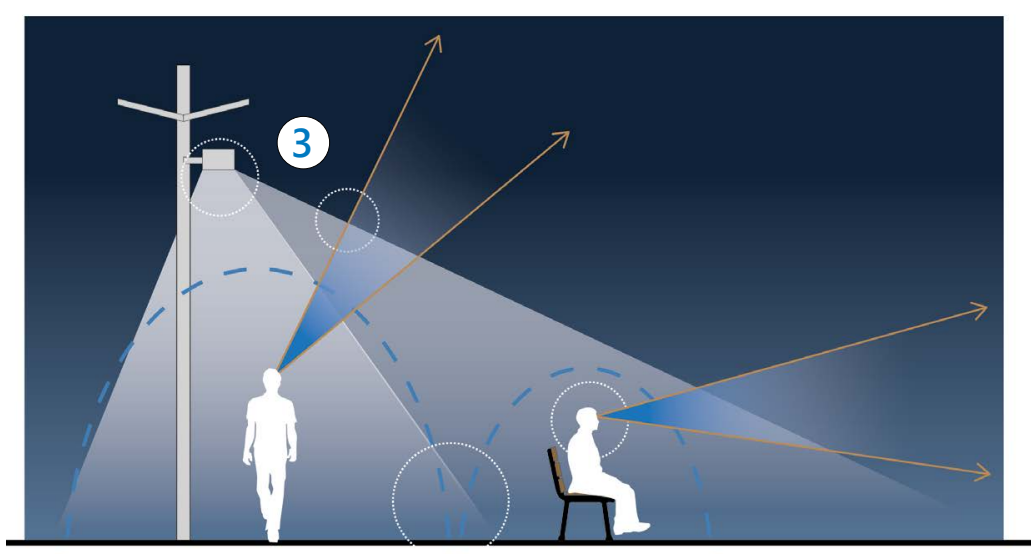

While they are shielded, light that shines down from above creates glare which prevents seating underneath from being used for stargazing (1). The seating angle prioritizes the view looking forward and can not afford prolonged time spent comfortably looking up at the stars (2)
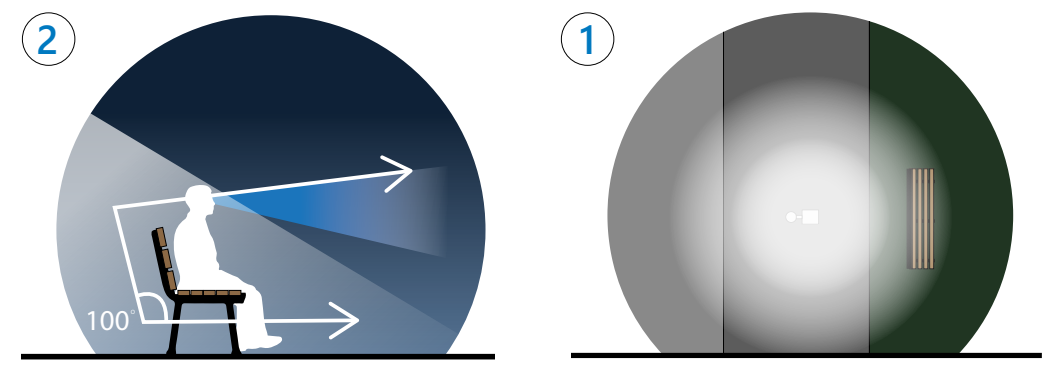


\section{Town Belt}

\section{Relationship between Surrounding Light and vegetation}

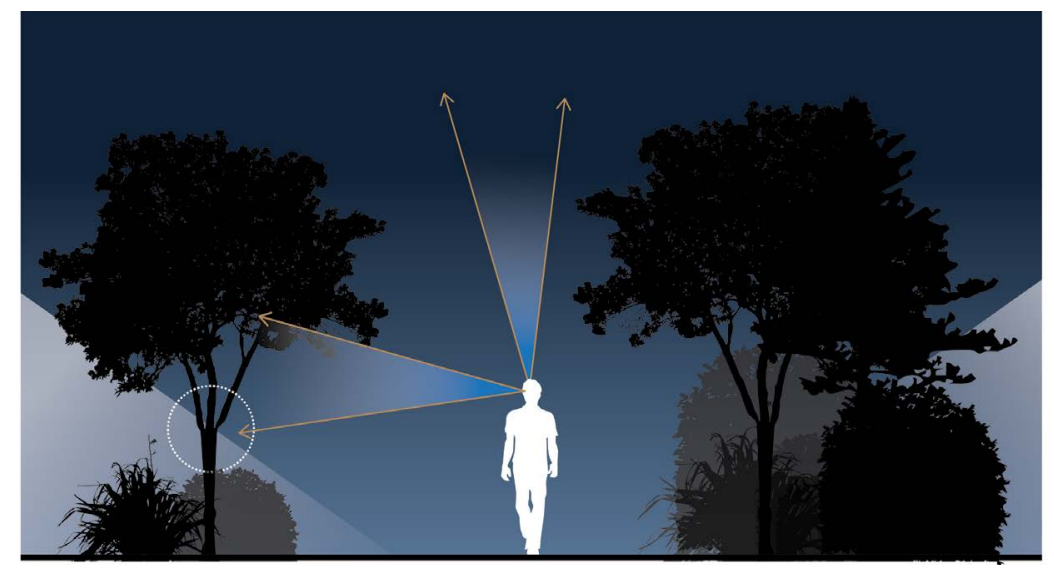

The findings from the analysis reflect the theories discovered in the theoretical framework. Vegetation that was close together was uncomfortable to be around; denser or taller vegetation often led to increased feelings of anxiety and discomfort, and the silhouette of the vegetation was frightening. However, as concluded from the waterfront, the vegetation blocked surrounding light from interfering with the gaze upwards.

\section{Relationship between elevation, open space and direction you're facing}

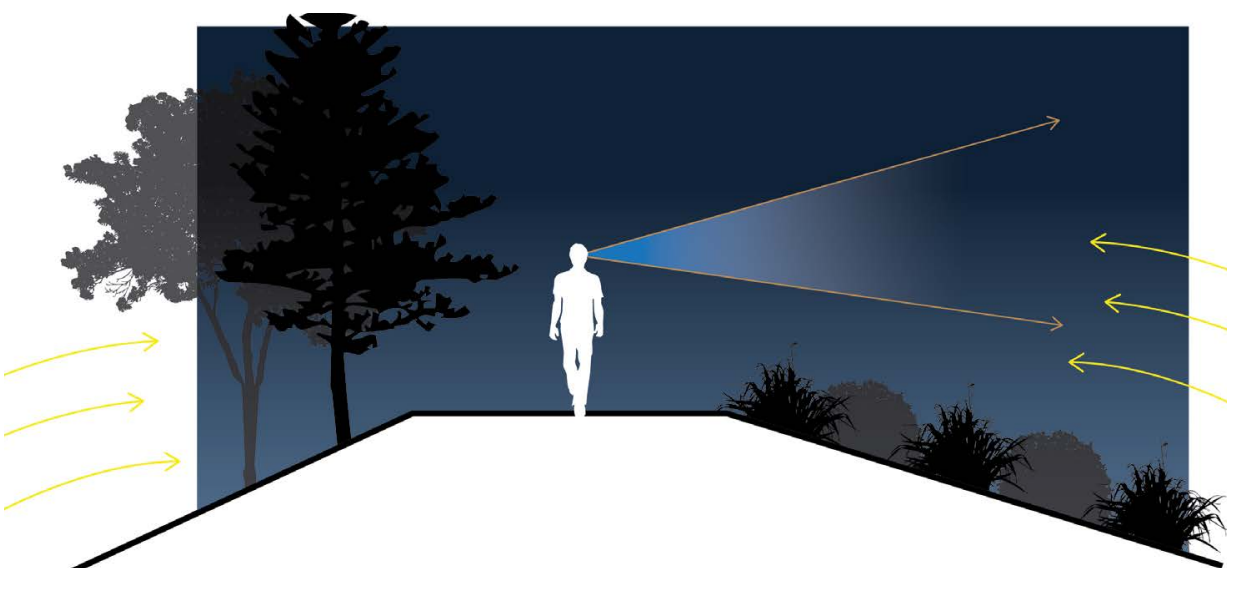

In general, being positioned at a site with a higher elevation often meant increased feelings of comfort due to increased prospect but impaired the night time experience due to the glow of the city/suburb lights entering the view shaft.

However, sites at a higher elevation with surrounding vegetation at proximity were more uncomfortable due to the decreased prospect then sites at a lower elevation with more open space. 


\section{South Coast}

Open Pathways for viewshafts important

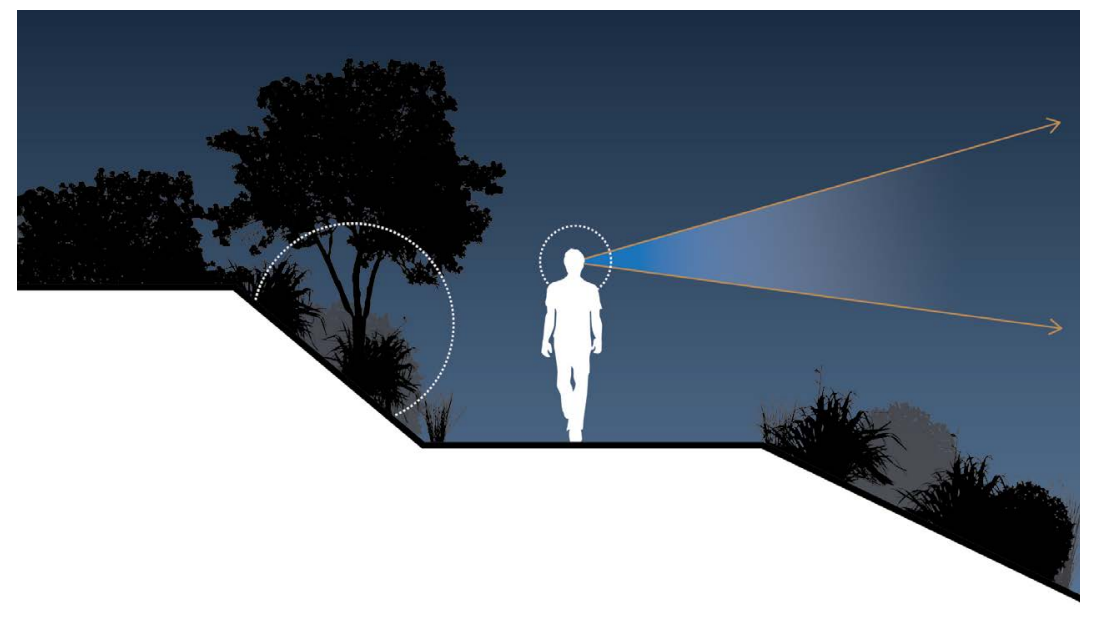

If there was thick vegetation on one side of the path, but an open view shaft to the ocean on the other, this increased feelings of prospect, not just because of the open view, but as the sight of the stars provided visual stimuli to focus on, resulting in a decreased focus on what was unable to be seen.

With the surrounding light blocked by the topography and vegetation, this afforded full engagement with the sky through the use of the other senses.

Increased use of and reliance on other senses

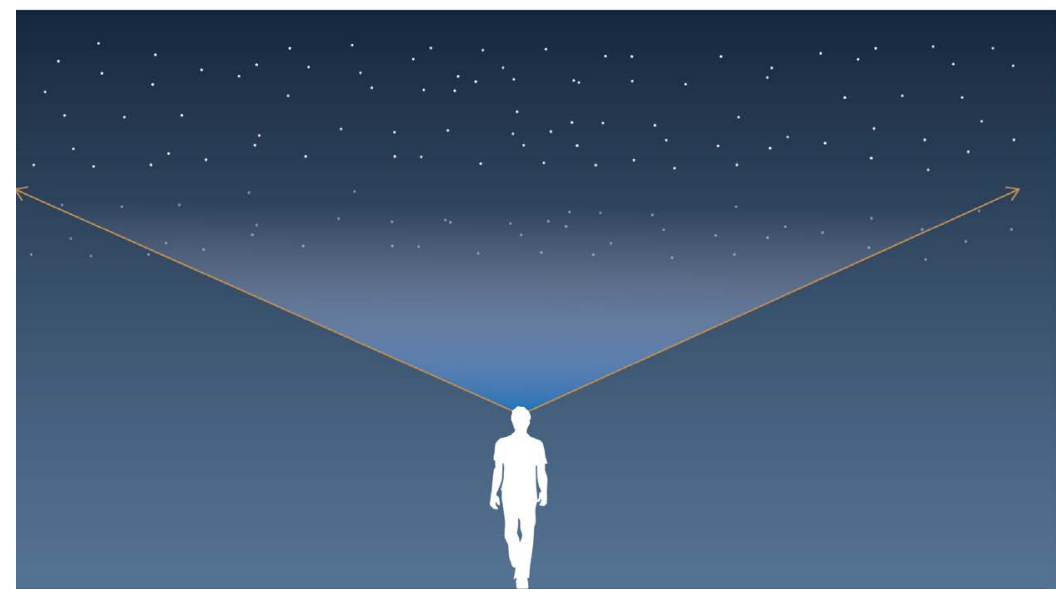

With the surrounding light blocked by the topography and vegetation, this afforded full engagement with the sky through the use of the other senses. 


\subsection{Reflection}

These Fieldwork Findings conclude that it is essential to explore every relationship between the landscape features when considering the night time experience. Each of them has its purpose during the day, but they need work cohesively at night to provide an experience that encourages stargazing. Four primary relationships were derived from the findings, which are between:

- Lighting and the view upwards

- Lighting and seating

- Vegetation and perceived comfort

- Elevation of the site and perceived comfort

These relationships were broken down further into three primary landscape features to be explored in the Design Toolkit and later applied to specific sites. These are:

- Lighting

- Vegetation

- Seating

Elevation of the site justified the site selection following the testing in Design Toolkit.

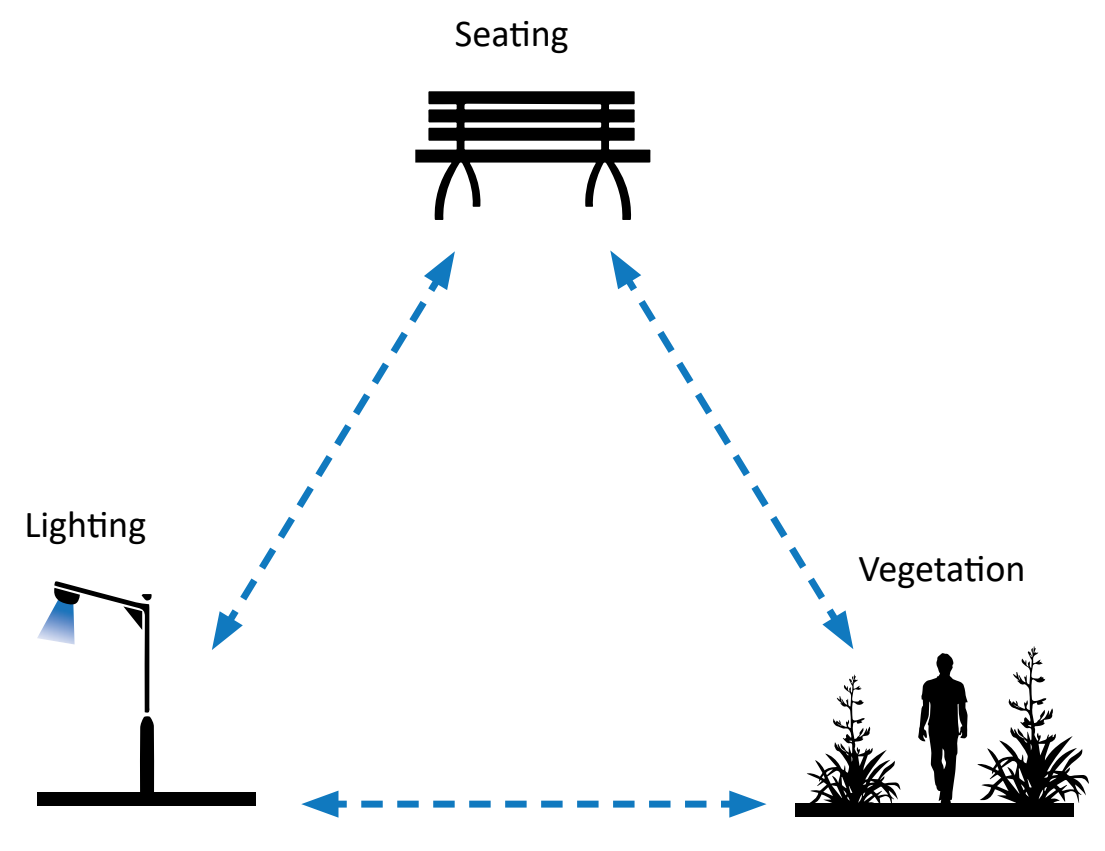



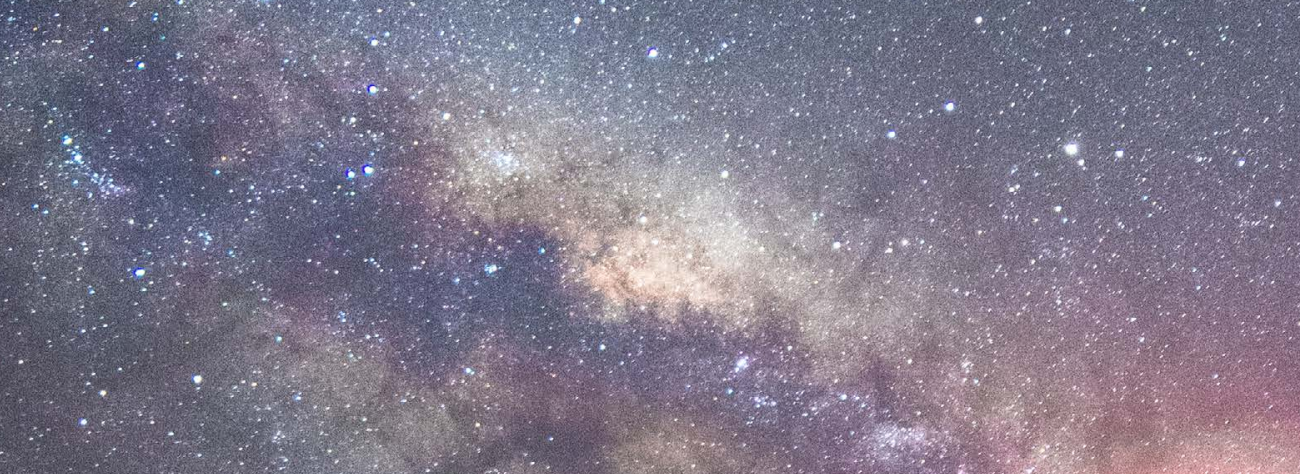

\section{TOOLKIT EXPLORAT ON}

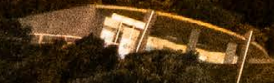

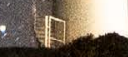

.
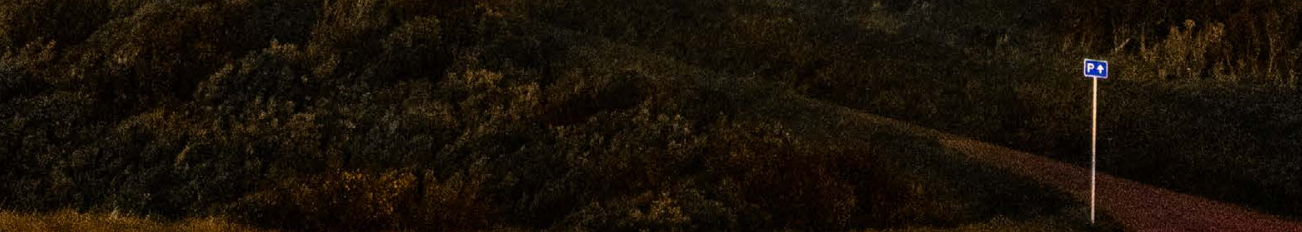


\section{Introduction.}

The toolkit was a method of generating design ideas that could improve the night time experience. The toolkit's goal was to assess specific landscape features' individual ability to provide a better night time experience or tarnish the ability to have this experience. The relationships between each feature and the night were researched in further detail with design solutions offered on their re purposing from day into night. 


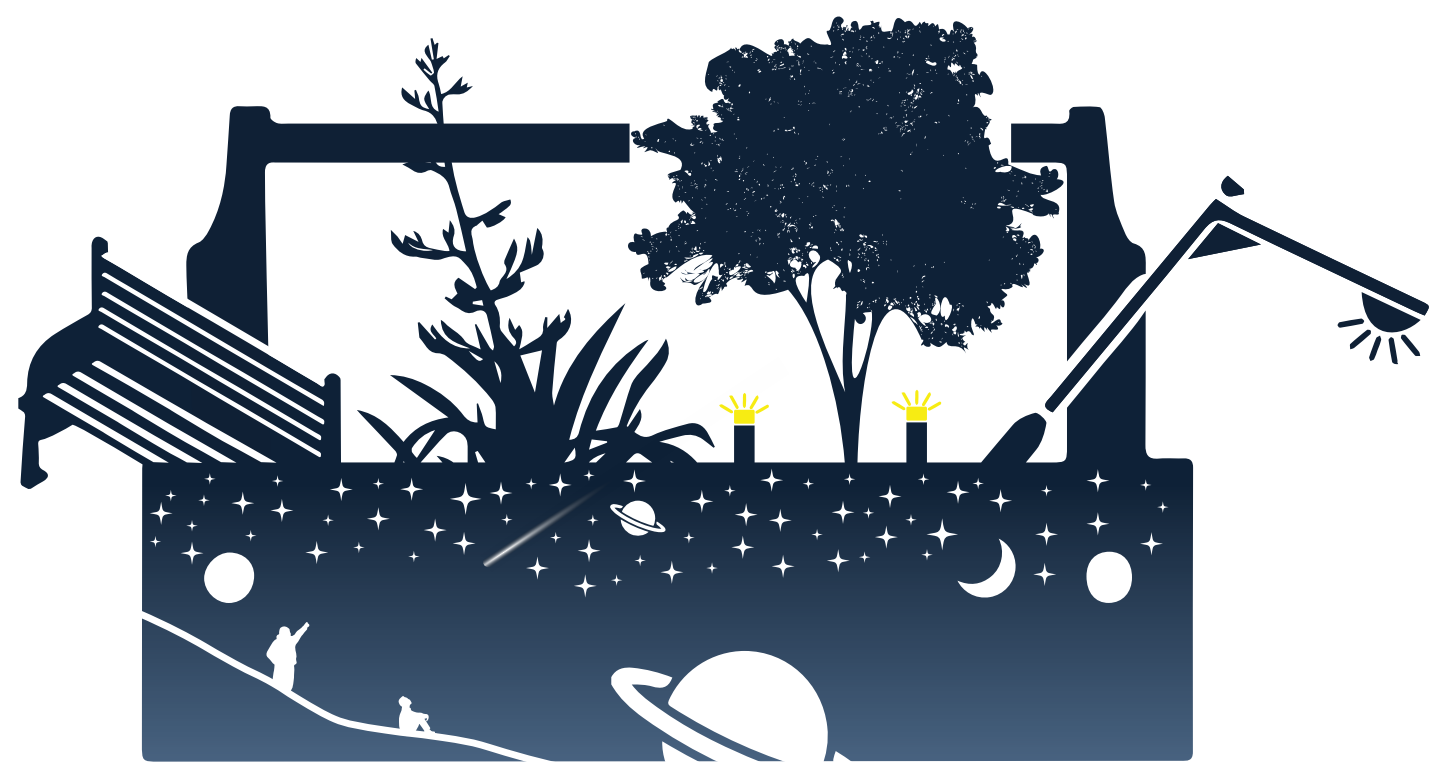

Fig 6.2 The Design Toolkit 


\subsection{Toolkit}

Three Landscape characteristics/relationships were identified from the analysis and backed up by the literature and case study findings to have the most critical influence on the nighttime experience. These are:

- Lighting \& night experience

- Vegetation Structure \& Lighting

- Seating \& changes in view

These affect our perception of comfort at night, impact the number of stars we can see in the sky and change the direction we gaze in public space.

The toolkit first illustrates the current utilization of the feature as seen in the three areas, then pinpoints the exact problem that negatively impacts the experience at night. 


\subsection{Lighting \& night experience}

Lighting is the most crucial landscape characteristic to consider when designing the night time experience.

Lighting standards are complex, detailed, and well-researched, and this thesis does not propose to ignore this.

Despite repeatedly concluding that the current lighting methods are detrimental to the night time experience, lighting still increased perceived safety, but not because of the increased visibility. There were areas on the South coast that felt just as comfortable as fully lit areas on the Waterfront-visually connecting to surrounding light sources, either in the distance or immediately, increased comfort in darker, more enclosed areas. The toolkit investigates repurposing light first not to impair the night sky's view and second provides a visual aid so that people have something to focus on while adjusting to the darker environment. Overall it investigates how new lighting techniques can encourage social interaction. 


\section{Current Utilization and understanding of Lighting}

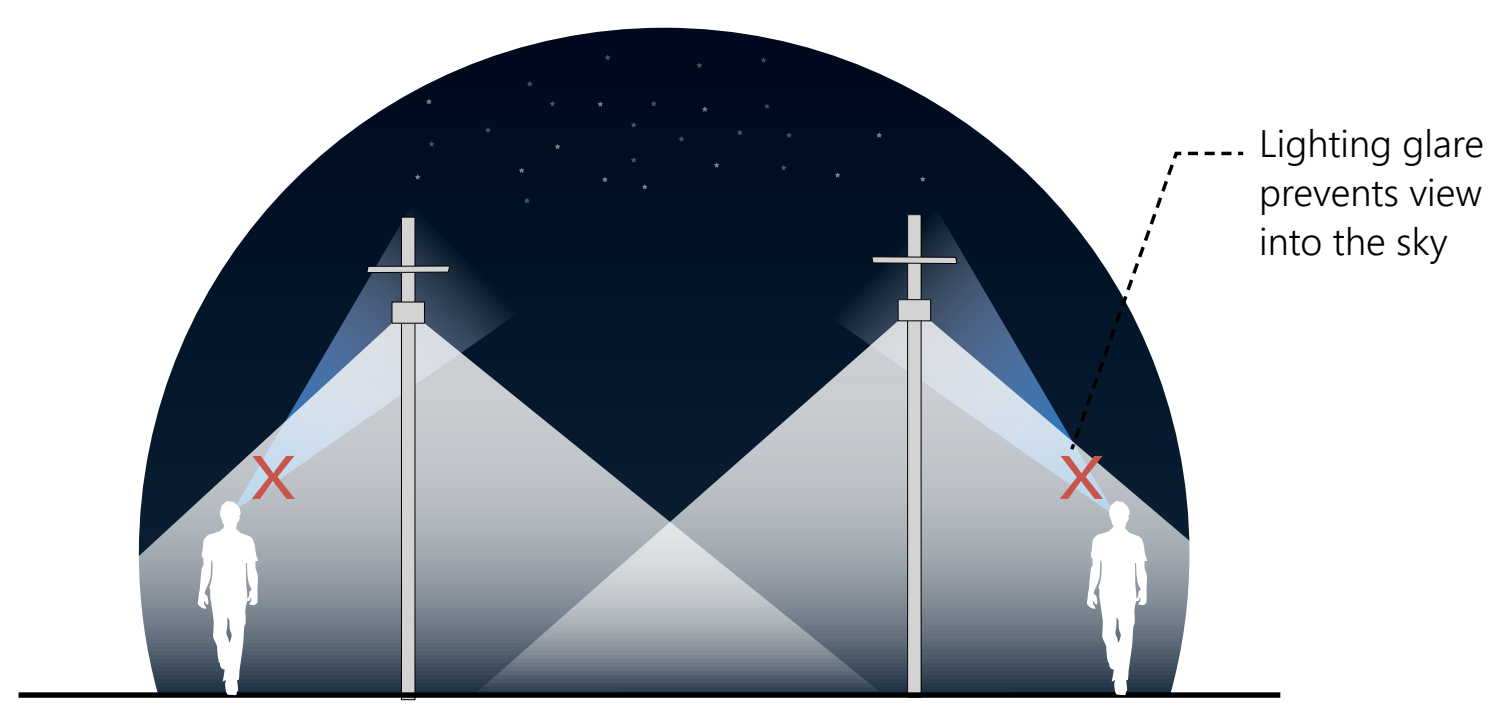

Potential of Lighting

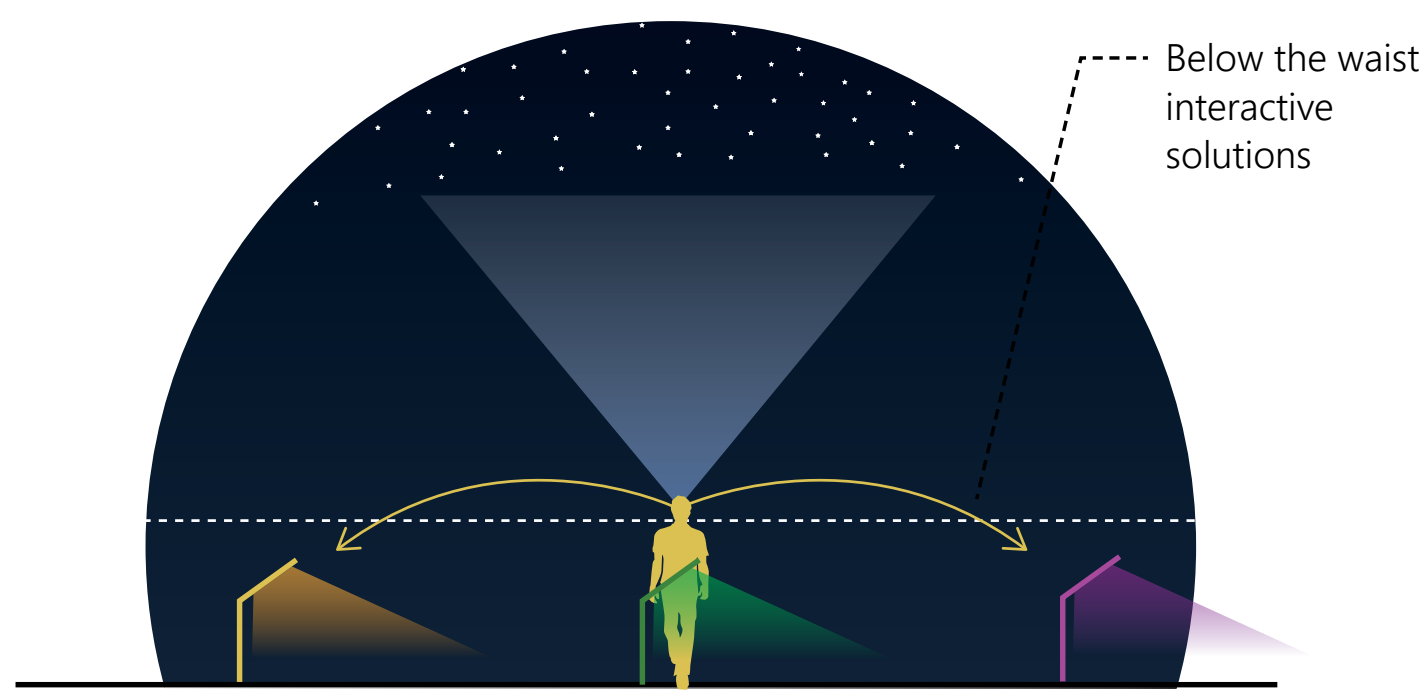

Fig 6.4 Existing vs Proposed Lighting 


\section{Revisiting Literature}

The findings from the precedents present a variety of methods for encouraging interaction with space at night.

Lighting was utilized as a visual marker, something to focus on; instead of illuminating the space to make you feel safe, it provides stimuli to reduce the heightened sense of awareness.

Six lighting alternatives were generated that could be used individually or in conjunction with each other:

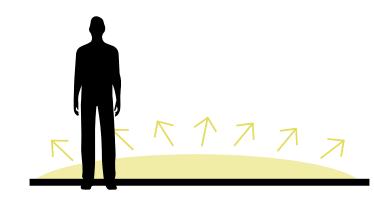

Low illuminance lighting solutions

Simple shielded path lighting that shines from below the waist

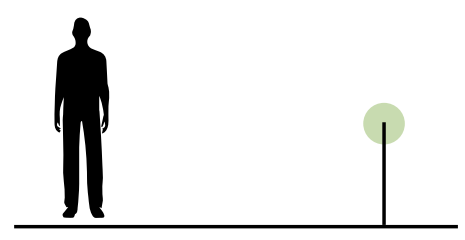

Using light as a visual marker (similar to tape around trees on bush walks) 


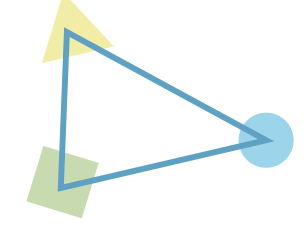

Small scale design elements in different locations

Multiple small scale interactive lighting elements focusing on colour

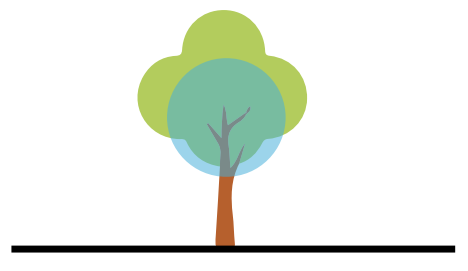

Using a sites natural features to display lighting

Using natural features on the site as placeholders for lighting fixtures

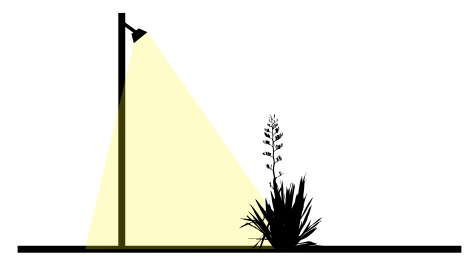

Vegetation used to create spaces between lighting for stargazing

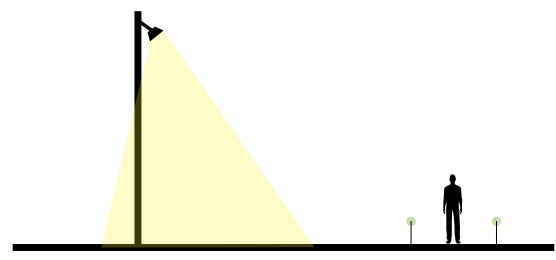

Lowering the overall illuminance of the overhead lighting and subsiding the lost illumination with lower path lighting 


\section{Lighting Solutions}

(1) Remove excessive lighting

- The removal of every second and third light with vegetation in between the gaps would create dark spots to be used for stargazing. A reclined seat can then be placed in this area.
Overall comfort level

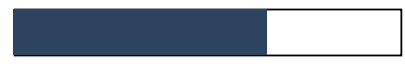

Star Visibility

(2) Using natural features to hold the lighting

- The natural features can be used as placeholders for various lighting types with multiple different colours to create an ambience. However, this could prove disruptive to natural wildlife living in the vegetation at night.

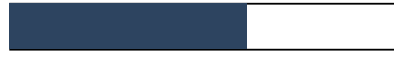

SV

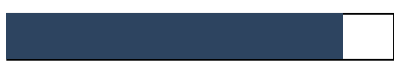

(3) Using spot lighting instead high illumination lights

- If light shining down from above is essential, spotlighting can illuminate one half of the space, while the other half can be set up for stargazing.

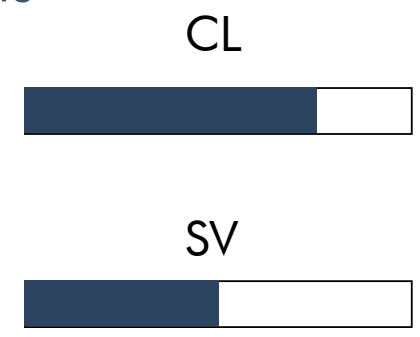



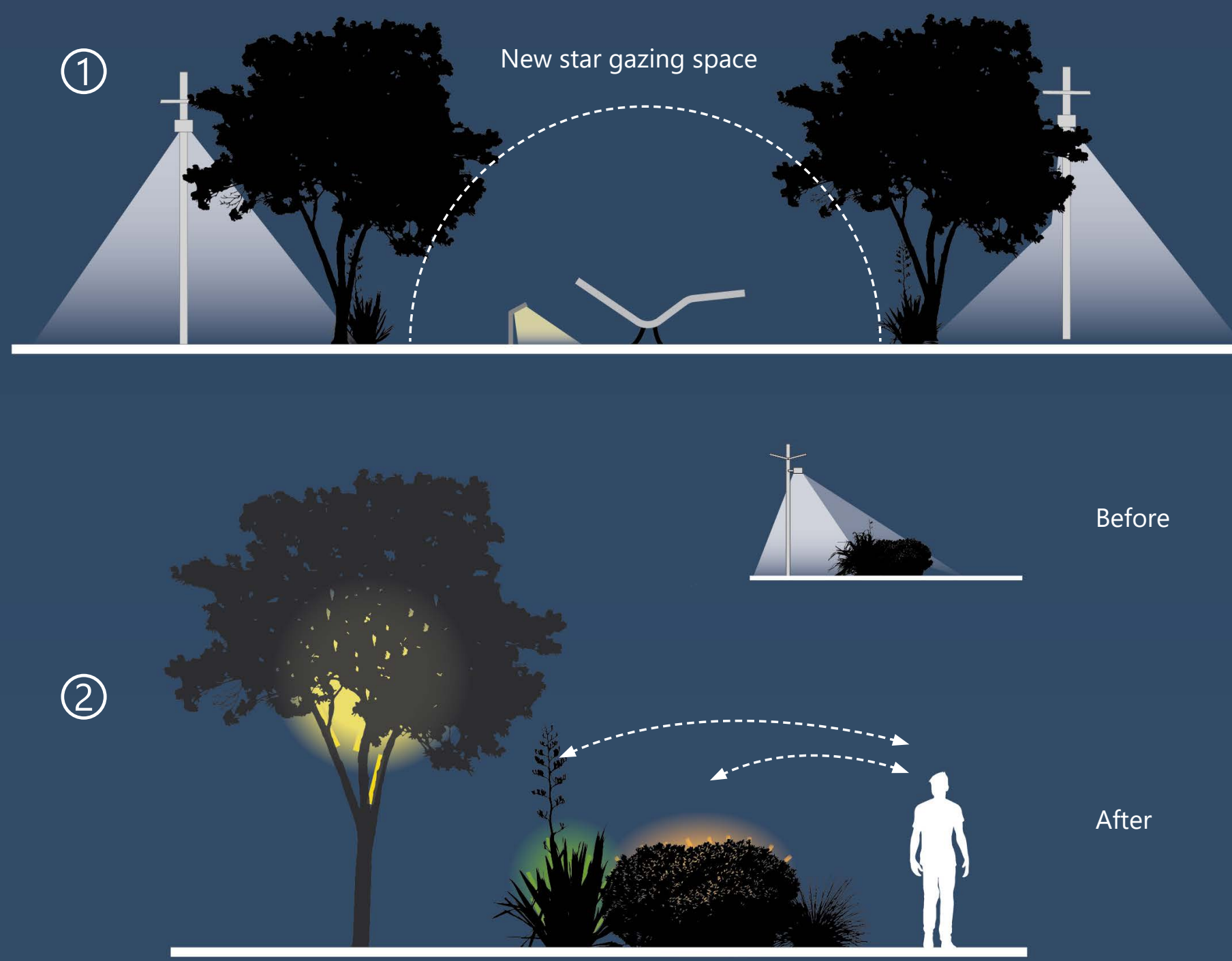

Before

Various colours used to create different emotions

Vegetation sets new boundary

(3)

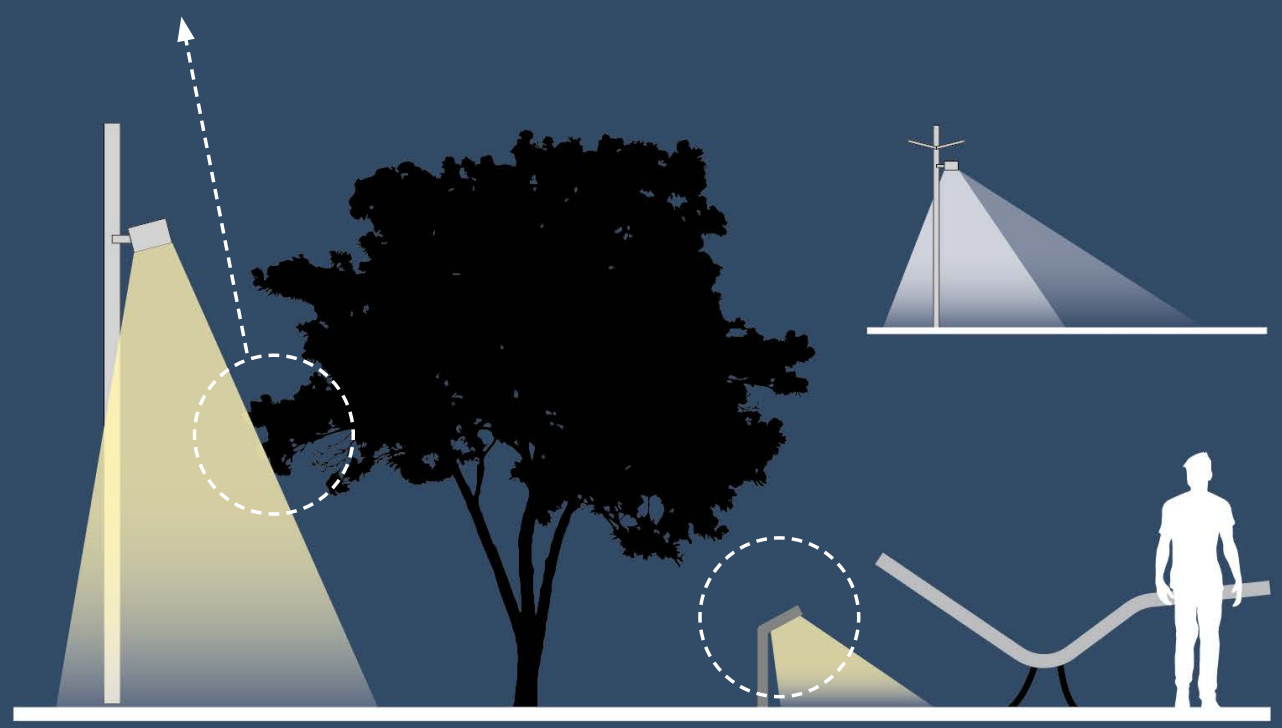

Before

Path lighting shows direction to seat for star gazing 


\section{Lighting Solutions}

(4) Path lighting

- Path lighting focuses on only illuminating a specific area as the primary path while leaving the surrounding area in darkness.

(5) Using light as a visual marker

- Removing all lighting and replacing with lights with a very minimal glare that serve as visual markers to follow This would be possible in areas still well illuminated from the surrounding light entering the space

(6) Multiple small scale interactive lighting

- Light sources serve as interactive installations that encourage people to visit the space and gives them visual stimuli to focus on so as not feel anxious.
Overall comfort level

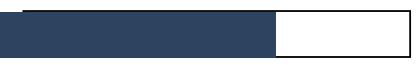

Star Visibility

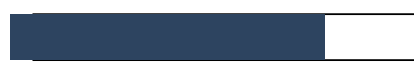

$\mathrm{CL}$

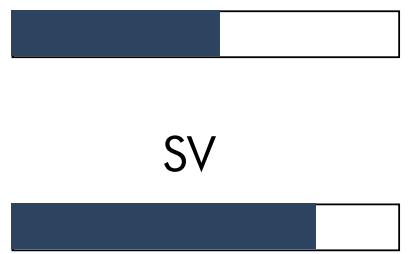

$\mathrm{CL}$

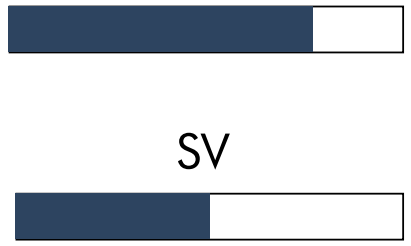


(4)

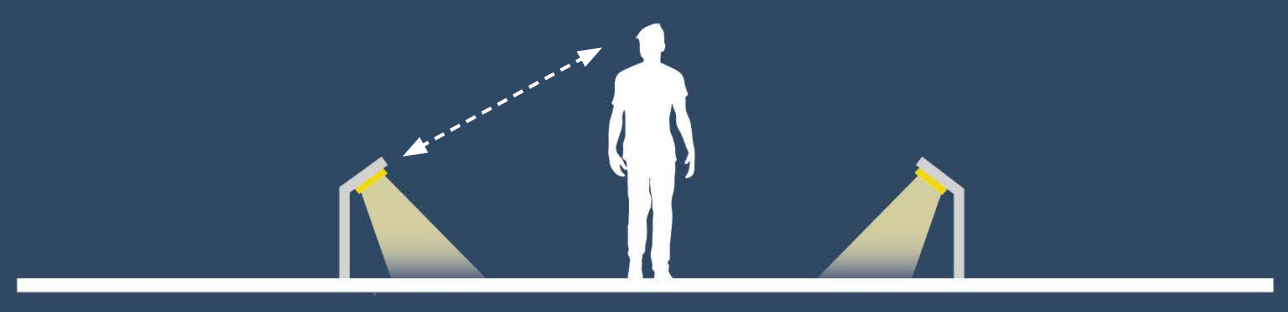

(5)

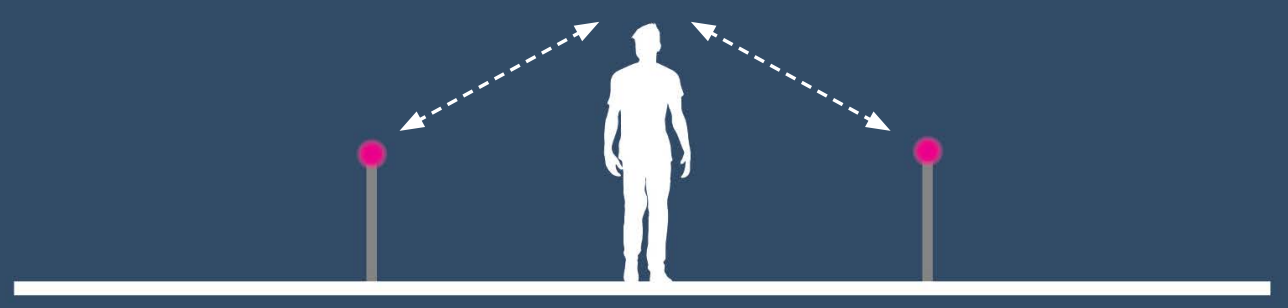

(6)

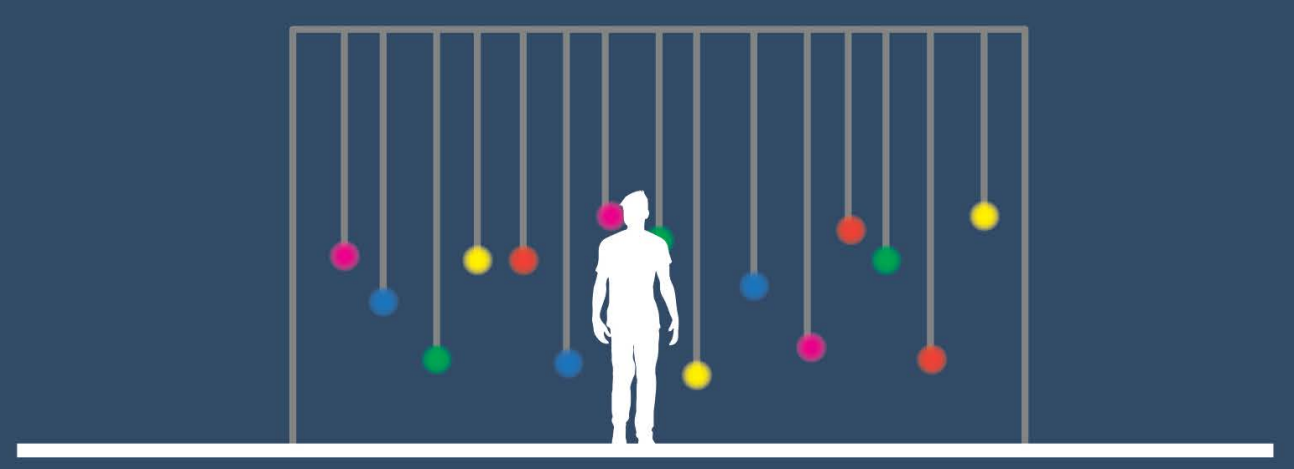




\subsection{Vegetation Structure \& Existing Lighting}

As stated in the literature and proven in the fieldwork analysis, vegetation and greenery directly impact our perception of outdoor space at night and could be linked to why people will not travel to stargaze. The existing design approach encompassing vegetation and lighting is that lighting is not fulfilling its purpose if vegetation inhibits its glare's intended range. However, for stargazing, we can look at this differently. Vegetation strategically placed to block the glare on one side of the mast allows one half of the space to be illuminated while the other half is utilized for stargazing.

Of course, why not just put a wall in front of the light? People associate places at night with entrapment; placing a solid wall would decrease prospect. Using vegetation decreases fear of entrapment as there is increased prospect with the provided transparency. This also allows vegetation to have a dual purpose in our public spaces.

Using the main species found in the three areas studied, the following iterations test what effect their combined silhouettes have on the glare produced from the overhead lighting. The aim is to find out the balance between having enough vegetation and ensuring that it does not feel too uncomfortable for the user.

There are two potential functions for vegetation at night.

- To act as the barrier between light protruding into a space designed for stargazing

- To help define the specific star gazing space boundaries without the need for opaque walls.
Fig 6.8 Relationship between Lighting and Vegetation 


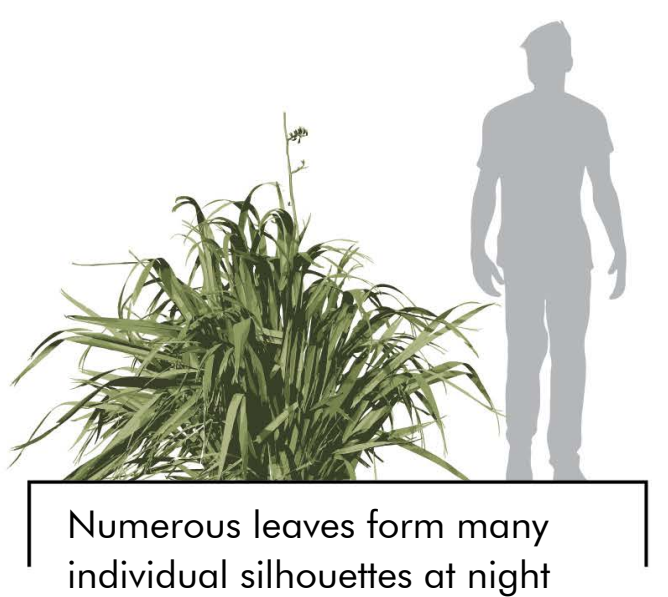

individual silhouettes at night
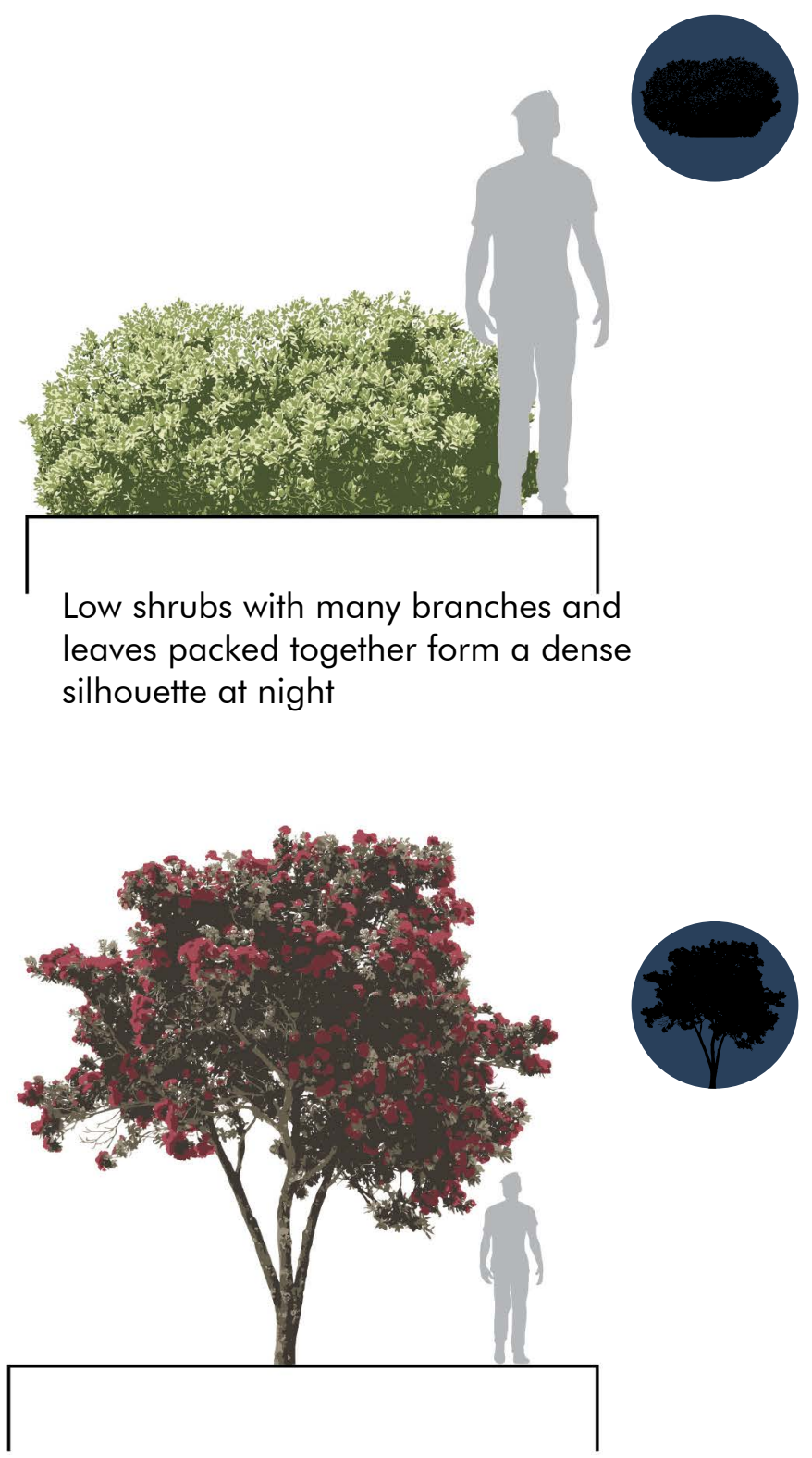

Medium sized tree with wide canopy presents large dense silhovette against the night

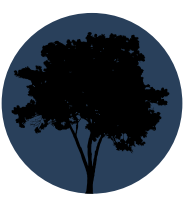

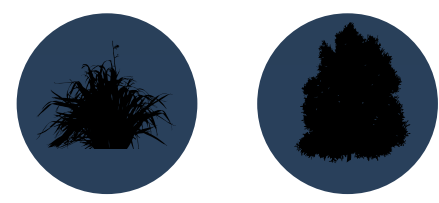

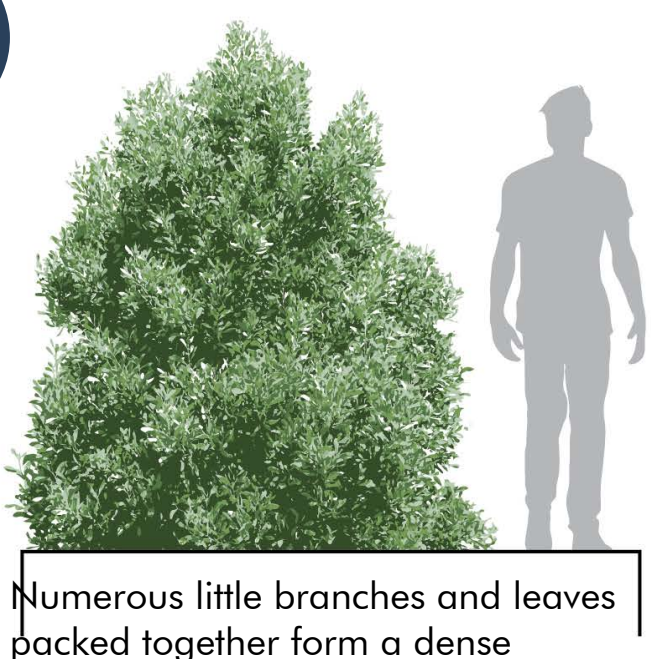
packed together form a dense silhovette at night
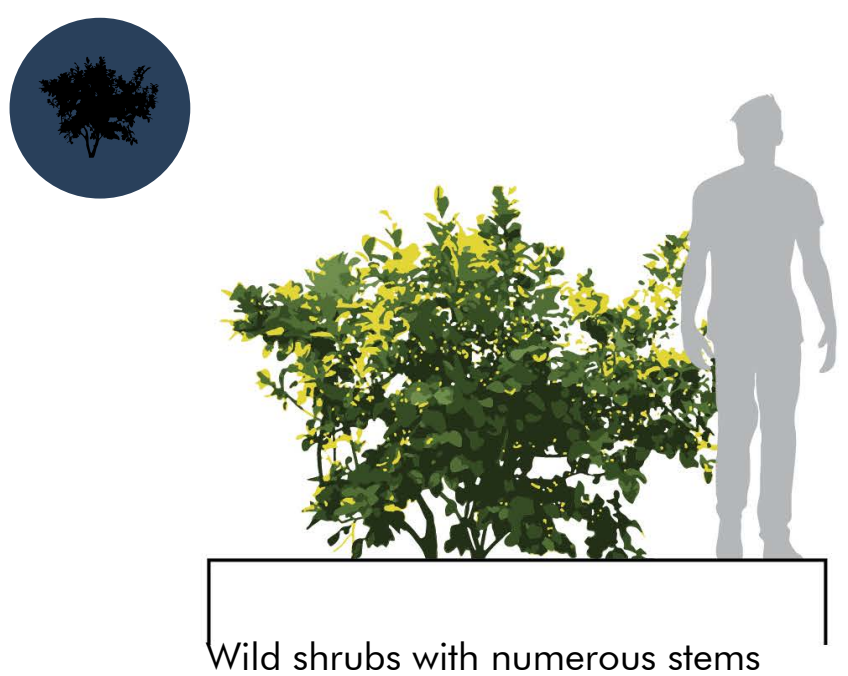
containing thorns present a hazardous and frightening silhovette at night
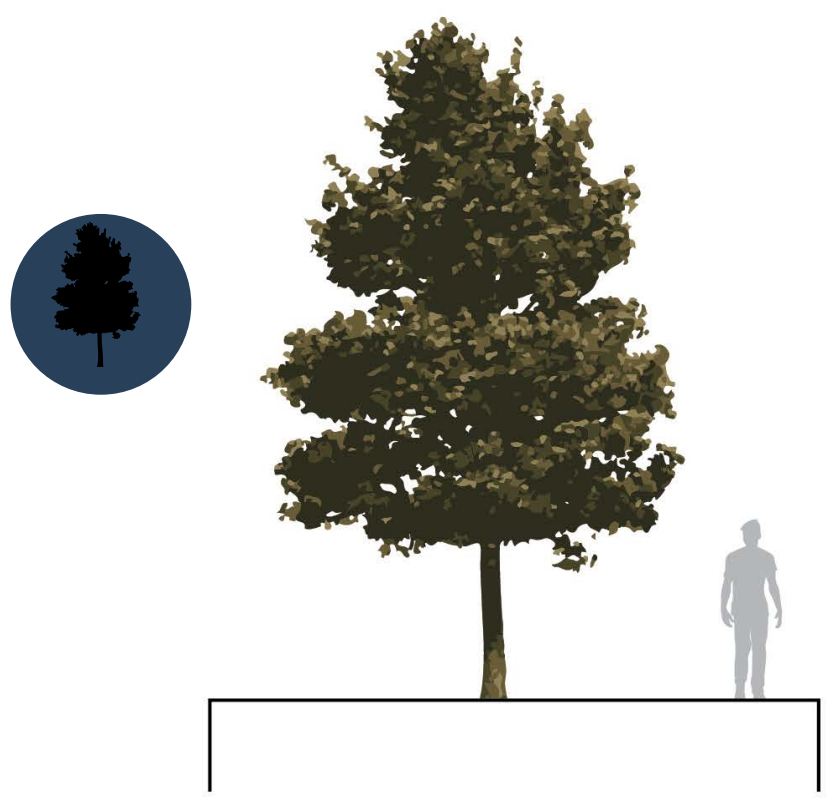

Tall tree with a high crown presents large dense silhovette against the night 


\section{Vegetation Typologies}

\section{(1) Small Vegetation}

- Low grasses and shrubs allow more light to enter the space, but their small silhouettes do not feel as uncomfortable to be next to

\section{(2) Tall Vegetation}

- Taller vegetation allows less surrounding light to penetrate the space; however, it increases feelings of discomfort due to the ominous silhouette it has in the dark.

- In spaces such as the Waterfront, this could be a practical choice, as the prospect of entrapment would be reduced knowing there is a higher chance of people surrounding the space.

\section{(3) Thin Vegetation}

- A thin vegetation line allows more surrounding light to infiltrate the space but presents a less intimidating surrounding boundary line.

\section{(4) Thick Vegetation}

- A thick vegetation line (more plants between the light source and the user) does not have much of a change from the findings explored in iteration three. When the plant's height is still below the eye level, this is not as intimidating as in iteration two.
Overall comfort level

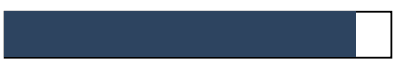

Star Visibility

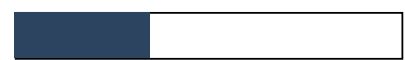

$\mathrm{CL}$

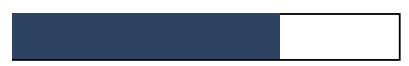

SV

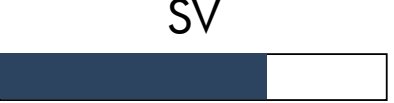

$\mathrm{CL}$

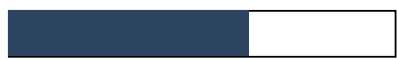

SV

$\mathrm{CL}$

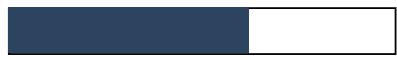

SV 
(1)

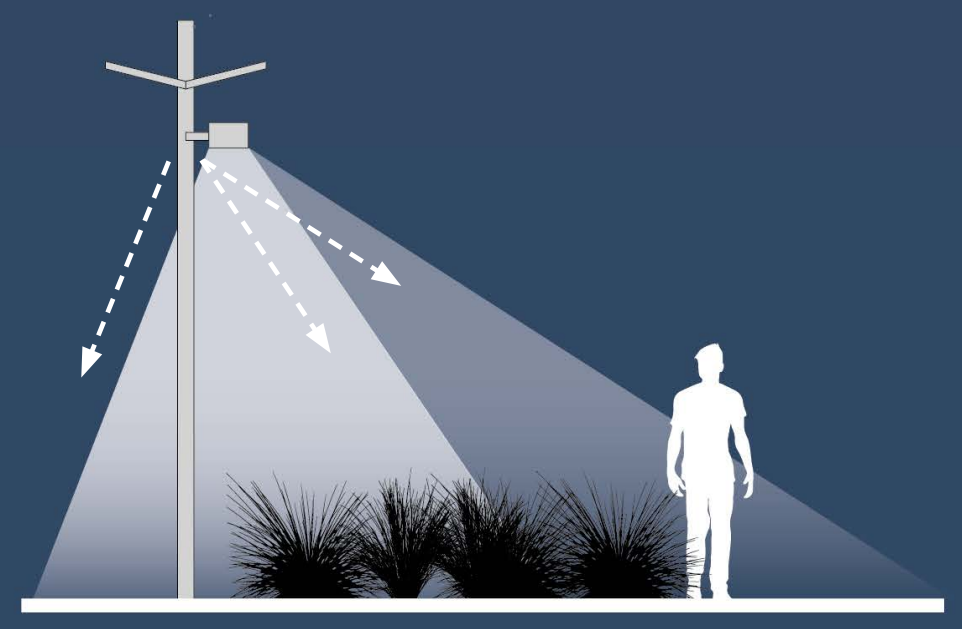

(2)

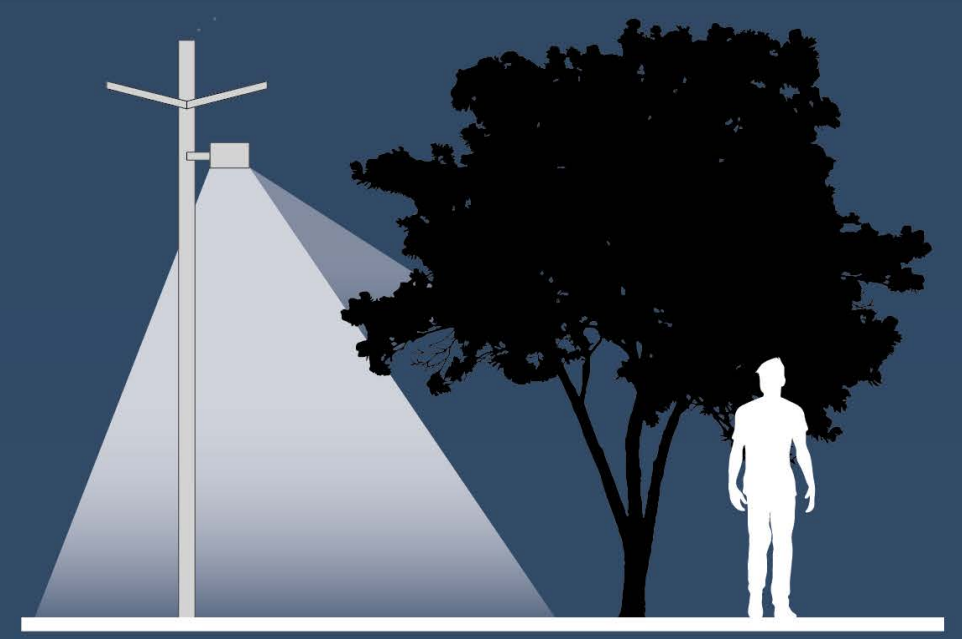

(3)

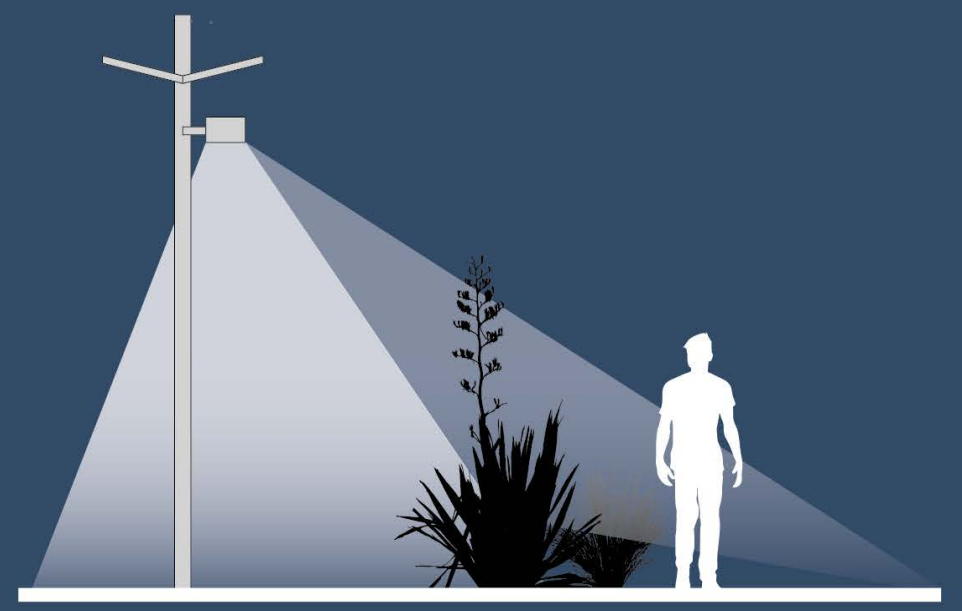

(4)

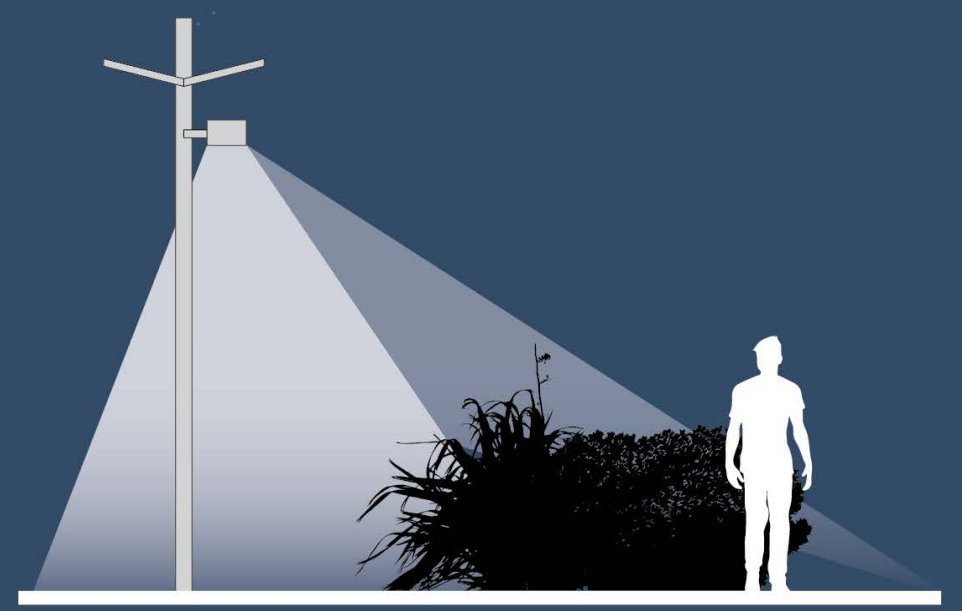




\section{Vegetation Typologies}

\section{(5) Tall and Small Vegetation}

- The combination of tall and small vegetation presents a solid boundary line that blocks the light glare from above and below. However, light could still shine through the middle. This decreases fear of entrapment having the visual connection to the surrounding light from the city and suburbs.

\section{(6) Tall and Thin Vegetation}

- A tall, thin density tree line would block light from entering the space, but their silhouette in the dark would be quite frightening at proximity.
$\mathrm{CL}$

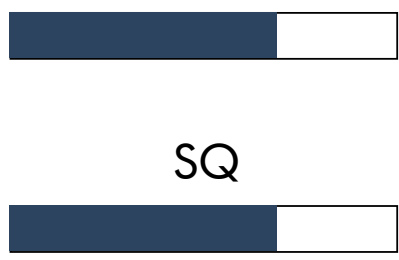

\section{(7) Dense and Tall Vegetation + Gap for light}

- Tall/medium height vegetation shields the space from almost any light infiltrating from surrounding buildings and street lights. However, it is not dense enough to evoke fears of entrapment. The vegetation below provides an edge to space for its daytime function. The gap in the middle allows people to see out beyond the space. This is the most effective planting option that prioritizes our perceived safety.

\section{(8) Dense and Tall Vegetation with no Gap}

- This presents the most heavily shielded option. The tall vegetation above shields all surrounding light infiltrating the space

- The vegetation below blocks any light glare reflecting off the ground. A minimal amount of light is allowed to pass through the middle, yet this decreases prospect. This is the most effective planting option that prioritizes a near perfectly uninterrupted view upwards. 
(5)

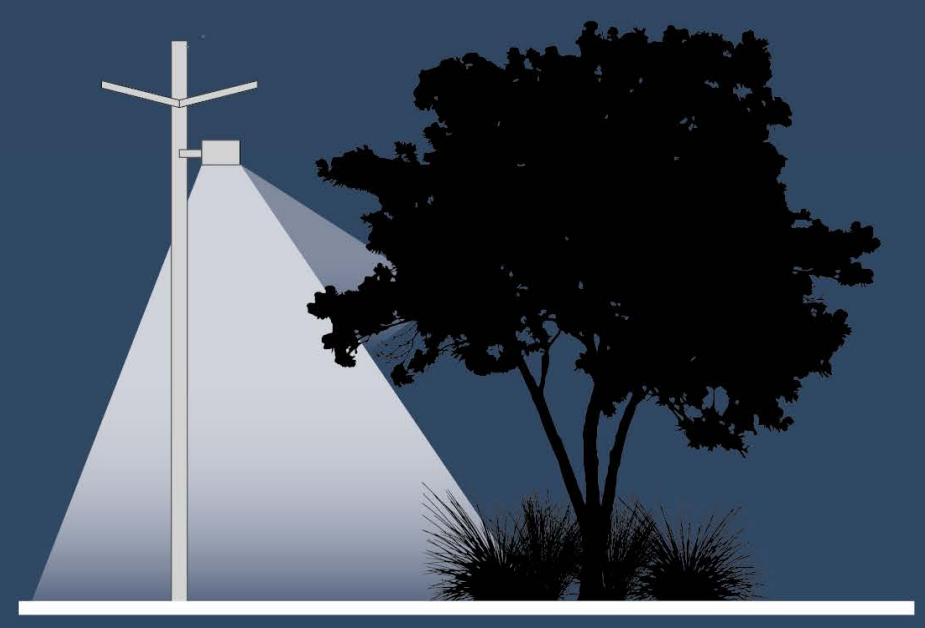

(6)

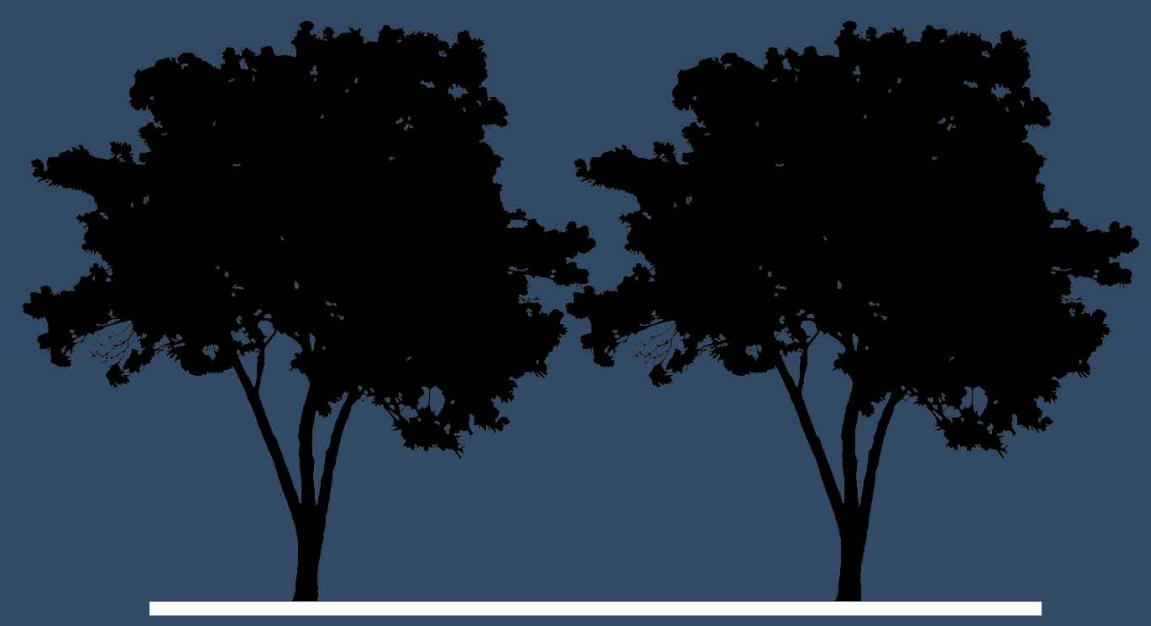

(7)

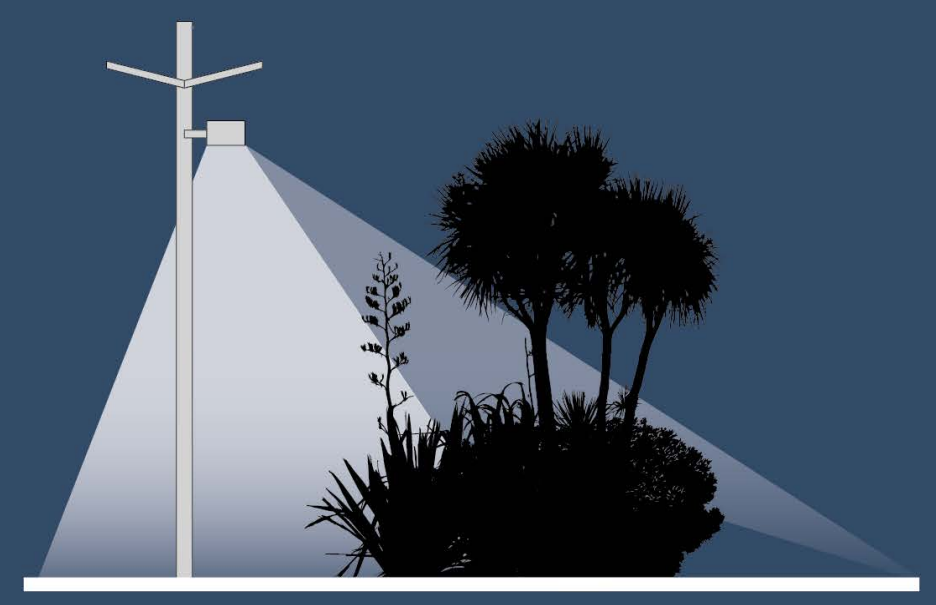

(8)

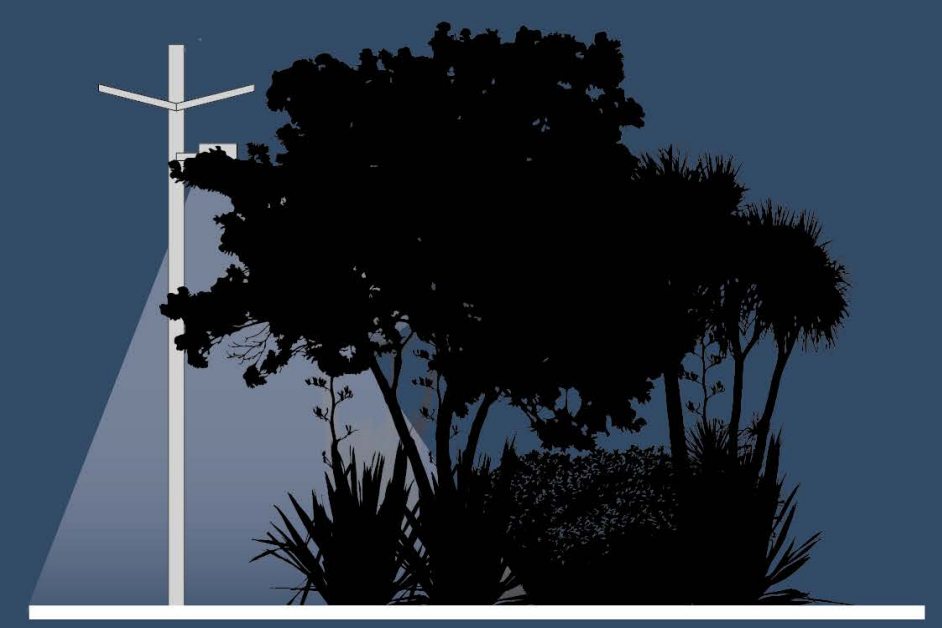




\subsection{Seating \& Change in View}

In all of the locations visited across all three areas, the seating either did not have a backrest or was set at a 90-100 degree angle (fig 1), which could not facilitate a comfortable experience looking up. Lying down on the bench was not possible either, due to the light from above shining directly down into it. Manually holding the gaze up to the sky was uncomfortable, often resulting in a sore neck.

Lying on the ground was not always an appealing option either, as most sites consisted of concrete, often dirty, and grass, which was not necessarily unappealing but was sometimes wet or had uneven ground.

Based on these findings, it was clear that there needed to be some form of seating provided in public space that could encourage the user to spend extended time stargazing while feeling comfortable. It takes around 20 minutes for the human eye to adjust to the darkness, so the concept needs to support the human body fully.
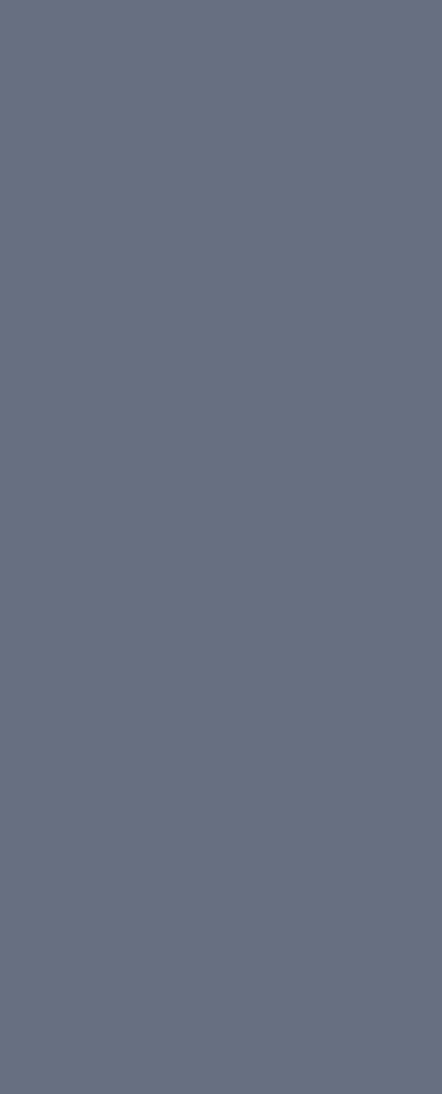

Fig 6.12 Current Seat Affordance 

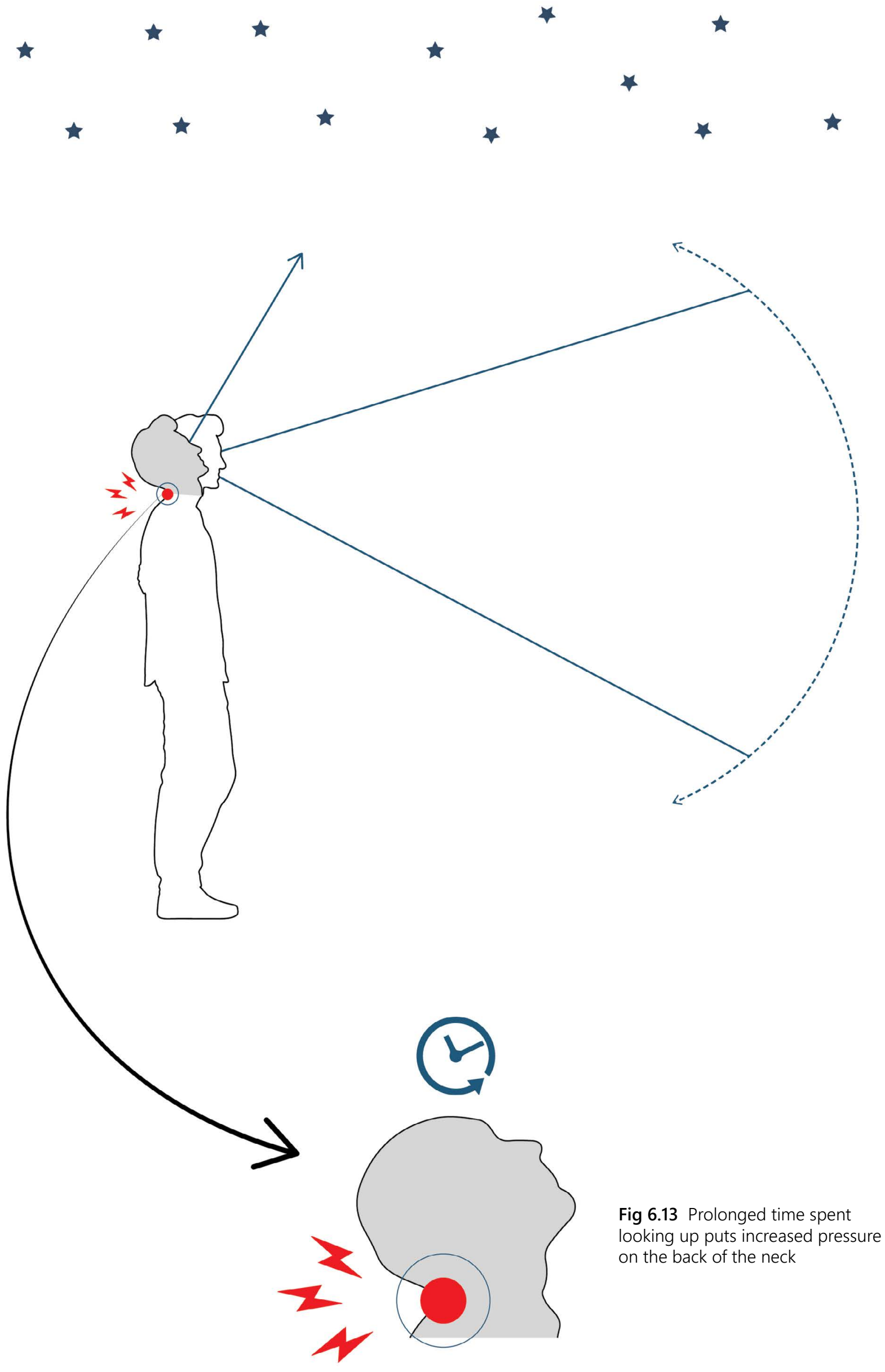


\section{Human Ergonomics}

Research into examples of this in existing landscape and interior design revealed four main body parts as key to achieving this comfort:

The Neck

The Spine

The hips

The Knees
Each of them controls a certain rotation point of the body, which means the seat design needs to support each of the body parts between them to take the pressure off when looking up at the sky.

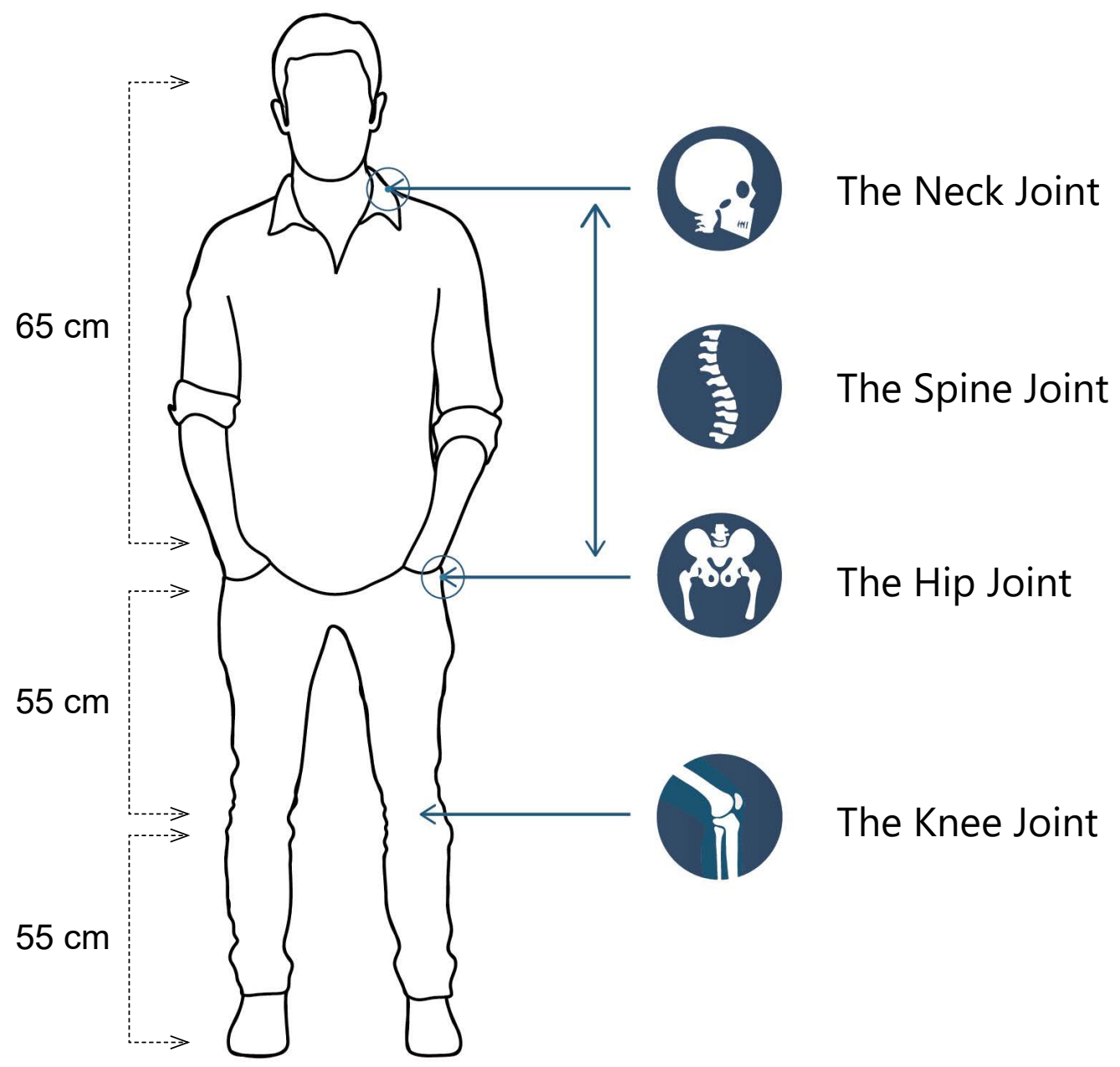

Fig 6.14 Main joints of the Body 
(1) Standard Fowler Position Supporting back at 45-60 degrees

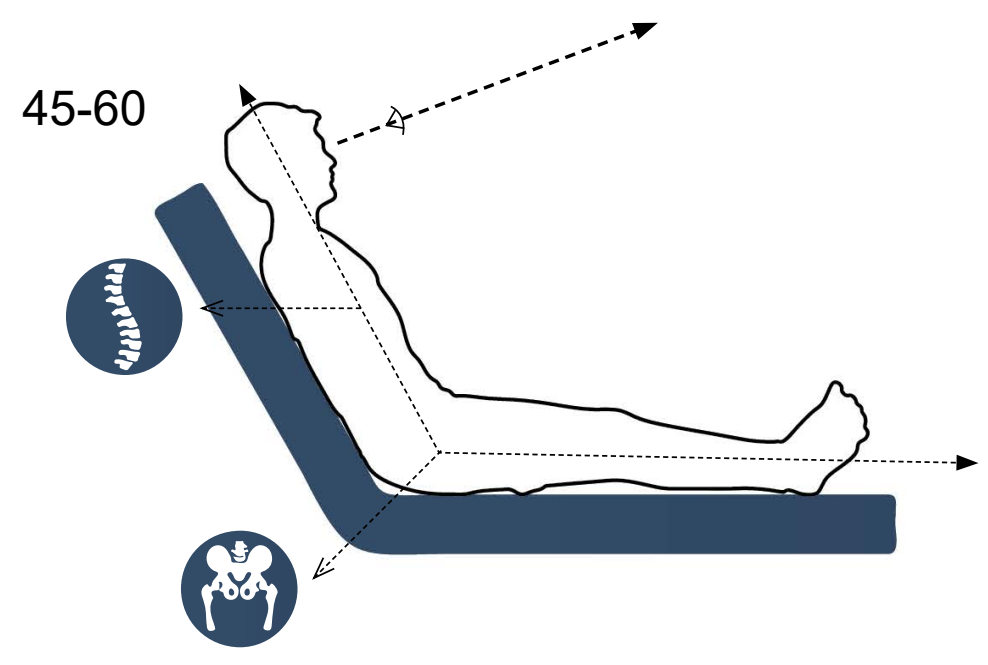

(2) Semi Fowler Position Supporting back at 30-45 degrees

(3) Low Fowler Position supporting back and knees at 15-30 Degrees

(4) Zero degrees supporting
body as a whole

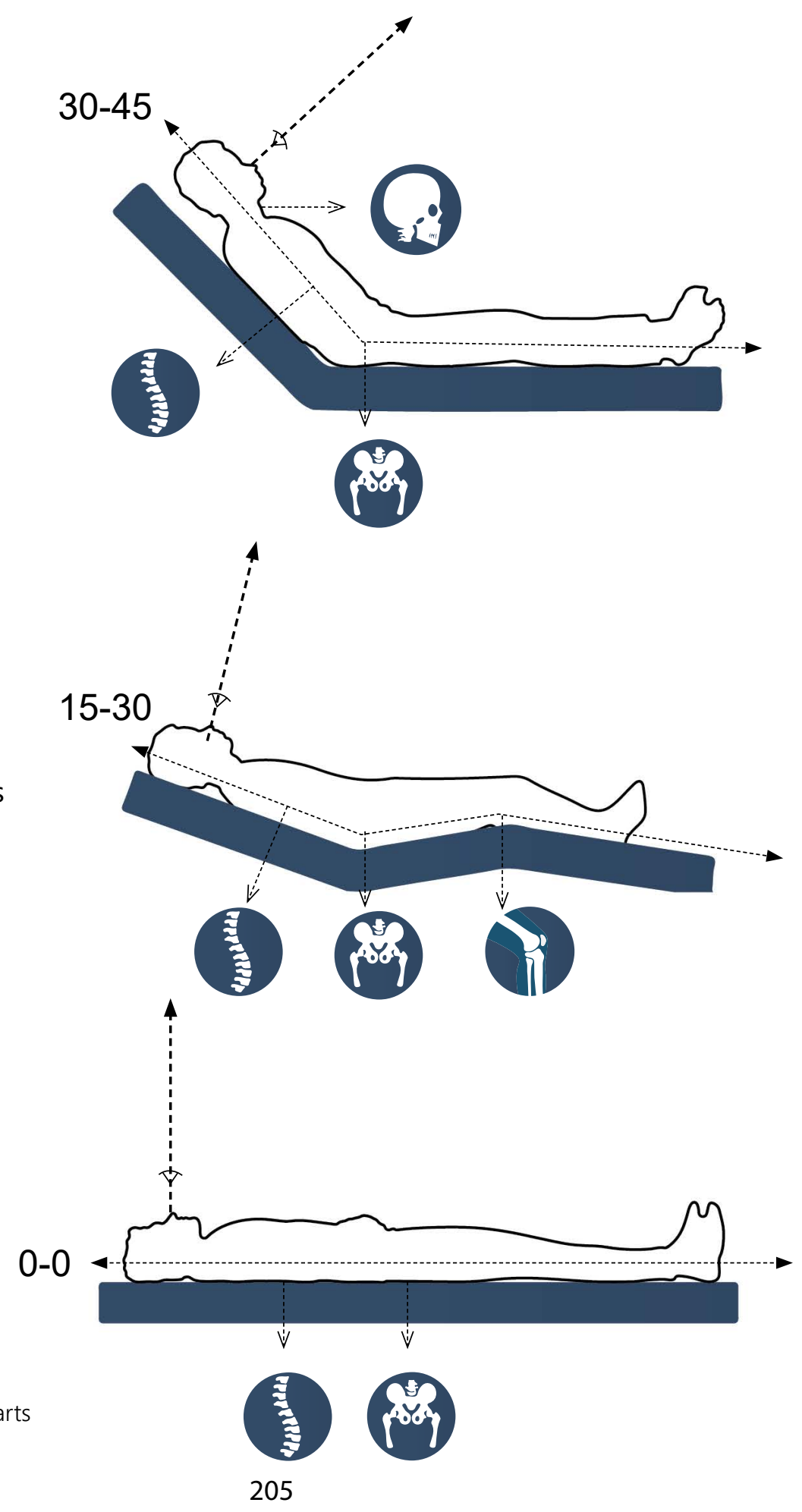

Fig 6.15 Fowler Positions: Different body parts supported 


\section{Case Study}

\section{Seating Seatoun Waterfront}

Seatoun Waterfront, Wellington, New Zealand (n.d)

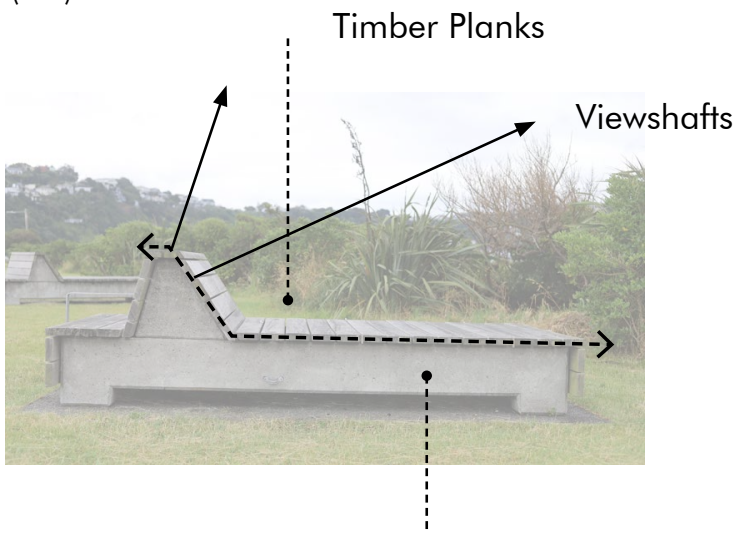

Concrete Base

Unire/Unite

Maxxi Plaza, Rome Italy

Urban Movement Design, 2012

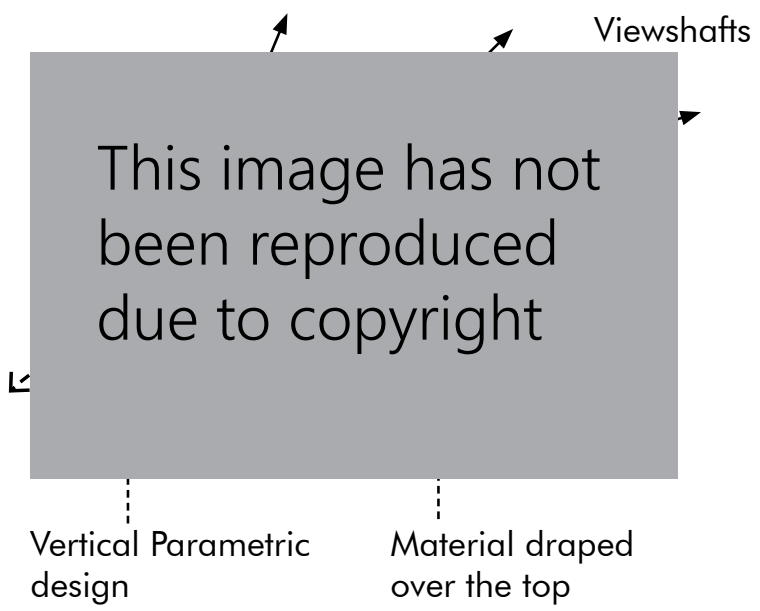

\section{Reclined Seating at Cog Park}

Cog Park, Wellington, New Zealand (Metal Art, n.d)

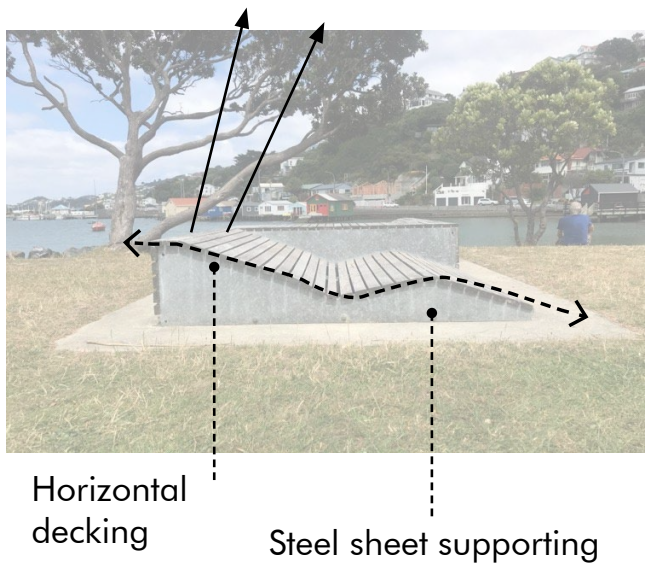

Supported Joints
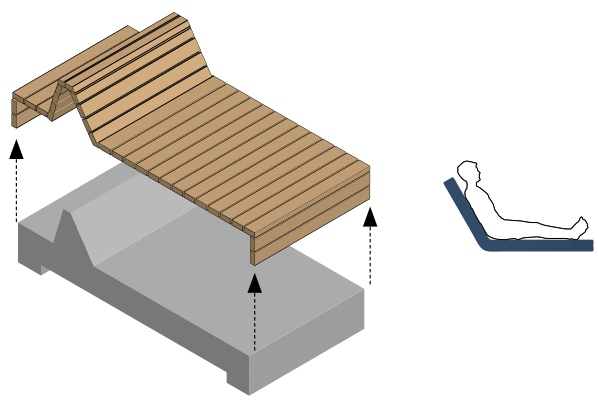

000
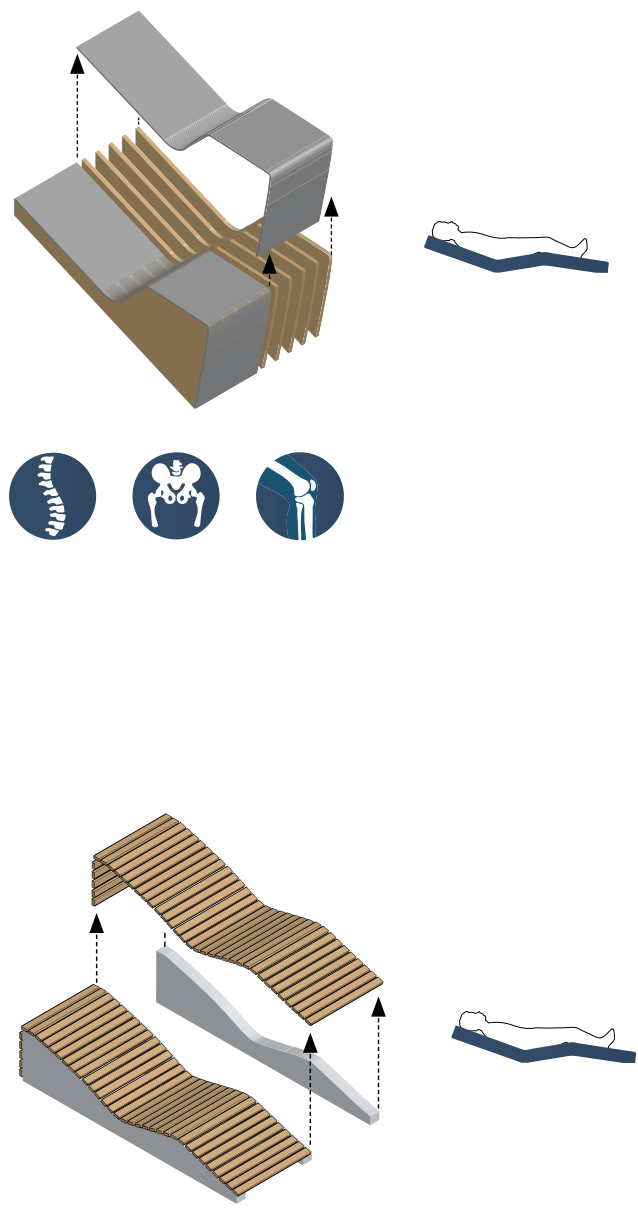

Fig 6.16 Seating Case Studies 


\section{Findings}

\section{Primary Joints}

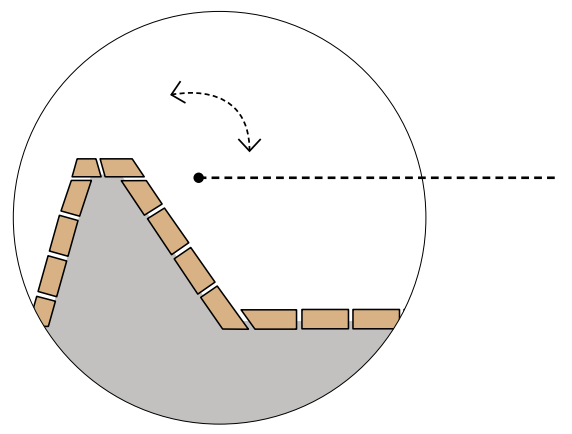

This angle allows the rest to neck, but also directs view upwards

A second small precedent study was completed to learn more about the relationship between seating, comfort and the change in view. The precedents here depict three types of recliners that promote a different angle of view.

Site visits to this seat showed it supported the back and neck well, and directed the view out towards the sky

\section{Q 1}

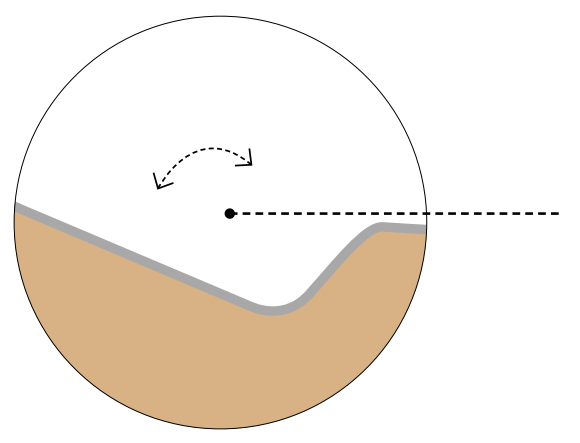

This angle takes the gravitational weight off the legs

This design is unique to the other two as it fully supports the lower legs through the angle below the knee. The curved angles may also be more comfortable to bend the joints over.

This reclined position supports the back and neck, providing longer periods spent looking up

Site visits to this seat showed it was very comfortable and supported all the joints. It was noticeably more comfortable having the flat bit at the top to rest the neck on. 


\section{Design Exploration}

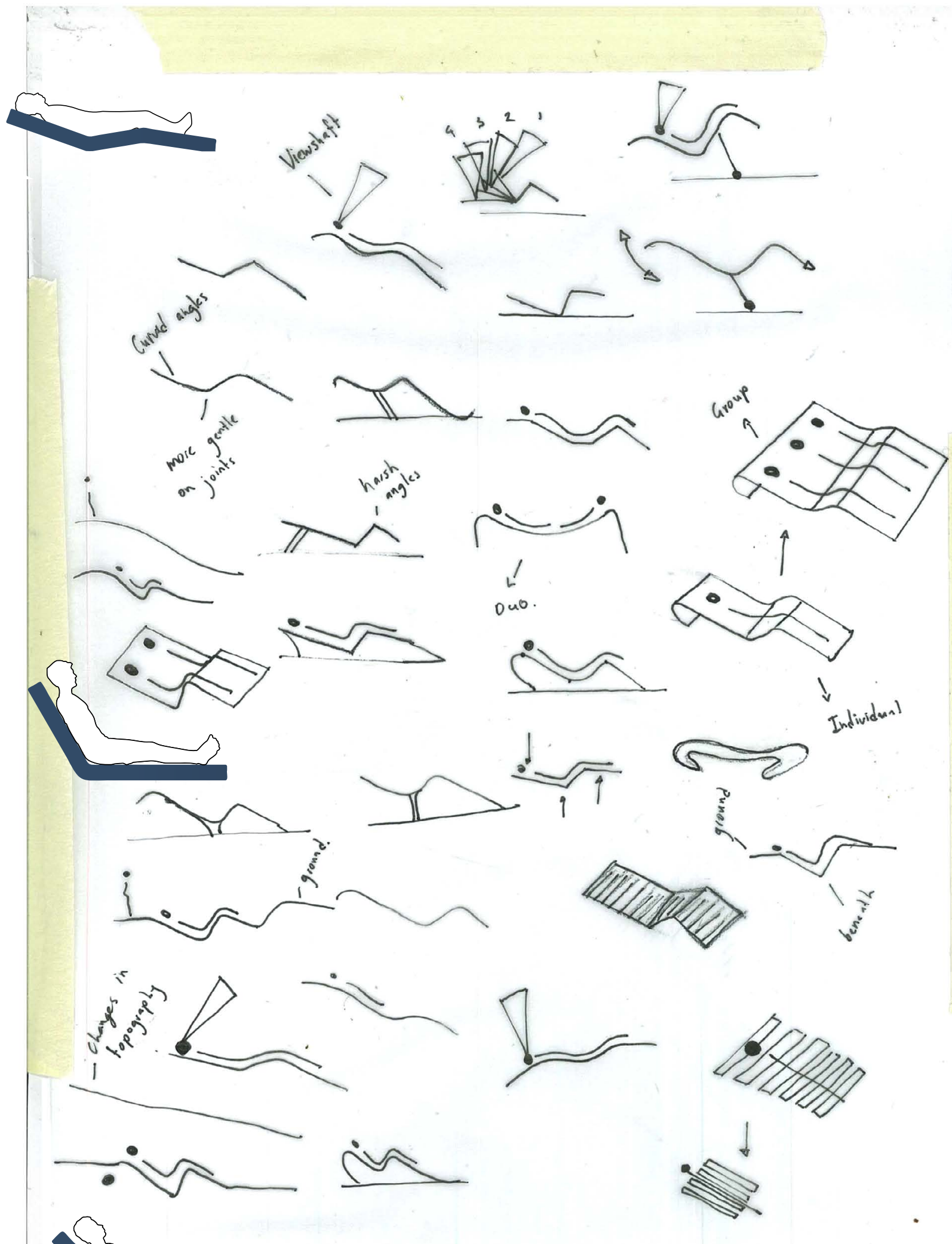

Fig 6.17 Initial Seating Sketches 


\subsection{Reflection}

The toolkit successfully helped derive design solutions for improving the night time experience in the three areas.

The findings from lighting indicate the effect of using colour and below the waist lighting to create interaction with the space at night.

Vegetation findings concluded that there are two density and structure typologies that are beneficial to the night time experience. A tall/ medium height vegetation line with a gap in the middle is the most effective planting option for the night time experience that prioritizes perceived safety, as it shields the majority of light from entering the space while allowing a gap in sight to the distant environment.

A tall/ medium height vegetation line without a gap in the middle is the most effective planting option that prioritizes an uninterrupted view upwards as it allows a minimal amount of light to pass into the space.

Seating needs to support the four main joints in the body to provide a comfortable experience. In areas where the sky is more light polluted near the horizon, the stars are at a higher quality closer to the zenith. The seat angle would need to be more reclined to direct the gaze further above. In areas with less pollution near the horizon, the stars are at a higher quality closer to the horizon, which means the seat angle could be more or less reclined depending on what stars are the intended focus. The most comfortable angle based on existing designs' fieldwork revealed a 15-20 degree angle that takes the weight of gravity entirely off the spine.

These findings were applied into 2 areas in Wellington for futher development. 


\section{Introduction.}

This chapter aimed to develop a site-specific design from the toolkit's application in areas studied in the Initial fieldwork. This took place in the South Coast and Waterfront environments, representing the opposites of light pollution in Public Space. Lighting was tested on the South Coast as due to the darker environment, the exact impact on perceived comfort could be recognized with greater ease. Seating was tested in the Waterfront to respond to the significant number of existing seats that did not provide a nighttime experience. New vegetation methods were not iterated, but the learnings on their silhouette's impact were applied in the detailed analysis at Moa Point.

Design methods included the utilization of sketches/sections/ plans, digital models, physical models, and physical journeys out to the site at night using lighting appliances at the 1:1 scale. 


\subsection{Chosen Sites}

A comparative study between areas on the South Coast and Waterfront using specific landscape characteristics from the analysis summaries helped justify the best areas to test the toolkit. The town belt was left out of this research as it was more beneficial to test the toolkit in areas that were complete opposites in lighting and space use to see the effect of light pollution. The Town Belt had a similar environment to areas on the South Coast.

This study concluded that Moa Point and the Waterfront on the east side of Te Papa were the best sites for design to take place. 


\section{Justifying Waterfront site chosen to test toolkit research}

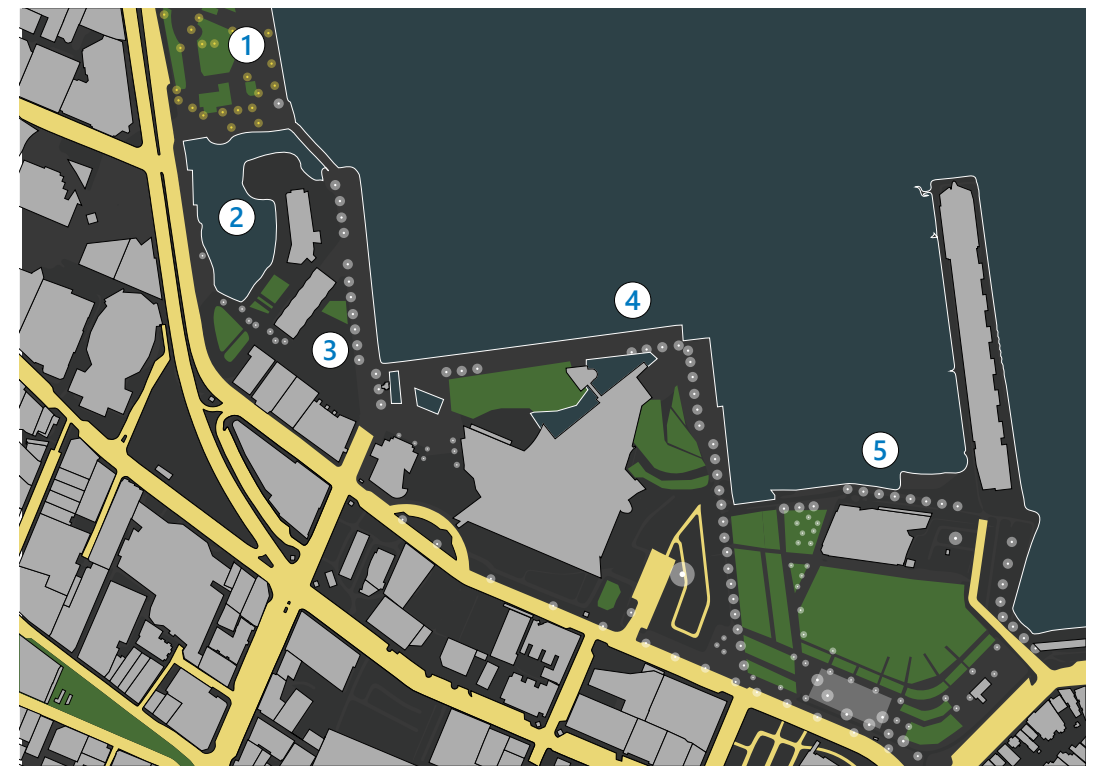

Key Principles for Waterfront

\section{Shielded from overhead Light}

(How dark the space is )

- Are there lights shining down from above creating glare in the space? There should be no glare immediately in the space

\section{Surrounding light}

- Does the surrounding environment interfere with the ability to star gaze in the space? What is causing this?

- E.g bright lights shining in the distance which would distract the person in the space.

\section{Openness}

- Does the site make the user feel entrapped?

- The site should be open and not confined by vegetation or walls of buildings. For the person to be able to feel comfortable in the space at night they need to feel relaxed and have sight of their extended surroundings

\section{Vegetation Structure and amount}

- Is the existing vegetation frightening to be around?

- the site must not make the user feel entrapped
To further justify site selection, 5 specific landscape characters were identified from the analysis findings. The sites were revisited measuring these 5 typologies and how comfortable they made the user feel

\section{Measuring System}

$$
\begin{aligned}
& \text { Yes/No } \\
& \text { Yes/No } \\
& \text { Yes/No } / \text { No } \\
& \text { Yes / No }
\end{aligned}
$$




\begin{tabular}{|c|c|c|c|c|c|}
\hline & $\begin{array}{l}\text { Frank Kitts } \\
\text { Park }\end{array}$ & $\begin{array}{l}\text { Whairepo } \\
\text { Lagoon } \\
\text { (Vege Patch) }\end{array}$ & Odlinz Plaza & $\begin{array}{c}\text { Back of Te } \\
\text { Papa }\end{array}$ & $\begin{array}{c}\text { East } \\
\text { Waitangi } \\
\text { Park }\end{array}$ \\
\hline $\begin{array}{l}\text { Overhead } \\
\text { lighting }\end{array}$ & Yes & No & Yes & Yes \& No & Yes \\
\hline $\begin{array}{c}\text { Does the } \\
\text { surrounding } \\
\text { environement } \\
\text { impair the } \\
\text { view? }\end{array}$ & $\begin{array}{l}\text { Yes } \\
\text { (Port) }\end{array}$ & Yes \& No & $\begin{array}{l}\text { Yes } \\
\text { (City) }\end{array}$ & Partially & No \\
\hline Openness & Yes & No & Yes & Yes & No \\
\hline $\begin{array}{l}\text { Is vegetation } \\
\text { scary to be } \\
\text { around? }\end{array}$ & No & Yes & No & No & No \\
\hline $\begin{array}{l}\text { Suitable for } \\
\text { stargazing? }\end{array}$ & No & No & No & Yes & No \\
\hline
\end{tabular}

\section{Final Site Chosen: East Side of Te Papa}

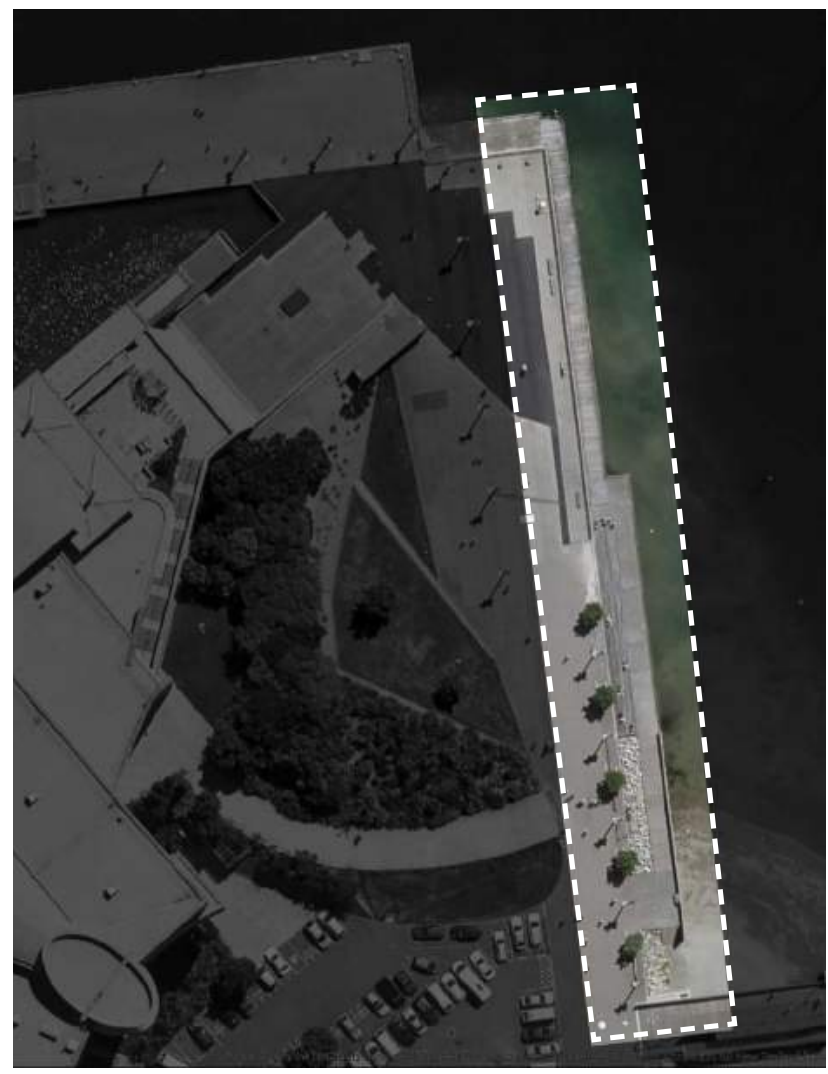

The site that fits the criteria best for stargazing is a walkway on the east side of Te Papa.

- There was overhead lighting, but because the walkway dropped down, it took the user out of this glare

- The dropped position also shielded the user from the surrounding city lights

- The portlights are visible, but the walkways position next to the marina means the boats moored there block most of the glare from entering the space.

- The apartments in front did not generate any light glare that impaired the view upwards

- The site was very open, and multiple escape routes could be visible

- There was no vegetation in the space

- The site contained no seating that encouraged the view upwards, providing a good testing ground for the toolkit. 


\section{Justifying South Coast Site chosen to test toolkit research}

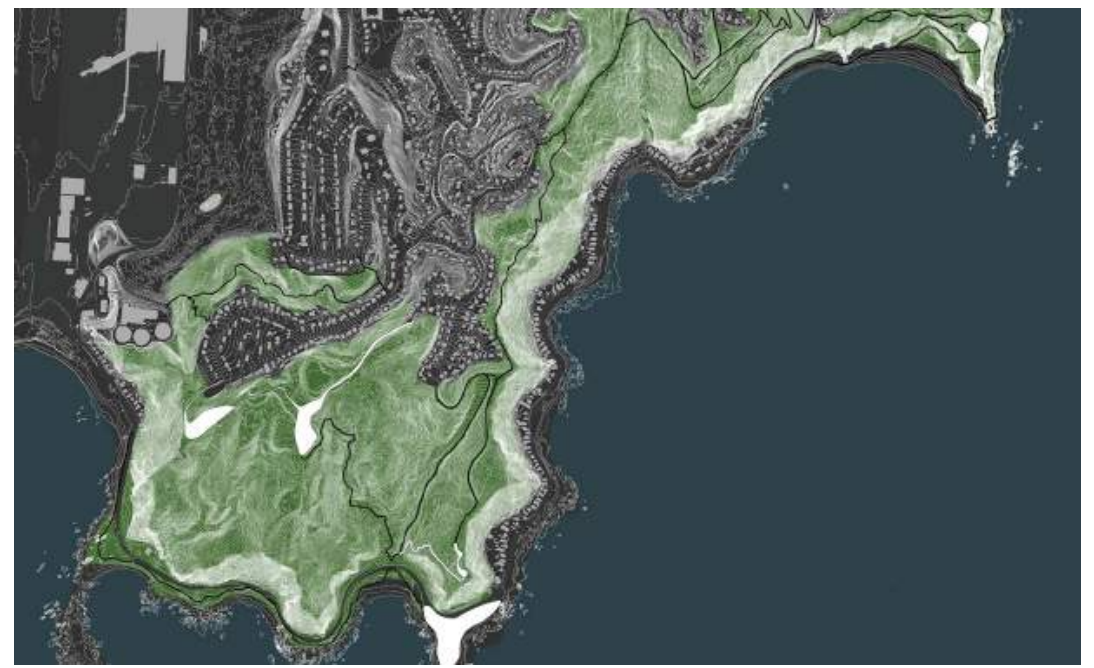

\section{Key Principles for South Coast}

\section{Shielded from overhead Light} (How dark is the space? )

- Are there lights shining down from above creating glare in the space? There should be no glare immediately in the space

\section{Amount of viewshaft}

- How many areas of the night sky can be seen from the space?

\section{Access points}

- Enclosed or open access points?(enclosed by vegetation or open)

- Multiple or single access points

\section{Openness}

- Does the site make the user feel entrapped?

- The site should be open and not confined by vegetation or walls of buildings.

\section{Vegetation Structure and amount}

- Is the existing vegetation frightening to be around?

- The site must not make the user feel entrapped

\section{Elevation}

- The site must be at a higher elevation for increased prospect
To further justify site selection, 5 specific landscape characters were identified from the analysis findings. The sites were revisited measuring these 5 typologies and how comfortable they made the user feel.

\section{Measuring System}

$$
\text { Yes / No }
$$

North/ East/South/West

$$
\begin{gathered}
\begin{array}{c}
\text { access } \\
\text { point } \\
\text { Open } \\
\text { access }
\end{array} \\
\text { Enclosed } \\
\text { access }
\end{gathered}
$$

$$
\text { Yes / No }
$$$$
\text { Yes / No }
$$

$$
\text { High / Low }
$$




\begin{tabular}{|c|c|c|c|c|}
\hline & Forset Dorset & Wahine Reserve & $\begin{array}{c}\text { Ataturk } \\
\text { Memorial }\end{array}$ & Moa Point \\
\hline $\begin{array}{l}\text { Overhead } \\
\text { lighting }\end{array}$ & No & No & No & No \\
\hline $\begin{array}{l}\text { Amount of } \\
\text { viewshafts }\end{array}$ & $E-S-S E$ & $E-S-S E$ & $N-E-S-W$ & $N-E-S-W$ \\
\hline Access points & $2 /$ Enclosed & $1 /$ Enclosed & $2 / \begin{array}{l}\text { Open \& } \\
\text { Closed }\end{array}$ & $2 /$ Enclosed \\
\hline Openness & Yes & Yes & Yes \& No & No \\
\hline $\begin{array}{l}\text { Is vegetation } \\
\text { scary to be } \\
\text { around? }\end{array}$ & $\begin{array}{l}\text { In some } \\
\text { areas, Yes }\end{array}$ & $\begin{array}{l}\text { In some } \\
\text { areas, Yes }\end{array}$ & $\begin{array}{l}\text { In some } \\
\text { areas, Yes }\end{array}$ & $\begin{array}{l}\text { In some } \\
\text { areas, Yes }\end{array}$ \\
\hline Elevation & High & Low & High & High \\
\hline $\begin{array}{l}\text { Suitable for } \\
\text { stargazing? }\end{array}$ & Yes & Yes & Yes & Yes \\
\hline
\end{tabular}

\section{Final Site Chosen: Moa Point}

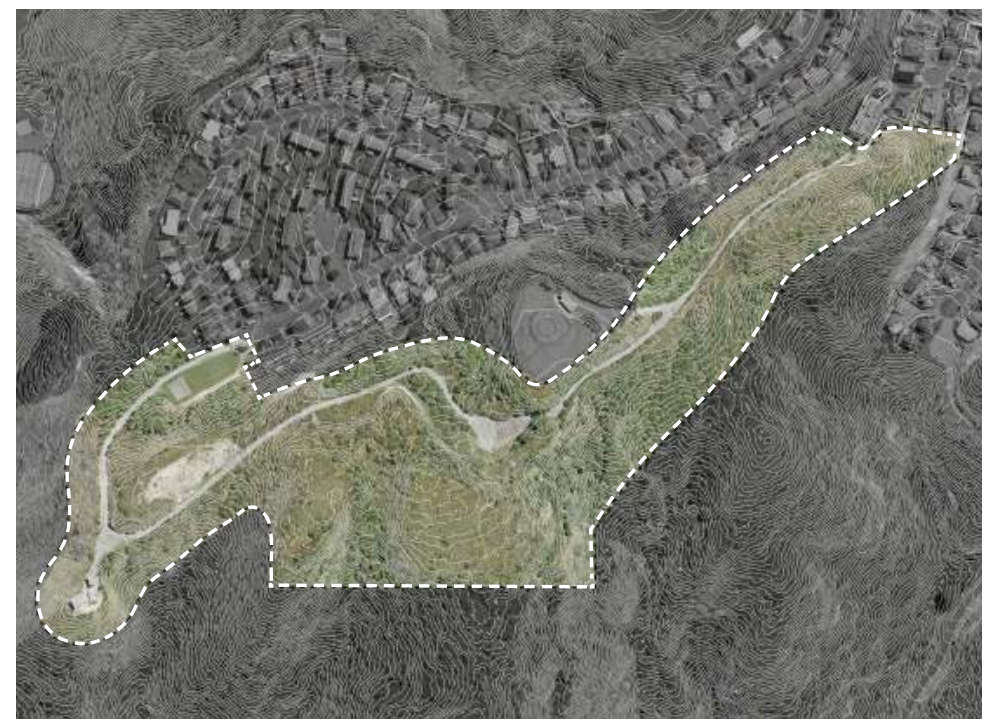

All the sites have open views over the south coast, with areas where no visual connection can be made to the cities glare. Moa Point was chosen because:

- The site was very dark and had multiple access points

- Some of these access points had views over the coast and city, while others were enclosed by vegetation

- It has the highest elevation out of any of the sites which

- presented the largest view shaft of the south coast, including the west side of Wellington

- It was chosen over Ataturk (close second choice) as it was believed it could provide a more extensive range of design testing in the various typologies of open and closed space it ha 
Moa Point 



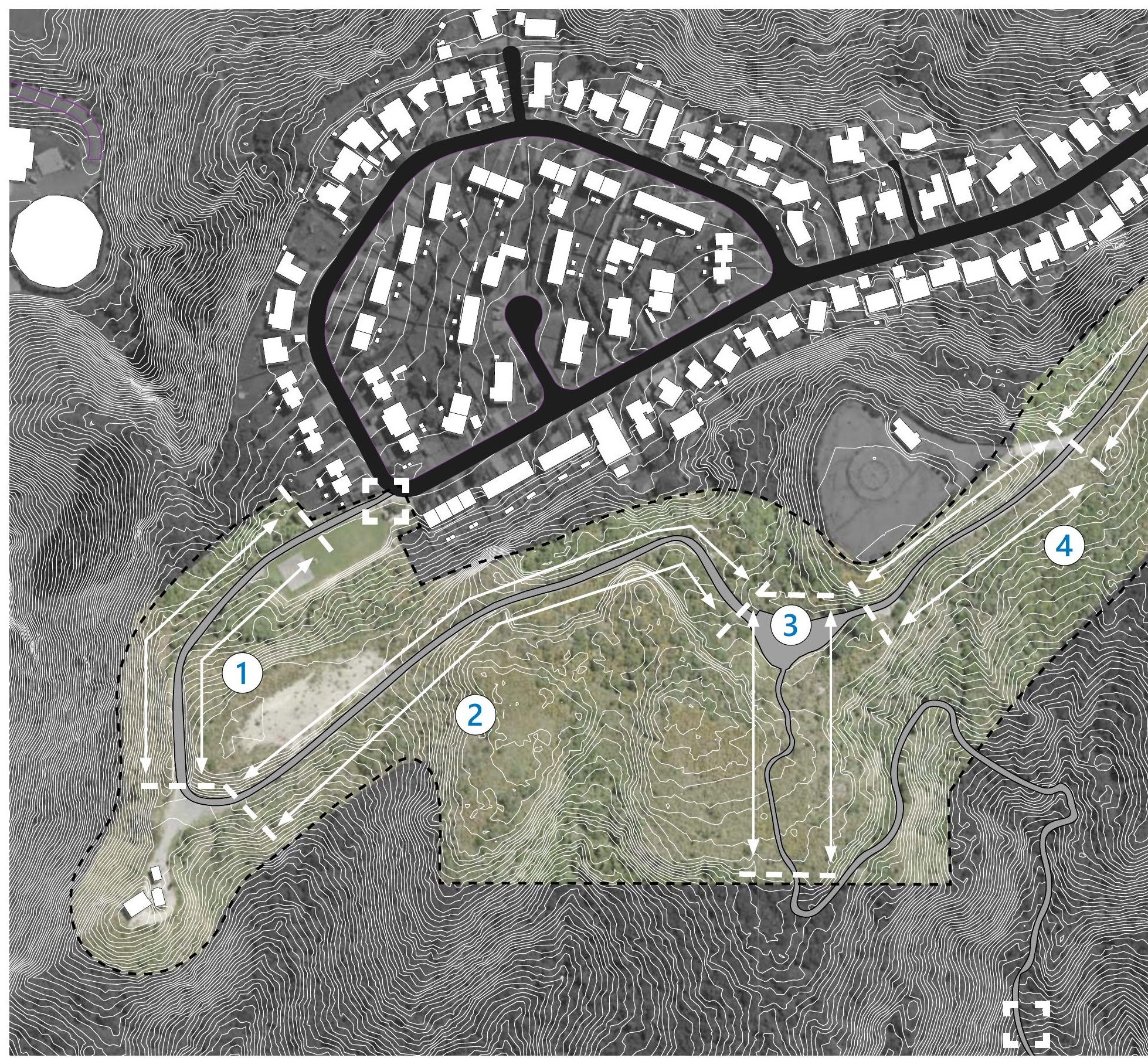

Fig 7.3 Moa Point Walking Track 


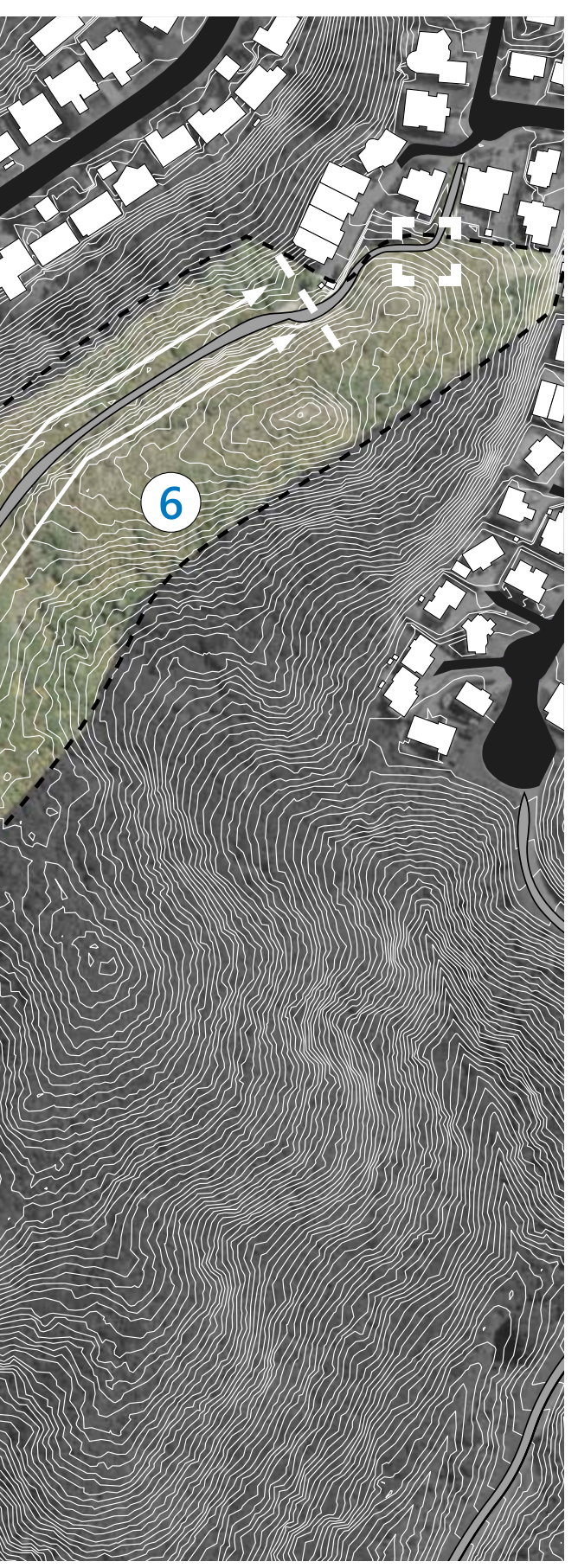

\subsection{Moa Point}

There is no official name for the specific area studied, and the official Moa Point boundaries end before the area studied begins. However, it is referred to as the Moa Point track in this chapter. Its official use is an access road to the navigational aid site but provides an enjoyable walking track with beautiful views over Kilbirnie and the South Coast. Around two months were spent travelling out to Moa Point during the day and at night further to understand its nocturnal environment and the stars' connection. A variety of different spaces affected perceived comfort and provided a better view of the stars.

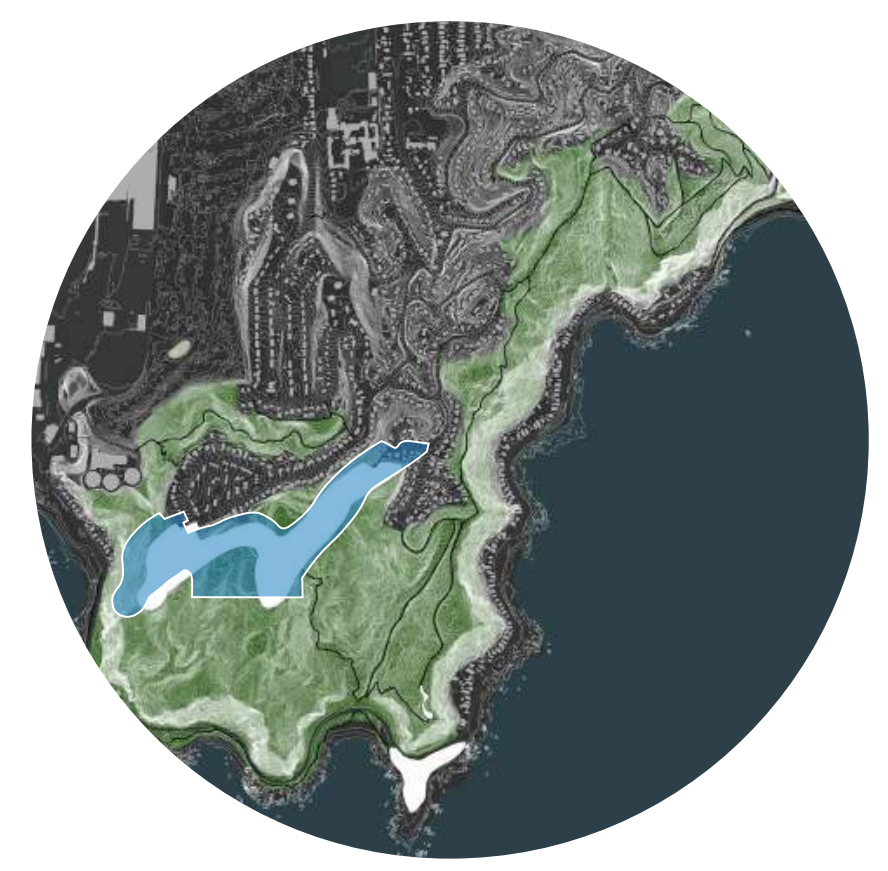

i _ Site Boundaries

Walking Track

Entry Points 


\section{Viewshafts out of the site}

Moa Point was split into 5 sections for designing. Each section afforded a different view from the site due to the surrounding topography and vegetation. These sections are:

- West side of the track / West view (towards Lyall bay and Melrose)

- West side of the track / South View

- Middle of the track / South, South East, South West View

- East side of the track / East view (towards Wainuiamata

- Far east side of the track / North View (towards Roseneath and Kilbernie

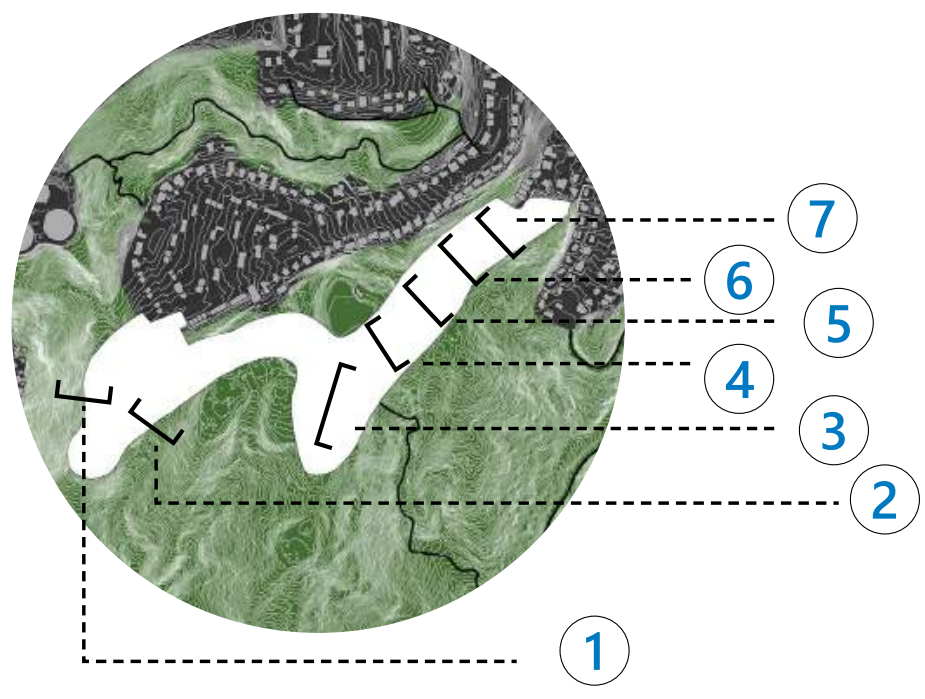

Far West Section / West Viewshaft

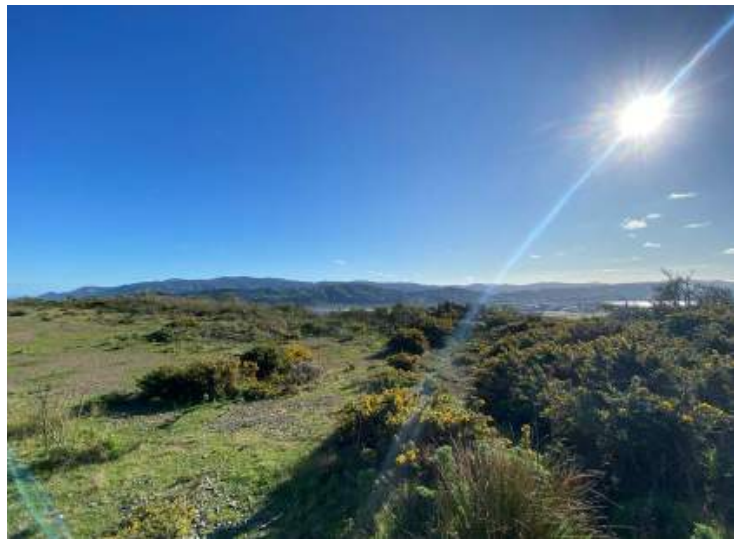


West Section / South viewshaft
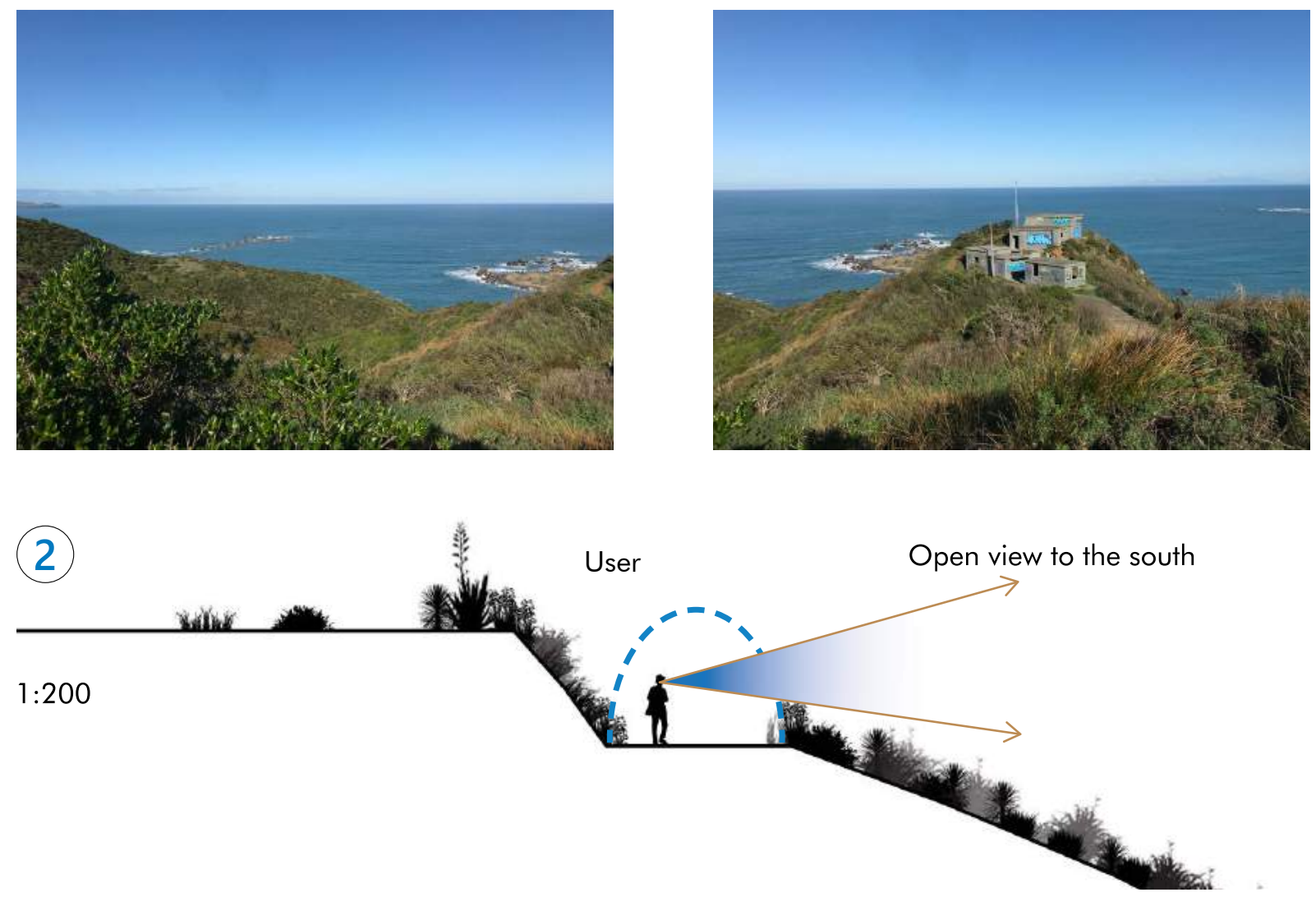

Middle Section / All around viewshafts
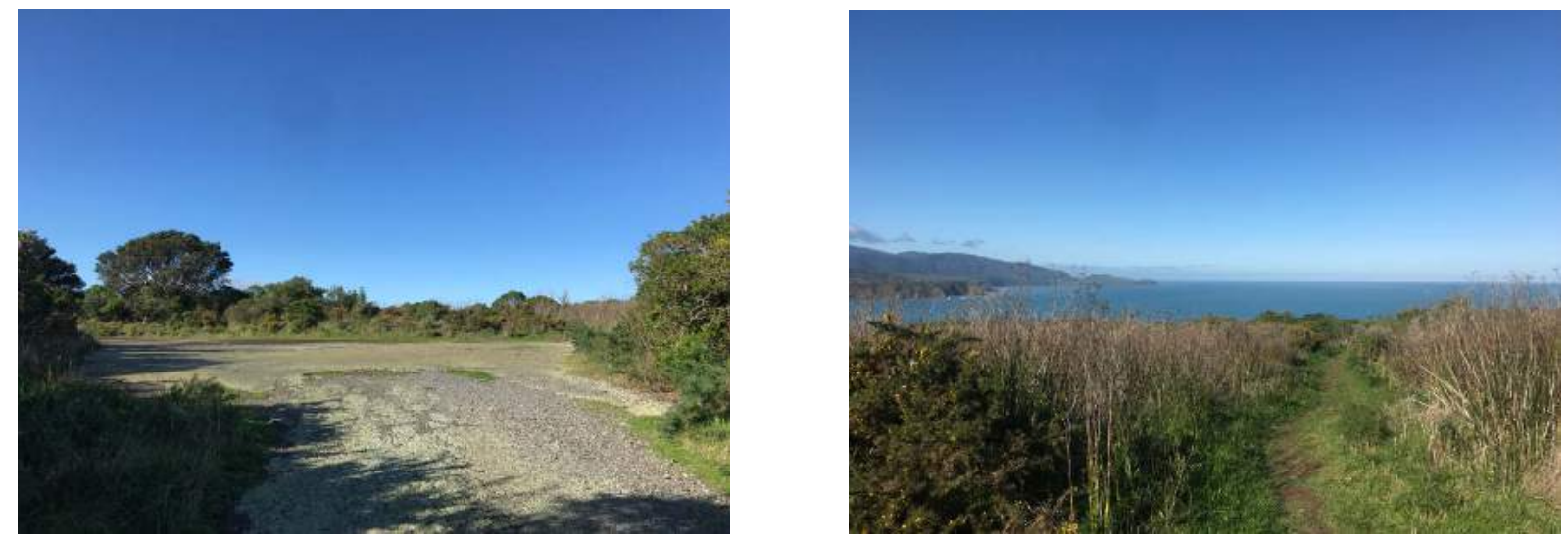

(3)

Walkway through Wild Fennel / Best stargazing spot

Wide, open flat space

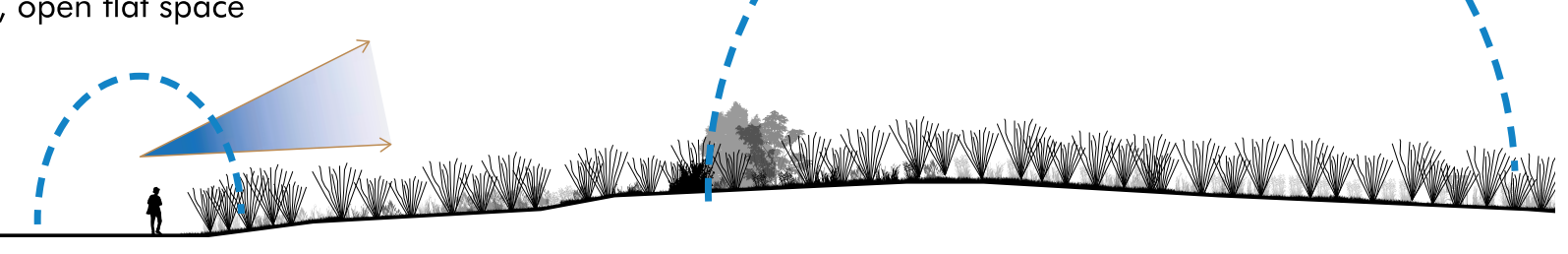


East Section / South View
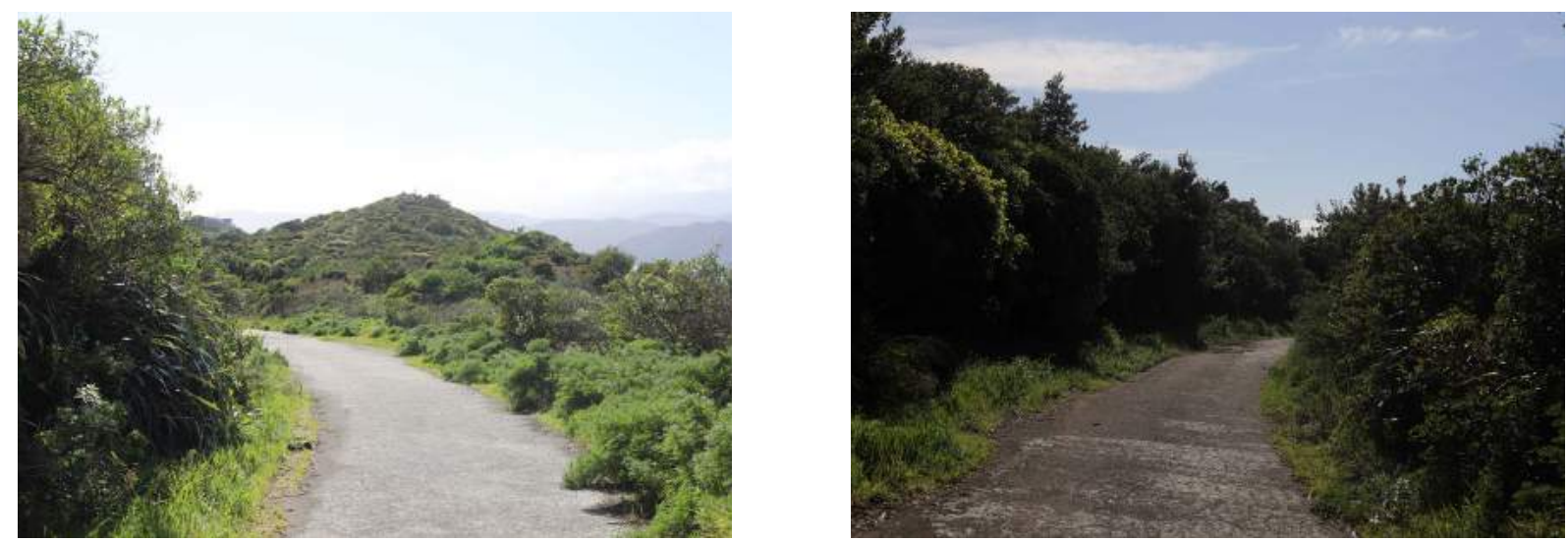

(4)

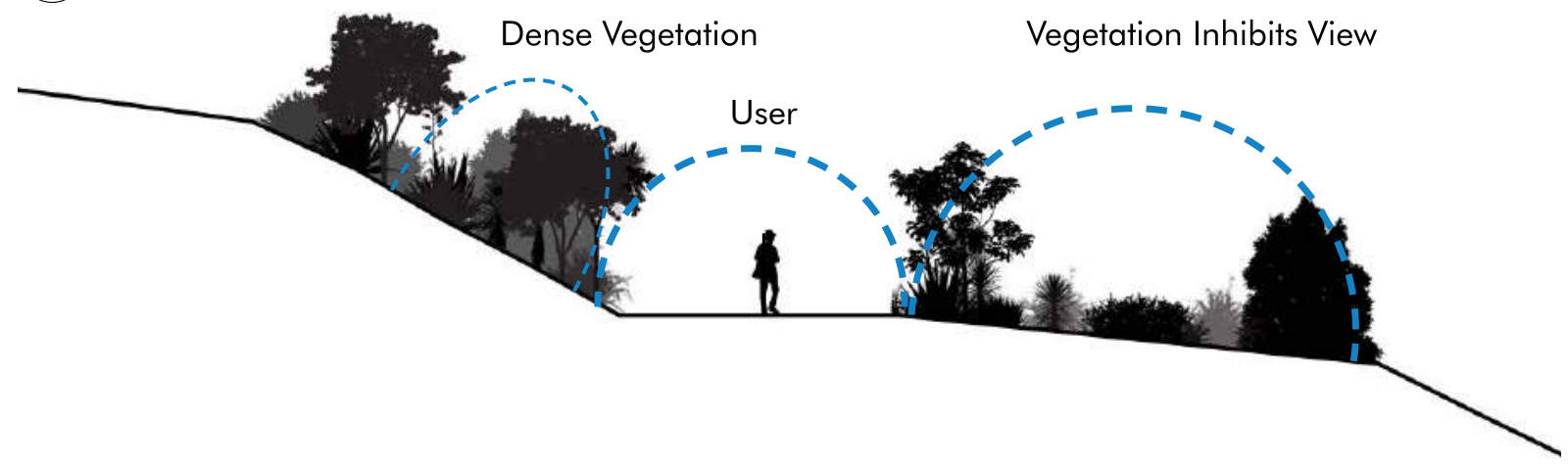

(5)

Far East Section / South Viewshafts More open view to south

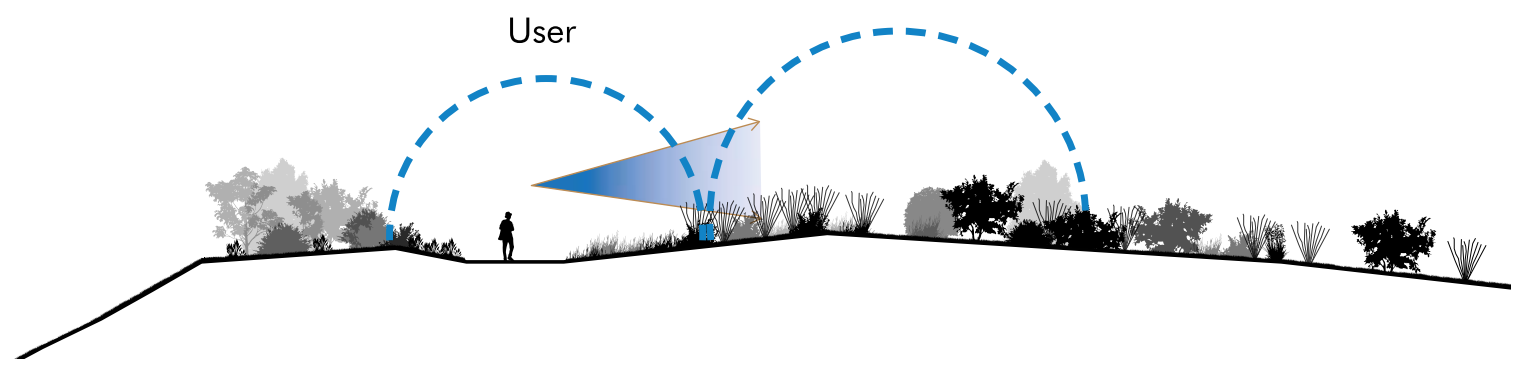

$1: 200$ 


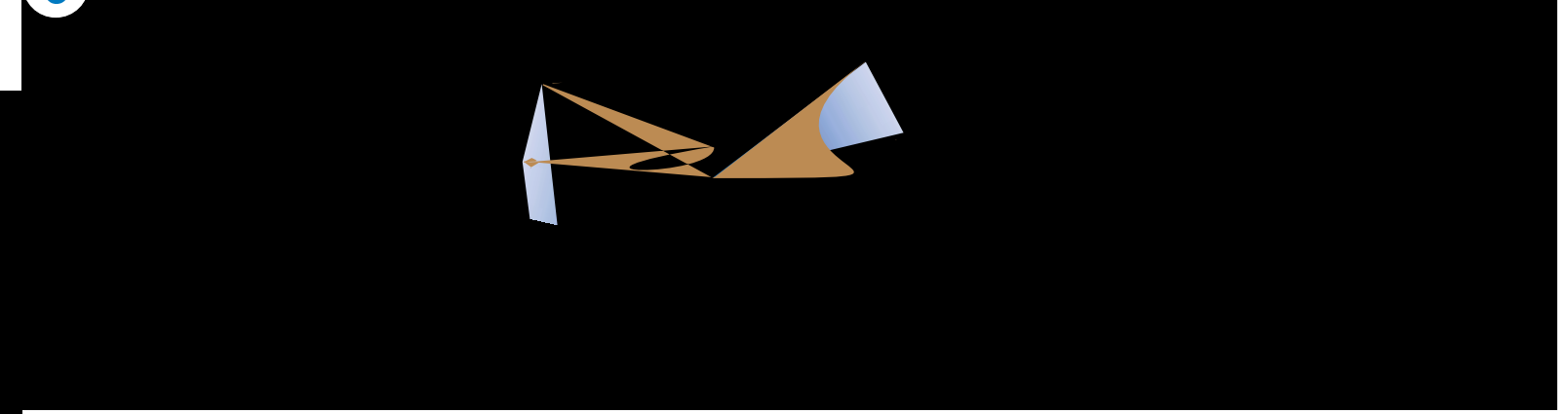




\section{Design Criteria}

The toolkit testing was split amongst the Waterfront and South coast. Lighting was the primary characteristic investigated in Moa Point. The site was already very dark, so the lighting iterations had to investigate how their presence could encourage social interaction in the space without disrupting the current experience. Four design principles derived from the toolkit as initially found in the literature were established as rules to protect the light:

- Multiple small scale interactive lighting elements focusing on colour

- Using natural features on the site as placeholders for lighting fixtures

- Simple shielded path lighting that shines from below the waist

- Using light as a visual marker (similar to tape around trees on bush walks)

- Using the stars as inspiration for lighting

The toolkit findings were then implemented with other design specific to Moa Point to test if it can encourage interaction at night.

\section{Lighting Experimentation}

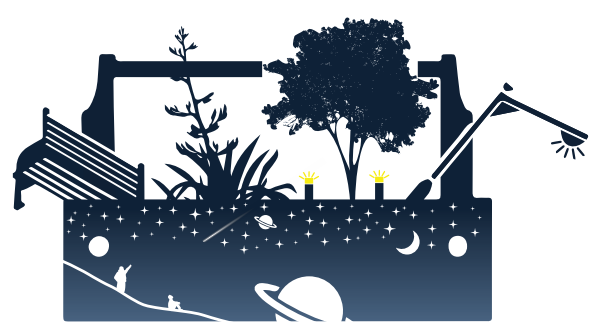

\section{Merging toolkit with site specific design}

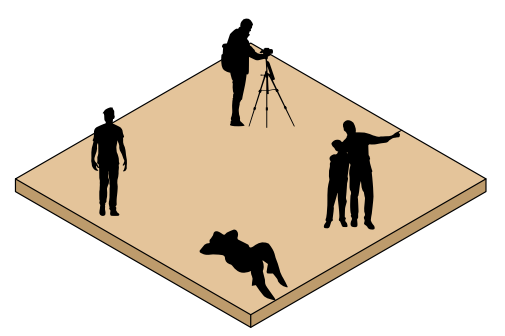

Maori Astronomy

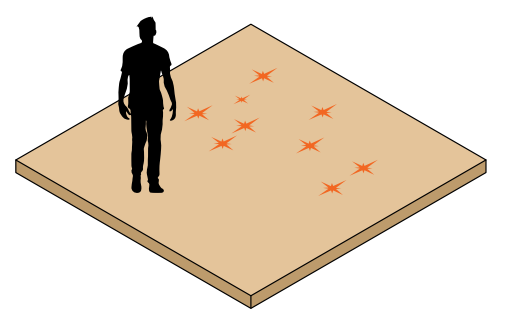




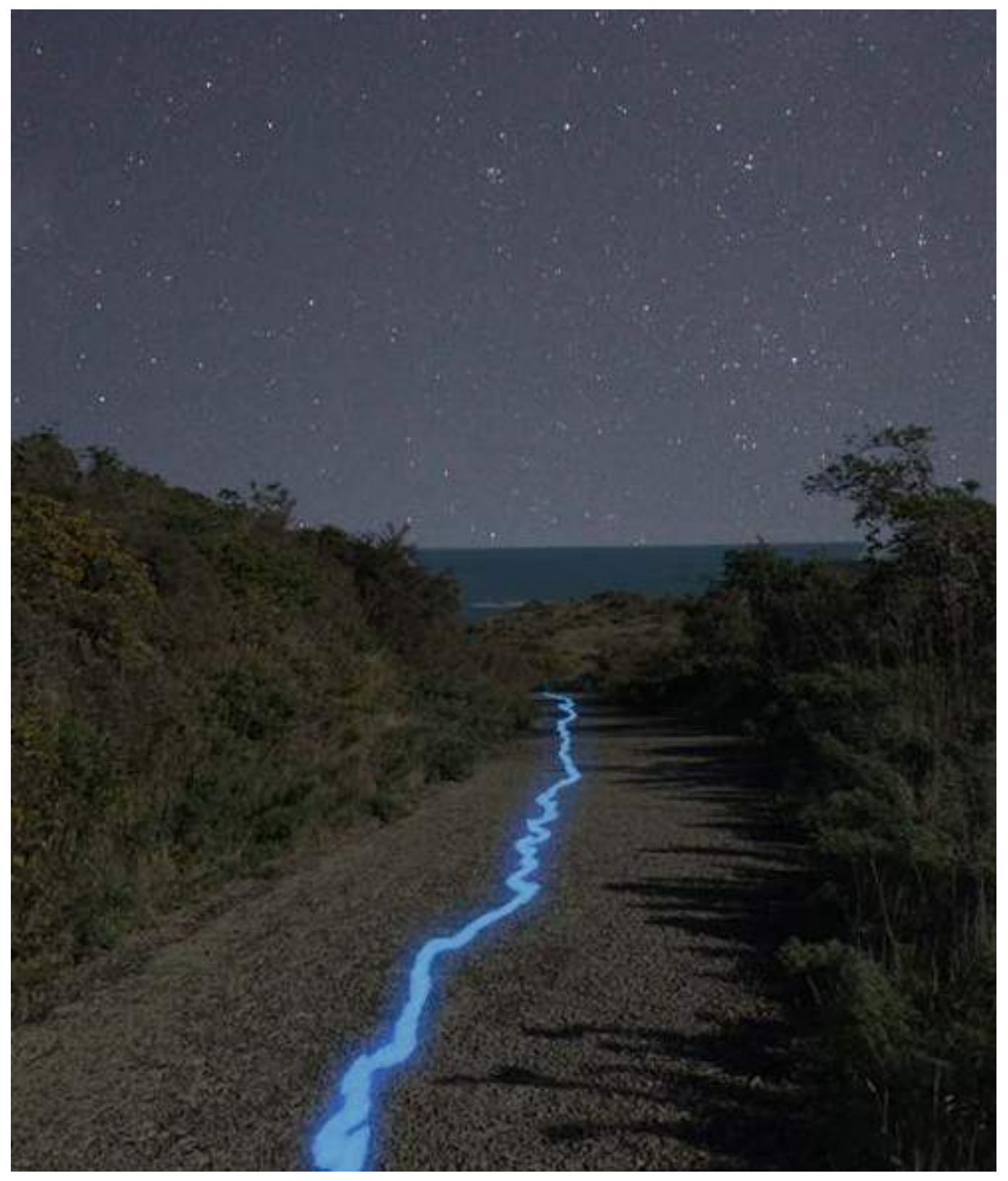

Fig 7.5 Light trail experimentation West Moa

Point 


\section{Lighting Experimentation - Bulb Colour}

Lighting testing was implemented using two separate processes, physical testing at 1:1 and digital collaging. In the physical testing, solarpowered lighting was purchased and taken out to the site at night. One testing process involved using directional 10-lumen garden lights and fairy lights (inspired by the Van Gogh path). The use of

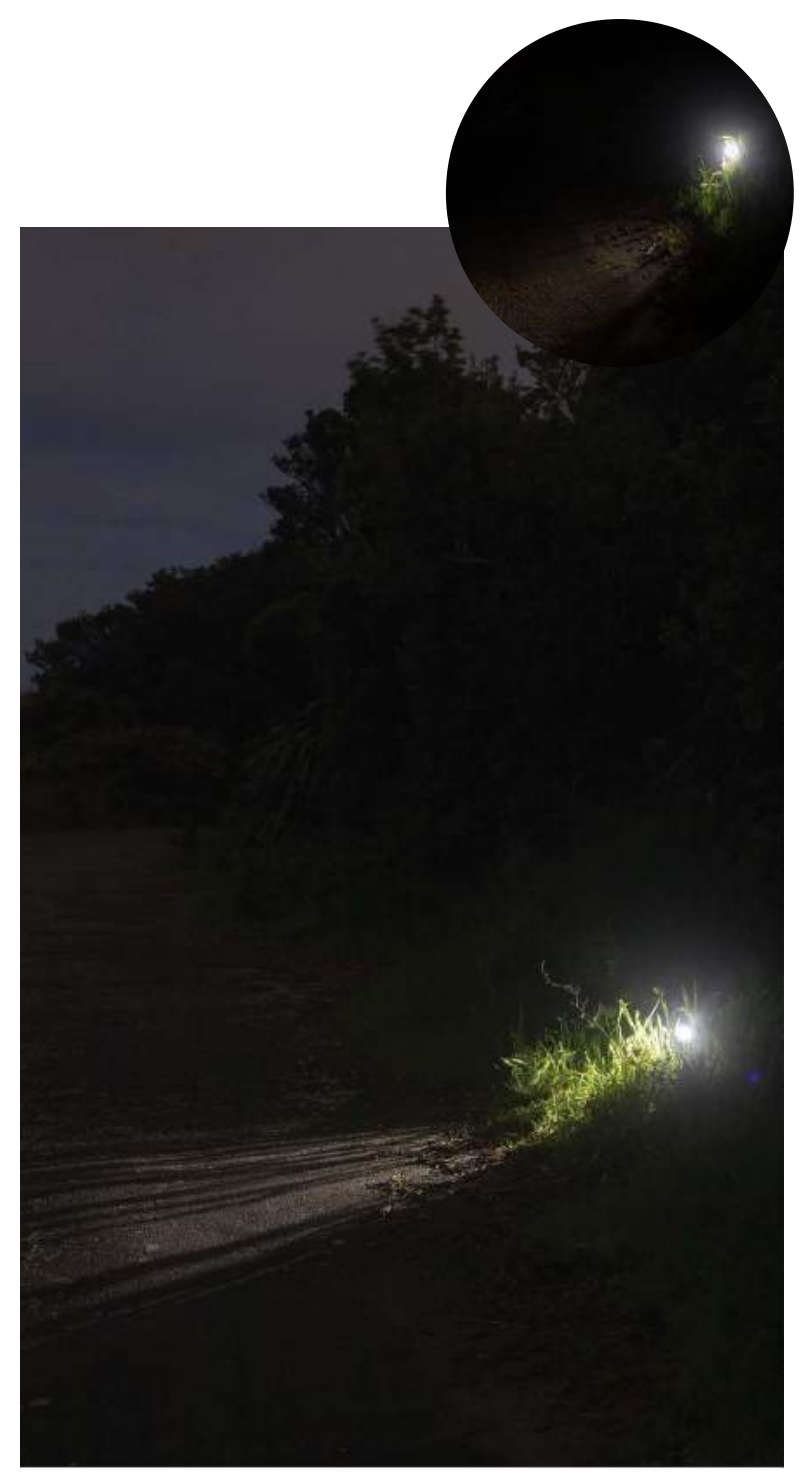

\section{AS SHOT - COLD}

The colour temperature as shot from the camera. This temperature felt not too harsh to or soft

\section{Comfort}

Fig 7.6 Bulb Colour Experimentation a camera and tripod recorded testing of bulb temperature and glare direction.

In digital collaging, the process involved applying existing lighting methods that promote interaction with a night space into the walking track areas.

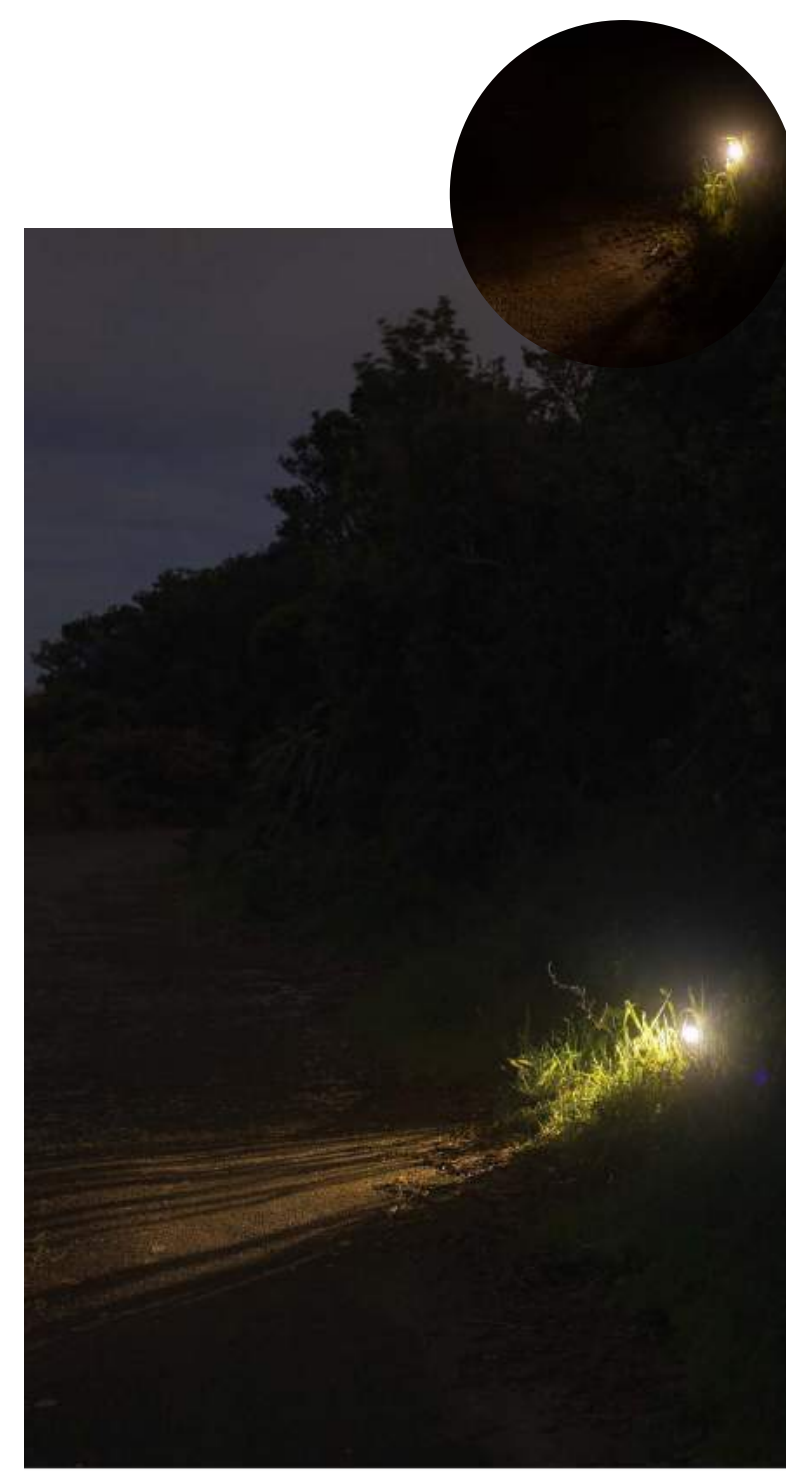

\section{WARMER}

In comparison to the cold colour this felt a lot more inviting to be close to, due to the soft tones

\section{Comfort}


In these iterations, solar-charged garden lights from Bunnings with a ten $\mathrm{w}$ lumen rating were implemented on-site as path lighting. Four colours were tested against perceived comfort representing the four light temperatures commonly seen in outdoor public spaces; cold

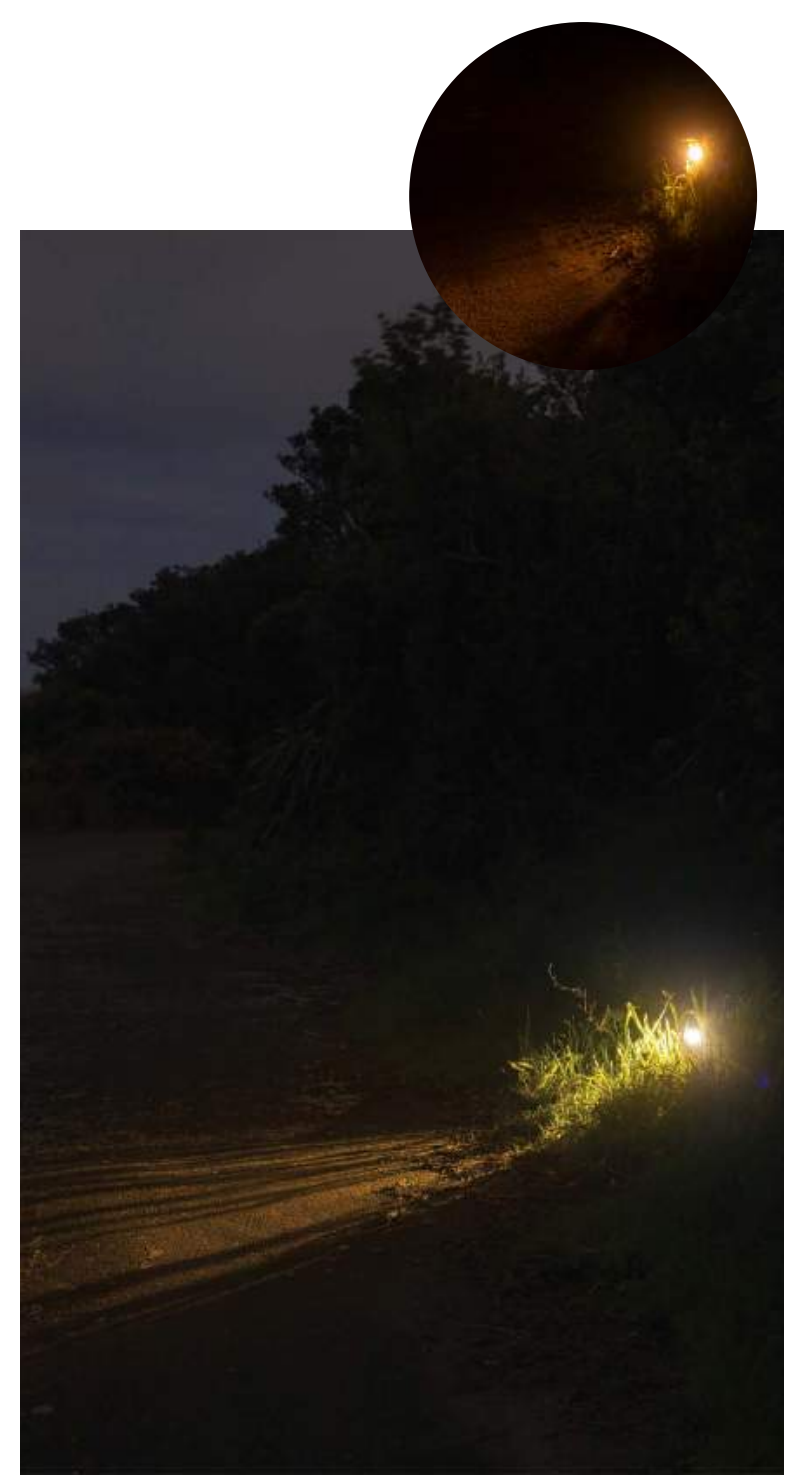

\section{VERY WARM}

This colour felt very comforting in the site. However the strong orange was a little too intense in the site

\section{Comfort}

Fig 7.8 Bulb Colour Experimentation (Very Warm)
(LEDs), warm, very warm (sodium vapour), and very harsh blue (extreme LEDs).

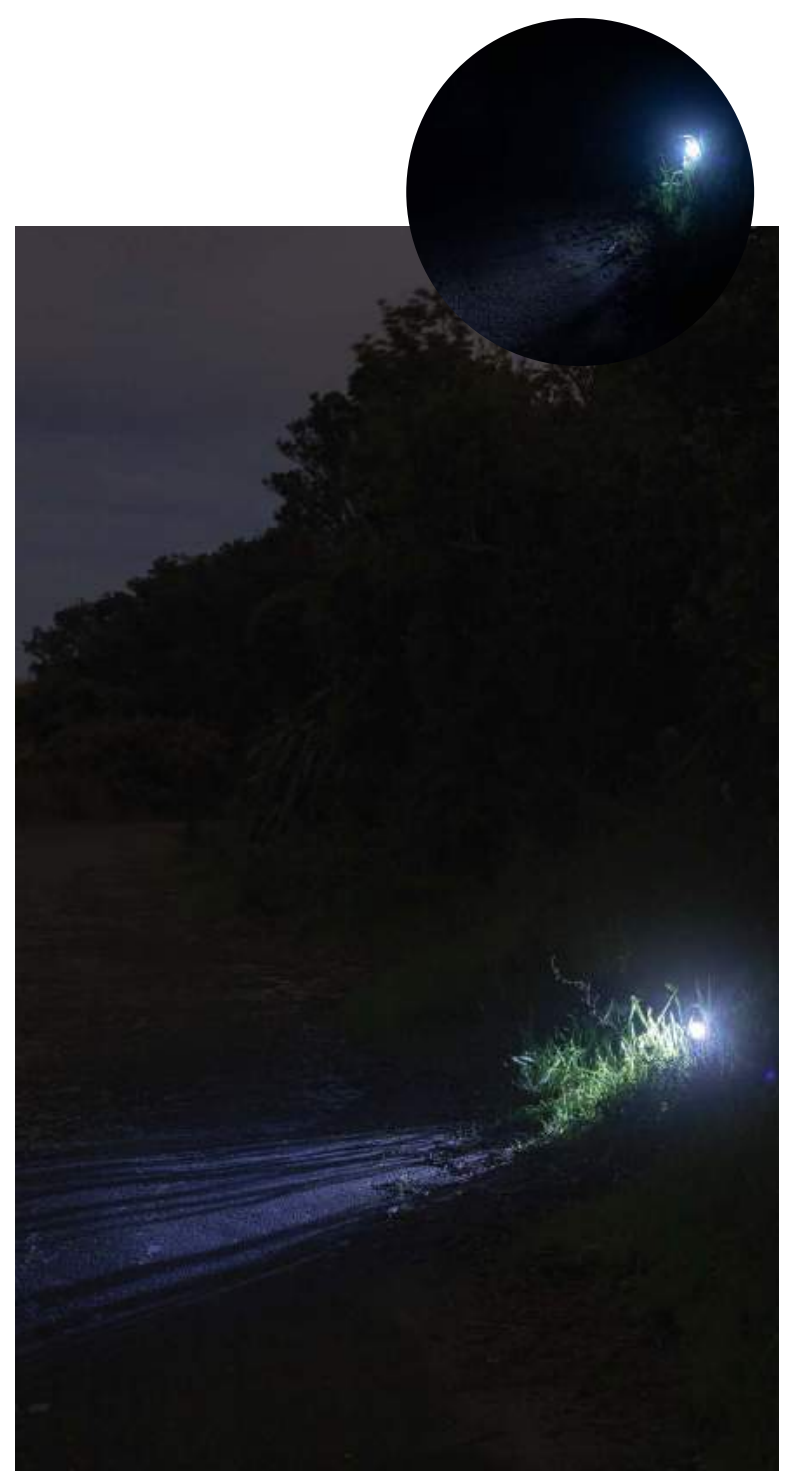

\section{VERY HARSH/BLUE}

This colour was the most intense, and the most iritating to look at in the site.

\section{Comfort}

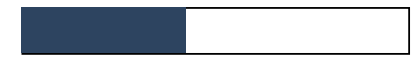

Fig 7.9 Bulb Colour Experimentation (Very Harsh) 


\section{Lighting Experimentation - Path Lighting}

The following physical lighting test was using the garden lights as path lighting and analyzing their direction on the perceived comfort in the space.

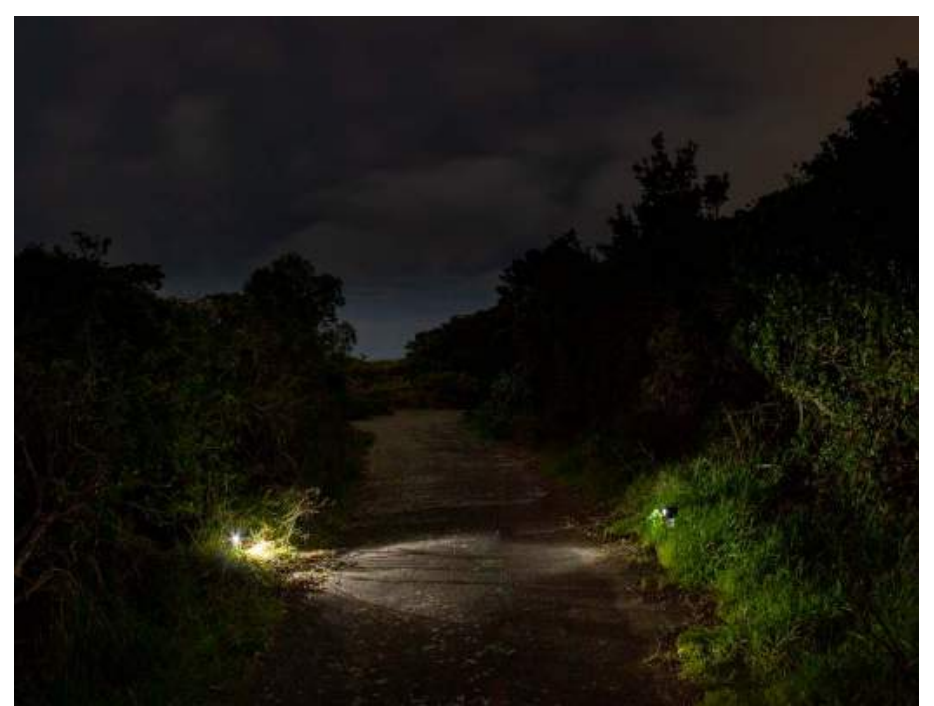

Comfort

Fig 7.10 PL - Angled towards path

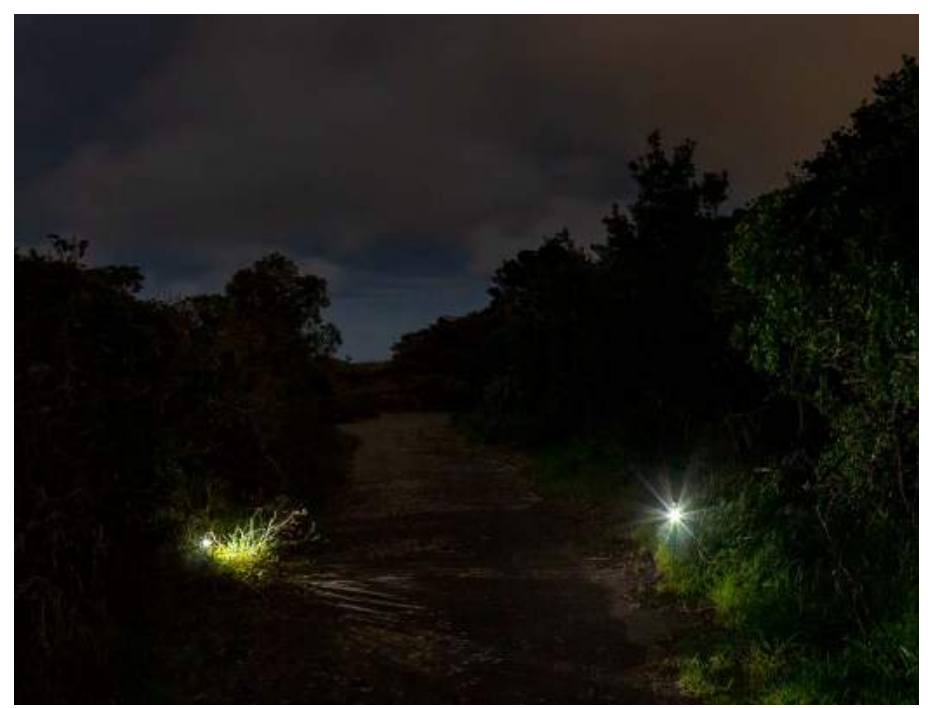

Comfort

Fig 7.11 PL - Angled towards user

\section{Angled towards Path}

The first iteration angled the lights towards the path. Perhaps the most obvious option, this gave the path the most amount of luminance.

\section{Angled towards user walking}

The second iteration angled the lights towards the user of the space. This was not a very good option as while the light glare was minimal; it interrupted the view upwards. It also is not very functional for people travelling in the opposite direction. 


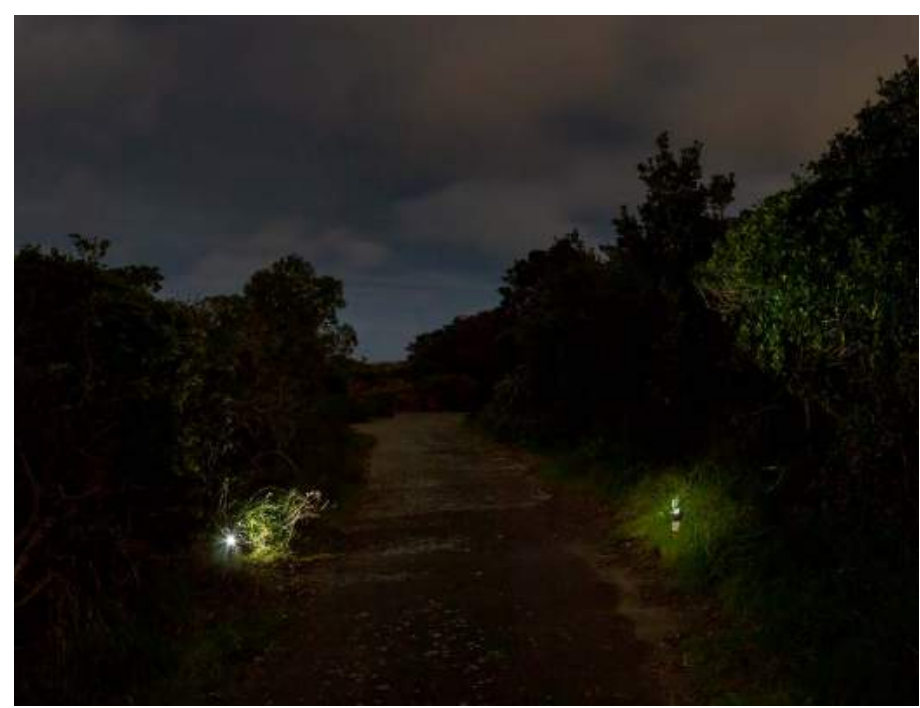

Comfort

Fig 7.12 PL - Angled upwards

\section{Angled Upwards}

The third iteration angled the path lighting upwards. This option did not illuminate the path at all.

\section{Angled towards bushes}

The third iteration angled the light towards the bushes. This created silhouettes, which were not a very pleasant experience.

Comfort

Fig 7.13 PL - Angled towards bush 


\section{Lighting Experimentation - Path Lighting}

This testing involved using fairy lights to create a

light path to be used as a visual cue.

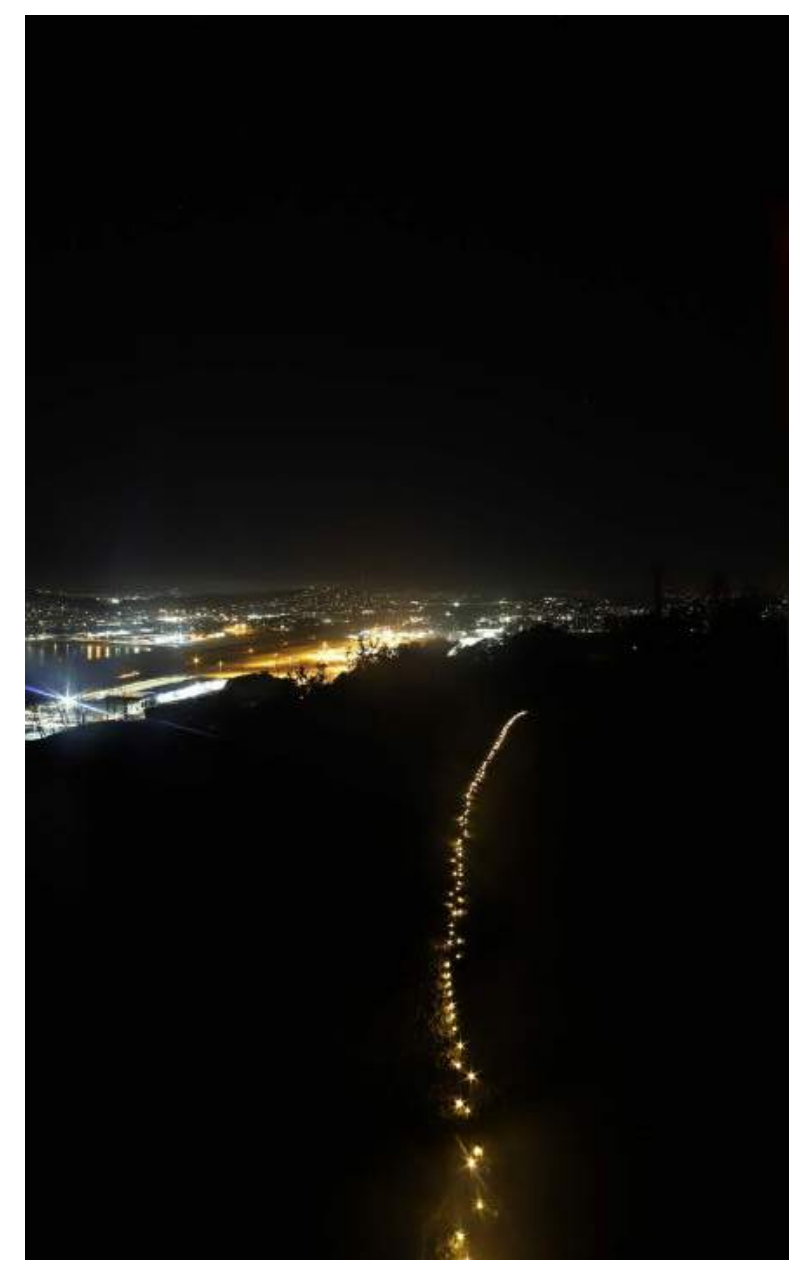

\section{Straight Line}

200 fairy lights arranged in a straight line with the city in the background. The fairy lights in this arrangement provided a little bit of path illumination

\section{Comfort}

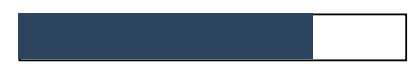

Fig 7.14 Fairy lights - Straight line

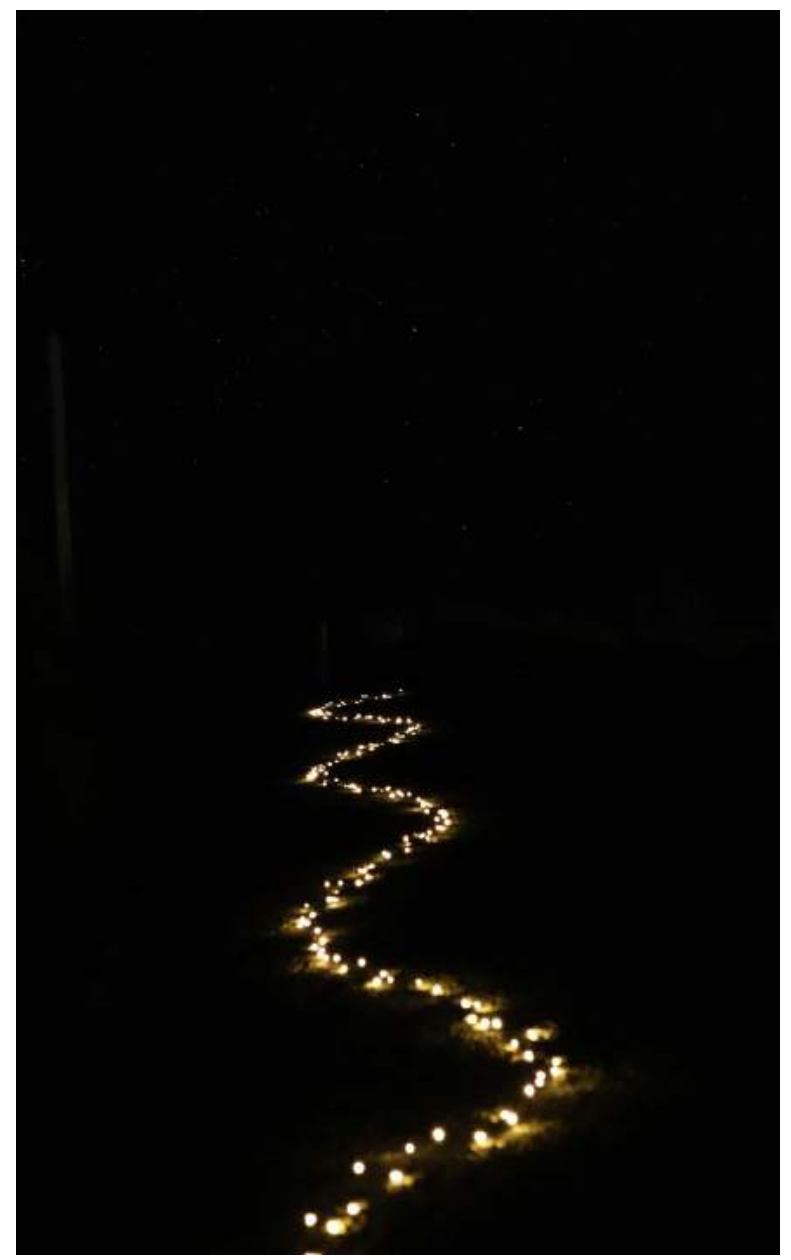

\section{Squiggle}

The squiggle pattern covered more surface area of the path and was more engaging to walk along

\section{Comfort}

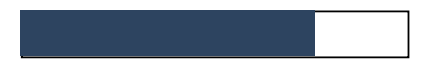

Fig 7.15 Fairy lights - Curved line 


\section{Lighting Experimentation - Digital Iterations}

The final lighting test was digital collaging. Examples of lighting that promote interaction with space were analyzed, and their design variations apply to the site.

Light as a visual marker

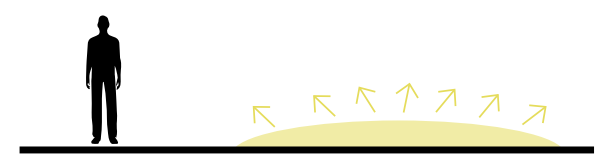

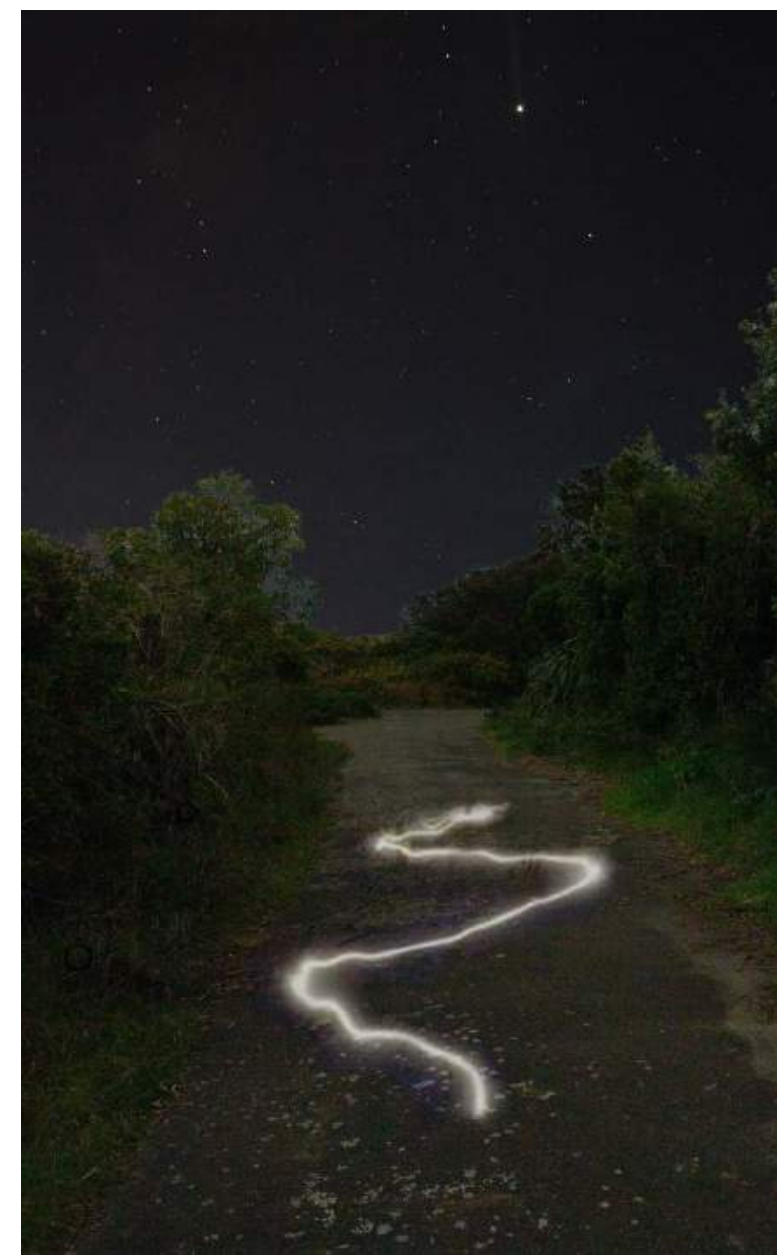

Iteration 1: Light Trail

The light trail using small LEDs in the ground provides a visual cue to follow.

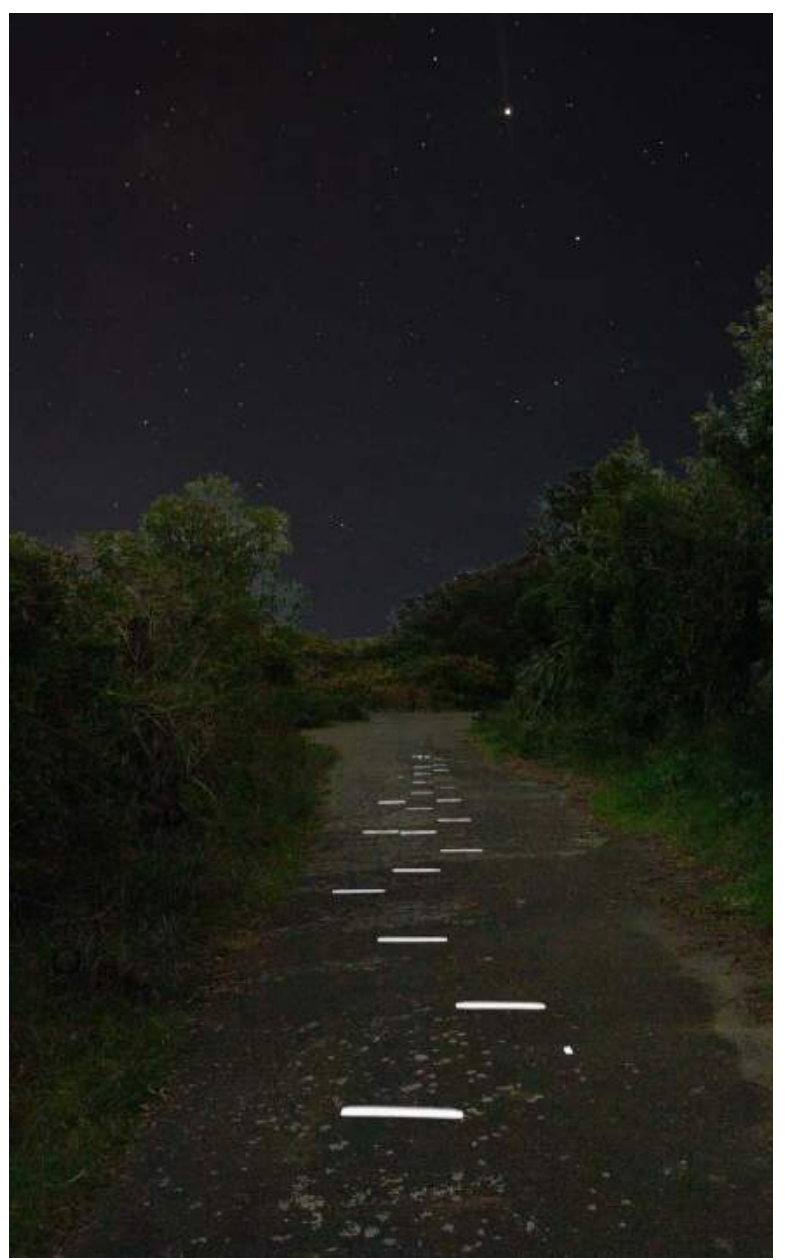

\section{Iteration 2: Alternating lights}

Alternating lights provide another visual marker to follow.
Comfort

Fig 7.16 Digital - Light trail
Comfort

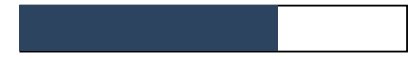

Fig 7.17 Digital Alternating lights 


\section{Lighting Experimentation - Digital Iterations}

Bringing the sky into the space $+$

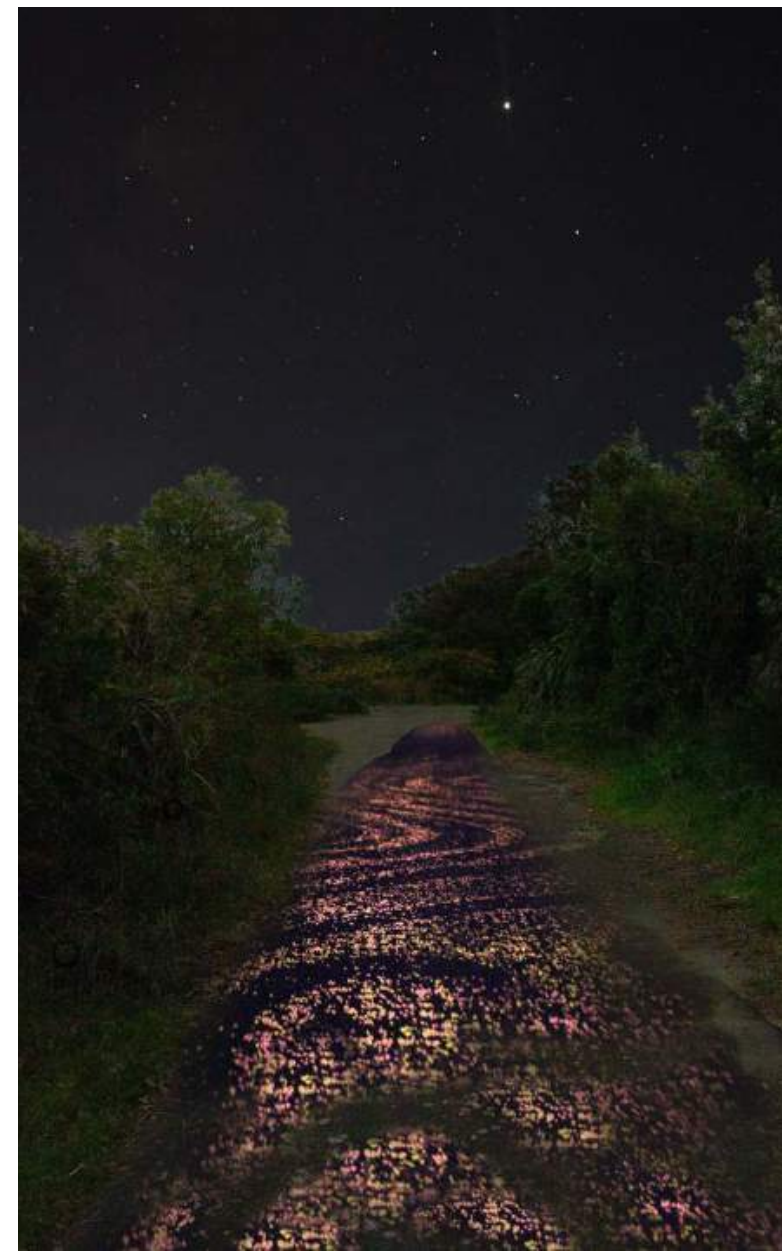

Iteration 3: Glow in the Dark stones

The Van Gogh Path inspires this. The stones would not add any light glare but provide a path boundary and visual stimuli to focus on while adjusting to the darkness.

Comfort

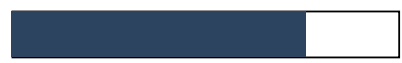

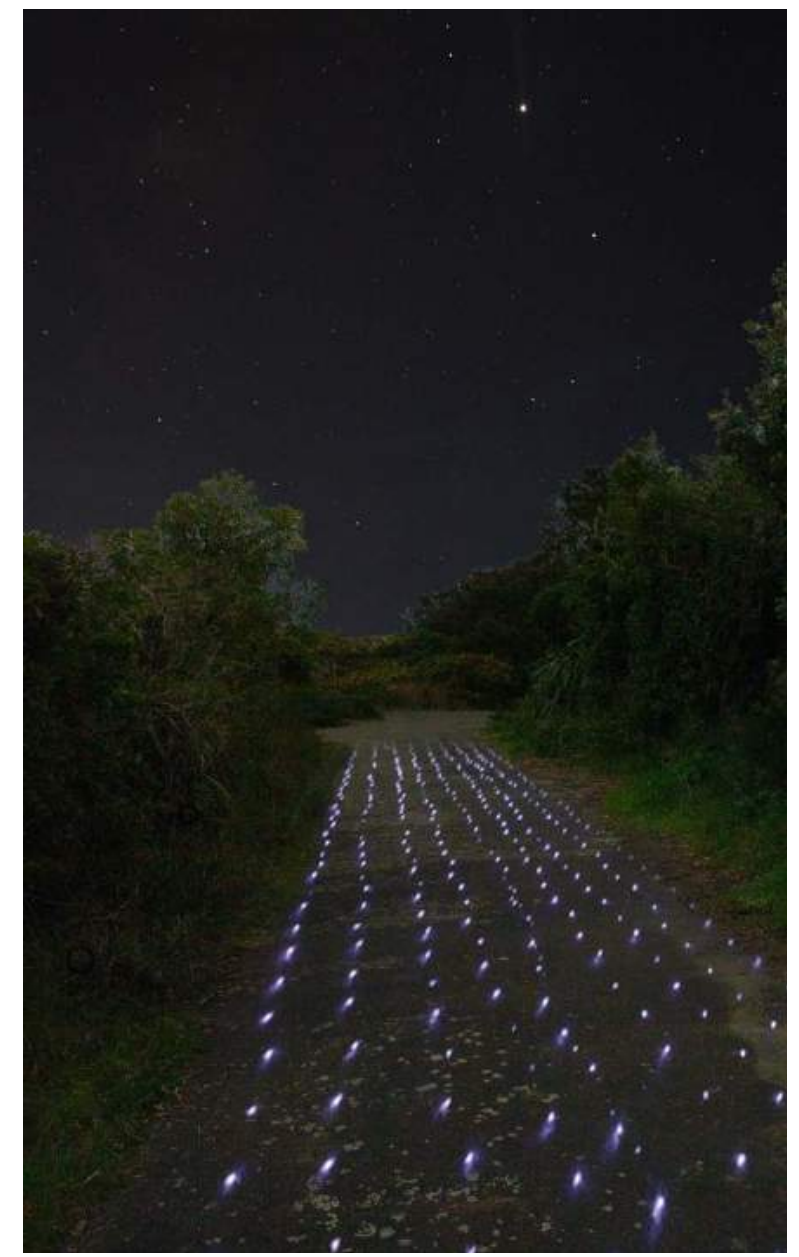

Iteration 4: Bringing the stars into the space

This option may be a little too intense for the pathway. 


\title{
Lighting Experimentation - Digital Iterations
}

\author{
Using nature as a placeholder
}

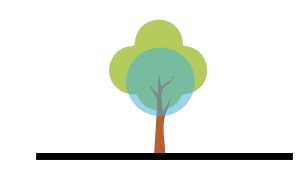

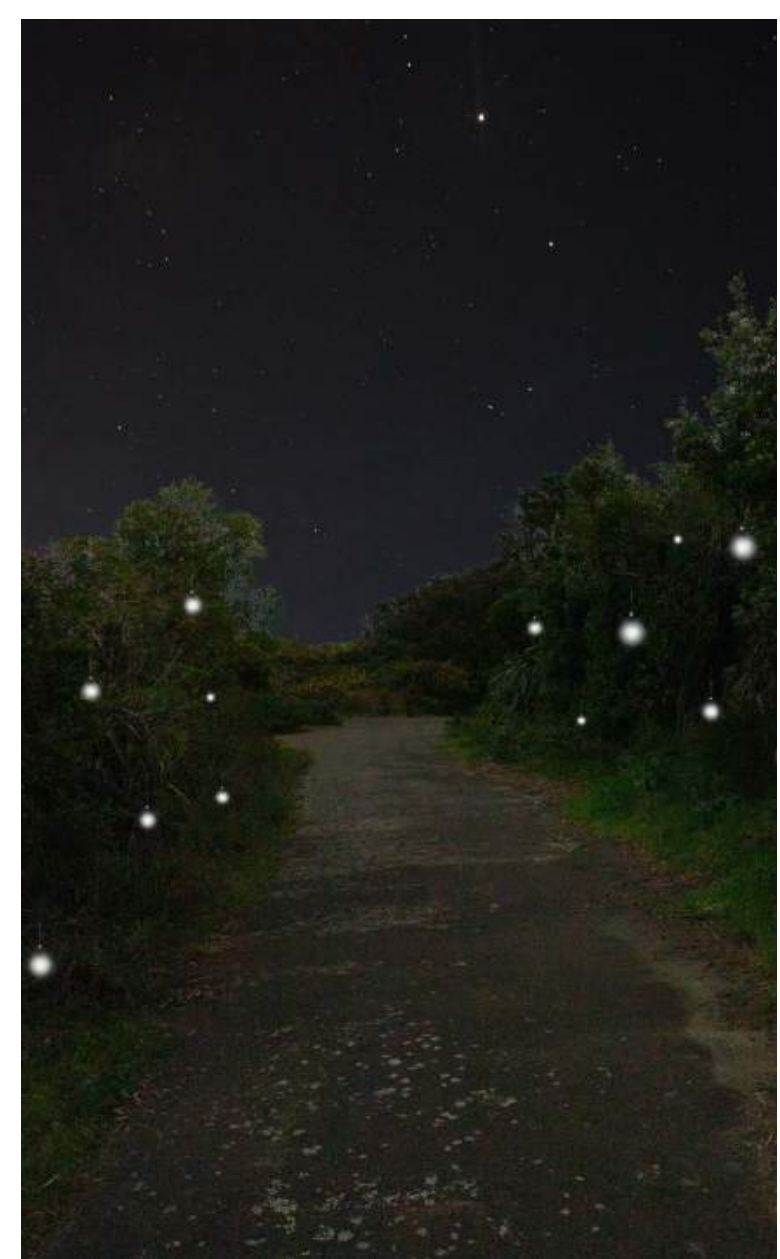

Iteration 5: Hanging Lights

Hanging lights may create undesired shadows in the bushes.

Comfort maintain on the site.

Comfort

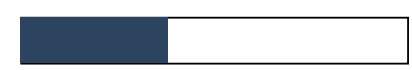



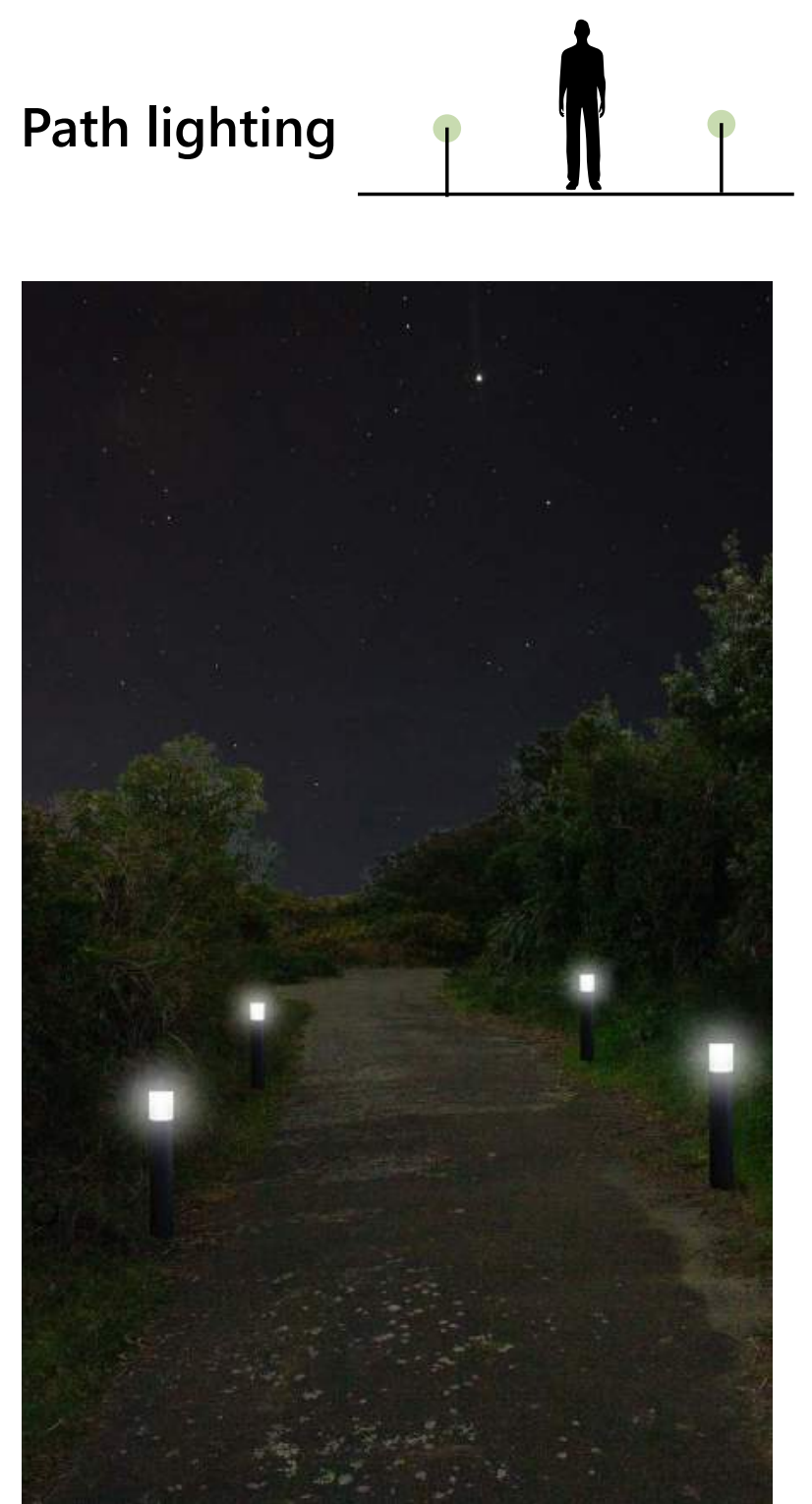

Iteration 7: Path Lights

This option is functional but overused.

Comfort

Fig 7.22 Digital - Path lighting

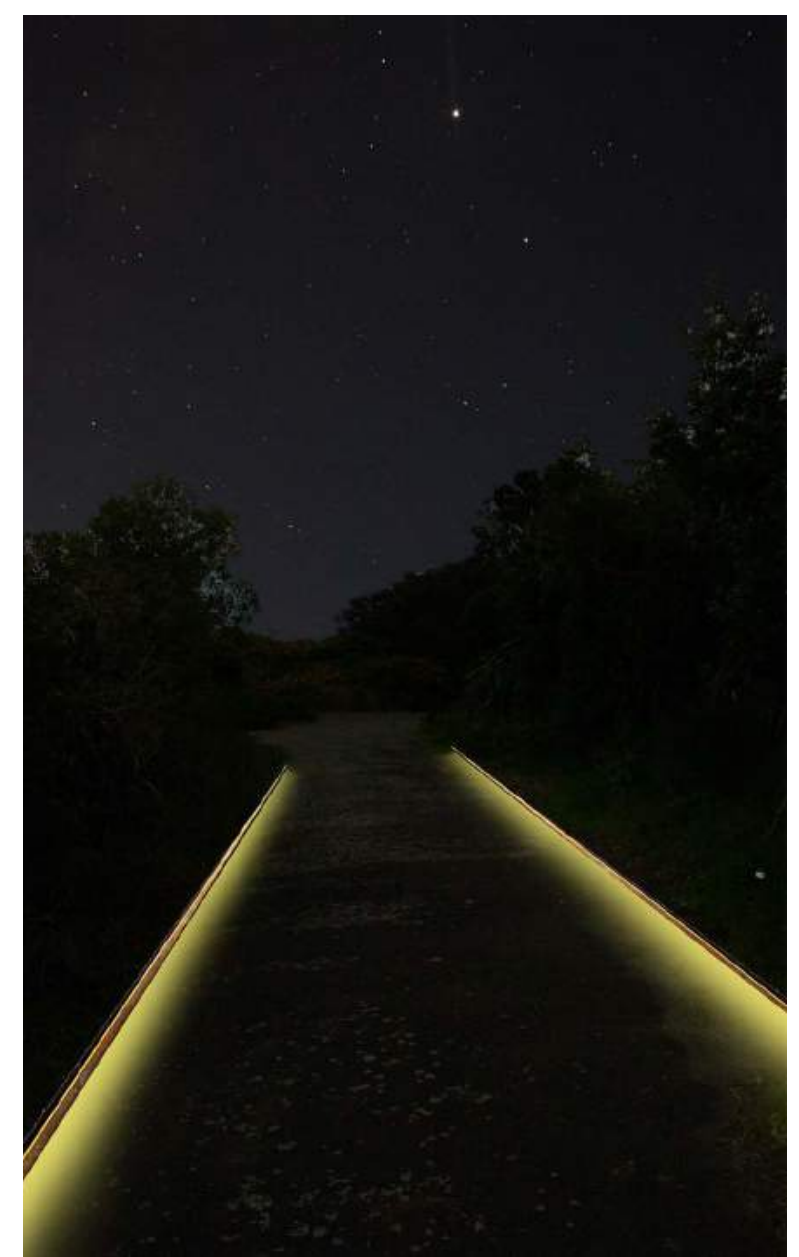

\section{Iteration 8: Light strips}

These provide a solid edge to the site, but they are also a little too intense in the site.

Comfort

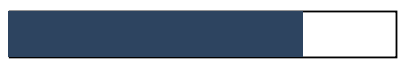




\section{Platform Design}

As shown in the fieldwork, stargazing in built areas of the natural environment was more comfortable, such as on gravel/concrete paths and lookout points rather than on grass by the bushes. A platform provides the boundary to the stargazing place and illustrates this is a space with a purpose. Once the platform is set, lighting and seating can be added to it as part of the overall design.
Quick platform models were developed testing size and shape. From the initial fieldwork, it was discovered that there was a different experience being alone out on the South Coast than in the Town belt and Waterfront with the odd person walking past. The platform needed to account for the personal experience and one that may be shared with friends.

\section{Perceived comfort with surrounding people}

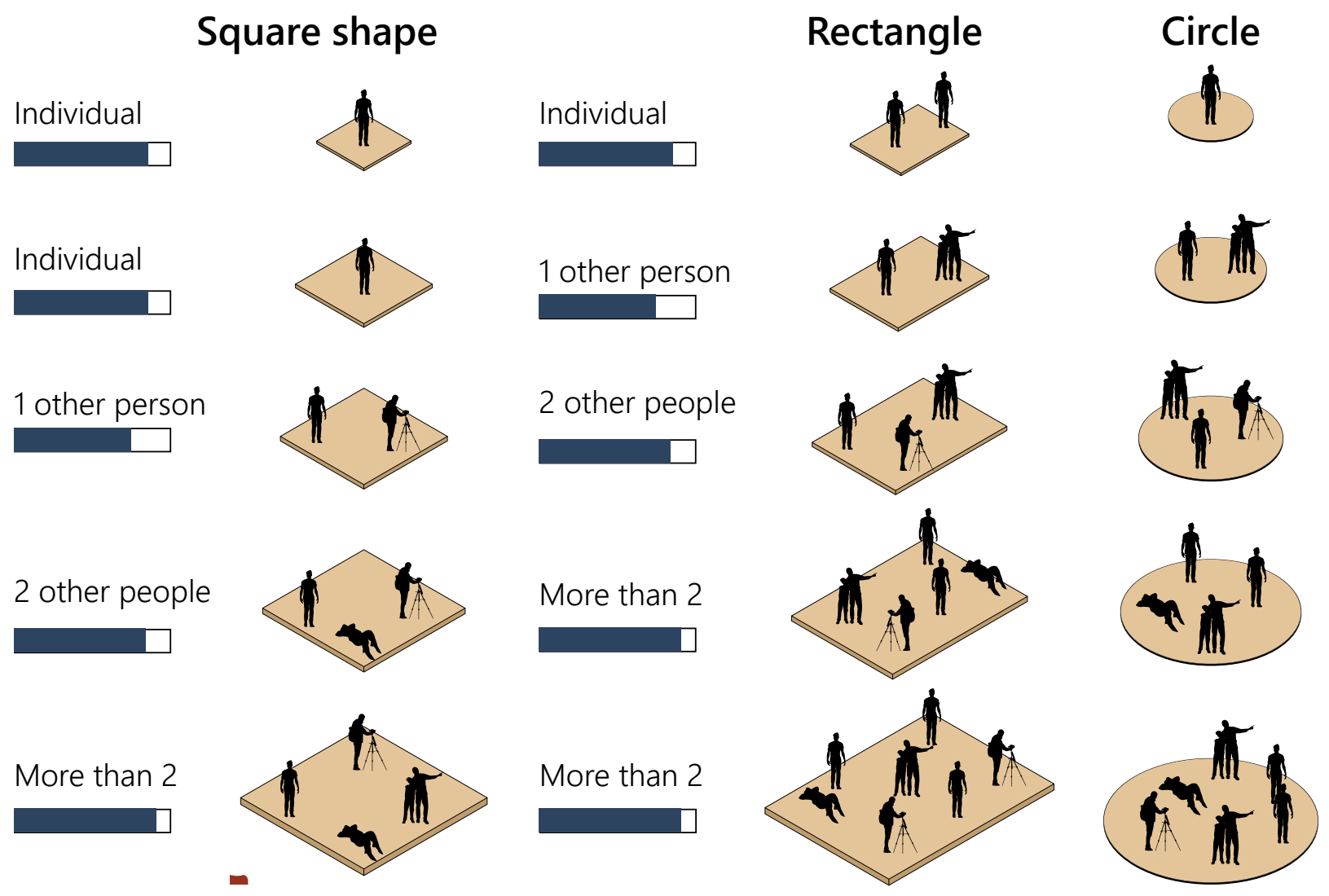

- One other person on the platform is uncomfortable due to no one else being around

Fig 7.24 Platform shape design

- Two other people would increase comfort further

- More than two would feel comfortable 


\section{Platform Iterations}

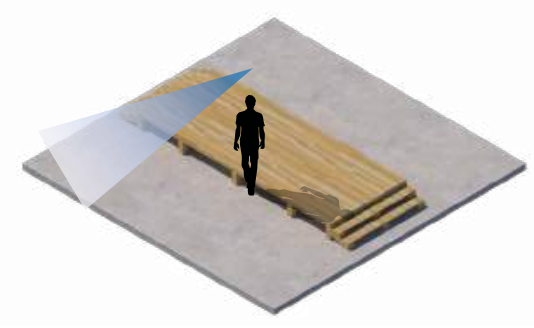

- Simple timber deck signifies this is a place set to stargaze

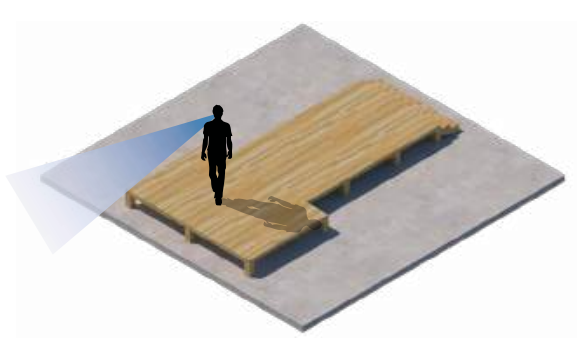

- simple timber deck with a main lookout

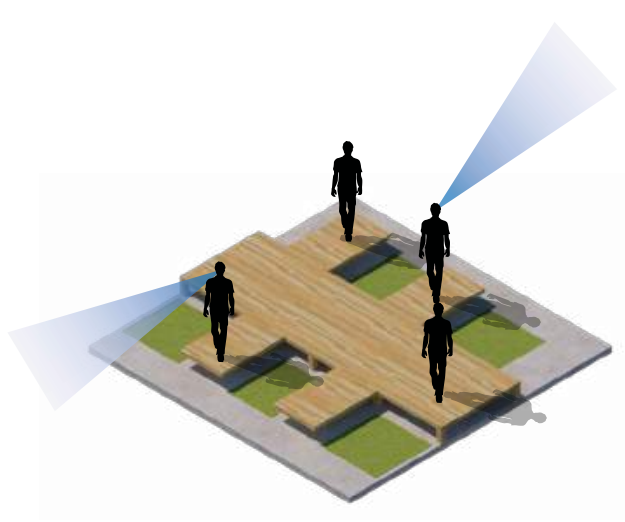

- A design that affords the group experience. Multiple lookouts branching off from the central platform with a reclined seating placed in each one allow multiple areas of the sky to be views and enjoyed.

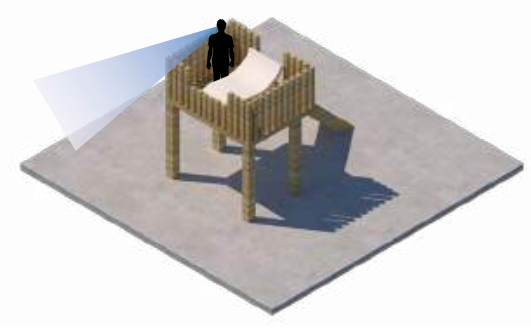

- Raised lookout creates a space to be used for the individual. It increases prospect due to its elevation.

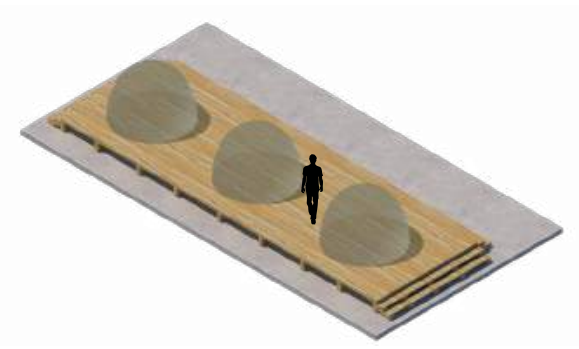

- Simple timber deck with the addition of glass domes on top for shelter from elements while stargazing 


\section{Platform \& Toolkit Experimentation}

The lighting experimentation and platform design findings were merged to create initial concepts on what the stargazing experience might look like at Moa Point. The theory surrounding vegetation and its ability to shield glare was also brought into the design concepts. Iterations 1 and 2 were placed in areas of the path where it was open on both sides, and Iterations 3 and 4 were placed in areas where there were existing vegetation and an open view.

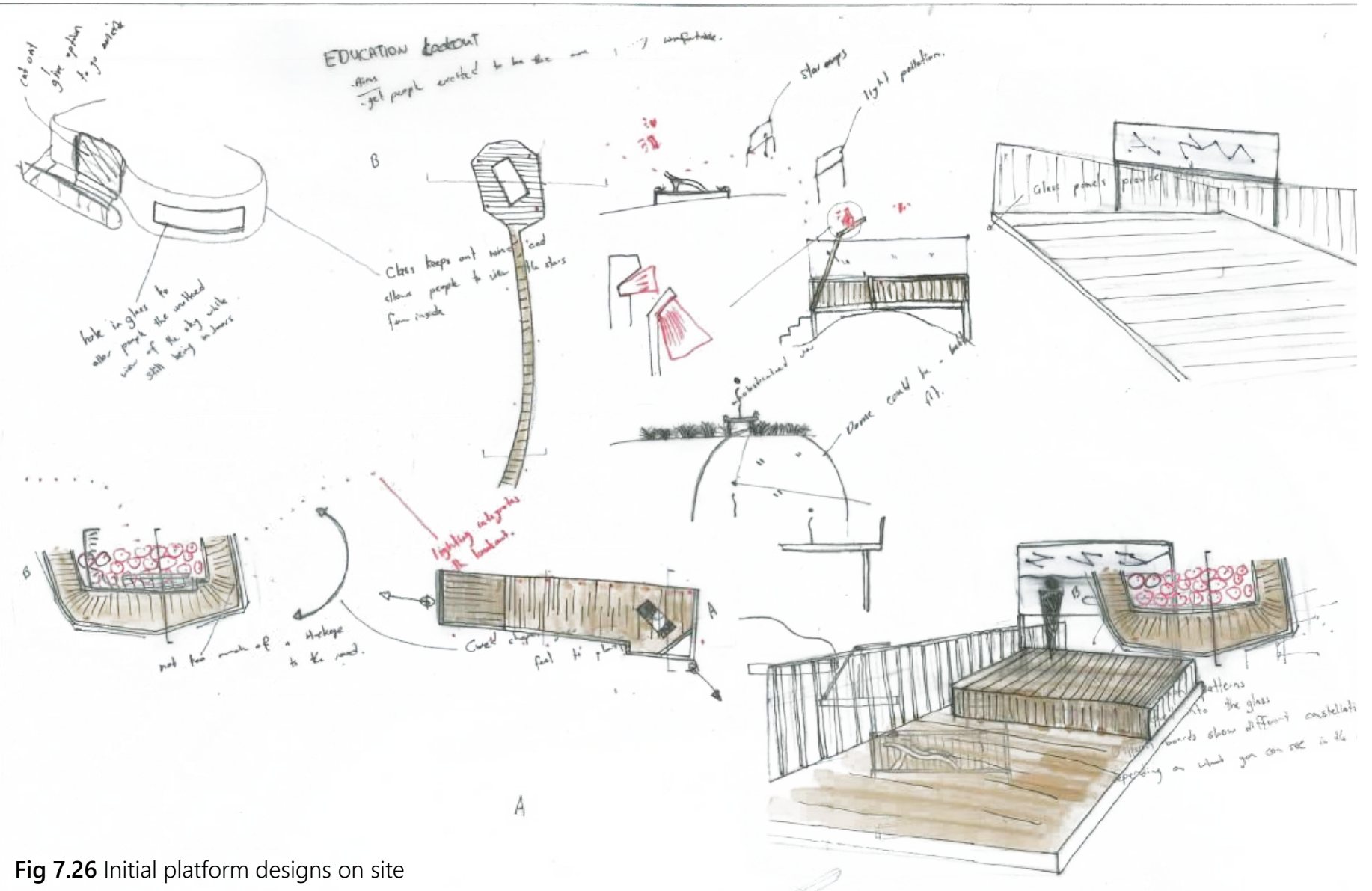




\section{Platform \& Toolkit Experimentation}

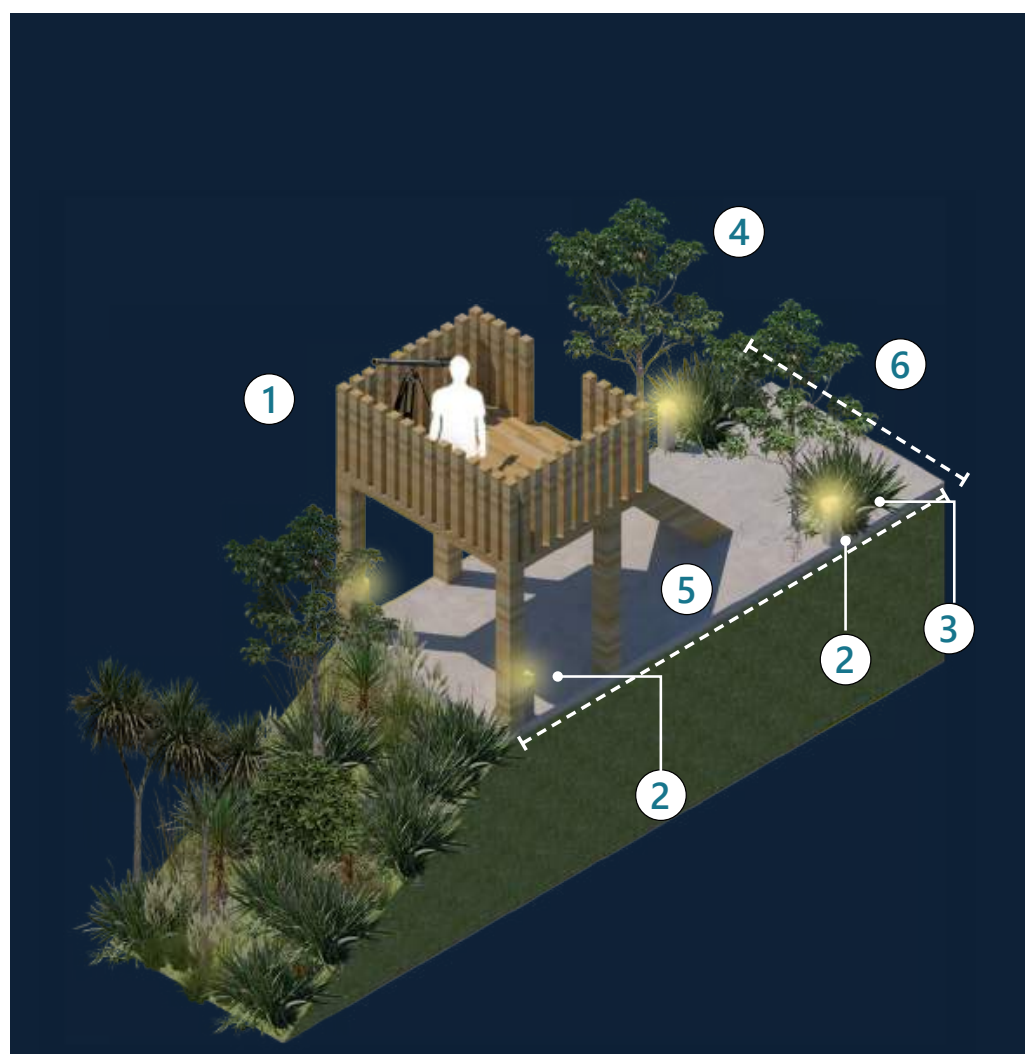

\section{Raised Lookout}

This iteration combines 4 different design features. These are located in the East Section facing east.

1. A raised Lookout gives you your own space away from the dark path

2. Low / Warm lighting for visual markers

3. Low / medium vegetation to shield path from light glare from platform space

4. Lightly dense/medium/tall vegetation to shield platform from glare

5. Existing path

6. New Path

1. A raised Lookout gives you your own space away from the dark path

2. Reclined Seating

3. Low / Warm lighting for visual markers

4. Low / medium vegetation to shield path from light glare from platform space

5. Lightly dense/medium/tall vegetation to shield platform from glare

6. Existing path

7. New Path 


\section{Platform \& Toolkit Experimentation}

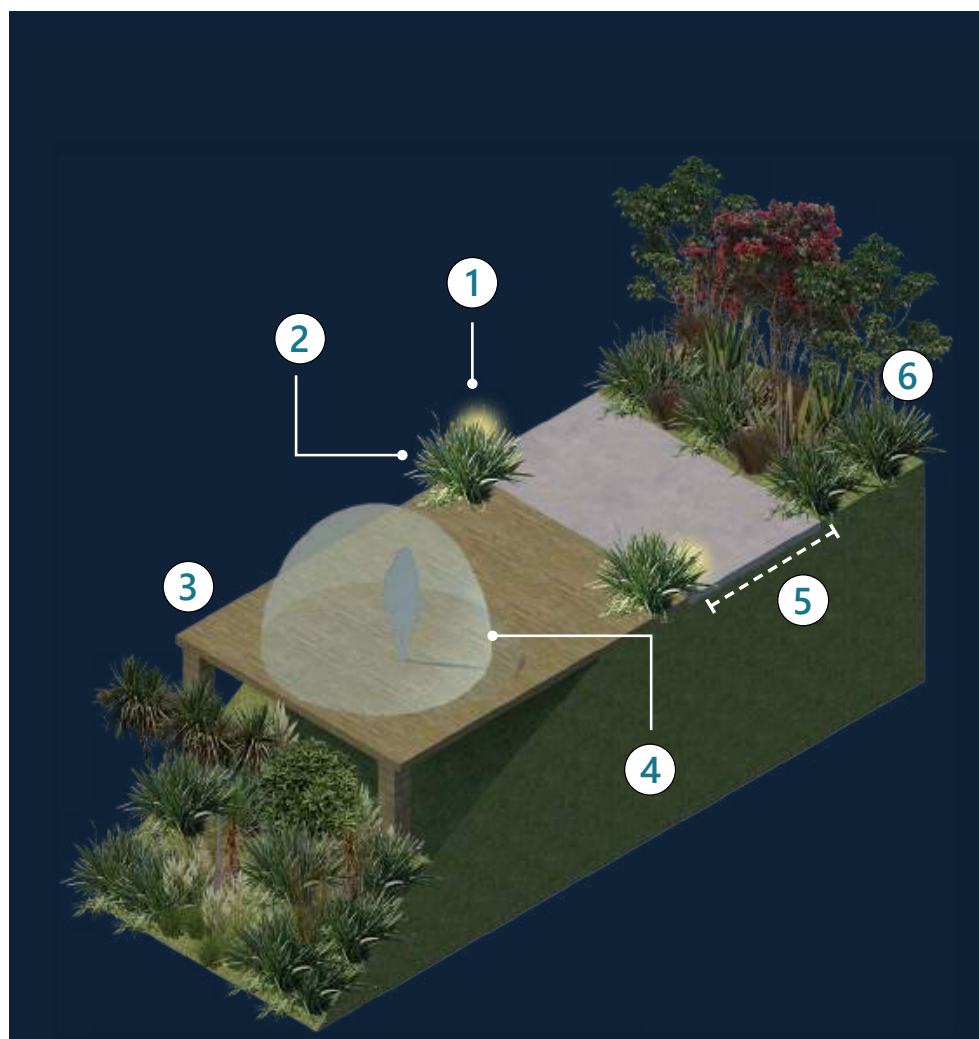

\section{Glass Dome}

1. Low path lighting is used along the existing path to provide visual markers

2. Low vegetation is used on the south side of these. This protects the users in the dome from the path lighting

3. A wooden raised platform extends the current path. This could be better integrated into the hillside

4. A glass dome lies on top of the platform. This gives the user their own space when they visit the site at night.

5. Existing Path

6. Existing vegetation

Glass Dome + Seating

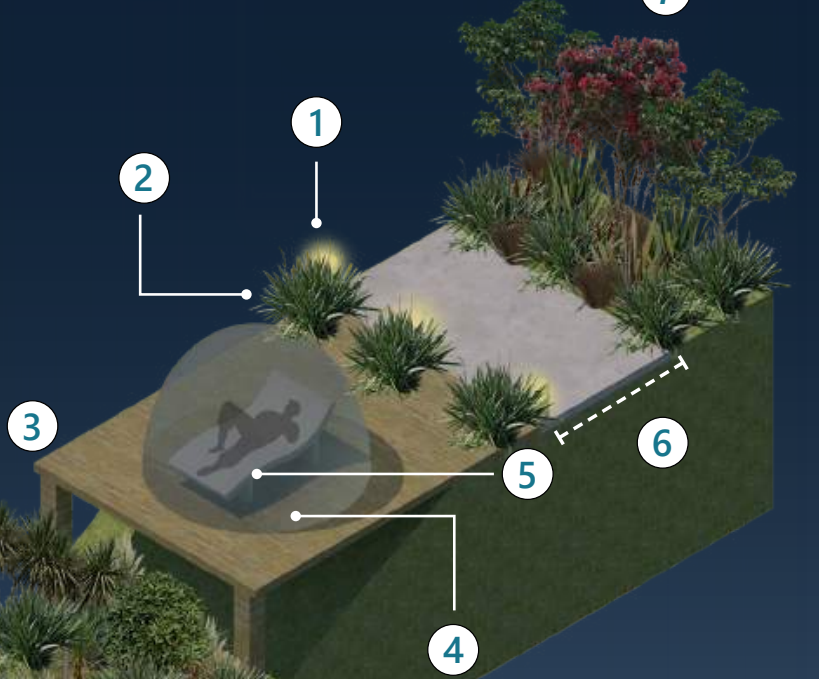

1. Low path lighting is used along the existing path to provide visual markers

2. Low vegetation is used on the south side of these. This protects the users in the dome from the path lighting. Additional vegetation is added directly behind seating to prevent glare from entering

3. A wooden raised platform extends the current path. This could be better integrated into the hillside

4. A glass dome lies on top of the platform. This gives the user their own space when they visit the site at night.

5. Reclined seating within the dome

6. Existing Path

7. Existing vegetation 


\section{Moa Point - Integrating Maori Astronomy}

\section{Matariki}

At this stage in research, Maori astronomy was brought into the design process due to the expansive views the site offers at night. Many distant stars and constellations could be seen on clear nights. Specifically, it has excellent views of where Matariki appears with its heliacal rising in the east. This can also be seen by placing the Maori navigational compass over a site plan, which shows the exact location Matariki will rise.

However, this is facing the light pollution from Wellington and Lower Hutt (Fig 7.30), which makes the star cluster very hard to see. The design process aimed to use the appearance of Matariki, the findings from the toolkit and the platform design to inspire the next stage of the design process. This concept was explored through multiple sketches on and offsite.

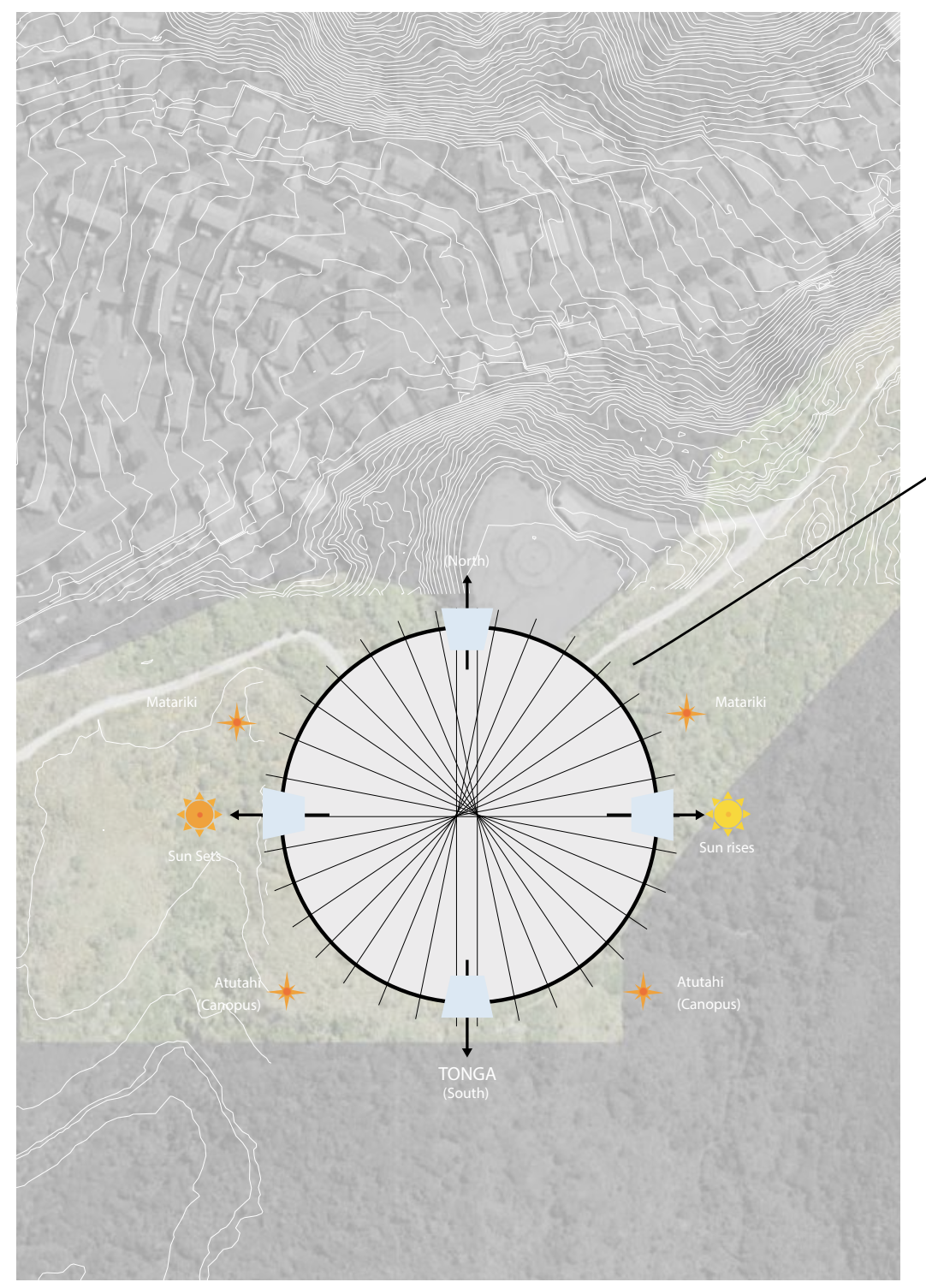

Fig 7.28 Star Compass on Moa Point 
Matariki rising location

This image has not been reproduced due to copyright

This image has not been reproduced due to copyright

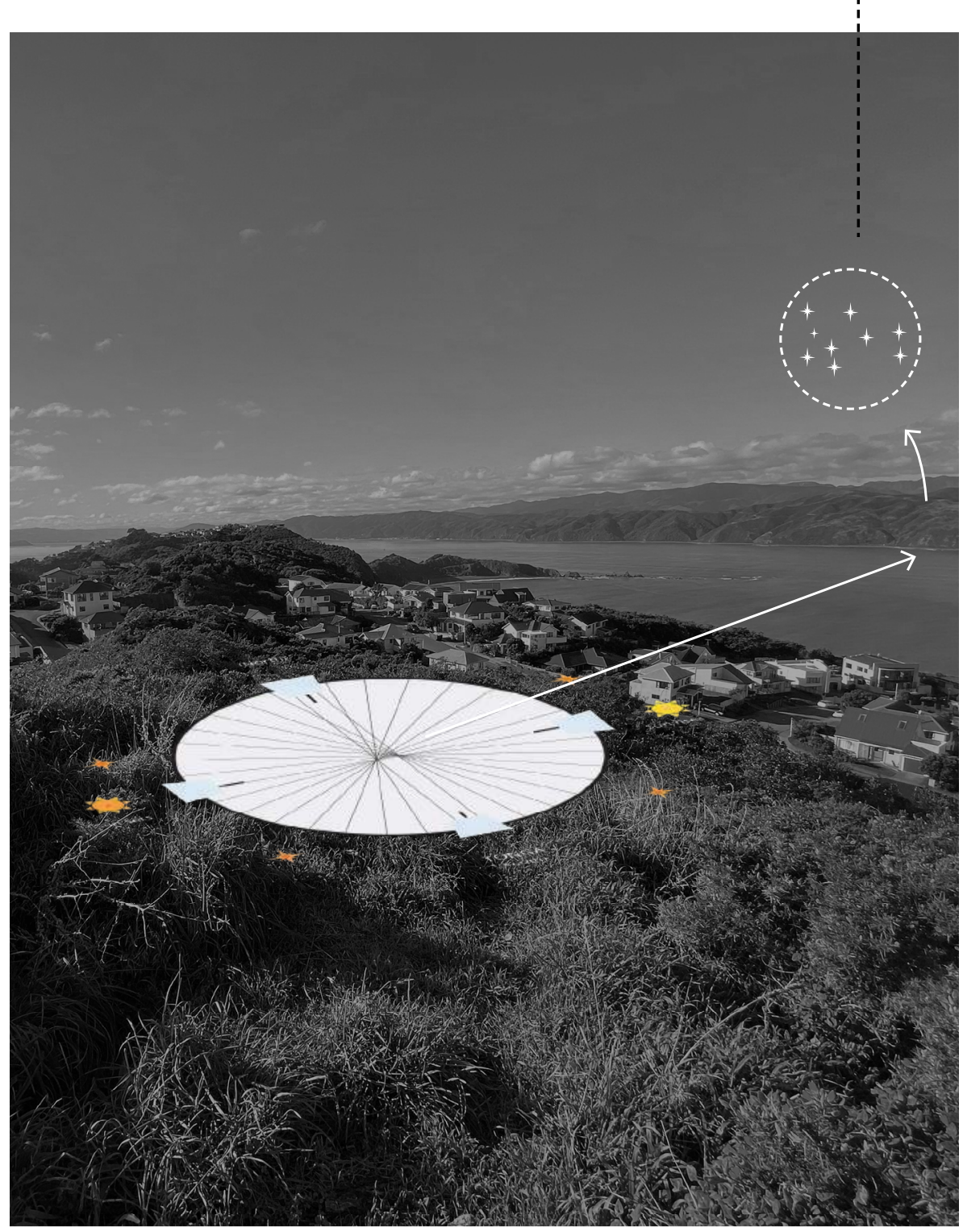

Fig 7.29 Matariki Location in the sky

Fig 7.30 View towards Lower hutt and Eastbourne 


\section{Initial Concept}

The middle of the site was chosen for the developed design as it was the most open and comfortable area because of the lack of dense vegetation enclosing it. Its raised elevation also provided the most amount of prospect. The initial concept centered around a series of platforms arranged in a layout inspired by the nine stars of Matariki. Each platform had a different size to provide an individual or group experience. Many different methods of seating were explored as well for the individual or group experience.

\section{Central Moa Point 1:2500}

This image has not been reproduced due to copyright

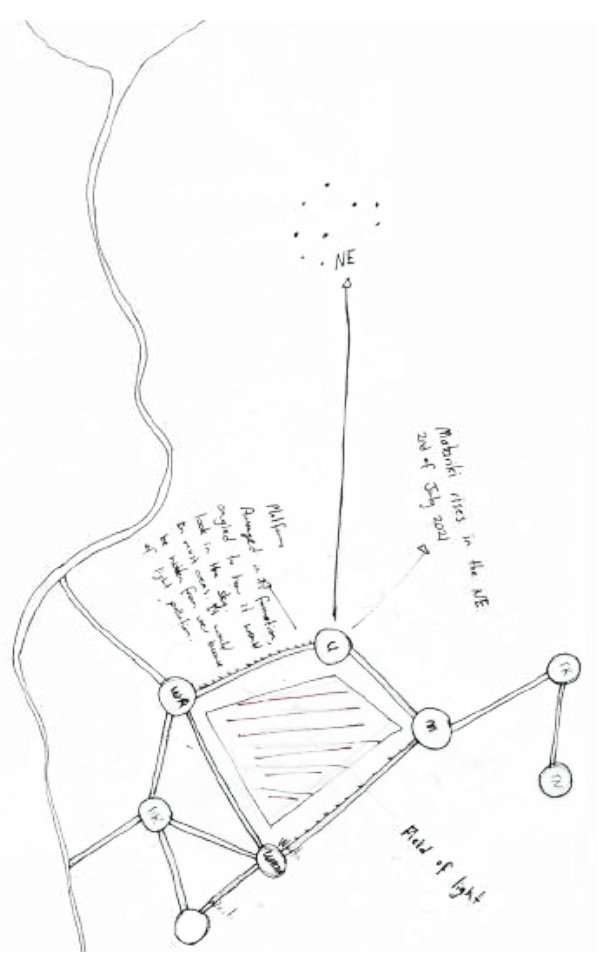

Fig 7.31 Chosen Area for design
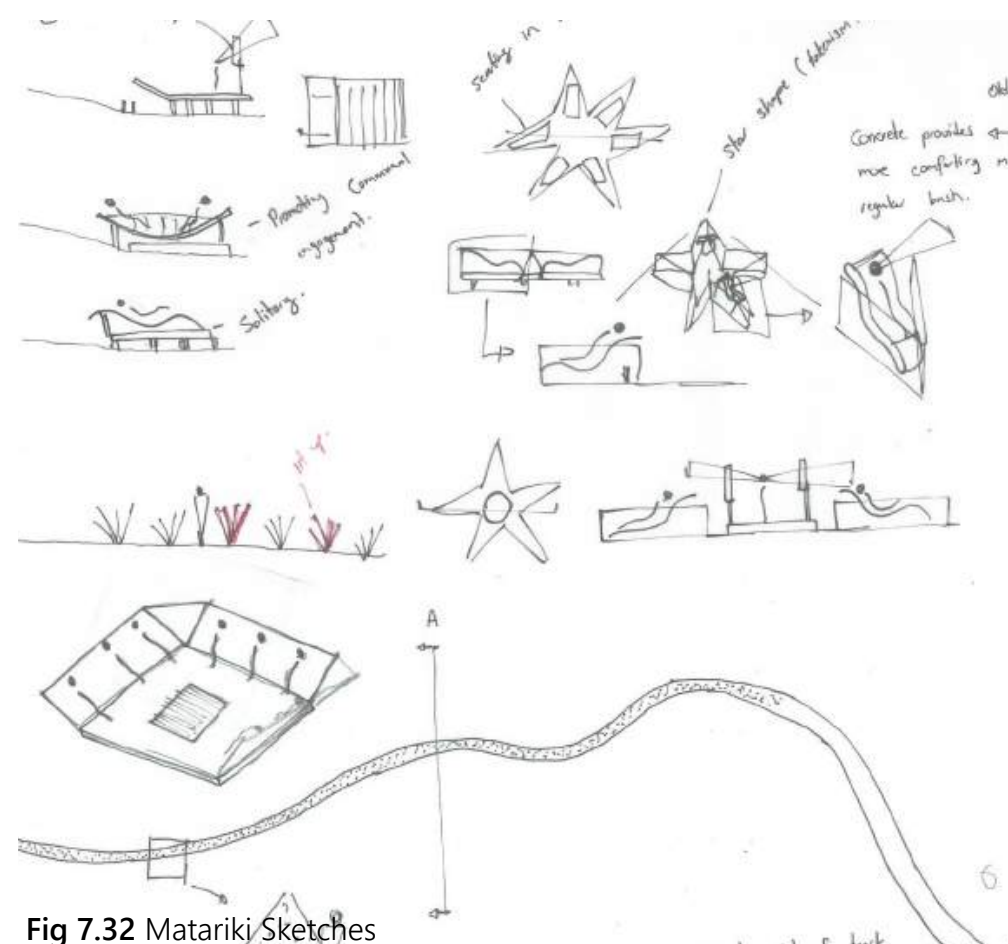

Fig 7.32 Matariki Sketches 


\section{Initial Sketches}

Fig 7.33 Maori Astronomy sketches

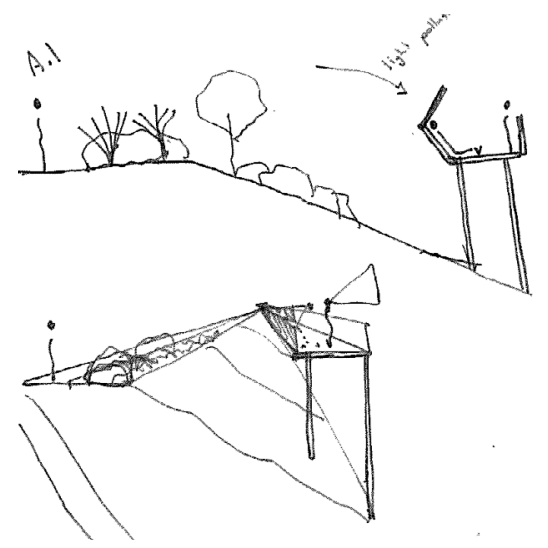

- Represents a star compass

- Represents the southern cross
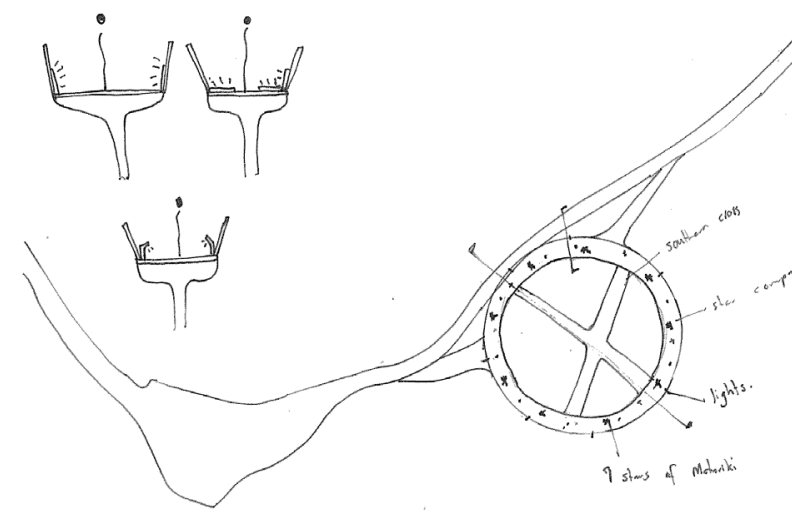

M.

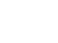

- Dual raised platforms

- Higher platform references $T e_{B}$

Waka o Tama Rereti

- Lower platform is the milky way he

is creating
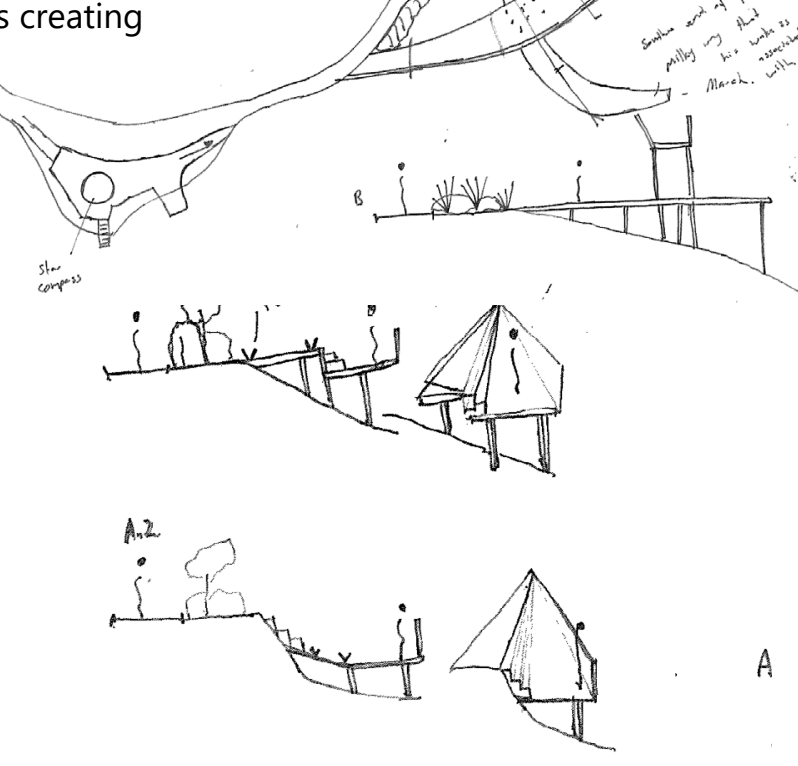

A

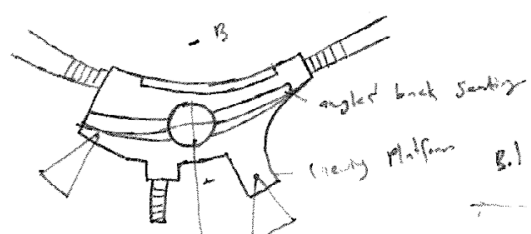

B.)

A.

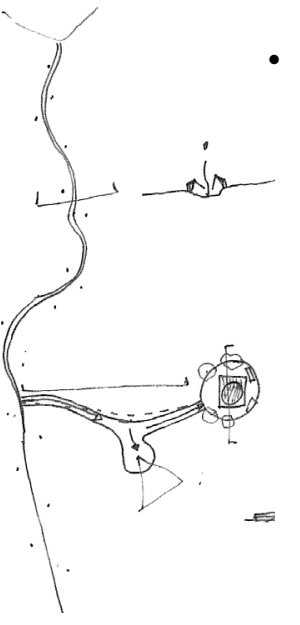

- Communal star gazing platform with illuminated trail
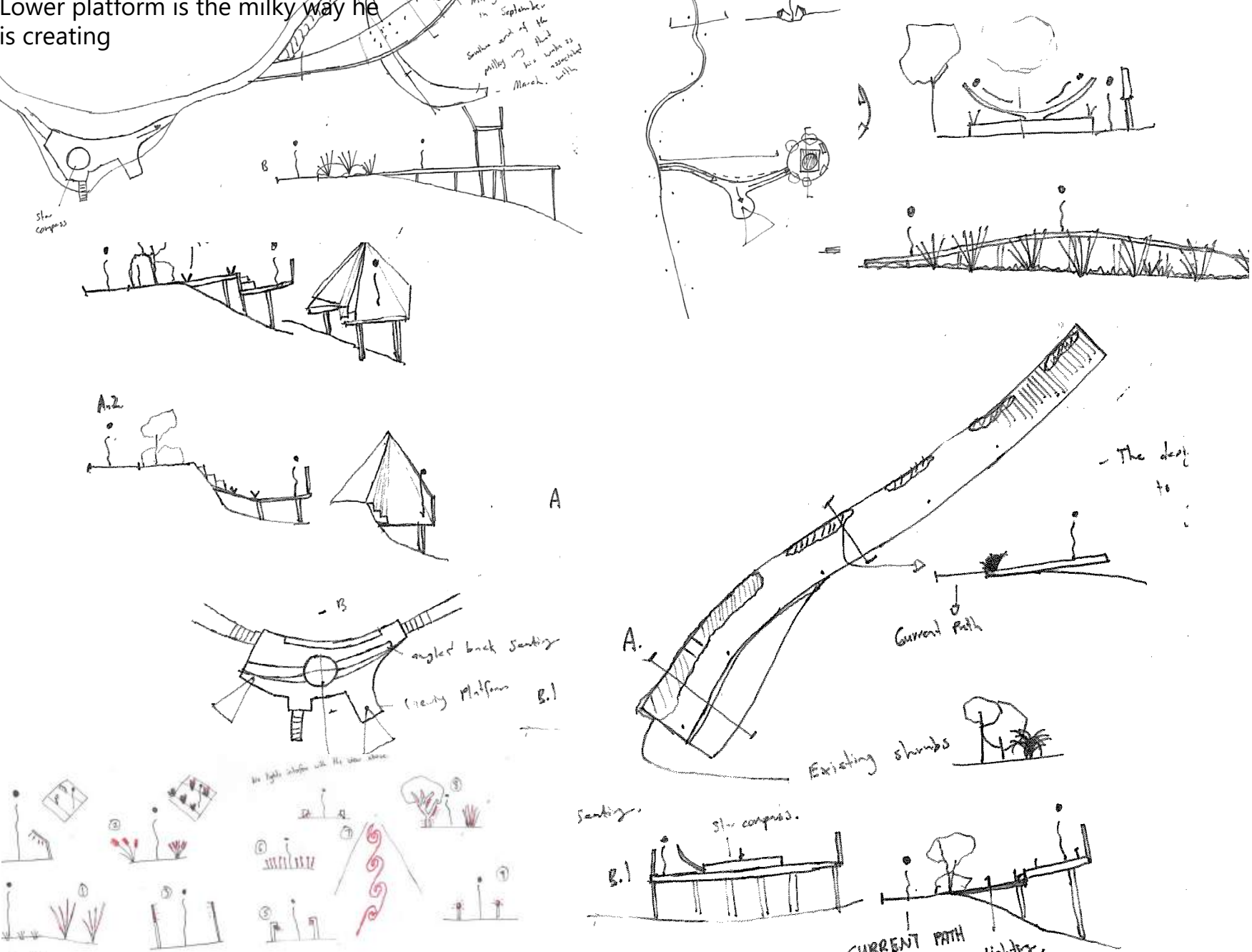

inativ
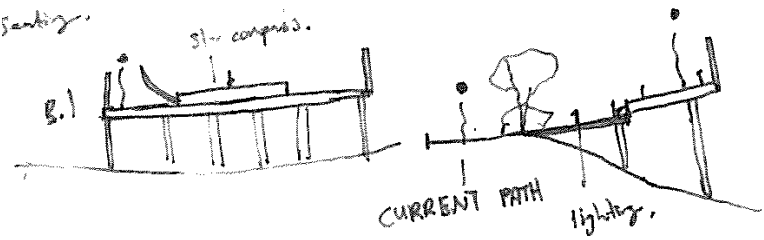

(1) to view the night sky 


\section{Developed Concept}

\section{Developed design 1:2000}

The design reached the development stage incorporating nine platforms arranged in the formation of the stars in Matariki. Each platform had four individual seats and connected to the other platforms via raised decking. The main design components were:

1. Raised timber decking for prospect

2. Path lighting along with the decking

3. Natural features used to hold lighting fixtures

4. Reclined Seating to enjoy the stars

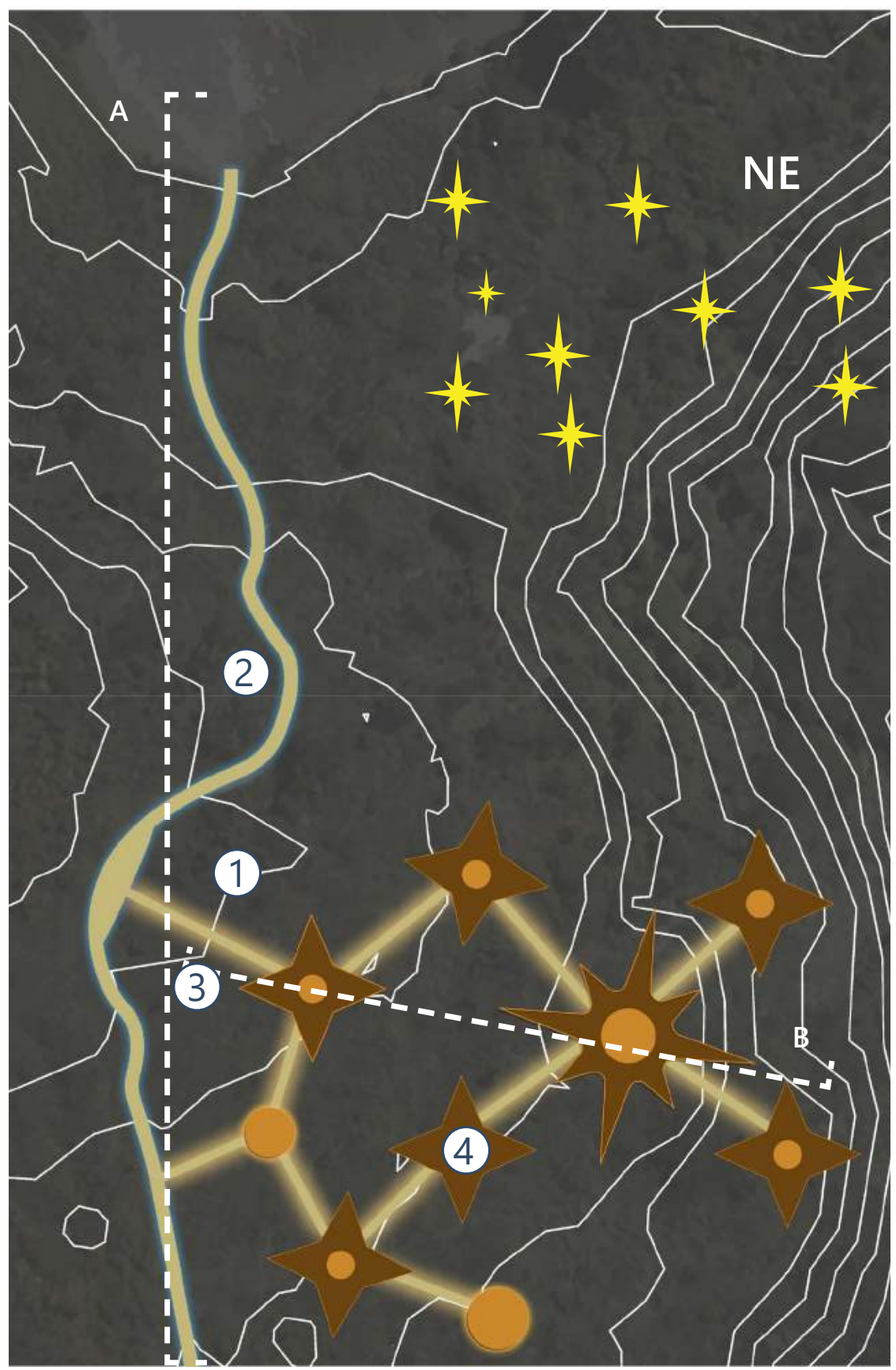

Fig 7.34 Final Matariki Concept 
W. 


\subsection{Moa Point Reflection}

The key learnings from Moa Point were:

- Even in a very dark environment, lighting as a visual marker was enough to increase comfort and reduce fear in the space.

- Lighting that was a warm colour proved to be most comforting, and using the form of a light trail was able to provide comfort without creating glare. It also provided curiosity and interaction, which simple path lighting may not provide.

The platform iterations showed it is comforting to frame around the stargazing space to provide a feeling of security.

However, the design testing also showed it did not need to be any more complicated than just a raised deck. The elevated timber lookout provided increased prospect but was perceived as less comforting as there was only one entry in and out.

After spending a significant amount of time in Moa Point in the darkness, it was realized there is more to the experience than just the sight of the stars. The sound of silence beside the ambiance of bushes swaying in the wind provided space to reflect and think clearly. The glass dome would provide shelter, but it would create separation from this experience.

The Matariki design stopped at the development stage because it was over complicating the project's simple nature: connecting to the night sky. The design focused on the ground instead of the night sky and disrupted the nocturnal environment with the added lighting. The only focus should be connecting to the night sky and increasing perceived safety.

However, the research into Matariki proved helpful and was kept as a theme for the next design phase. 


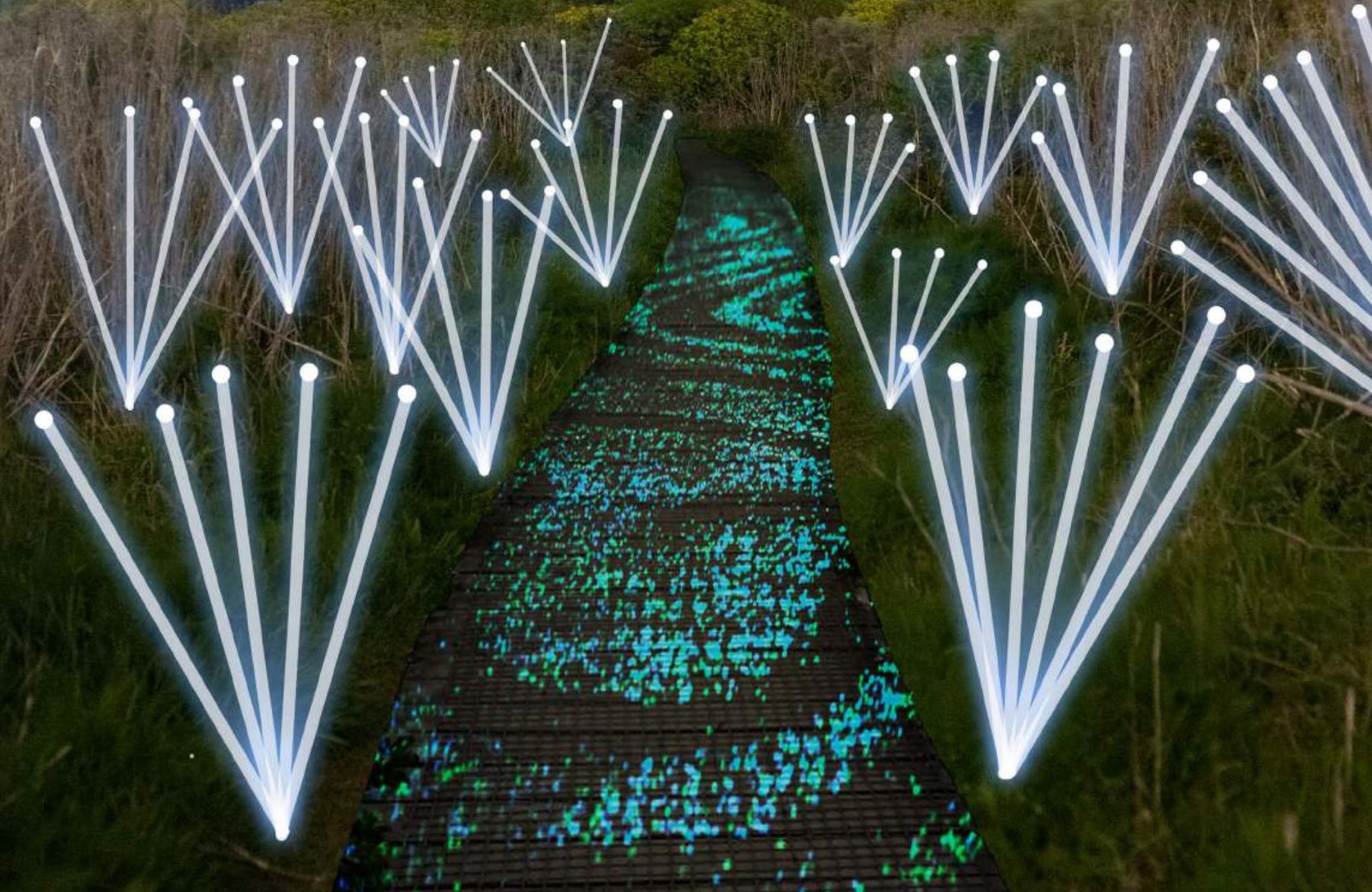

Fig 7.36 Matariki Concept Using natural features to hold lighting

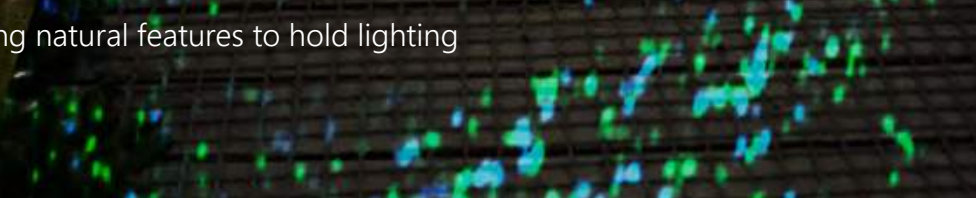





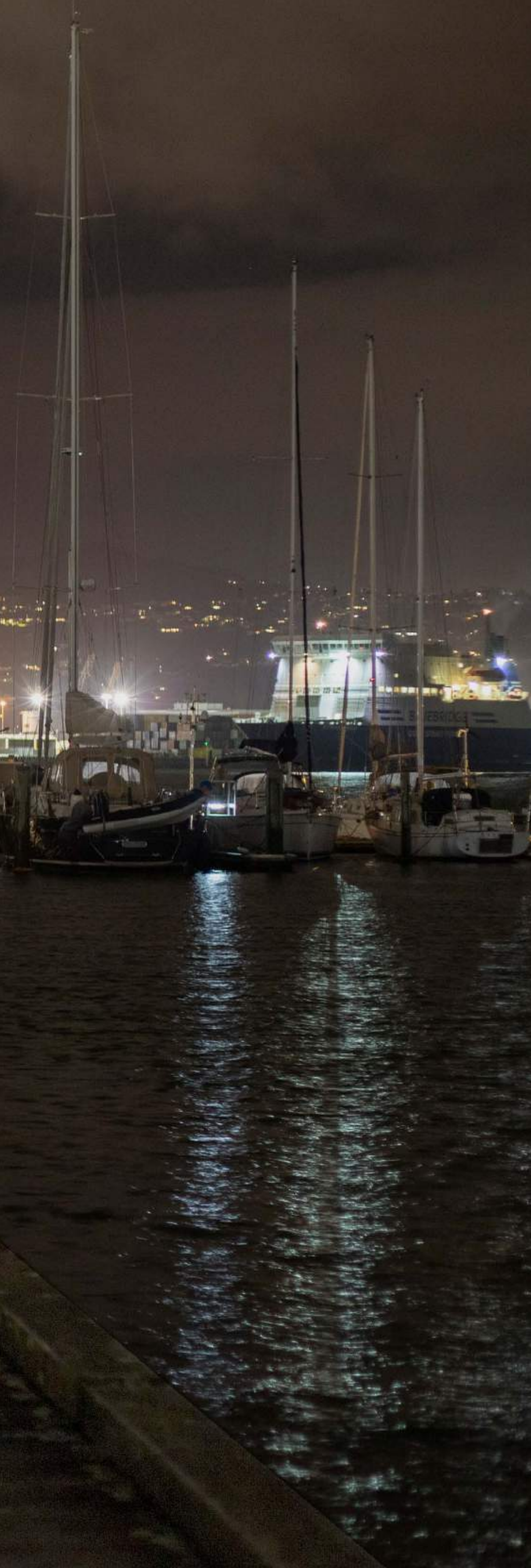




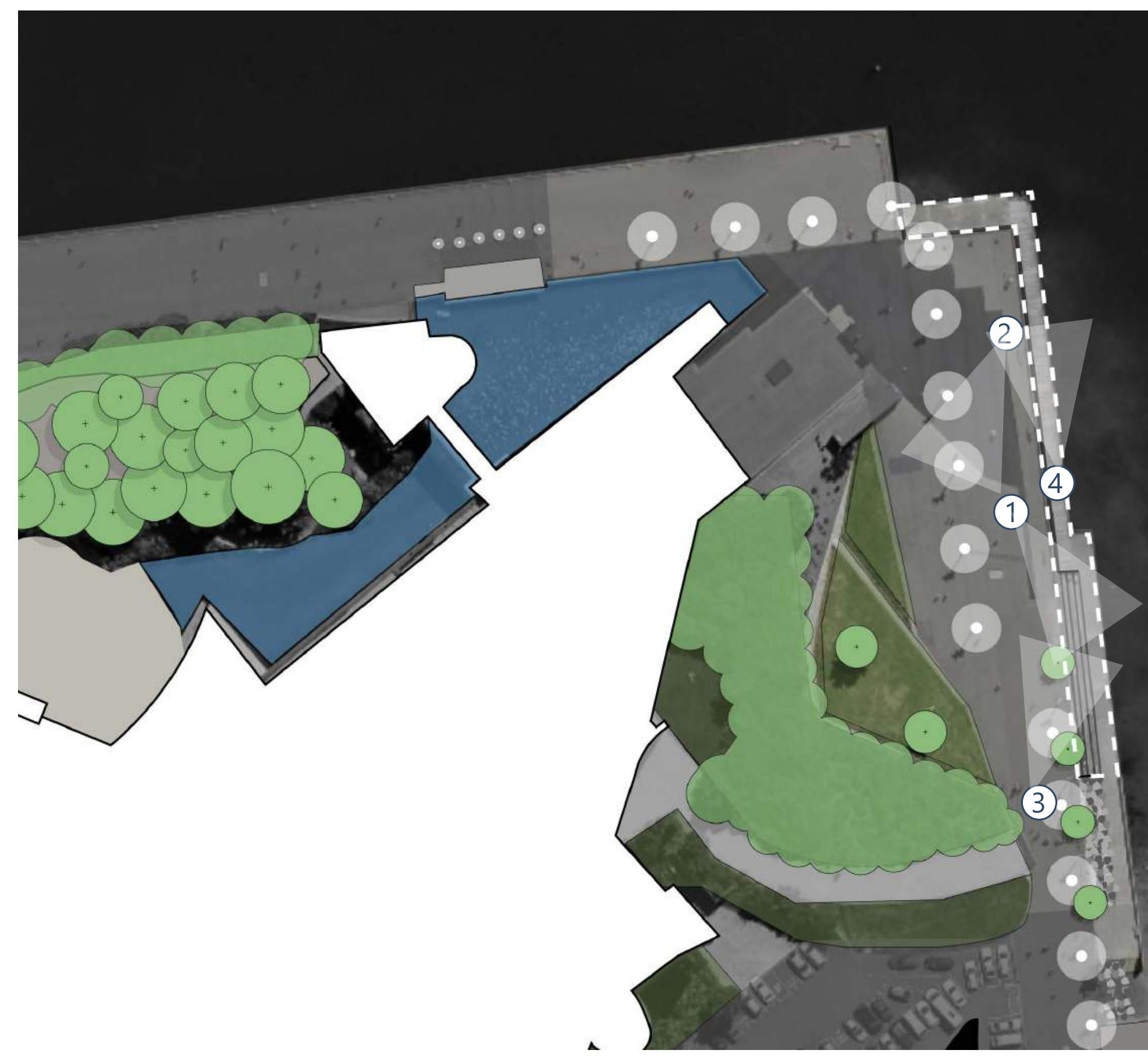

Fig 7.38 Dropped Walkway site plan 


\subsection{Te Papa Waterfront Walkway}

There is no official name for the area chosen on the Waterfront, but it is referred to as Te Papa Waterfront Walkway in this chapter. The site is a dropped down pathway next to the Wellington Marina in front of Clyde quay wharf. It was chosen because the surrounding environment produces the least visible light glare that interacts with the night time experience. It was also chosen because it uses terraced seating leading to the water's edge used a lot during the day but is missing interaction at night.

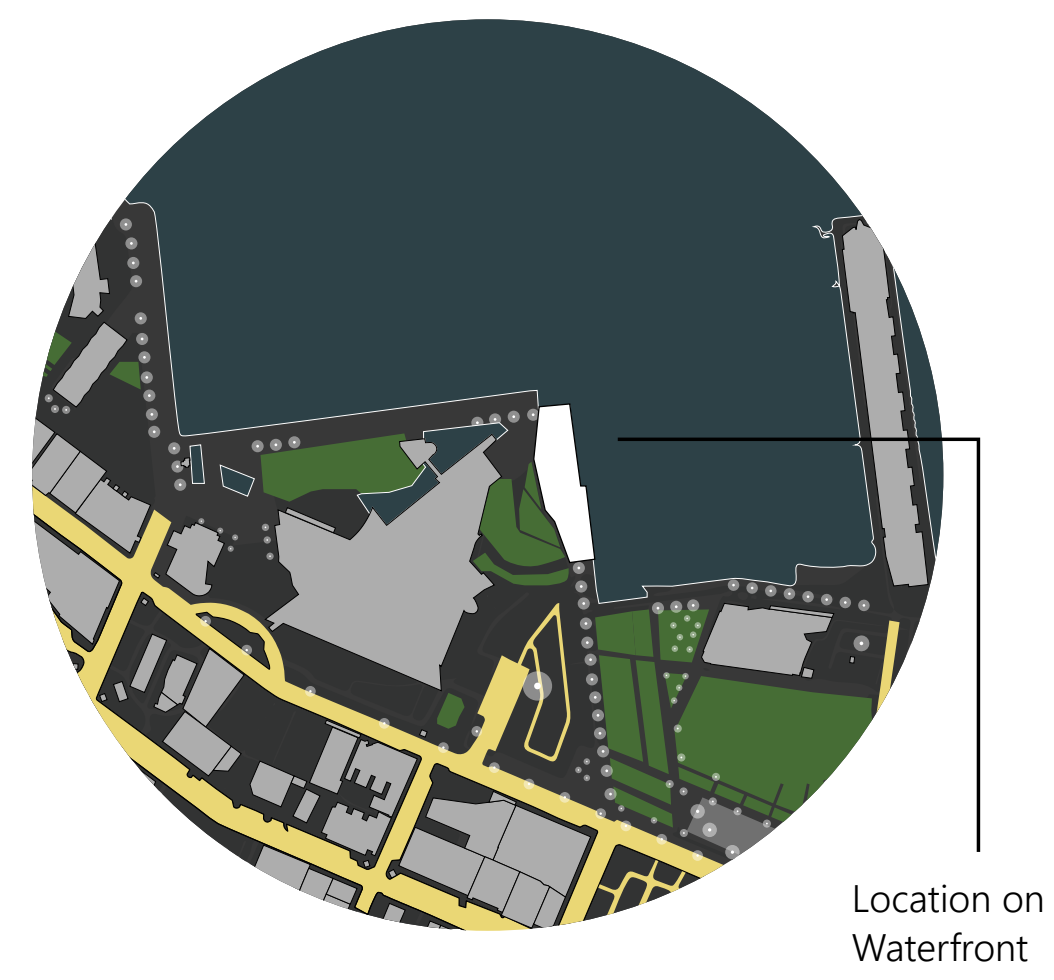

Dropped down Walkway 


\section{Day}

(1)

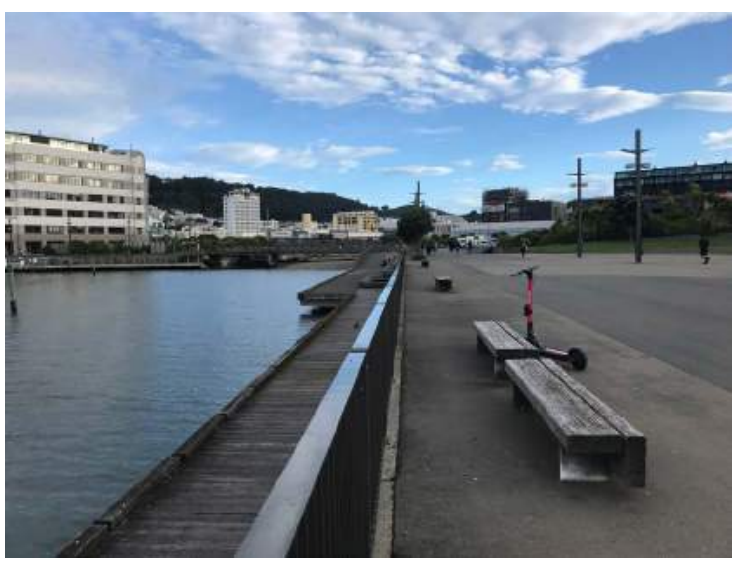

(2)

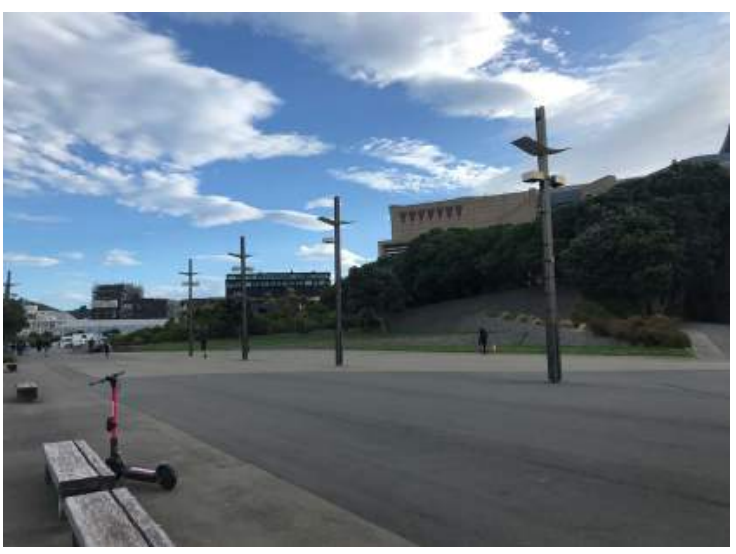

(3)

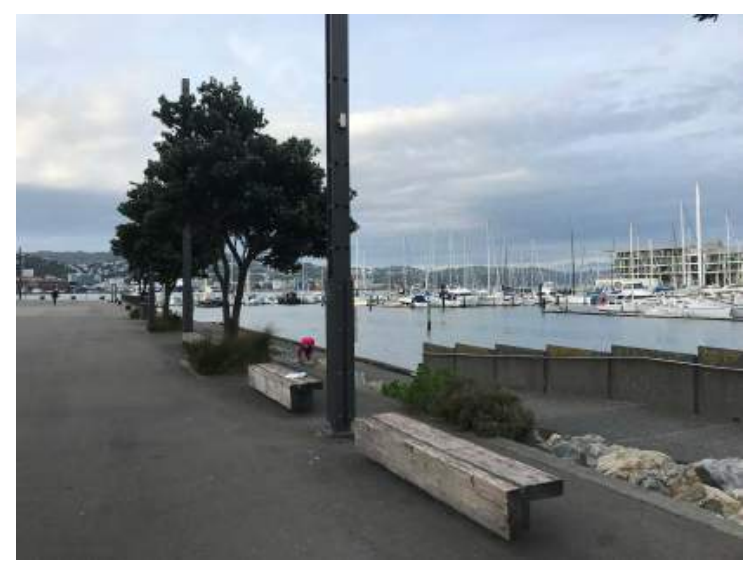

(4)

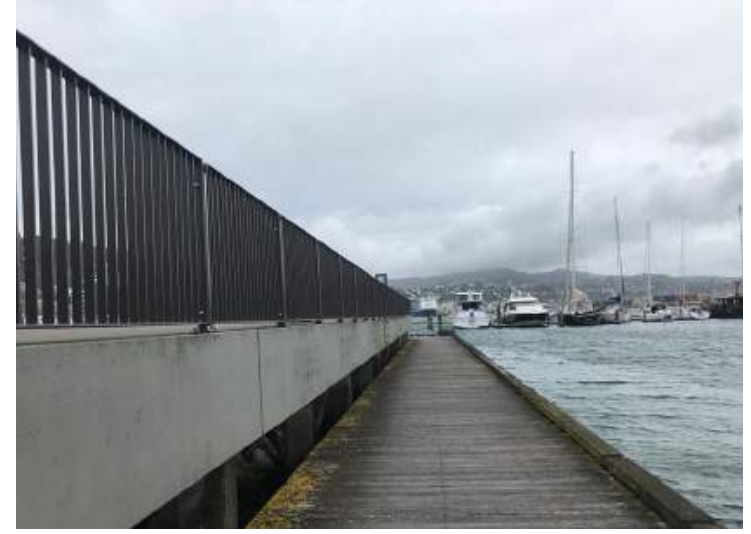

Fig 7.39 Day n Night Images dropped Walkway

\section{Night}
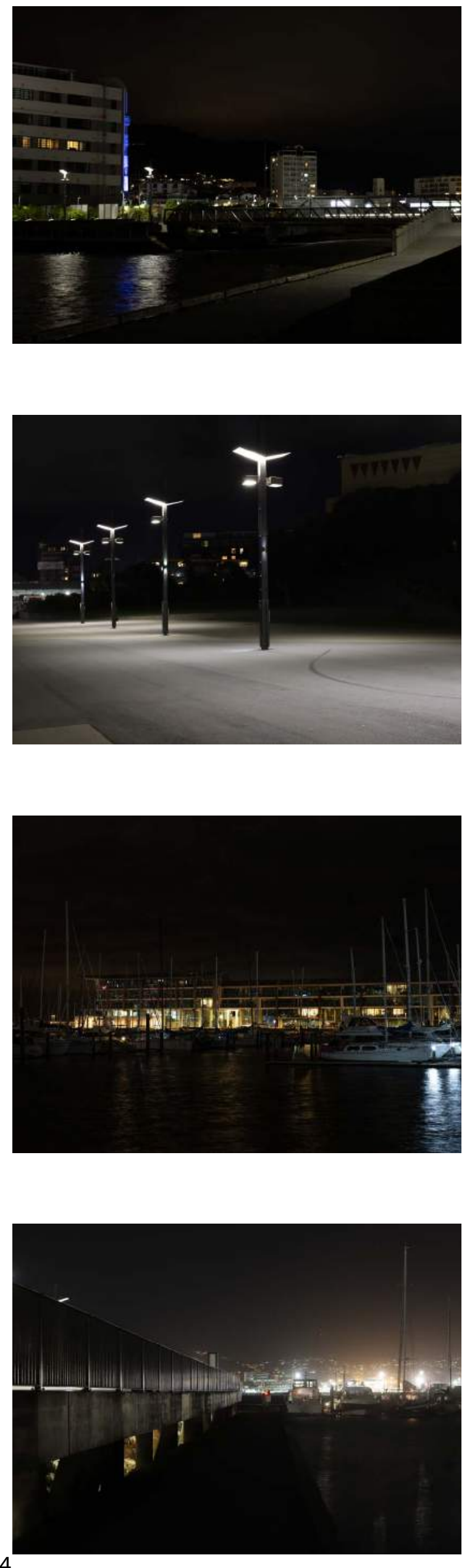
Site Conditions 


\section{Design Criteria}

As the area provided no seating that would support the body in a reclined position, seating was the primary characteristic investigated in this space. The design focused on the view perpendicular to the walkway, east above Clyde Quay Wharf. The lighting from the apartments was not too bright to disrupt the view. There were fewer stars visible at first glance here, so the design focused on encouraging people to stay for more extended periods to let their eyes adjust.

\section{Seating Design}

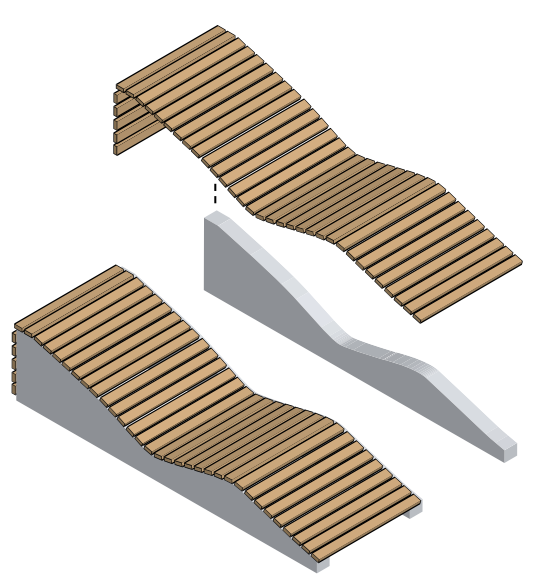




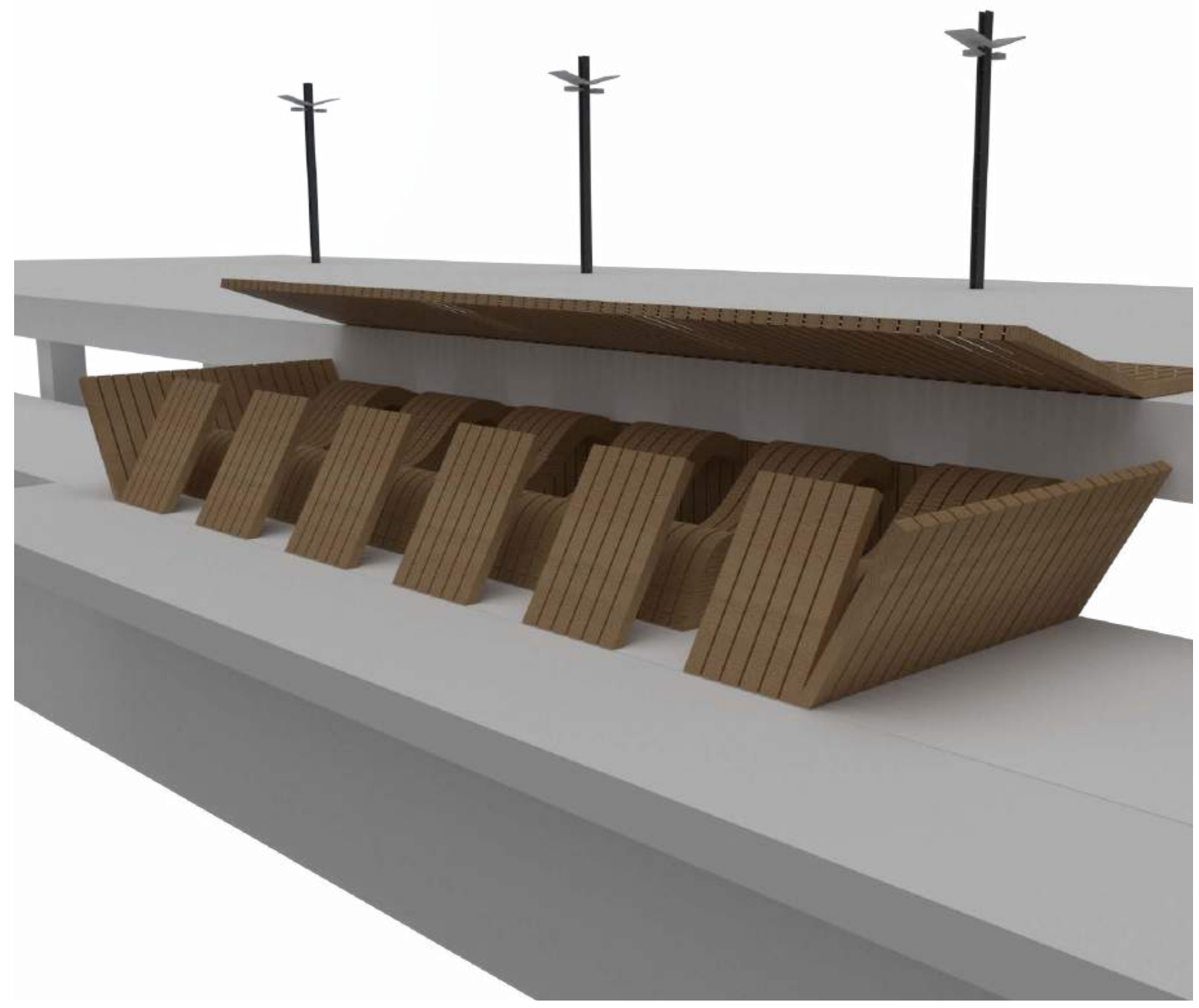

Fig 7.41 1st ever seating Iteration on Waterfront 


\section{Initial Sketches}

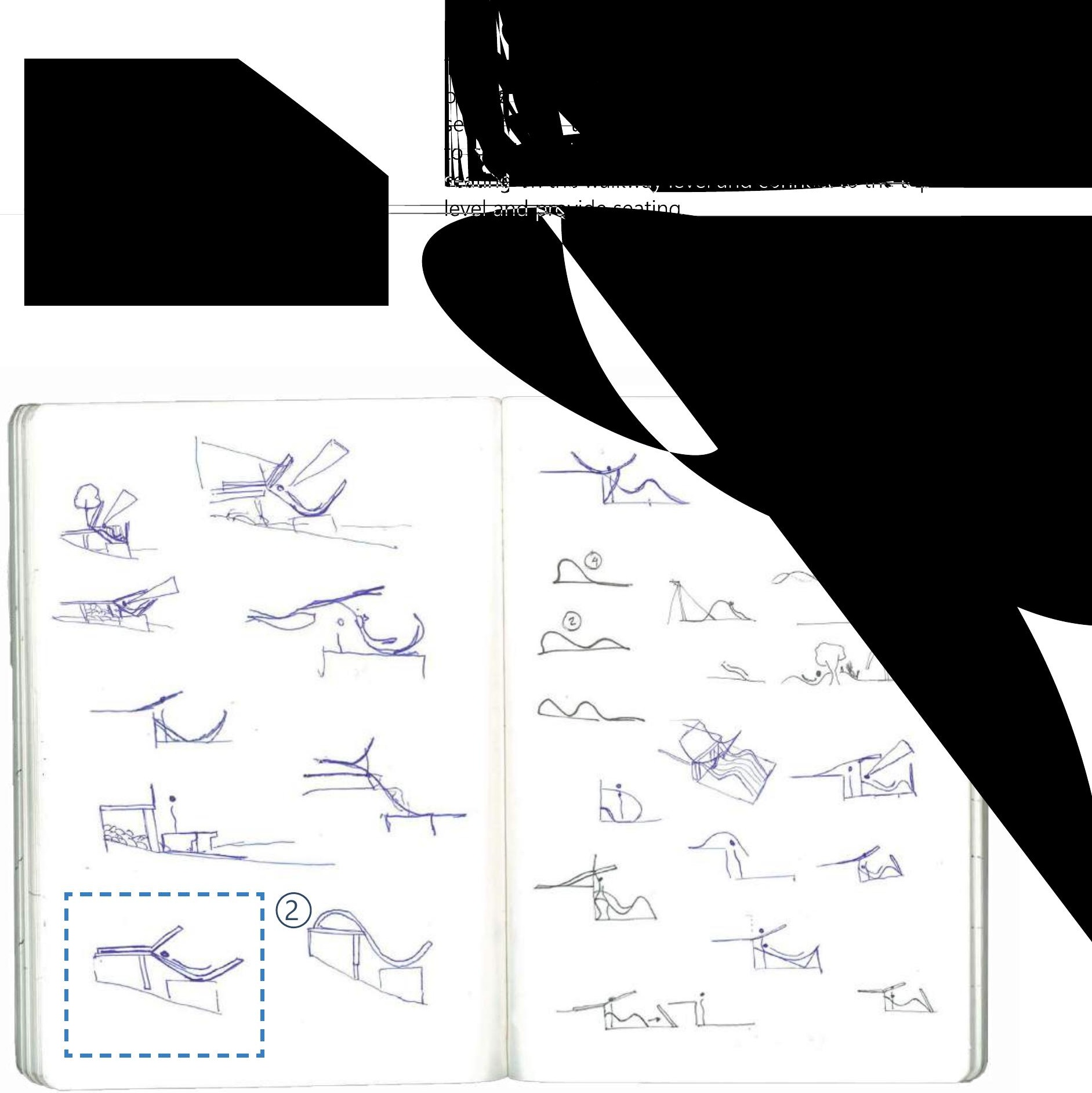

Fig 7.42 Sketches from Dropped Walkway 


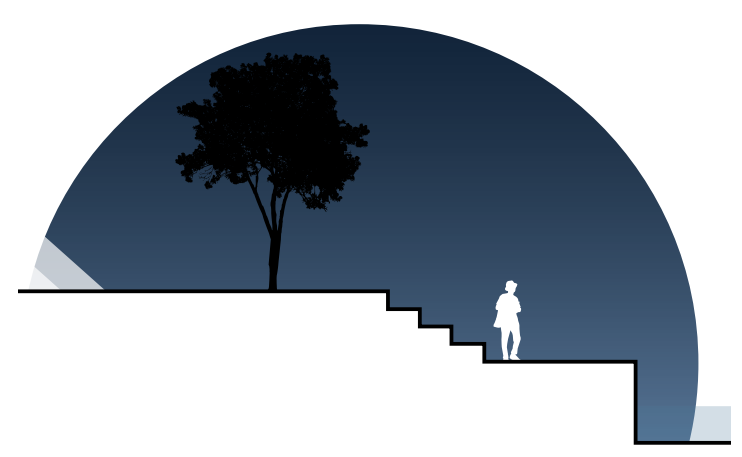

In the terraced seating, the design aimed to provide an additional seating experience for the night.

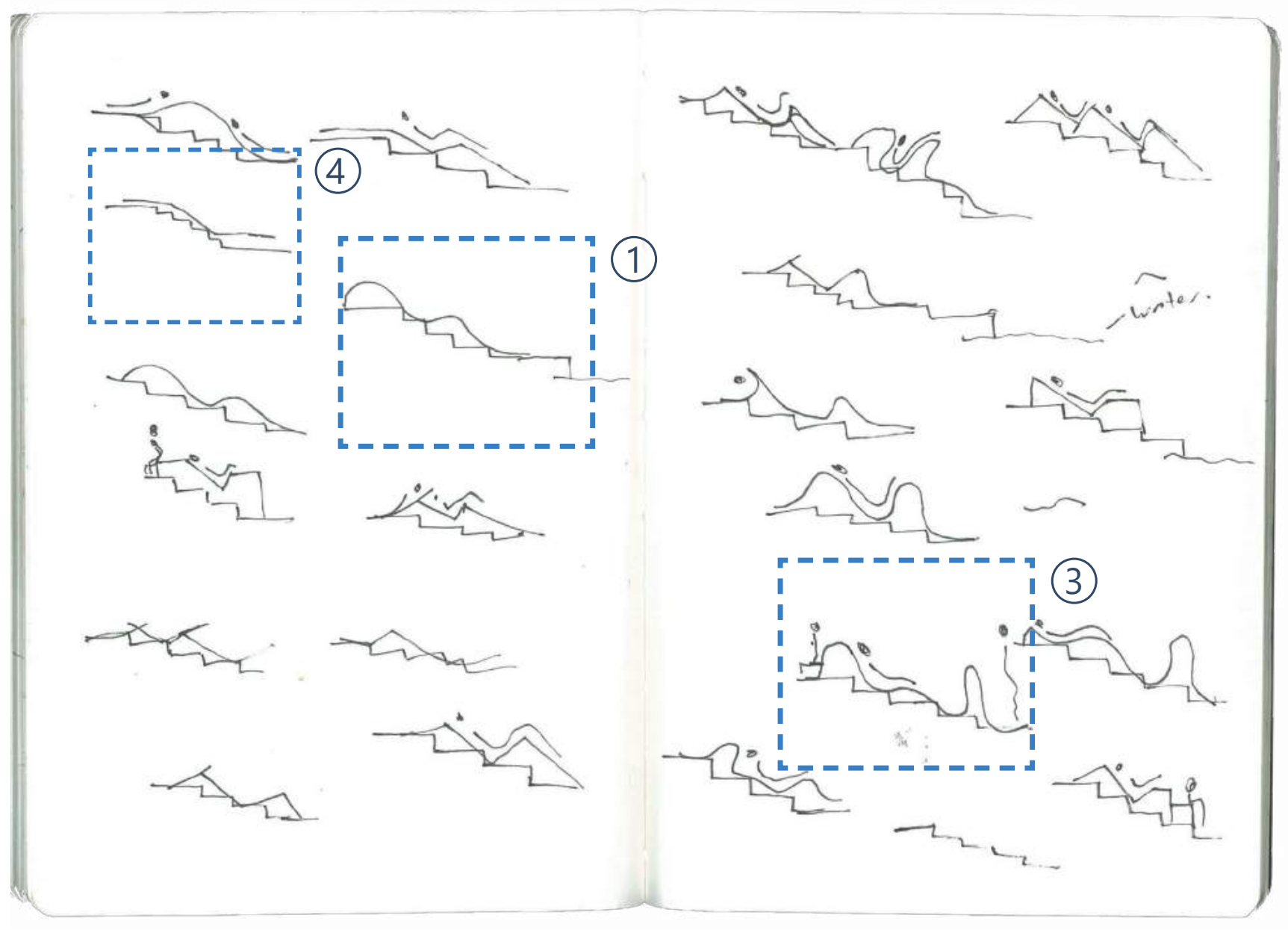

Fig 7.43 Sketches on Terraced Seating 


\section{Form Exploration - Digital Modelling}

The terraced seating area provided a better site for further testing. Placing seating on the flat section blocked the entire walkway, and it was not justifiable widening the walkway when the terraced area was nearby. The next phase of design

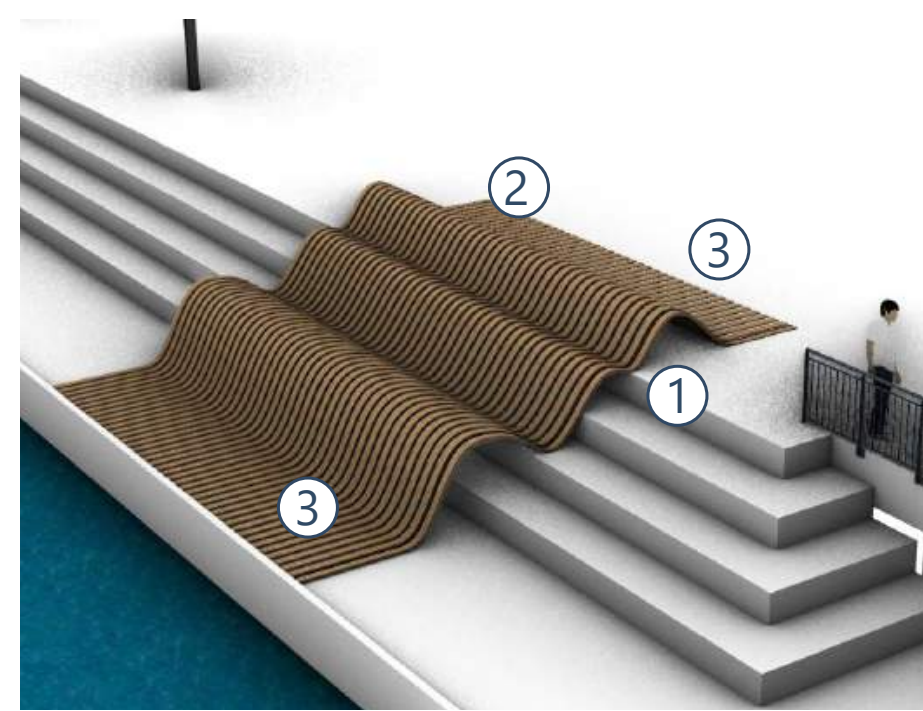

Fig 7.44 Seating Waterfront Design 11

Comfort (Physical comfort)

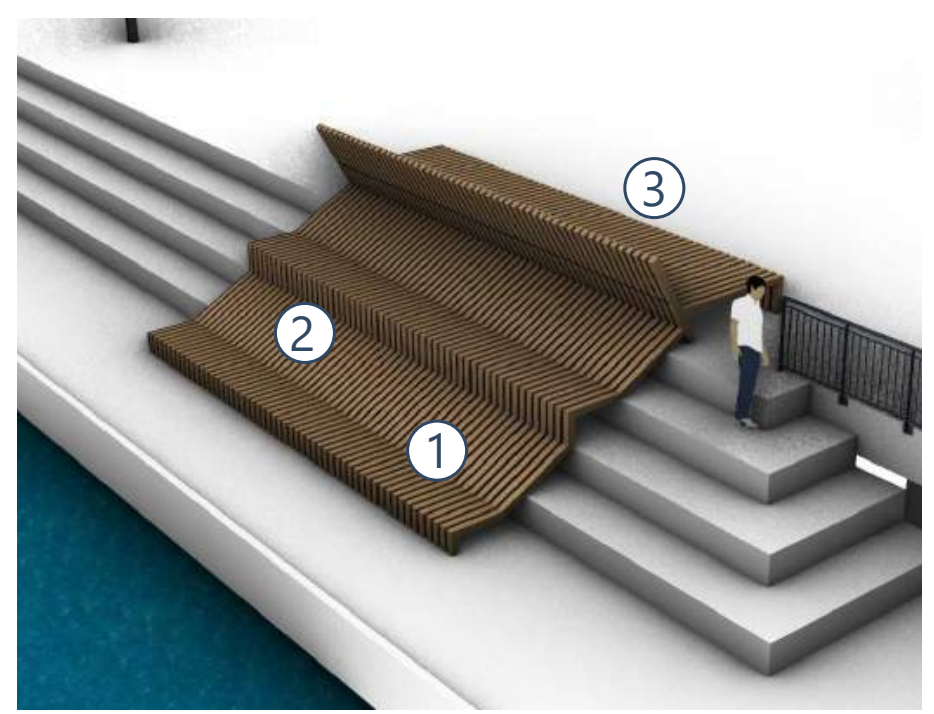

Fig 7.45 Seating Waterfront Design 12

Comfort (Physical comfort) took four main ideas from the sketchbook and generated concepts through digital modelling.

\section{Iteration (1)}

1. Focusing on the natural curve of the body in a reclined position.

2. Uses parametric design

3. Keeps the design flowing into the existing surfaces

\section{Iteration (2)}

1. Uses parametric design

2. Provides seating for night time use

3. Provides seating facing the other way for daytime use 


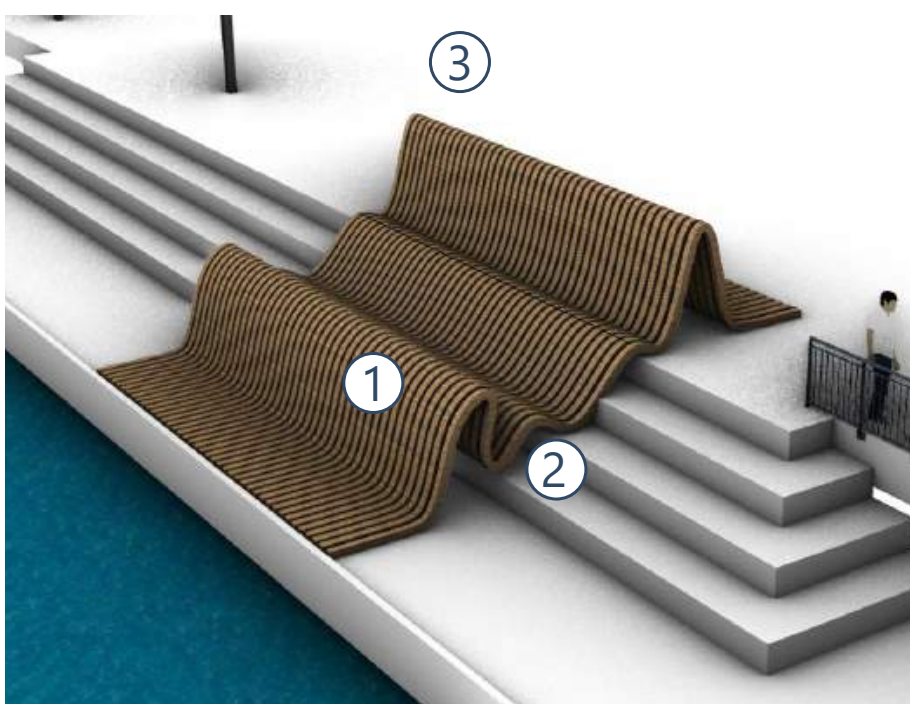

Fig 7.46 Seating Waterfront Design I3

Comfort (Physical comfort)
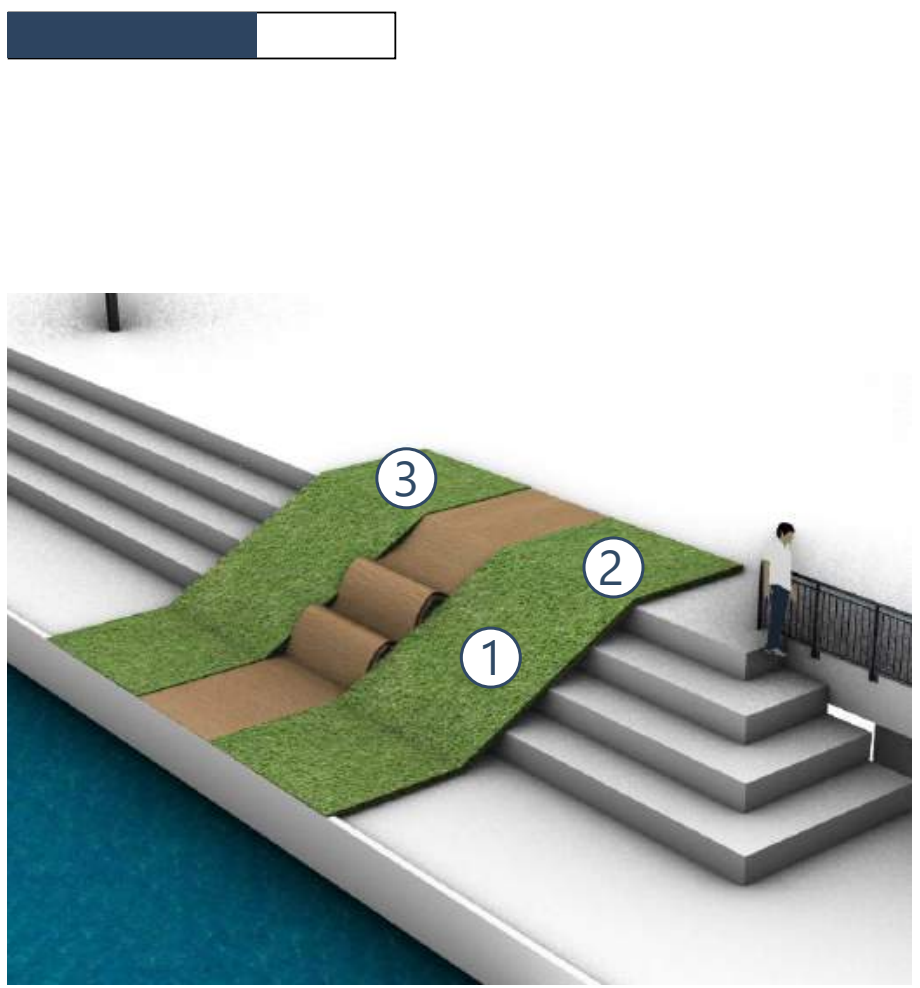

Comfort (Physical comfort)

\section{Iteration (3)}

1. Parametric design

2. Too many curves

3. The high curve at the back prevents the glare of light from entering the space.

\section{Iteration (4)}

1. Brings natural feature into the site

2. Alternative to parametric design

3. Middle section is awkward 


\section{Form Exploration - Physical Modelling}

Modelling in $3 d$ software produced very linear iterations; physical modelling with clay afforded more creative ideas on form and shape to be generated.

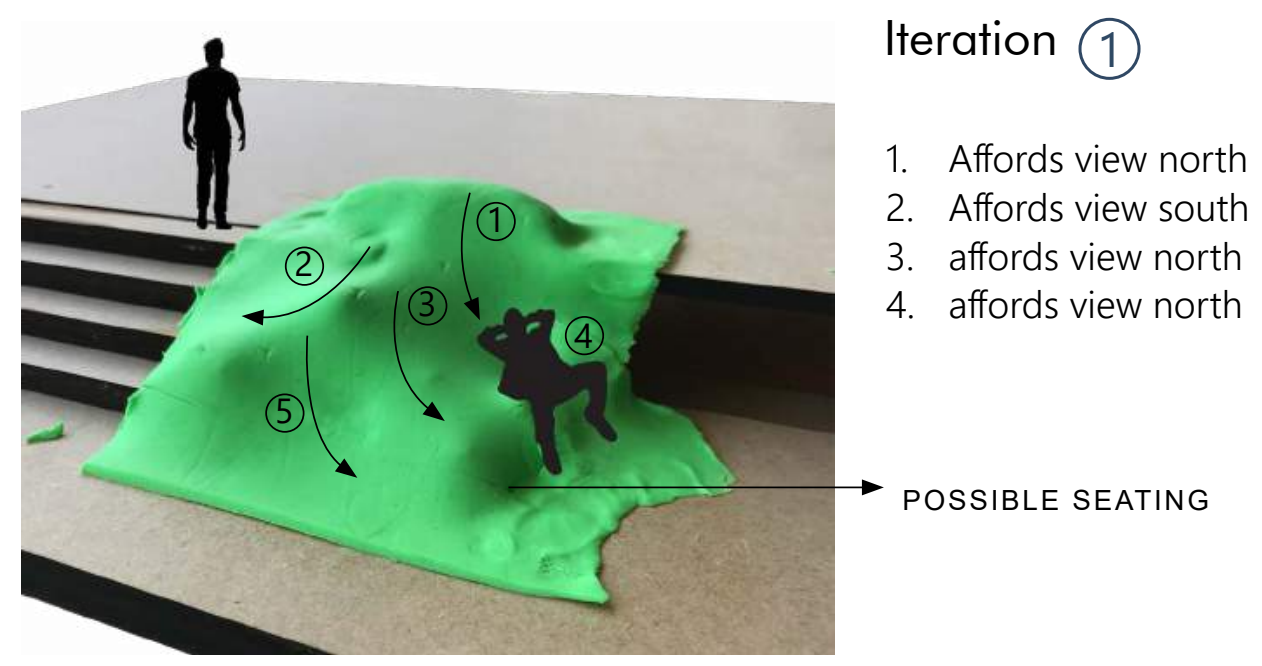

Fig 7.48 Clay Modelling Waterfront I1

Comfort (Physical comfort)

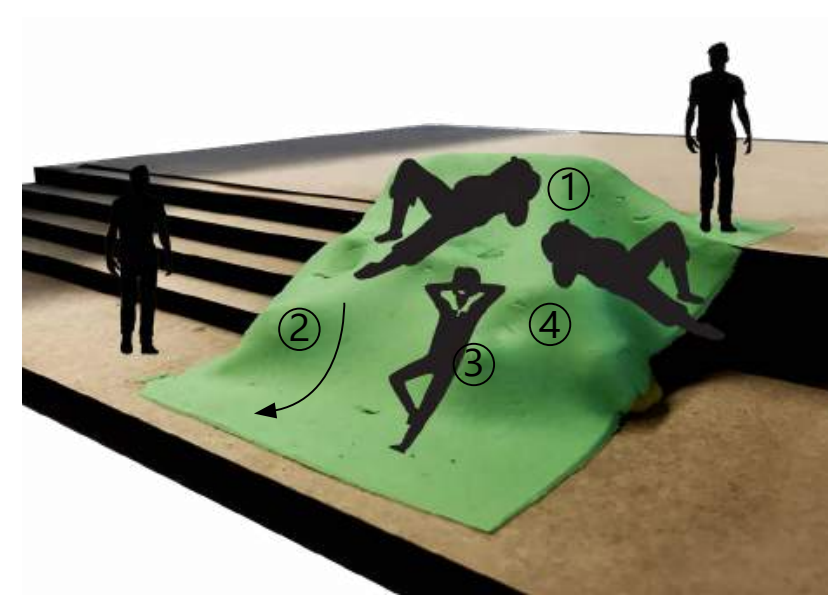

Fig 7.49 Clay Modelling Waterfront I2
Iteration (2)

1. Affords view direclty upwards

2. affords view east

3. affords view east

4. affords view north upwards

Comfort (Physical comfort) 


\section{Iteration (3)}

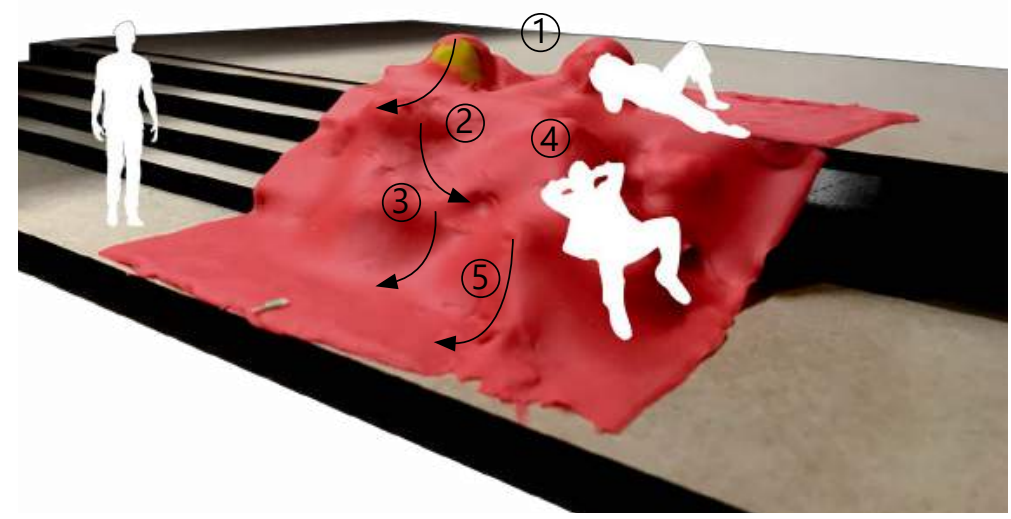

1. Mound affords view to north

2. Affords view to north, may be uncomfortable

3. Affords view to east

4. Affords view to north

5. affords view east

Fig 7.50 Clay Modelling Waterfront I3

\section{Comfort (Physical comfort)}

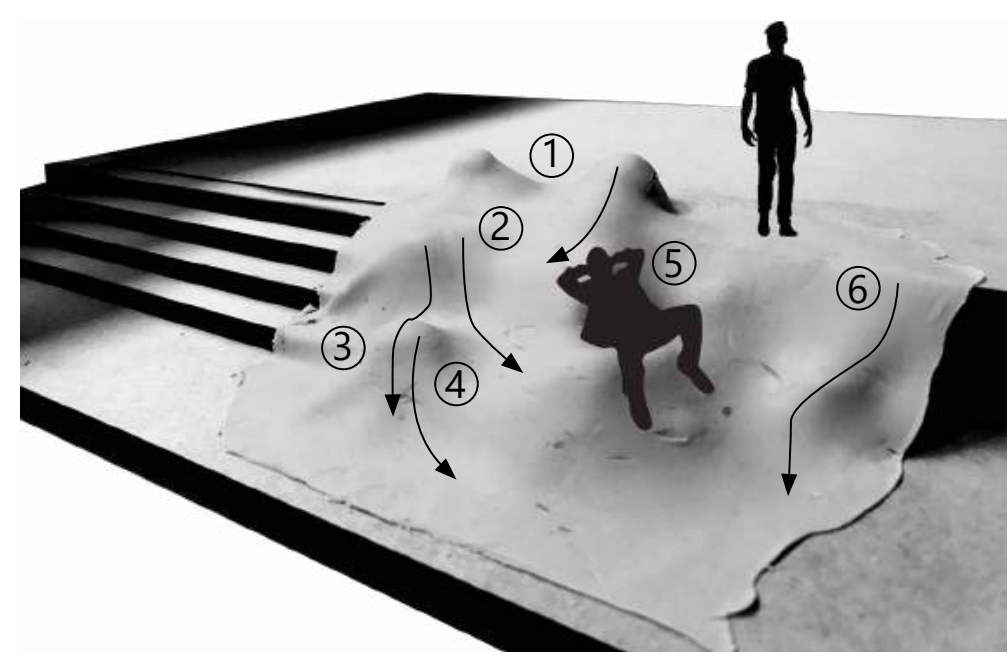

Iteration (4)

1. Affords view upwards to the east

2. Affords view north

3. Affords view east

4. Affords view north but would not be very comfortable

5. Affords view east

Fig 7.51 Clay Modelling Waterfront 14

Comfort (Physical comfort) 


\subsection{Waterfront Reflection}

The key learnings from the Waterfront were:

- Curved Seating may be more comfortable than straight angled seating.

- Seating that supports every joint may be more comfortable than a flat angled surface, which rotates the whole body to shift the view.

- Timber is an excellent material to use for the design as it can easily construct curved seating.

- Physical modelling provided more freedom designing then digital modelling. 


\subsection{Chapter reflection}

After designing in both Moa Point and the Waterfront, the research process moved away from these sites. The Waterfront was too polluted for a successful night time experience to take place.

Moa Point was abandoned as the space provided was too large to deliver a successful design. The main star gazing spot was right in the middle, which could only be accessed by walking through enclosed pathways which were quite frightening even for the researcher.

Moa point also was challenging to get to at night. The access points were in the middle of suburban housing with no other parking beside street parking. Every site visit triggered the nearby houses safety lights and awakened many pets, which may disrupt the people living nearby.

The findings from both the Waterfront and Moa point were valuable to the research and were taken into the final site design at Ataturk Memorial, which the site justification showed to be the second-best choice out of the spaces on the South Coast. 

This chapter discusses the development of site-specific design from the toolkit in the final site, Ataturk Memorial. Further analysis was conducted in the site and its specific landscape characteristics. Findings from the design development in Moa Point and the waterfront were brought into the site and developed further, through reoccurring site visits during the day and at night. Maori Astronomy was also researched in greater depth and applied to the site's specific location. At the end of the process a third concept was generated. 


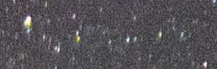

$\therefore+\div, \div$,

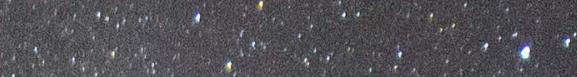

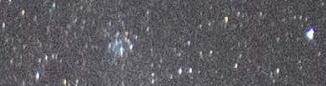

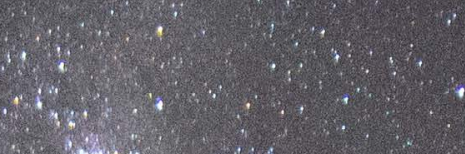

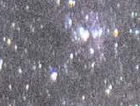

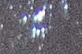

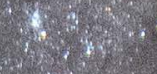

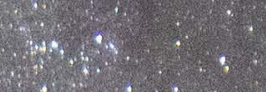

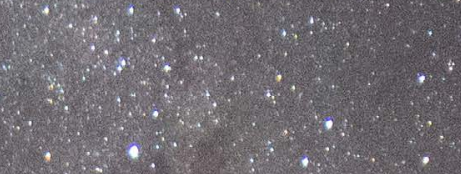

$\because ;$

$\div \div$

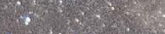
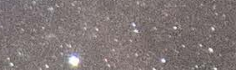

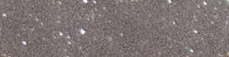

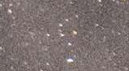




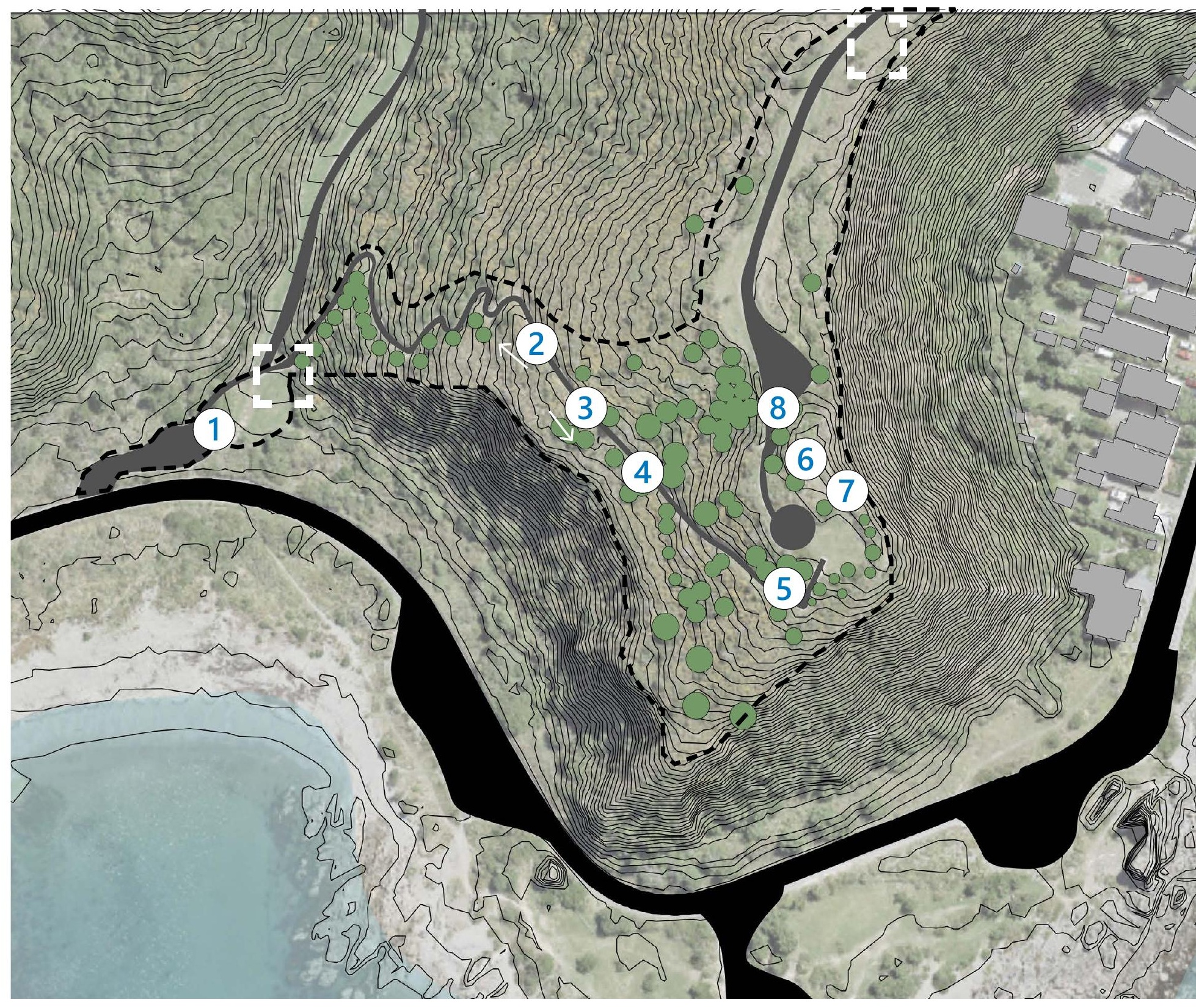

Fig 8.3 Ataturk site plan 


\subsection{Ataturk}

Ataturk memorial was chosen as it is a popular destination for the surrounding communities and its elevation provides expansive views over the south coast. It is easily accessible via two access points both by foot. Many families, couples, pet owners and the elderly visited the site during the day, but it was devoid of life at night.

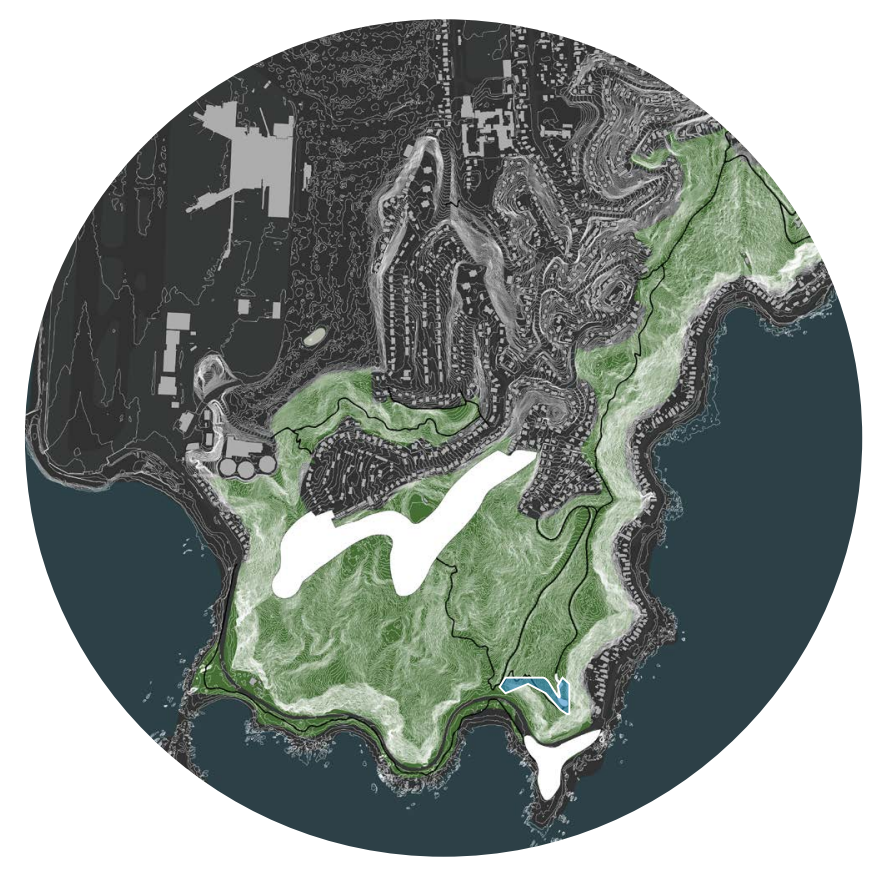

I - I Site Boundaries

Walking Track

Entry Points 


\section{Day vs Night Photos}

(1)
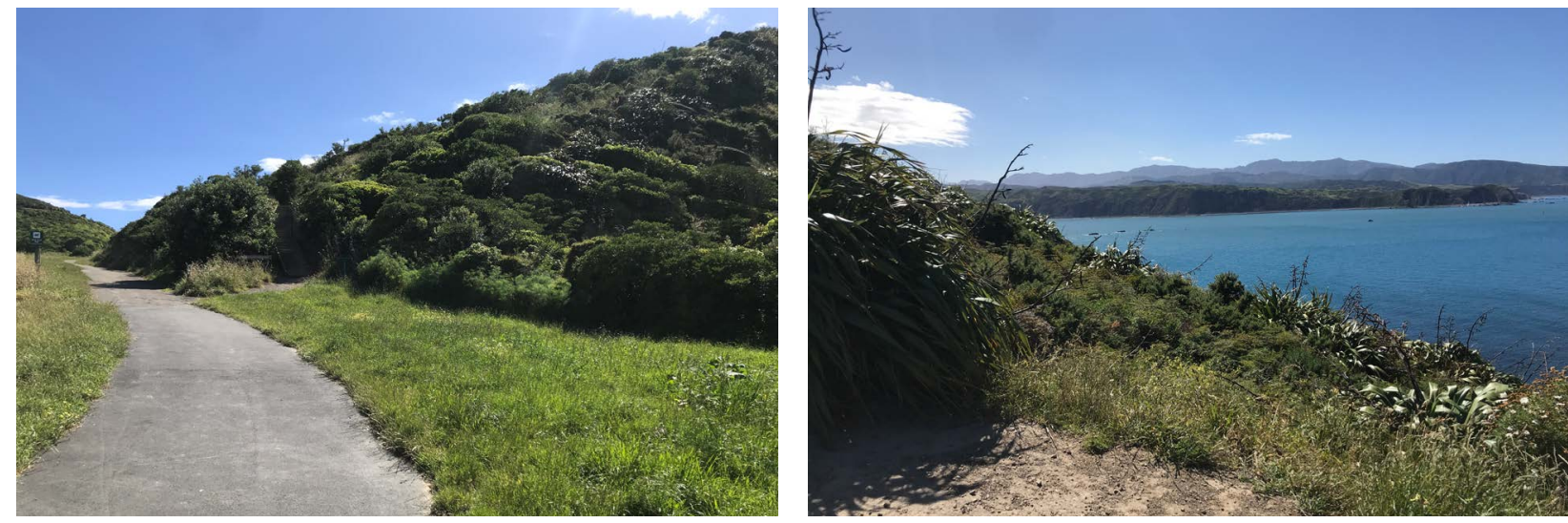

(2)

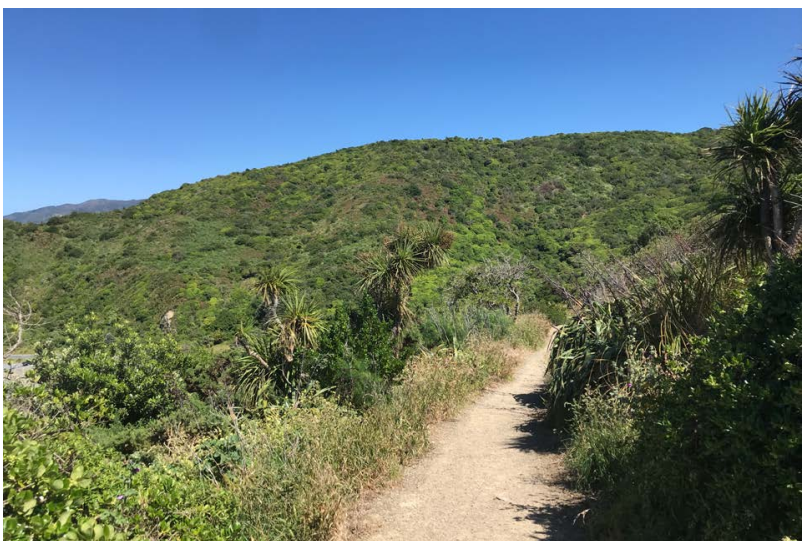

(3)

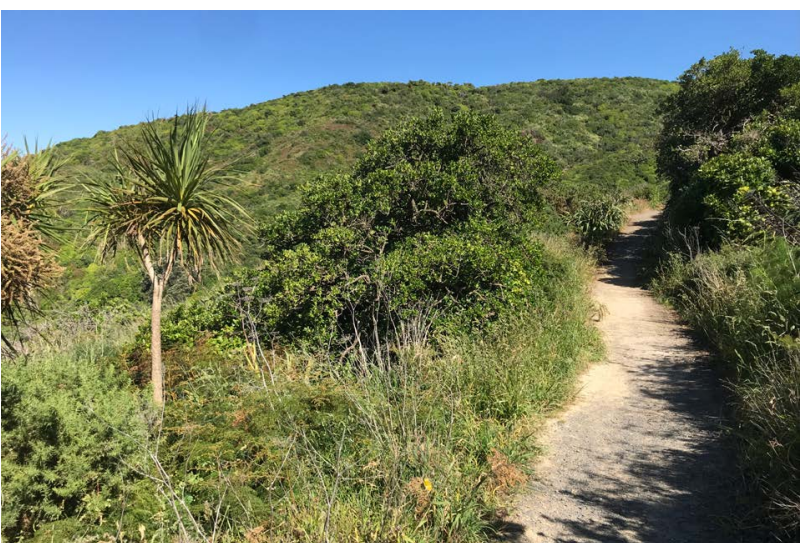

(4)

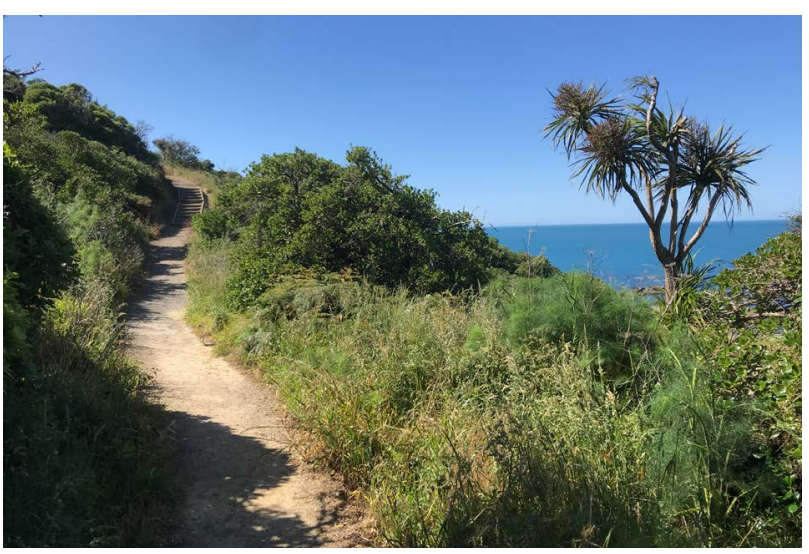

(5)

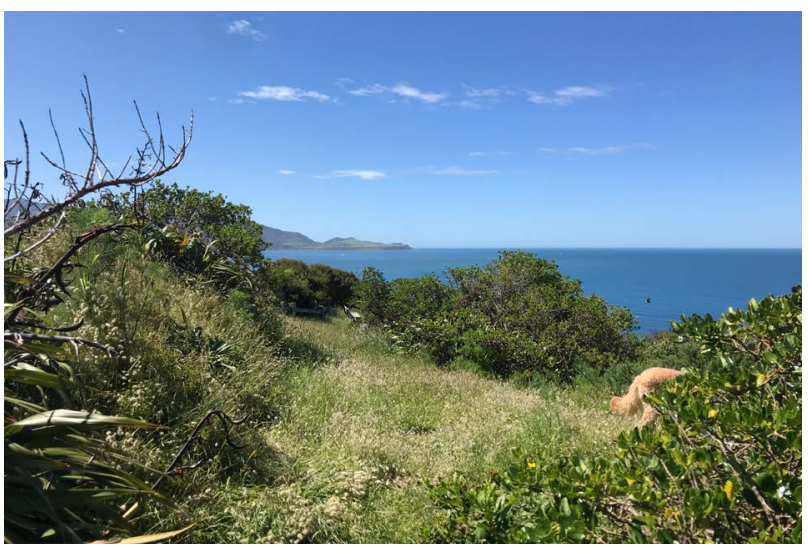

(6)

(7)

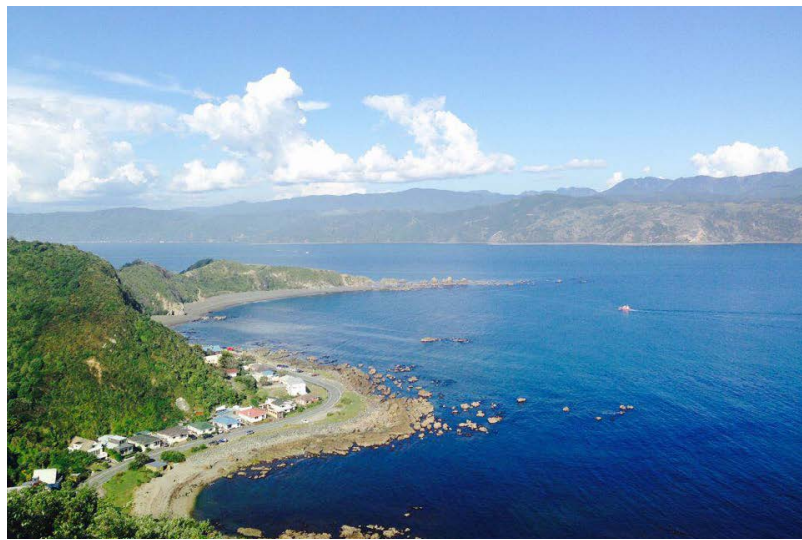

(8)

Fig 8.4 Ataturk Day photos 
(1)
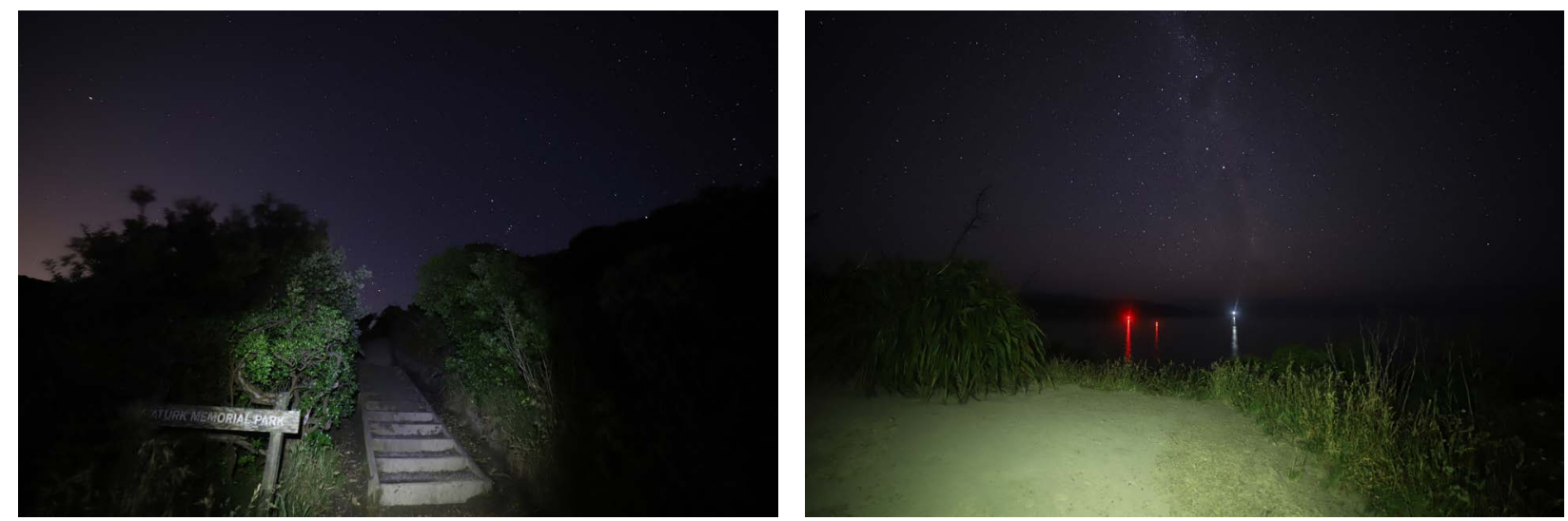

(5)

(2)
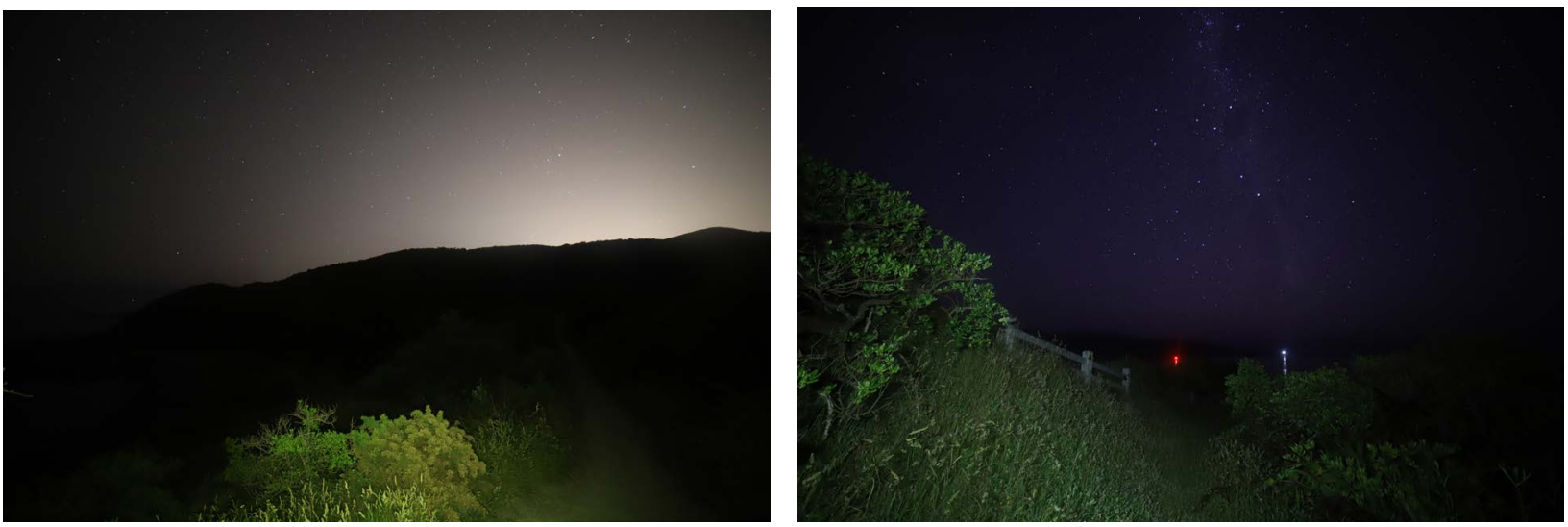

(6)

(3)
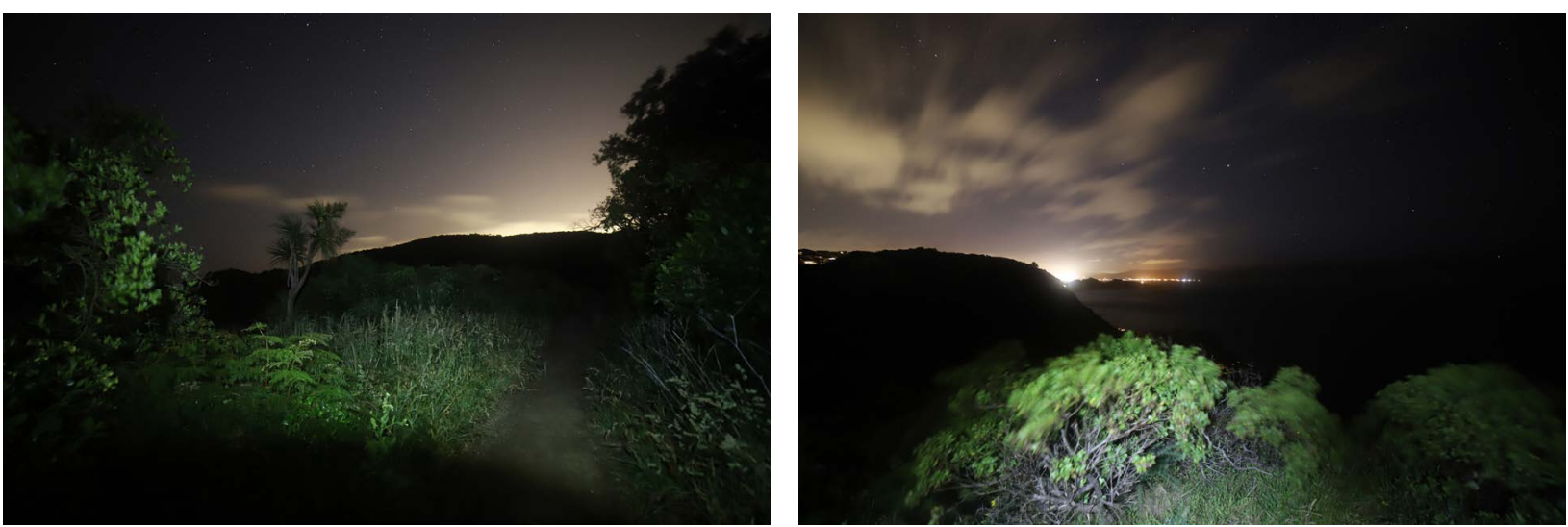

(7)

(4)
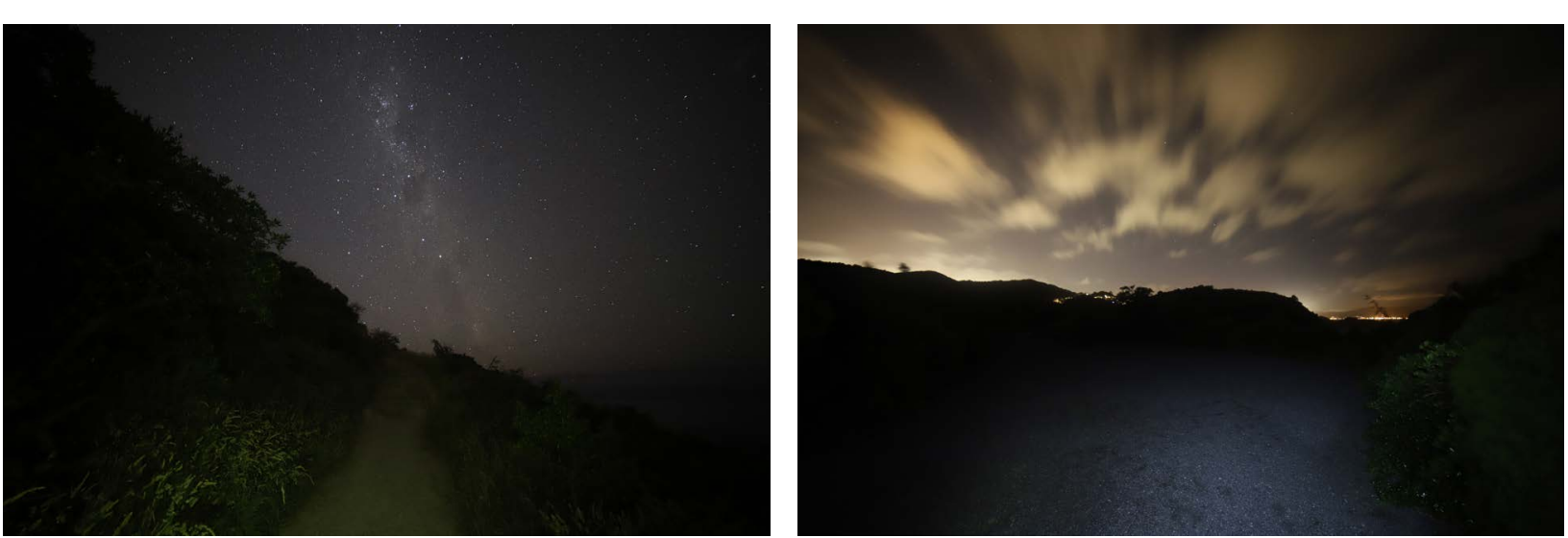

8

Fig 8.5 Ataturk Night photos 


\section{Design Criteria}

In Ataturk, the design process focused heavily on how to frame the space for stargazing and how this could flow with the existing landscape. Platform design, seating and their relationship to the existing site was the primary feature tested and developed at Ataturk. The view shaft out over the south coast was an important driver for the design process, investigating how the platforms and seating could orientate the users view to a specific part of the night sky. Site visits to and from the site were hugely important to the design process to compare the design during the day to the experience at night. 

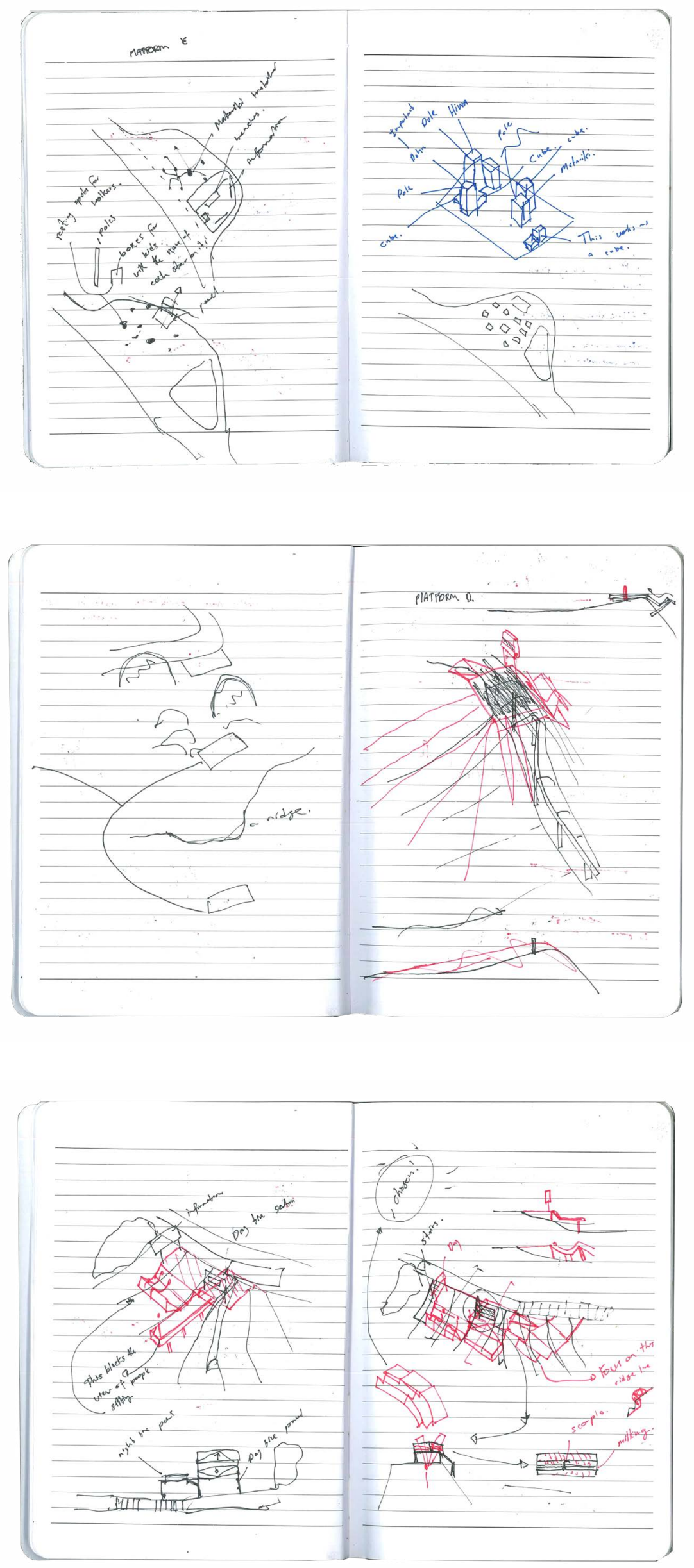

Fig 8.6 On site Platform sketches 


\section{Observational analysis}

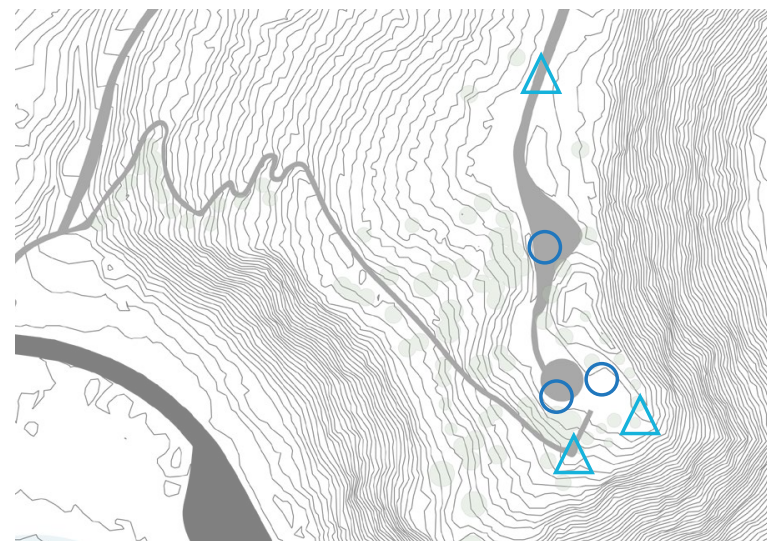
3 people moved through the $\quad \triangle^{\text {Resting spots }}$
space

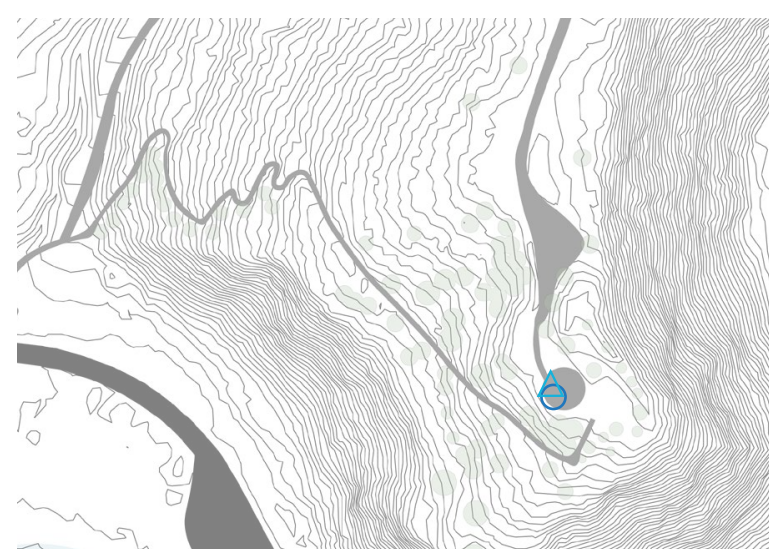

Resting spots

2 people moved through the $\triangle^{\text {Look out spots }}$ space
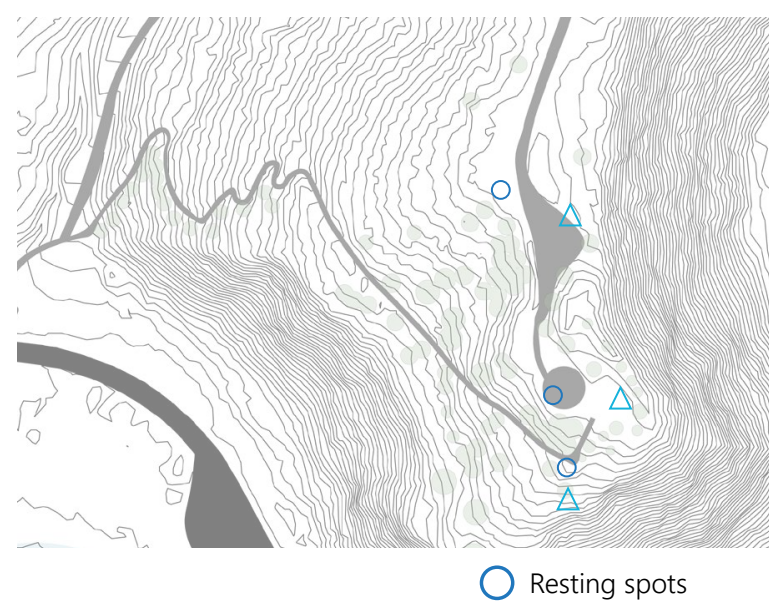

3 People moved through the $\triangle$ Look out spots space

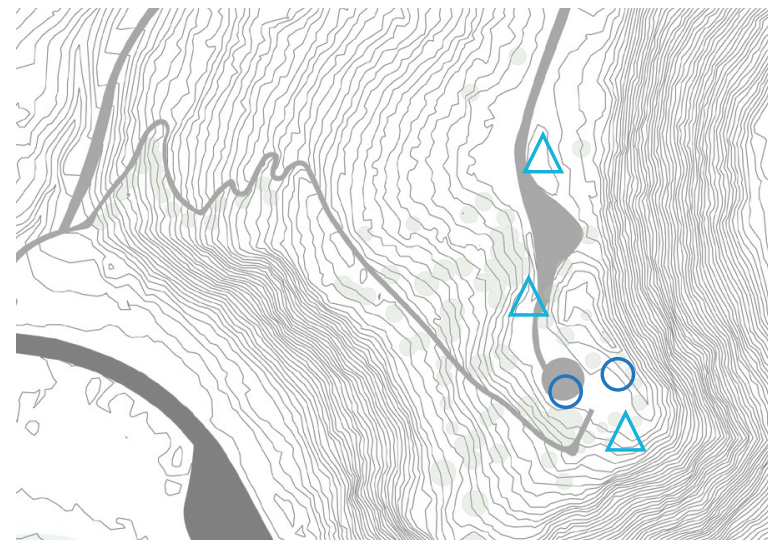

$\triangle_{\text {Resting spots }}$
$\triangle$ Look out spots

8 people moved through the space

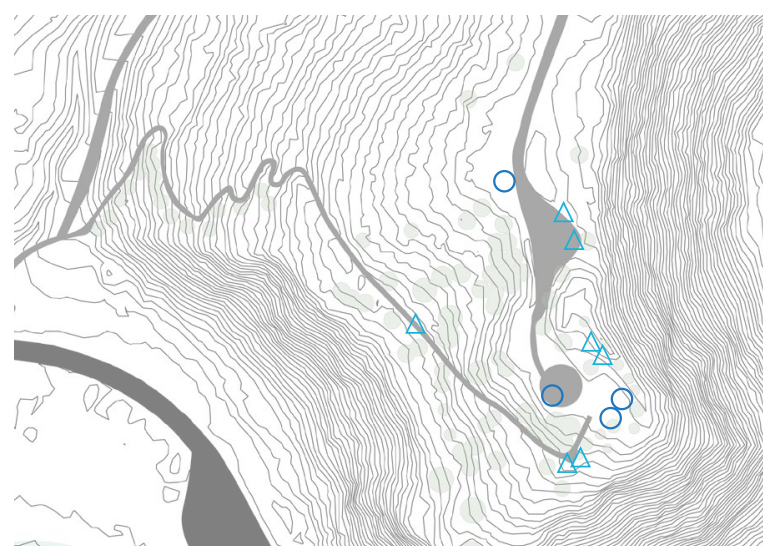

Resting spots

12 people moved through the $\triangle^{\text {Look out spots }}$ space

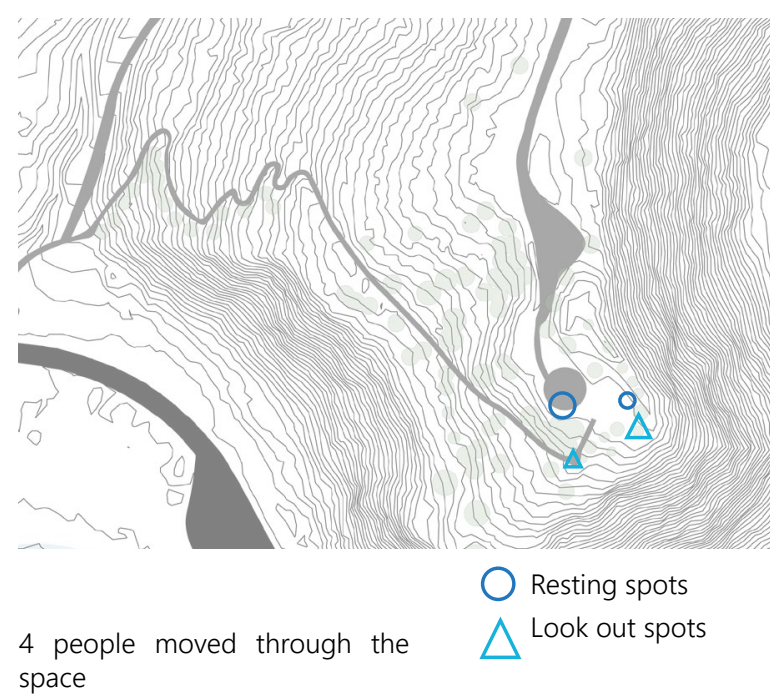

Fig 8.7 Ataturk Observational Analysis 


\section{Users of the space}

\section{Affordances}

Observational analysis revealed the site had visitors of all ages and relationships. But the majority of regular visitors were the elderly and the individual runner or dog walker. This showed that the design of the seating and platforms would need to be at a smaller scale.
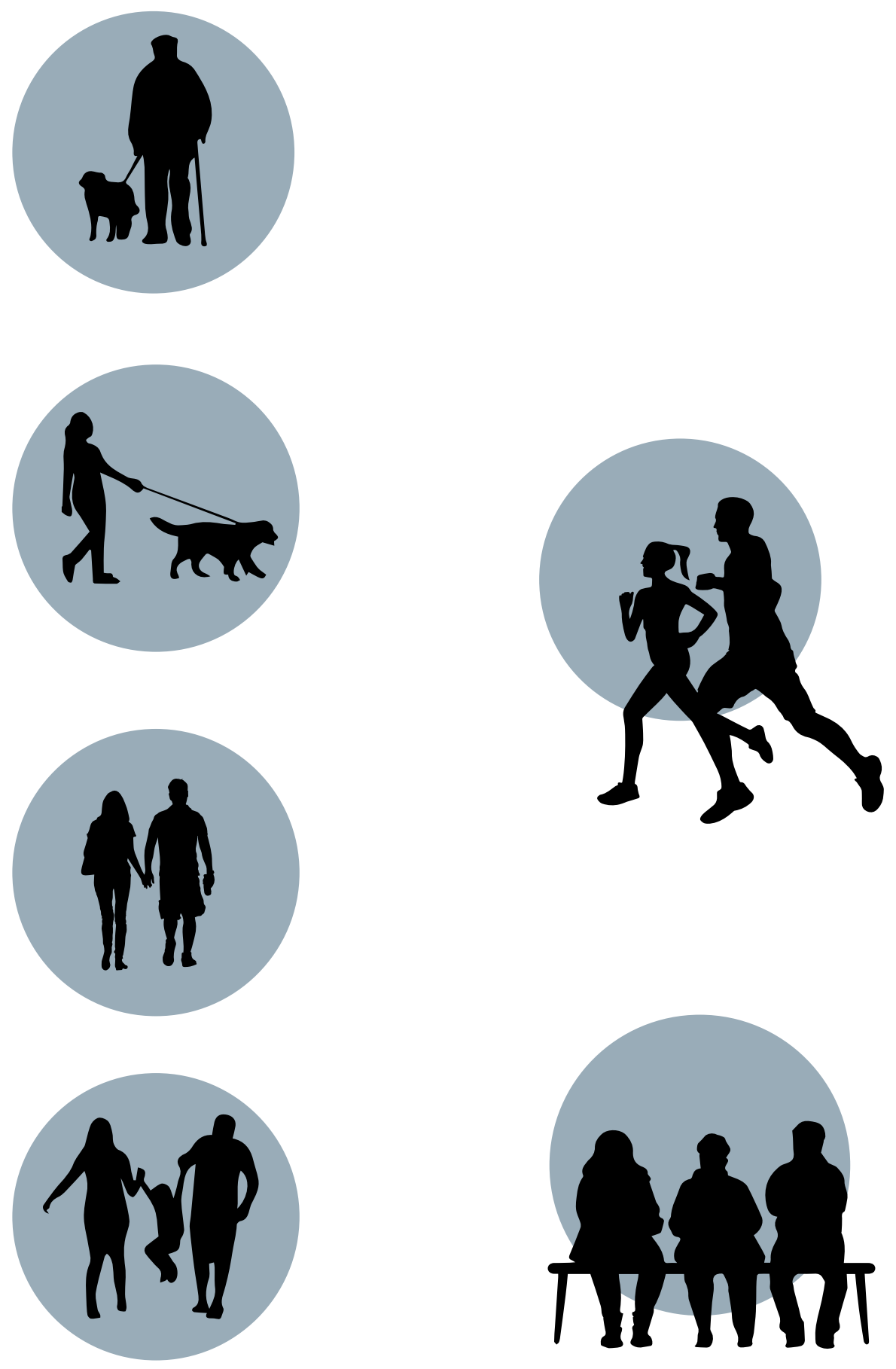

Fig 8.8 Users of the space 


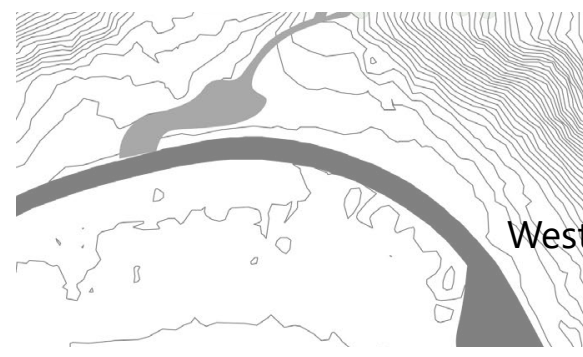

March - Mid Start of the year

Facing East - 6:30 am

These images have not been reproduced due to copyright

Facing West - 6:30 am

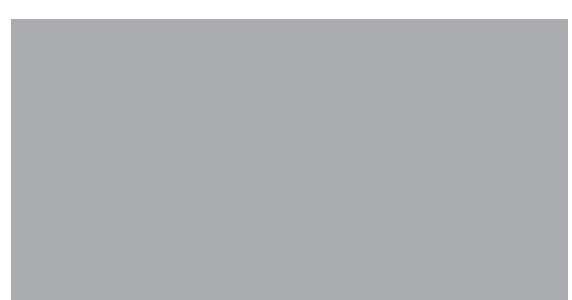

Facing East - 9:08 pm

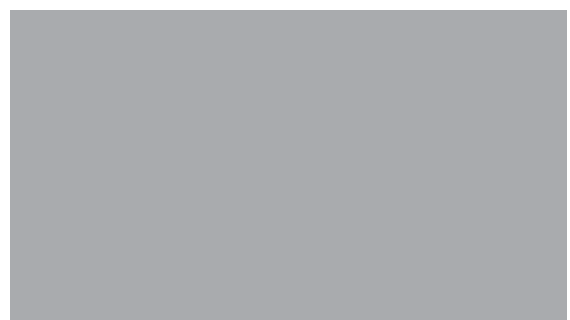

Facing West - 9:08 pm

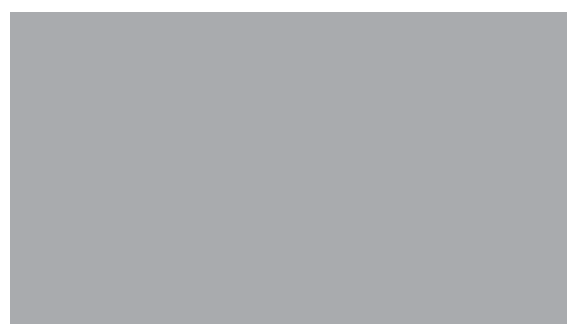

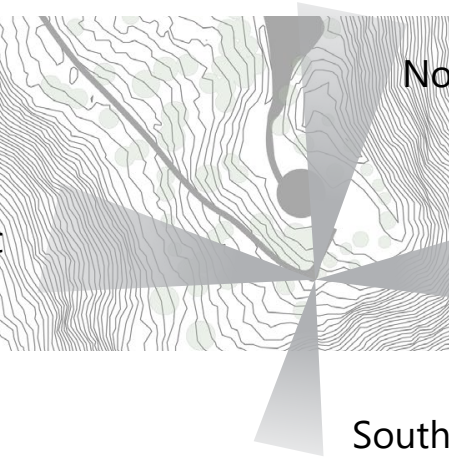

July - Middle of the Year

Facing East 6:30 am

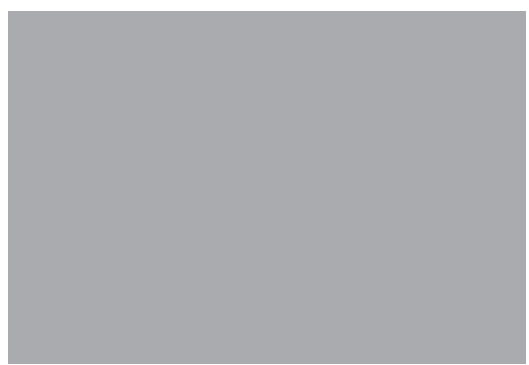

Facing West 6:30 am

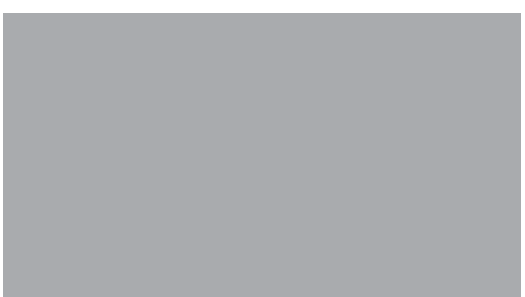

Facing East 6:51 pm

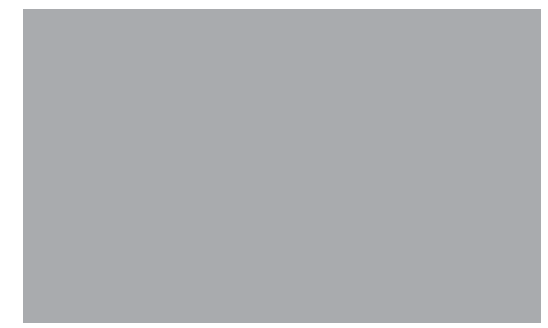

Facing West 6:51 pm

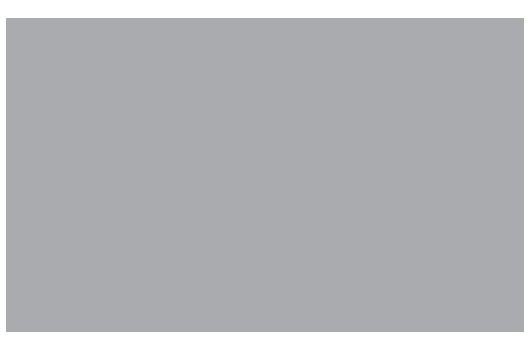

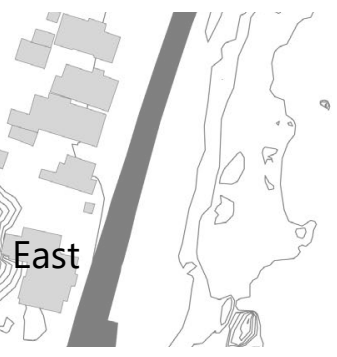

October - End of Milky way visibility until January

Facing West 5:27am

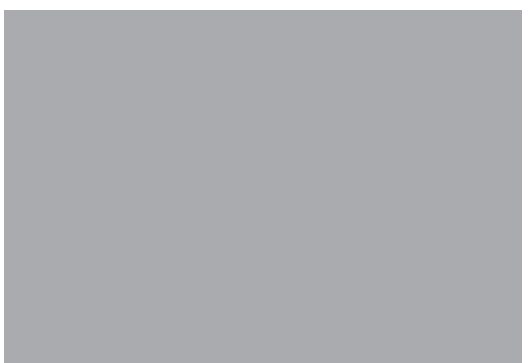

Facing East 5:27 am

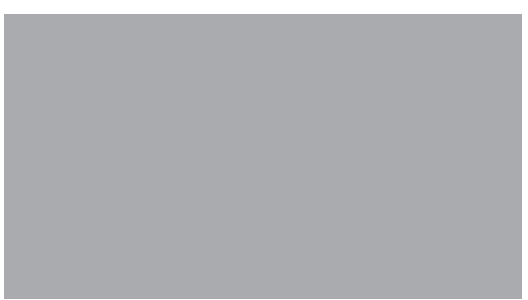

Facing East 9:24 pm

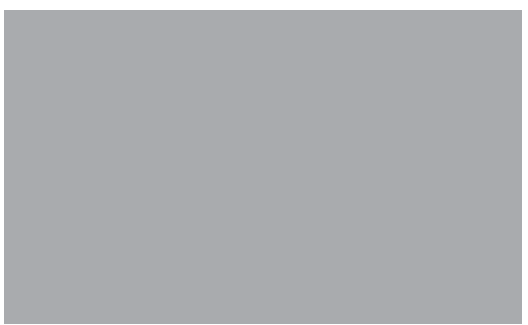

Facing West 9:24 pm

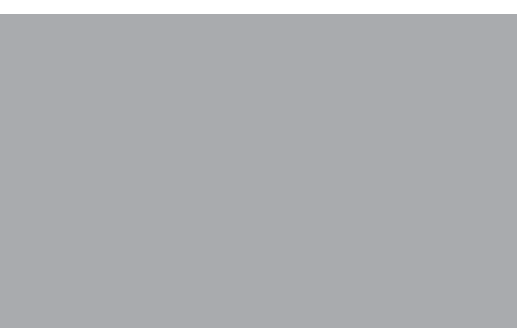

Fig 8.9 Star Movements throughout the year (skyportal, 2020) 


\section{Stars Visible from Ataturk}

Orions belt

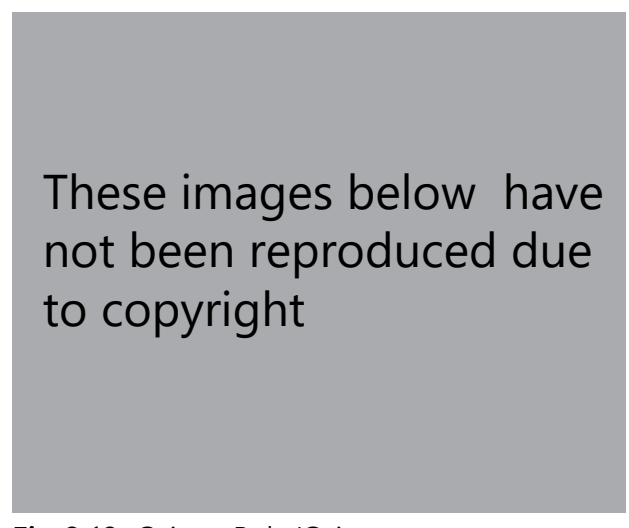

Fig 8.10 Orions Belt (Orions Belt, n.d.)

Matariki

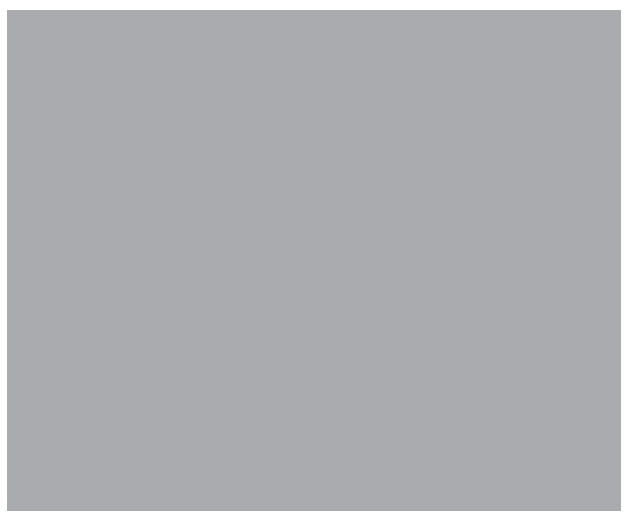

Fig 8.11 Matariki (Gillespie, 2017)

Scorpio

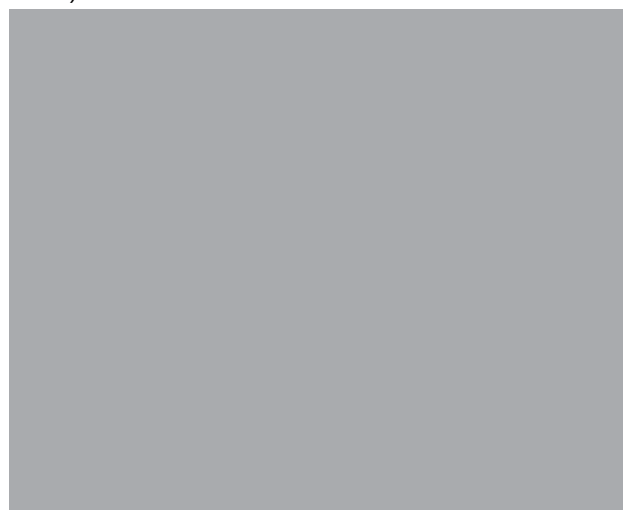

Fig 8.12 Sirius (Dyer, 2015)

Sirius

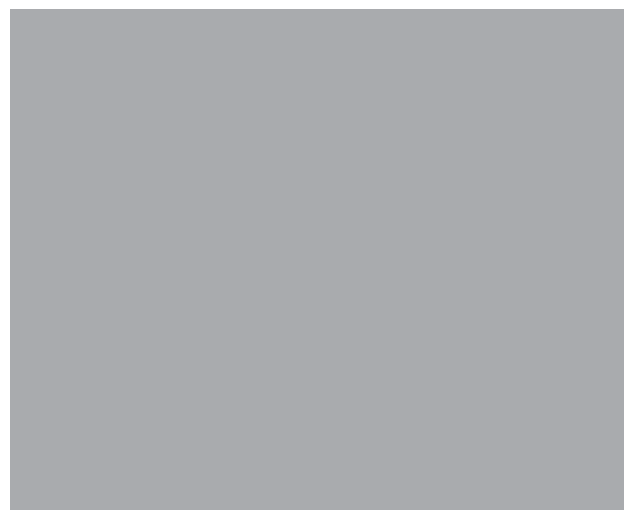

Fig 8.13 Scorpio (Picking, 2006)
A star study was completed to gain an understanding of what could be seen in the night sky from the site. Four celestial bodies were found to be seen the most from the site through out the year, Orions Belt, Matariki, Sirius and Scorpio. These are also four very important stars in Maori Astronomy. Reflecting on the literature, the sky father Ranginui is held up by 4 posts. These 4 posts are formed by Sirius, Orions belt, Matariki and Scorpio, which bends over with the weight of his legs.

This image has not been reproduced due to copyright

Scorpio

Sirius

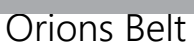

Matariki

Fig 8.14 Ranginui being held up in the sky on the 4 posts (Hall, 2004, p. 20)

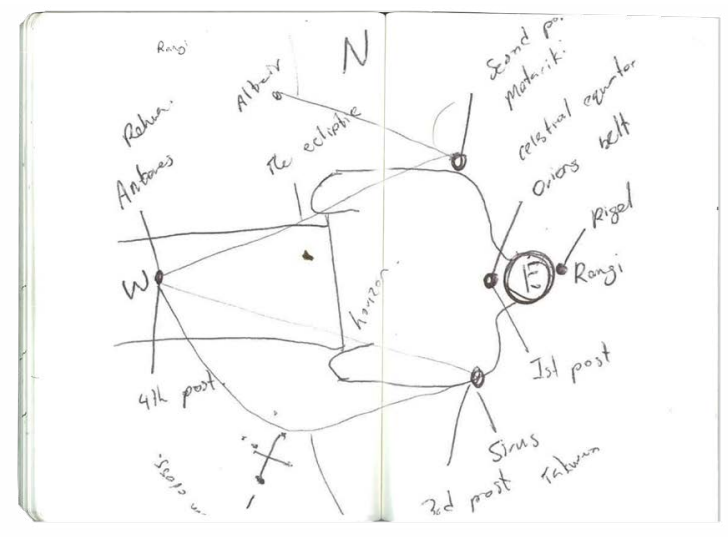




\section{Revisiting Platform}

The Platform was initiated as a design feature to provide a sense of security and safety for the user while they are star gazing. As found in the previous star study, each area of the night sky has a completely different appearance in a different direction and at a different time of the year. In the beginning of the year, the Milky Way core appears in the east and at the end of the year in the west.

The success of the night time experience is achieved by spending a long period of time in a space to let the eyes adjust to the darkness. Creating multiple platforms in the site allows different areas of the night sky to be viewed depending on the time of year.

Merging toolkit with site specific design

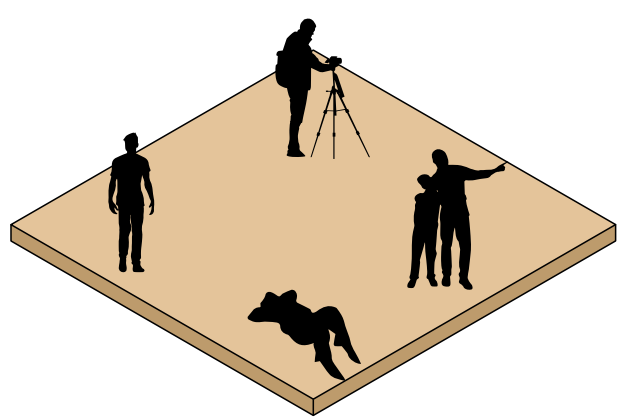

Maori Astronomy

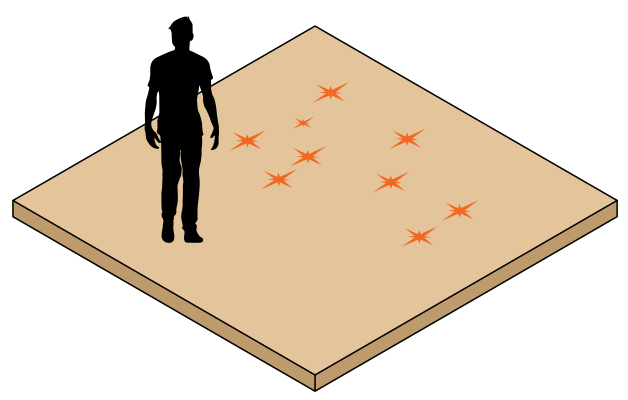




\section{Platform shape design}

Platforms could be implemented along the pathway that runs from the car park to the memorial lookout. As the site is on a hill, there are multiple ways it could interact with the landscape

Set out directly from the path

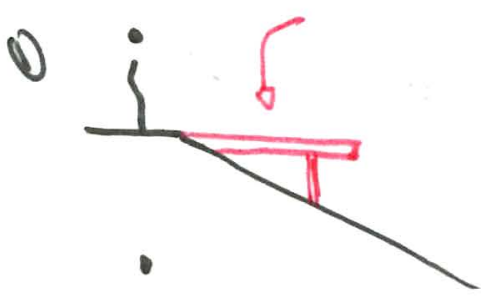

Set down from the path

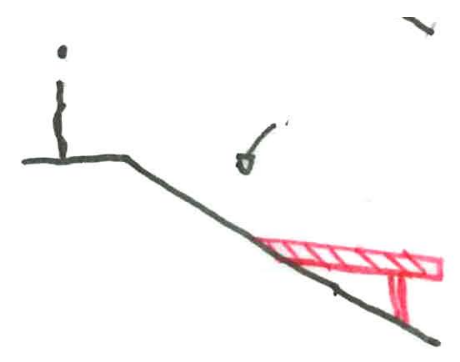

Vegetation between path and platform

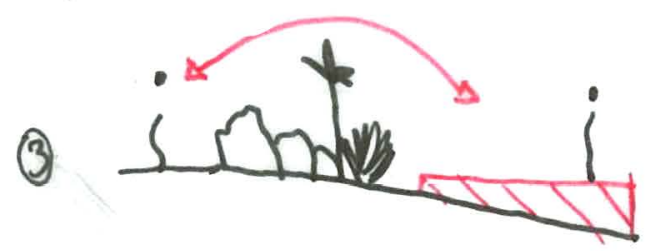

Integrated with landscape

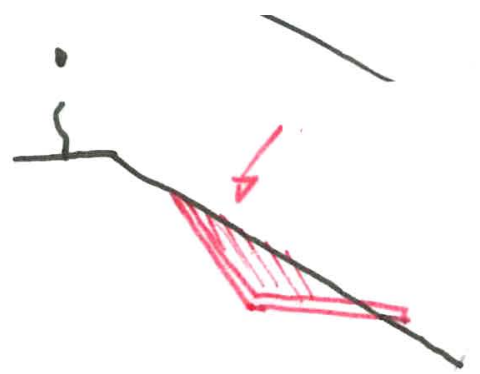

Down and next to path

(2)

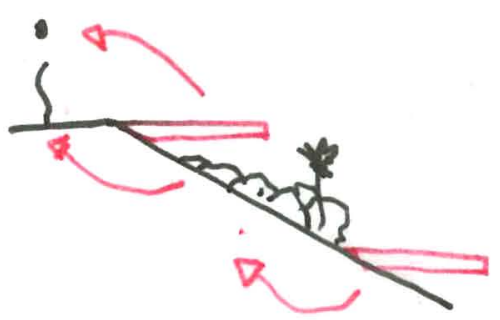

No Vegetation

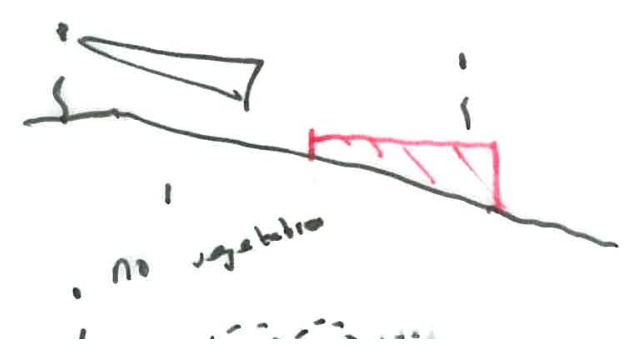




\subsection{Platform location + Amount II}

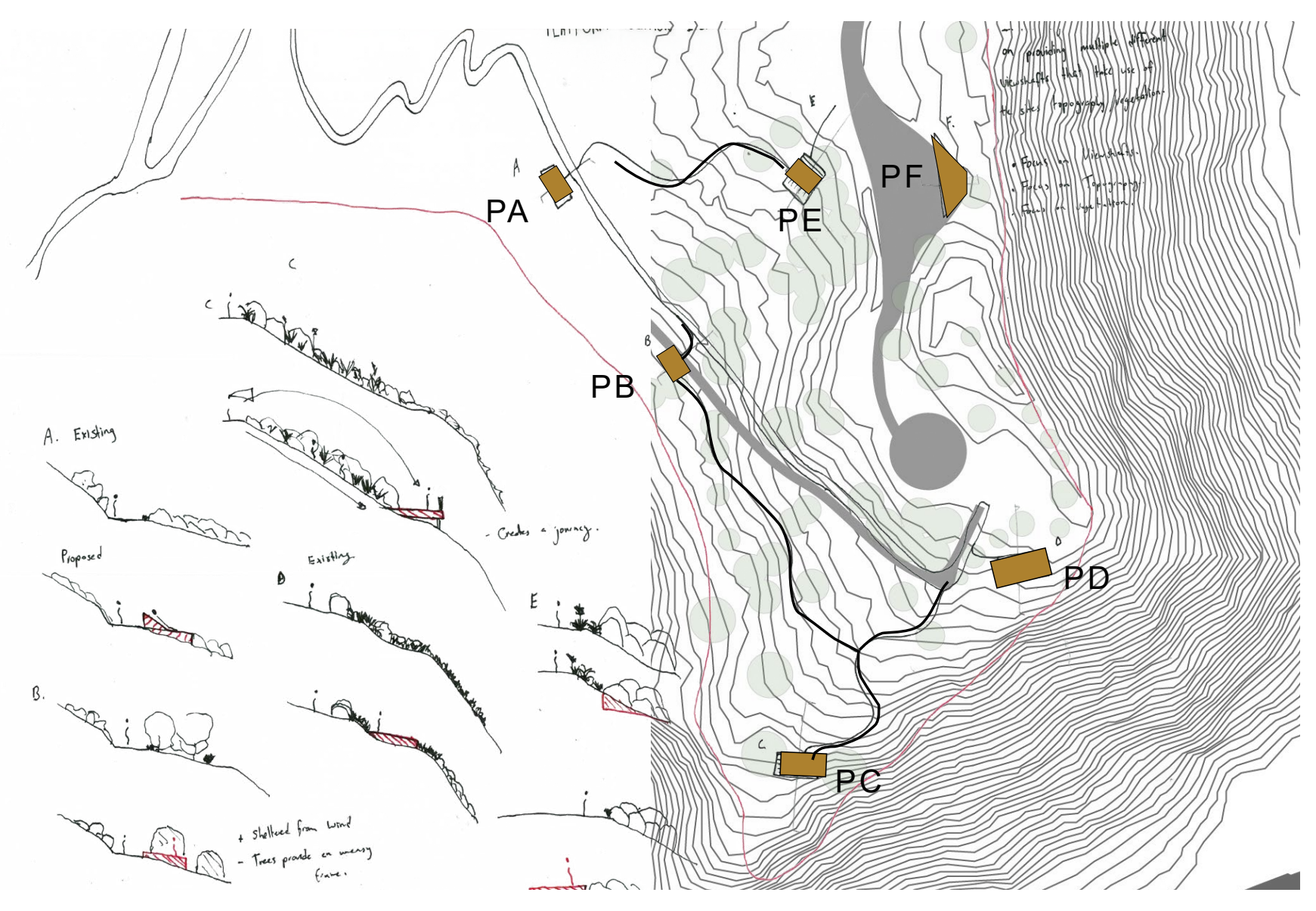

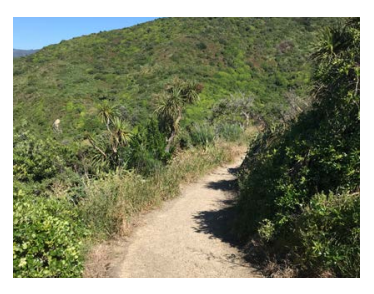

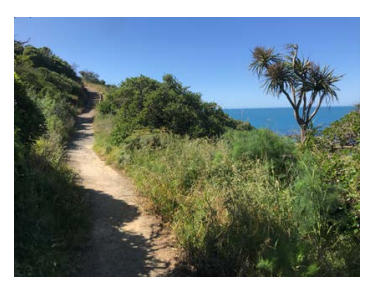

PA

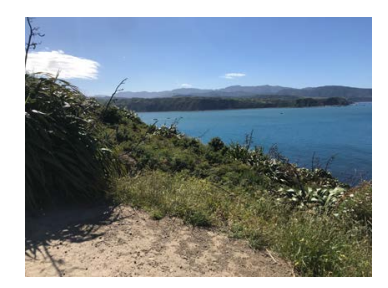

PB
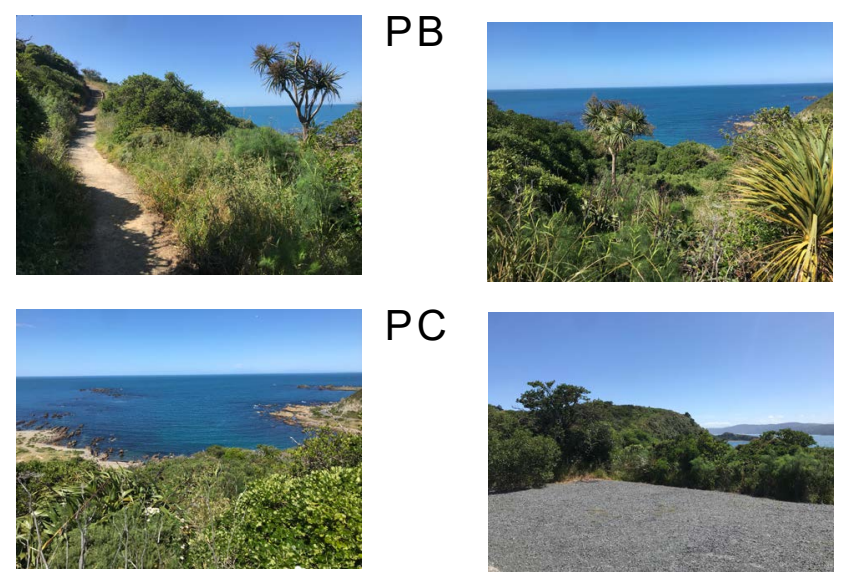

PC

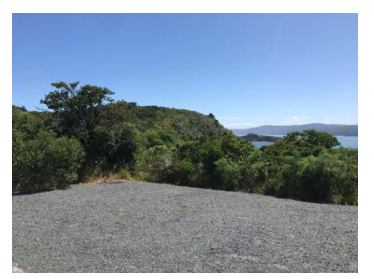

PD There are 4 viewshafts that are accessible from the site.

- North East - The location that matariki rises in July

- South East - The location that the milky way first rises in

PE - South West - Where the milky way is seen easier later on in the year

- West - Where the milky way sets later on in the year

\section{REFLECTION}

PF

- Development is needed on the platform size, location and orientation

- The platforms should be placed at different heights in the site, in areas with different slope angles to provide a varied experience.

- Platforms should try to provide a different experience from the last one. 


\section{Platform location + Amount 12}

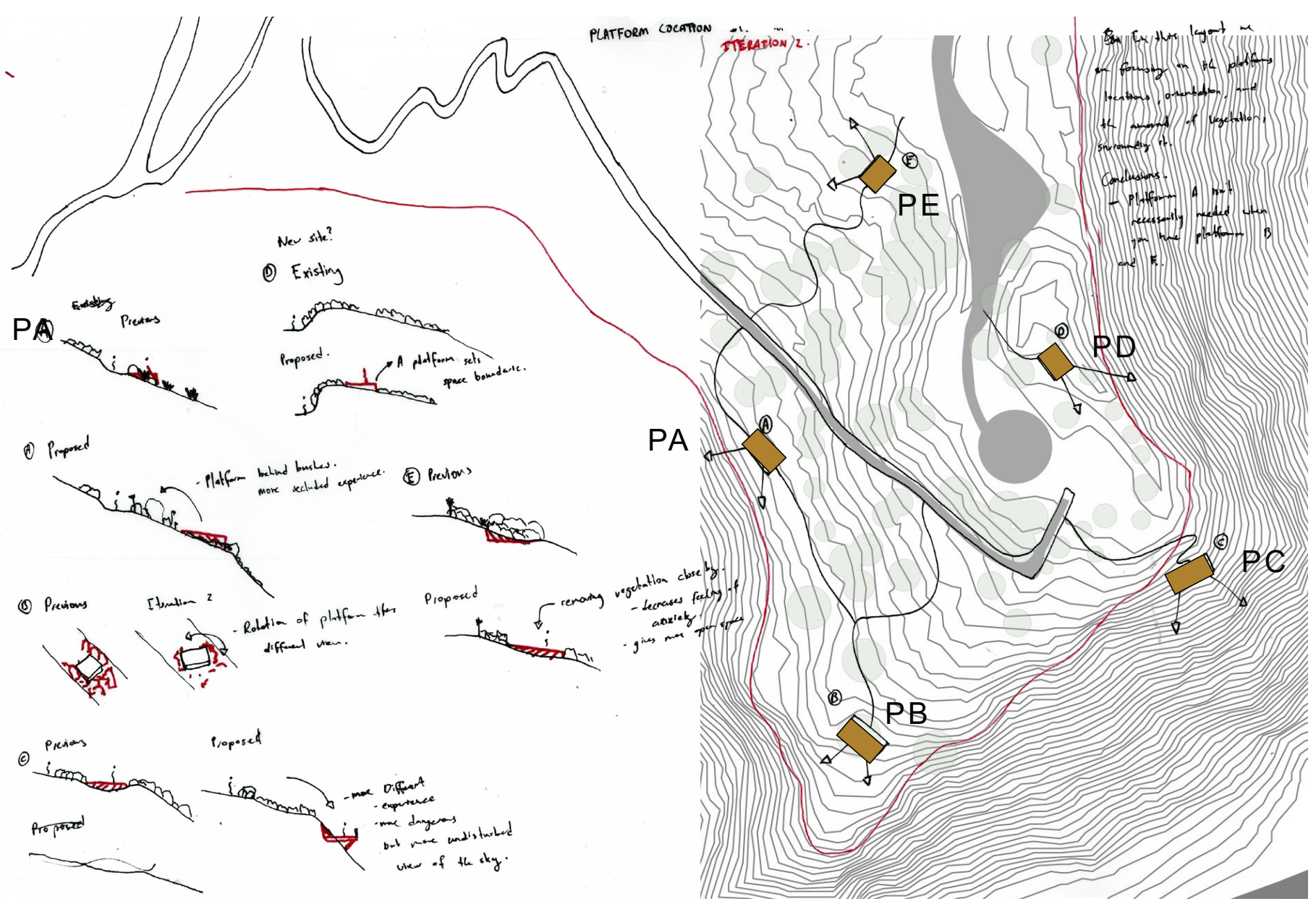

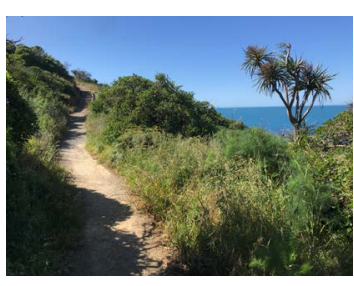
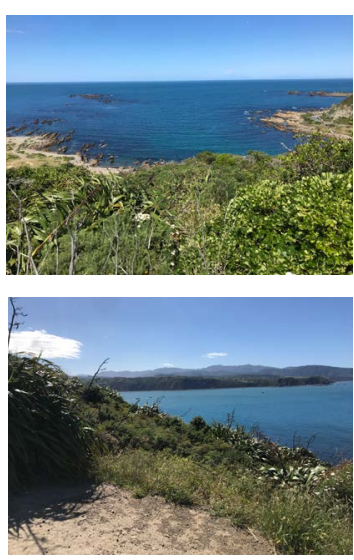

PA

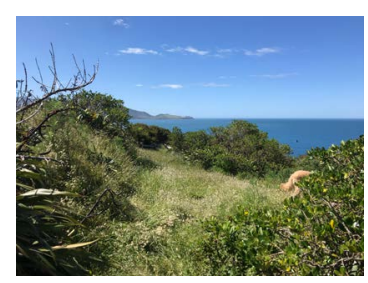

PB

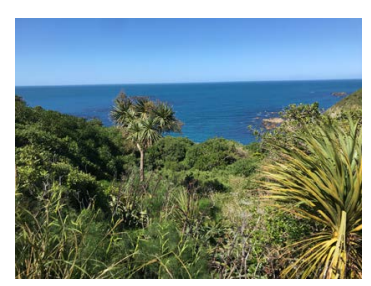

PC

\section{PD REFLECTION}

- Platform A isn't needed. It offers the same view shaft as B and E (south / south west).

- The orientation of Platform B (platform C in iteration 1) would be more ideal in this position.

PE

- The Location of platform $C$ would be easier to access closer to the main path.

- Platform D offers the same view shaft as platform $C$ and may not be needed

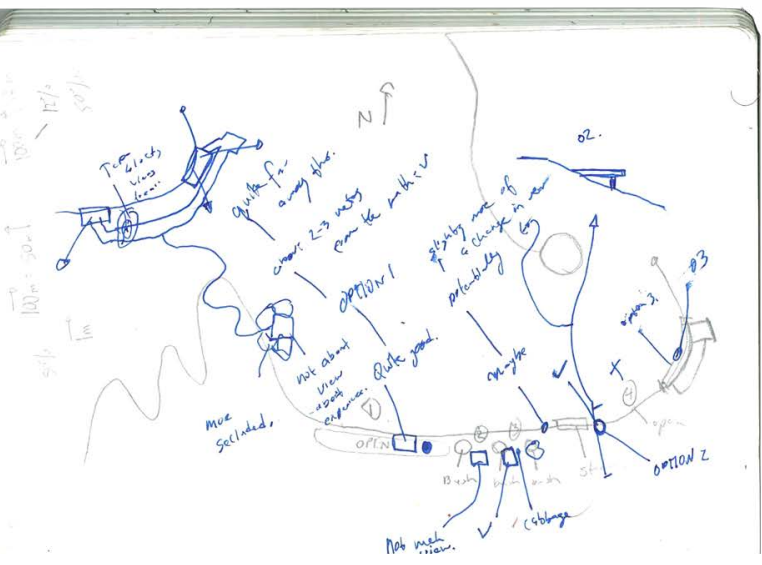




\section{Platform location + Amount I3}
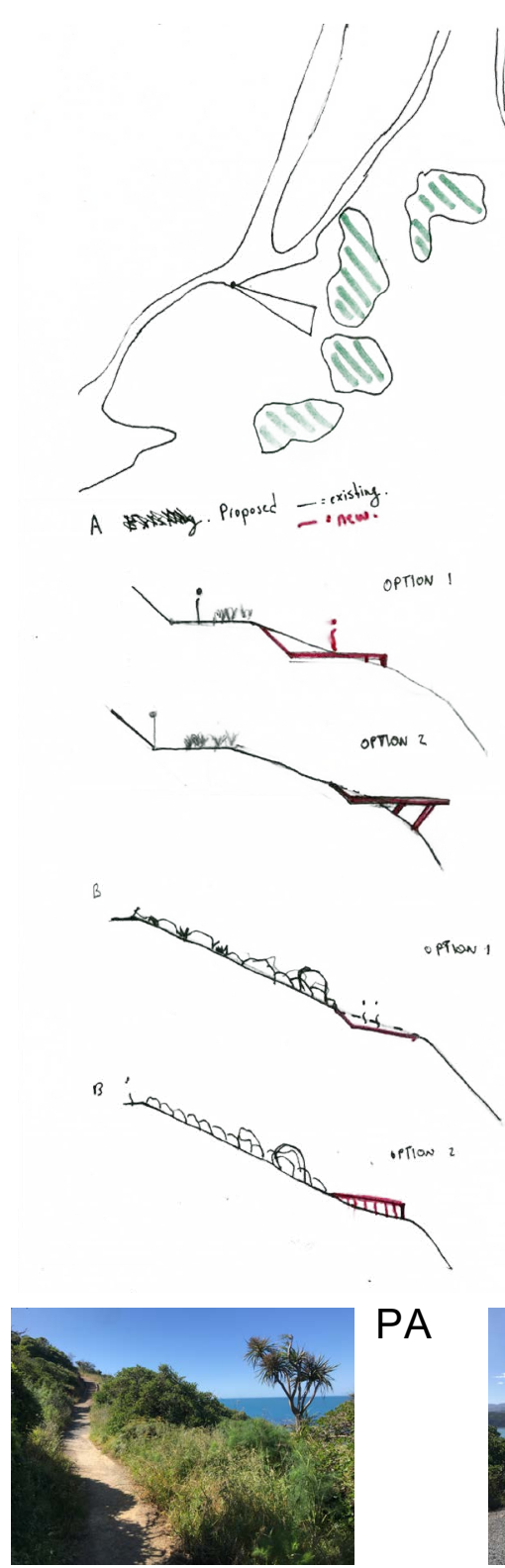

PA
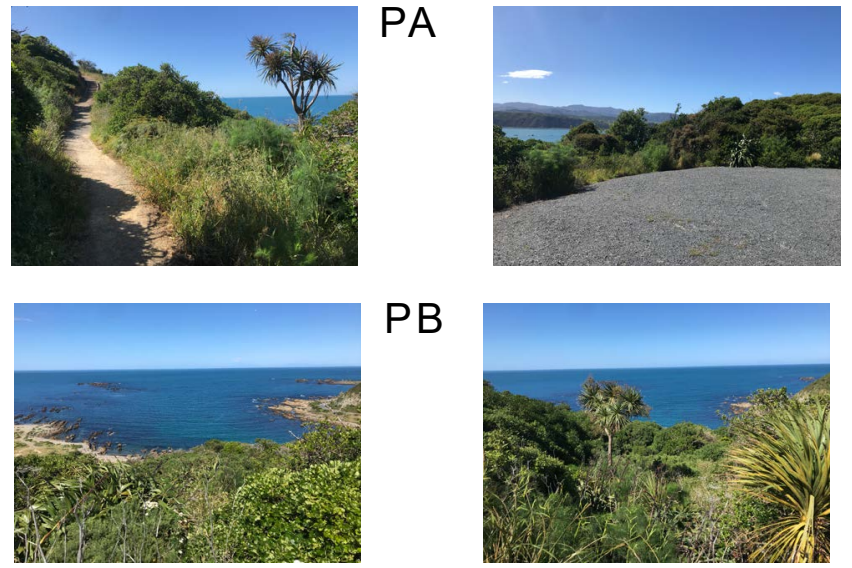

PB

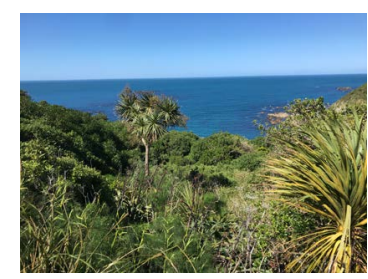

PC

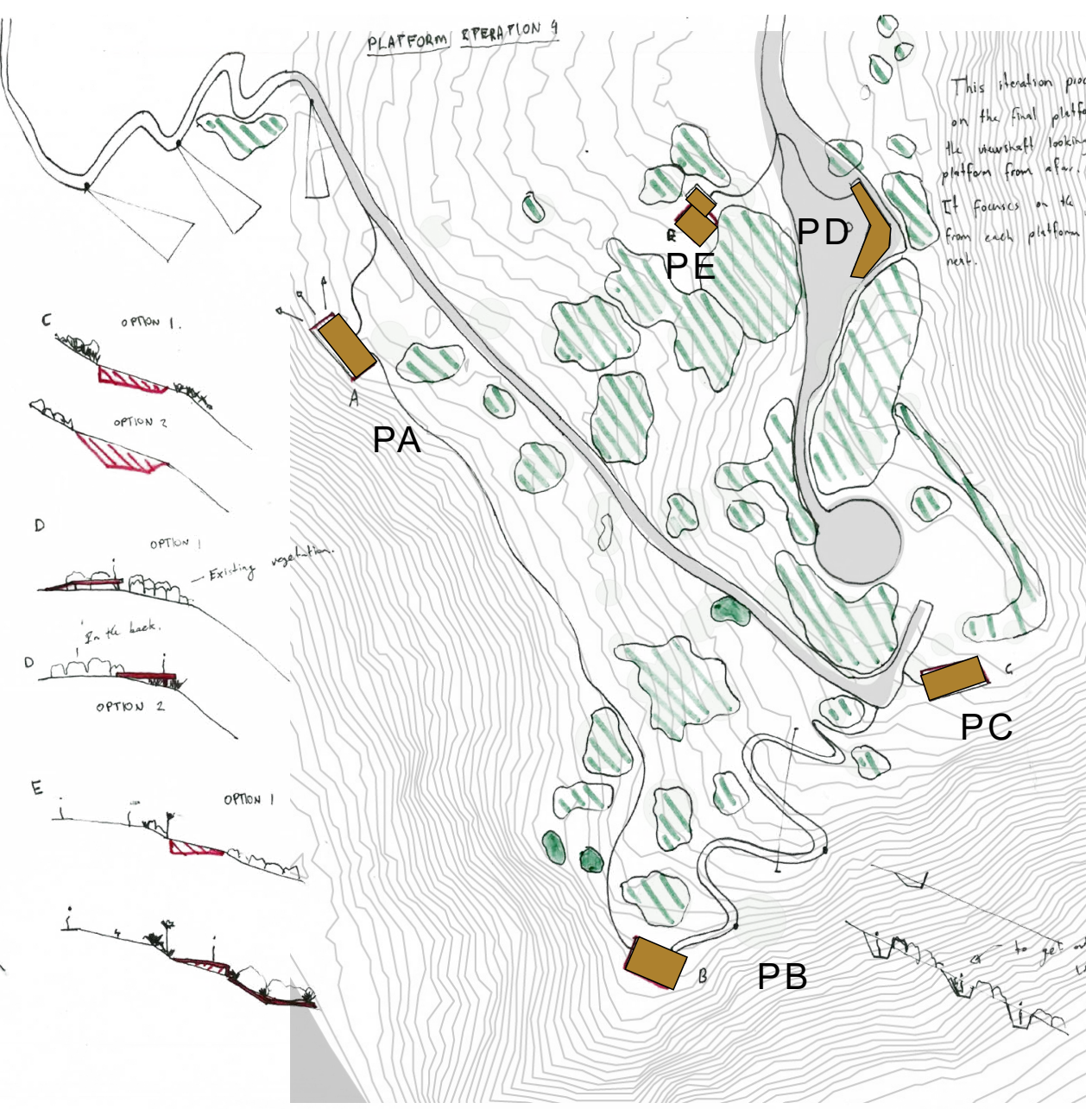

PD REFLECTION

- Platform A should be moved closer to the other platforms

- Platform B will be removed as it does not provide a unique view shaft

$\mathrm{PE} \quad$ - Platform $C$ will be right next to the path for easier access

- Platform D will be set on the gravel path. This will serve as an introductory platform with information boards.

- Platform E will be removed as it provides a similar view shaft to platform $A$

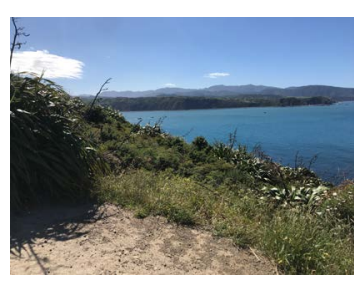




\section{Final location + Amount}
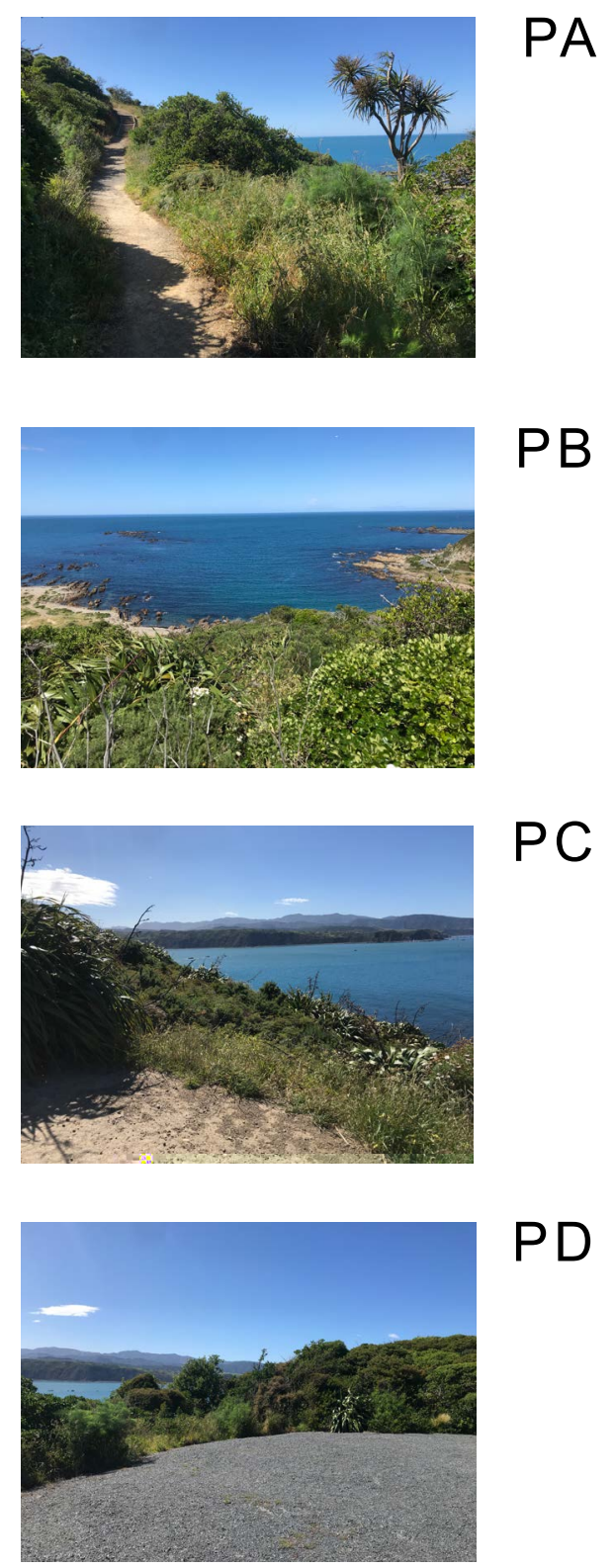

PD

The final layout consists of four platforms that target the West, South, East and North areas of the night sky. Each platform represents a post that holds rangi in the sky
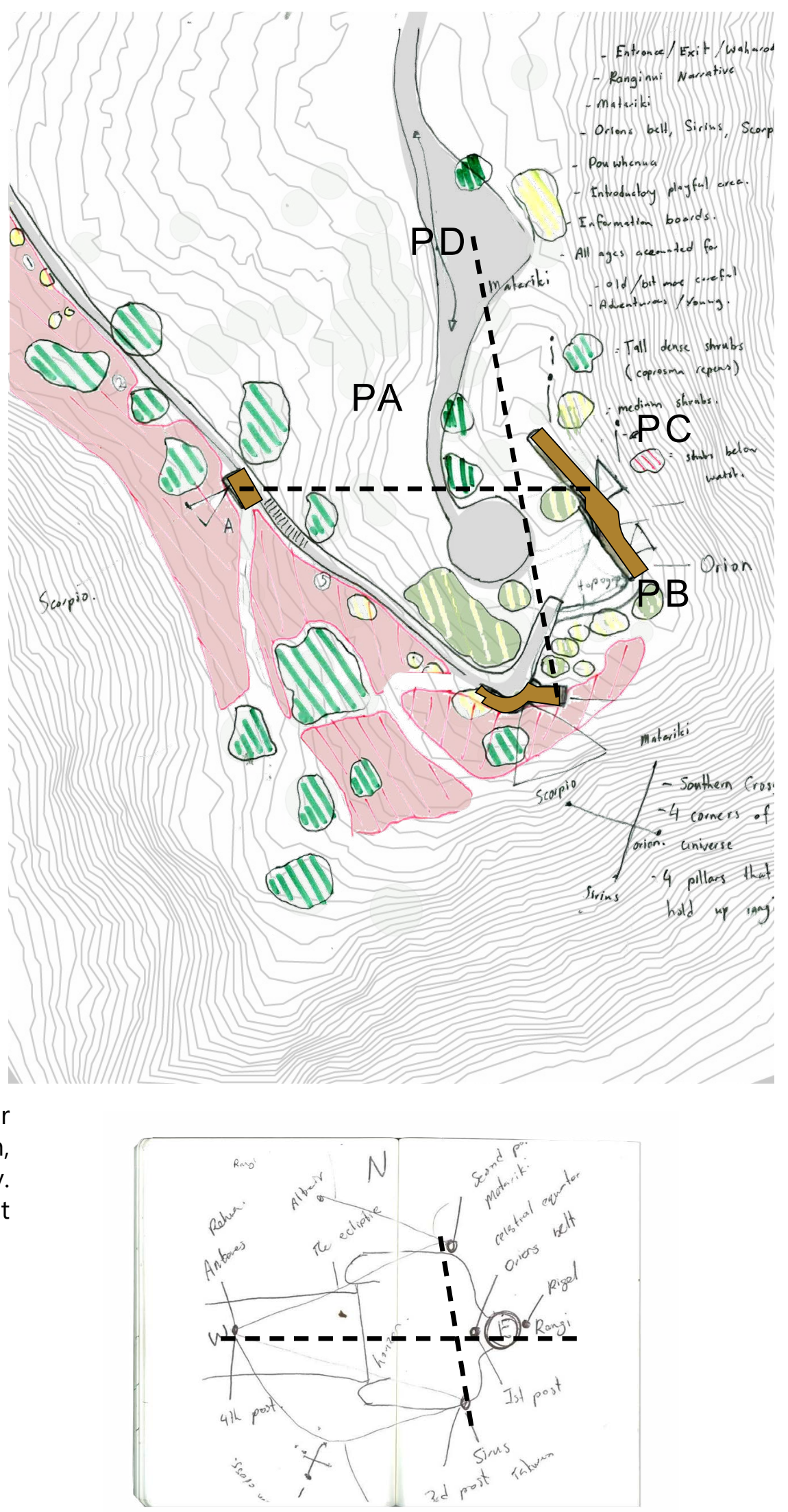

Fig 8.17 Representation of Rangi in the 


\section{4 areas for design}
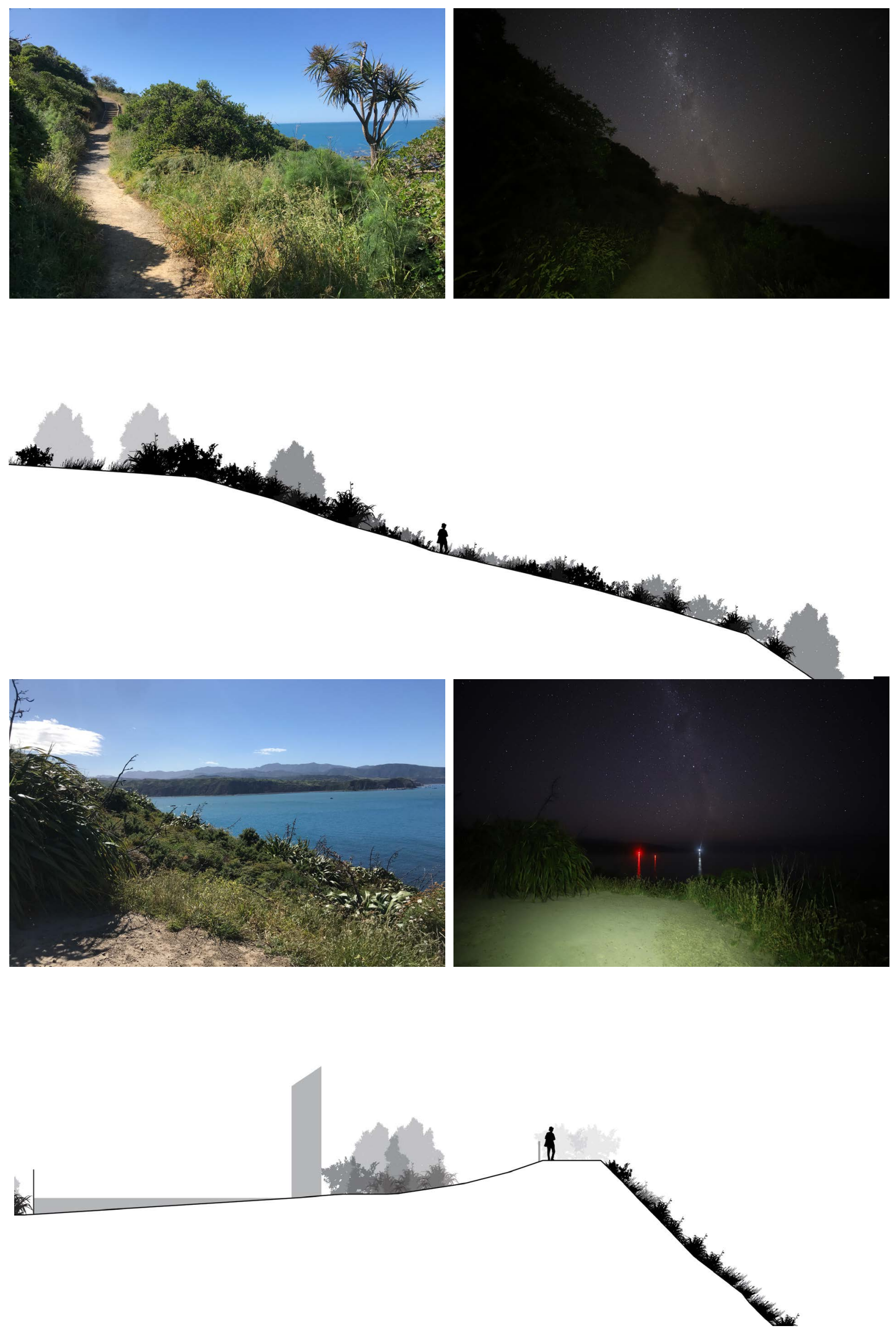

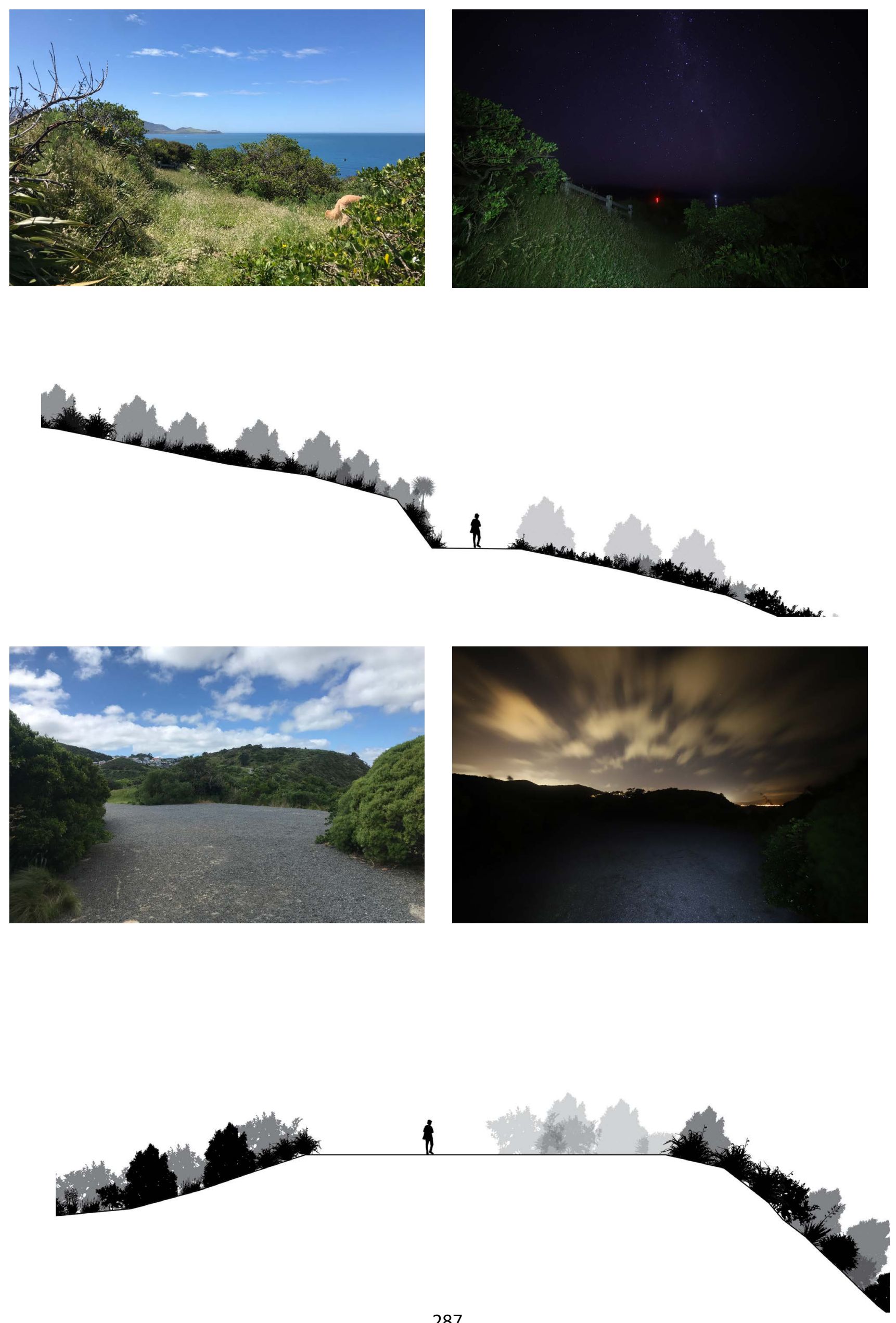
8.3 Individual Platform design

Scorpio Platform Testing
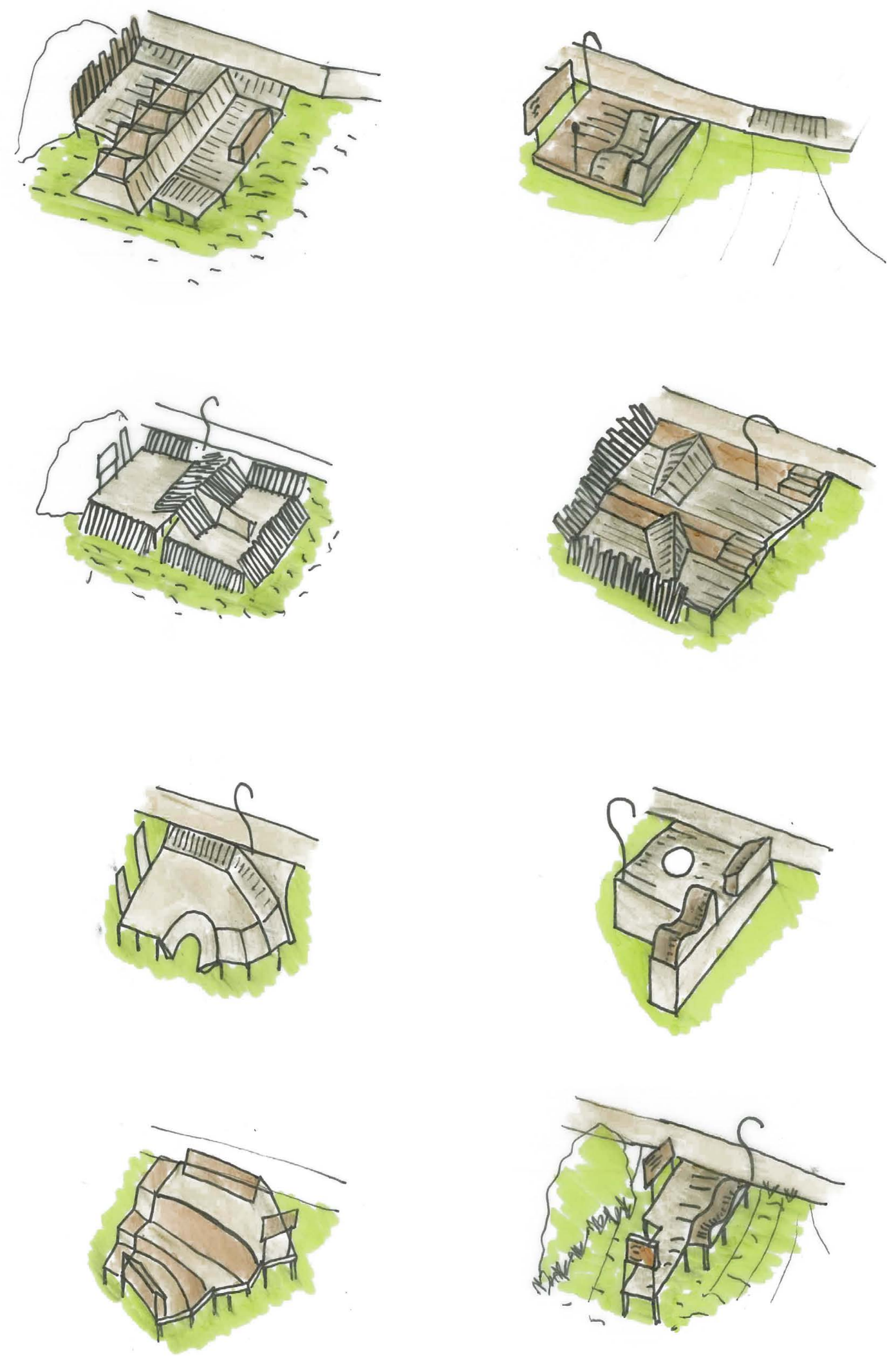


\section{Concept design}

This image has not been reproduced due to copyright
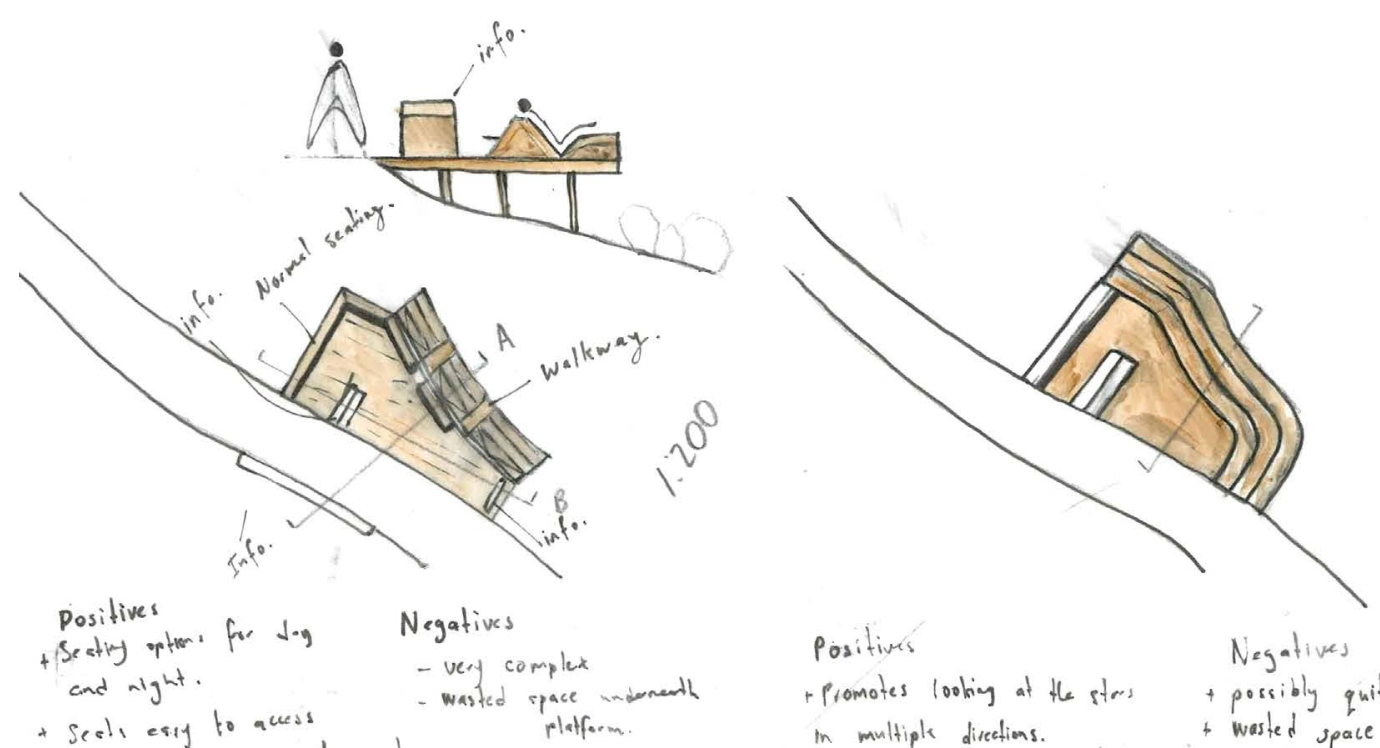

+ Sestr esey to acuess
+ Seots raised off gromad doesn't

+ Seots raised off gromend
make you foel traped.

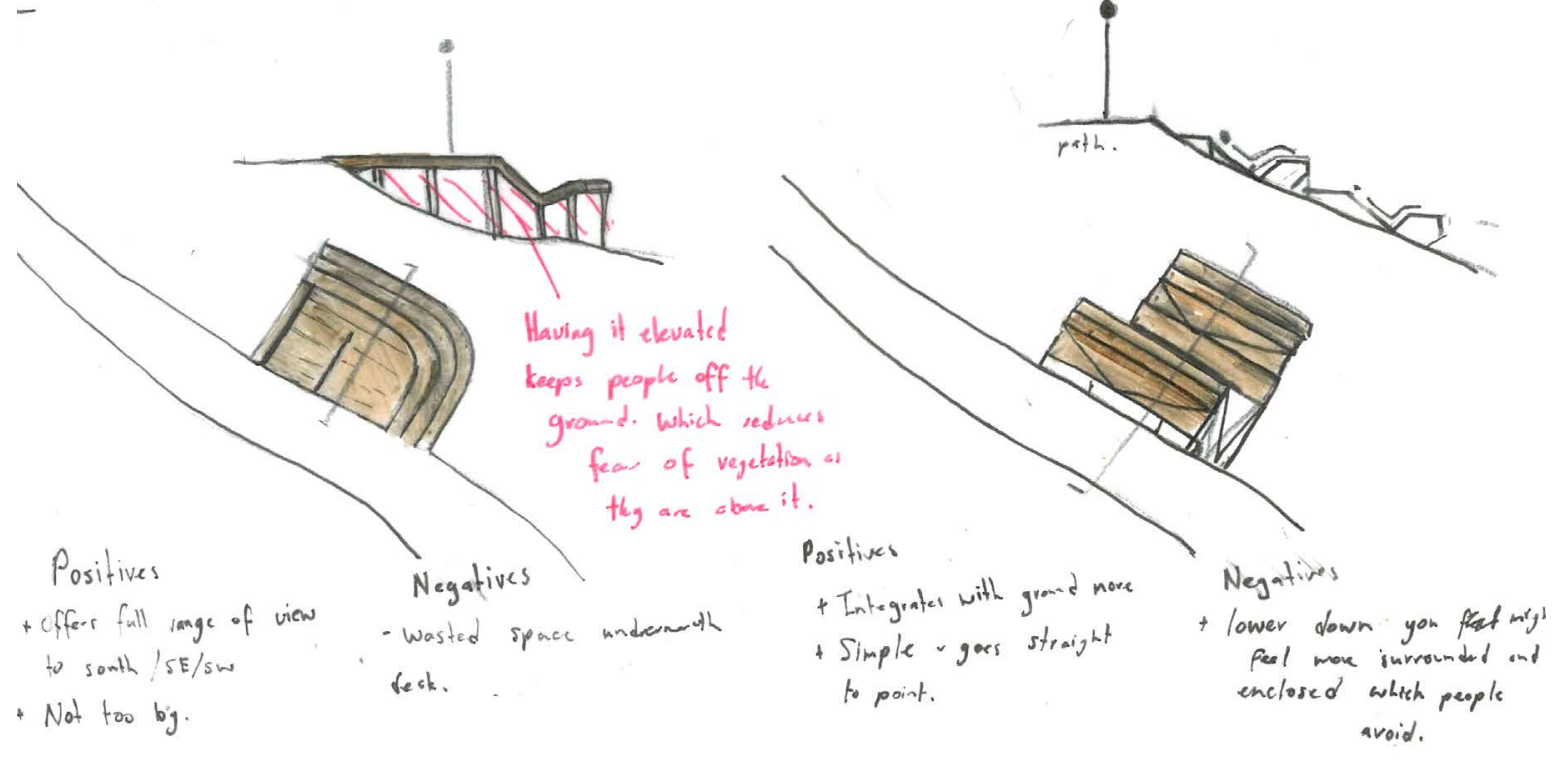




\section{Sirius Platform Testing}

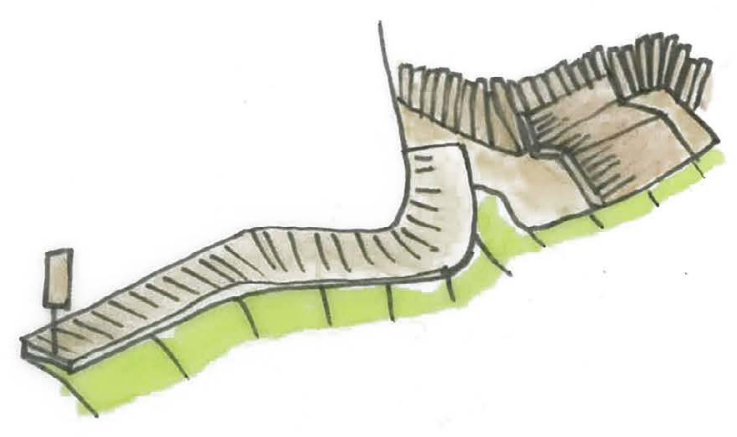

This image has not been reproduced due to copyright
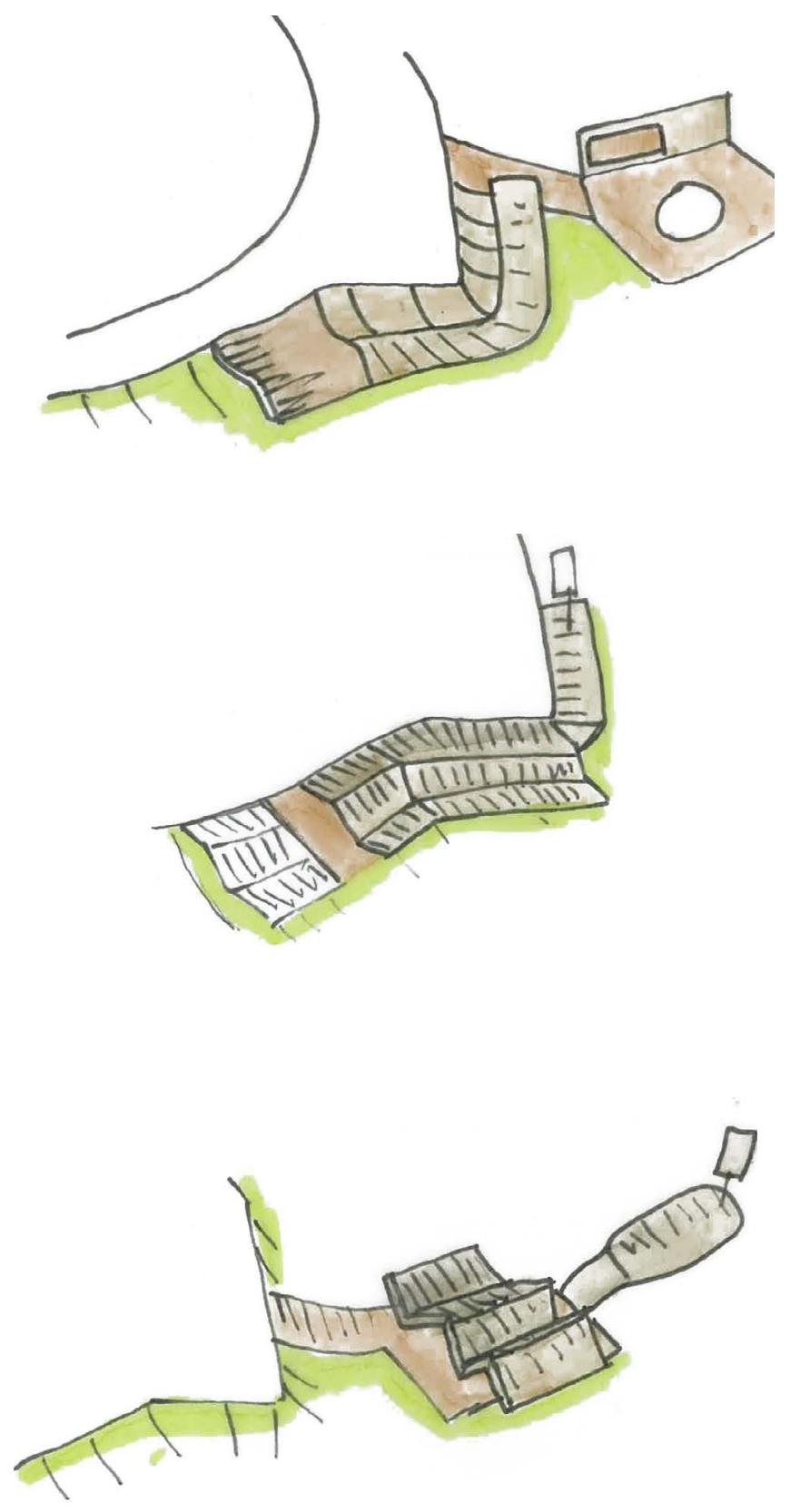


\section{Orions Belt Platform Testing}

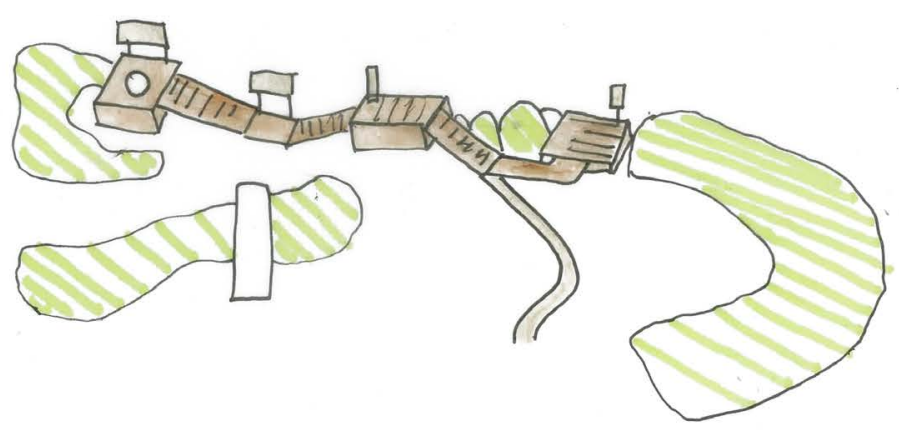

This image has not been reproduced due to copyright
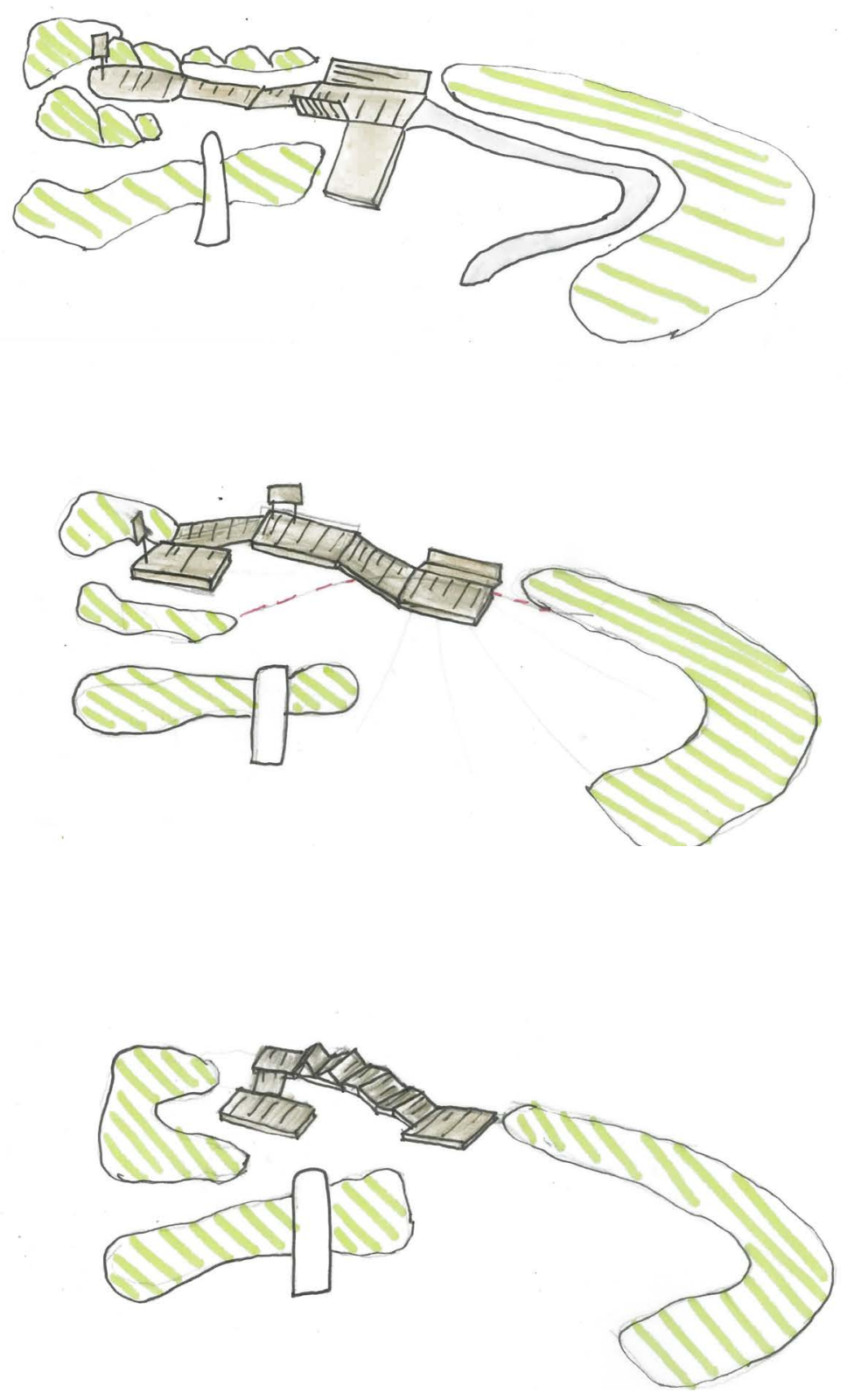


\section{Matariki Platform testing}

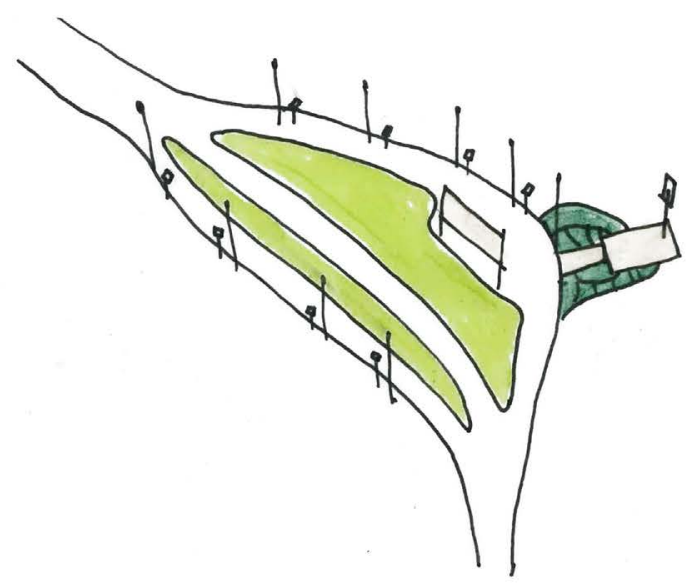

This image has not been reproduced due to copyright
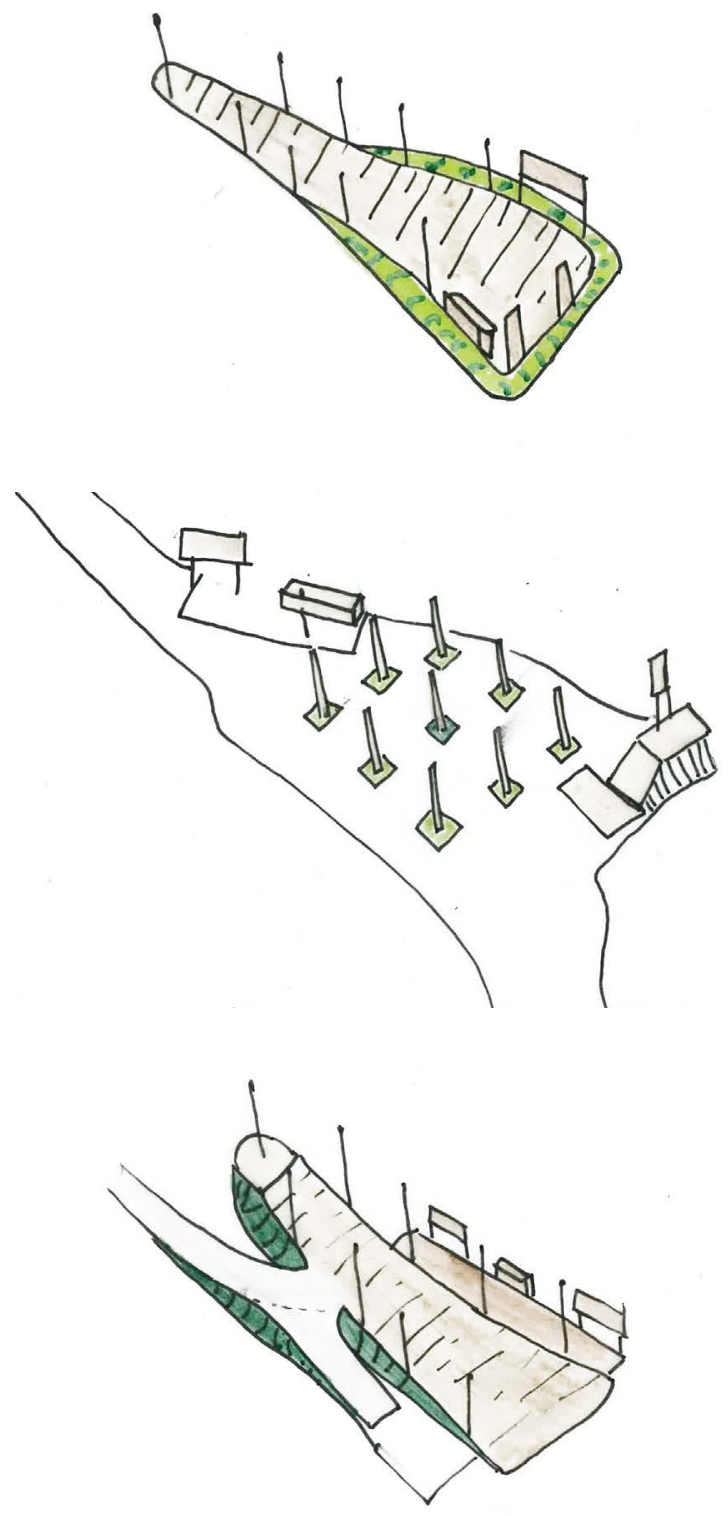


\section{Matariki Hierarchy}

The matariki platform focused on providing a visual representation of the star cluster that could be used during the day and at night. A visual representation of the star cluster was designed using the brightness of each star in astronomy and its individual meaning in Maori culture as two different design routes.

In Maori culture there is a hierarchy determined by the stars gender, importance and place in the natural environment:

1. Waita = "salt" and food from the sea

2. Tupuanuku = Food grown in the ground

3. Waiti = "water" and food from lakes and rivers

4. Tupuarangi $=$ Food from the sky

5. Waipunarangi $=$ The rain

6. Ururangi $=$ The winds of the sky

7. Pohutukawa $=$ Connects Maori to the deceased

8. Matariki - Health and Wellbeing

9. Hiwa-i-te-rangi = Reflection

In astronomy, based on sky brightness the hierarchy of the stars would be:

1. 1. (Brightest) Matariki

2. Tupuarangi

3. Waipuna a rangi

4. Waiti

5. Ururangi

6. Waita

7. Tupuanuku

8. Hiwa-i-te-rangi

9. Pohutukawa

These two differing orders were testing through adjusting the heights of poles (symbolic) cubes (sitting during the day) and grass mounds (lying on at night).

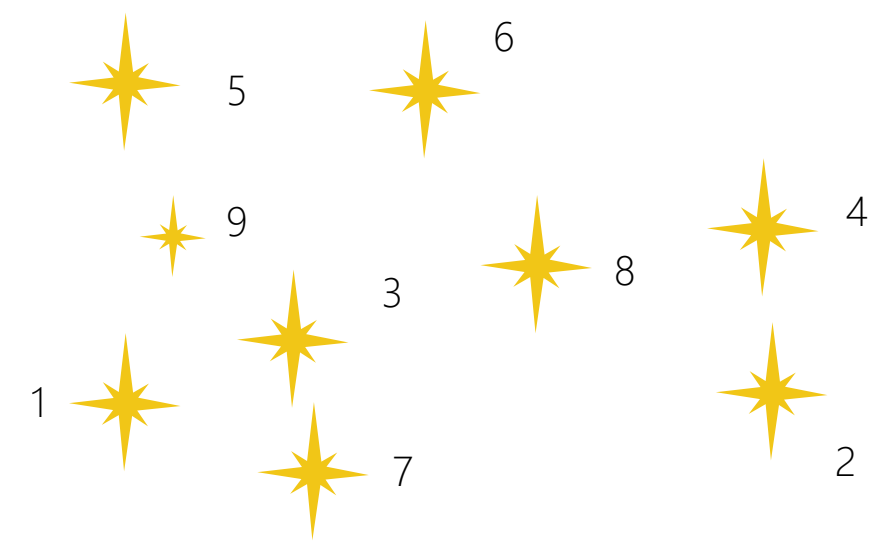




\section{Concept design}

Based on Maori Genealogy

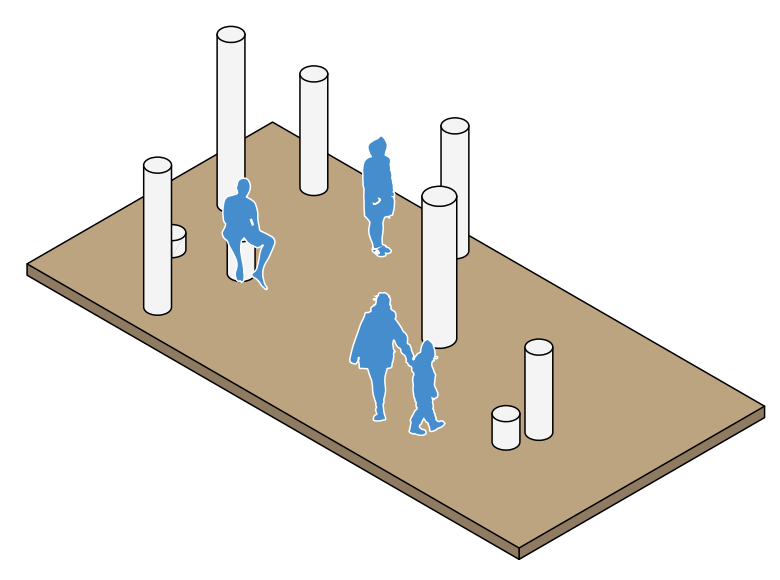

Based on Sky Brightness

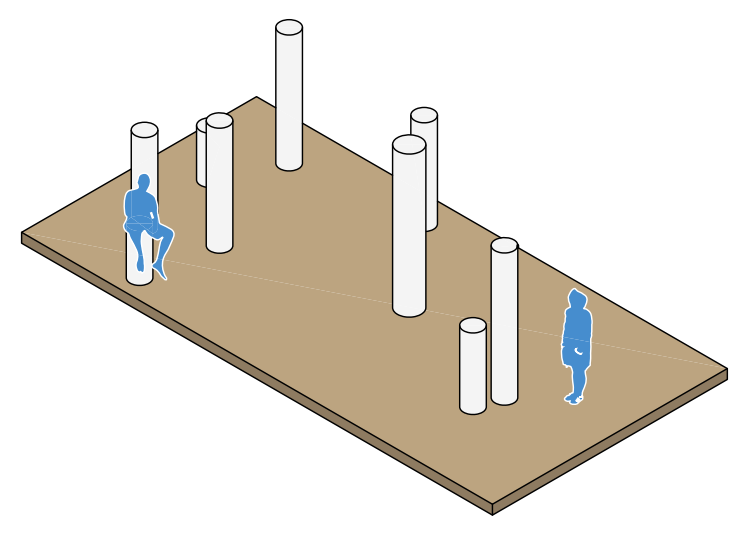

Maori Genealogy - Poles most Important

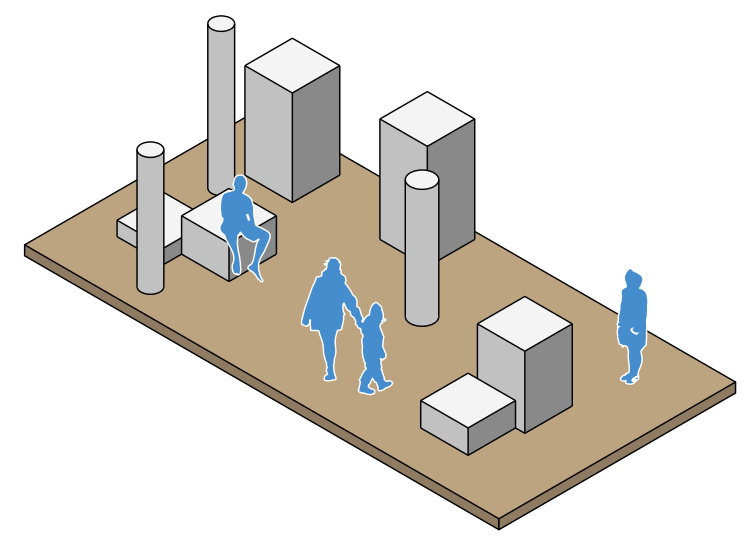

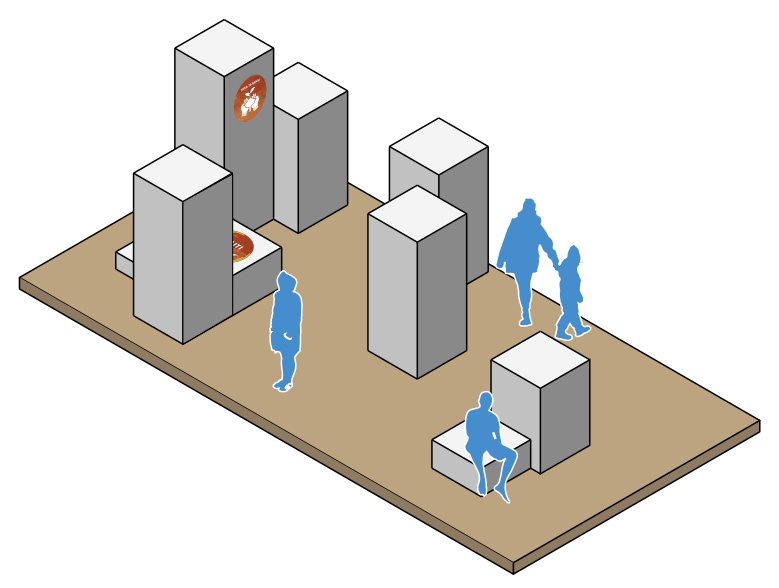

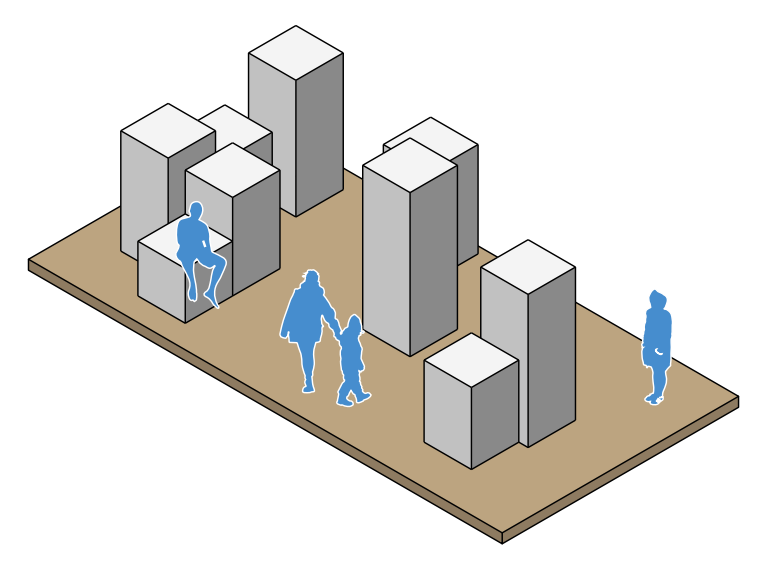

Maori Genealogy - Cubes most important

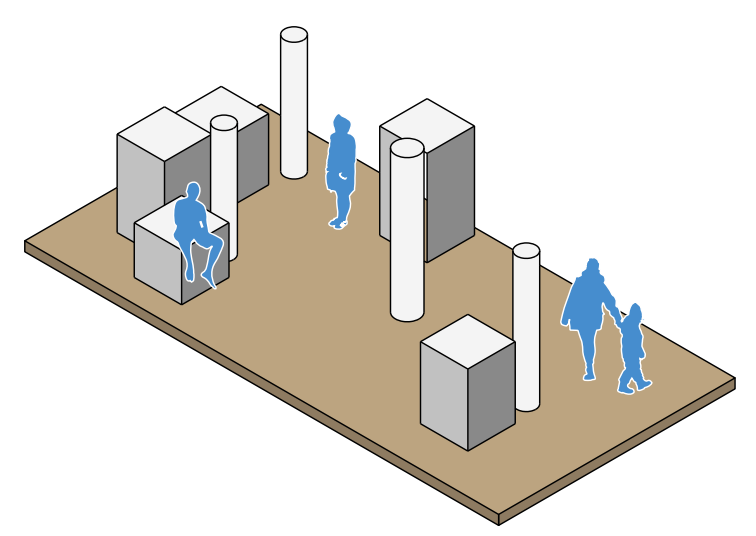




\section{Maori Genealogy - Mounds Iteration 1}

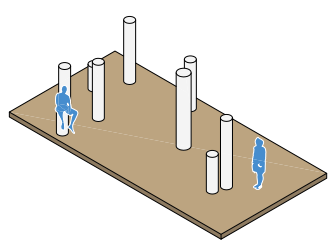

Mounds Iteration 2

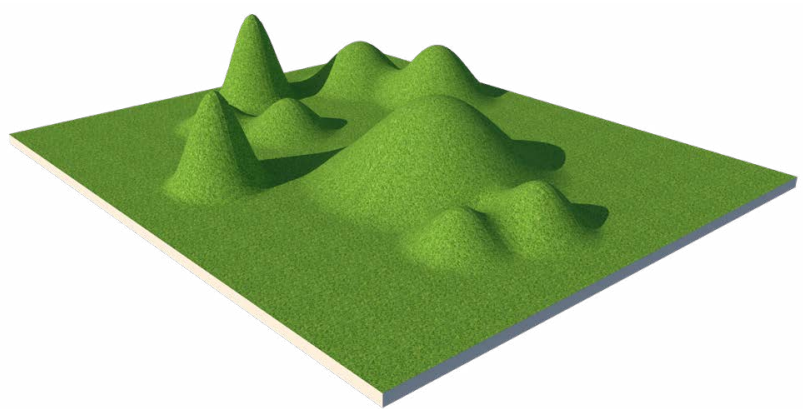

Mounds Iteration 3

- Two sets of cubes for daytime use

- One set of mounds for night time

- 3 poles for Matariki, Pohutukawa and Hiwa-ite-rangi 
8.4 Developed Design design - Sirius Platform

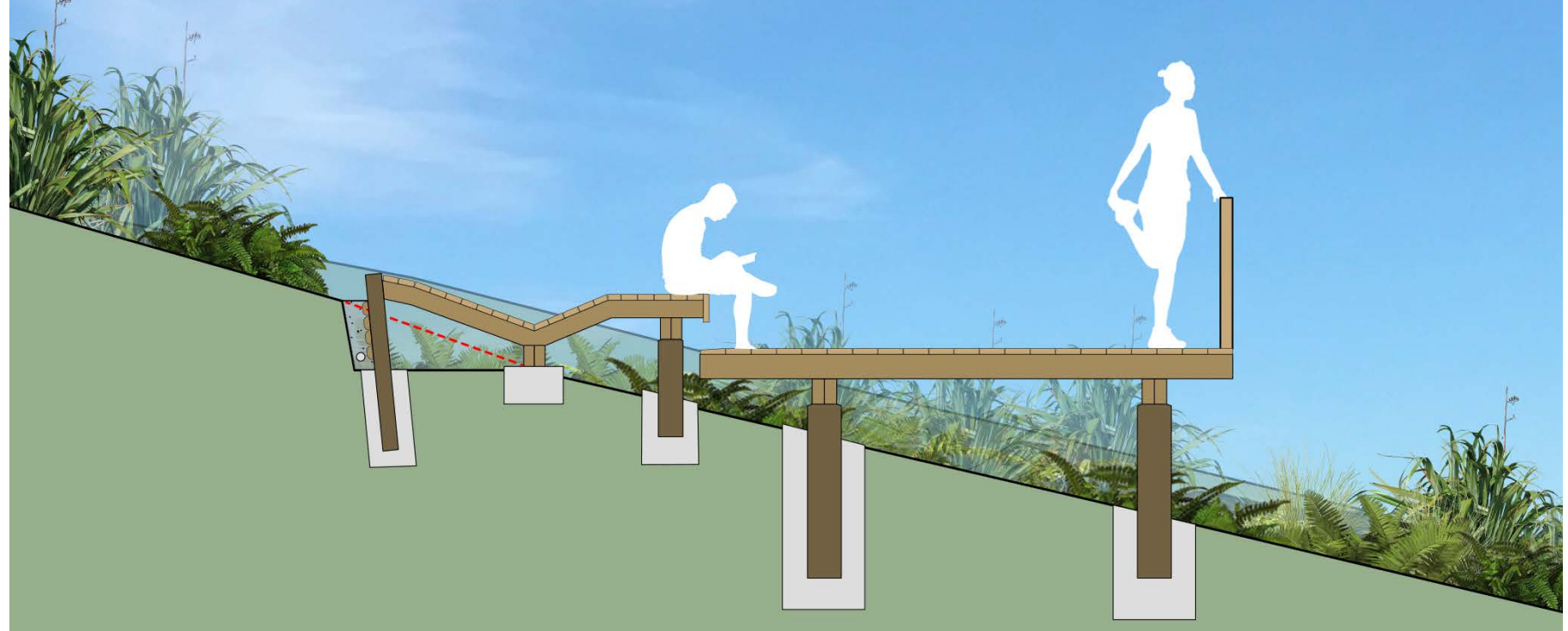




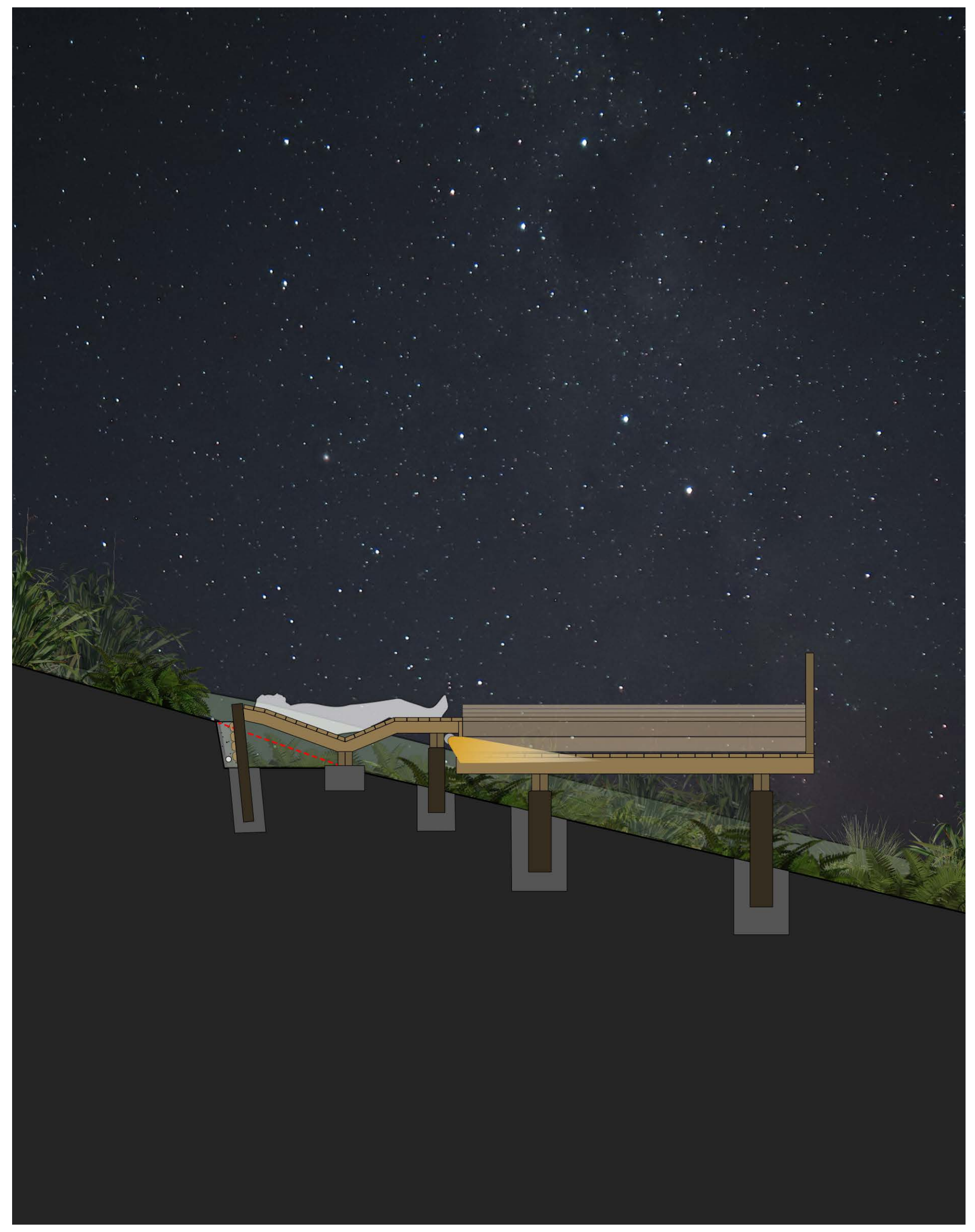




\section{Developed Design design - Orions Belt Platform}
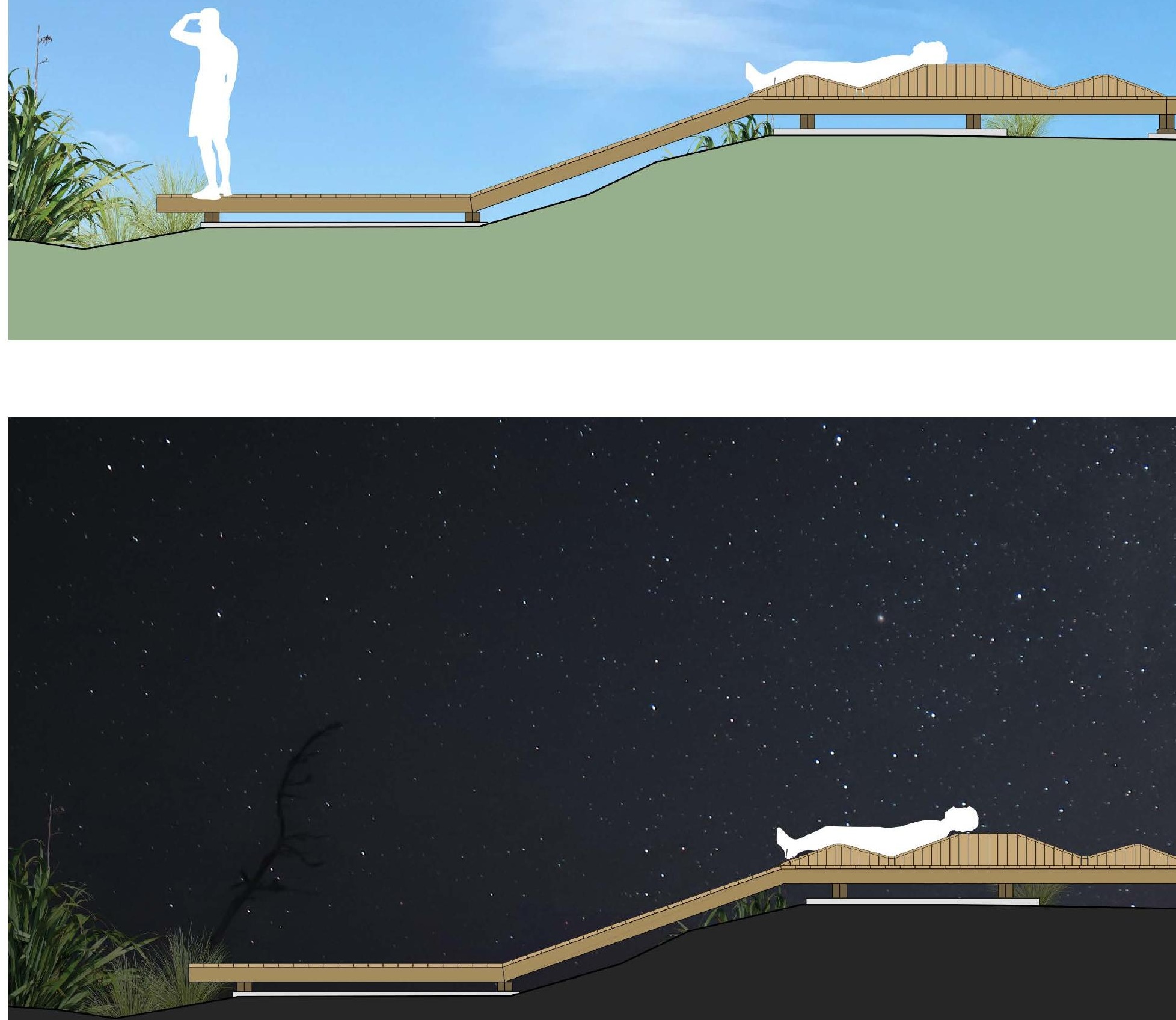

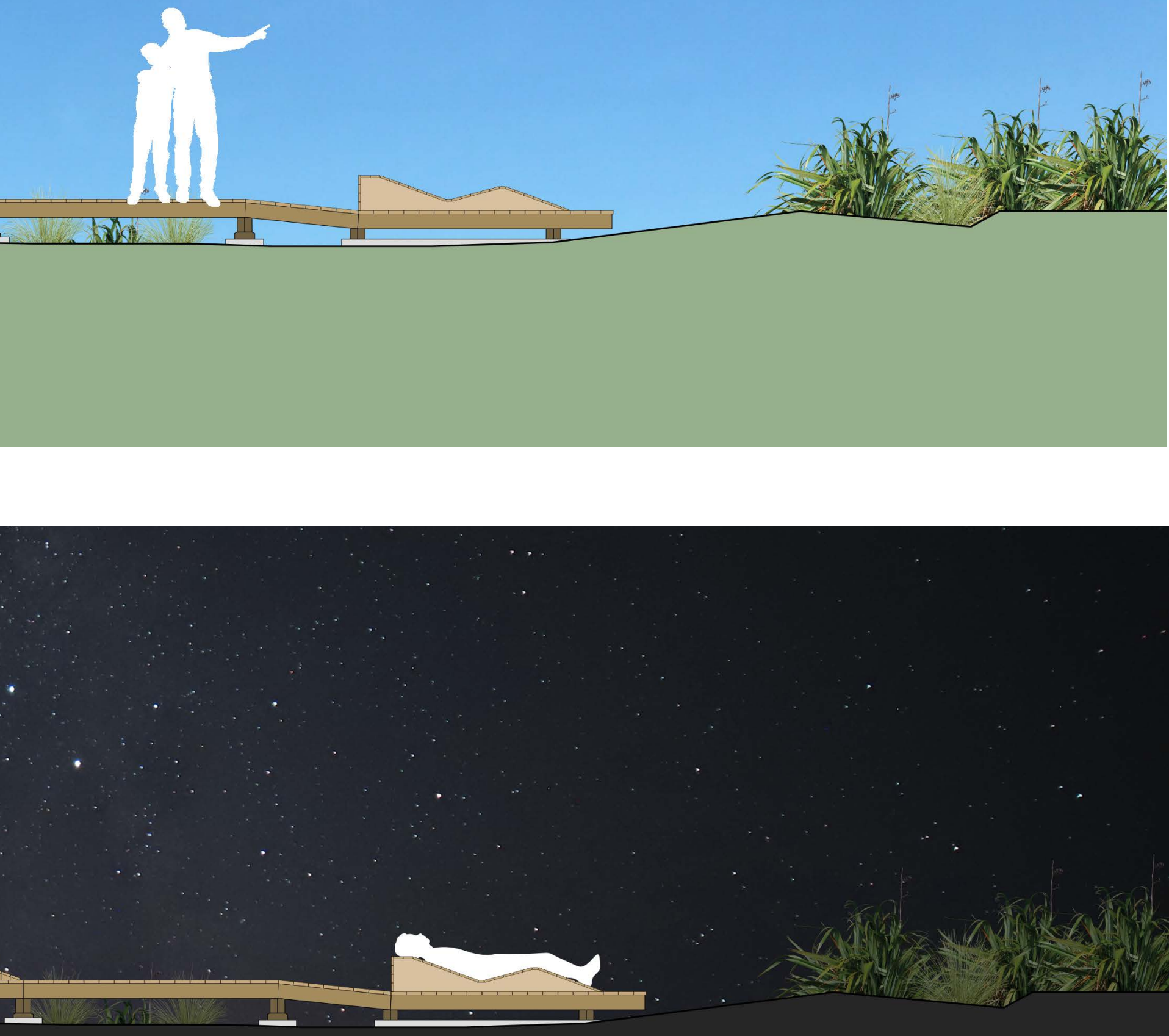


\section{Design Reflection}

Rigorous fieldwork and site analysis was undertaken throughout the design process. The Platform designs generated during the day, in the classroom and on site, were later tested at night only to find they didn't provide a comfortable experience. Similarly design thinking generated on site visits at night did not properly align with space context during the day. A large portion of the research was spent traveling back and forth to the site during the day and at night trying to figure out the best platform location and platform size. Unfortunately this took up too much time and smaller details such as lighting and materiality were not fully explored which led to the incompletion of the design.

However, the design work completed developed a strong connection between the stars and the ground-based elements used to connect to them. The relationship between the platform, seating and existing landscape was able to be realized in two of the platforms and visually represented in the thesis document. A clear relationship is shown between how the platform provides for the day time and for the night time experience. 


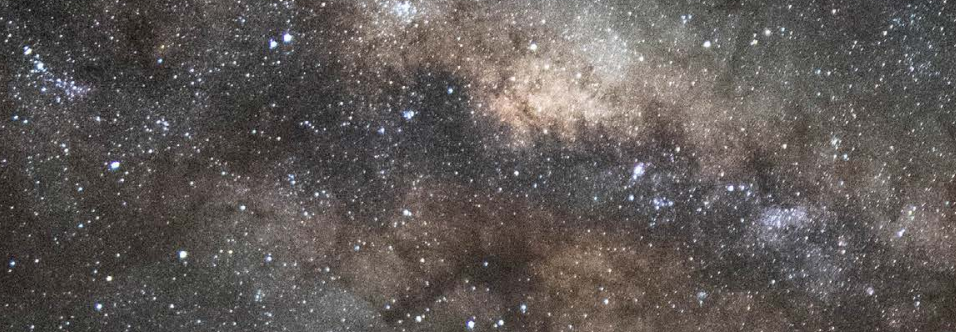

REFLECTION

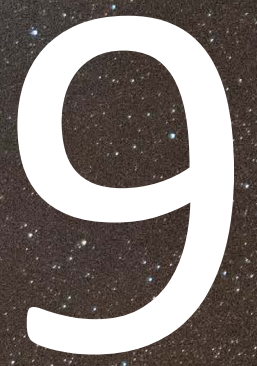




\section{Introduction.}

This chapter discusses the final conclusions, challenges faced in the research and steps moving forward for the research. 


\subsection{Conclusion}

Light pollution is a global problem that impacts how we perceive our environment at night. Most people in the world have grown up in their cities without perceiving stars and other celestial bodies. Lighting is often overused, which has led to the stars inability to be seen from most outdoor public spaces. The design community has seemingly accepted this replicating the day time experience at night. Spaces are only brought to life at night when a new purpose emerges, such as light installations or events.

This research aimed to understand how Landscape Architecture can help reconnect people with the missing night-time experience. This was achieved through multiple site explorations investigating the change in experience from day to night in some of Wellingtons public spaces.

Due to Wellingtons low light pollution levels and peculiar geomorphology, Wellington provides the opportunity to assess multiple typologies of public space each with its unique night sky above. This provided a range of design possibilities by responding to the differing levels of light pollution.

\section{Literature \& Precedent Review}

In the early stages of the process, finding relevant literature and existing case studies proved difficult. Due to the relatively new topic the research was investigating, there was limited information related to the use of design to connect to the night sky. Findings from literature were not found until the experiential fieldwork began and a sense of the night time experience was revealed.

\section{Experiential Fieldwork}

The experiential fieldwork was a great success and the most critical part of the research. Due to the limited existing case studies, the fieldwork initially began to highlight how landscape design was used at night. However, it transformed into a detailed investigation of the surrounding nocturnal environment and how existing landscape and design characteristics influence night time experience.

Findings showed that public space is not designed considering the night time experience. Specifically, three spatial components, Lighting, Vegetation and Seating, significantly impaired the ability to have an enjoyable night time experience.

\section{Toolkit}

The toolkit was generated from specific landscape characteristics extracted through fieldwork. The toolkit was developed with the aim to provide design tools to enhance night time experience. Alternatives to lighting that encouraged social interaction and reduced glare were tested. New uses of vegetation were tested in order to filter lighting while not making the user feel entrapped. Seating options were explored in order to support the body and ensure that the user felt comfortable while stargazing. 


\section{Strategic Design Implementation}

Specific areas in the Waterfront and South coast were chosen via a site selection process to implement the toolkit. In the waterfront, the area behind Te Papa was explored as this was shown to have the least amount of surrounding light glare entering the field of view. Seating was tested in this context as the absence of seating encouraging looking up was primarily concentrated to this area. The waterfront study provided the scale on how big the seats should be for the human body.

Moa Point was chosen as it provided a wide variety of spaces. Lighting was tested on the south coast because it was the darkest area researched. It was important to test the links between lighting and this strong night time experience.

This allowed developing lighting design tests on site. Using physical 1:1 lighting testing proved to be a successful design method as it provided real-life interpretation on perceived comfort.

The second process was the design at Ataturk. This took the combined findings from the toolkit in the waterfront and south coast and specifically applied them into a new site

\section{Concluding remarks}

This thesis challenges how we perceive the night time environment in our public spaces. It celebrates its ability to create positive change in our mental health, allowing reflection and contemplation of our lives. It encourages designers to think about how outdoor space could serve a different purpose, not just to extend daytime use. It aims to bring more awareness about stargazing and learning about the nightsky. This research's possibilities are endless, and further investigation into the relationship between the surrounding environment and comfort at night would be beneficial in supporting this idea. 


\subsection{Limitations}

The lack of existing research and understanding concerning engagement with the stars meant it was difficult to find knowledge to justify decision decisions. I had to develop my own process relying on my interpretations from fieldwork. Ultimately, this led to many different design paths explored, being difficult to know which would be the most beneficial to continue with.

Conducting the fieldwork alone led to my singular perspective in the analysis and design solutions. Organizing focus groups and engaging with the community would have provided a more comprehensive perspective about all ages and genders' night-time experiences. This was almost initiated with many survey drafts being generated but could not be carried out due to Covid-19. It proved to be more efficient for the thesis to conduct research by myself.

\section{Maori Astronomy}

A key area missing from the thesis was the engagement with Maori. Due to Covid 19, it was difficult to contact these groups for discussion. As the thesis research continued, more time was spent outdoors during the day and at night. The focus shifted from the night sky's cultural history to understanding human comfort in night-time spaces,

leading to the removal of the cultural component as a primary research topic. However, the connection between Maori and the night sky was acknowledged and influenced the design exploration.

\section{Toolkit}

There was not enough time to test the application of the toolkit in the three areas where analysis was developed. The town belt was avoided and the work at the waterfront limited. At the same time specific aspects of the toolkit were investigated in the different sites instead of applying all the components of the toolkit to every site. These aspects were developed to different design levels but none received full development into a final design concept. Ataturk was most developed out of three, but they all should have been developed further. 


\subsection{Moving Forward}

I believe this research has great potential to contribute to change in the way we think about our public space at night. An extensive conversation on light pollution and the night sky is developing, but it seems to mainly come from astronomers, photographers, scientists, lighting designers and environmental managers. Landscape architects are missing from the discussion. This research aims to contribute to building this specific knowledge from New Zealand's context.

This research's most significant opportunity is intertwining Astronomy as a more considerable influence on the design outcome. The night sky is constantly changing, and the design should respond to the stars' movements throughout the night and the year.

The design approach was very static and should have responded to this rotation allowing the platforms and seating to be adjusted and moved.

This research has the opportunity to be implemented in any city, so no matter where my career leads me in the future I aim to continue to investigate the night time experience. It's a process that I feel more people need to participate in as its rewards are unparalleled to any other experience provided in nature. 


\subsection{References}

About IDA. (2020). International Dark-Sky Association. https://www.darksky.org/about/

Arnold, N. (2019). Southern Nights. Harper Collins.

Bannister, L. (2020, August). The Smart City Opportunity. LIGHTING MAGAZINE, 20-24.

Bell, R., Irvine, K., Wilson, C., \& Warber, S. (2014). Dark Nature: Exploring potential benefits of nocturnal nature-based interaction for human and environmental health. European Journal of Ecopsychology, 5.

Best, E. (1922). THE ASTRONOMICAL KNOWLEDGE OF THE MAORI, GENUINE AND EMPIRICAL. The Dominion Museum. http://nzetc.victoria.ac.nz/collections.html

Biospharenreservat Rhon. (n.d.). Astronomical observation platform on the Hohe Geba. Biospharenreservat Rhon. Retrieved February 22, 2021, from https://www.biosphaerenreservat-rhoen. $\mathrm{de} /$ natur/sternenpark-rhoen/fuehrungen-und-himmelsschauplaetze/beobachtungsplattformen/

Blair, A. (2018). An Exploration of the Role that the Night Sky Plays in the Lives of the Dark Sky Island Community of Sark. Journal of Skyscape Archaeology, 3(2), 236-252. https://doi. org/10.1558/jsa.34689

Blöbaum, A., \& Hunecke, M. (2005). Perceived Danger in Urban Public Space: The Impacts of Physical Features and Personal Factors. Environment and Behavior, 37(4), 465-486. https://doi. org/10.1177/0013916504269643

Davoudian, N. (2019). Urban lighting for people: Evidence-based lighting design for the built environment (1st Edition). RIBA. https://books.google.co.nz/books?id=YvSfDwAAQBAJ\&p$\mathrm{g}=$ PA5\&lpg=PA5\&dq=The+Chicago+Alley+Lighting+Project:+Final+Evaluation+Report\&source=bl\&ots=9ddMm3FOUH\&sig=ACfU3U04tkdKN-FdzkNIOHU3n62clilyCA\&hl=en\&sa=X\&ved=2ahUKEwin26K8odroAhWBYisKHWCmD_4Q6AEwA3oECAwQKA\#v=onepage\&q\&f=false

Edensor, T. (2015). The gloomy city. Urban Studies, 52(3), 422-438. JSTOR.

Emanuel, D. (2017, September 1). The psychology of black and why we're scared of the dark [News Outlet]. CNN Edition. https://edition.cnn.com/2017/09/01/health/colorscope-black-fearof-darkness/index.html

Entwistle, J., \& Slater, D. (2020). Light as material/lighting as practice: Urban lighting and energy. Science Museum Group Journal, 9(9). https://doi.org/10.15180/180906 
Falchi, F., Cinzano, P., Duriscoe, D., Kyba, C. C. M., Elvidge, C. D., Baugh, K., Portnov, B. A., Rybnikova, N. A., \& Furgoni, R. (2016). The new world atlas of artificial night sky brightness. Science Advances, 2(6), e1600377. https://doi.org/10.1126/sciadv.1600377

Final pou at Atea a Rangi Star Compass for Solstice. (2017, December 14). Community Scoop. http://community.scoop.co.nz/2017/12/final-pou-at-atea-a-rangi-star-compass-for-solstice/

Harris, P., Matamua, R., Smith, T., Kerr, H., \& Waaka, T. (2013). A review of Māori astronomy in Aotearoa-New Zealand. Journal of Astronomical History and Heritage, 16(3), 325-336.

Hilary, O. (2014). Why Dark Skies Matter more than you know. Adventure Journal.

Ingold, T. (2011). Being alive: Essays on movement, knowledge and description. Routledge.

Jansson, M., Fors, H., Lindgren, T., \& Wiström, B. (2013). Perceived personal safety in relation to urban woodland vegetation - A review. Urban Forestry \& Urban Greening, 12(2), 127-133. https://doi.org/10.1016/j.ufug.2013.01.005

Levos, J., \& Lowery Zacchilli, T. (2015). Nyctophobia: From Imagined to Realistic Fears of the Dark. Psi Chi Journal of Psychological Research, 20(2), 102-110. https://doi.org/10.24839/21648204.JN20.2.102

Lighting, Crime and Safety. (n.d.). International Dark-Sky Association. Retrieved February 24, 2020, from https://www.darksky.org/light-pollution/lighting-crime-and-safety/

Loewen, L. J., Steel, G. D., \& Suedfeld, P. (1993). Perceived safety from crime in the urban environment. Journal of Environmental Psychology, 13(4), 323-331. https://doi.org/10.1016/S02724944(05)80254-3

Matamua, R. (2017). Matariki: The star of the year. Huia.

Morrow, E. N., \& Hutton, S. A. (2000). The Chicago Alley Lighting Project: Final Evaluation Report. http://icjia.org/assets/pdf/ResearchReports/Chicago\%20Alley\%20Lighting\%20Project.pdf

NZILA. (2019). Ātea a Rangi, Waitangi Regional Park. New Zealand Institute of Landscape Architects. https://nzila.co.nz/showcase/atea-a-rangi-waitangi-regional-park

Rahm, J., Sternudd, C., \& Johansson, M. (2020). "In the evening, I don't walk in the park": The interplay between street lighting and greenery in perceived safety. URBAN DESIGN International. https://doi.org/10.1057/s41289-020-00134-6 


\subsection{List of Figures}

All Images are authors own unless specified

Fig 1.6 Global Artificial sky Brightness, (Falchi et al., 2016)

Falchi, F. (2016, June 10). Global Artificial Sky Brightness [Illustration]. Science Advances. https:// advances.sciencemag.org/content/2/6/e1600377

Fig 2.3 Penguin viewing platform

Royal Albatross Centre. (n.d.). Blue Penguin Viewing Platform [Photograph]. Dunedin. https://www. dunedinnz.com/visit/see-and-do/tours/wildlife/blue-penguins-pukekura

Fig 2.4 Astro Platform (Rhon Biosphere Reserve, 2016)

Scholze, A. (n.d.). Astronomical devices for sky observation are set up on the Hohe Geba [Photograph]. Biosphaerenreservat Rhon. https://www.biosphaerenreservat-rhoen.de/natur/sternenpark-rhoen/ fuehrungen-und-himmelsschauplaetze/beobachtungsplattformen/

Fig 2.7 Ambient Lighting in Garema Place (Street Furniture, 2017)

Chan, J. (2017). A family photo at night [Photograph]. Street Furniture Australia. https://streetfurniture. com/wp-content/uploads/2017/02/Street-Furniture-Australia-Backyard-Experiment-White-Paper. pdf

Fig 2.8 Van Gogh Path (Studio Roosegaarde, 2014)

Studio Roosegaarde. (n.d.). Van Gogh Path [Photograph]. Studio Roosegaarde. https://www. studioroosegaarde.net/project/van-gogh-path

Fig 2.13 Milky Way Rising over the Star Compass (Caldwell, 2018)

Caldwell, A. (2018, February 16). Atea a Rangi ( Celestial Compass ) [Photograph]. Flickr. https:// www.flickr.com/photos/ajecaldwell/25679299137/in/photostream/

\section{Fig 3.2 Visual Impact of light pollution}

Falchi, F. (2016, June 10). Global Artificial Sky Brightness [Illustration]. Science Advances. https:// advances.sciencemag.org/content/2/6/e1600377

Fig 3.4 Light pollution in Wellington - faichi

Falchi, F. (2016, June 10). Global Artificial Sky Brightness [Illustration]. Science Advances. https:// advances.sciencemag.org/content/2/6/e1600377

Fig 3.14 Artificial sky brightness

Falchi, F. (2016, June 10). Global Artificial Sky Brightness [Illustration]. Science Advances. https:// advances.sciencemag.org/content/2/6/e1600377 


\section{Fig 3.15 Artificial sky brightness}

Falchi, F. (2016, June 10). Global Artificial Sky Brightness [Illustration]. Science Advances. https://advances. sciencemag.org/content/2/6/e1600377

\section{Fig 3.16 Bortle class Identifier}

Falchi, F., Cinzano, P., Duriscoe, D., Kyba, C. C. M., Elvidge, C. D., Baugh, K., Portnov, B., Rybnikova, N. A., \& Furgoni, R. (2016). Supplement to: The New World Atlas of Artificial Night Sky Brightness (1.1, p. 26001739 Bytes, 1 Files) [Application/octet-stream]. GFZ Data Services. https://doi.org/10.5880/GFZ.1.4.2016.001

\section{Fig 6.16 Unite seating}

Urban Movement Design. (2012, June 31). [Curved Seating for Yoga]. ArchDaily. https://www.archdaily. com/258787/urban-movement-design-debuts-unireunite-at-maxxi

\section{Fig 7.29 Matariki location In the sky = Iphone app}

SkyPortal. (2020). Location of Matariki in the Sky [Screenshot]. https://apps.apple.com/us/app/celestronskyportal/id877780544

Fig 8.8 Star movements throughout the year - skyportal 2020

SkyPortal. (2020b). Star movements throughout the year [Screenshot]. https://apps.apple.com/us/app/ celestron-skyportal/id877780544

Fig $8.10 \quad$ Orions belt

Orions Belt. (n.d.). [Photograph]. Universe Today. https://www.universetoday.com/85736/orions-beltstars/

Fig $8.11 \quad$ Matariki

Gillespie, J. (2017, October 19). Mountaintop Matariki [Photograph]. Flickr. https://www.flickr.com/ photos/darkskyprojectnz/37760599416

Fig $8.12 \quad$ Sirius

Dyer, A. (2015). Sirius Dog Star [Photograph]. Smithzonian Magazine. https://www.smithsonianmag. com/smart-news/night-sky-wonders-ring-new-year-180957688/

Fig 8.13 Scorpio

Picking, C. J. (2006). Scorpius Constellation [Photograph]. Starry Night Skies Photography. http://www. starrynightphotos.com/constellations/scorpius.htm

Fig 8.14 Ranginui being held up on the 4 posts in the sky

Hall, R. (2004). The separation of Rangi and Papa [lllustration]. In Work of the Gods (pp. 20-21). 
Rankin, J., \& Mays, R. (2017, May 16). LED street lights are fine, but there are not enough of them. Manawatu Standard. https://www.stuff.co.nz/manawatu-standard/news/92600978/led-streetlights-are-fine-but-there-are-not-enough-of-them? $\mathrm{rm}=\mathrm{m}$

Star Park Rhön. (n.d.). Biospharenreservat Rhon. Retrieved February 22, 2021, from https://www. biosphaerenreservat-rhoen.de/natur/sternenpark-rhoen/

Street Furniture Australia. (2017). \#BackyardExperiment. Street Furniture Australia. https://streetfurniture.com/projects/backyardexperiment/

Studio Roosegaarde. (2014). Van Gogh Path. https://www.studioroosegaarde.net/project/vangogh-path 
